\title{
A TWO-DIMENSIONAL SIMULATION OF TRITIUM TRANSPORT IN THE VADOSE ZONE AT THE NEVADA TEST SITE
}

\author{
by \\ Wyn C. Ross \\ Stephen W. Wheatcraft
}

September 1994 


\section{DISCLAIMER}

Portions of this document may be illegible in electronic image products. Images are produced from the best available original document. 
This report was prepared as an account of work sponsored by the United States Government. Neither the United States nor the United States Department of Energy, nor any of their employees, makes any warranty, express or implied, or assumes any legal liability or responsibility for the accuracy, completeness or usefuiness of any information, apparatus, product or process disclosed, or represents that its use would not infringe privately owned rights. Reference herein to any specific commercial project, process, or service by trade name, mark, manufacturer, or otherwise, does not necessarily constitute or imply its endorsement, recommendation, or favoring by the United States Government or any agency thereof. The views and opinions of authors expressed herein do not necessarily state or reflect those of the United States Government or any agency thereof.

This report has been reproduced directly from the best available copy.

Available to DOE and DOE contractors from the Office of Scientific and Technical Information, P.O. Box 62, Oak Ridge, TN 37831; prices available from (615) 576-8401.

Available to the public from the National Technical Information Service, U.S. Department of Commerce, 5285 Port Royal Rd., Springfield, VA 22161. 


\title{
A TWO-DIMENSIONAL SIMULATION OF TRITIUM TRANSPORT IN THE VADOSE ZONE AT THE NEVADA TEST SITE
}

\author{
by \\ Wyn C. Ross \\ Stephen W. Wheatcraft \\ Water Resources Center \\ Desert Research Institute \\ University and Community College System of Nevada
}

Publication \#45098

prepared for

Nevada Operations Office

U.S. Department of Energy

Las Vegas, Nevada

September 1994

The work upon which this report is based was supported by the U.S. Department of Energy under Contract \#DE-AC08-80NV10162. 


\section{CONTENTS}

$\begin{array}{lll}\text { ABSTRACT } & \text { vi }\end{array}$

INTRODUCTION 1

General

Objective $\quad 4$

HYDROGEOLOGY 10

Location 10

Geology 10

$\begin{array}{ll}\text { Hydrology } & 10\end{array}$

CANAL INFILTRATION MODEL $\quad 15$

The SATURN Model $\quad 15$

SATURN Input Requirements $\quad 15$

Parameter Estimation $\quad 15$

Laboratory Saturated Hydraulic Conductivity Determination $\quad 16$

Unsaturated Properties of the Porous Medium 16

Instantaneous Profile Test 19

Introduction $\quad 19$

$\begin{array}{ll}\text { Theory } & 19\end{array}$

Experimental Design $\quad 20$

Data Collection $\quad 22$

In-Situ Saturated Hydraulic Conductivity Determination $\quad 22$

$\begin{array}{ll}\text { Soil Moisture Characteristic Curves } & 23\end{array}$

Unsaturated Hydraulic Conductivity Determination $\quad 23$

Model Definition $\quad 32$

MATHEMATICAL FORMULATION $\quad 39$

Governing Equations--Flow $\quad 39$

Governing Equations--Transport 40

GROUNDWATER FLOW SIMULATION $\quad 42$

$\begin{array}{ll}\text { TRITIUM TRANSPORT SIMULATION } & 48\end{array}$

INFILTRATION OF CONSERVATIVE TRACER AT RNM CANAL $\quad 52$

Tracer Test Lysimeter Installation $\quad \mathbf{5 2}$

Tracer Test $\quad 52$

$\begin{array}{lr}\text { CONCLUSIONS } & 58\end{array}$

REFERENCES $\quad 59$ 
APPENDICES

A: Neutron Data

B: Tensiometer Data

C: Instantaneous Profile Test Flow Data

D: Plots of Moisture Content Versus Time

E: Plots of Hydraulic Head Versus Depth

F: Soil Moisture Characteristic Curves - van Genuchten Model

G: Plots of Hydraulic Conductivity Versus Moisture Content Mualem Model

H: Plots of Hydraulic Conductivity Versus Degree of Saturation Field Measured

I: Simulated Moisture Distribution

J: Simulated Velocity Field

K: Sensitivity of Solution to Changes in Dispersivity

L: Sensitivity of Solution to Changes in Molecular Diffusion Coefficient

M: Simulated Distribution of Tritium

N: Contour Plots of Simulated Tritium Concentration 


\section{FIGURES}

1. Cross Section Showing RNM-2S and the Cambric Detonation Point. 2

2. Map of West-Central Frenchman Flat Showing Location of RNM Site. 3

3. Cambric Site of the Radionuclide Migration Program. 5

4. RNM Canal Transmission Losses. $\quad 6$

5. Tritium Concentration (corrected to Cambric Zero Time) at RNM-2S $\begin{array}{ll}\text { versus Time. } & 7\end{array}$

6. Tritium Concentration (corrected to Cambric Zero Time) at RNM-2S versus Volume Pumped.

7. Plot Showing Concentration versus Volume Pumped. Tritium Data are Corrected to Shot Time.

8. Geologic Section at RNM Site. 11

9. Location of Section Line A-A'. 12

10. Map of Frenchman Flat Showing the Locations of Drill Holes. 14

11. Results of Permeameter Tests on Cores from US1 and US2. 17

12. Instantaneous Profile Test Site. 21

13. Depth of Ponding versus Time. 24

14. Hydraulic Conductivity versus Moisture Content, Hole N1. 30

15. Hydraulic Conductivity versus Moisture Content, Hole N2. 31

16. Original Sample Space Discretization into Nodes and Elements. 34

17. Location of Elements. 36

18. Location of Nodes. $\quad 37$

19. Discretization of Sample Space Showing Boundary Conditions. 38

20. Graphical Representation of Numerical Instabilities. 44

21. Effect of Anisotropy on Solution Stability. 45

22. Simulated Steady-State Element Saturation Values (\%). 46

23. Qualitative Representation of the Vertical and Horizontal Components of the Simulated Steady-State Flow Field. Dots Represent Velocity Components Less than $1 \mathrm{~cm} /$ day. 
24. Solution Sensitivity to Changes in Longitudinal Dispersivity.

25. Contour Plots of Simulated Tritium Concentration at Selected Time Steps.

26. Tracer Test Site.

27. Suction Lysimeter Installation.

28. Plot Showing Simulated and Observed Bromide Concentration.

\section{TABLES}

1. Porosity and Saturated Hydraulic Conductivity of Samples from Drill Holes US1 and US2.

2. Comparison of Saturated Hydraulic Conductivity Estimates. 25

3. Calculation of Soil Moisture Flux--N1 (instantaneous profile test). 26

4. Calculation of Soil Moisture Flux--N2 (instantaneous profile test). 27

5. Calculation of Hydraulic Conductivity--N1 (instantaneous profile test). 28

6. Calculation of Hydraulic Conductivity--N2 (instantaneous profile test). 29

7. RNM Canal Model Input Data. 33

8. Results of Lysimeter Sampling. 


\begin{abstract}
The site of a 0.75-kiloton underground nuclear explosion, the Cambric event, was selected for the study of radionuclide transport in the hydrologic environment. Water samples from RNM-2S, a well located $91 \mathrm{~m}$ from Cambric, have been analyzed for tritium and other radionuclides since the initiation of pumping. Water from RNM-2S flows to Frenchman Lake via an unlined canal. Flume data indicate canal transmission losses of approximately 2 $\mathrm{m}^{3} /$ day/meter of canal. To determine if infiltrating canal water might be recirculated by RNM-2S, and therefore provide an additional radionuclide input to water samples collected at RNM-2S, a two-dimensional variably saturated solute transport computer model (SATURN, Huyakorn et al., 1983) was used to simulate the movement of tritium from the canal to the water table. Results indicate that recirculated canal water has not had a significant effect on the breakthrough of tritium at RNM-2S.
\end{abstract}




\section{INTRODUCTION}

\section{GENERAL}

The Radionuclide Migration (RNM) Program was initiated in 1974 by the Nevada Operations Office of the Department of Energy to study the distribution of radionuclides around an underground nuclear cavity. The goals of the RNM Program were to determine the rates of migration of radionuclides in a variety of underground media at the Nevada Test Site (NTS) and to determine the potential for radionuclide migration, both on and off the NTS, from underground nuclear explosions. The possible contamination of water supplies was of particular concern.

The site of a 0.75-kiloton underground nuclear test, the Cambric event, was selected for the study. The Cambric test was conducted on May 14, 1965, in the tuffaceous alluvium of Frenchman Flat. The detonation point was $73 \mathrm{~m}$ below the water table, at a depth from the surface of $294 \mathrm{~m}$.

The Cambric site was selected for the following reasons:

- The event took place within the NTS Area 5 water supply aquifer.

- Sufficient time had elapsed since the detonation for water in the cavity and rubble chimney to return to the preshot level.

- The site was far from areas of active nuclear testing.

- The detonation point was fairly close to the ground surface making re-entry drilling and sampling less difficult and expensive.

- The highly permeable alluvium with its lack of fractures would make a good medium for hydrologic studies.

- The chimney region contained uranium, plutonium, and fission products.

- Sufficient tritium was present to constitute an excellent tracer for water from the cavity region.

A re-entry well (RNM-1) was completed in May 1974 and samples were taken to determine the radionuclide content of the water and the postshot debris. A second well (RNM-2S) was positioned $91 \mathrm{~m}$ from the Cambric cavity (Figure 1). Pumping of RNM-2S was initiated in October 1975 to induce a hydraulic gradient from the Cambric cavity and provide an opportunity to study radionuclide migration under field conditions. Water from RNM-2S is piped to an unlined canal which runs approximately $1.6 \mathrm{~km}$ to the north end of Frenchman Lake, where the water discharges to a bermed area near the playa. Figure 2 is a map of west-central Frenchman Flat.

RNM-2S was pumped almost continuously from 1975 until August 1991. In August 1991, the pump was turned off permanently, although it may be pumped on an infrequent basis in the future for occasional samples (Duncan, 1992). Water samples from RNM-2S were analyzed for 


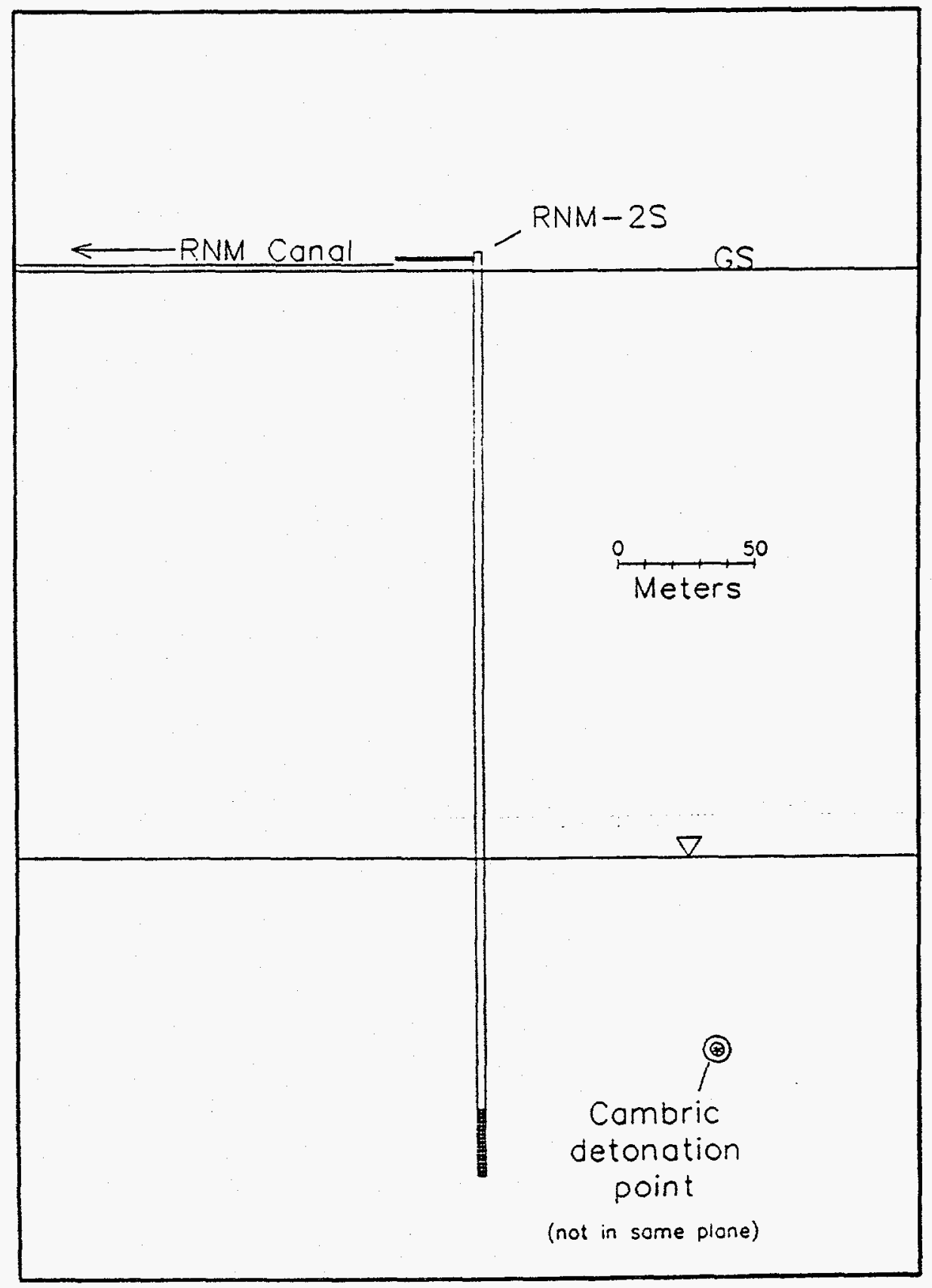

Figure 1. Cross Section Showing RNM-2S and the Cambric Detonation Point. 

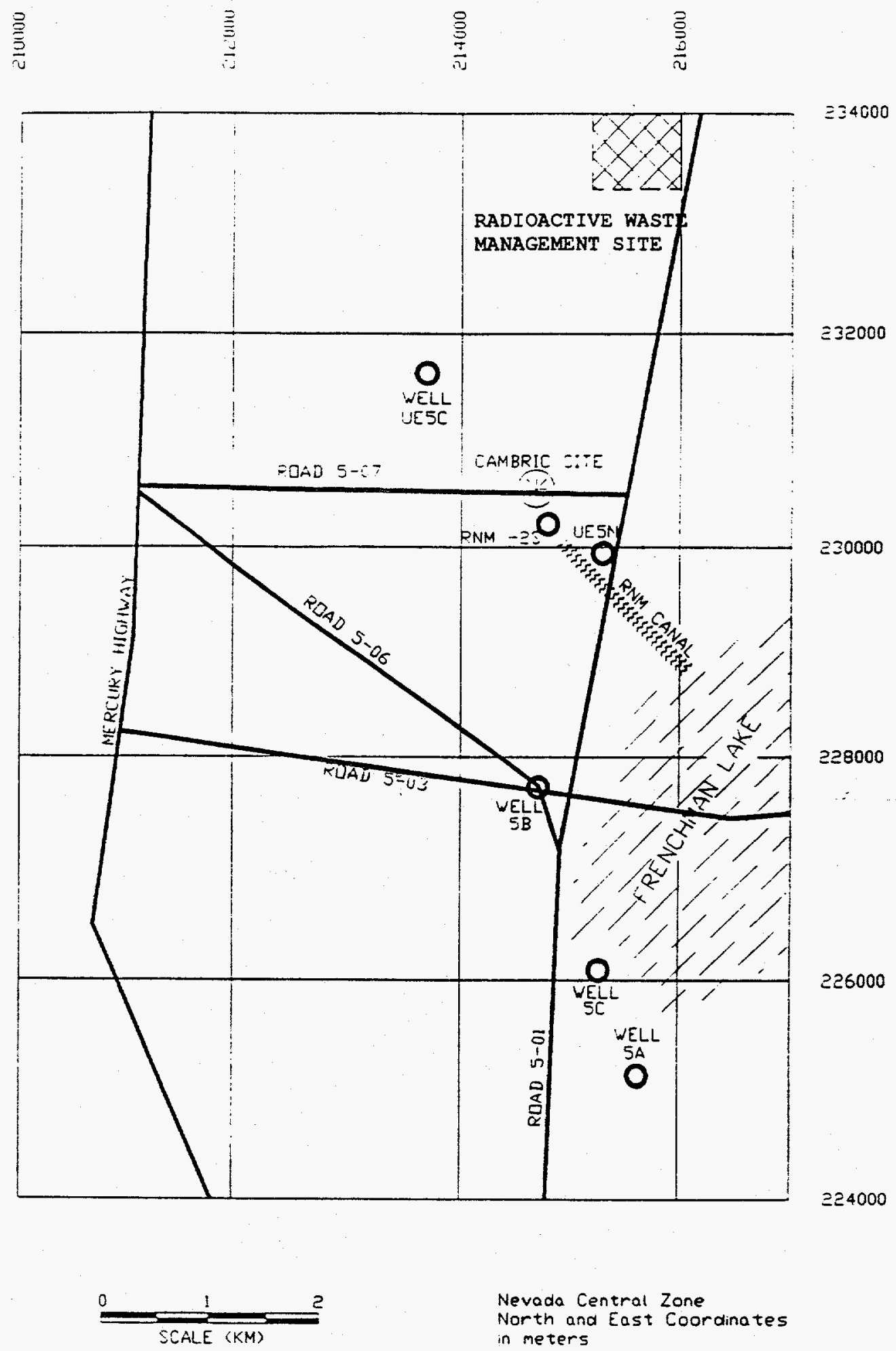

Nevada Central Zone

North and East Coordinates

in meters

Figure 2. Map of West-Central Frenchman Flat Showing Location of RNM Site (after Hoffman et al., 1977). 
tritium and other radionuclides at weekly or biweekly intervals from the initiation of pumping until the pump was turned orf in 1991.

Three Parshall flumes were installed along the canal at the positions shown in Figure 3. Data from these flumes indicate that there is significant transmission loss along the canal (Figure 4). If the infiltrating canal water is captured by RNM-2S, it would constitute an additional source of tritium to the well, thereby affecting the tritium breakthrough. The purpose of this report is to quantify the flow of water and transport of tritium from the canal to the water table. An unsaturated groundwater flow and solute transport computer model, SATURN, was used to simulate 1,500 days of infiltration through the vadose zone beneath the RNM canal.

In this study, many assumptions were made regarding the hydraulic properties of the media, and the physical and chemical properties of, and interactions between, the various components of the system: water, air, solute, and soil. The utility of the simulation results are limited by the accuracy of the parameter estimates, and the validity of the model assumptions.

The applicability of this study can only be evaluated if there is an understanding of the assumptions and the data limitations that were involved. For this reason, the description of the geology and hydrology of Frenchman Flat is followed by a thorough discussion of the model data requirements, and the field and laboratory experiments involved in their estimation. Next, a brief derivation of the governing equations is given followed by a description of the solution domain discretization and the assignment of initial and boundary conditions. Finally, the results of the groundwater flow and tritium transport simulations are presented.

\section{OBJECTIVE}

The initial pumping rate of RNM-2S was $0.94-1.14 \mathrm{~m}^{3} / \mathrm{min}$. At this rate, tritium from the cavity region was expected to arrive at the well after about $9.5 \times 10^{5} \mathrm{~m}^{3}$ had been pumped. This estimate was based on the volume of water contained in a sphere with a radius of $91 \mathrm{~m}$, and a porosity of 0.3 :

$$
V=\frac{4}{3} \pi r^{3} n=\frac{4}{3} \pi 91 m^{3} 0.3=9.5 \times 10^{5} m^{3}
$$

By August 1977 , more than $1.14 \times 10^{6} \mathrm{~m}^{3}$ had been pumped from RNM-2S without detection of Cambric tritium. In October 1977, a higher capacity pump was installed and pumping was resumed at a rate of about $2.3 \mathrm{~m}^{3} / \mathrm{min}$. After $2 \times 10^{6} \mathrm{~m}^{3}$ had been pumped, significant amounts of tritium finally reached RNM-2S (Figures 5 and 6). Theories to explain the late arrival of tritium at RNM-2S include: inhomogeneities in the aquifer; diffusion of tritium into stagnant, immobile regions in the flow path; exchange of tritium with structural water, and adsorption of tritium on the surface of clay particles. Recirculation of water infiltrating from the discharge canal might also have had an affect on tritium breakthrough at RNM-2S.

A three-dimensional solute transport model was used to simulate tritium and chlorine-36 breakthrough at RNM-2S (Burbey, 1984). A good match between simulated and observed 


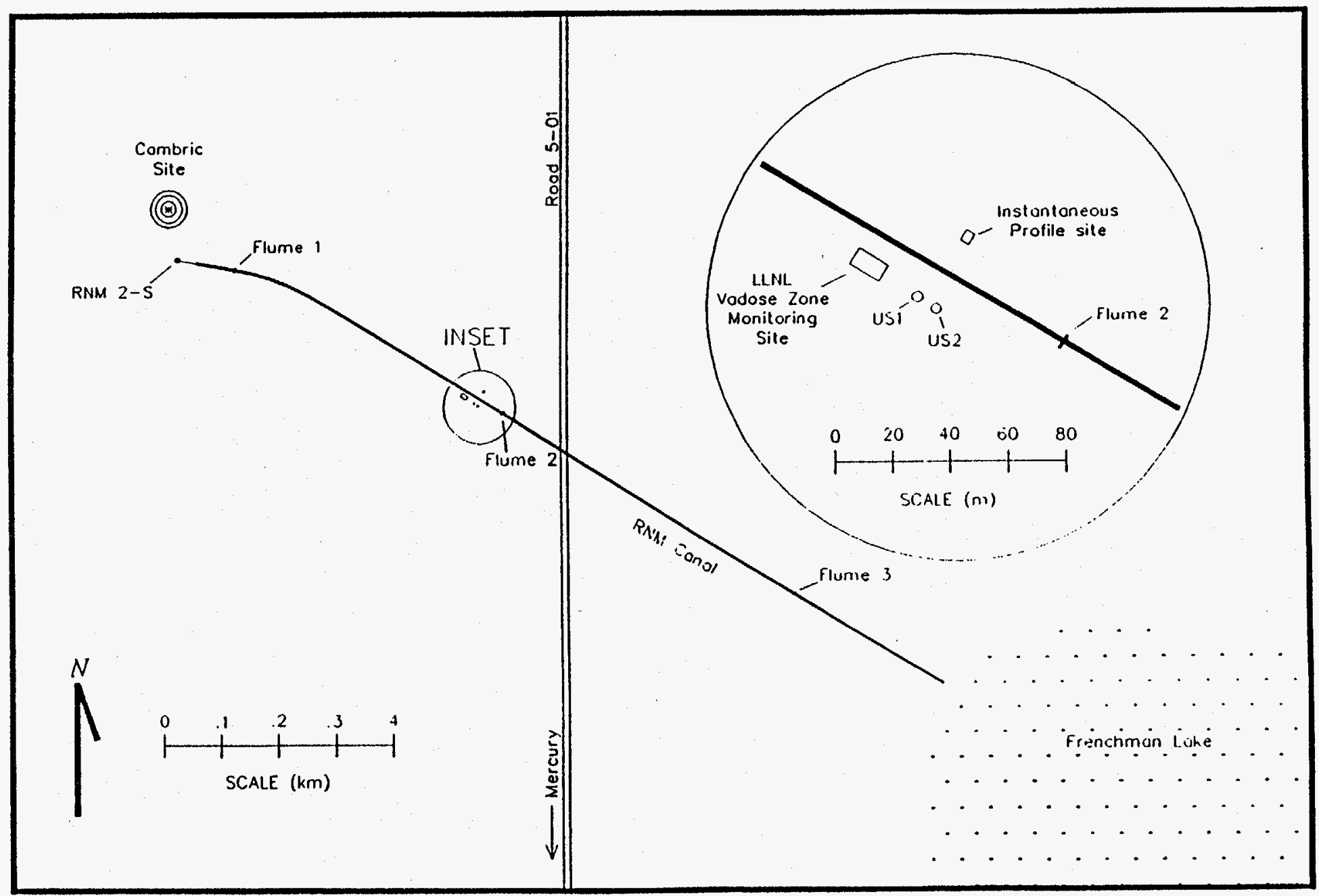

Figure 3. Cambric Site of the Radionuclide Migration Program. 


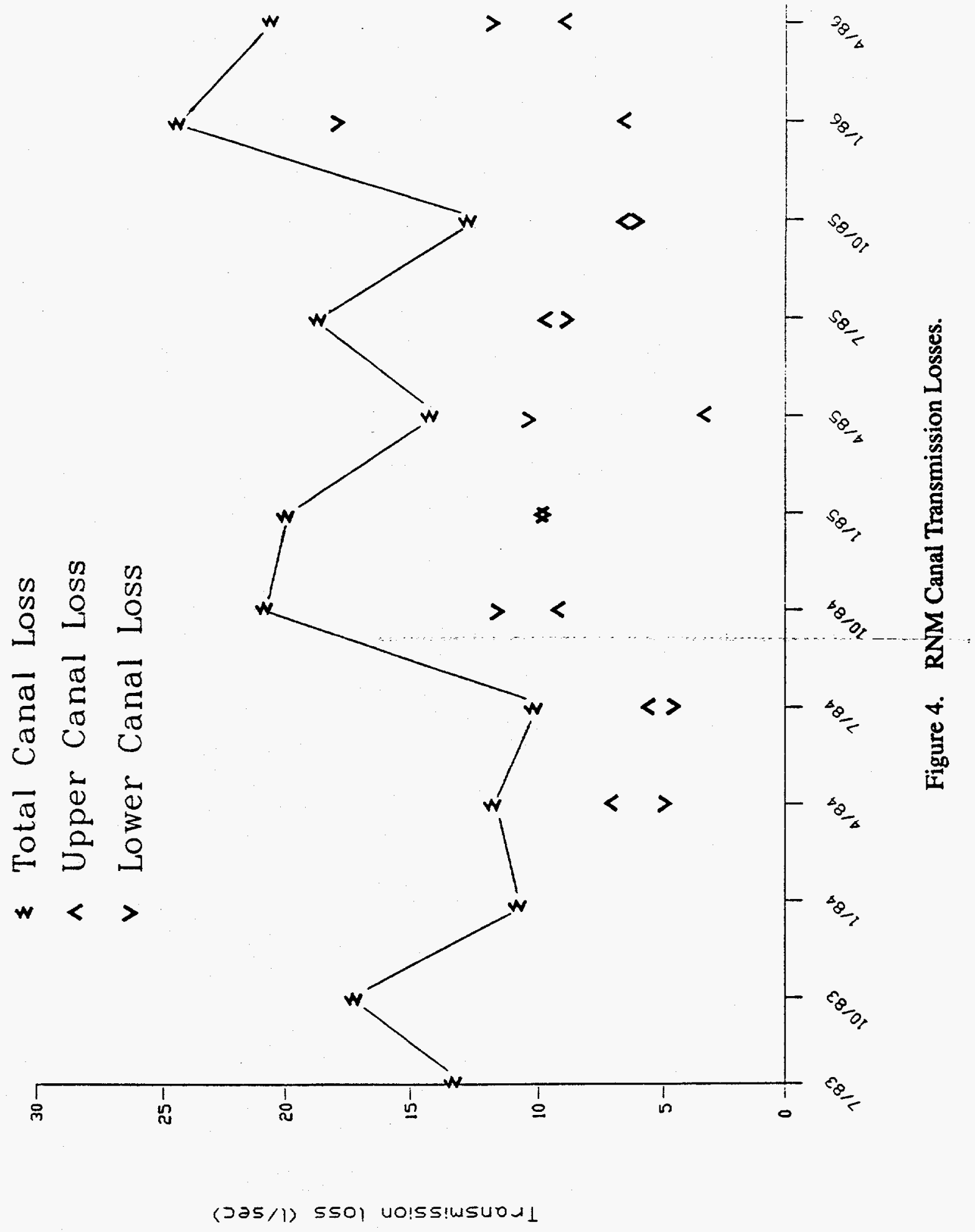




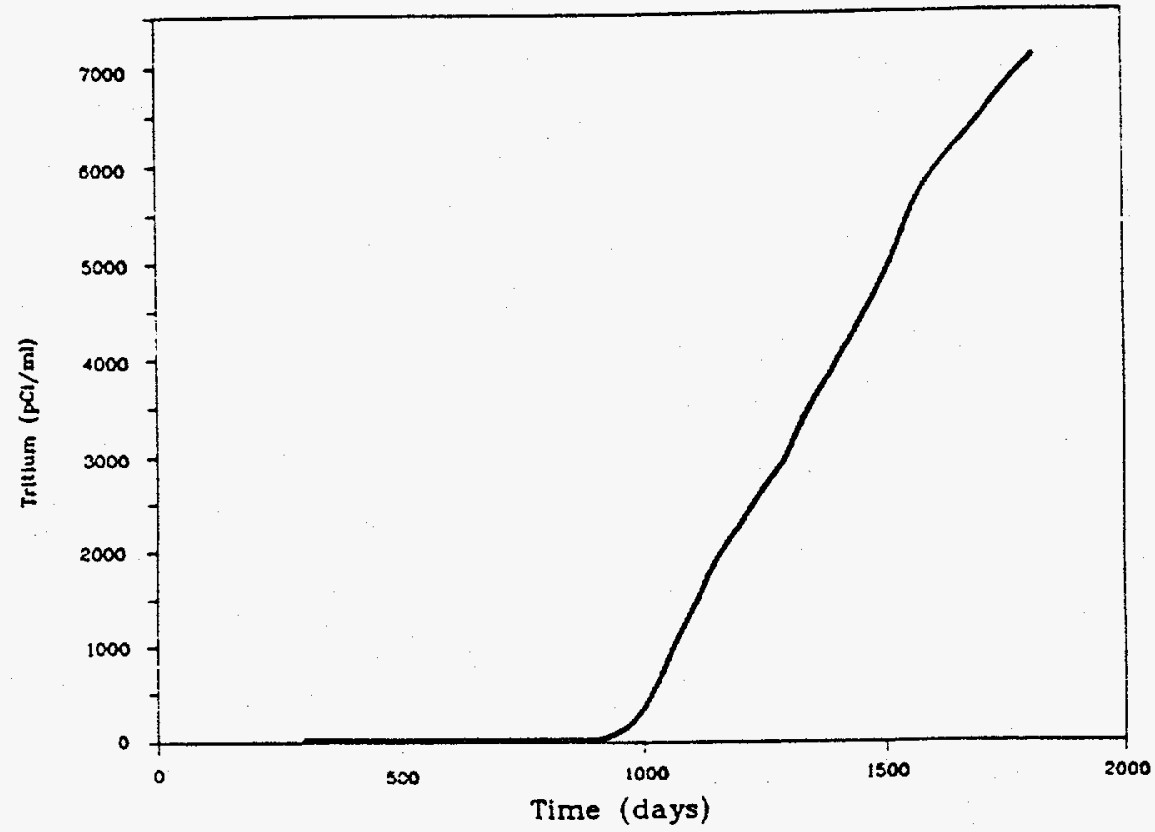

Figure 5. Tritium Concentration (corrected to Cambric Zero Time) at RNM-2S versus Time (after Daniels, 1981).

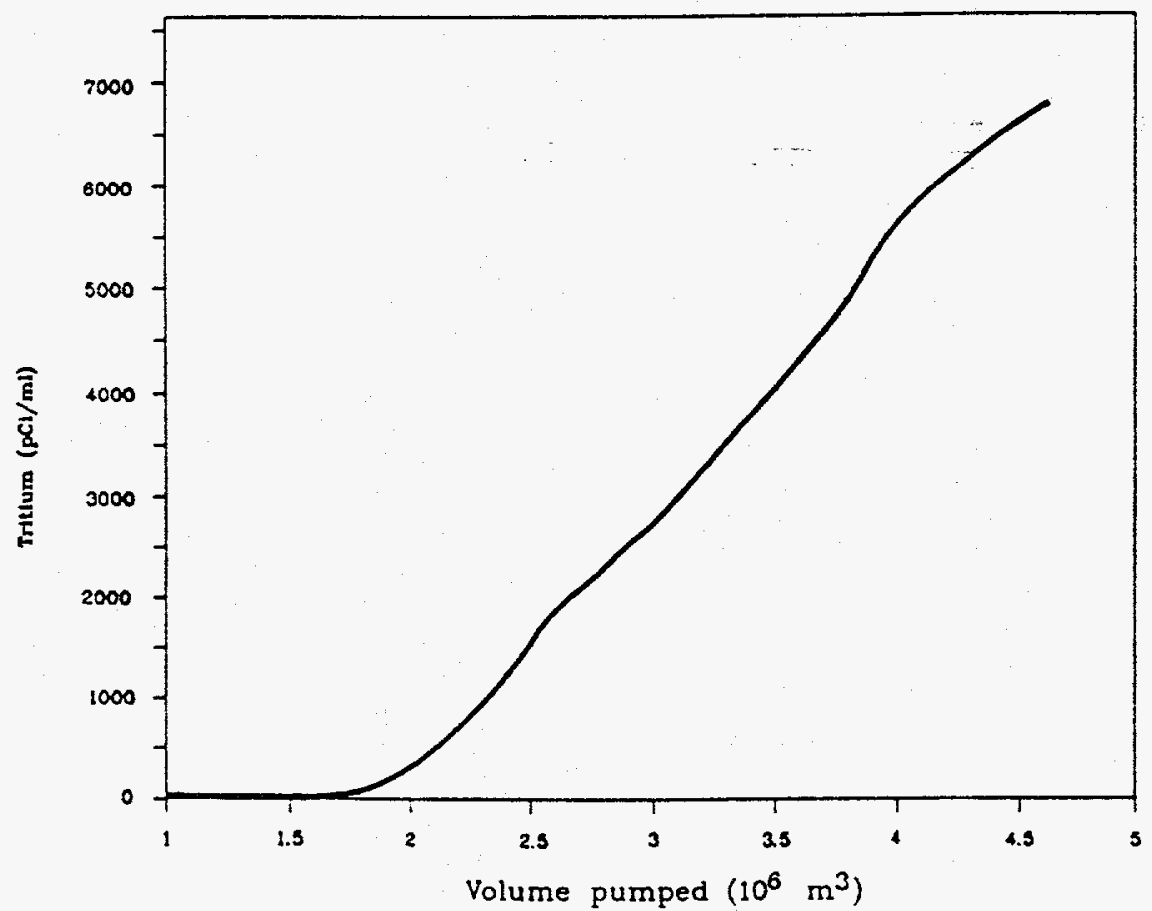

Figure 6. Tritium Concentration (corrected to Cambric Zero Time) at RNM-2S versus Volume Pumped (after Daniels, 1981). 
tritium breakthrough at RNM-2S was achieved by incorporating a low permeability layer (presumed to be playa type sediments) between the pump intake and the cavity region, and by assuming a distribution coefficient for tritium of $0.8 \mathrm{ml} / \mathrm{g}$ (Figure 7). Burbey and Wheatcraft (1986) also required the limited sorption for tritium in their studies at the Cambric site.

Distribution coefficients represent the partitioning of a contaminant between the solution and the solids, in this case, the water and the aquifer material. The distribution coefficient can be represented as

$$
\mathrm{K}_{\mathrm{d}}=\frac{\text { mass of solute on the solid phase per unit mass of solid phase }}{\text { concentration of solute in solution }}
$$

A high distribution coefficient indicates a strong tendency for sorption.

The goal of this study was to describe the flow of water and the transport of Cambric tritium to the water table beneath the RNM canal. The fairly complete record of the radionuclide input to the canal, together with detailed data on the canal transmission losses, provides a unique opportunity for study of transport processes in the thick, unsaturated alluvial deposits, characteristic of much of the arid southwest. This study will, hopefully, contribute to our general understanding of flow and transport in this environment. In addition, this report will demonstrate the problems and limitations inherent in numerical simulation of recharge through deep, variably saturated media. If the simulation results indicate that the recirculation of canal tritium may have significantly affected the breakthrough at RNM-2S, the results of this modeling effort could be used as input to a three-dimensional saturated transport model to simulate the arrival of Cambric tritium at $R N M-2 S$, incorporating this additional tritium source. 


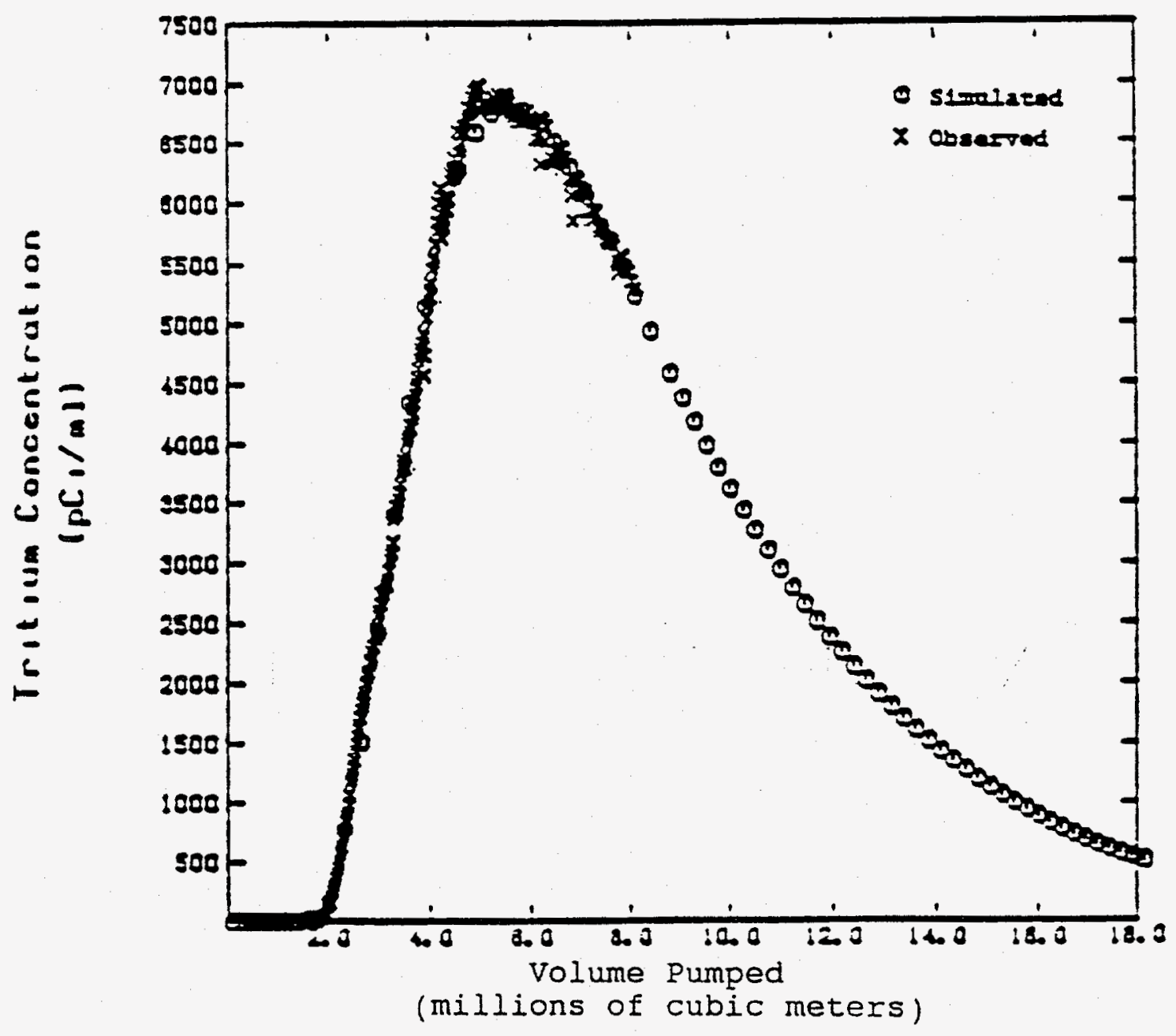

Figure 7. Plot Showing Concentration versus Volume Pumped. Tritium Data are Corrected to Shot Time (after Burbey, 1984). 


\section{HYDROGEOLOGY}

\section{LOCATION}

The Nevada Test Site, an area of about $3,600 \mathrm{~km}^{2}$, is located approximately $104 \mathrm{~km}$ northwest of Las Vegas in the Nevada desert. This area is in the southernmost part of the Great Basin section of the Basin and Range physiographic province defined by Fenneman (1931). Frenchman Flat, the site of the Cambric event, is in the southeast portion of the NTS.

Frenchman Flat is a gently sloping ( 10 to $12 \mathrm{~m} / \mathrm{km}$ ) closed basin with interior surface drainage to a normally dry playa, Frenchman Lake. Well-defined drainage channels in the mountainous areas and upper alluvial slopes become braided as they approach the lower desert floor. All channels are ephemeral, flowing only in response to precipitation. Runoff, rapidly lost to infiltration and evaporation, rarely reaches Frenchman Lake.

The study area lies in the most arid part of Nevada, the most arid State in the Union (Winograd et al., 1971). The average annual precipitation on Frenchman Flat is only about 15 $\mathrm{cm}$. The potential annual evaporation from lake and reservoir surfaces in this area has been estimated to range from 152 to $208 \mathrm{~cm}$ (Meyers and Nodenson, 1962).

\section{GEOLOGY}

Frenchman Flat lies in the transitional zone between the Tertiary volcanic rocks of south-central Nevada and the Paleozoic rocks, primarily carbonates, that characterize eastem Nevada. Mountain ranges to the south, southeast, and east of Frenchman Flat consist of lower Paleozoic limestone, dolomite, and quartzite. Tertiary volcanics, mostly tuffs, compose the hills to the north and west.

Erosion and sedimentation have filled the valley with alluvium and playa sediments. In central Frenchman Flat, the alluvium is at least $500 \mathrm{~m}$ thick and probably reaches a maximum thickness of 700 to $800 \mathrm{~m}$ (Hoffman et al., 1977). Figure 8 shows a cross section of the geology at the Cambric site along the section indicated in Figure 9 (the depths to Tertiary and Paleozoic rocks are speculative). For detailed information on the geology of the NTS, the reader is referred to Winograd et al. (1971) and Carr (1975).

\section{HYDROLOGY}

Frenchman Flat lies within the Ash Meadows groundwater system, an $11,500 \mathrm{~km}^{2}$ area in which water flows in a southwesterly direction to discharge at Ash Meadows in the Amargosa Desert.

Winograd et al. (1971) grouped the numerous geologic formations and members of the NTS region into units of hydrologic significance. The resulting 10 hydrogeologic units in order of decreasing age are: lower clastic aquitard; lower carbonate aquifer, upper clastic aquitard; upper carbonate aquifer; tuff aquitard; lava-flow aquitard; bedded tuff aquifer; welded tuff 


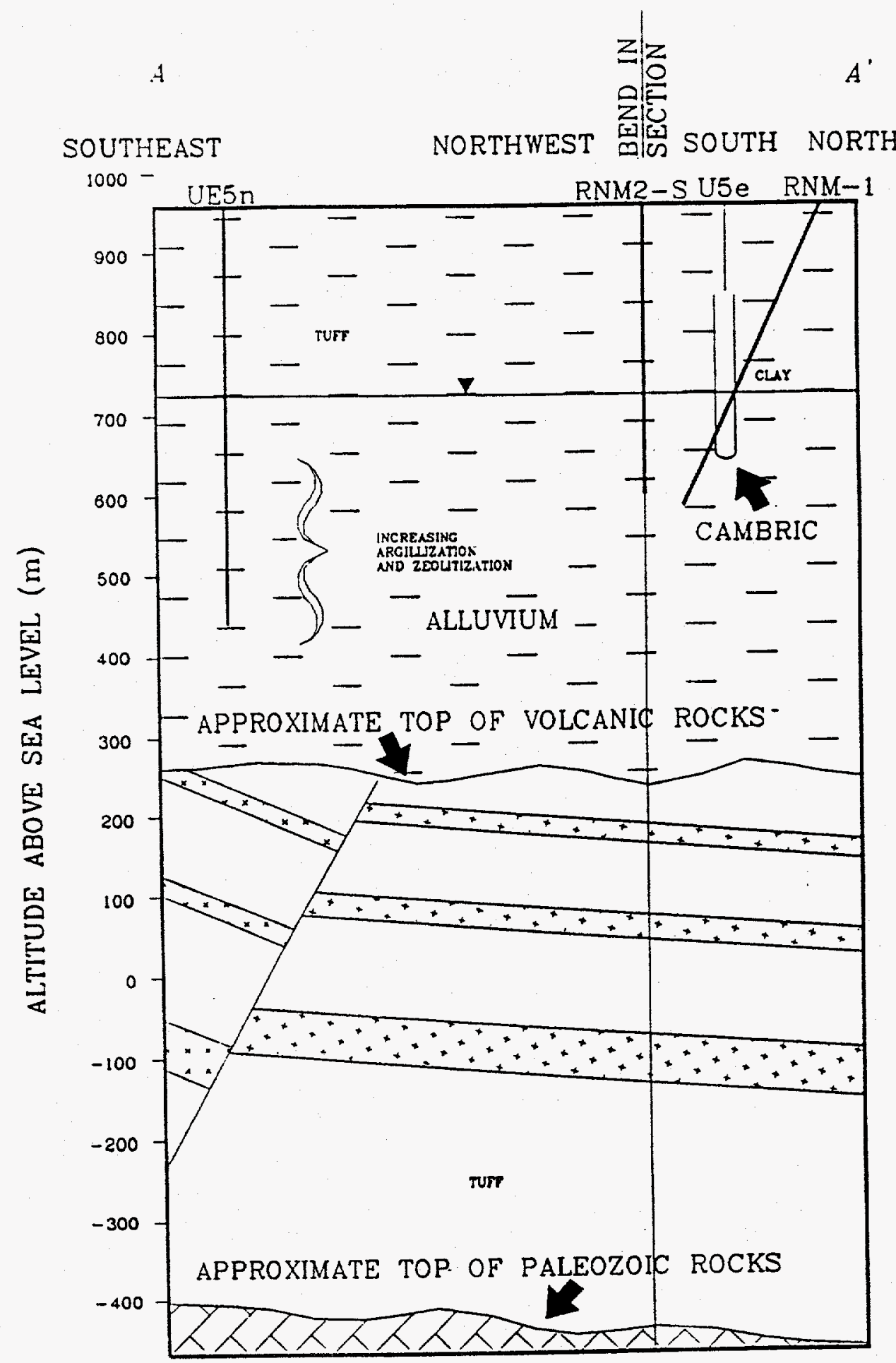

Figure 8. Geologic Section at RNM Site (after Hoffman et al., 1977). See Figure 10 for the Location of Section Line A- $\mathrm{A}^{\prime}$. 


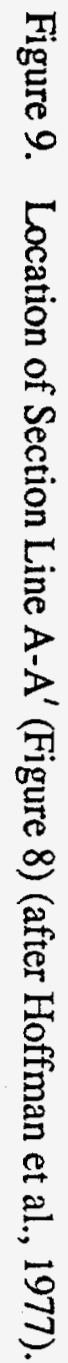

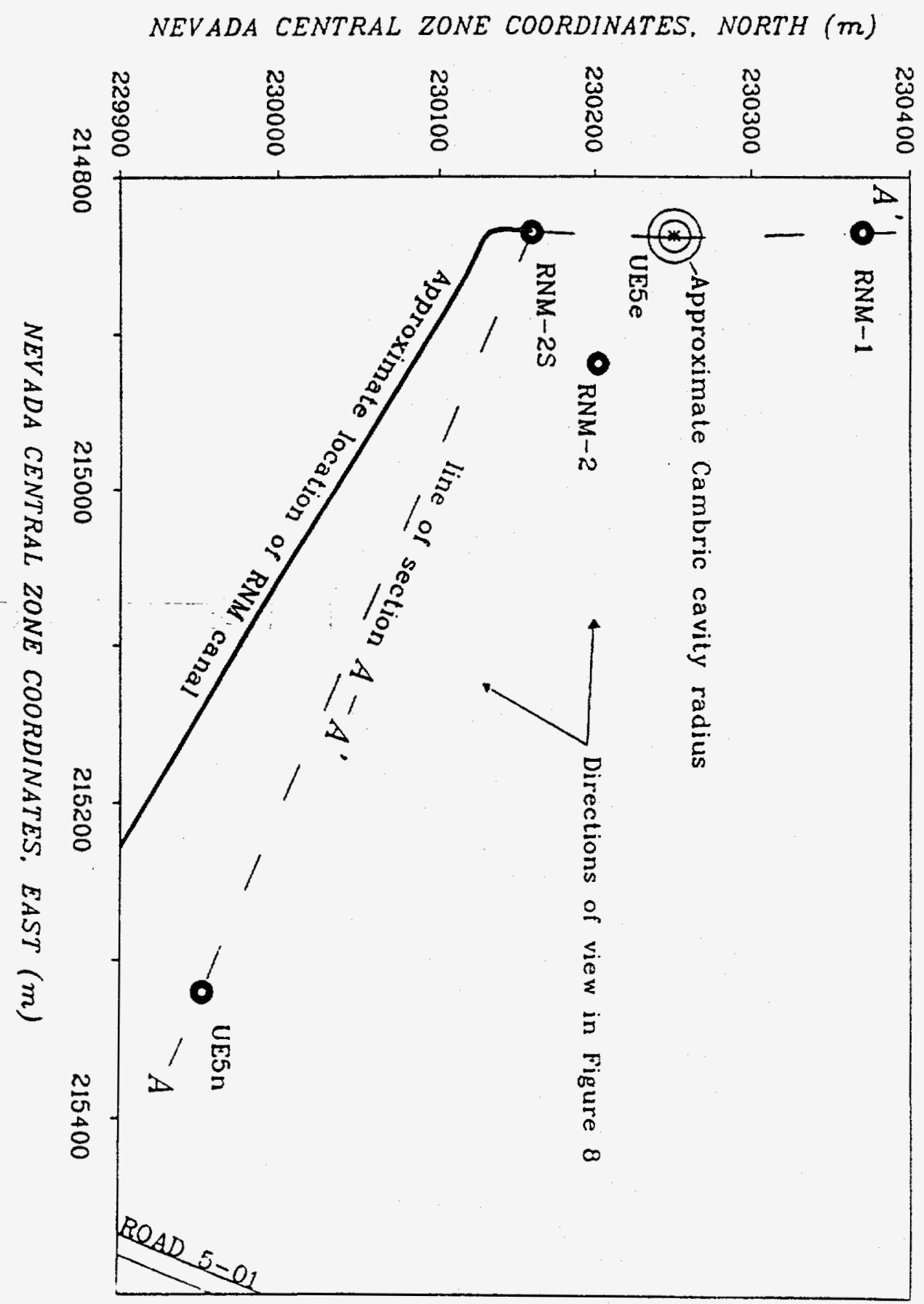


aquifer; lava-flow aquifer; and valley-fill aquifer. This study considers flow only in the valley-fill aquifer. See Winograd et al. (1971) for detailed description of the other hydrogeologic units.

Alluvial fan, fluvial, fanglomerate, lake bed, and mudflow deposits compose the valley fill (Winograd et al., 1971). It is the major water supply aquifer in Frenchman Flat, western Emigrant Valley, and the Amargosa Desert. The valley fill is at least $570 \mathrm{~m}$ thick beneath central Yucca Flat and at least $366 \mathrm{~m}$ thick beneath central Frenchman Flat. Well data at the Cambric site (RNM-1, RNM-2, UE5N) indicate that the alluvial fill in the vicinity of the RNM site is remarkably uniform (Hoffman et al., 1977). Medium to coarse sand is the dominant grain size. Pebbles were found in most samples and cuttings, and gravel and cobble beds were observed in the upper $200 \mathrm{~m}$. The sand particles and pebbles were derived mainly from Tertiary volcanics.

The static water table at the RNM site is $221 \mathrm{~m}$ below the land surface. The saturated hydraulic conductivity of RNM-1 sidewall samples was estimated from particle-size distribution to be about $4 \mathrm{~m} /$ day (although this value might be too high due to a loss of fines). Tests of wells RNM-2S, U5B, and U5C yielded values of saturated hydraulic conductivity of $1.5,1.4$, and $0.2 \mathrm{~m} /$ day, respectively. Figure 10 shows the locations of the wells in the vicinity of the Cambric site. 


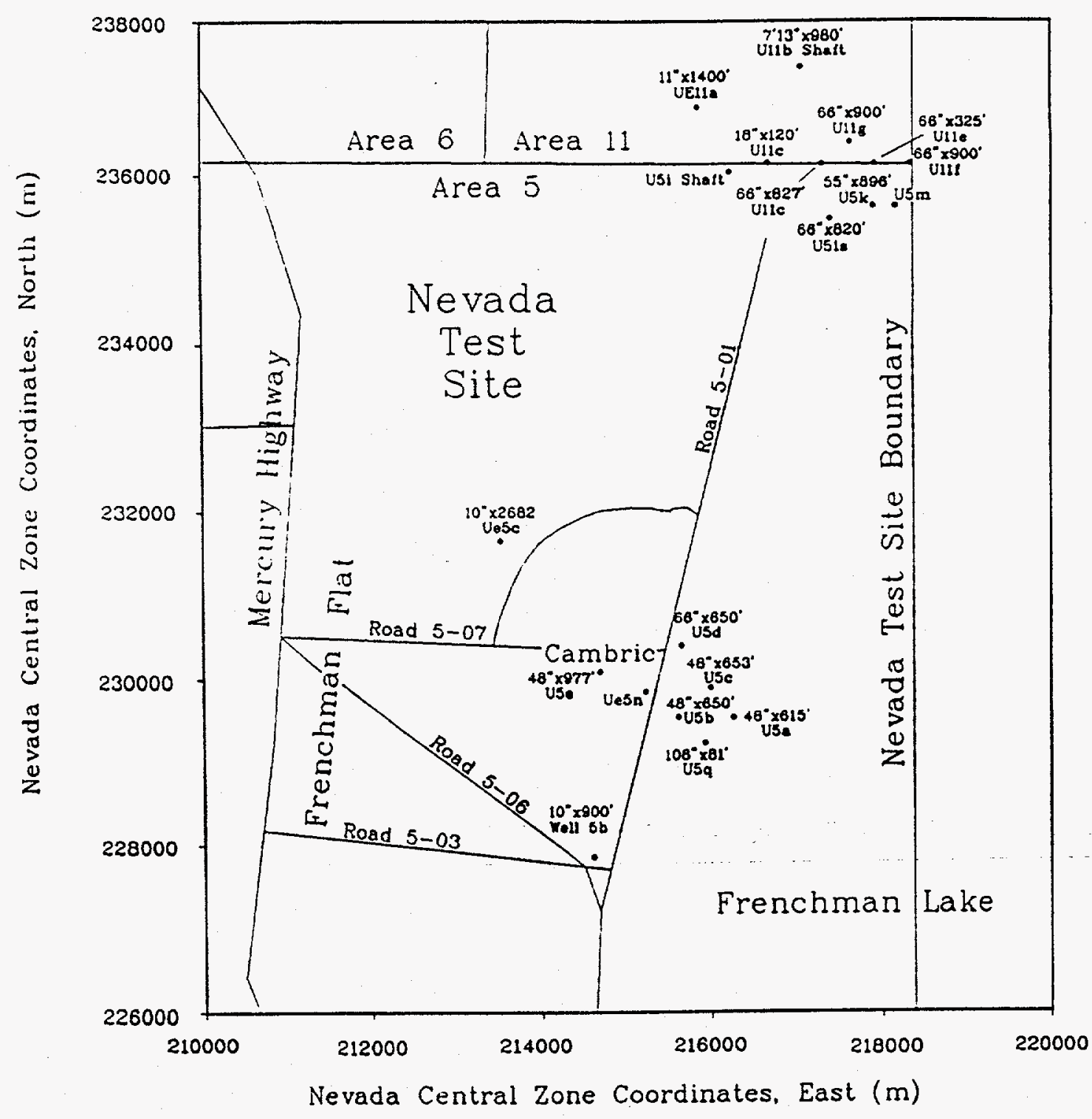

Figure 10. Map of Frenchman Flat Showing the Locations of Drill Holes (after Ramspott, 1977). 


\section{CANAL INFILTRATION MODEL}

\section{THE SATURN MODEL}

A variably saturated groundwater flow and solute transport numerical model, SATURN (Huyakorn et al., 1983), was used to simulate the flow of water and the transport of tritium from the RNM canal, through the thick unsaturated alluvial sediments to the water table. The two-dimensional model domain consisted of a vertical plane, normal to the canal, extending vertically from the ground surface to a depth of $225 \mathrm{~m}$ (approximately $4 \mathrm{~m}$ below the precanal water table), and laterally from the center of the canal to a distance of $200 \mathrm{~m}$. Only flow on one side of the canal was simulated, exploiting the symmetry of the flow system. For reasons discussed later, flow beneath the canal is believed to have been at steady state prior to the arrival of Cambric tritium at RNM-2S, allowing the flow and transport simulations to be conducted sequentially. A total of 1,500 days of tritium transport were simulated, beginning when Cambric tritium was first detected at RNM-2S.

\section{SATURN INPUT REQUIREMENTS}

Input data for SATURN include the following:

1. Flow Simulation--porous media properties.

Saturated hydraulic conductivity components, $\mathrm{K}_{\mathrm{xx}}, \mathrm{K}_{\mathrm{zz}}, \mathrm{K}_{\mathrm{xz}}$

Saturated specific storage

Effective porosity

Tabulated data of, or parameters of analytical expressions for; unsaturated hydraulic conductivity versus moisture content matric suction versus moisture content

2. Transport Simulation.

A. Porous media properties

Longitudinal dispersivity

Transverse dispersivity

Molecular diffusion coefficients, $D_{\mathbf{x x}}$ and $D_{\mathrm{zz}}$

Effective porosity

B. Properties of the solute species

Retardation coefficient

Initial inventory

\section{PARAMETER ESTIMATION}

Input data for the porous media properties were based on field and laboratory tests and on the literature. Input data regarding properties of water and tritium were from the literature. Saturated hydraulic conductivity was measured both in the field and in the laboratory, and compared to values from the literature. The unsaturated hydraulic conductivity function and the 
soil moisture characteristic were measured in situ by the instantaneous profile method (Hillel et al., 1972). Values of parameters in the analytical expressions relating matric suction and unsaturated hydraulic conductivity to moisture content were then determined by regression analysis (van Genuchten, 1978), and compared with the field measurements.

\section{Laboratory Saturated Hydraulic Conductivity Determination}

Core samples from holes US1 and US2 (Figure 3) were used to determine the saturated hydraulic conductivity of the alluvium. At three-meter intervals, one meter of $10-\mathrm{cm}$-diameter core was taken, where possible. The core was collected in brass sample sleeves, in $7.6-\mathrm{cm}$ and $15.2-\mathrm{cm}$ sections. Each section was separated with a knife and sealed with plastic end caps in the field.

The grain-size distribution of sidewall samples from RNM-1 was used to calculate an average hydraulic conductivity for the alluvium of about $4 \mathrm{~m} /$ day, although this estimate may be too high due to loss of fines. Tests of wells RNM-2S, U5B, and U5C yielded conductivities of $1.5 \mathrm{~m} /$ day, $1.4 \mathrm{~m} /$ day, and $0.2 \mathrm{~m} /$ day, respectfully (Hoffman et al., 1977). Klute (1965) suggests a constant head permeameter be used for samples with conductivities greater than approximately $0.14 \mathrm{~m} / \mathrm{day}$, and falling head methods for samples with lower conductivities.

A constant head permeameter was constructed for the testing. A pair of end caps were equipped with inflow and outflow fittings, allowing the cores to be tested in the sample sleeves, thus minimizing the disturbance of the sample and preserving as much of the soil structure as possible. Blocking of sample pores by air can result in sizable error in permeameter measurements. The entrapment of air in a sample during saturation will result in a falsely low measured conductivity. To avoid this, interstitial air in the cores was displaced with carbon dioxide prior to saturation. Carbon dioxide $\left(\mathrm{CO}_{2}\right)$ is far more soluble in water than air. For example, at $25^{\circ} \mathrm{C}, 759 \mathrm{ml}$ of $\mathrm{CO}_{2}$ can be absorbed by one liter of water (this is the volume of gas when reduced to $0^{\circ} \mathrm{C}$ and $760 \mathrm{~mm} \mathrm{Hg}$ ). Under similar conditions, only about $17 \mathrm{ml}$ of air can be dissolved in the same volume of water. In addition, the samples were saturated under a vacuum, from the bottom. To prevent any gas from coming out of solution during testing, degassed water was used. The results of the permeameter testing are given in Figure 11. After the permeameter testing, the saturated soil cores were weighed and oven dried at $105^{\circ} \mathrm{C}$ to determine the porosity. Porosity and saturated hydraulic conductivity data are presented in Table 1.

\section{Unsaturated Properties of the Porous Medium}

Quantitative description of unsaturated flow requires a knowledge of the water retention characteristics of the soil involved, and the functional dependence of hydraulic conductivity on moisture content or matric suction.

The difficulties associated with the direct measurement of unsaturated hydraulic conductivity have created substantial interest in methods of determining the hydraulic conductivity of an unsaturated soil from characteristics that are more easily quantified. According to Mualem (1976), these methods are of two types. The first relates the hydraulic 


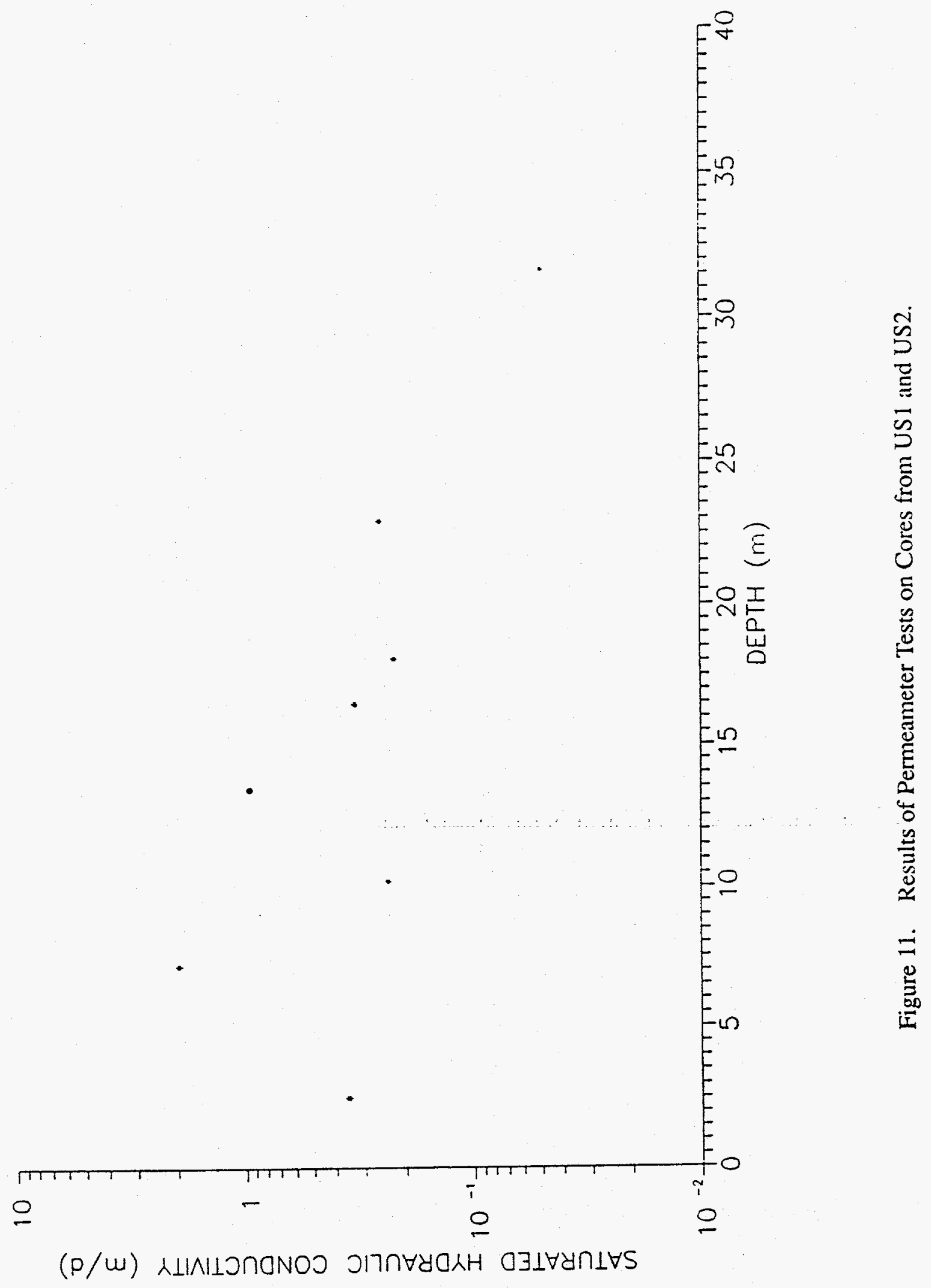


TABLE 1. POROSITY AND SATURATED HYDRAULIC CONDUCTIVITY OF SAMPLES FROM DRILL HOLES US1 AND US2.

\begin{tabular}{ccc}
\hline $\begin{array}{c}\text { Depth } \\
(\mathrm{m})\end{array}$ & Porosity & $\begin{array}{c}\text { Saturated } \\
\text { Hydraulic Conductivity } \\
(\mathrm{m} / \text { day })\end{array}$ \\
\hline 2.50 & 0.32 & $3.54 \times 10^{-1}$ \\
7.14 & 0.33 & 1.96 \\
10.18 & 0.33 & $2.35 \times 10^{-1}$ \\
13.39 & 0.33 & $9.42 \times 10^{-1}$ \\
16.43 & 0.33 & $3.24 \times 10^{-1}$ \\
18.04 & 0.36 & $2.19 \times 10^{-1}$ \\
22.86 & 0.36 & $2.51 \times 10^{-1}$ \\
31.60 & 0.36 & $4.84 \times 10^{-2}$ \\
\hline
\end{tabular}

conductivity to the soil characteristic (Childs and Collis-George, 1950; Marshall, 1958; Millington and Quirk, 1961; Jackson et al., 1965; Kunze et al., 1968; Farrell and Larson, 1972). The second method assumes that the hydraulic conductivity is a power function of the effective saturation (Brooks and Corey, 1964; Brutsaert, 1967; Jones and Wagenet, 1984).

SATURN assumes the following relationship between relative hydraulic conductivity, $\mathrm{k}_{\mathrm{r}}$, and dimensionless moisture content, $\hat{\Theta}$ :

$$
k_{r}=\frac{k(\Theta)}{k_{s a t}}=\hat{\Theta}^{n}
$$

where

$$
\hat{\Theta}=\frac{\Theta-\Theta_{r}}{\Theta_{s}-\Theta_{r}}
$$

where $\Theta, \Theta_{\mathrm{s}}$, and $\Theta_{\mathrm{r}}$ are the actual, saturated, and residual water contents, respectively. To assess the validity of the above assumption, measured hydraulic conductivity values were needed.

Klute (1972) surveyed the various methods for measuring the hydraulic conductivity of unsaturated soils. The methods are grouped into two types: steady-state and unsteady. In steady-state methods, the hydraulic gradient and volumetric flux are measured in a one-dimensional steady-state flow system. The hydraulic conductivity at the existing moisture content is then obtained from the Darcy equation.

Transient methods use the time dependence of some property of the flow system to determine the hydraulic conductivity. These methods can be classified as outflow-inflow 
methods, or instantaneous profile methods. A variety of outflow-inflow methods have been proposed (Gardner, 1956; Miller and Elrick, 1958; Rijtema, 1959; Kunze and Kirkham, 1962; Bruce and Klute, 1956; Jackson et al., 1963; Doering, 1965; Peek, 1966). Many investigators have applied forms of the instantaneous profile method to determine unsaturated hydraulic conductivity in the laboratory (Richards and Weeks, 1953; Watson, 1966; Vachaud, 1967; Weeks and Richards, 1967; Flocher et al., 1968; Cassel et al., 1968; Rogers and Klute, 1971; Vachaud and Thony, 1971); and in the field (Richards et al., 1956; Ogata and Richards, 1957; Nielson et al., 1962; Rose et al., 1965; van Bavel et al., 1968a, 1968b; Davidson et al., 1969; Gardner, 1970). The instantaneous profile method used to determine the hydraulic conductivity function of the soil at the RNM site is outlined by Hillel et al. (1972).

\section{Instantaneous Profile Test}

\section{Introduction}

Unsaturated hydraulic conductivity as a function of moisture content was determined by the instantaneous profile technique (Hillel et al., 1972). This method, based upon monitoring the internal drainage of a soil profile, requires the frequent and simultaneous measurement of moisture content and matric suction. From these measurements, the soil moisture characteristic, and instantaneous head gradients and moisture fluxes can be determined. The hydraulic conductivity is then obtained as the ratio of the flux to the head gradient. The instantaneous profile technique is an unsteady method that, when applied to a field soil, eliminates the problems associated with laboratory techniques, such as compaction or disaggregation of the sample, loss of soil structure, nonrepresentative sampling, or a change in sample orientation. According to Watson (1966), one attraction to this approach is that unlike steady-state methods where the dynamic effects present in unsteady flow are assumed to have a negligible effect on the 'steady-state' hydraulic conductivity, the instantaneous profile method determines conductivities at a particular instance in time.

\section{Theory}

Darcy's law for unsaturated vertical flow can be written as:

$$
q=-K(\Theta) \frac{\partial H}{\partial z}
$$

where $q$ is the fluid flux, $K(\Theta)$ is the unsaturated hydraulic conductivity as a function of moisture content, $\mathrm{H}$ is the hydraulic head, and $\mathrm{z}$ is the vertical dimension.

The general equation of continuity for flow through porous media is

$$
\frac{\partial \Theta}{\partial t}=-\nabla \cdot q
$$

where $t$ is time.

For one-dimensional vertical flow, equation (6) can be written 


$$
\frac{\partial \Theta}{\partial t}=-\frac{\partial q}{\partial z}
$$

Thus,

$$
\frac{\partial \Theta}{\partial t}=\frac{\partial}{\partial z}\left[K(\Theta) \frac{\partial H}{\partial z}\right]
$$

Integrating, we obtain

$$
\int_{0}^{z} \frac{\partial \Theta}{\partial t} d z=q=\left[K(\Theta) \frac{\partial H}{\partial z}\right] z
$$

The integral can be evaluated from the moisture data, and an instantaneous flux obtained. The hydraulic head gradient is calculated from tensiometer measurements. Finally,

$$
K(\Theta)=\frac{q}{\partial H / \partial z}
$$

\section{Experimental Design}

The site selected for the instantaneous profile test is located approximately $50 \mathrm{~m}$ northwest of flume 2 (Figure 3). An area of about $3 \mathrm{~m} \mathrm{x} 4 \mathrm{~m}$ was excavated to a depth of $15 \mathrm{~cm}$, and was enclosed by a $20-\mathrm{cm}$ soil berm. The plot was designed to be large enough so that only vertical infiltration occurred in the vicinity of the neutron tubes and tensiometers.

Two holes (designated N1 and N2 in Figure 12) for neutron access tubes were hand augered to a depth of $250 \mathrm{~cm}$. The bottoms of the tubes were stoppered to prevent the entry of water. 5.08-cm I.D. aluminum neutron access tubes were installed and backfilled with a slurry made from the cuttings.

Two tensiometer arrays--five tensiometers each--were installed in the positions shown, with the shallowest tensiometer at $26 \mathrm{~cm}$, the deepest at $214 \mathrm{~cm}$. The porous tips were packed with mud made of fines from the auger cuttings. The holes were then backfilled with a slurry also made from the cuttings. The exposed tubing and gauges were covered with thick fiberglass insulation to prevent freezing.

A single temperature probe was installed at the position indicated, at a depth of $60 \mathrm{~cm}$ to detect the advancing wetting front. A staff gauge was placed in the plot for water depth measurement. Figure 12 shows the locations of the instruments at the test plot.

Two outflow tubes were installed on the southeast corner of the plot to prevent erosion of the berm when the inflow exceeded the infiltration rate during the initial wetting of the profile. An inflow tube was positioned near the center of the plot with a slotted PVC diffuser attached to the end to prevent scour of the plot bottom. 


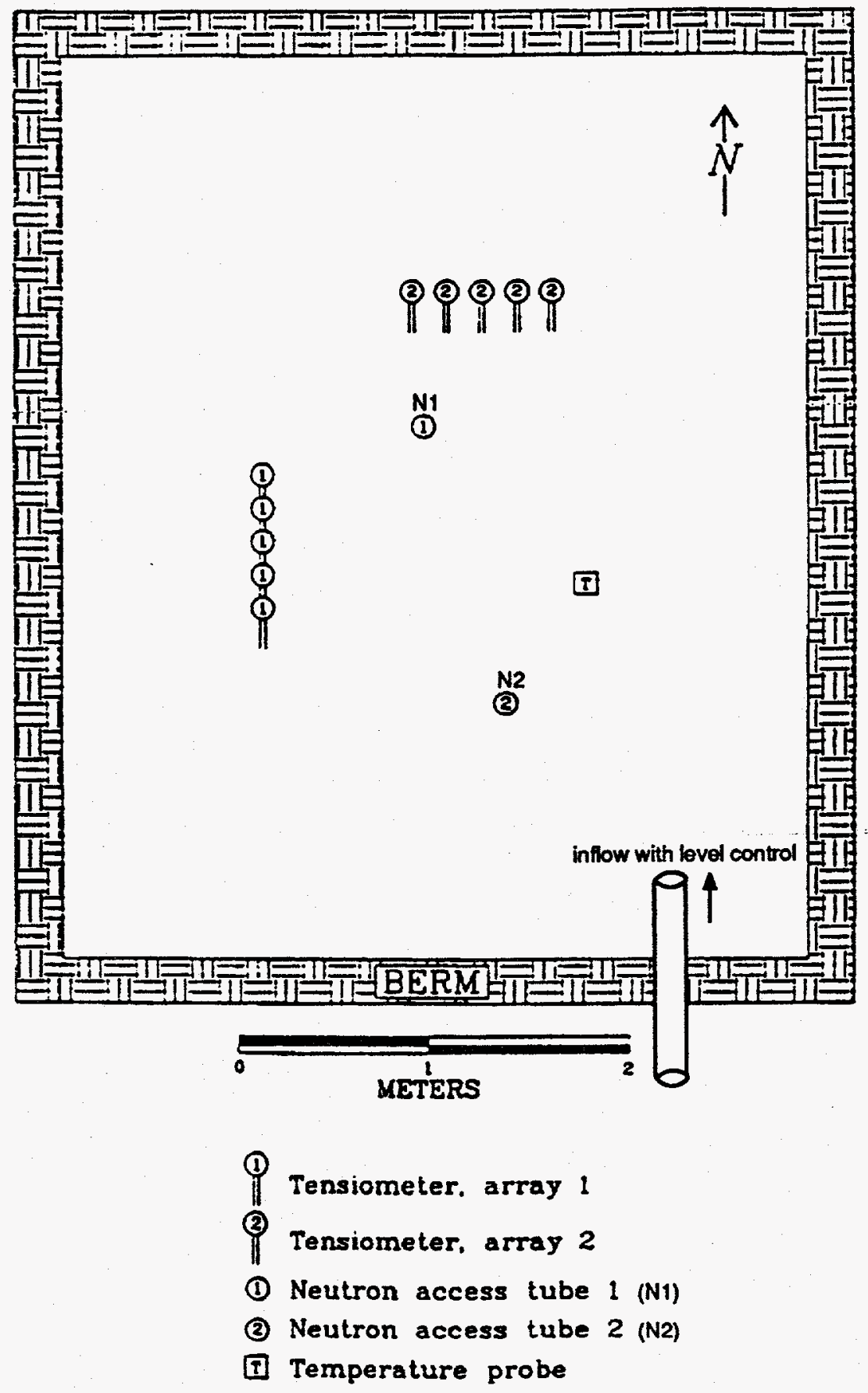

Figure 12. Instantaneous Profile Test Site. 


\section{Data Collection}

Prior to flooding the plot, both neutron tubes were logged at $0.3-\mathrm{m}$ intervals and all tensiometer readings were recorded. Water for the test was pumped from the RNM canal to the plot, a distance of about $40 \mathrm{~m}$. By keeping the inflow slightly greater than the infiltration rate, a constant head of approximately $10 \mathrm{~cm}$ was maintained at the level of the outflow tubes. Soil moisture and matric suction were monitored to determine when the profile was saturated.

After about three days, the tensiometer and neutron readings had stabilized, indicating that infiltration through the profile had reached steady state. The steady-state infiltration rate was determined by two methods. In the first method, the inflow-outflow rates were measured and the difference attributed to infiltration. In the second method, the pump was shut off and the depth of water on the plot was measured as a function of time, and an average flux obtained. Both methods ignore evaporation, considered to be negligible compared to the inflow-outflow rates and considering the relatively short period of the experiment.

As soon as the water level reached the soil surface, the plot was covered with black plastic and frequent and concurrent measurements of soil wetness and matric suction were taken. Neutron moisture meter data and tensiometer data are listed in Appendices A and B, respectively. Only N1 was logged for the first 1.5 hours. The time between measurements increased as the plot drained and changes in soil moisture and suction occurred less rapidly.

Twenty-three days after cessation of pumping, three soil samples were taken for calibration of the neutron probe. Core barrels (5-cm I.D.) were driven from $50 \mathrm{~cm}$ to $60 \mathrm{~cm}$ below the plot bottom at a distance of $15 \mathrm{~cm}$ from $\mathrm{N} 2$. N2 was then logged at this interval.

\section{In-Situ Saturated Hydraulic Conductivity Determination}

After the neutron and tensiometer readings had stabilized, inflow and outflow were measured to determine the infiltration flux. Three measurements at the inflow tube, and three at each outflow tube were made and are listed in Appendix $C$. The measurements at each tube were averaged and the flux of infiltration computed as

$$
\begin{gathered}
q=\frac{\bar{I}-\overline{O_{1}}-\overline{O_{2}}}{A} \\
=\frac{\left(8.914 \times 10^{2} \frac{\mathrm{cm}^{3}}{\mathrm{sec}}\right)-\left(3.709 \times 10^{2} \frac{\mathrm{cm}^{3}}{\mathrm{sec}}\right)-\left(1.495 \times 10^{2} \frac{\mathrm{cm}^{3}}{\mathrm{sec}}\right)}{1.93 \times 10^{5} \mathrm{~cm}^{2}} \\
=1.92 \times 10^{-3} \frac{\mathrm{cm}}{\mathrm{sec}}
\end{gathered}
$$

where $\mathrm{q}$ is the infiltration flux (neglecting evaporation), $\bar{I}$ is the average inflow, $\bar{O}_{1}$ is the average outflow at tube $1, \bar{O}_{2}$ is the average outflow at tube 2 , and $\mathrm{A}$ is the area of the plot.

A second measurement of the infiltration flux was made by recording the rate at which the water level dropped on the plot after the pump was turned off (data are listed in Appendix C). 
The water level dropped $4.27 \mathrm{~cm}$ in 3,540 seconds for an average flux of $1.21 \times 10^{-3} \mathrm{~cm} / \mathrm{sec}$, again ignoring evaporation.

For saturated vertical flow in a free-draining medium, if the ponding depth is negligible, a unit hydraulic gradient will exist, and the fluid flux will equal the saturated hydraulic conductivity (Black et al., 1969; Davidson et al., 1969; Hillel, 1971). As can be seen by Figure 13, the infiltration rate is independent of the depth of ponding, which can be considered negligible, and the infiltration fluxes can be used as estimates of the saturated hydraulic conductivity. Conductivities, thus obtained, agree fairly well with values from other methods (Table 2).

\section{Soil Moisture Characteristic Curves}

Soil moisture characteristic curves were produced for each depth at which moisture content was measured. Moisture values from N1 and N2 were averaged. Where data from N2 were not available (the first three hours after the pump was turned off), data from N1 were used. Matric suctions for these depths were obtained by averaging data from the two tensiometer arrays and then interpolating to the neutron log depths.

The curves indicate considerable variability in hydraulic properties with depth. A nonlinear, least squares, curve-fitting algorithm (van Genuchten, 1978) was used to obtain equations for the curves of the form:

$$
\Theta=\left(n-\Theta_{r}\right)\left\{\frac{1}{1+\left(a \mid \psi-\psi_{a}\right)^{\beta}}\right\}^{\gamma}+\Theta_{r}
$$

where $\Theta$ is the moisture content, $\alpha, \beta$, and $\gamma$ are parameters to be determined by the curve-fitting algorithm, $\psi$ is the pressure head, $\psi_{\mathbf{a}}$ is the air-entry pressure head, $n$ is the porosity, and $\Theta_{\mathrm{r}}$ is the residual moisture content.

\section{Unsaturated Hydraulic Conductivity Determination}

Appendix D contains plots of volumetric moisture content $(\Theta)$ versus time, for each depth. The flux through each depth increment $(\mathrm{dz})$ is determined by integrating the moisture versus time curve with respect to depth (Tables 3 and 4). Values of $\frac{\partial \Theta}{\partial t}$ were obtained by fitting a smooth curve to the data and measuring the tangents to the curves at $t=1,2,5,10$, and 20 days.

Appendix E contains plots of total head $(\mathrm{H})$ versus depth (z) for 1, 2, 5, 10, and 20 days. The total head is calculated as

$$
H=\bar{\Psi}+z
$$




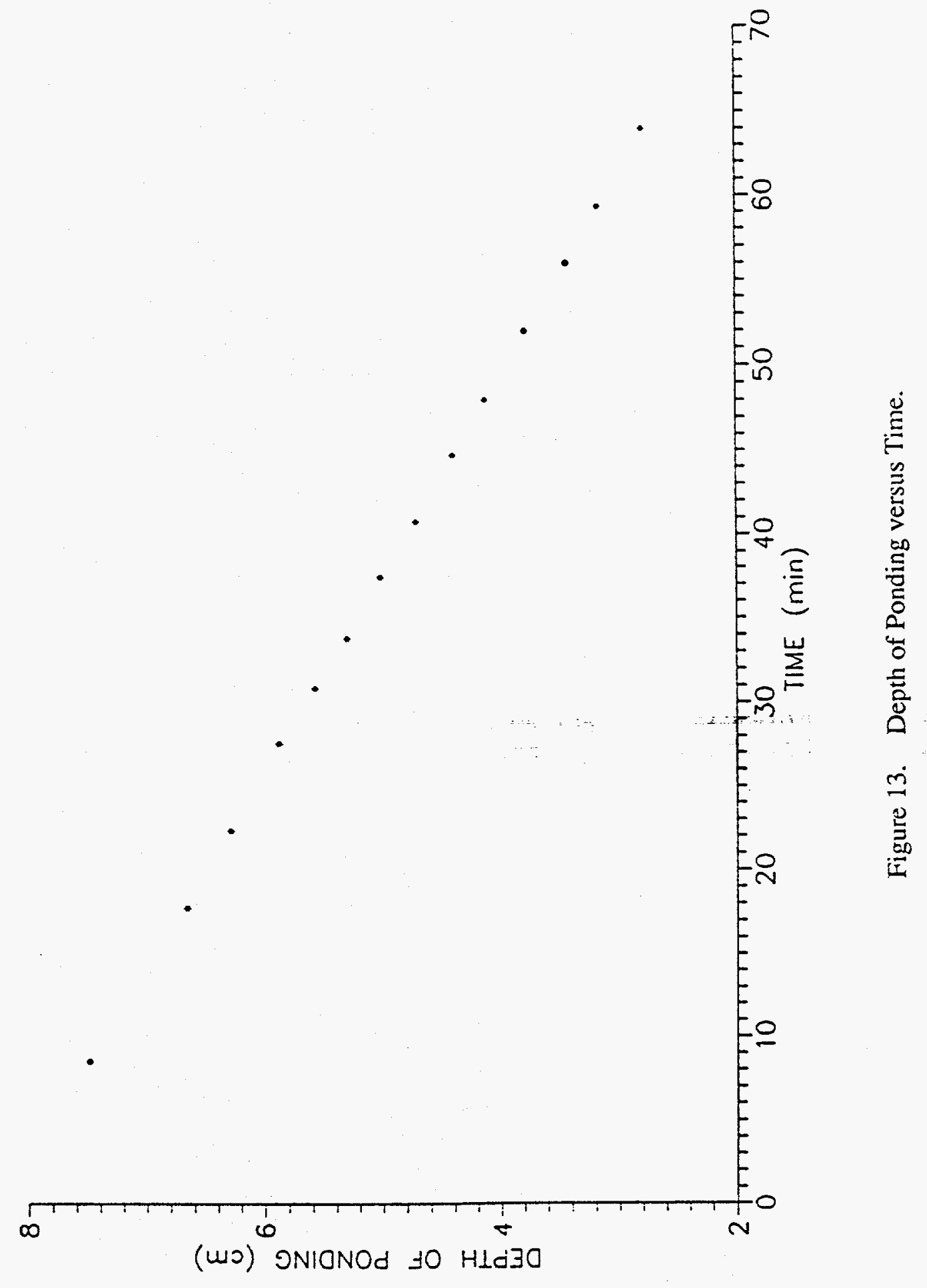


TABLE 2. COMPARISON OF SATURATED HYDRAULIC CONDUCTIVITY ESTIMATES.

\begin{tabular}{cccc}
\hline \multicolumn{4}{c}{ Saturated Hydraulic Conductivity (m/day) } \\
\hline Canal & Inst. Profile & Permeameter & Literature \\
\hline $5.43 \times 10^{-1}(1)$ & $1.66(2)$ & $3.54 \times 10^{-1}(4)$ & $4.0(5)$ \\
- & $1.05(3)$ & 1.96 & $1.5(6)$ \\
- & - & $2.35 \times 10^{-1}$ & $1.4(7)$ \\
- & - & $9.42 \times 10^{-1}$ & $2.0 \times 10^{-1}(8)$ \\
- & - & $3.24 \times 10^{-1}$ & - \\
- & - & $2.19 \times 10^{-1}$ & - \\
- & - & $2.51 \times 10^{-1}$ & - \\
- & - & $4.84 \times 10^{-2}$ & - \\
\hline
\end{tabular}

1. (Canal transmission loss)/(Area of canal bottom).

2. (Inflow - outflow)/(Area of plot).

3. (Water level drop)/(Unit time).

4. Constant-head permeameter tests on samples from US1 and US2.

5. RNM-1 sidewall samples (Hoffman et al., 1977).

6. Test of well RNM-2S (Hoffman et al., 1977).

7. Test of well 5B (Hoffman et al., 1977).

8. Test of well 5C (Hoffman et al., 1977).

where $\bar{\psi}$ is the average matric suction of the two tensiometer arrays. Matric suctions at $1,2,5$, 10 , and 20 days were interpolated from data taken at times which were, in part, determined by technician availability. The hydraulic gradients, $\frac{\partial H}{\partial z}$, are obtained from these plots.

Hydraulic conductivity as a function of moisture content, $K(\Theta)$, for each depth is calculated by dividing the fluxes by the corresponding hydraulic gradient (Tables 5 and 6). Figures 14 and 15 are plots of $K(\Theta)$ versus $\Theta$, for N1 and N2, respectively. Again, vertical heterogeneities are very apparent.

The SATURN code requires specification of the functional dependence of saturation on pressure, and that of relative permeability on saturation or pressure. The saturated hydraulic conductivity and soil moisture characteristic data obtained in the instantaneous profile test were used as input for SOHYP (van Genuchten, 1978), a computer model for calculating the soil hydraulic properties from soil moisture retention data. SOHYP utilizes a nonlinear, least squares, curve-fitting algorithm to obtain an equation of the soil moisture characteristic curve. The resulting equation is substituted in the predictive conductivity model of Mualem (1976). The equation relating relative hydraulic conductivity, $k_{r}$, to dimensionless moisture content, $\hat{\boldsymbol{\theta}}$, is 
TABLE 3. CALCULATION OF SOIL MOISTURE FLUX--N1 (instantaneous profile test).

\begin{tabular}{|c|c|c|c|c|}
\hline $\begin{array}{l}\text { Time } \\
\text { (days) }\end{array}$ & $\begin{array}{c}\mathrm{z} \\
(\mathrm{cm})\end{array}$ & $\frac{\delta \Theta}{\delta t}$ & $\begin{array}{l}d z\left(\frac{\delta \Theta}{\delta t}\right) \\
(\mathrm{cm} / \mathrm{hrs})\end{array}$ & $q=\sum_{(\mathrm{cm} / \mathrm{hrs})} d z\left(\frac{\delta \Theta}{\delta t}\right)$ \\
\hline 1 day & $\begin{array}{r}0-15 \\
15-45 \\
45-75 \\
75-105 \\
105-135 \\
135-165 \\
165-195\end{array}$ & $\begin{array}{l}7.55 \times 10^{-4} \\
7.55 \times 10^{-4} \\
1.39 \times 10^{-3} \\
6.16 \times 10^{-4} \\
1.09 \times 10^{-3} \\
1.01 \times 10^{-3} \\
1.36 \times 10^{-3}\end{array}$ & $\begin{array}{l}1.13 \times 10^{-2} \\
2.26 \times 10^{-2} \\
4.18 \times 10^{-2} \\
1.85 \times 10^{-2} \\
3.26 \times 10^{-2} \\
3.02 \times 10^{-2} \\
4.08 \times 10^{-2}\end{array}$ & $\begin{array}{l}1.13 \times 10^{-2} \\
3.40 \times 10^{-2} \\
7.58 \times 10^{-2} \\
9.42 \times 10^{-2} \\
1.27 \times 10^{-1} \\
1.57 \times 10^{-1} \\
1.98 \times 10^{-1}\end{array}$ \\
\hline 2 days & $\begin{array}{r}0-15 \\
15-45 \\
45-75 \\
75-105 \\
105-135 \\
135-165 \\
165-195\end{array}$ & $\begin{array}{l}2.59 \times 10^{-4} \\
2.59 \times 10^{-4} \\
4.00 \times 10^{-4} \\
3.35 \times 10^{-4} \\
6.95 \times 10^{-4} \\
3.68 \times 10^{-4} \\
5.11 \times 10^{-4}\end{array}$ & $\begin{array}{l}3.88 \times 10^{-3} \\
7.77 \times 10^{-3} \\
1.20 \times 10^{-2} \\
1.01 \times 10^{-2} \\
2.09 \times 10^{-2} \\
1.10 \times 10^{-2} \\
1.53 \times 10^{-2}\end{array}$ & $\begin{array}{l}3.88 \times 10^{-3} \\
1.17 \times 10^{-2} \\
2.37 \times 10^{-2} \\
3.37 \times 10^{-2} \\
5.46 \times 10^{-2} \\
6.56 \times 10^{-2} \\
8.09 \times 10^{-2}\end{array}$ \\
\hline 5 days & $\begin{array}{r}0-15 \\
15-45 \\
45-75 \\
75-105 \\
105-135 \\
135-165 \\
165-195\end{array}$ & $\begin{array}{l}1.57 \times 10^{-4} \\
1.57 \times 10^{-4} \\
1.50 \times 10^{-4} \\
1.17 \times 10^{-4} \\
3.98 \times 10^{-4} \\
2.33 \times 10^{-4} \\
1.75 \times 10^{-4}\end{array}$ & $\begin{array}{l}2.36 \times 10^{-3} \\
4.72 \times 10^{-3} \\
4.50 \times 10^{-3} \\
3.51 \times 10^{-3} \\
1.19 \times 10^{-2} \\
6.98 \times 10^{-3} \\
5.25 \times 10^{-3}\end{array}$ & $\begin{array}{l}2.36 \times 10^{-3} \\
7.08 \times 10^{-3} \\
1.16 \times 10^{-2} \\
1.51 \times 10^{-2} \\
2.70 \times 10^{-2} \\
3.40 \times 10^{-2} \\
3.93 \times 10^{-2}\end{array}$ \\
\hline 10 days & $\begin{array}{r}0-15 \\
15-45 \\
45-75 \\
75-105 \\
105-135 \\
135-165 \\
165-195\end{array}$ & $\begin{array}{l}1.70 \times 10^{-5} \\
1.70 \times 10^{-5} \\
5.80 \times 10^{-5} \\
6.70 \times 10^{-5} \\
2.10 \times 10^{-5} \\
3.30 \times 10^{-5} \\
5.80 \times 10^{-5}\end{array}$ & $\begin{array}{l}2.50 \times 10^{-4} \\
5.00 \times 10^{-4} \\
1.75 \times 10^{-3} \\
2.00 \times 10^{-3} \\
6.25 \times 10^{-4} \\
1.00 \times 10^{-3} \\
1.75 \times 10^{-3}\end{array}$ & $\begin{array}{l}2.50 \times 10^{-4} \\
7.50 \times 10^{-4} \\
2.50 \times 10^{-3} \\
4.50 \times 10^{-3} \\
5.12 \times 10^{-3} \\
6.12 \times 10^{-3} \\
7.88 \times 10^{-3}\end{array}$ \\
\hline 20 days & $\begin{array}{r}0-15 \\
15-45 \\
45-75 \\
75-105 \\
105-135 \\
135-165 \\
165-195\end{array}$ & $\begin{array}{c}0.0 \\
0.0 \\
0.0 \\
1.10 \times 10^{-5} \\
6.00 \times 10^{-6} \\
0.0 \\
3.10 \times 10^{-5}\end{array}$ & $\begin{array}{c}0.0 \\
0.0 \\
0.0 \\
3.13 \times 10^{-4} \\
1.88 \times 10^{-4} \\
0.0 \\
9.37 \times 10^{-4}\end{array}$ & $\begin{array}{c}0.0 \\
0.0 \\
0.0 \\
3.13 \times 10^{-4} \\
5.00 \times 10^{-4} \\
5.00 \times 10^{-4} \\
1.44 \times 10^{-3}\end{array}$ \\
\hline
\end{tabular}


TABLE 4. CALCULATION OF SOL MOISTURE FLUX--N2 (instantaneous profile test).

\begin{tabular}{|c|c|c|c|c|}
\hline $\begin{array}{l}\text { Time } \\
\text { (days) }\end{array}$ & $\begin{array}{c}\mathrm{z} \\
(\mathrm{cm})\end{array}$ & $\frac{\frac{\delta \Theta}{\delta t}}{\left(\mathrm{hr}^{-1}\right)}$ & $\begin{array}{l}d z\left(\frac{\delta \Theta}{\delta t}\right) \\
(\mathrm{cm} / \mathrm{hrs})\end{array}$ & $q=\sum_{(\mathrm{cm} / \mathrm{hrs})} d z\left(\frac{\delta \Theta}{\delta t}\right)$ \\
\hline 1 day & $\begin{array}{r}0-15 \\
15-45 \\
45-75 \\
75-105 \\
105-135 \\
135-165 \\
165-195\end{array}$ & $\begin{array}{l}1.75 \times 10^{-3} \\
1.75 \times 10^{-3} \\
2.09 \times 10^{-3} \\
1.39 \times 10^{-3} \\
1.04 \times 10^{-3} \\
1.16 \times 10^{-3} \\
1.18 \times 10^{-3}\end{array}$ & $\begin{array}{l}2.63 \times 10^{-2} \\
5.25 \times 10^{-2} \\
6.27 \times 10^{-2} \\
4.18 \times 10^{-2} \\
3.12 \times 10^{-2} \\
3.47 \times 10^{-2} \\
3.54 \times 10^{-2}\end{array}$ & $\begin{array}{l}2.63 \times 10^{-2} \\
7.88 \times 10^{-2} \\
1.42 \times 10^{-1} \\
1.83 \times 10^{-1} \\
2.15 \times 10^{-1} \\
2.49 \times 10^{-1} \\
2.85 \times 10^{-1}\end{array}$ \\
\hline 2 days & $\begin{array}{r}0-15 \\
15-45 \\
45-75 \\
75-105 \\
105-135 \\
135-165 \\
165-195\end{array}$ & $\begin{array}{l}6.71 \times 10^{-4} \\
6.71 \times 10^{-4} \\
5.90 \times 10^{-4} \\
8.48 \times 10^{-4} \\
4.47 \times 10^{-4} \\
6.25 \times 10^{-4} \\
5.94 \times 10^{-4}\end{array}$ & $\begin{array}{l}1.01 \times 10^{-2} \\
2.01 \times 10^{-2} \\
1.77 \times 10^{-2} \\
2.54 \times 10^{-2} \\
1.34 \times 10^{-2} \\
1.88 \times 10^{-2} \\
1.78 \times 10^{-2}\end{array}$ & $\begin{array}{l}1.01 \times 10^{-2} \\
3.02 \times 10^{-2} \\
4.79 \times 10^{-2} \\
7.33 \times 10^{-2} \\
8.68 \times 10^{-2} \\
1.06 \times 10^{-1} \\
1.23 \times 10^{-1}\end{array}$ \\
\hline 5 days & $\begin{array}{r}0-15 \\
15-45 \\
45-75 \\
75-105 \\
105-135 \\
135-165 \\
165-195\end{array}$ & $\begin{array}{l}9.40 \times 10^{-5} \\
9.40 \times 10^{-5} \\
1.58 \times 10^{-4} \\
1.15 \times 10^{-4} \\
7.10 \times 10^{-5} \\
2.90 \times 10^{-5} \\
9.21 \times 10^{-5}\end{array}$ & $\begin{array}{l}1.41 \times 10^{-3} \\
2.81 \times 10^{-3} \\
4.75 \times 10^{-3} \\
3.44 \times 10^{-3} \\
2.12 \times 10^{-3} \\
8.75 \times 10^{-4} \\
2.75 \times 10^{-3}\end{array}$ & $\begin{array}{l}1.41 \times 10^{-3} \\
4.22 \times 10^{-3} \\
8.97 \times 10^{-3} \\
1.24 \times 10^{-2} \\
1.45 \times 10^{-2} \\
1.54 \times 10^{-2} \\
1.82 \times 10^{-2}\end{array}$ \\
\hline 10 days & $\begin{array}{r}0-15 \\
15-45 \\
45-75 \\
75-105 \\
105-135 \\
135-165 \\
165-195\end{array}$ & $\begin{array}{l}4.60 \times 10^{-5} \\
4.60 \times 10^{-5} \\
6.20 \times 10^{-5} \\
1.90 \times 10^{-5} \\
7.10 \times 10^{-5} \\
2.90 \times 10^{-5} \\
4.00 \times 10^{-5}\end{array}$ & $\begin{array}{l}6.87 \times 10^{-4} \\
1.38 \times 10^{-3} \\
1.88 \times 10^{-3} \\
5.62 \times 10^{-4} \\
2.12 \times 10^{-3} \\
8.75 \times 10^{-4} \\
1.19 \times 10^{-3}\end{array}$ & $\begin{array}{l}6.87 \times 10^{-4} \\
2.06 \times 10^{-3} \\
3.94 \times 10^{-3} \\
4.50 \times 10^{-3} \\
6.62 \times 10^{-3} \\
7.50 \times 10^{-3} \\
8.69 \times 10^{-3}\end{array}$ \\
\hline 20 days & $\begin{array}{r}0-15 \\
15-45 \\
45-75 \\
75-105 \\
105-135 \\
135-165 \\
165-195\end{array}$ & $\begin{array}{c}0.0 \\
0.0 \\
2.70 \times 10^{-5} \\
4.00 \times 10^{-6} \\
0.0 \\
2.90 \times 10^{-5} \\
4.00 \times 10^{-5}\end{array}$ & $\begin{array}{c}0.0 \\
0.0 \\
8.12 \times 10^{-4} \\
1.25 \times 10^{-4} \\
0.0 \\
8.75 \times 10^{-4} \\
1.19 \times 10^{-3}\end{array}$ & $\begin{array}{c}0.0 \\
0.0 \\
8.12 \times 10^{-4} \\
9.37 \times 10^{-4} \\
9.37 \times 10^{-4} \\
1.81 \times 10^{-3} \\
3.00 \times 10^{-3}\end{array}$ \\
\hline
\end{tabular}


TABLE 5. CALCULATION OF HYDRAULIC CONDUCTIVITY--N1 (instantaneous profile test).

\begin{tabular}{|c|c|c|c|c|}
\hline $\begin{array}{c}\mathrm{z} \\
(\mathrm{cm})\end{array}$ & $\underset{(\mathrm{cm} / \mathrm{hr})}{\mathrm{q}}$ & $\begin{array}{c}\frac{\delta H}{\delta z} \\
(\mathrm{~cm} / \mathrm{cm})\end{array}$ & $\underset{(\mathrm{cm} / \mathrm{hr})}{\mathrm{K}}$ & $\stackrel{\Theta}{(\%)}$ \\
\hline 15 & $\begin{array}{l}1.13 \times 10^{-2} \\
2.36 \times 10^{-3} \\
2.50 \times 10^{-4}\end{array}$ & $\begin{array}{l}0.50 \\
0.26 \\
0.65\end{array}$ & $\begin{array}{l}2.26 \times 10^{-2} \\
9.08 \times 10^{-3} \\
3.80 \times 10^{-4}\end{array}$ & $\begin{array}{l}18.80 \\
16.70 \\
15.80\end{array}$ \\
\hline 45 & $\begin{array}{l}3.40 \times 10^{-2} \\
7.08 \times 10^{-3} \\
7.50 \times 10^{-4}\end{array}$ & $\begin{array}{l}0.50 \\
0.26 \\
0.65\end{array}$ & $\begin{array}{l}6.79 \times 10^{-2} \\
2.72 \times 10^{-2} \\
1.15 \times 10^{-3}\end{array}$ & $\begin{array}{l}18.80 \\
16.70 \\
15.80\end{array}$ \\
\hline 75 & $\begin{array}{l}7.58 \times 10^{-2} \\
2.37 \times 10^{-2} \\
1.16 \times 10^{-2} \\
2.50 \times 10^{-3}\end{array}$ & $\begin{array}{l}0.48 \\
0.40 \\
0.40 \\
0.31\end{array}$ & $\begin{array}{l}1.58 \times 10^{-1} \\
5.91 \times 10^{-2} \\
2.90 \times 10^{-2} \\
8.06 \times 10^{-3}\end{array}$ & $\begin{array}{l}22.50 \\
20.70 \\
19.20 \\
18.10\end{array}$ \\
\hline 105 & $\begin{array}{l}9.42 \times 10^{-2} \\
3.37 \times 10^{-2} \\
1.51 \times 10^{-2} \\
4.50 \times 10^{-3} \\
3.13 \times 10^{-4}\end{array}$ & $\begin{array}{l}0.51 \\
0.75 \\
0.45 \\
0.41 \\
0.19\end{array}$ & $\begin{array}{l}1.85 \times 10^{-1} \\
4.49 \times 10^{-2} \\
3.35 \times 10^{-2} \\
1.10 \times 10^{-2} \\
1.65 \times 10^{-3}\end{array}$ & $\begin{array}{l}21.30 \\
19.80 \\
18.50 \\
17.50 \\
16.70\end{array}$ \\
\hline 135 & $\begin{array}{l}1.27 \times 10^{-1} \\
5.46 \times 10^{-2} \\
2.70 \times 10^{-2} \\
5.12 \times 10^{-3} \\
5.00 \times 10^{-4}\end{array}$ & $\begin{array}{l}0.77 \\
0.87 \\
0.81 \\
0.76 \\
0.75\end{array}$ & $\begin{array}{l}1.65 \times 10^{-1} \\
6.26 \times 10^{-2} \\
3.34 \times 10^{-2} \\
6.74 \times 10^{-3} \\
6.70 \times 10^{-4}\end{array}$ & $\begin{array}{l}14.40 \\
13.40 \\
12.00 \\
11.20 \\
10.90\end{array}$ \\
\hline 165 & $\begin{array}{l}1.57 \times 10^{-1} \\
6.56 \times 10^{-2} \\
3.40 \times 10^{-2} \\
6.12 \times 10^{-3} \\
5.00 \times 10^{-4}\end{array}$ & $\begin{array}{l}0.77 \\
0.87 \\
0.81 \\
0.76 \\
0.75\end{array}$ & $\begin{array}{l}2.04 \times 10^{-1} \\
7.54 \times 10^{-2} \\
4.20 \times 10^{-2} \\
8.06 \times 10^{-3} \\
6.70 \times 10^{-4}\end{array}$ & $\begin{array}{l}12.70 \\
12.20 \\
11.60 \\
10.90 \\
10.90\end{array}$ \\
\hline 195 & $\begin{array}{l}1.98 \times 10^{-1} \\
8.09 \times 10^{-2} \\
3.93 \times 10^{-2} \\
7.88 \times 10^{-3} \\
1.44 \times 10^{-3}\end{array}$ & $\begin{array}{l}0.77 \\
0.87 \\
0.81 \\
0.76 \\
0.75\end{array}$ & $\begin{array}{l}2.57 \times 10^{-1} \\
9.30 \times 10^{-2} \\
4.85 \times 10^{-2} \\
1.04 \times 10^{-2} \\
1.92 \times 10^{-3}\end{array}$ & $\begin{array}{l}18.60 \\
17.90 \\
16.60 \\
15.50 \\
14.80\end{array}$ \\
\hline
\end{tabular}


TABLE 6. CALCULATION OF HYDRAULIC CONDUCTIVITY--N2 (instantaneous profile test).

\begin{tabular}{|c|c|c|c|c|}
\hline $\begin{array}{c}\mathrm{z} \\
(\mathrm{cm})\end{array}$ & $\underset{(\mathrm{cm} / \mathrm{hr})}{\mathrm{q}}$ & $\begin{array}{c}\frac{\delta H}{\delta z} \\
(\mathrm{~cm} / \mathrm{cm})\end{array}$ & $\underset{(\mathrm{cm} / \mathrm{hr})}{\mathrm{K}}$ & $\stackrel{\Theta}{(\%)}$ \\
\hline 15 & $\begin{array}{l}2.63 \times 10^{-2} \\
1.41 \times 10^{-3} \\
6.87 \times 10^{-4}\end{array}$ & $\begin{array}{l}0.50 \\
0.26 \\
0.65\end{array}$ & $\begin{array}{l}5.26 \times 10^{-2} \\
5.41 \times 10^{-3} \\
1.06 \times 10^{-3}\end{array}$ & $\begin{array}{l}19.30 \\
16.10 \\
15.60\end{array}$ \\
\hline 45 & $\begin{array}{l}7.88 \times 10^{-2} \\
4.22 \times 10^{-3} \\
2.06 \times 10^{-3}\end{array}$ & $\begin{array}{l}0.50 \\
0.26 \\
0.65\end{array}$ & $\begin{array}{l}1.58 \times 10^{-1} \\
1.62 \times 10^{-2} \\
3.17 \times 10^{-3}\end{array}$ & $\begin{array}{l}19.30 \\
16.10 \\
15.60\end{array}$ \\
\hline 75 & $\begin{array}{l}1.42 \times 10^{-1} \\
4.79 \times 10^{-2} \\
8.97 \times 10^{-3} \\
3.94 \times 10^{-3} \\
8.12 \times 10^{-4}\end{array}$ & $\begin{array}{l}0.48 \\
0.40 \\
0.40 \\
0.31 \\
0.42\end{array}$ & $\begin{array}{l}2.95 \times 10^{-1} \\
1.20 \times 10^{-1} \\
2.24 \times 10^{-2} \\
1.27 \times 10^{-2} \\
1.93 \times 10^{-3}\end{array}$ & $\begin{array}{l}22.50 \\
20.90 \\
19.10 \\
17.80 \\
16.90\end{array}$ \\
\hline 105 & $\begin{array}{l}1.83 \times 10^{-1} \\
7.33 \times 10^{-2} \\
1.24 \times 10^{-2} \\
4.50 \times 10^{-3} \\
9.37 \times 10^{-4}\end{array}$ & $\begin{array}{l}0.51 \\
0.75 \\
0.45 \\
0.41 \\
0.19\end{array}$ & $\begin{array}{l}3.96 \times 10^{-1} \\
9.78 \times 10^{-2} \\
2.76 \times 10^{-2} \\
1.10 \times 10^{-2} \\
4.93 \times 10^{-3}\end{array}$ & $\begin{array}{l}20.40 \\
18.80 \\
17.60 \\
17.00 \\
16.70\end{array}$ \\
\hline 135 & $\begin{array}{l}2.15 \times 10^{-1} \\
8.68 \times 10^{-2} \\
1.45 \times 10^{-2} \\
6.62 \times 10^{-3} \\
9.37 \times 10^{-4}\end{array}$ & $\begin{array}{l}0.77 \\
0.87 \\
0.81 \\
0.76 \\
0.75\end{array}$ & $\begin{array}{l}2.79 \times 10^{-1} \\
9.97 \times 10^{-2} \\
1.79 \times 10^{-2} \\
8.72 \times 10^{-3} \\
1.25 \times 10^{-3}\end{array}$ & $\begin{array}{l}16.50 \\
15.00 \\
14.60 \\
13.80 \\
13.20\end{array}$ \\
\hline 165 & $\begin{array}{l}2.49 \times 10^{-1} \\
1.06 \times 10^{-1} \\
1.54 \times 10^{-2} \\
7.50 \times 10^{-3} \\
1.81 \times 10^{-3}\end{array}$ & $\begin{array}{l}0.77 \\
0.87 \\
0.81 \\
0.76 \\
0.75\end{array}$ & $\begin{array}{l}3.24 \times 10^{-1} \\
1.21 \times 10^{-1} \\
1.90 \times 10^{-2} \\
9.87 \times 10^{-3} \\
2.42 \times 10^{-3}\end{array}$ & $\begin{array}{l}17.30 \\
15.90 \\
15.20 \\
14.60 \\
14.10\end{array}$ \\
\hline 195 & $\begin{array}{l}2.85 \times 10^{-1} \\
1.23 \times 10^{-1} \\
1.82 \times 10^{-2} \\
8.69 \times 10^{-3} \\
3.00 \times 10^{-3}\end{array}$ & $\begin{array}{l}0.77 \\
0.87 \\
0.81 \\
0.76 \\
0.75\end{array}$ & $\begin{array}{l}3.70 \times 10^{-1} \\
1.42 \times 10^{-1} \\
2.42 \times 10^{-2} \\
1.43 \times 10^{-2} \\
4.00 \times 10^{-3}\end{array}$ & $\begin{array}{l}19.70 \\
18.50 \\
18.00 \\
17.00 \\
16.10\end{array}$ \\
\hline
\end{tabular}




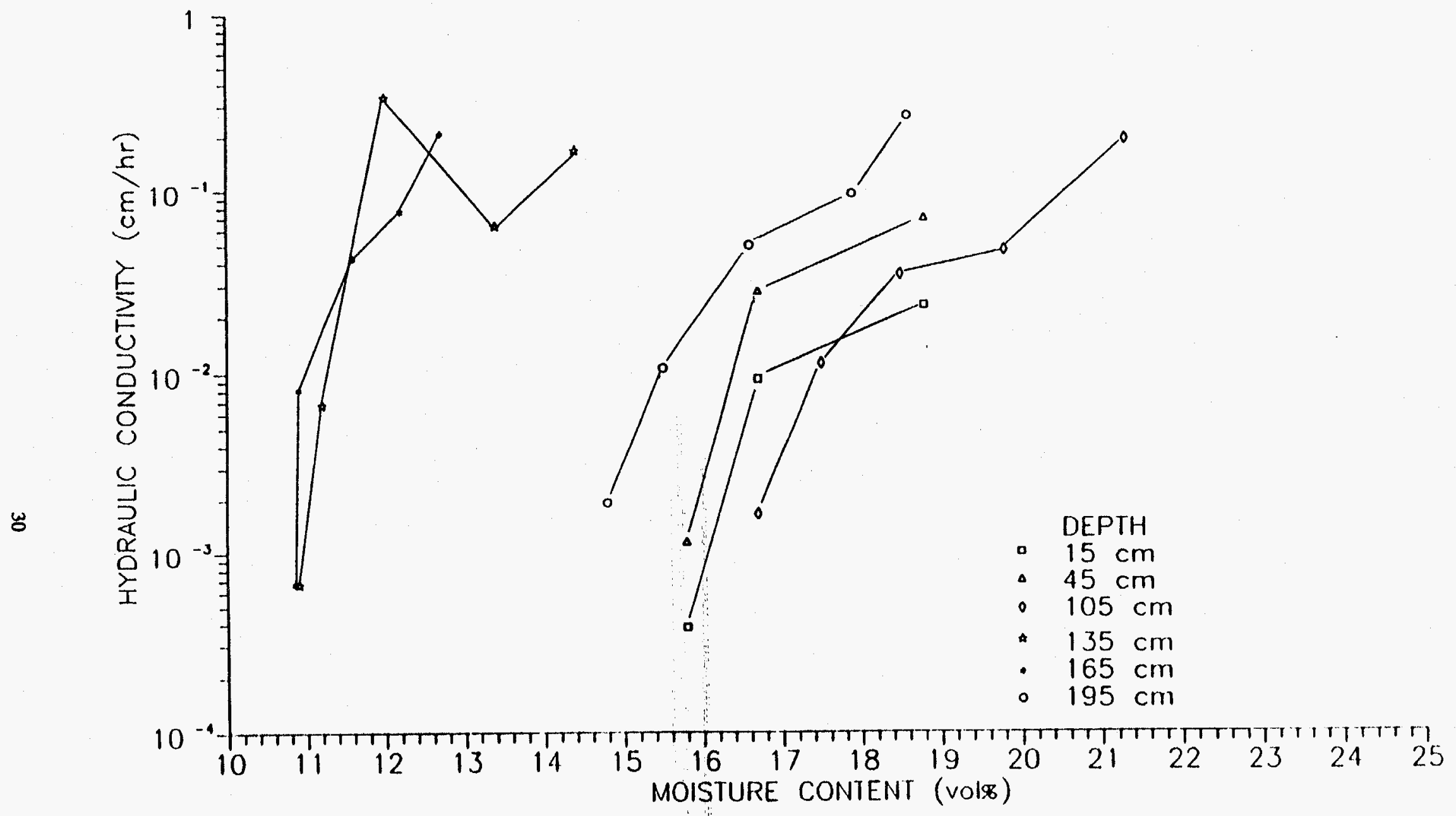

Figure 14. Hydraulic Conductivity versus Moisture Content, Hole N1. 


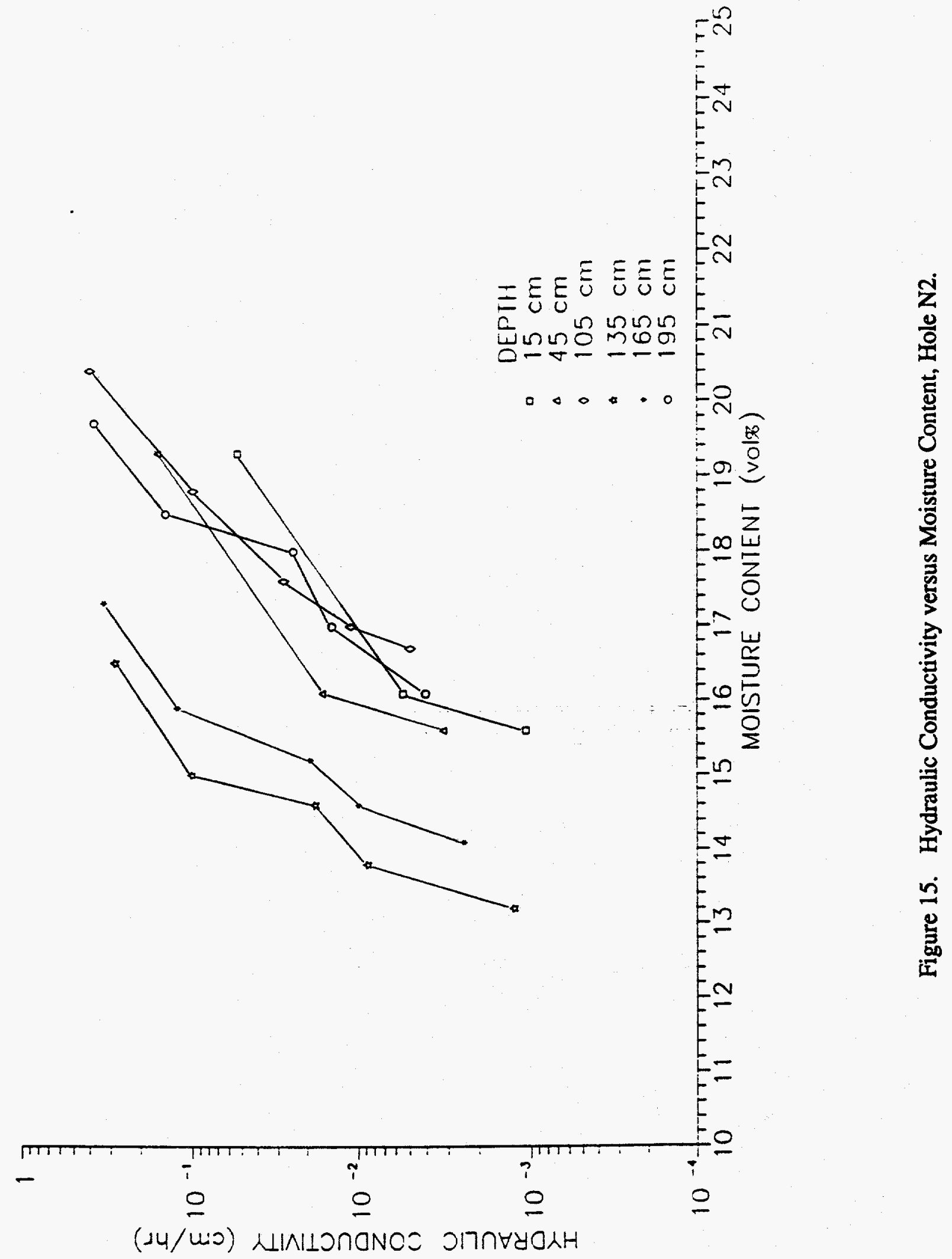




$$
k_{r}(\hat{\Theta})=\hat{\Theta}^{1 / 2}\left\{1-\left\{1-\hat{\Theta}^{1 / \gamma}\right\}^{\gamma}\right\}^{2}
$$

and

$$
\hat{\Theta}=\frac{\Theta-\Theta_{r}}{\Theta_{s}-\Theta_{r}}=\left\{\frac{1}{1+\left(a h \psi-\psi_{a} \mid\right)^{\beta}}\right\}^{\gamma}
$$

where $\alpha, \beta$, and $\gamma$ are parameters to be determined by the curve-fitting algorithm, $\psi$ is the pressure head, $\psi_{\mathrm{a}}$ is the air-entry pressure head, $\Theta, \Theta_{\mathrm{s}}$, and $\Theta_{\mathrm{r}}$ are the actual, saturated, and residual moisture contents, respectively. Detailed derivations of these equations can be found in van Genuchten (1978) and Mualem (1976). SATURN uses equation (14) to relate moisture content to matric suction, and equation (3) to relate hydraulic conductivity to moisture content.

The range of moisture values observed in the instantaneous profile test was fairly small: 12 percent to 33 percent. To aid in the curve fitting process, a point at the dry, high tension end of the curve was taken from NTS soil moisture retention data assembled by Romney et al. (1973). The data selected were from a soil sample collected $3 \mathrm{~km}$ southwest of the RNM site at approximately the same elevation on Frenchman Flat as the instantaneous profile test site. Since most of the transport in this study occurred at relatively high moisture content, the shape of the characteristic curve at high tensions should have little affect on the numerical solutions of SATURN.

The soil moisture characteristic curves generated by the van Genuchten model are presented together with the field data in Appendix F. Although the water retention curve fit was consistently good, the hydraulic conductivity curves generated with equation (13) generally poorly matched the field data. Appendix $G$ contains plots comparing hydraulic conductivities measured by the instantaneous profile test with those generated by equation (13).

Appendix $\mathrm{H}$ shows unsaturated hydraulic conductivity as a function of degree of saturation as determined by the instantaneous profile test, together with curves generated by equation (3) using values for the parameter $n$ of 3 to 8 . The slopes of the generated curves are consistently less than the slopes of lines fit to the field data, regardless of the choice of $n$.

One possible solution to this problem would be to use a different function to relate hydraulic conductivity to saturation. Many such equations can be found in the literature (Sisson et al., 1980; Mualem, 1976). However, only the binary code was available for use in this investigation making any program modifications impossible. Table 7 lists the SATURN input requirements, and the values used for the canal simulations.

\section{Model Definition}

The original solution domain was a rectangular grid in the $\mathrm{x}-\mathrm{z}$ plane consisting of $\mathbf{5 5 1}$ rectangular elements defined by 600 nodes (Figure 16). Only one side of the canal was modeled, 
TABLE 7. RNM CANAL MODEL INPUT DATA.

\begin{tabular}{|c|c|}
\hline Parameter & Value \\
\hline Number of nodes & 780 \\
\hline Number of elements & 711 \\
\hline Time-step type & Central difference \\
\hline $\begin{array}{l}\text { Saturated hydraulic conductivity component } \mathrm{K}_{\mathrm{xx}} \text {, } \\
\text { material } 1\end{array}$ & $0.543 \mathrm{~m} /$ day \\
\hline $\begin{array}{l}\text { Saturated hydraulic conductivity component } \mathrm{K}_{\mathrm{zz}} \text {, } \\
\text { material } 1\end{array}$ & $0.543 \mathrm{~m} /$ day \\
\hline $\begin{array}{l}\text { Saturated hydraulic conductivity component } \mathrm{K}_{\mathrm{xz}} \text {, } \\
\text { material } 1\end{array}$ & $0 \mathrm{~m} /$ day \\
\hline $\begin{array}{l}\text { Saturated hydraulic conductivity component } K_{\mathrm{xx}} \text {, } \\
\text { material } 2\end{array}$ & $0.543 \mathrm{~m} /$ day \\
\hline $\begin{array}{l}\text { Saturated hydraulic conductivity component } \mathrm{K}_{\mathrm{zz}} \text {, } \\
\text { material } 2\end{array}$ & $0.543 \mathrm{~m} /$ day \\
\hline $\begin{array}{l}\text { Saturated hydraulic conductivity component } \mathrm{K}_{\mathrm{xz}} \text {, } \\
\text { material } 2\end{array}$ & $0 \mathrm{~m} /$ day \\
\hline Effective porosity & 0.33 \\
\hline Residual water phase saturation & 0.284 \\
\hline Functional coefficient $n(1)$ & 4.0 \\
\hline Functional coefficient $\alpha$ (2) & 0.0181 \\
\hline Functional coefficient $\beta$ (2) & 2.36 \\
\hline Functional coefficient $\gamma(2)$ & 0.577 \\
\hline Decay coefficient & $1.55 \times 10^{-4}$ day $^{-1}$ \\
\hline Retardation coefficient, $R_{o}$ & 0.8 \\
\hline Longitudinal dispersivity, $\alpha_{\mathrm{L}}$ & $10 \mathrm{~m}$ \\
\hline Transverse dispersivity, $\alpha_{T}$ & $3 \mathrm{~m}$ \\
\hline Molecular diffusion component, $\mathrm{D}_{\mathrm{xx}}^{\mathrm{o}}$ & $1.0 \times 10^{-7} \mathrm{~m}^{2} /$ day \\
\hline Molecular diffusion component, $\mathrm{D}_{\mathrm{zz}}^{\circ}$ & $1.0 \times 10^{-7} \mathrm{~m}^{2} /$ day \\
\hline
\end{tabular}

(1) $K_{n w}=\frac{\left(S_{w}-S_{w r}\right)^{n}}{\left(1-S_{w r}\right)^{n}}$

(2) $S_{w}-S_{w r}=\frac{\left(1-S_{w r}\right)}{\left[1+\left(a h \psi-\psi_{a} \mid\right)^{\beta}\right]^{\gamma}}$ 
NODES

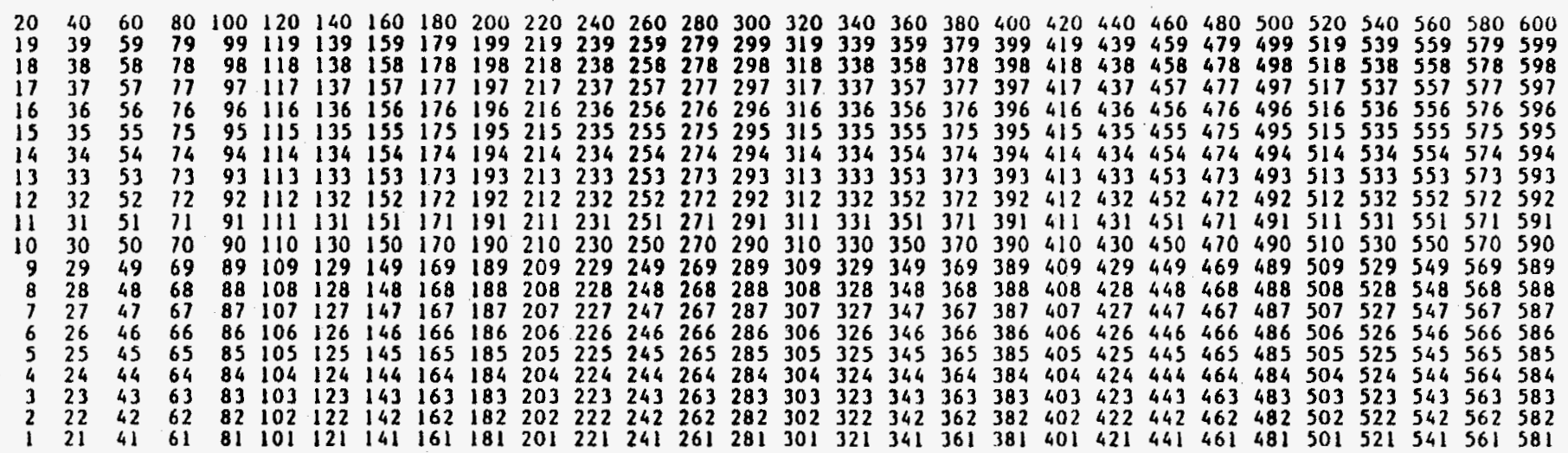

ELEMEN'TS

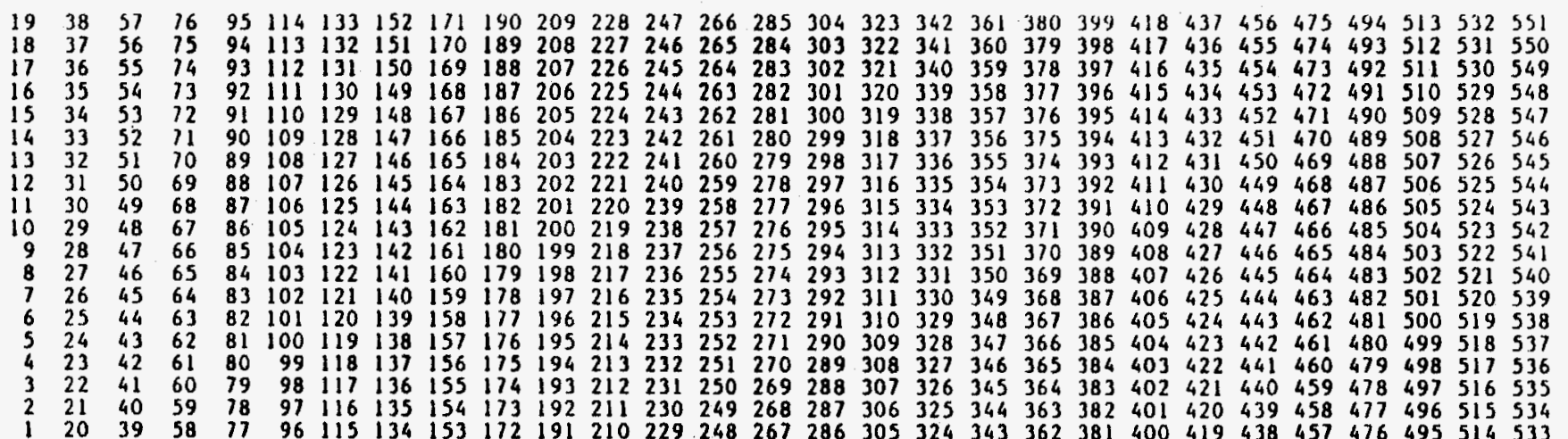

Figure 16. Original Sample Space Discretization into Nodes and Elements. 
exploiting the symmetry of the flow system. The grid extended to a depth of $270 \mathrm{~m}$ ( $50 \mathrm{~m}$ below the water table) and to a distance of $1,000 \mathrm{~m}$ in the horizontal direction. Node spacing increased with depth and with horizontal distance from the canal. Element size ranged from $0.5 \mathrm{~m} \times 0.5 \mathrm{~m}$ at the canal to $50 \mathrm{~m} \times 200 \mathrm{~m}$ for elements furthest from the canal.

At the canal, pressure heads were held constant at $+20 \mathrm{~cm}$. Initial hydraulic heads at and below the water table were hydrostatic. All other nodes were initially $-100 \mathrm{~cm}$ (approximately 60 percent saturated). Although this degree of saturation is unrealistically high, a lower value of initial saturation caused numerical instabilities in the program and, regardless of the time-step size, nonconvergence.

The vertical boundary beneath the canal $(x=0)$ was treated as a no-flow boundary because of the symmetry of the flow system. Vertical flow through the lower boundary was ignored; therefore, a no-flow boundary was assigned at the bottom of the model domain. It was assumed that any groundwater mound that might develop below the canal would not extend $1,000 \mathrm{~m}$ to the right boundary, thus nodes at and below the water table on the right boundary were held constant at hydrostatic pressure. Assuming only vertical flow in the unsaturated zone at $\mathrm{x}=$ $1,000 \mathrm{~m}$, the remainder of the right boundary was treated as a no-flow boundary. In light of the low annual precipitation on Frenchman Flat, and ignoring evapotranspiration, the ground surface to the right of the canal was treated as a no-flow boundary.

At the beginning of the simulation, with the wetting front in the small elements, solution convergence was rapid. As the front moved into progressively larger elements, more iterations were required at each time step for convergence. When the vertical spacing of nodes at the wetting front exceeded $10 \mathrm{~m}$, the solution became unstable and the program failed to converge. Decreasing the time-step size had little effect on solution stability. To resolve the problem, a new grid with a maximum node spacing of $10 \mathrm{~m}$ was developed.

Execution time required for each iteration is roughly proportional to the number of nodes in the grid. To maintain about the same number of nodes (thereby keeping execution time at a reasonable level), while greatly increasing overall node density, the size of the solution domain had to be reduced. This was accomplished in two ways: 1) the horizontal extent of the grid was reduced from 1,000 m to $200 \mathrm{~m}$; and 2) rather than a rectangular sample space, the upper-right portion of the grid was eliminated, leaving a stair-stepped boundary on the right (Figure 17). The new grid consists of 711 elements and 780 nodes (Figures 17 and 18). As in the original grid, node spacing increased with depth and horizontal distance from the canal; however, in the new grid, node spacing is reduced as the water table is approached. This is to aid in the numerical handling of the range of pressures and hydraulic conductivities encountered at the saturated-unsaturated interface. Figure 19 shows the elements (to scale) with the model boundary conditions.

Boundary and initial conditions for the new grid are essentially the same as those for the old grid, with the exception of the initial saturation of the nodes above the water table. These nodes were given a hydrostatic pressure $\left(\frac{p}{\varrho g}=-\right.$ distance above the water table) up to a maximum suction of $-100 \mathrm{~cm}$. 


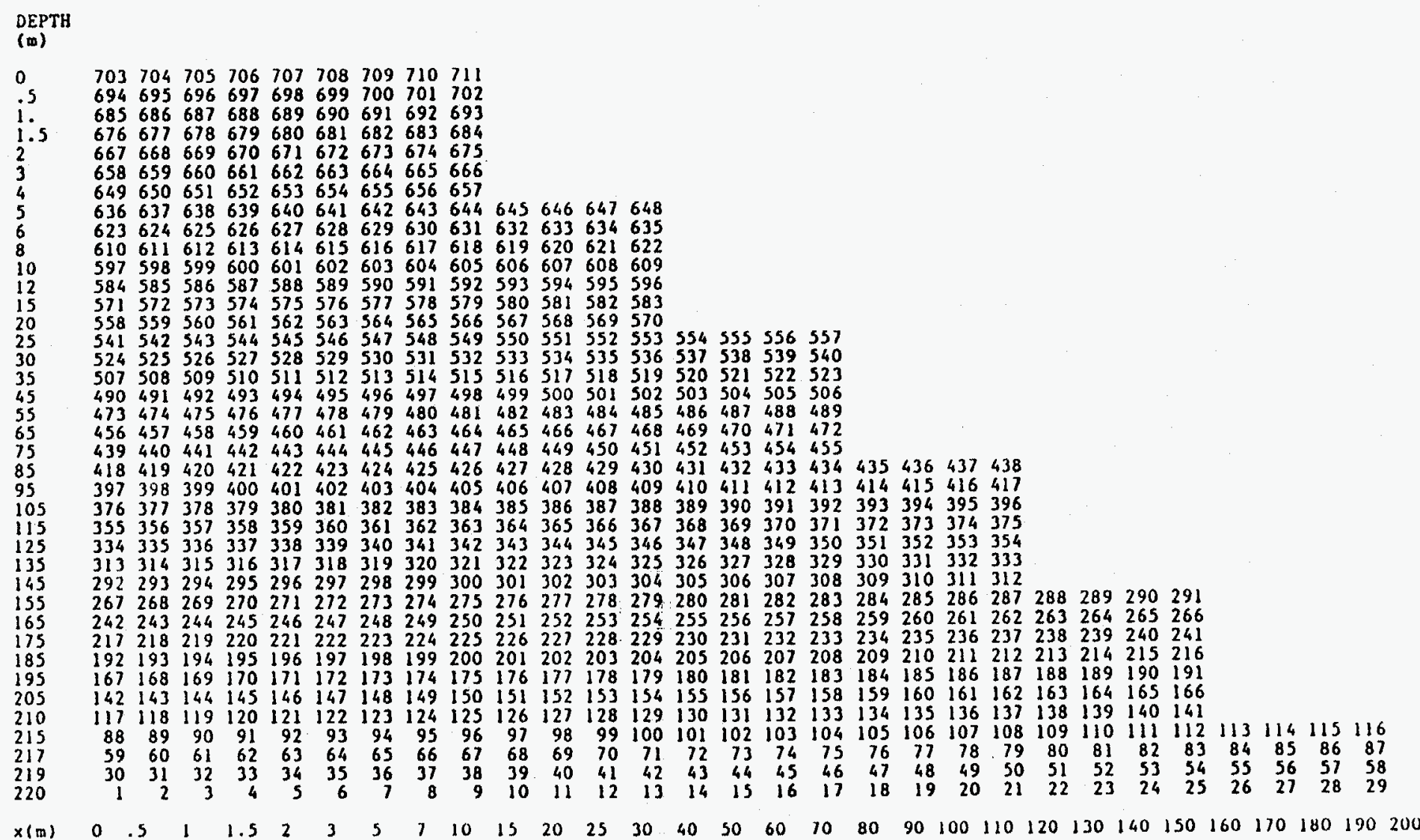

Figure 17. Location of Elements. 


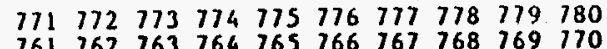
761762763764765766767768769770

741742743744745746747748749750

731732733734735736737738739740

72172272372472572673778 7.

697698699700701702703704705706707708709710

683684685686687688689690691692693694695696

669670671672673674675676677678679680681682

655656657658659660661662663664665666667668

641642643644645646647648649650651652653654

$627628629630631632633634635636 \quad 637638639640$

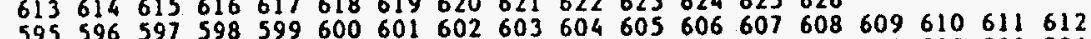

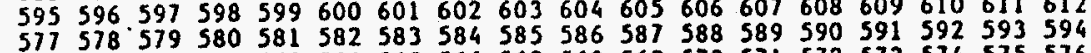

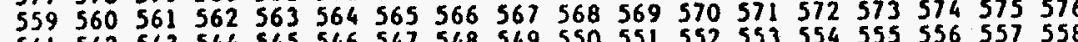

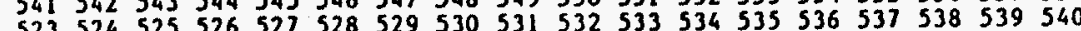

505506507508509510511512513514515516517518519520521522

487488489490491492493494495496497498499500501502503504

$-465466467468469470471442047474475476477478479480481482483484485486$

443444445446447448449450451452453454453556457458459460461462463464

421422423424425426427428429430431452 435 4564534584315416449418419420

377378379300331302303384395336397383389390391392393394395396397398

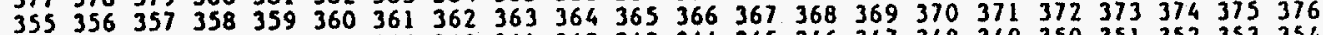

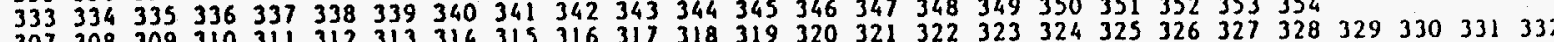

281 2822832842852862872882892902912922932942952962972982993003013026303304305306

$255256257258259260261262263264265266267268 \quad 269270271272273274275276277278279280$

2292302312322332342352362372382392402412422432442452462472482492502515252253354

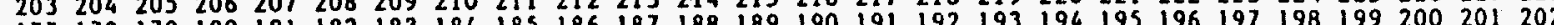

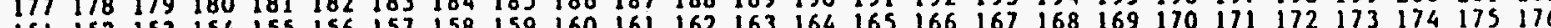

151

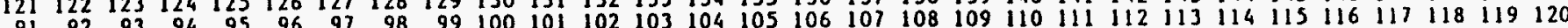

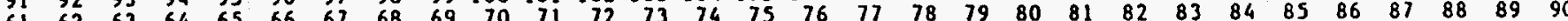

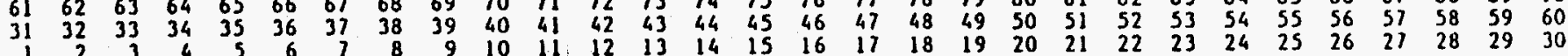
$\begin{array}{llllllllllllllllllllllllllllllllllllllll}0 & 5 & 1 & 1.5 & 2 & 3 & 5 & 7 & 10 & 15 & 20 & 25 & 30 & 40 & 50 & 60 & 70 & 80 & 90 & 100 & 110 & 120 & 130 & 140 & 150 & 160 & 170 & 180 & 190 & 200\end{array}$

Figure 18. Location of Nodes. 


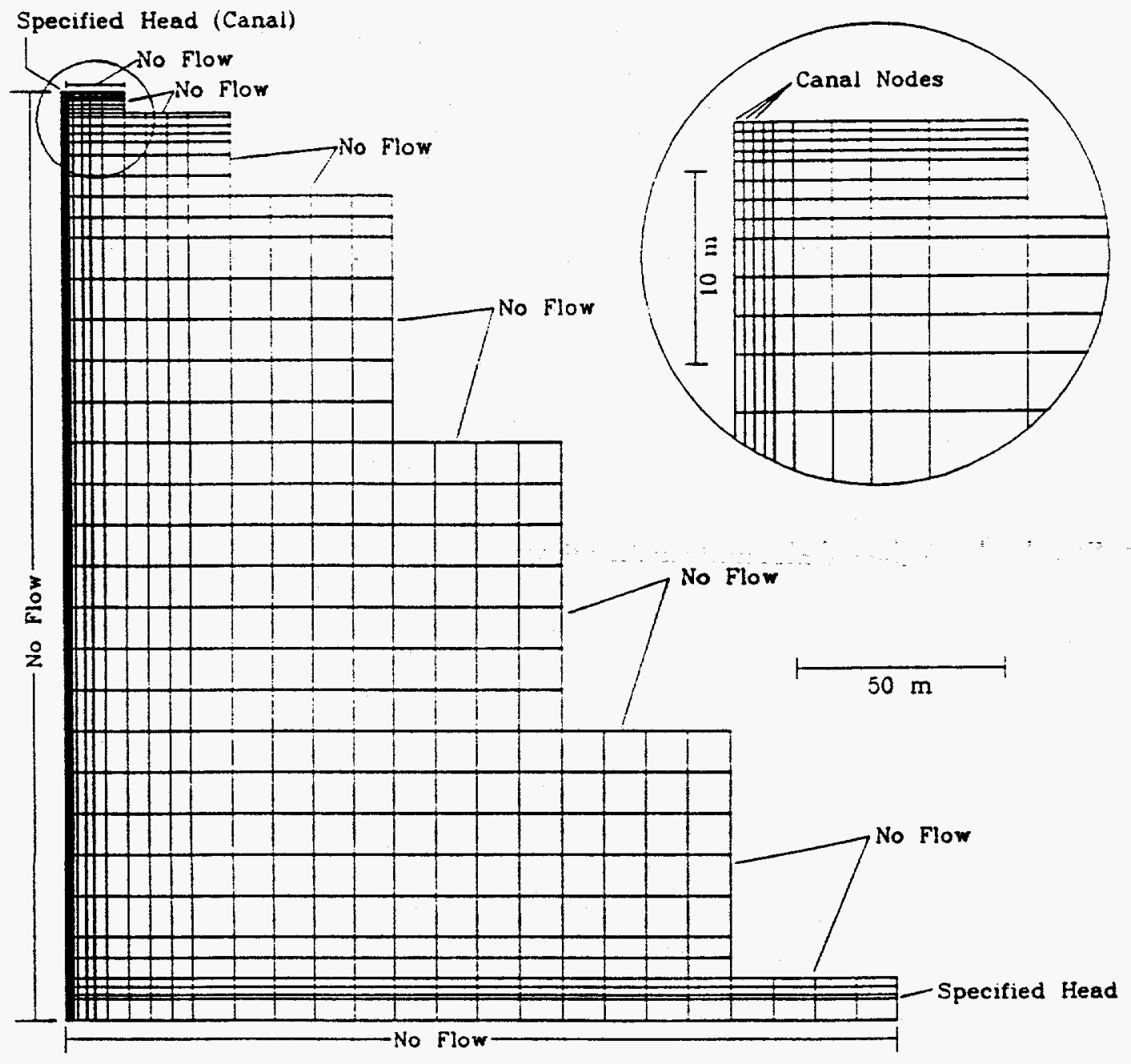

Figure 19. Discretization of Sample Space Showing Boundary Conditions. 


\section{MATHEMATICAL FORMULATION}

\section{GOVERNING EQUATIONS--FLOW}

Combining the continuity equation and Darcy's law written for variably saturated soil in two dimensions yields:

$$
\frac{\partial}{x_{i}}\left\{\varrho_{w} k_{i j} k_{n w}\left(\frac{\partial \psi}{\partial x_{j}}+e_{j}\right)\right\}=\frac{\partial}{\partial t}\left(\varrho_{w} \phi S_{w}\right)-\varrho_{w} q
$$

where $\varrho_{w}$ is the density of water, $\psi$ is the pressure head, $k_{i j}$ is the saturated hydraulic conductivity tensor, $k_{r w}$ is the relative permeability with respect to the water phase, $x_{i}(i=1,2)$ are spatial coordinates, $t$ is elapsed time, $e_{j}$ is the unit vector in the direction of the $x_{2}$ axis (assumed to be vertically upward), $S_{w}$ is water saturation, $\phi$ is the effective porosity, and $q$ is the volumetric flow rate via sources or sinks per unit volume of the porous medium.

For a slightly compressible fluid $\left(\frac{\partial \varrho_{w}}{\partial x}=\frac{\partial \varrho_{w}}{\partial t}=0\right)$, equation (15) can be written:

$$
\frac{\partial}{\partial x_{i}}\left\{k_{i j} k_{n w}\left(\frac{\partial \psi}{\partial x_{j}}+e_{j}\right)\right\}=\left(S_{w} S_{s}+\phi \frac{\partial S_{w}}{d \psi}\right) \frac{\partial \psi}{\partial t}-q
$$

or

$$
\frac{\partial}{\partial x_{i}}\left\{k_{i j} k_{r v}\left(\frac{\partial \psi}{\partial x_{j}}+e_{j}\right)\right\}=\eta \frac{\partial \psi}{\partial t}-q
$$

where

$$
\eta=S_{w} S_{s}+\phi \frac{d S_{w}}{d \psi}
$$

and $S_{s}=$ the specific storage $=\varrho_{w} g(\phi \beta+\alpha)$, where $g$ is the gravitational constant and $\alpha$ and $\beta$ are coefficients of compressibility of the porous medium and water, respectively.

The boundary and initial conditions of the variably saturated flow problem can be expressed as:

$$
\begin{gathered}
\psi\left(x_{i}, 0\right)=\psi_{0}\left(x_{i}\right) \\
\psi\left(x_{i}, t\right)=\hat{\psi} \text { on } B_{1}
\end{gathered}
$$

and

$$
v_{i} n_{i}=v_{n} \text { on } B_{2}
$$


where $\psi_{0}$ is the initial head value, $B_{1}$ is the portion of the flow boundary where $\psi$ is prescribed as $\hat{\psi}, B_{2}$ is the portion of the flow boundary where the outward fluid flux is prescribed as $v_{n}$, and $n_{i}$ is the outward unit normal vector on $\mathrm{B}_{2}$.

SATURN solves equation (17) by the Galerkin finite element method subject to equations (19) to (21). The Darcy velocity components are then calculated from:

$$
q_{i}=-K_{i j} k_{r w}\left(\frac{\partial \psi}{\partial x_{j}}+e_{j}\right)
$$

\section{GOVERNING EQUATIONS--TRANSPORT}

The governing equation for two-dimensional transport of a nonconservative solute in a variably saturated medium can be written:

$$
\begin{aligned}
& \frac{\partial}{\partial x_{i}}\left(D_{i j} \frac{\partial c}{\partial x_{j}}\right)-\frac{\partial}{\partial x_{i}}\left(v_{i} c\right)= \\
& \frac{\partial}{\partial t}\left\{\phi S_{w} c+\varrho_{s}(1-\phi) c_{s}\right\}-q c^{*}+\lambda\left\{\phi S_{w} c+\varrho_{s}(1-\phi) c_{s}\right\}
\end{aligned}
$$

where $D_{i j}$ is the apparent hydrodynamic dispersion tensor, $c$ is the solute concentration in the fluid, $v_{i}$ is the Darcy velocity, $\varrho_{s}$ is the density of the solid grains, $c_{s}$ is the adsorbed concentration, $\lambda$ is the first-order decay coefficient, and $c^{*}$ is the solute concentration of the injected fluid.

If the adsorption relationship can be described by a linear equilibrium isotherm, equation (23) becomes:

$$
\begin{aligned}
& \frac{\partial}{\partial x_{i}}\left(D_{i j} \frac{\partial c}{\partial x_{j}}\right)-\frac{\partial}{\partial x_{i}}\left(v_{i} c\right)= \\
& \frac{\partial}{\partial t}\left\{\phi S_{w}\left(1+\frac{\varrho_{s}(1-\phi) k_{d}}{\phi S_{w}} c\right\}+\lambda \phi S_{w}\left\{1+\frac{\varrho_{s}(1-\phi) k_{d}}{\phi S_{w}}\right\} c-q c^{*}\right.
\end{aligned}
$$

where $k_{d}$ is the equilibrium constant.

Equation (24) can be written:

$$
\frac{\partial}{\partial x_{i}}\left(D_{i j} \frac{\partial c}{\partial x_{j}}\right)-\frac{\partial}{\partial x_{i}}\left(v_{i} c\right)=\frac{\partial}{\partial t}\left(\phi S_{w} R c\right)+\lambda \phi S_{w} R c-q c^{*}
$$

where $R$ is the retention factor defined as:

$$
R=1+\frac{\varrho_{s}(1-\phi) k_{d}}{\phi S_{w}}=1+\frac{\varrho_{b} k_{d}}{\phi S_{w}}
$$


and $\varrho_{b}$ is the bulk density, $(1-\phi) Q_{s}$.

Expanding equation (25), and using equation (26), assuming $\frac{\partial}{\partial t}\left(\varrho_{b} k_{d}\right)=0$ :

$$
\frac{\partial}{\partial x_{i}}\left(D_{i j} \frac{\partial c}{\partial x_{j}}-v_{i} \frac{\partial c}{\partial x_{i}}=\phi S_{w} R\left(\frac{\partial c}{\partial t}+\lambda c\right)+q\left(c-c^{*}\right)\right)
$$

SATURN approximates equation (27) using the upstream weighted residual finite-element technique of Huyakorn and Nilkuha (1979). The initial and boundary conditions of equation (27) can be written:

$$
\begin{gathered}
c\left(x_{1}, x_{2}, 0\right)=c_{0} \\
c\left(x_{1}, x_{2}, t\right)=\hat{c} \text { on } B_{1}^{\prime} \\
D_{i j} \frac{\partial c}{\partial x_{j}} n_{i}=q_{c}^{D} \text { on } B_{2}^{\prime} \\
D_{i j} \frac{\partial c}{\partial x_{j}} n_{i}-v_{i} n_{i} c=q_{c}^{T} \text { on } B_{3}^{\prime}
\end{gathered}
$$

where $B_{1}^{\prime}$ is the portion of the boundary where the concentration is prescribed as $\hat{c}$, and $B_{2}^{\prime}$ and $B_{3}^{\prime}$ are portions of the boundary where the dispersive and total solute mass fluxes are prescribed as $\mathrm{q}_{c}^{\mathrm{D}}$ and $\mathrm{q}_{c}^{\mathrm{T}}$, respectively. 


\section{GROUNDWATER FLOW SIMULATION}

Prior to simulating infiltration from the canal, the applicability of the SATURN code to the hydrologic conditions at the RNM site (i.e., line infiltration through $200 \mathrm{~m}$ of unsaturated alluvium) was assessed with test simulations. In the first simulation attempts, the medium was considered dry and the nodes representing the line source were assigned a specified flux equal to the observed canal transmission loss. When the solution failed to converge, the time-step size was reduced. When further reduction in time-step size was no longer practical, the moisture content of the medium was raised. All combinations of time-step size and moisture content resulted in nonconvergence when the line source was represented by specified flux nodes.

The line source nodes were then assigned a slight positive hydraulic head $(+20 \mathrm{~cm})$ and the medium was again assumed dry. As before, the solution did not converge. It appeared that the sharp saturated/unsaturated interface was the source of the numerical problem. The moisture content was raised to 20 percent (approximately $2 / 3$ saturated) and convergence was rapid.

As a result of these test runs, the simulation strategy for the RNM canal was to represent the canal by constant head nodes. The initial moisture content of the alluvium was 20 percent and allowed to drain to approximately a steady-state condition.

The RNM canal transmission loss is approximately $0.2 \mathrm{~cm}^{3} / \mathrm{sec} / \mathrm{cm}$. Cambric tritium did not arrive at RNM-2S for approximately 1,050 days after pumping was initiated. If the soil beneath the canal had a uniform porosity of 0.3 and was initially dry, it would only take about 380 days to completely saturate a column soil $10 \mathrm{~m}$ wide from the canal to the water table at the observed canal infiltration rate. For this reason, it is assumed that the flow system had reached steady-state prior to the arrival of Cambric tritium at RNM-2S.

Three indicators were used to determine when steady state in the model was reached:

- No change in the moisture contents with time.

- No change in the velocity field with time.

- No change in storage (a net boundary flux close to 0 ).

At steady state, and for all but the first few days of simulation, the flow at the constant head nodes representing the canal totaled $1.0 \times 10^{4} \mathrm{~cm}^{3} /$ day $/ \mathrm{cm}$. Because only one side of the canal was represented by the solution domain, the flow for each $\mathrm{cm}$ of canal is then $2.0 \times 10^{4}$ $\mathrm{cm}^{3} / \mathrm{day} / \mathrm{cm}$. The distance between flumes 1 and 3 is $1,100 \mathrm{~m}$. If the transmission losses were uniform between the flumes, the total loss for this section of canal would be $2 \times 10^{9} \mathrm{~cm}^{3} /$ day $\left(2.3 \times 10^{4} \mathrm{~cm}^{3} / \mathrm{sec}\right)$. Although slightly higher than the mean loss, this value lies within the observed values of the canal transmission losses as measured by the flume data (Figure 4).

At the beginning of the flow simulation, the solution domain was assumed to consist of a single, isotropic material with the hydraulic properties given earlier in this report. This assumption proved unsatisfactory as water rapidly accumulated in the system and a large groundwater mound soon developed beneath the canal. The net boundary flux was consistently positive indicating a net increase in storage. As the saturated-unsaturated interface rose into the 
larger elements, the solution became unstable and more iterations were required for convergence at each time step (Figure 20).

By increasing horizontal hydraulic conductivity of the bottom three rows of nodes from $6.29 \times 10^{-4} \mathrm{~cm} / \mathrm{sec}$ to $6.29 \times 10^{-3} \mathrm{~cm} / \mathrm{sec},\left(\mathrm{k}_{\mathrm{xx}} / \mathrm{k}_{\mathrm{zz}}=10\right)$ the net boundary flux became negative, and the groundwater mound beneath the canal began to. lower. As the saturated-unsaturated interface dropped, the solution instability rapidly decreased as seen in Figure 21 .

Once the groundwater mound had been reduced to near the initial water level, the horizontal hydraulic conductivity in the bottom three rows of nodes was adjusted to bring the net boundary flux to near 0 . This occurred when $k_{x x} / k_{z z}=4.79$. When the net boundary flux was within 0.1 percent, the flow simulation was terminated. The steady-state moisture contents and velocity field were then used as input to the transport simulation. Figures 22 and 23 show the steady-state saturation values and velocity field, respectively. Appendix I contains element saturation values at selected time steps. Appendix $J$ contains graphical representations of the velocity field at selected time steps.

At the time these simulations were run, it took several weeks of computer time to go from initial to steady-state conditions for the flow. As a result, it was impractical to conduct sensitivity analysis on any of the material or unsaturated hydraulic properties with regard to the flow solution. The steady-state flow solution shown in Figures 22 and 23 was used for all of the solute transport runs. 


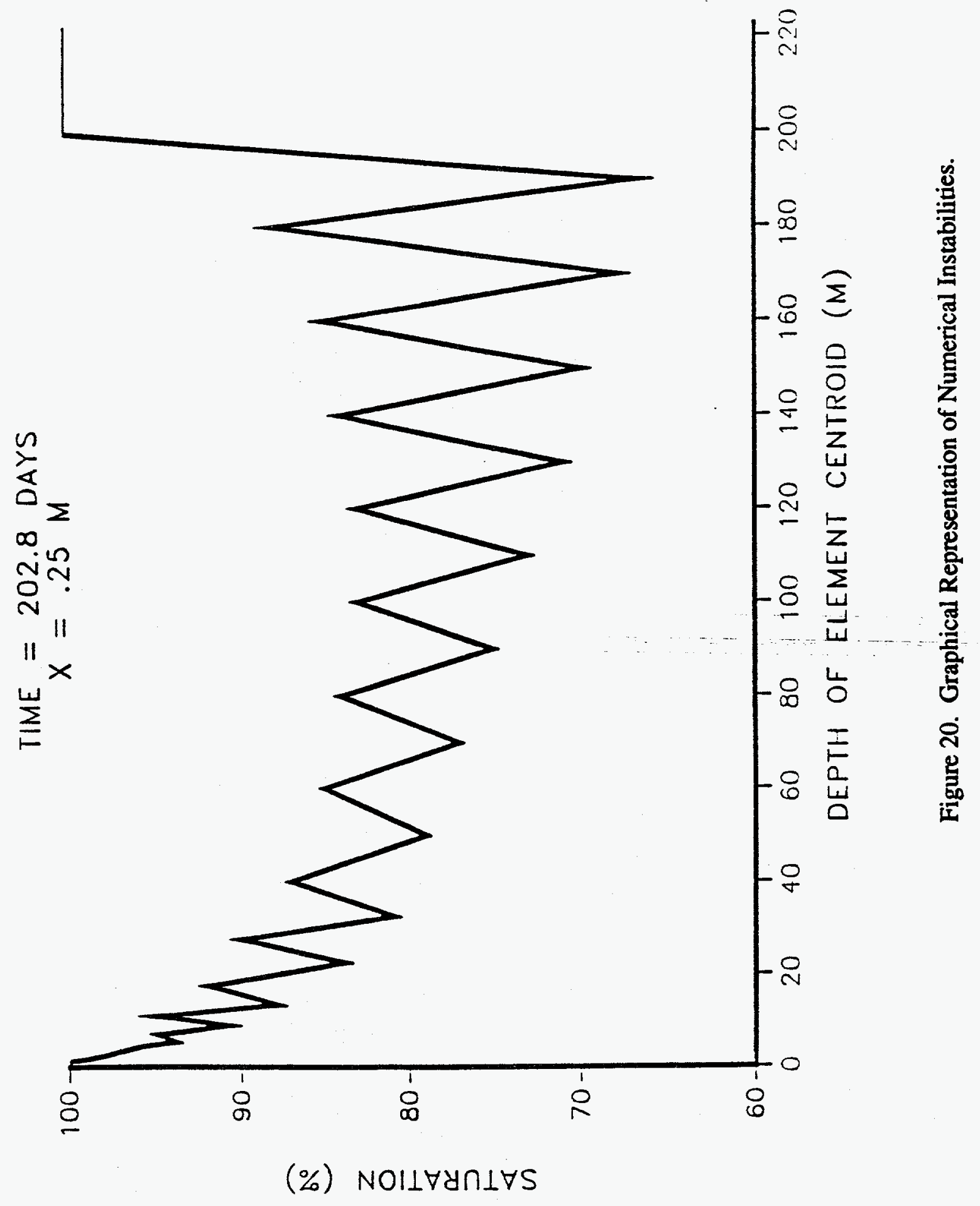




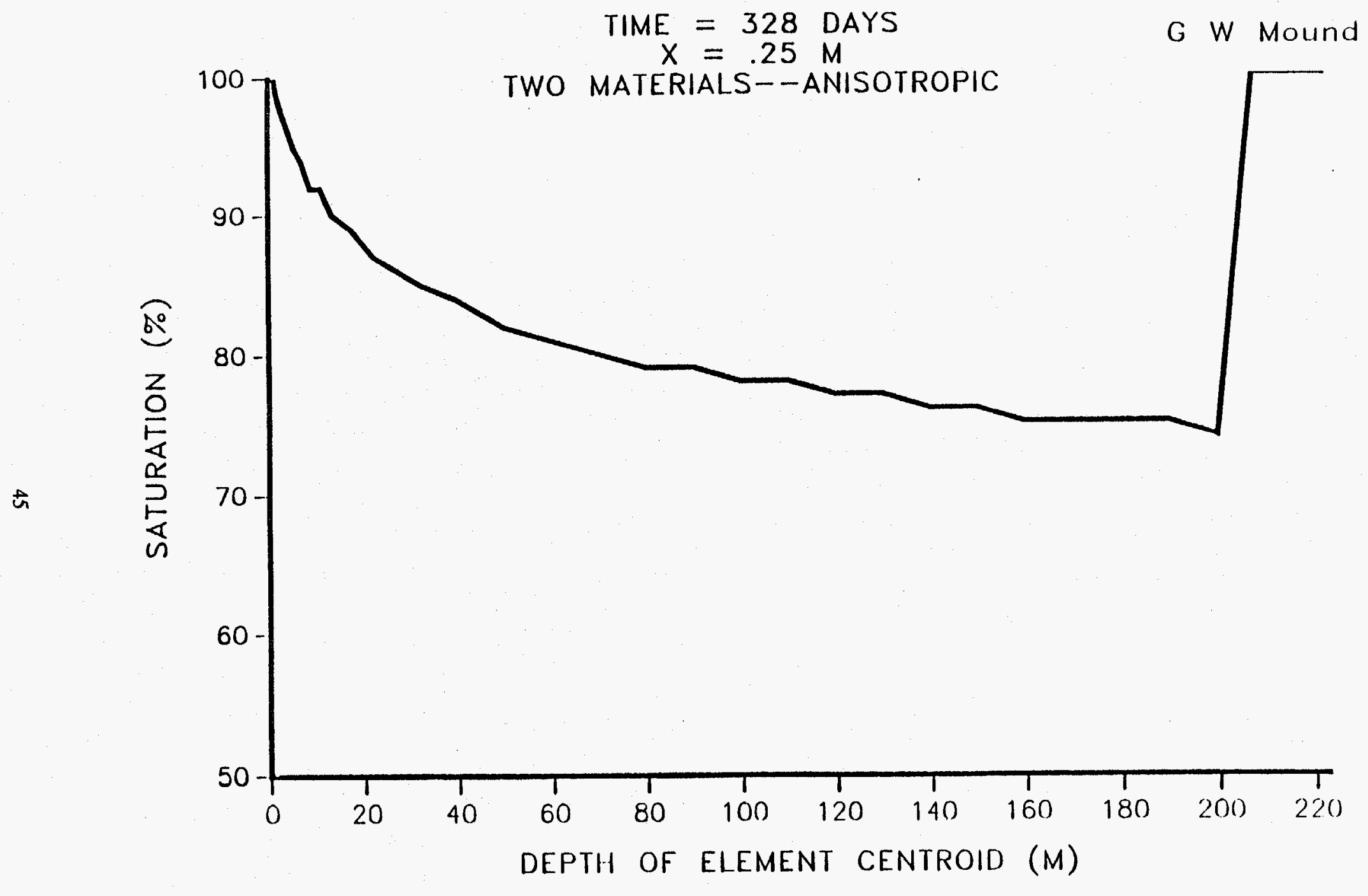

Figure 21. Effect of Anisotropy on Solution Stability. 


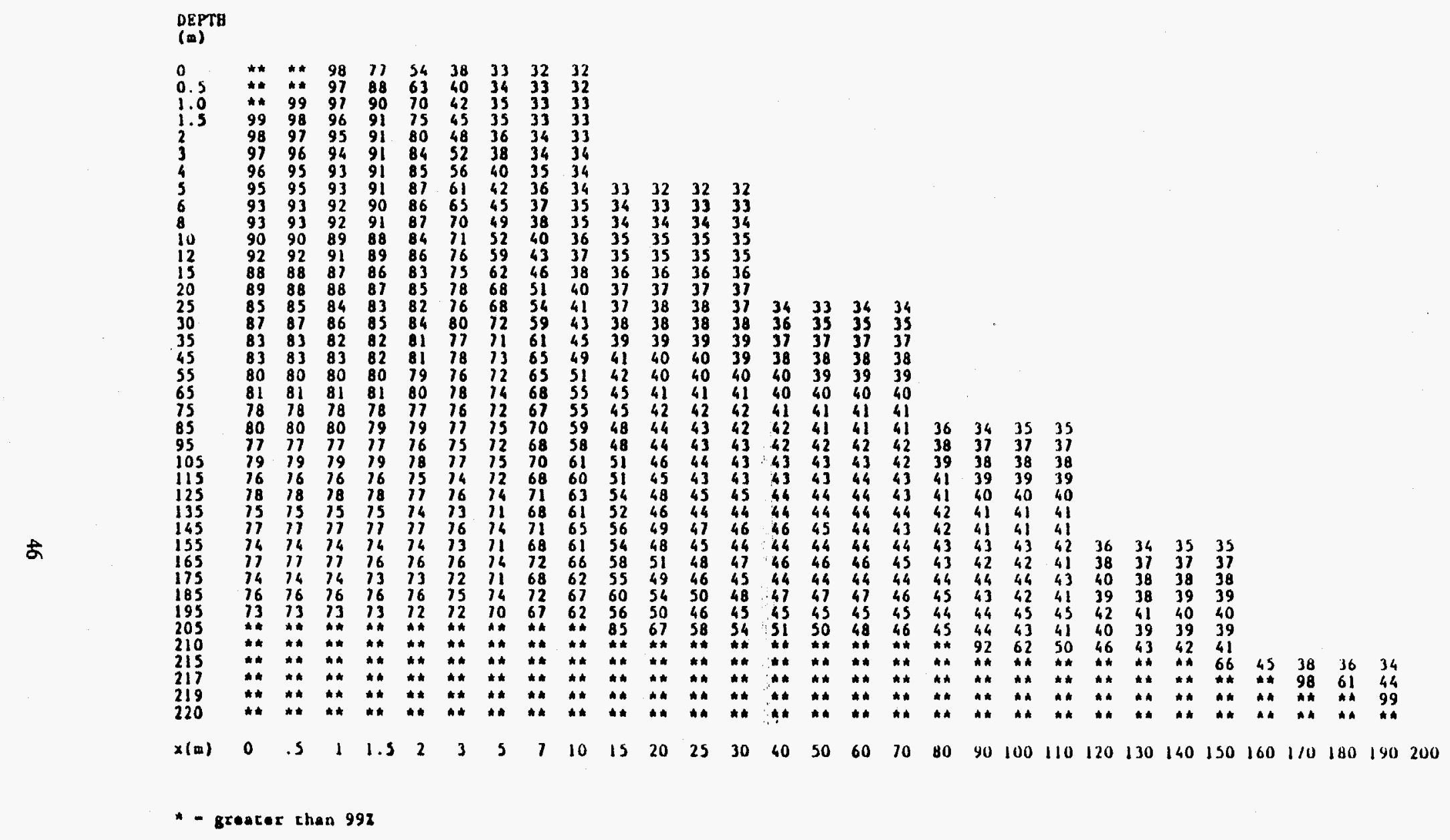

Figure 22. Simulated Steady-State Element Saturation Values (\%). 


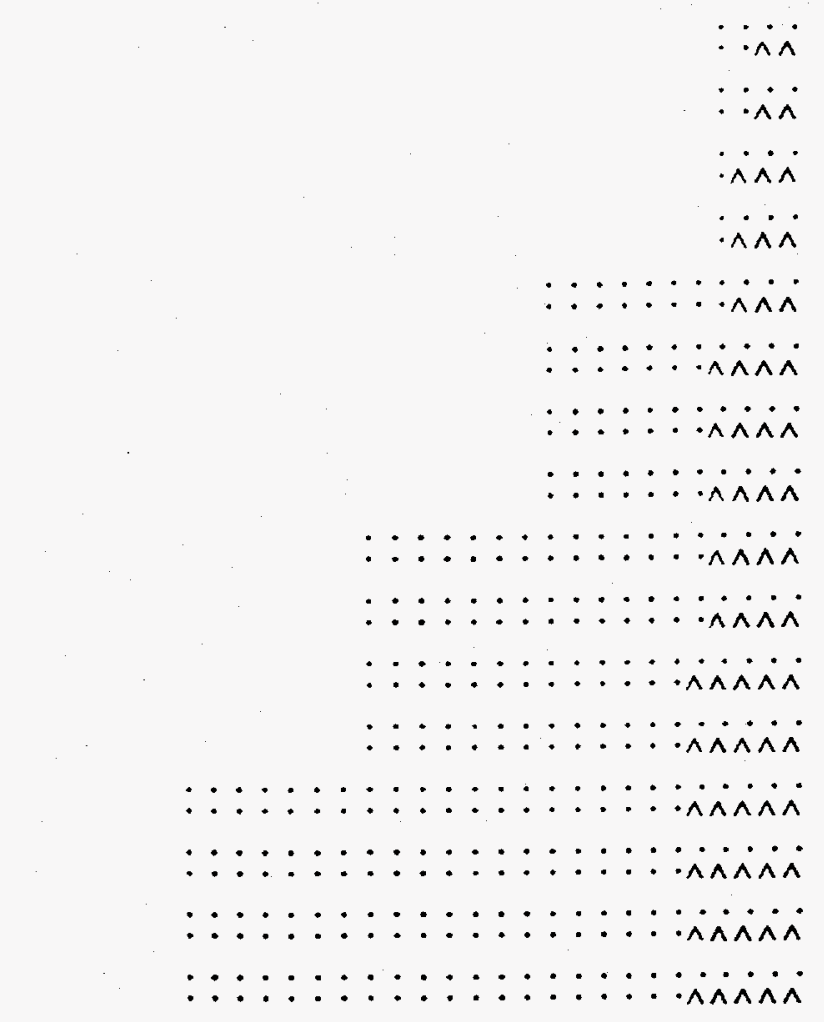

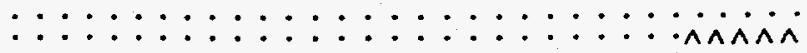

...........................

$\cdots \cdots \wedge \wedge \wedge \wedge$

$\therefore \therefore: \therefore \therefore: \therefore: \therefore \therefore \therefore: \because \therefore: \wedge \wedge \wedge \wedge \wedge$

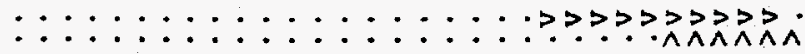

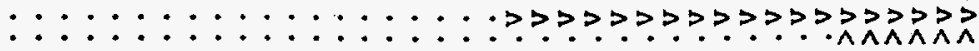

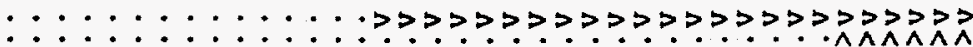

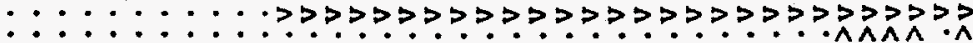

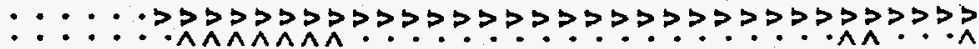

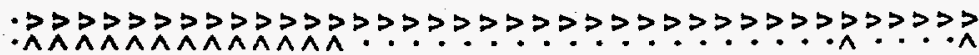

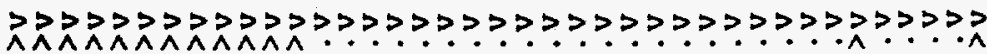

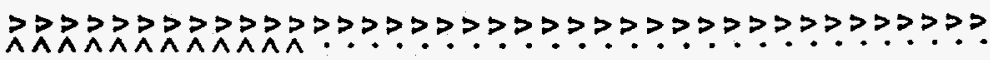

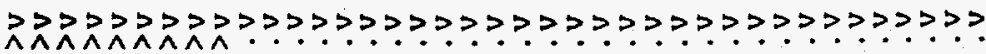

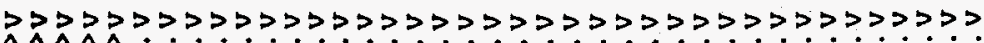

in

Inuninisininininininountao

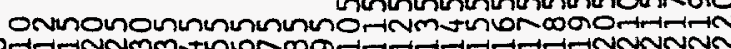




\section{TRITIUM TRANSPORT SIMULATION}

The flow field was assumed to be at steady state during the transport portion of the simulation. Element velocity components and water saturation data, determined in the last step of the flow simulation, defined the steady-state condition for the transport simulation.

Dispersivity values were estimated from the literature. A longitudinal dispersivity of $10 \mathrm{~m}$ and a transverse dispersivity of $3 \mathrm{~m}$ were assumed. According to Gelhar (1986) and Walton (1984), these values are reasonable for the simulated medium and the scale of the experiment. Values of longitudinal dispersivity ranging from $1 \mathrm{~m}$ to $100 \mathrm{~m}$, and transverse dispersivity ranging from $0.1 \mathrm{~m}$ to $30 \mathrm{~m}$, were simulated in sensitivity analyses. The sensitivity of the solution to changes in longitudinal dispersivity can be seen in Figure 24. The plots show simulated tritium concentration versus depth below ground surface for $x=0$ (directly beneath the center of the canal) at $\mathrm{T}=251$ days (since first detection of Cambric tritium at RNM-2S). Relative to other input parameters (e.g., hydraulic conductivity), variations in longitudinal dispersivity had little effect on simulation results. Appendix $\mathrm{K}$ contains plots showing the complete distribution of tritium in the solution domain for different values of longitudinal and transverse dispersivity at selected time steps.

Diffusion coefficients were also taken from the literature. The medium was assumed to be isotropic with respect to diffusion. A value of $1.0 \times 10^{-3} \mathrm{~cm}^{2} /$ day was selected for both the $D_{x x}$ and $D_{z z}$ components of molecular diffusion. Values of molecular diffusion from $10^{-5} \mathrm{~cm}^{2} /$ day to $10^{-1} \mathrm{~cm}^{2} /$ day were simulated in the sensitivity analyses. As expected, with water velocities as high as those in the simulations, the system is insensitive to changes in molecular diffusion coefficients (Appendix L).

The initial tritium concentration was assumed to be zero throughout the profile. At the canal nodes, the tritium concentration was specified at each time step. Tritium data, collected at irregular time intervals at RNM-2S (Figure 5), were interpolated to the simulation time steps, and input to the system at the canal nodes.

Fifteen hundred days of tritium transport were simulated. The first time step corresponds to the first detection of Cambric tritium at RNM-2S (July 1978); the last to August 1982. Figure 25 shows contour plots of simulated tritium concentration at selected times. The plots show a fairly smooth transition from low tritium concentrations to high, both in the horizontal and vertical directions, reflecting the smooth breakthrough at RNM-2S and the numerical stability of the solution. It took approximately $\mathbf{5 5 0}$ days for Cambric tritium to arrive at the water table. Once infiltrating canal water reaches the saturated zone, flow is primarily horizontal, away from the canal with concentrations increasing with depth at about the same gradient as the horizontal concentration gradient in the unsaturated zone. Appendix $M$ contains tritium concentrations at selected times. Appendix $\mathrm{N}$ contains contour plots of simulated tritium concentrations. 

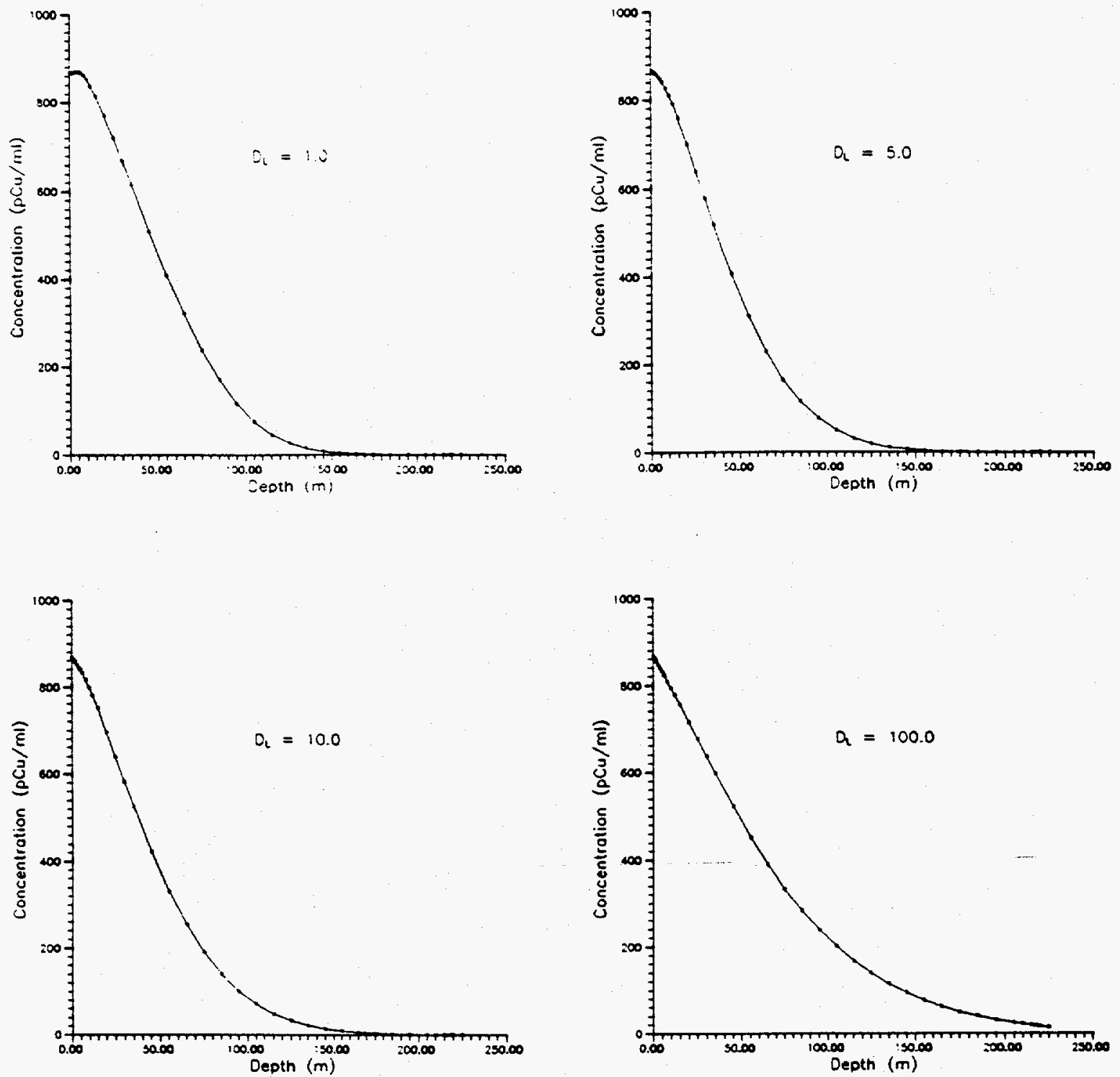

Figure 24. Solution Sensitivity to Changes in Longitudinal Dispersivity. 


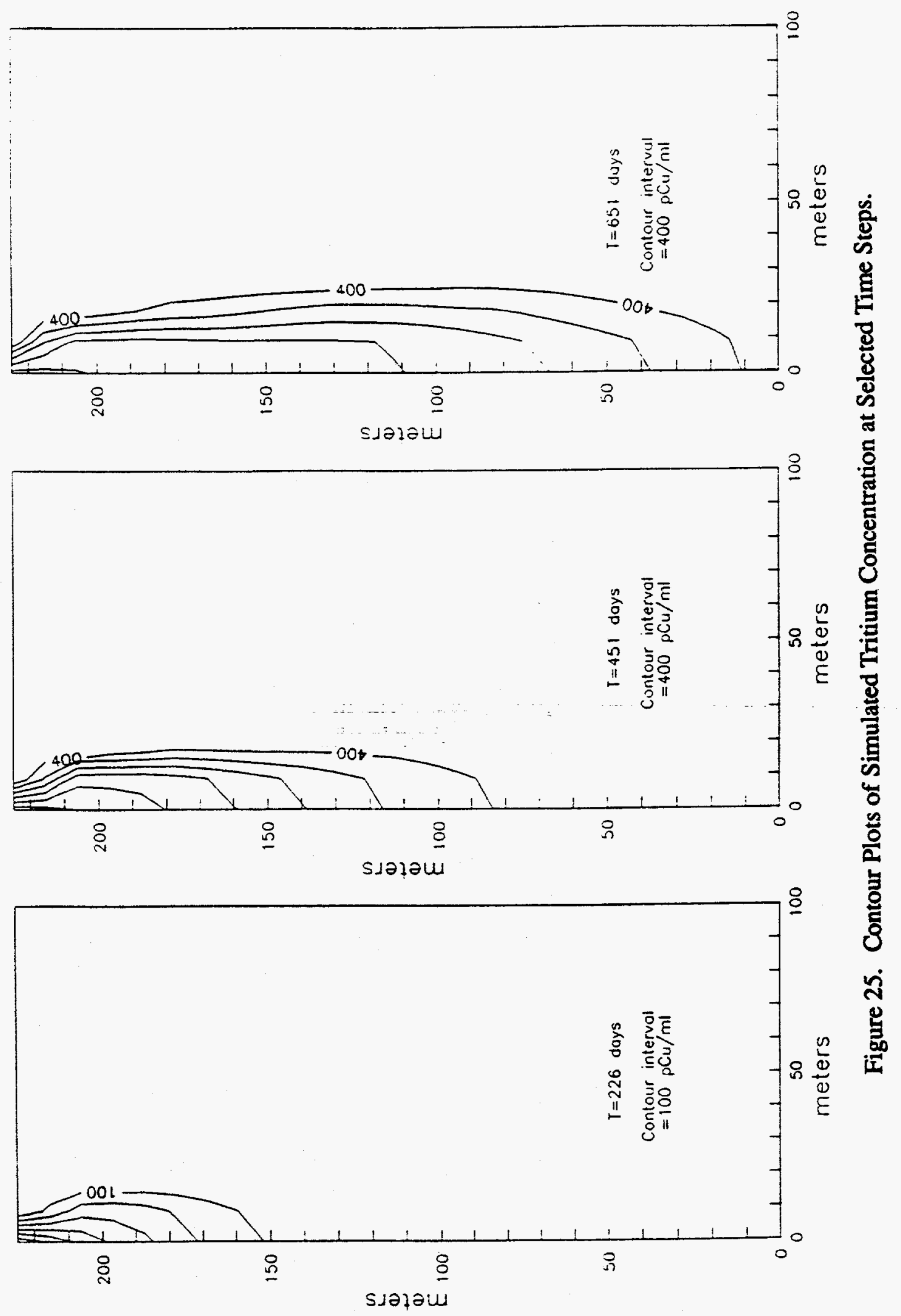



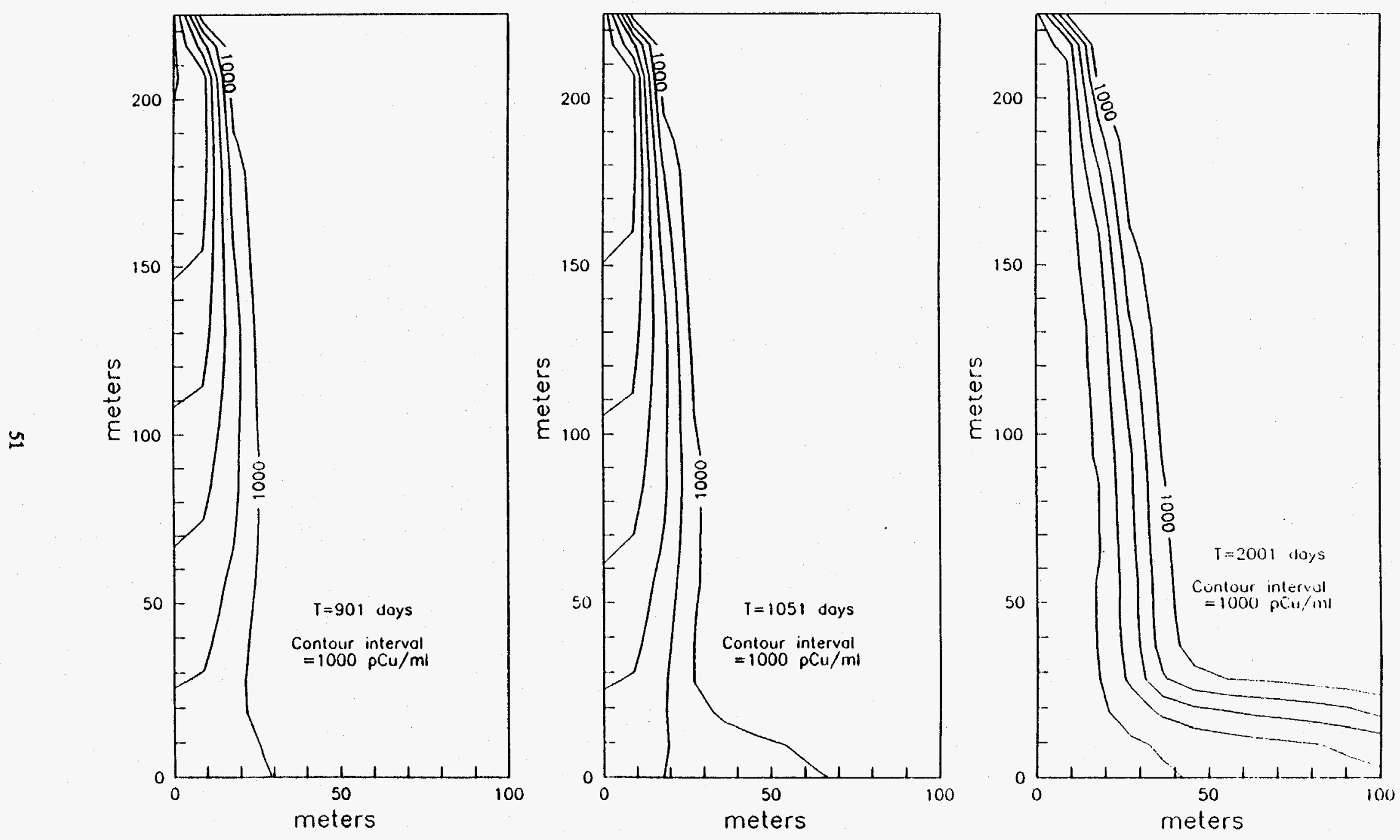

Figure 25. Contour Plots of Simulated Tritium Concentration at Selected Time Steps (continued). 


\section{INFILTRATION OF CONSERVATIVE TRACER AT RNM CANAL}

At the time of the flow and transport simulations, few data were available for calibration of the model. From flume data, an estimate of the canal transmission loss was calculated. The instantaneous profile test yielded an approximation of the bulk, near-surface unsaturated hydraulic properties. Substantial information about the tritium content of the infiltrating canal water was obtained from analysis of water samples collected at RNM-2S. Laboratory tests on soil cores taken from drill holes US1 and US2 provided porosity and saturated hydraulic conductivity data and some indication of the spatial (vertical) variability of the near-surface alluvium at the canal. Data collected by other researchers from nearby drill holes also contributed to the parameter estimation process.

These limited data, from either the near surface or nearby drill holes, were used to determine the hydraulic and chemical parameters of the model. Heterogeneities, incorporated in early model runs, led to numerical instabilities and, in light of the sparsity of data from the deep alluvium, were subsequently removed. The result was a single, homogeneous solution domain with hydraulic properties determined from mostly near-surface observations. A simulation conducted under these constraints would, at best, yield a rough approximation of the hydrologic conditions beneath the RNM canal.

A tracer test (March 22, 1986) provided an opportunity to evaluate the simulation results. A solution of sodium bromide and low-tritium water was introduced into the canal channel and recovered at a lysimeter installation $30 \mathrm{~m}$ below the ground surface, $28.9 \mathrm{~m}$ south of the canal (Figure 26). The event was simulated with SATURN using the steady-state flow field employed in the tritium transport model. Simulated and observed breakthrough curves were then developed.

\section{TRACER TEST LYSIMETER INSTALLATION}

On May 6, 1985, a suction lysimeter was installed in US2 at a depth of $28.9 \mathrm{~m}$ (Figure 26). Additional lysimeters were installed in US2 at shallower depths, but were damaged during installation. A sand pack and bentonite seals were trimmed into the positions shown in Figure 27. The samples were obtained by applying a 0.5 bar suction to the system. Samples were then pushed to the surface with 50 psi of nitrogen.

\section{TRACER TEST}

The tracer test was initiated on March 22, 1986. Water for the tracer solution was obtained from an NTS Area 6 well and contained $0.15 \mathrm{mg} / \mathrm{l}$ bromide. Sodium bromide was added to the water, raising the bromide concentration to $231 \mathrm{mg} /$. Analyses of canal water, sampled immediately prior to the tracer test, reported bromide concentrations of $0.11 \mathrm{mg} /$. The canal was dammed and diverted around the tracer test site through a plastic tube, and back into the canal channel at the location shown in Figure 26. Standing water was then allowed to infiltrate. Two additional dams were constructed to assure an even distribution of tracer over the desired length. 


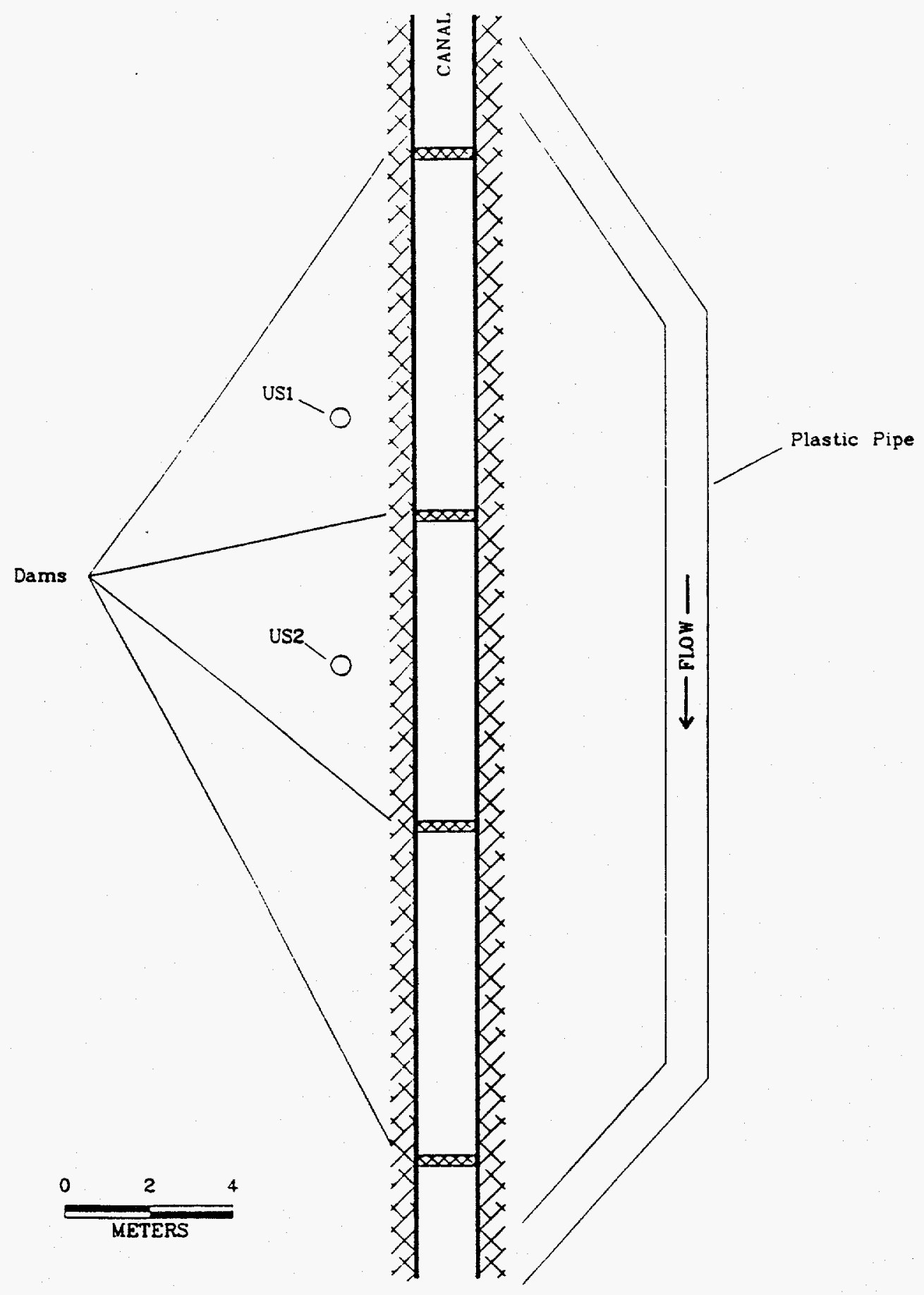

Figure 26. Tracer Test Site. 


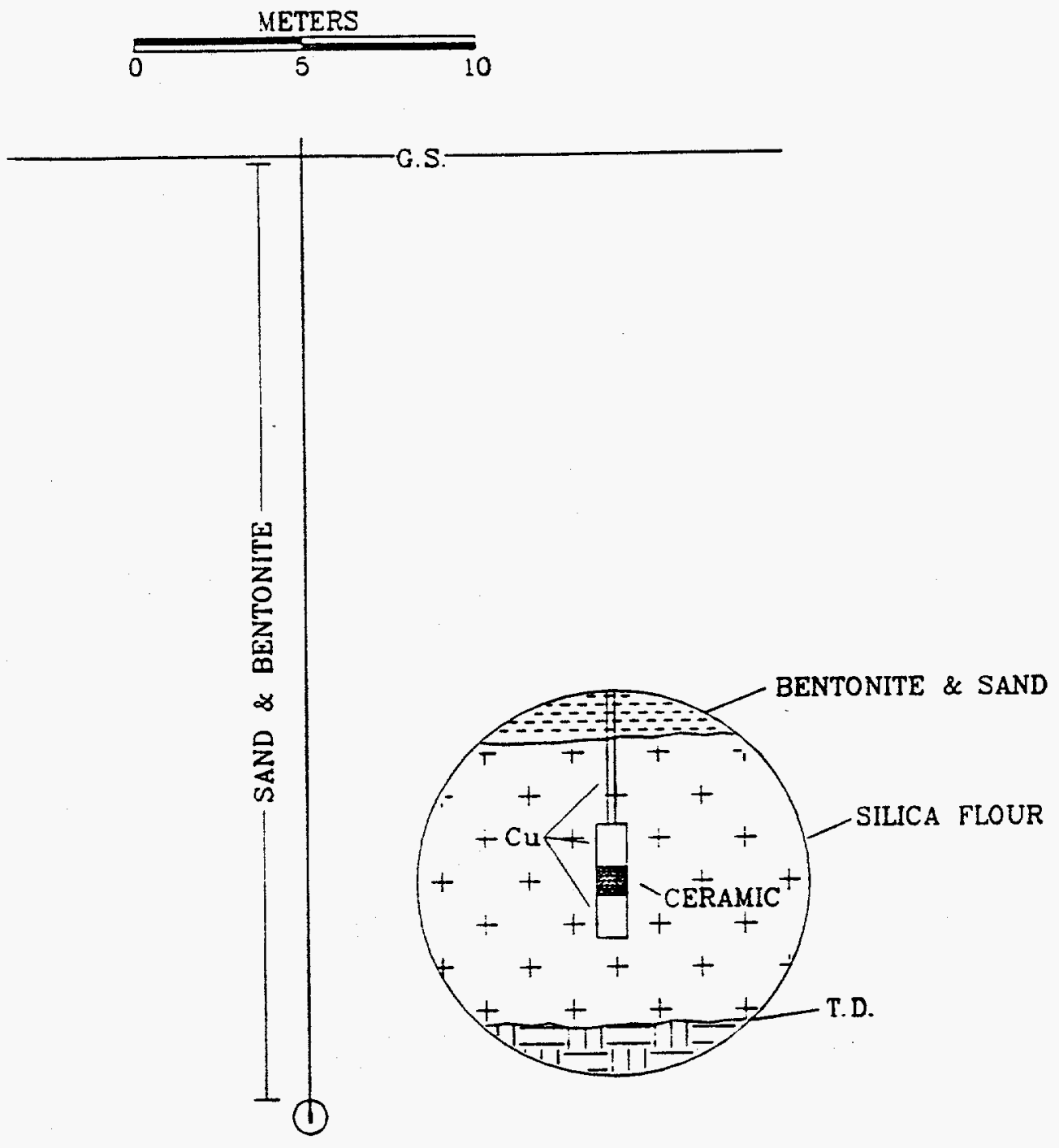

Figure 27. Suction Lysimeter Installation. 
When nearly all of the standing water had infiltrated, approximately 3,8001 of tracer solution was introduced into the canal sections. Each of the three sections received about one third of tracer solution. After 5.5 hours, nearly all of the tracer solution had infiltrated, and the canal was undammed and flow was returned to the channel.

Lysimeter samples were collected at the times listed in Table 8 and analyzed for bromide.

Bromide breakthrough at the lysimeter is plotted in Figure 28.

The tracer test was simulated by setting the bromide concentration at the canal nodes to $230 \mathrm{mg} / \mathrm{l}$ for the appropriate number of time steps, and by specifying node 583 , which is in the same location (in the finite element grid) as the lysimeter, as an observation node.

Although the simulated breakthrough curve has the same basic shape and maximum concentration as the observed data, the model predicted a much earlier breakthrough than was observed. Perhaps the most likely explanation for the delayed arrival of the bromide, was the model assumption that the upper portion of solution domain consisted of a single homogeneous, isotropic material with hydraulic properties observed in surface deposits.

With the fluxes and moisture contents likely to be present beneath the canal, a horizontal, fine-grained layer, similar to those observed in drill holes throughout Frenchman Flat, would form a barrier to the downward movement of fluid resulting in an increase in the horizontal component of flow. Although this type of layering was not observed in visual inspections of US 1 and US2 cuttings and cores, or reflected in permeameter tests conducted on the cores, if present between the canal and the lysimeter installation, a delayed breakthrough of bromide at the lysimeter would occur.

TABLE 8. RESULTS OF LYSIMETER SAMPLING.

\begin{tabular}{ccc}
\hline Date & $\begin{array}{c}\text { Days Since } \\
\text { Injection }\end{array}$ & $\begin{array}{c}\text { Bromide Concentration } \\
(\mathrm{mg} / \mathrm{l})\end{array}$ \\
\hline $3-26-86$ & 0 & 0.15 \\
$3-31-86$ & 5 & 0.15 \\
$4-10-86$ & 15 & 0.15 \\
$4-21-86$ & 26 & 0.17 \\
$4-28-86$ & 33 & 0.15 \\
$5-15-86$ & 50 & 0.17 \\
$6-09-86$ & 75 & 0.27 \\
$6-17-86$ & 83 & 0.32 \\
$6-26-86$ & 92 & 0.34 \\
$7-07-86$ & 103 & 0.32 \\
$7-22-86$ & 118 & 0.27 \\
$8-04-86$ & 131 & 0.23 \\
$9-03-86$ & 161 & 0.20 \\
$9-10-86$ & 168 & 0.16 \\
\hline
\end{tabular}


BROMIDE CONCENTRATION (mg/1)

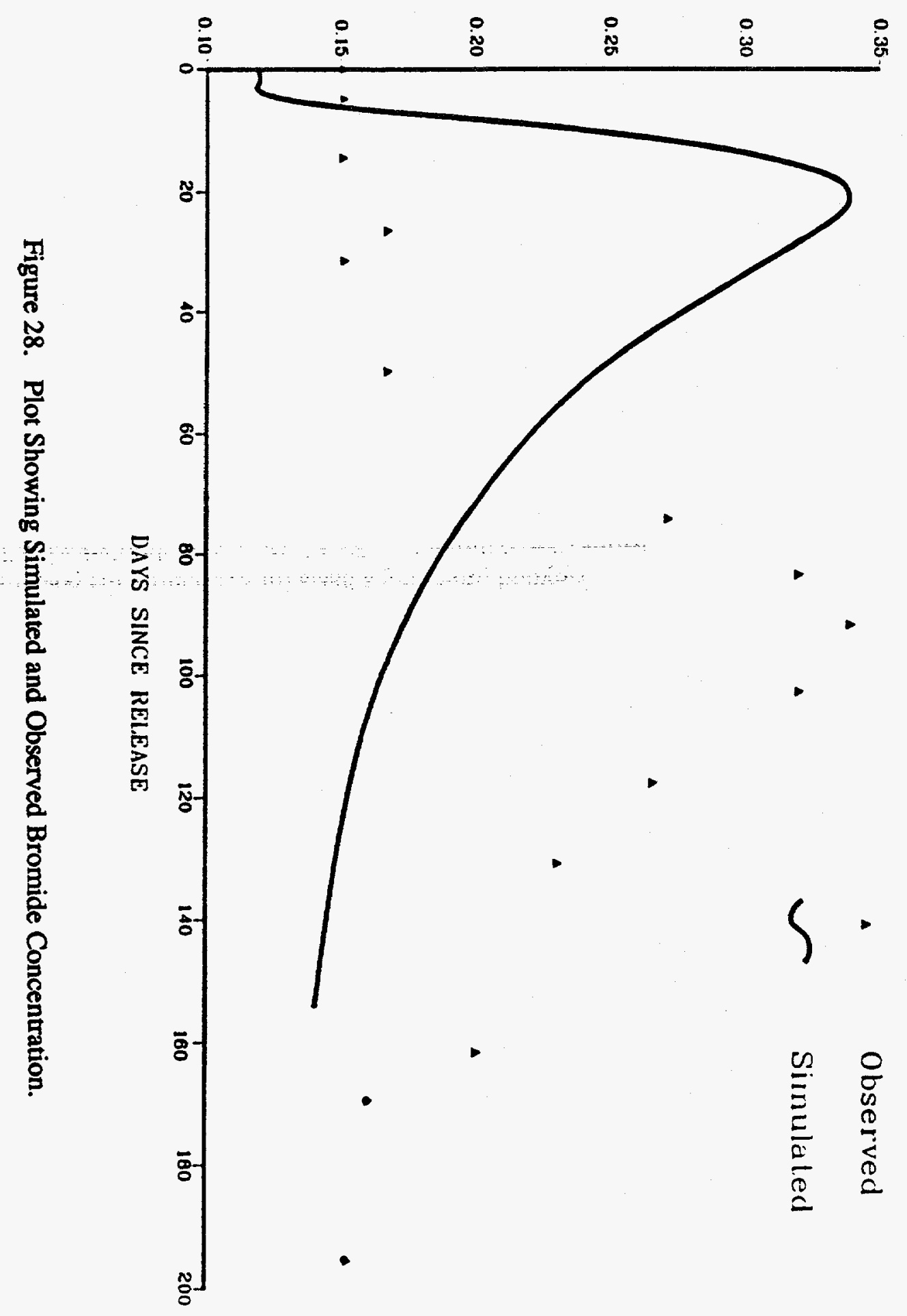


The 3,800 I of tracer solution took approximately 5.5 hours to infiltrate. This is 25 percent longer than calculations based on the average canal transmission loss would predict, and therefore longer than the model would predict, and is possibly a result of a lower than average hydraulic conductivity in that stretch of canal. This too may be partly responsible for the delayed breakthrough.

Increased lateral spreading of infiltrating canal water would occur if the horizontal components of the hydraulic conductivity tensor were greater than the vertical component. Such anisotropy, although common in alluvial environments, was not incorporated into the upper portion of the solution domain.

An improperly installed lysimeter could also have affected the breakthrough. If the diameter or the depth of the drill hole was significantly different from the values used to calculate the sand pack and grout locations and volumes, or if bends in the lysimeter tubes resulted in an improper placement of the lysimeter, the porous cup might not be in contact with the sand pack and might even be grouted off from the formation. Bridging in the drill hole could also result in an improper placement of the grout and sand pack. Although, it is unlikely that faulty lysimeter installation is entirely responsible for the delayed breakthrough, it could have been a factor.

As discussed in the previous chapter, only one steady-state flow solution was used as input to the solute transport runs, due to the large amount of time needed to produce even one flow solution (several weeks of computer time). If further modeling efforts were to be undertaken in the future, considerably more computer power is currently available, which would make it feasible to produce a better, more accurate flow solution, based in part on the results of the tracer test. 


\section{CONCLUSIONS}

As can be seen in Appendix $\mathrm{N}$, according to the simulation results, it would take approximately $\mathbf{5 5 0}$ days for Cambric tritium to travel from the canal to the water table. The perforations of RNM-2S are at approximately $100 \mathrm{~m}$ below the static water level $(230 \mathrm{~m}$ below ground surface). Assuming a porosity of 0.3 , the volume of water in a saturated sphere of radius $100 \mathrm{~m}$ would be

$$
\text { (0.3) } \frac{4}{3} \pi(100 m)^{3}=1.26 \times 10^{6} \mathrm{~m}^{3}
$$

At the pumping rates of RNM-2S $\left(2 \mathrm{~m}^{3} / \mathrm{min}\right), 1.82 \times 10^{6} \mathrm{~m}^{3}$ would be pumped in 550 days. Cambric tritium was first detected at RNM-2S after $2.3 \times 10^{6} \mathrm{~m}^{3}$ had been pumped. If the simulation results were accurate, and if the saturated zone in the vicinity of RNM-2S was homogeneous and isotropic with a porosity of 0.3 , then the first arrival of recirculated tritium at RNM-2S would occur after approximately $5 \times 10^{6} \mathrm{~m}^{3}$ had been pumped. As can be seen in Figure 7 , this is coincident with the peak in observed tritium concentration at RNM-2S.

This estimate assumes transport in a homogeneous, isotropic medium. Any departure from this assumption would increase the arrival time of recirculated tritium at RNM-2S. Results of the tracer test and observations made throughout Frenchman Flat (and alluvial basins in general) support the existence of heterogeneities in the flow system. In light of the above calculations, it appears unlikely that Cambric tritium, infiltrating from the RNM canal and recaptured by RNM-2S, had a significant effect on the breakthrough of tritium at RNM-2S.

Beyond providing a basis for evaluating the potential impact of infiltrating canal water in tritium breakthrough at RNM-2S, these simulations will hopefully contribute to the general understanding of flow and transport processes in the unsaturated zone at the RNM site. If the model assumptions were valid (the canal is underlain by a single homogeneous, isotropic medium with the hydraulic characteristics selected for the model; the stated initial and boundary conditions accurately describe the physical system; flow is steady state; the governing equations of flow and solute transport used in the numerical model are valid), the model would correctly simulate the movement of water and tritium beneath the RNM canal.

Understanding that the above assumptions are not entirely valid, the simulations provide a point of reference from which estimates of the behavior of water and solutes in more realistic (and hence more complicated) systems can be made. 


\section{REFERENCES}

Black, T.A., W.R. Gardner and G.W. Thurtell, 1969. The Prediction of Evaporation, Drainage and Soil Water Storage for a Bare Soil. Soil Sci. Soc. Amer. Proc. 33, pp. 655-660.

Brooks, R.H. and A.T. Corey, 1964. Hydraulic Properties of Porous Media. Hydrol. Pap. 3, Colorado State University, Fort Collins.

Bruce, R.R. and A. Klute, 1956. The Measurement of Soil Moisture Diffusivity. Soil Sci. Soc. Amer. Proc. 20, pp. 458-462.

Brutsaert, W., 1967. Some Methods of Calculating Unsaturated Permeability. Trans. ASAE 10, pp. 400-404.

Burbey, T.J., 1984. Numerical Simulation of Tritium and Chloride-36 Migration. Master's Thesis, University of Nevada, Reno.

Burbey, T.J. and S.W. Wheatcraft, 1986. Tritium and Chlorine-36 Migration from a Nuclear Explosion Cavity, Desert Research Institute, Publication No. 45050.

Carr, W.J., G.D. Bath, D.L. Healey and R.M. Hazelwood, 1975. Geology of Northern Frenchman Flat, Nevada Test Site. U.S. Geological Survey, USGS-474-216.

Cassel, D.K., A.W. Warrick, D.R. Nielson and J.W. Biggar, 1968. Soil Water Diffusivity Values Based Upon Time Dependent Soil Water Content Distributions. Soil Sci. Soc. Amer. Proc. 32, pp. 774-777.

Childs, E.C. and N. Collis-George, 1950. The Permeability of Porous Materials. Proc. Roy. Soc., Ser. A 201, pp. 392-405.

Daniels, W.R. (ed.), 1981. Laboratory and Field Studies Related to the Radionuclide Migration Project, October 1, 1979 to September 30, 1980. Los Alamos Scientific Laboratory, LA-8670-PR.

Davidson, J.M., L.R. Stone, D.R. Nielson and M.E. Larue, 1969. Field Measurement and Use of Soil Properties. Water Resources Res. 5, pp. 1312-1321.

Doering, E.J., 1965. Soil Water Diffusivity by the One-Step Method. J. Soil Sci. 99, pp. 322-326.

Duncan, D. W., 1992. Personal Communication.

Farrell, D.A. and W.E. Larson, 1972. Modeling the Pore Structure of Porous Media. Water Resources Res. 8, pp. 699-706.

Fenneman, N.M., 1931. Physiography of Western United States. McGraw-Hill, New York.

Flocher, W.J., M. Yamaguchi and D.R. Nielson, 1968. Capillary Conductivity and Soil Water Diffusivity Values from Vertical Soil Columns. Agron. J. 60, pp. 605-610. 
Gardner, W.R., 1956. Calculation of Capillary Conductivity from Pressure Plate Outflow Data. Soil Sci. Soc. Amer. Proc. 20, pp. 317-320.

Gardner, W.R., 1970. Field Measurement of Soil Water Diffusivity. Soil Sci. Soc. Amer. Proc. 20, pp. 832-833.

Gelhar, L.W., 1986. Stochastic Subsurface Hydrology from Theory to Applications. Water Resources Res. 22, pp. 135S-145S.

Hillel, D., 1971. Soil and Water: Physical Principles and Processes. Academic Press, Inc., New York.

Hillel, D., V.D. Krentos and Y. Stylianou, 1972. Procedure and Test of an Internal Drainage Method for Measuring Soil Hydraulic Characteristics In Situ. J. Soil Sci. 114, pp. 395-400.

Hoffman, D.C., R. Stone and W.W. Dudley, 1977. Radioactivity in the Underground Environment of the Cambric Nuclear Explosion at the Nevada Test Site. Rep. LA-6877-MS, Los Alamos Scientific Lab., Los Alamos, New Mexico.

Huyakorn, P.S. and K. Nilkuha, 1979. Solution of Transient Transport Equation Using an Upstream Finite Element Scheme. Appl. Math. Modeling 3, pp. 7-17.

Huyakorn, P.S., S.D. Thomas, J.W. Mercer and B.H. Lester, 1983. SATURN: A Finite Element Model for Simulating Saturated-Unsaturated Flow and Radionuclide Transport. Technical Report by GeoTrans Inc., Reston, Virginia.

Jackson, R.D., R.F. Reginato and C.H.M. van Bavel, 1963. Examination of the Pressure Plate Outflow Method for Measuring Capillary Conductivity. J. Soil Sci. 96, pp. 249-265.

Jackson, R.D., R.F. Reginato and C.H.N. van Bavel, 1965. Comparison of Measured and Calculated Hydraulic Conductivities of Unsaturated Soils. Water Resources Res. 1, pp. 375-380.

Jones, A.J. and R.J. Wagenet, 1984. In-Situ Estimation of Hydraulic Conductivity Using Simplified Methods. Water Resources Res. 20, pp. 1620-1626.

Klute, A. and C. Dirksen, 1986. Hydraulic Conductivity and Diffusivity: Laboratory Methods, in Methods of Soil Analysis, Part I, Physical and Mineralogical Methods, A. Klute (ed.), pp. 687-734.

Klute, A., 1972. The Determination of the Hydraulic Conductivity and Diffusivity of Unsaturated Soils. J. Soil Sci. 113, pp. 264-276.

Kunze, R.J. and D. Kirkham, 1962. Simplified Accounting for Membrane Impedance in Capillary Conductivity Determinations. Soil Sci. Soc. Amer. Proc. 26, pp. 421-426.

Kunze, R.J., G. Uehara and K. Graham, 1968. Factors Important in the Calculation of Hydraulic Conductivity. Soil Sci. Soc. Amer. Proc. 32, pp. 760-765. 
Marshall, T.J., 1958. A Relation between Permeability and Size Distribution of Pores. J. Soil Sci. 9, pp. 1-8.

Meyers, J.S., 1962. Evaporation from the 17 Western States, with a section on Evaporation Rates, by T.J. Nordenson, U.S. Geological Survey Professional Paper 272-D.

Miller, E.E. and D.E. Elrick, 1958. Dynamic Determination of Capillary Conductivity Extended for Non-negligible Membrane Impedance. Soil Sci. Soc. Amer. Proc. 22, pp. 483-486.

Millington, R.J. and J.P. Quirk, 1961. Permeability of Porous Solids. Trans. Faraday Soc. 57, pp. $1200-1206$.

Mualem, Y., 1976. A New Model for Predicting the Hydraulic Conductivity of Unsaturated Porous Media. Water Resources Res. 12, pp. 513-522.

Nielson, D.R., J.M. Davidson, J.W. Biggar and R.J. Miller, 1962. Water Movement Through Panoche Clay Loam Soil. Hilgardia 35, pp. 491-506.

Ogata, G. and L.A. Richards, 1957. Water Content Changes Following Irrigation of Bare Field Soil that is Protected from Evaporation. Soil Sci. Soc. Amer. Proc. 21, pp. 355-356.

Peek, A.J., 1966. Diffusivity Determination by a New Outflow Method. In: Water in the Unsaturated Zone, Vol. I, Publ. No. 82, Int. Assoc. Sci. Hydrol., pp. 191-202.

Ramspott, L.D. and R.D. McArthur, 1977. Results of Exploratory Drill Hole Ue5n, Frenchman Flat, Nevada Test Site. Lawrence Livermore Laboratory, Report UCID-17392.

Richards, L.A., W.R. Gardner and G. Ogata, 1956. Physical Processes Determining Water Loss from Soil. Soil Sci. Soc. Amer. Proc. 20, pp. 310-314.

Richards, S.J. and L.V. Weeks, 1953. Capillary Conductivity Values from Moisture Yield and Tension Measurements on Soil Columns. Soil Sci. Soc. Amer. Proc. 17, pp. 206-209.

Rijtema, P.E., 1959. Calculation of Capillary Conductivity from Pressure Plate Outflow Data with Non-negligible Membrane Impedance. Netherlands J. Agric. Sci. 7, pp. 209-215.

Rogers, J.S. and A. Klute, 1971. The Hydraulic Conductivity Water Content Relationship During Non-steady Flow through a Sand Column. Soil Sci. Soc. Amer. Proc. 35, pp. 695-700.

Romney, E.M., V.Q. Hale, A. Wallace, O.R. Hunt, G.V. Alexander, J.E. Kinnear and T.L. Ackerman, 1973. Some Characteristics of Soil and Perennial Vegetation in Northern Mojave Desert Areas of the Nevada Test Site. Rep. UCLA\#12-916, UCLA, Los Angeles, California.

Rose, C.W., W.R. Stern and J.E. Drummond, 1965. Determination of Hydraulic Conductivity as a Function of Depth and Water Content for Soil In Situ. Aust. J. Soil Res. 3, pp. 1-9. 
Sisson, J.B., A.H. Ferguson and M.Th. van Genuchten, 1980. Simple Method for Predicting Drainage from Field Plots. Soil Sci. Soc. Amer. J. 44, pp. 1147-1152.

Vachaud, G., 1967. Determination of the Hydraulic Conductivity of Unsaturated Soils from an Analysis of Transient Flow Data. Water Resources Res. 3, pp. 697-705.

Vachaud, G. and Jean-Louis Thony, 1971. Hysteresis During Infiltration and Redistribution in a Soil Column at Different Initial Water Contents. Water Resources Res. 7, pp. 111-127.

van Bavel, C.H.M., G.B. Stirk and K.J. Brust, 1968a. Hydraulic Properties of a Clay-Loam Soil and the Field Measurement of Water Uptaken by Roots. I: Interpretation of Water Content and Pressure Profiles. Soil Sci. Soc. Amer. Proc. 32, pp. 310-317.

van Bavel, C.H.M., K.J. Brust and G.B. Stirk, 1968b. Hydraulic Properties of a Clay-Loam Soil and the Field Measurement of Water Uptaken by Roots. II: The Water Balance of the Root Zone. Soil Sci. Soc. Amer. Proc. 32, pp. 317-321.

van Genuchten, R., 1978. Calculating the Unsaturated Hydraulic Conductivity with a New, Closed Form Analytical Model. Dep. Civ. Eng., Princeton University, Princeton, New Jersey, Water Resources Prog. Rep. 78-WR-08, 63 pp.

Walton, W.C., 1984. Practical Aspects of Groundwater Modeling. National Water Well Association.

Watson, K.K., 1966. An Instantaneous Profile Method for Determining the Unsaturated Hydraulic Conductivity of Porous Materials. Water Resources Res. 2, pp. 709-715.

Weeks, L.V. and S.J. Richards, 1967. Soil Water Properties Computed from Transient Flow Data. Soil Sci. Soc. Amer. Proc. 31, pp. 721-725.

Winograd, I.J., W. Thordarson and R.A. Young, 1971. Hydrology of the Nevada Test Site and Vicinity, Southeastern Nevada. U.S. Geological Survey Open File Report. 
Appendix A

Neutron data

A-1 


\begin{tabular}{|c|c|c|c|c|c|c|c|c|c|c|}
\hline \multicolumn{11}{|c|}{ Neutron Foie N1 } \\
\hline \multirow{2}{*}{$\begin{array}{l}\text { Time } \\
\text { (hrs.) }\end{array}$} & \multicolumn{10}{|c|}{ Deptn (cm) } \\
\hline & 45 & 75 & 105 & 135 & 165 & 105 & 225 & 255 & 300 & 320 \\
\hline 0. & 0.689 & 0.668 & 0.615 & 0.468 & 0.398 & 0.618 & 0.0 .8 & 0.0 .3 & - & U.6i: \\
\hline 0.50 & 0.675 & 0.671 & 0.595 & 0.463 & 0.389 & 0.610 & $0.65 \%$ & 0.071 & - & 0.642 \\
\hline 1.00 & 0.678 & 0.650 & 0.596 & 0.446 & 0.370 & 0.610 & 0.657 & 0.574 & $\cdot$ & 0.666 \\
\hline 1.42 & 0.666 & 0.648 & 0.582 & 0.436 & 0.381 & 0.599 & 0.641 & 0.552 & 0.551 & 0.622 \\
\hline 2.50 & 0.659 & 0.653 & 0.586 & 0.437 & 0.379 & 0.588 & 0.657 & 0.553 & - & 0.617 \\
\hline 3.50 & 0.639 & 0.640 & 0.585 & 0.442 & 0.370 & 0.576 & 0.629 & 0.569 & 0.553 & 0.594 \\
\hline 6.00 & 0.615 & 0.638 & 0.575 & 0.413 & 0.368 & 0.556 & 0.620 & 0.545 & 0.531 & 0.571 \\
\hline 10.00 & 0.557 & 0.620 & 0.356 & 0.391 & 0.341 & 0.541 & 0.574 & 0.525 & 0.533 & 0.566 \\
\hline 20.00 & 0.180 & 0.578 & 0.527 & 0.368 & 0.223 & 0.500 & 0.539 & 0.528 & 0.506 & 0.528 \\
\hline 24.25 & 0.474 & 0.558 & 0.531 & 0.371 & 0.334 & 0.467 & 0.528 & 0.514 & 0.515 & 0.511 \\
\hline 30.50 & 0.487 & 0.552 & 0.525 & 0.259 & 0.223 & 0.482 & 0.524 & 0.523 & 0.503 & 0.505 \\
\hline 43.50 & 0.463 & 0.521 & 0.500 & 0.352 & 0.222 & 0.454 & 0.513 & 0.510 & 0.495 & 0.493 \\
\hline 75.00 & 0.441 & 0.500 & 0.478 & 0.322 & 0.317 & 0.440 & 0.488 & 0.506 & 0.460 & 0.473 \\
\hline 169.00 & 0.407 & 0.465 & 0.453 & 0.302 & C.298 & 0.403 & $0.4 i \pi$ & $0.4: 2$ & - & 0.2 .8 \\
\hline 336.50 & 0.399 & 0.444 & 0.428 & 0.294 & 0.283 & 0.392 & 0.403 & 0.453 & - & 0.394 \\
\hline 552.00 & 0.398 & 0.446 & $0.4 \Omega 2$ & 0.290 & c.296 & 0.375 & 0.392 & 0.441 & 0.390 & 0.396 \\
\hline
\end{tabular}

\begin{tabular}{|c|c|c|c|c|c|c|c|c|c|c|}
\hline \multicolumn{11}{|c|}{ Neutron Elole $\Lambda^{2} 2$} \\
\hline \multirow{2}{*}{$\begin{array}{l}\text { Time } \\
\text { (ins.) }\end{array}$} & \multicolumn{10}{|c|}{ Depti $(\mathrm{cm})$} \\
\hline & 45 & .5 & 105 & 135 & 165 & 195 & 925 & 253 & 300 & 230 \\
\hline 1.12 & 0.729 & 0.215 & 0.634 & 0.505 & 0.520 & 0.599 & 0.553 & 0.510 & - & 0.640 \\
\hline 3.07 & 0.704 & 0.680 & 0.613 & 0.475 & 0.513 & $0.5 \% 1$ & 0.549 & 0.511 & 0.512 & 0.619 \\
\hline 6.00 & 0.641 & 0.673 & 0.586 & 0.468 & 0.502 & 0.553 & 0.541 & 0.495 & 0.499 & $0.5 \delta i$ \\
\hline 10.00 & 0.565 & 0.634 & 0.565 & 0.450 & 0.479 & 0.529 & 0.520 & 0.489 & 0.497 & 0.548 \\
\hline 20.00 & 0.487 & 0.578 & 0.532 & 0.414 & 0.440 & 0.518 & 0.499 & 0.457 & $0.4 \varepsilon 2$ & 0.502 \\
\hline 24.25 & 0.484 & 0.557 & 0.509 & 0.220 & 0.439 & 0.493 & 0.502 & 0.465 & $0.4 \overline{1}$ & 0.515 \\
\hline 30.50 & 0.493 & 0.581 & 0.515 & 0.407 & 0.418 & 0.505 & $0.48 \pi$ & 0.452 & 0.455 & 0.491 \\
\hline 43.50 & 0.466 & 0.324 & 0.455 & 0.387 & 0.406 & 0.467 & $0.4: 5$ & 0.423 & 0.415 & 0.460 \\
\hline 75.00 & 0.414 & 0.501 & 0.455 & 0.385 & 0.402 & 0.470 & 0.443 & 0.418 & 0.410 & 0.443 \\
\hline 169.00 & $0.40 \%$ & 0.457 & 0.435 & 0.369 & 0.278 & 0.439 & $0.22 \pi$ & 0.385 & - & 0.414 \\
\hline 336.00 & 0.389 & 0.439 & 0.228 & $0.3 \leq 5$ & 0.875 & 0.423 & 0.395 & $0.3=0$ & - & 0.400 \\
\hline $5 \equiv 2.00$ & 0.390 & 0.425 & 0.424 & 0.343 & 0.361 & 0.406 & 0.402 & C.:-2: & $0 . \hat{2} 3 \varepsilon$ & 0.386 \\
\hline
\end{tabular}


Appendix B

Tensiometer data

B-1 


\begin{tabular}{|c|c|c|c|c|c|c|c|c|c|c|}
\hline \multirow{6}{*}{$\begin{array}{l}\text { Time } \\
\text { (hrs.) }\end{array}$} & \multicolumn{10}{|c|}{ Tensiomerer Dara ( $\mathrm{cm}$ ) } \\
\hline & \multicolumn{4}{|c|}{ Array 1} & \multicolumn{2}{|c|}{1} & \multicolumn{3}{|c|}{ Arrar : } & \multirow[b]{3}{*}{214} \\
\hline & \multicolumn{9}{|c|}{ Tensiomerer Depths (cm) } & \\
\hline & 26 & 56 & 85 & 144 & 214 & 26 & 56 & 85 & 144 & \\
\hline & \multicolumn{10}{|c|}{ Tensiometer Lengths $(\mathrm{cm})$} \\
\hline & 35 & 65 & 95 & 156 & 250 & 35 & 65 & 95 & 156 & 250 \\
\hline .25 & 5.50 & 5.50 & 8.50 & 15.50 & 24.00 & 4.50 & 6.00 & 12.00 & 17.00 & 24.00 \\
\hline .75 & 8.00 & 8.50 & 10.50 & 16.00 & 24.00 & 8.00 & 8.50 & 13.50 & 18.00 & 24.00 \\
\hline 1.25 & 9.00 & 9.00 & 11.00 & 16.00 & 24.00 & 8.50 & 9.50 & 14.00 & 18.00 & 24.00 \\
\hline 1.75 & 10.00 & 10.00 & 11.50 & 17.00 & 25.00 & 10.00 & 10.00 & 14.00 & 18.50 & 25.00 \\
\hline 2.75 & 10.00 & 10.00 & 12.00 & 17.50 & 25.50 & 10.00 & 11.00 & 14.50 & 18.00 & 25.50 \\
\hline 3.75 & 10.00 & 10.50 & 11.50 & 18.00 & 25.50 & 10.00 & 11.00 & 15.50 & 19.00 & $\mathbf{2 5 . 5 0}$ \\
\hline 6.25 & 11.00 & 10.00 & 11.50 & 18.50 & 26.00 & 12.00 & 13.00 & 15.50 & 19.00 & 26.00 \\
\hline 10.25 & 12.00 & 11.00 & 11.50 & 18.50 & 26.50 & 12.50 & 14.00 & 17.00 & 19.50 & 26.50 \\
\hline 20.25 & 14.00 & 12.00 & 12.00 & 20.00 & 28.00 & 14.00 & 15.00 & 18.00 & 20.00 & 28.00 \\
\hline 24.5 & 14.00 & 15.50 & 15.50 & 20.00 & 28.00 & 14.00 & 16.00 & 19.00 & 20.50 & 28.00 \\
\hline 32.75 & 14.00 & 14.00 & 14.00 & 20.00 & 28.00 & 15.00 & 16.50 & 18.00 & 21.00 & 28.00 \\
\hline 45.75 & 15.00 & 12.00 & 12.00 & 20.00 & 29.00 & 15.00 & 17.00 & 19.50 & 21.00 & 29.00 \\
\hline 77.25 & 16.00 & 16.50 & 16.50 & 21.00 & 30.00 & 16.50 & 18.00 & 21.00 & 22.00 & 30.00 \\
\hline 171.25 & 18.00 & 17.00 & 17.00 & 22.00 & 30.00 & 18.00 & 20.00 & 22.00 & 23.00 & 30.00 \\
\hline 338.75 & 14.00 & 20.00 & 20.00 & 24.00 & 32.00 & 20.00 & 22.00 & 24.00 & 24.00 & 22.00 \\
\hline 554.75 & 20.00 & $=2.00$ & 23.00 & 25.00 & 32.00 & $2: .00$ & $\therefore .00$ & 24.00 & 24.00 & 22.00 \\
\hline
\end{tabular}


Appendix C

Instantaneous profile test flow data

$\mathrm{C}-1$ 


\begin{tabular}{|c|c|c|}
\hline \multicolumn{3}{|c|}{ Flow rates /cc/sec i } \\
\hline \hline Inflow & $\begin{array}{c}\text { Outflow } \\
\text { tube 1 }\end{array}$ & $\begin{array}{c}\text { Outfiow } \\
\text { tube 2 }\end{array}$ \\
\hline 943.4 & 368.8 & 150.2 \\
\hline 857.9 & 372.7 & 150.1 \\
\hline 87.0 & 370.5 & 149.0 \\
\hline
\end{tabular}

\begin{tabular}{|c|c||c|c|}
\hline \multicolumn{5}{|c|}{ Rate of Water Level Drod on Plot } \\
\hline \hline stage $(\mathrm{cm})$ & time $(\mathrm{min})$ & stage $(\mathrm{cm})$ & time $(\mathrm{min}$ \\
\hline 7.31 & 9 & 4.57 & 41 \\
\hline 6.40 & 18 & 4.26 & 45 \\
\hline 6.09 & 23 & 3.96 & 48 \\
\hline 5.79 & 28 & 3.65 & 52 \\
\hline 5.48 & 31 & 3.35 & 56 \\
\hline 5.18 & 34 & 3.04 & 59 \\
\hline 4.87 & 38 & 2.74 & 64 \\
\hline
\end{tabular}


Appendix D

Plots of moisture content vs time

D-1 
-oie vi iss-- 150 .

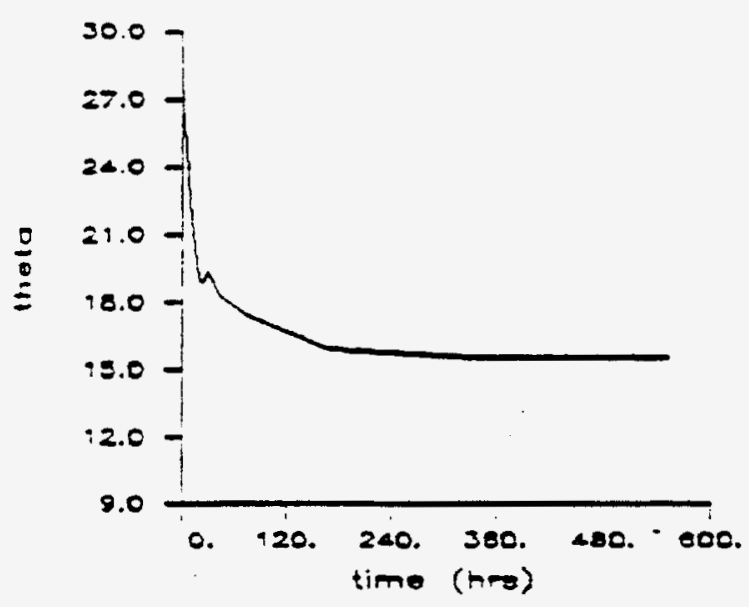

Hoil NI 75em-70Sem

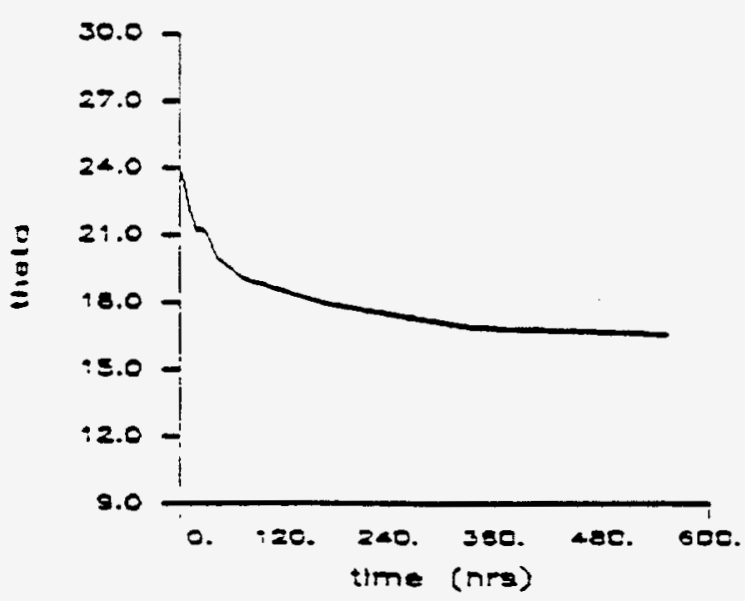

-oie : $^{\circ} \quad 450 m--50 m$

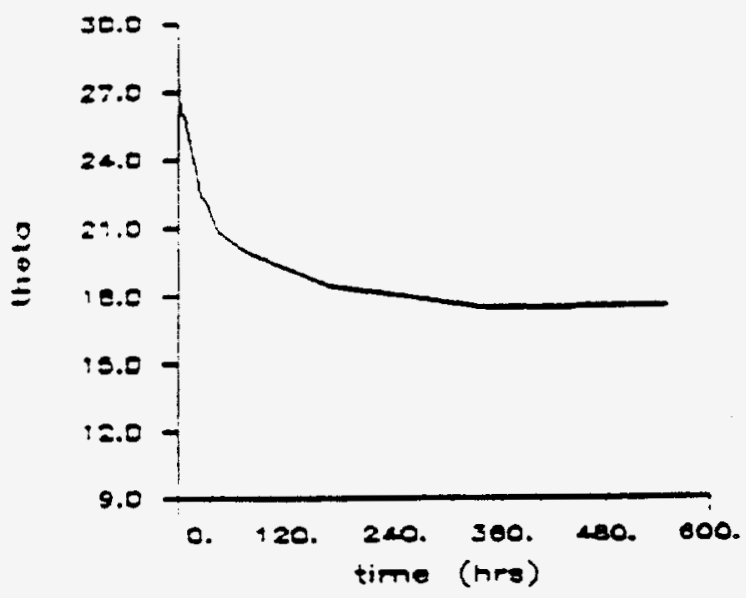

Hole NI 105em-135em

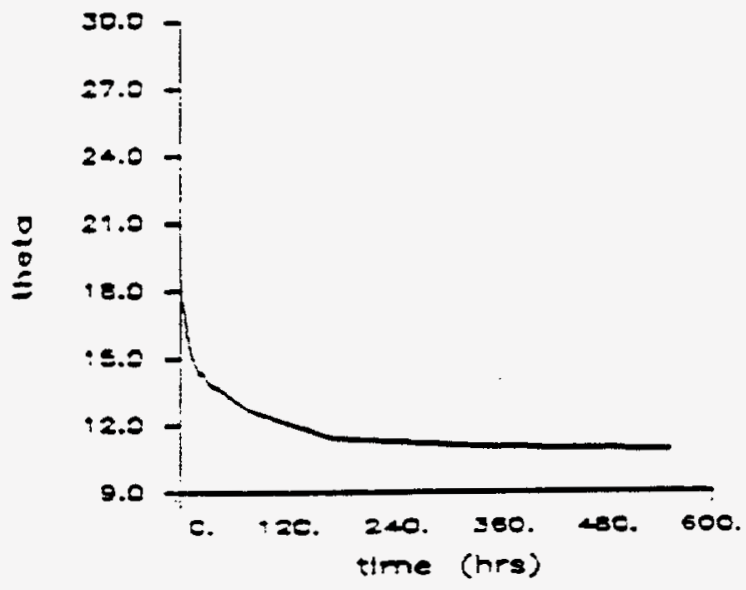



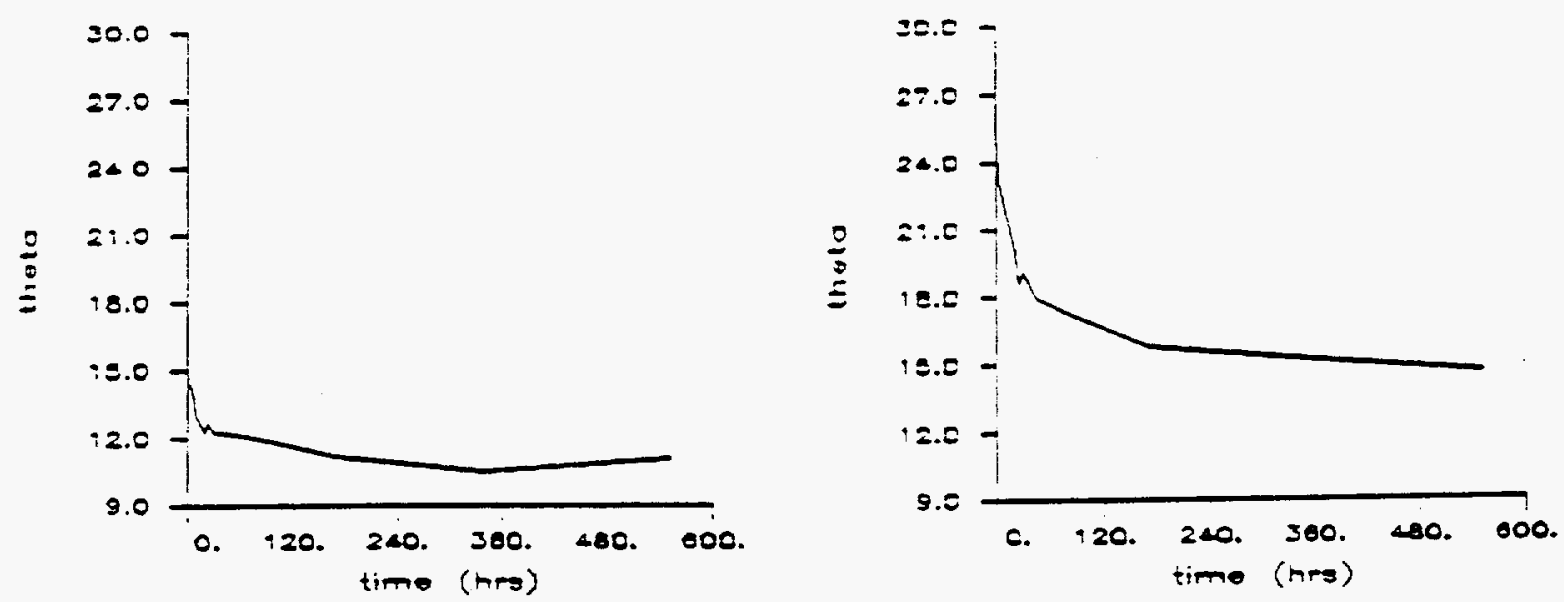

Hole NI i85cm-225cm

Hole NI 225em-255em
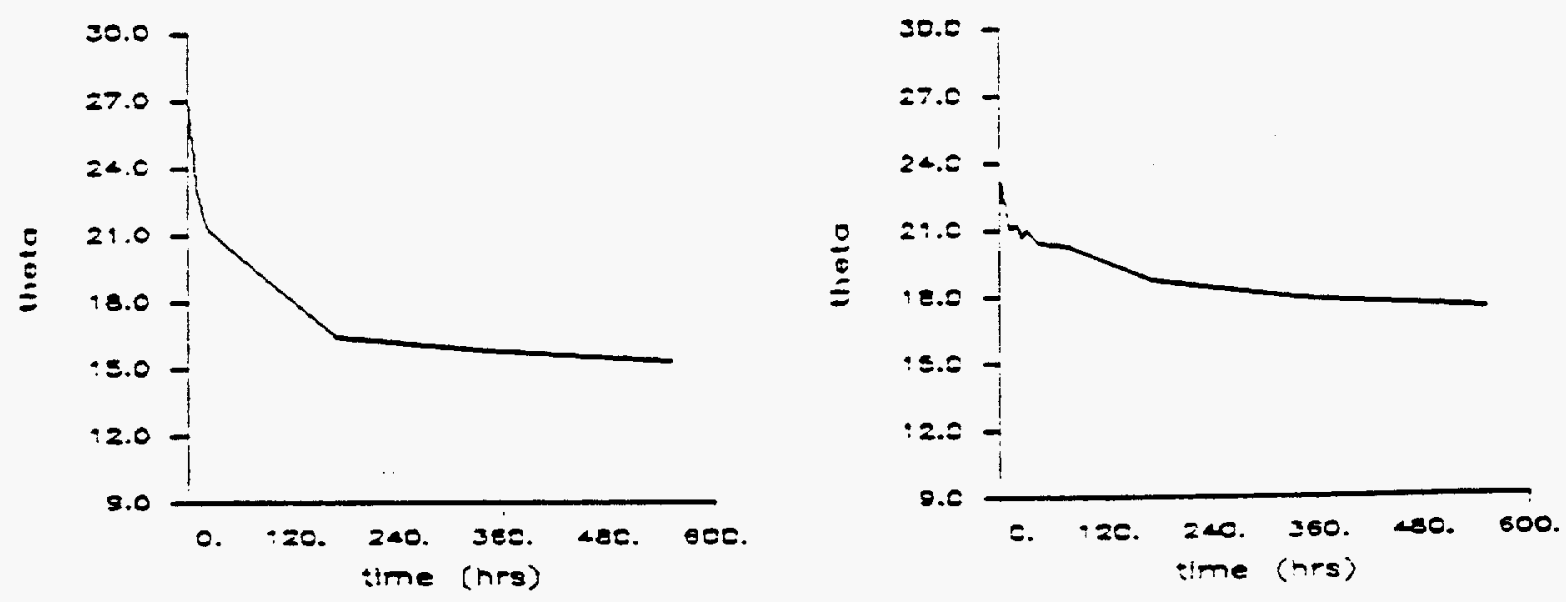
-o1e N: Z550-

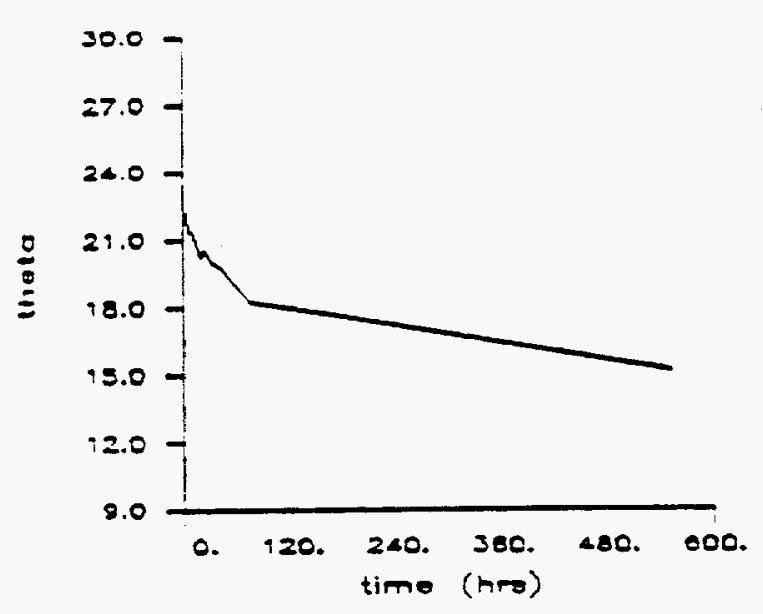

-ole Ni 28scm-3:sem

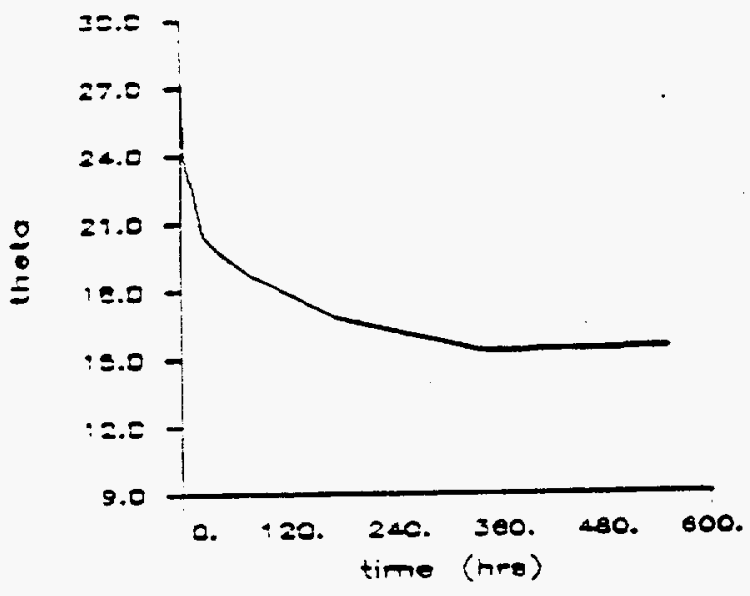


-oie i2 ise--45e-

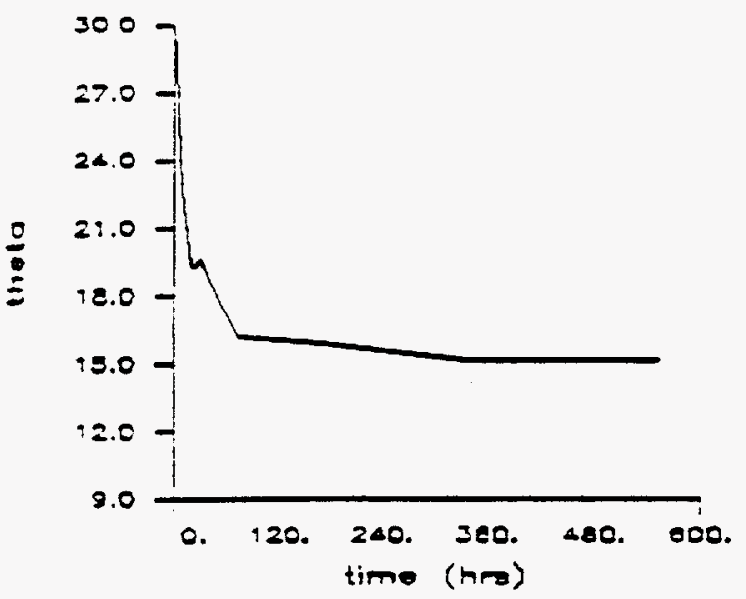

Hoie N2 75em-ic5em

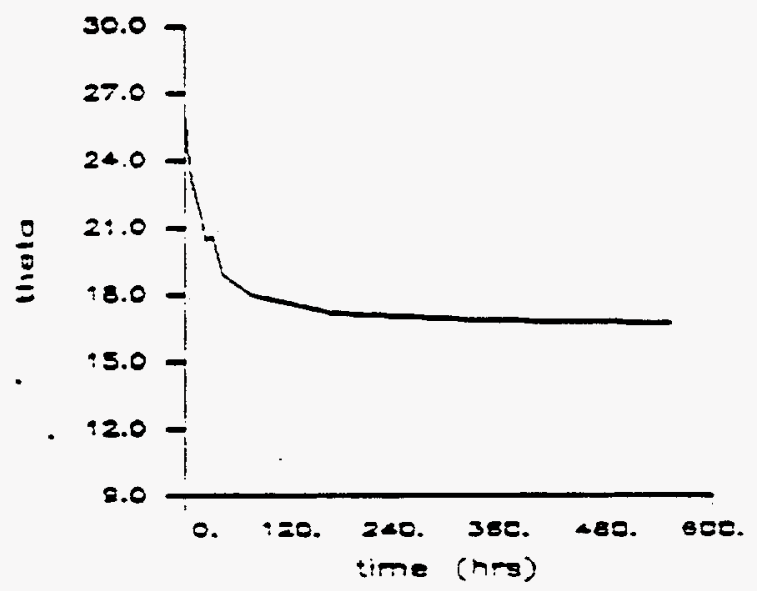

mole $N 2$ 45e-m- $-50 \mathrm{~cm}$

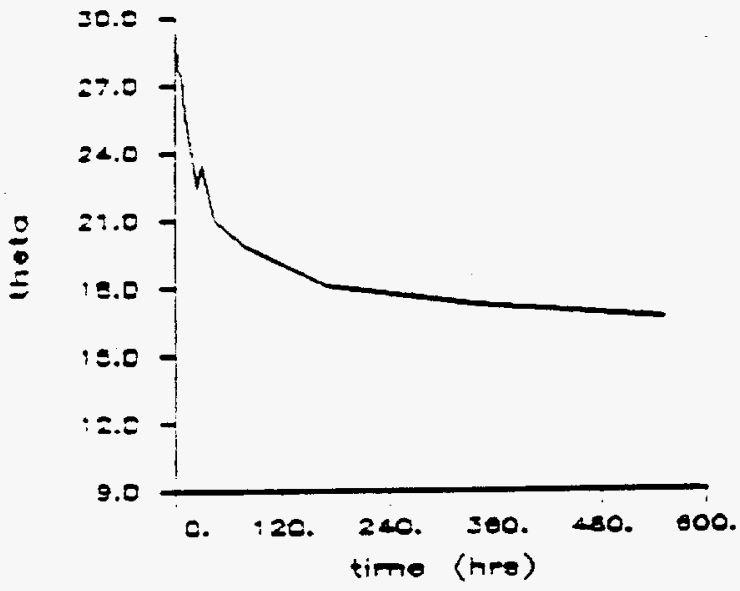

Hole N2 iCsem-i35em

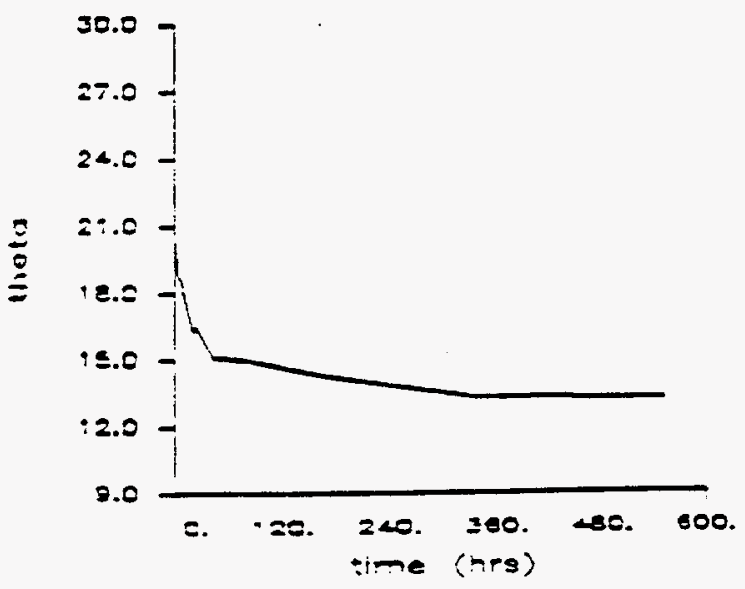



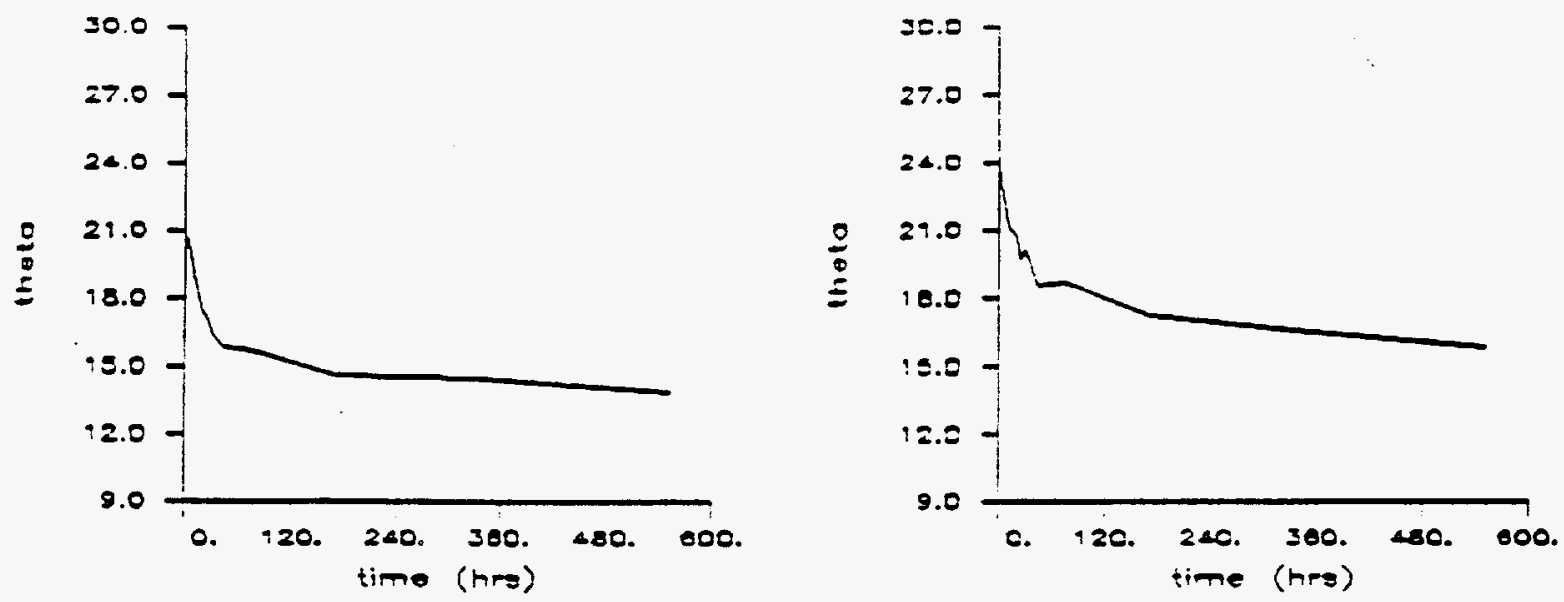

Hole N2 $195 \mathrm{~cm}-225 \mathrm{~cm}$

Hole N2 225em-255cm
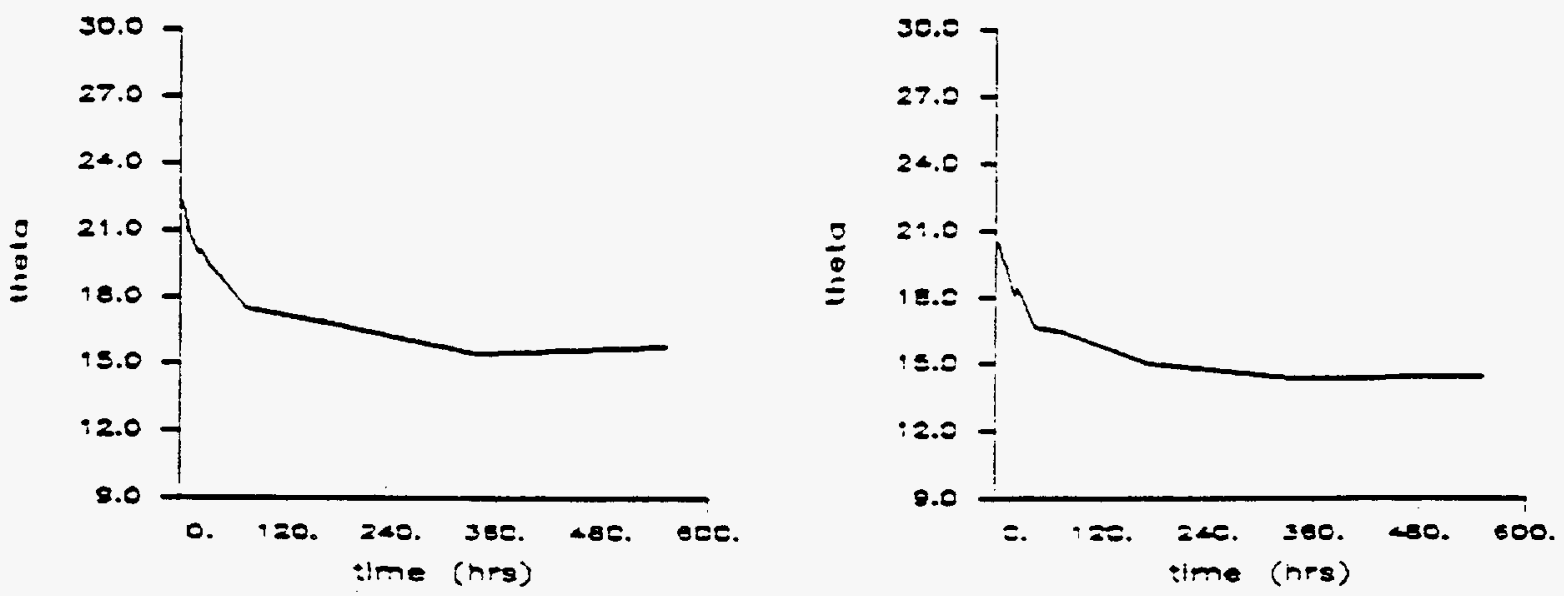
$7010 \mathrm{N2}$ IE5cm-235cm

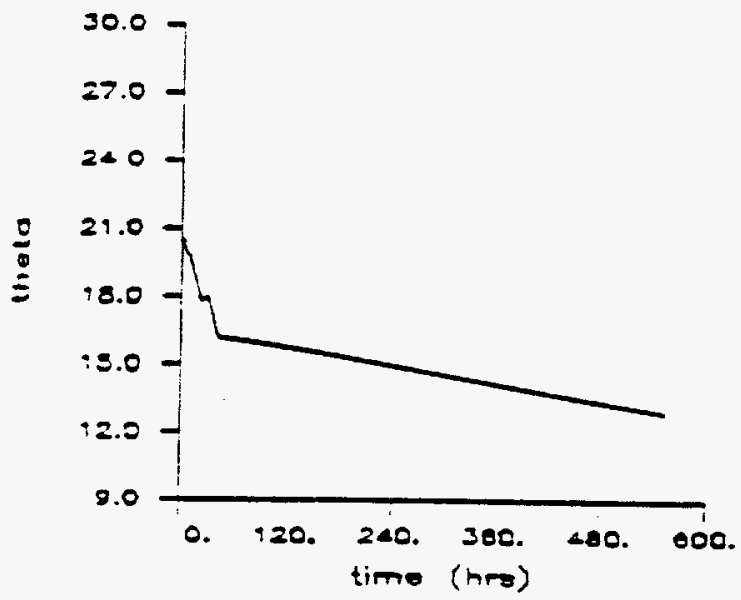

-

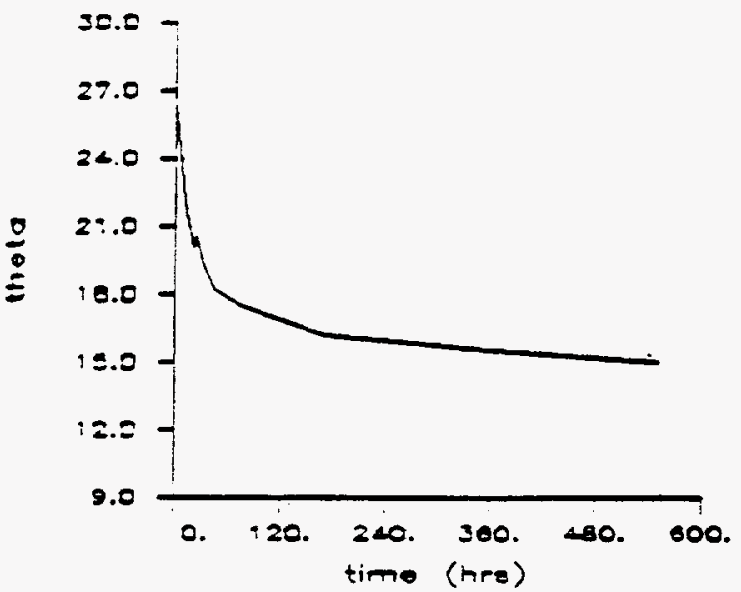


Appendix E

Plots of hydraulic head vs depth

E-1 


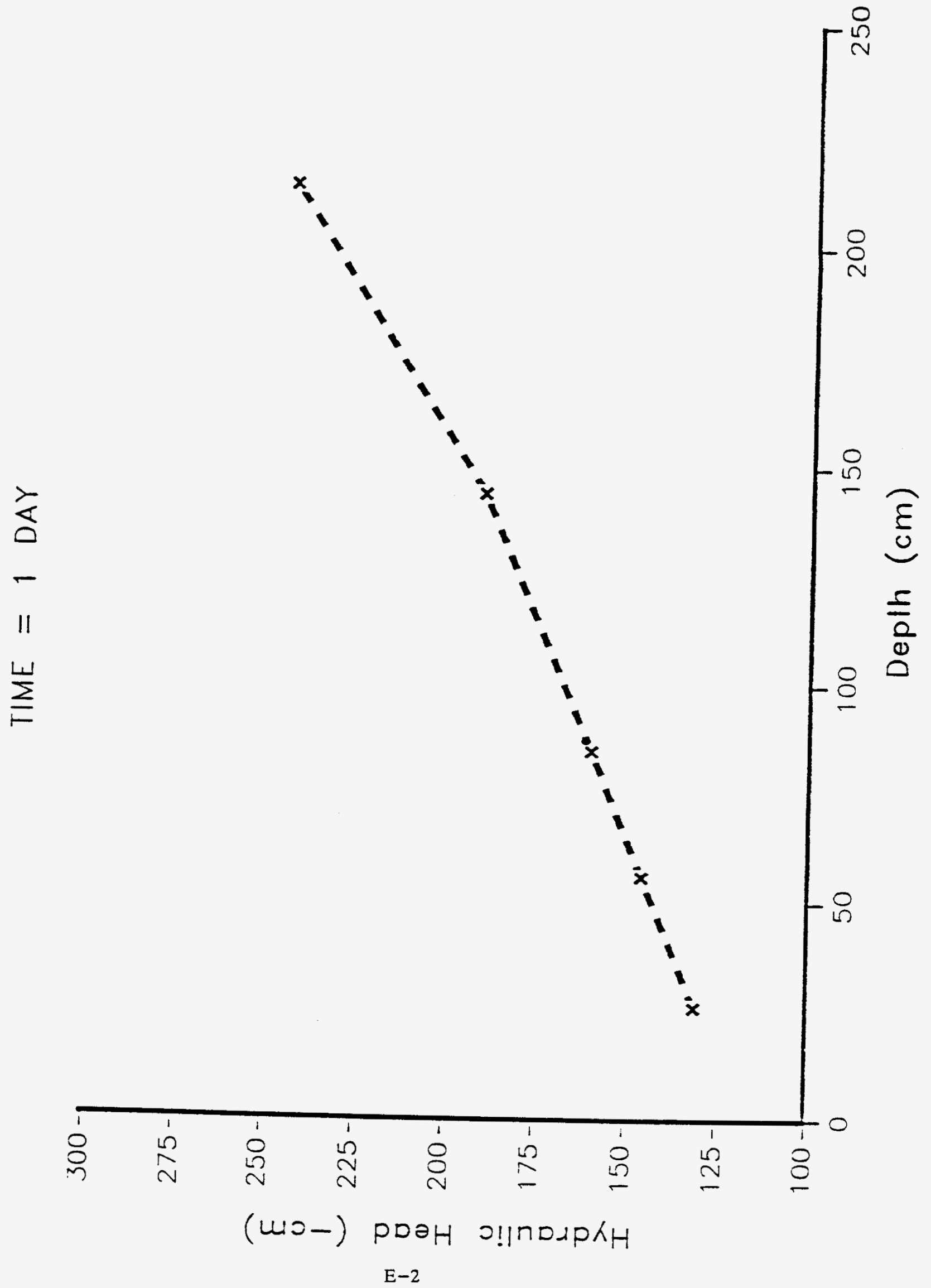


$n$
$\frac{\pi}{0}$
$N$
11
$\frac{\omega}{E}$

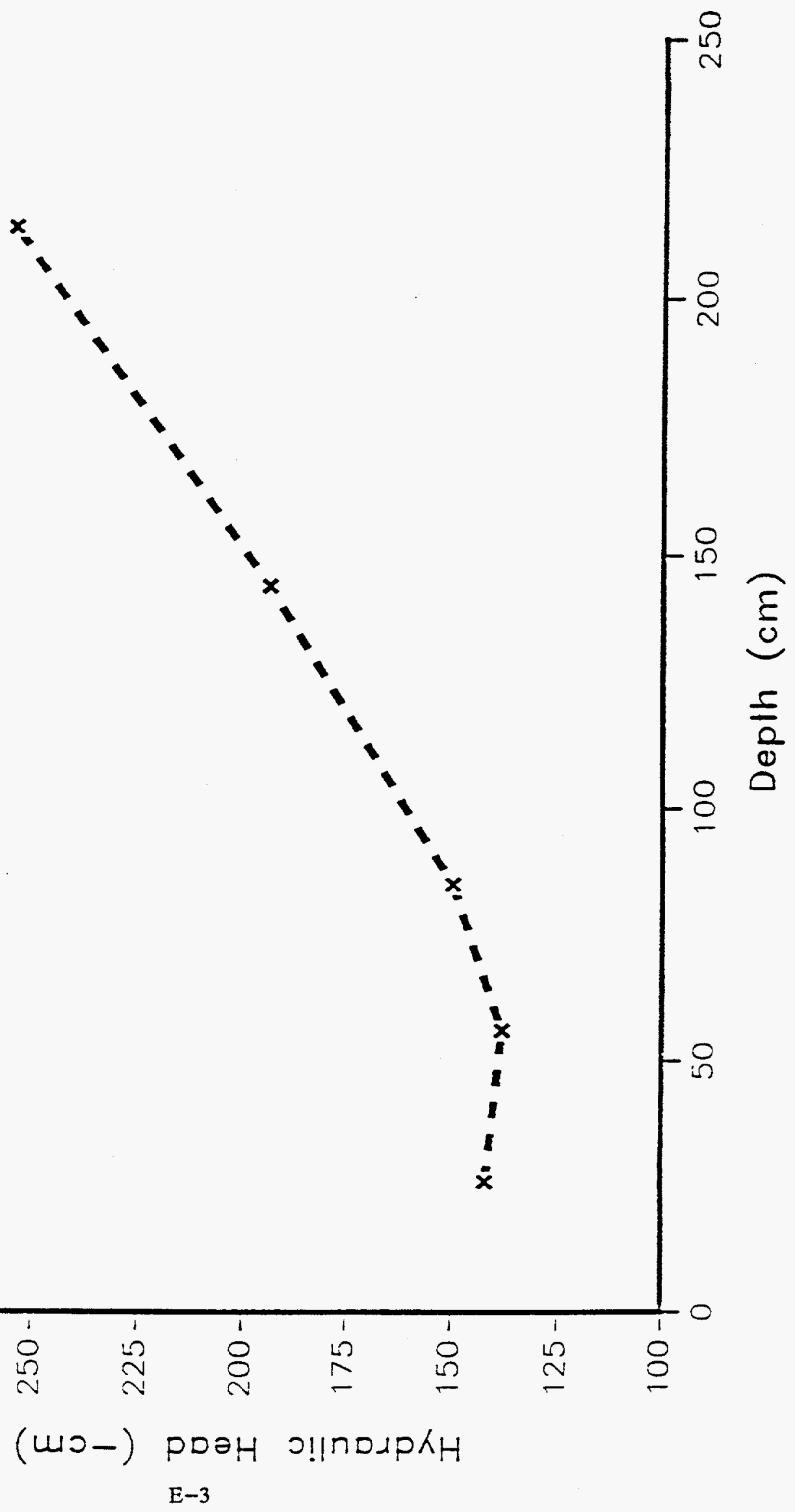




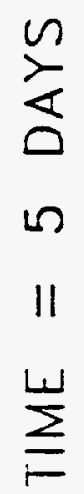

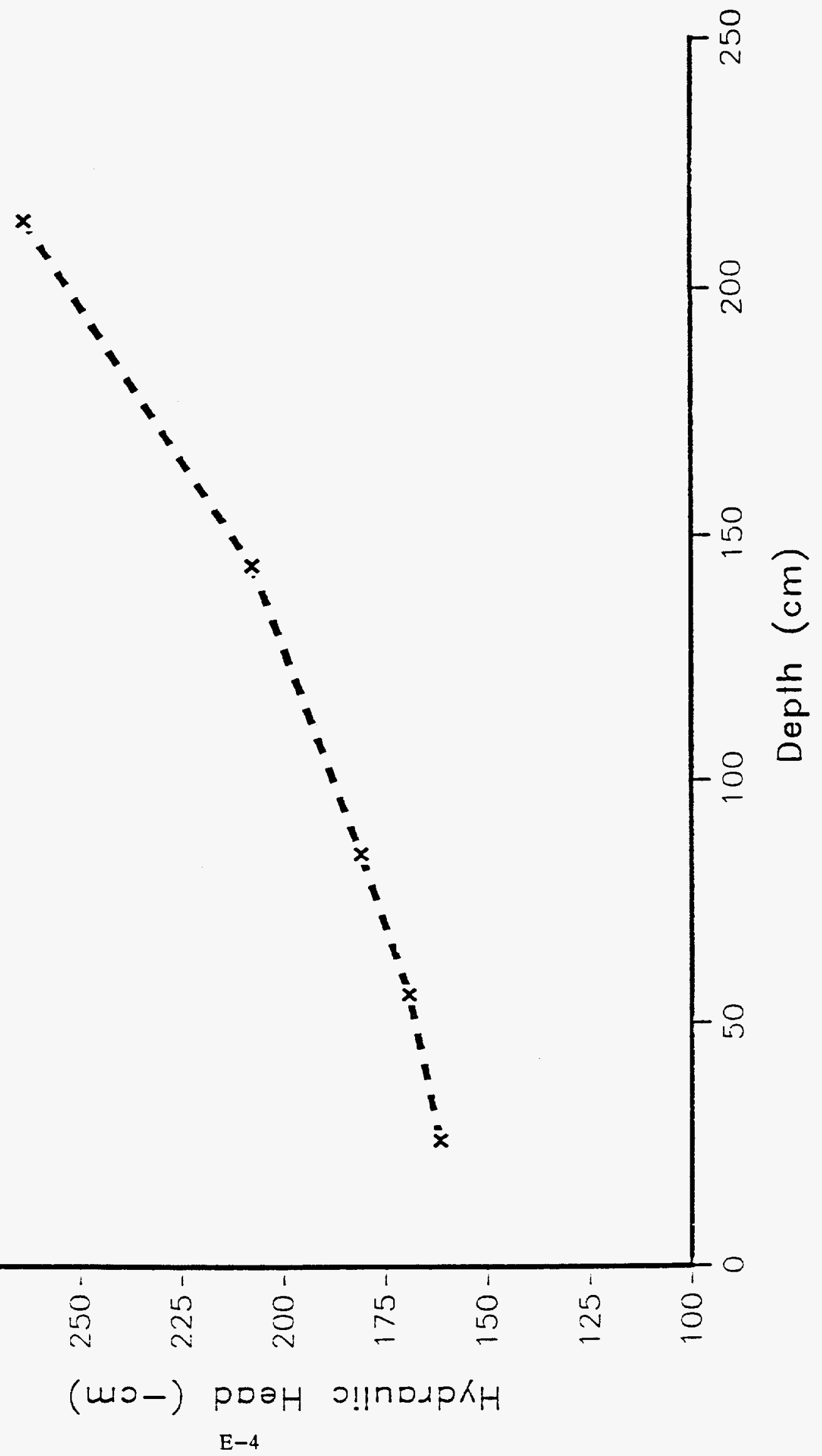


$n$
$\frac{1}{0}$
0
11
$\frac{\omega}{E}$

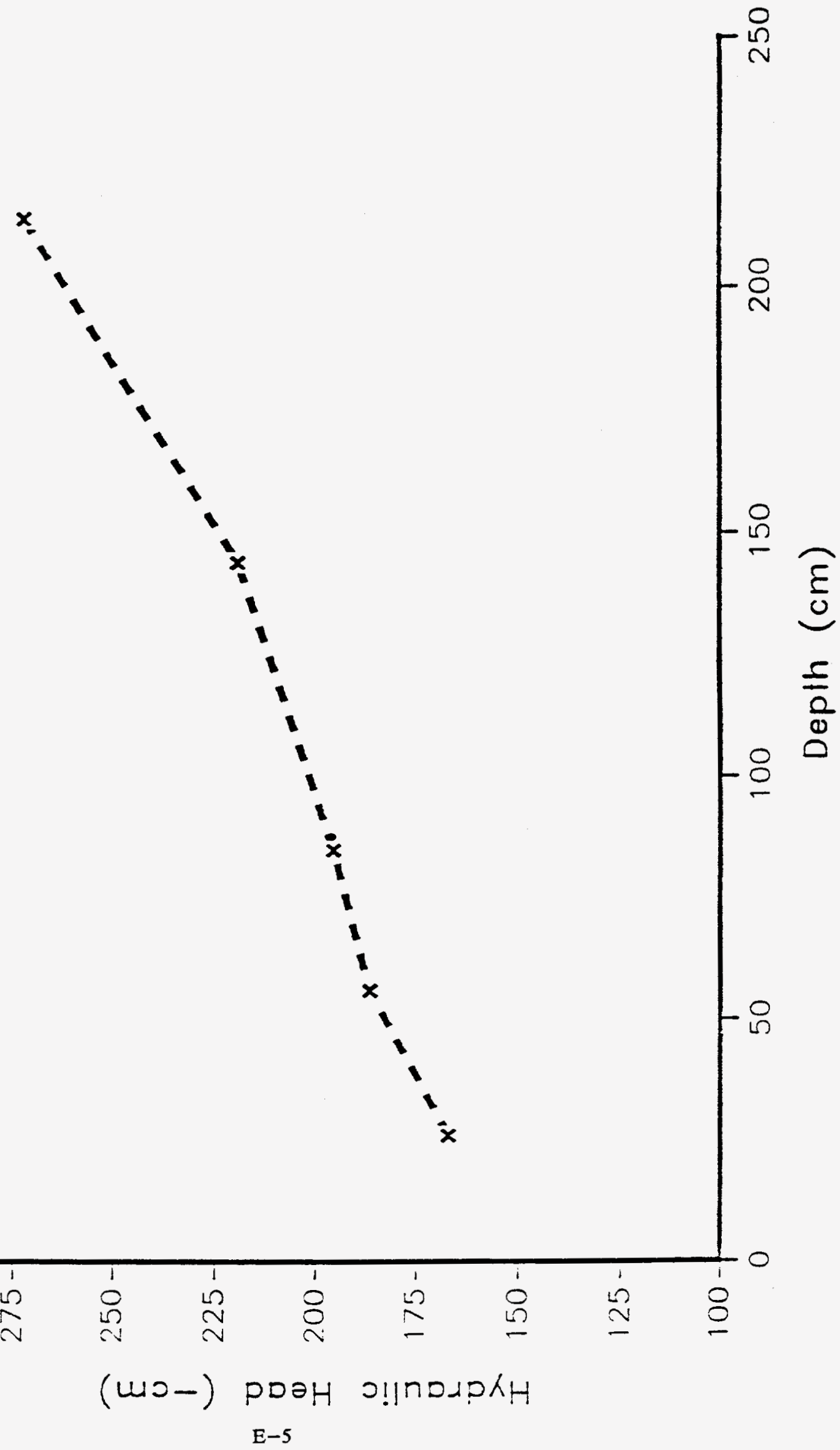




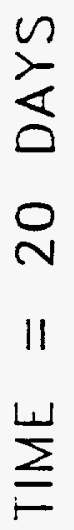
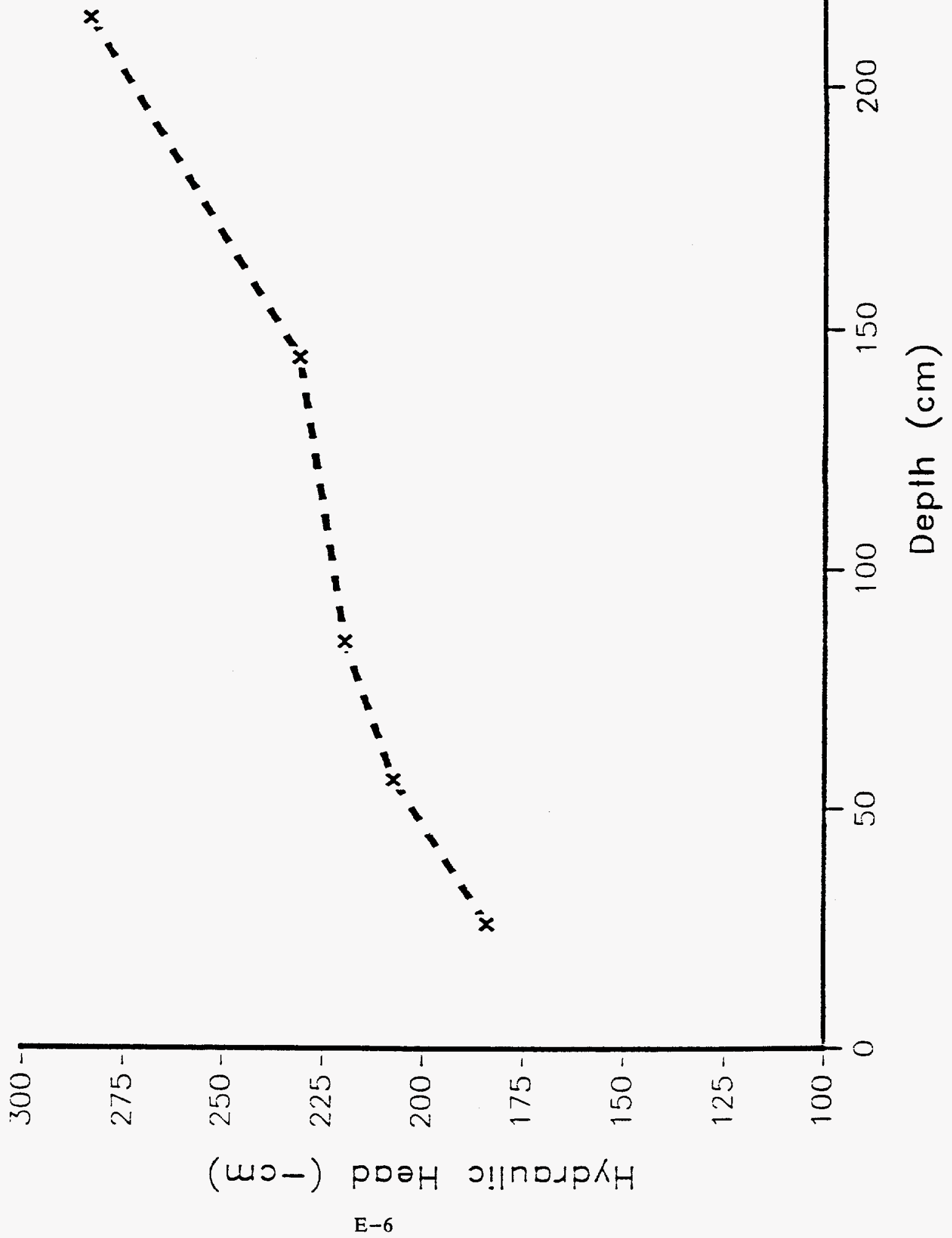
Appendix $\mathbf{F}$

Soil moisture characteristic curves -

van Genuchten model

$\mathrm{F}-1$ 


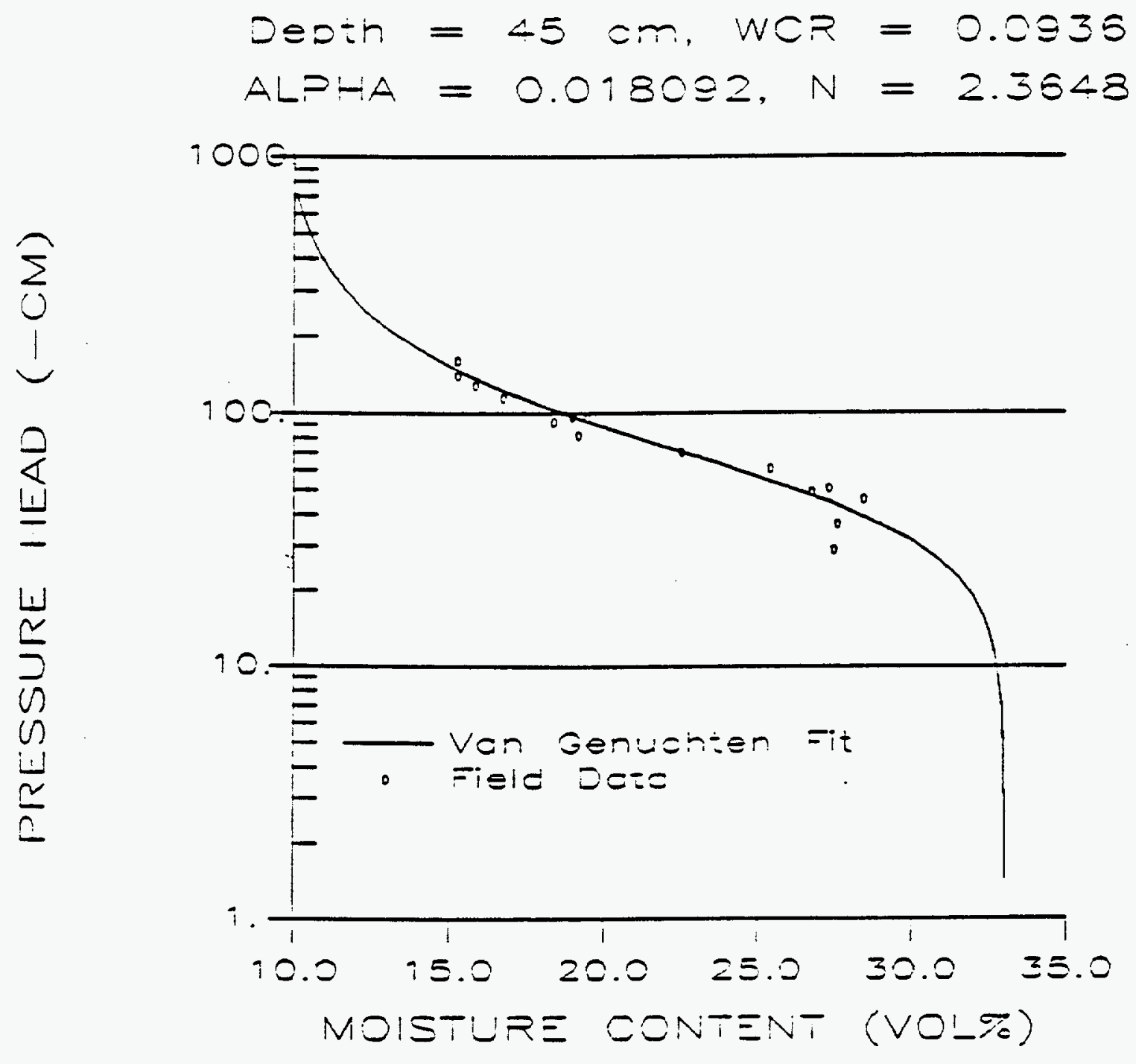




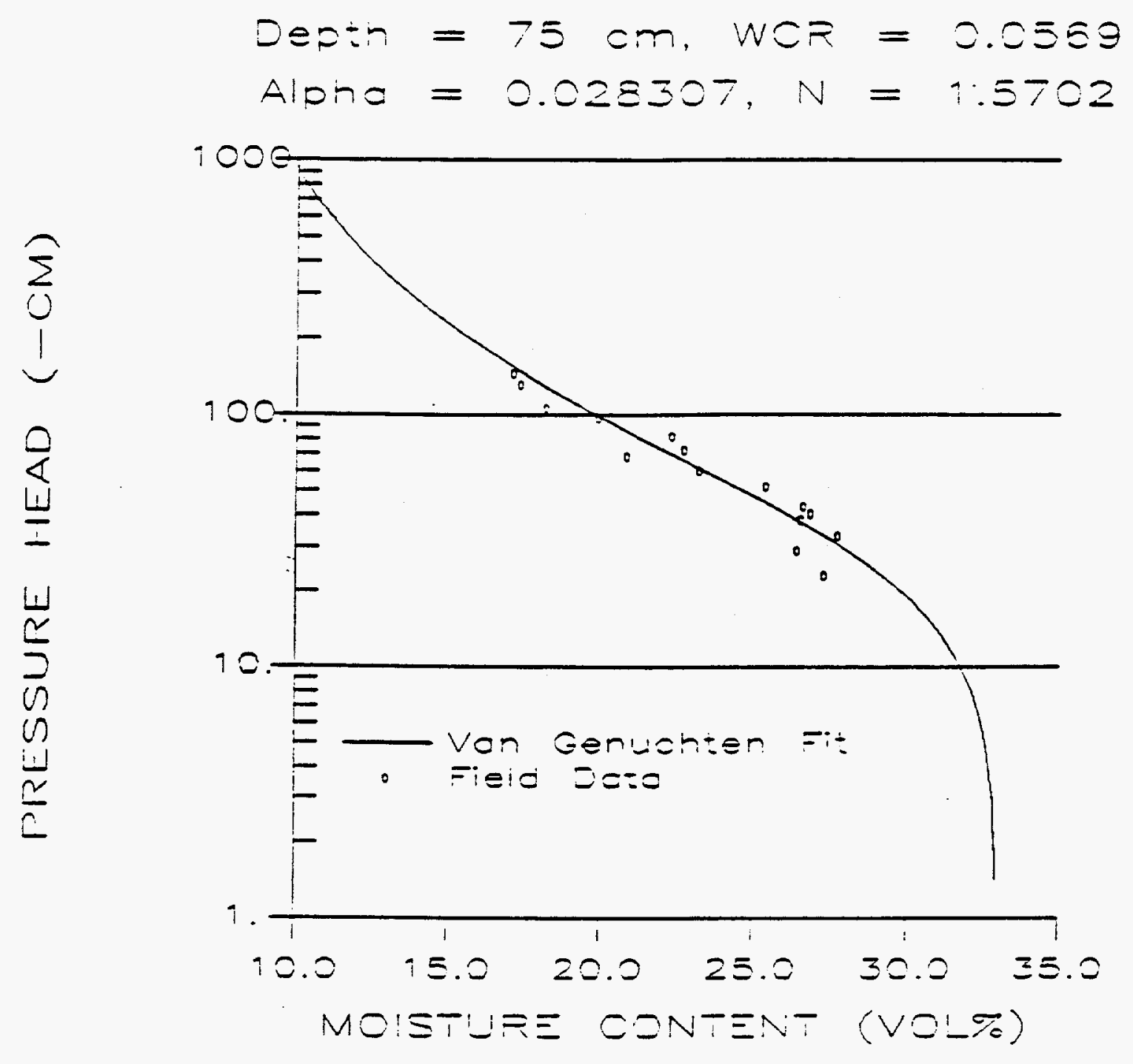


Depth $=105 \mathrm{~cm}$, WCR = 0.0175

Alpina $=0.084398, N=1.5049$

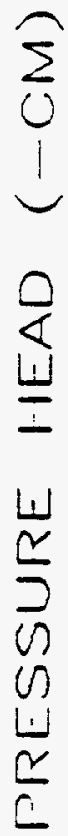

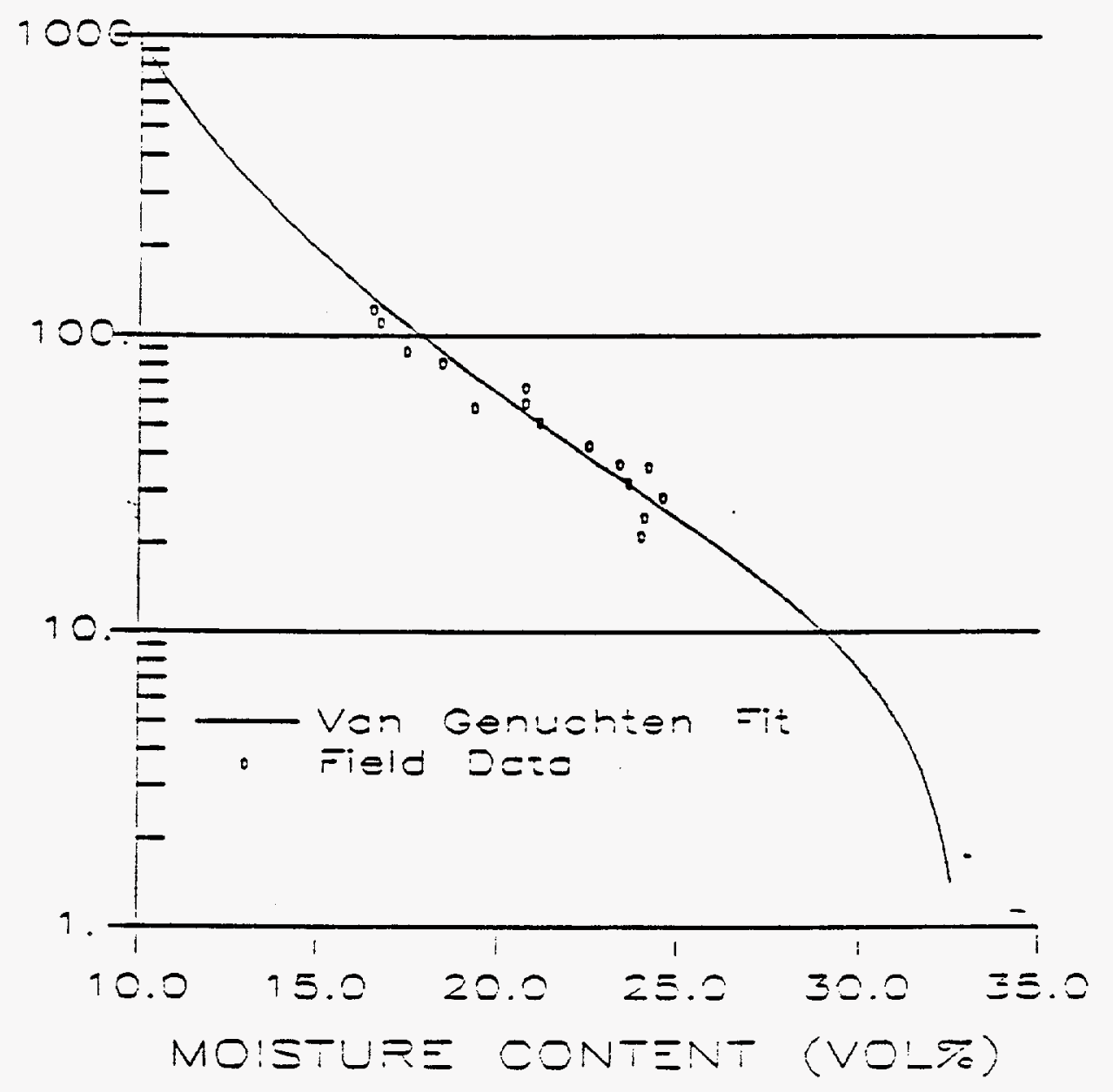




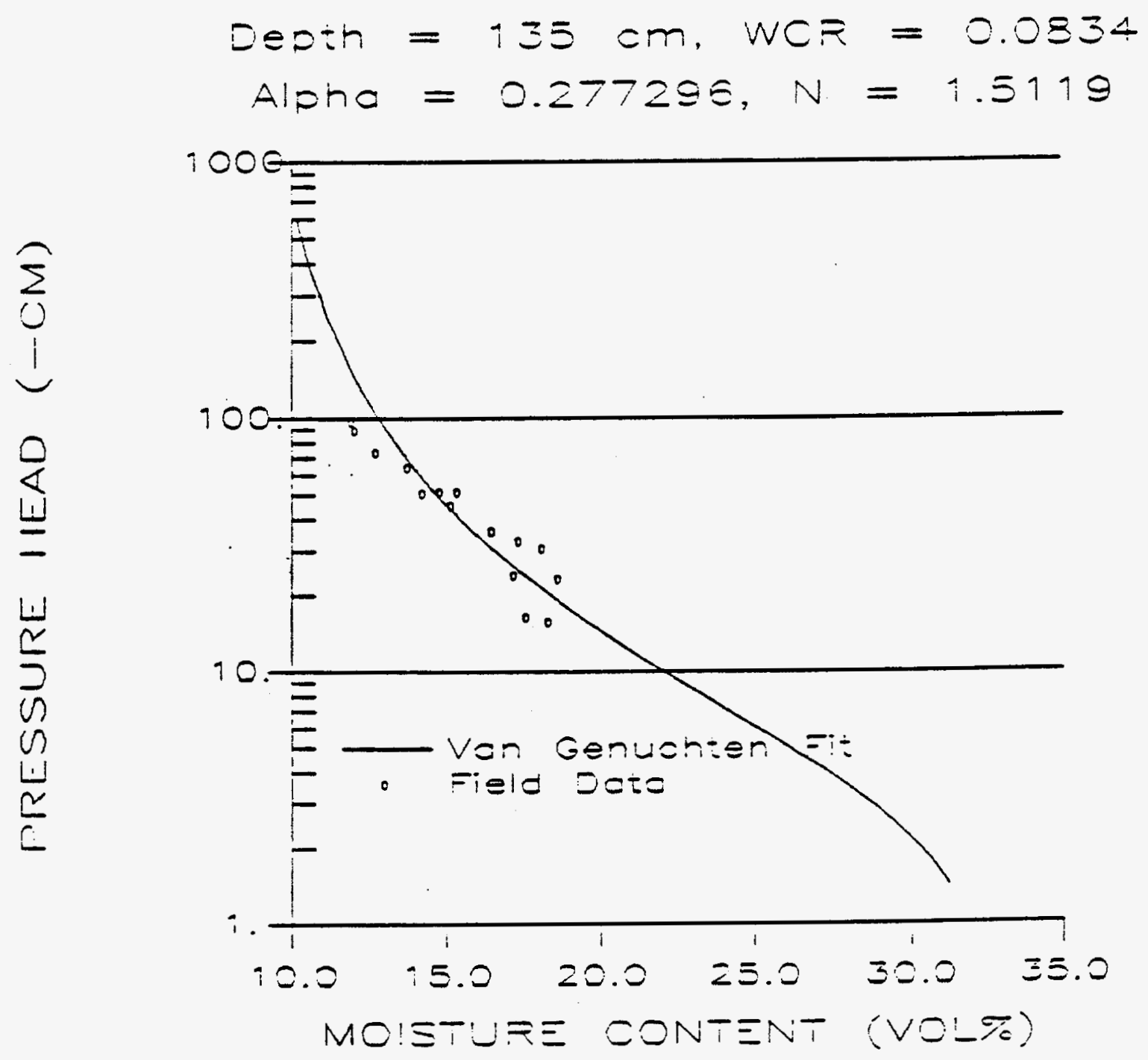

F-5 


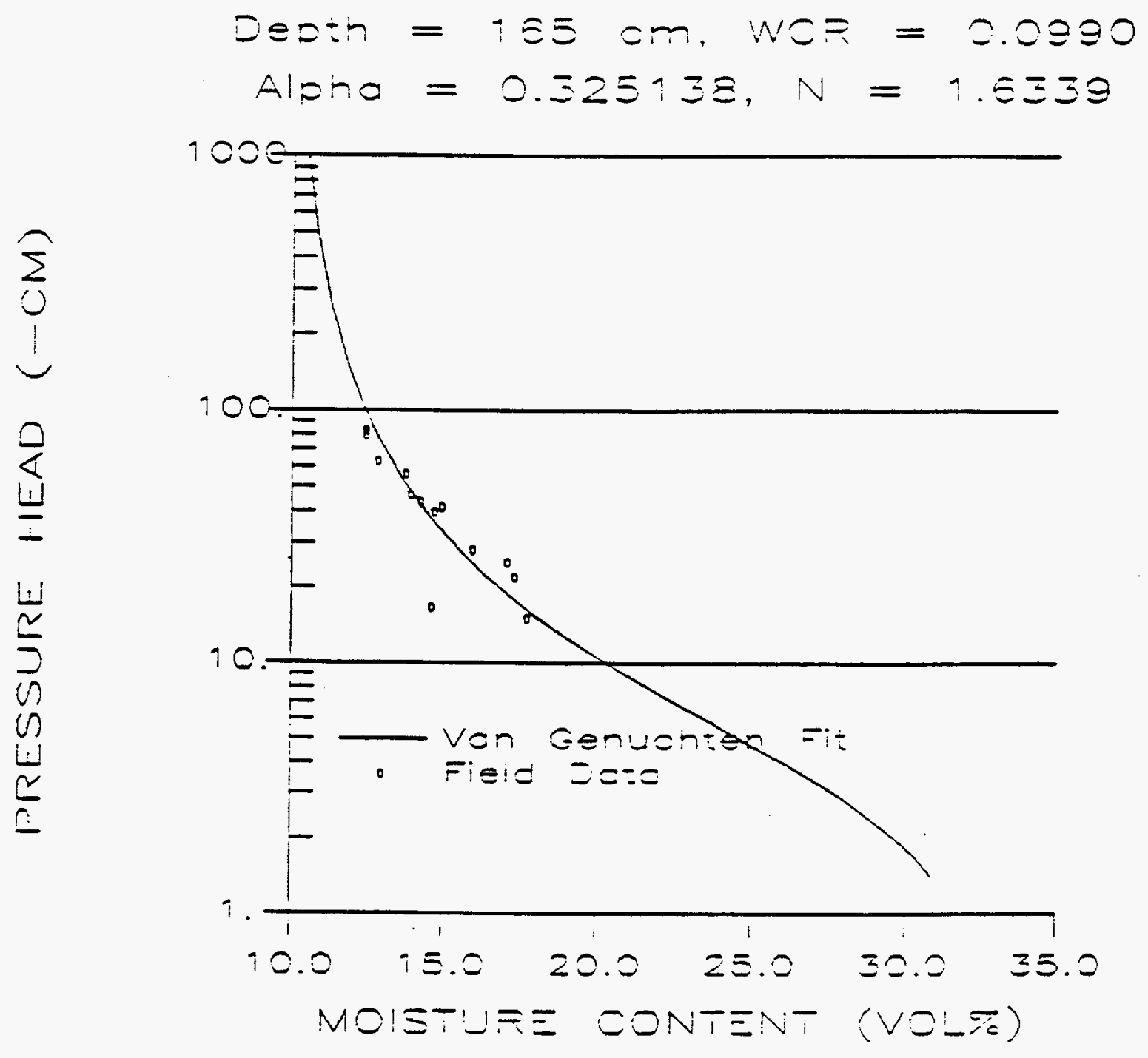


Death $=195 \mathrm{~cm}$, WCP $=0.0124$

$\frac{5}{1}$

$$
\text { Alonc }=0.434308, N=1.2130
$$

$\frac{2}{5}$

4
$\frac{1}{2}$
0
$\frac{1}{2}$
$\frac{1}{0}$

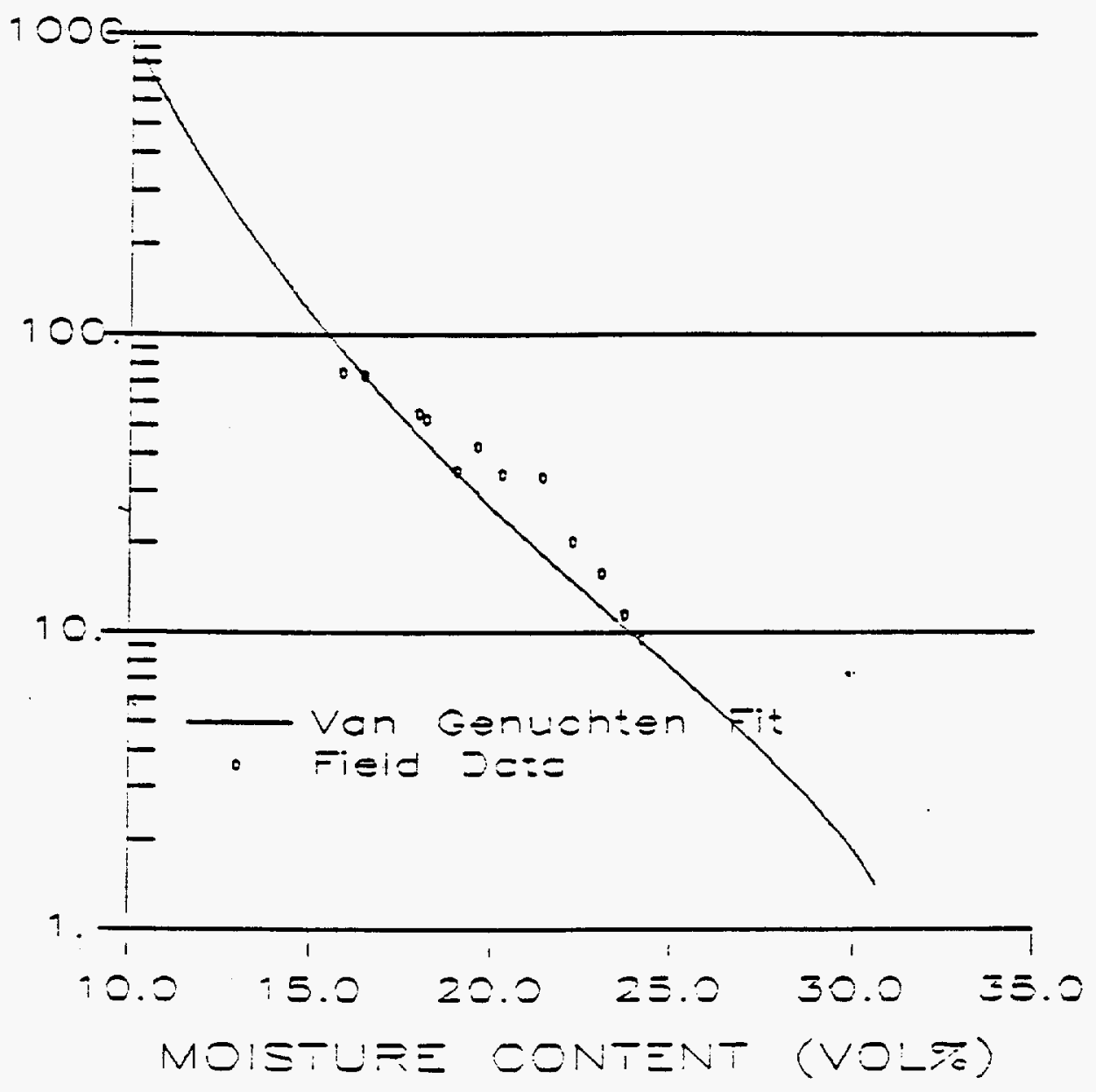


Appendix G

Plots of hydraulic conductivity vs moisture content -

Mualem model

G-1 


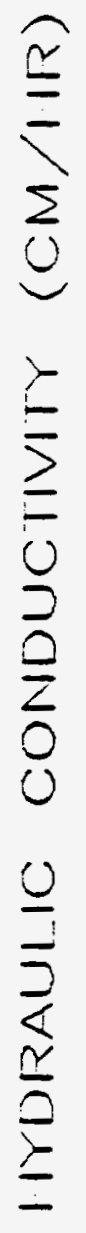

Desth $=45 \mathrm{~cm}$, WOF $=0.0935$ ALPHA $=0.018092, N=2.3648$
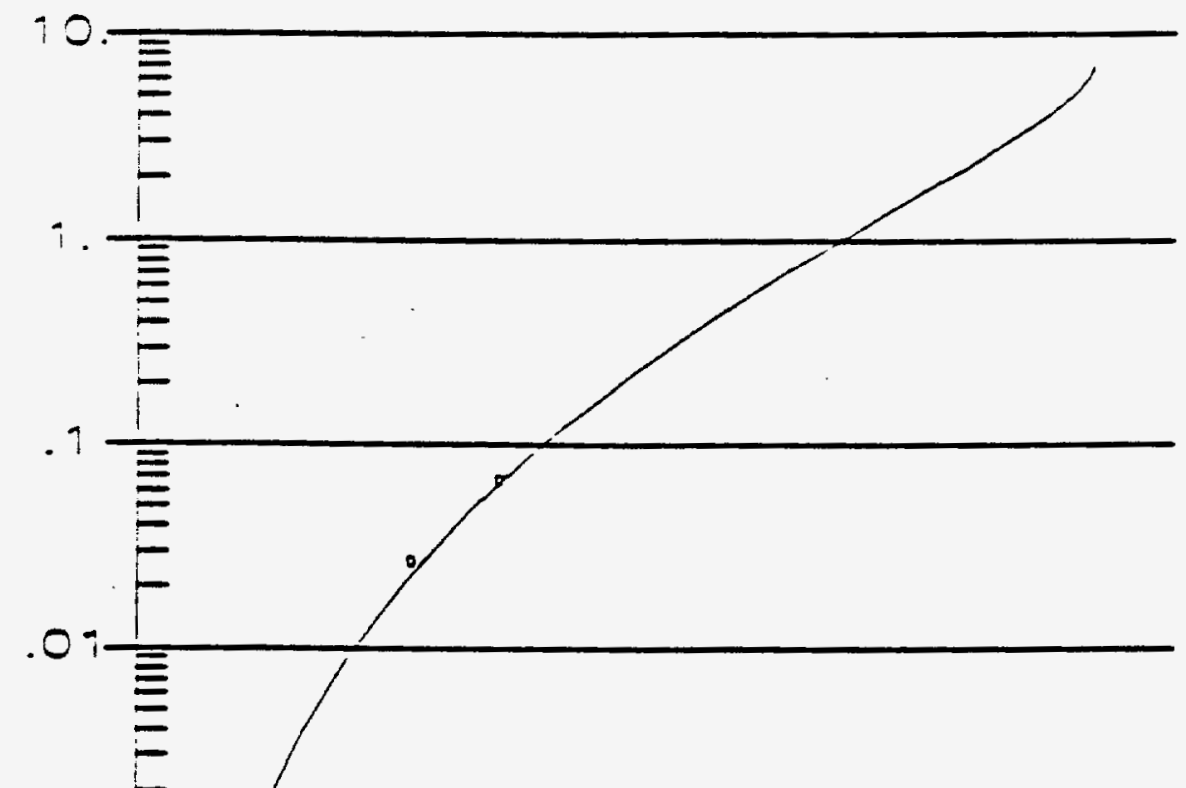

.00

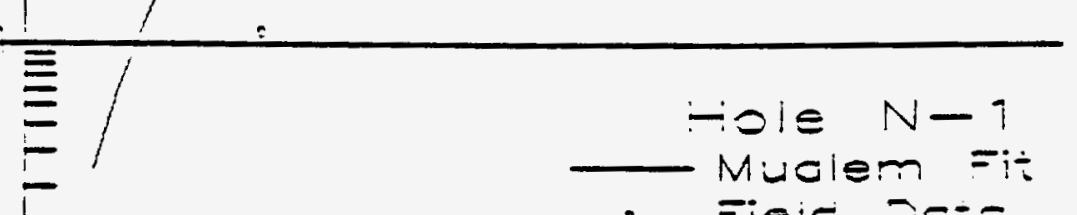

009

10.0

15.220 .0

1 i 1 MOISTUFE OONTENT (VOL\%) 

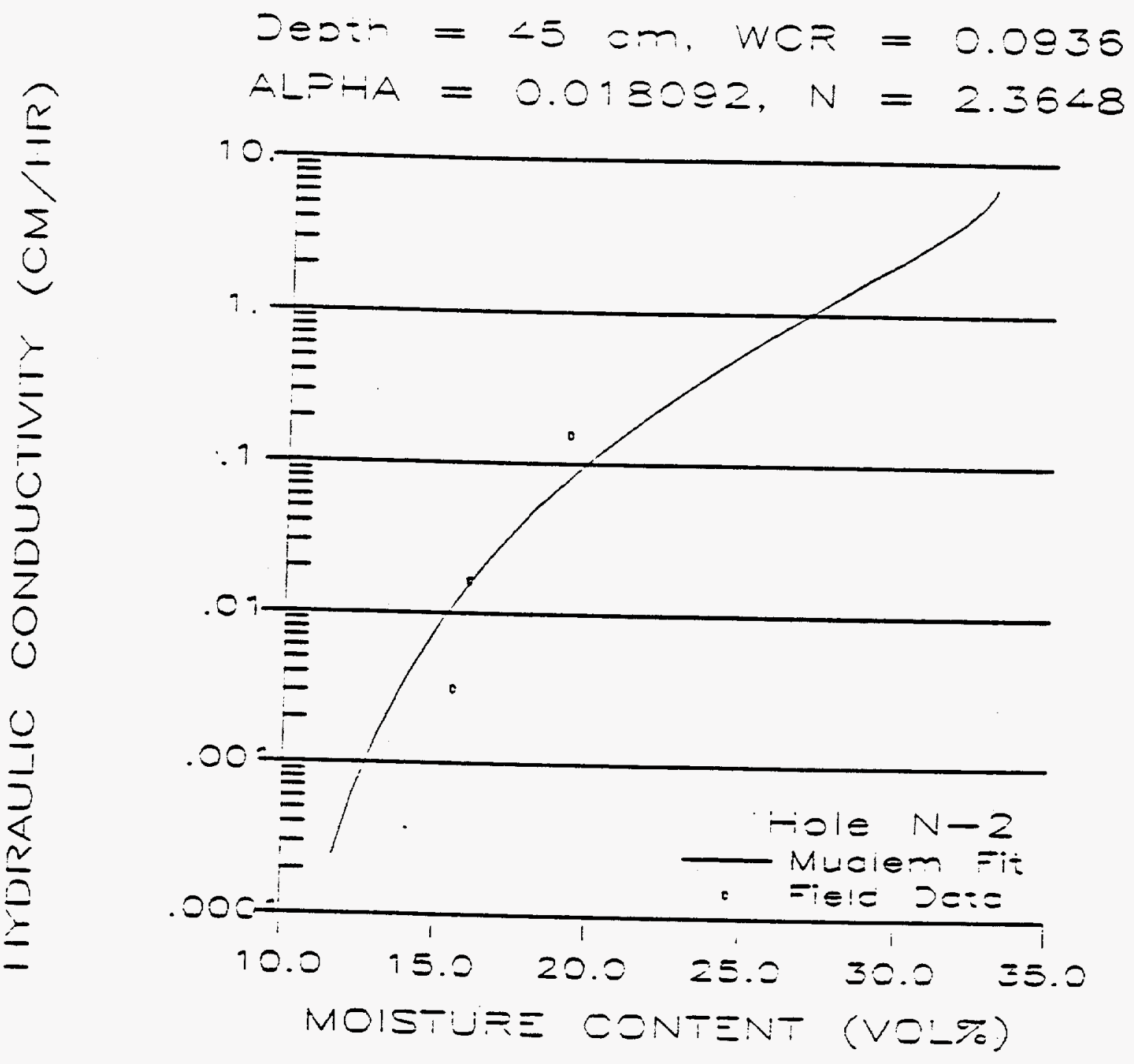


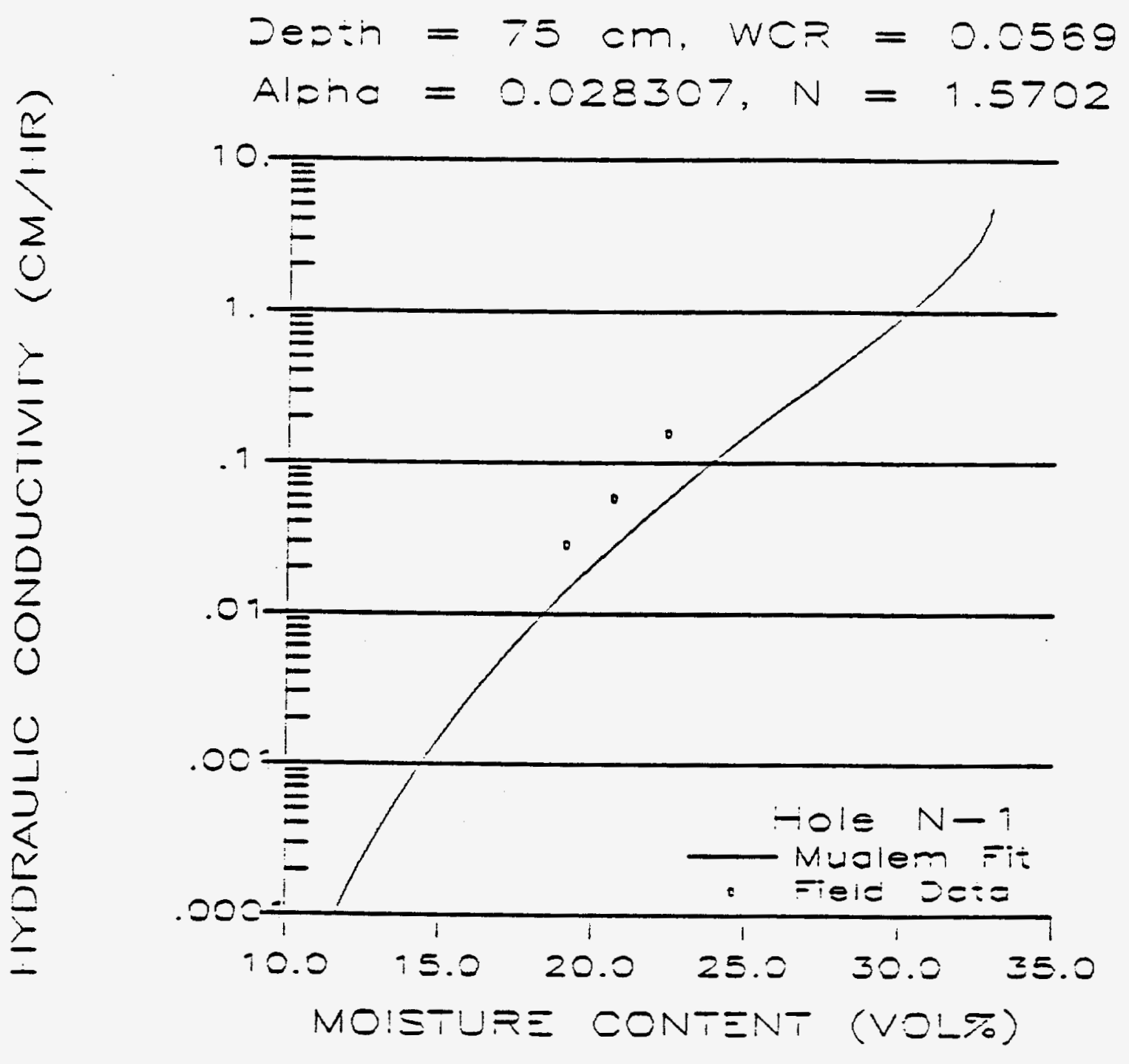




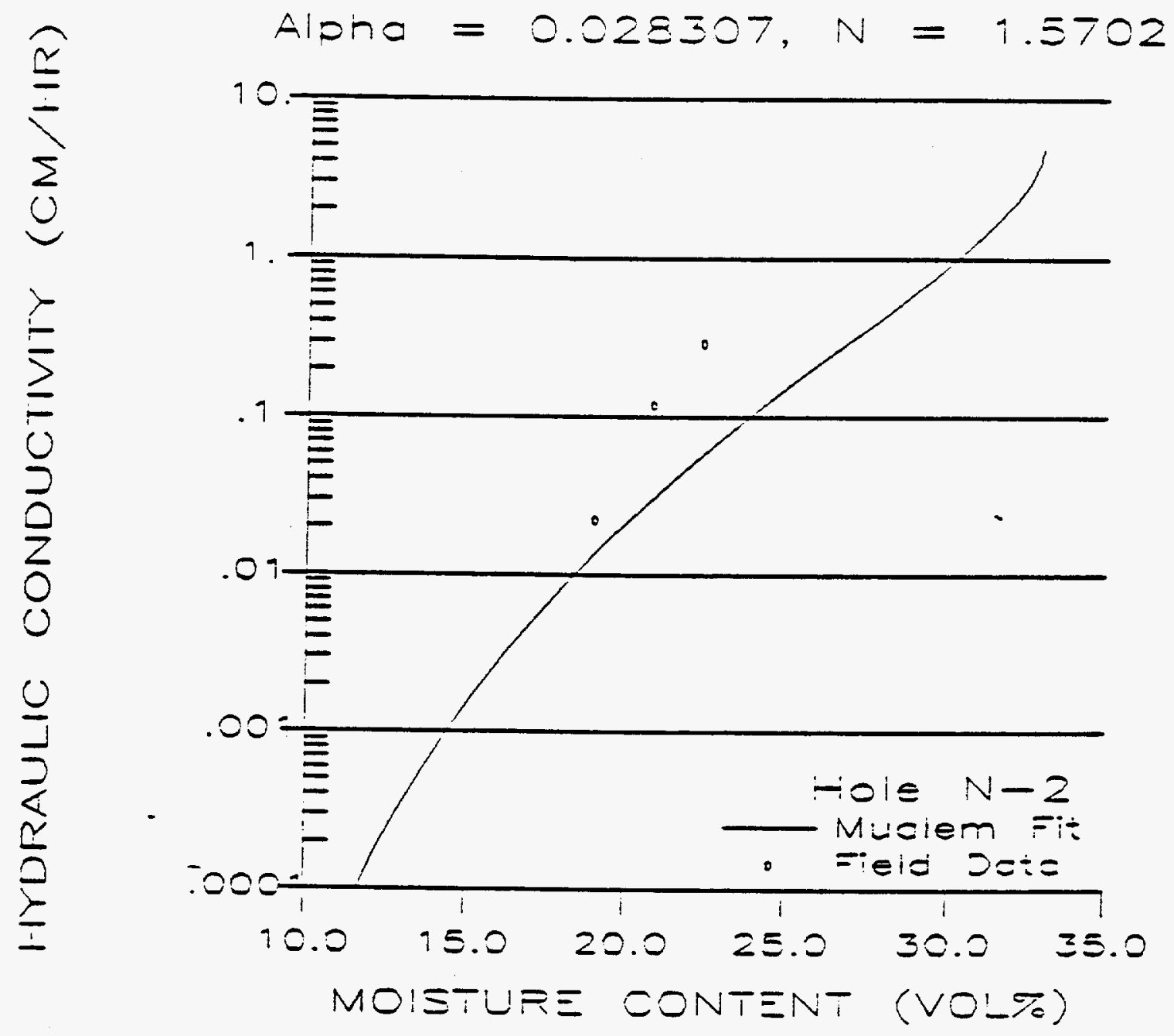




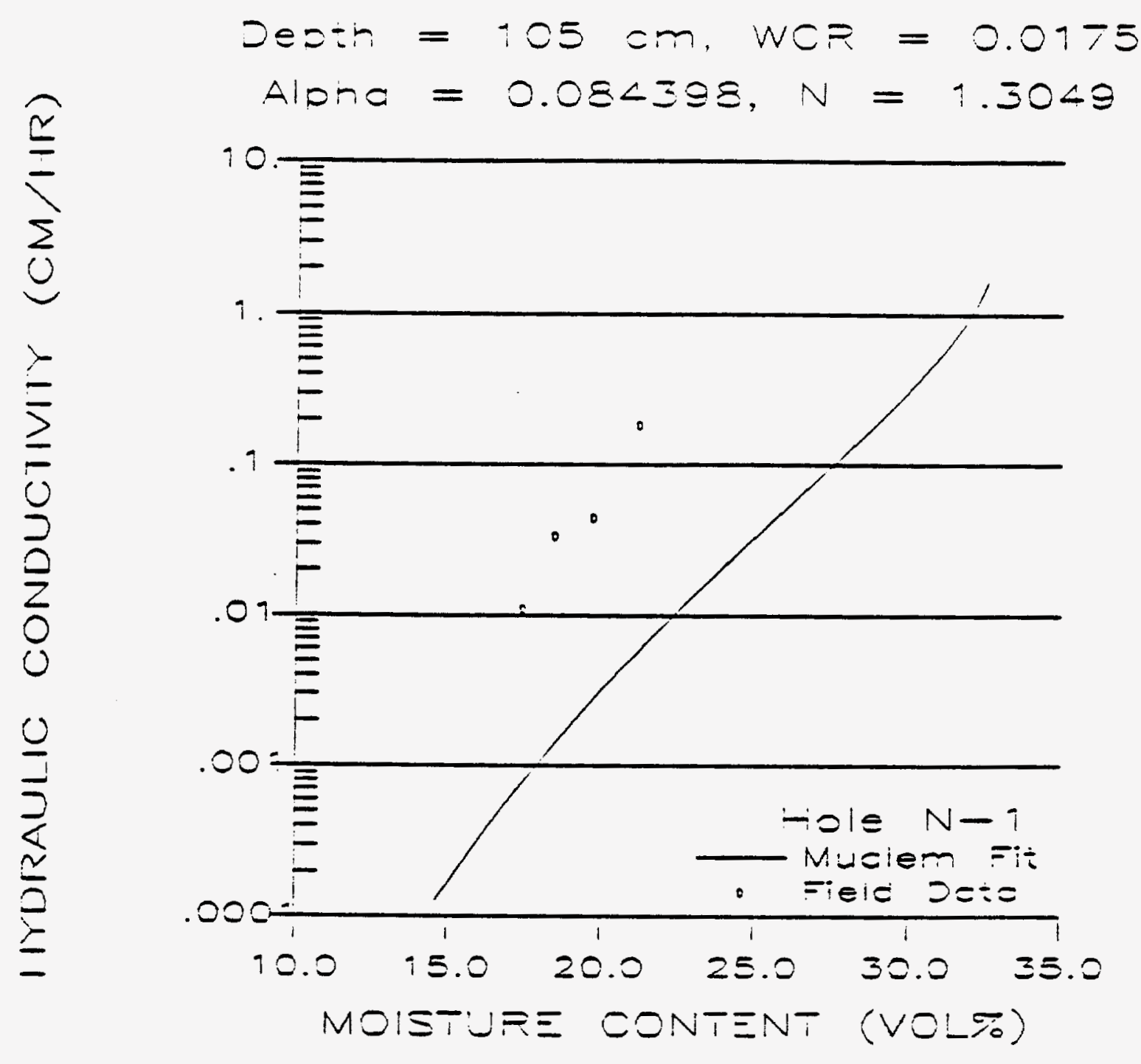




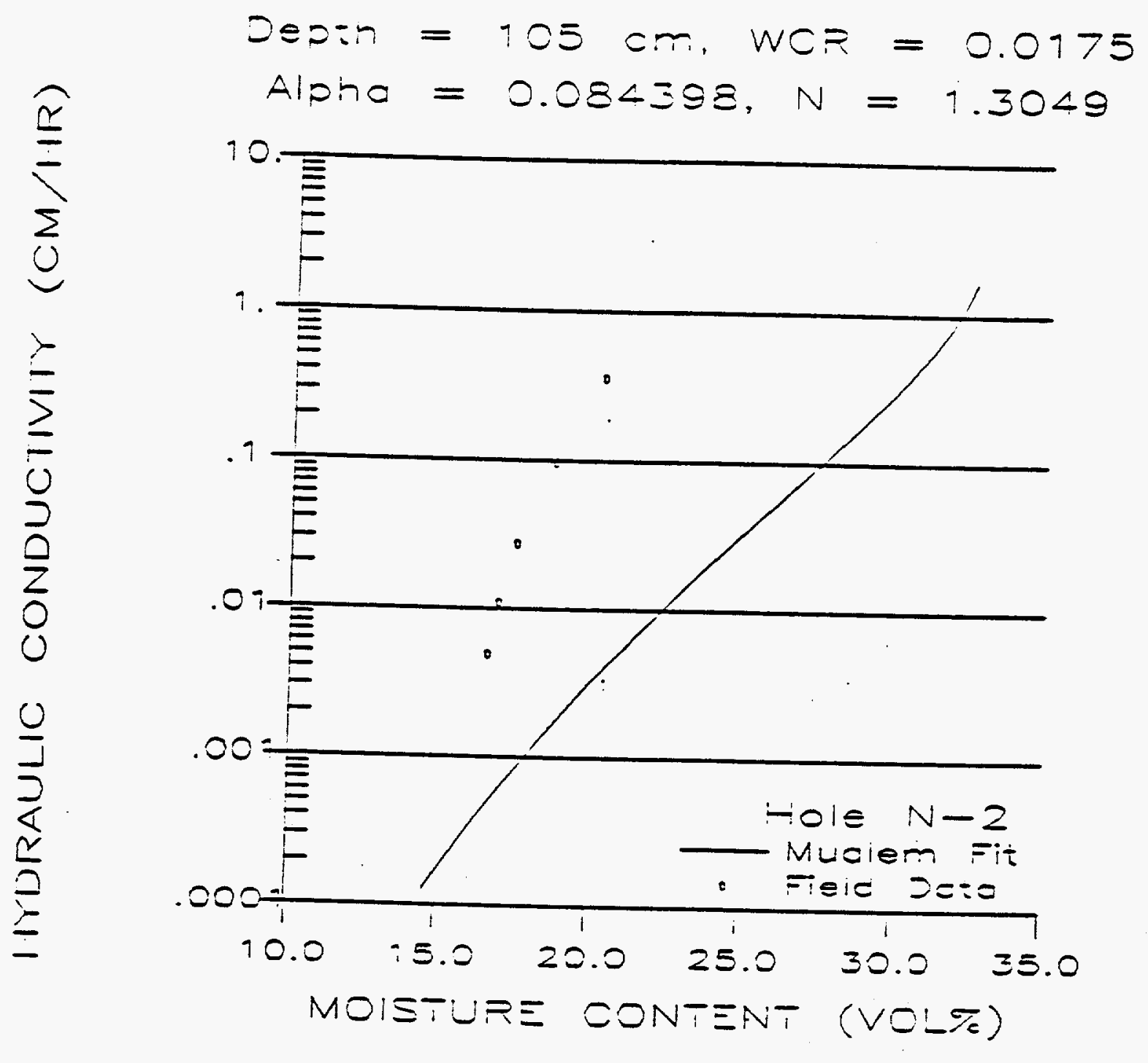




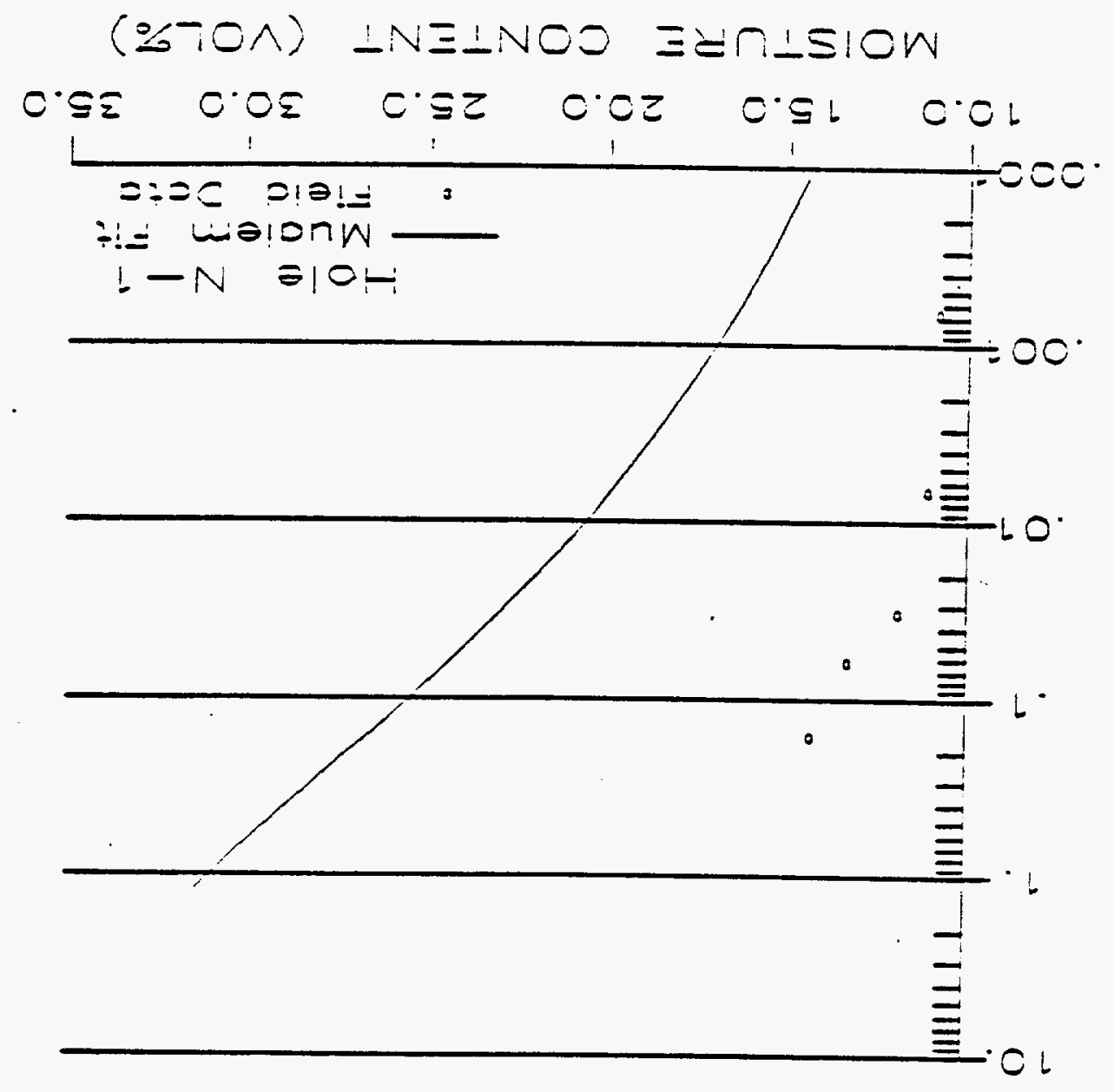

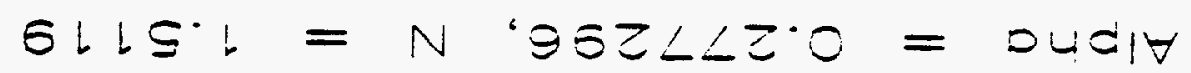

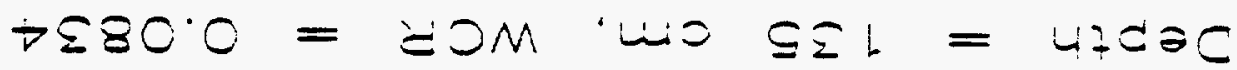




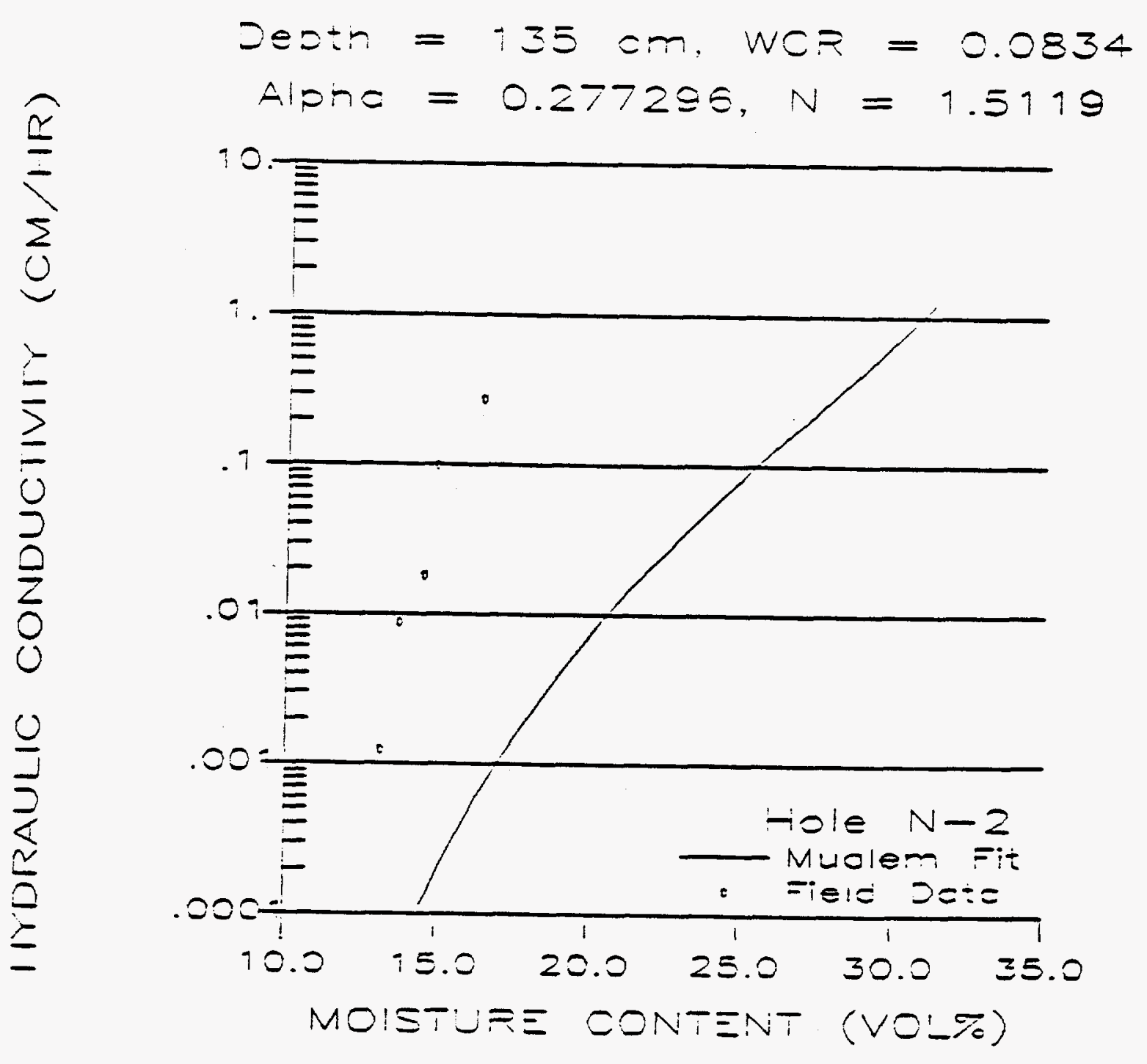




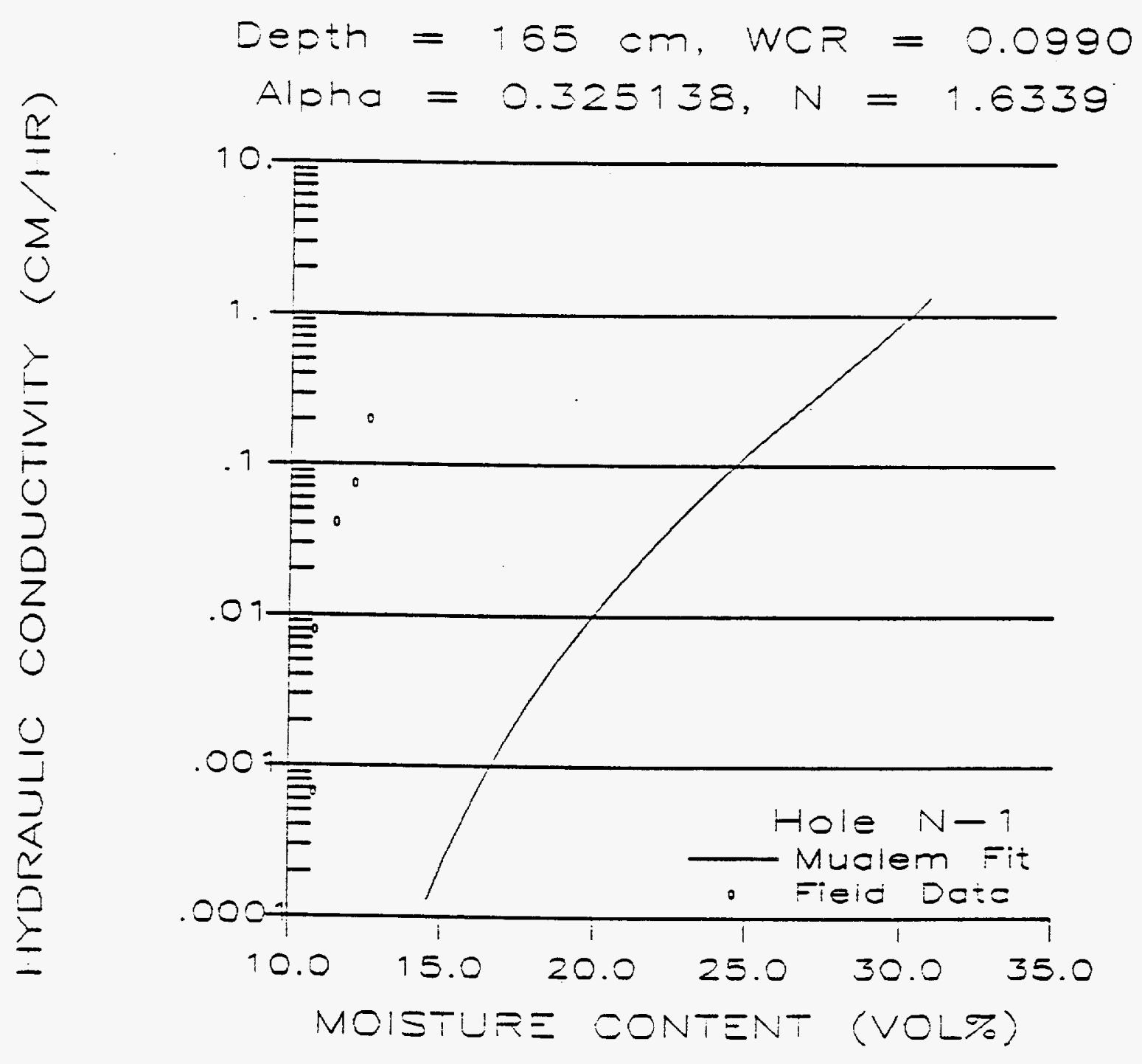




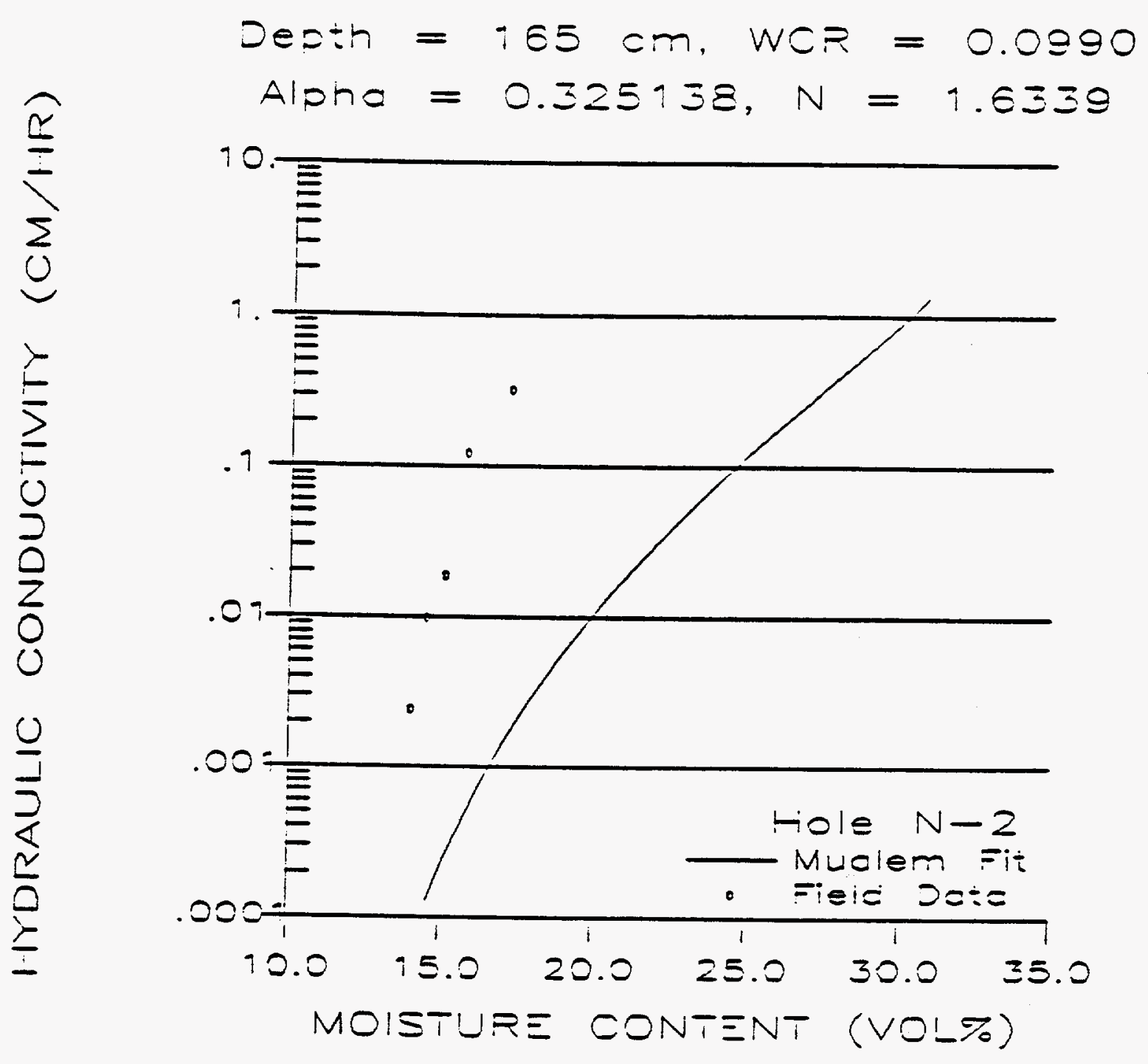




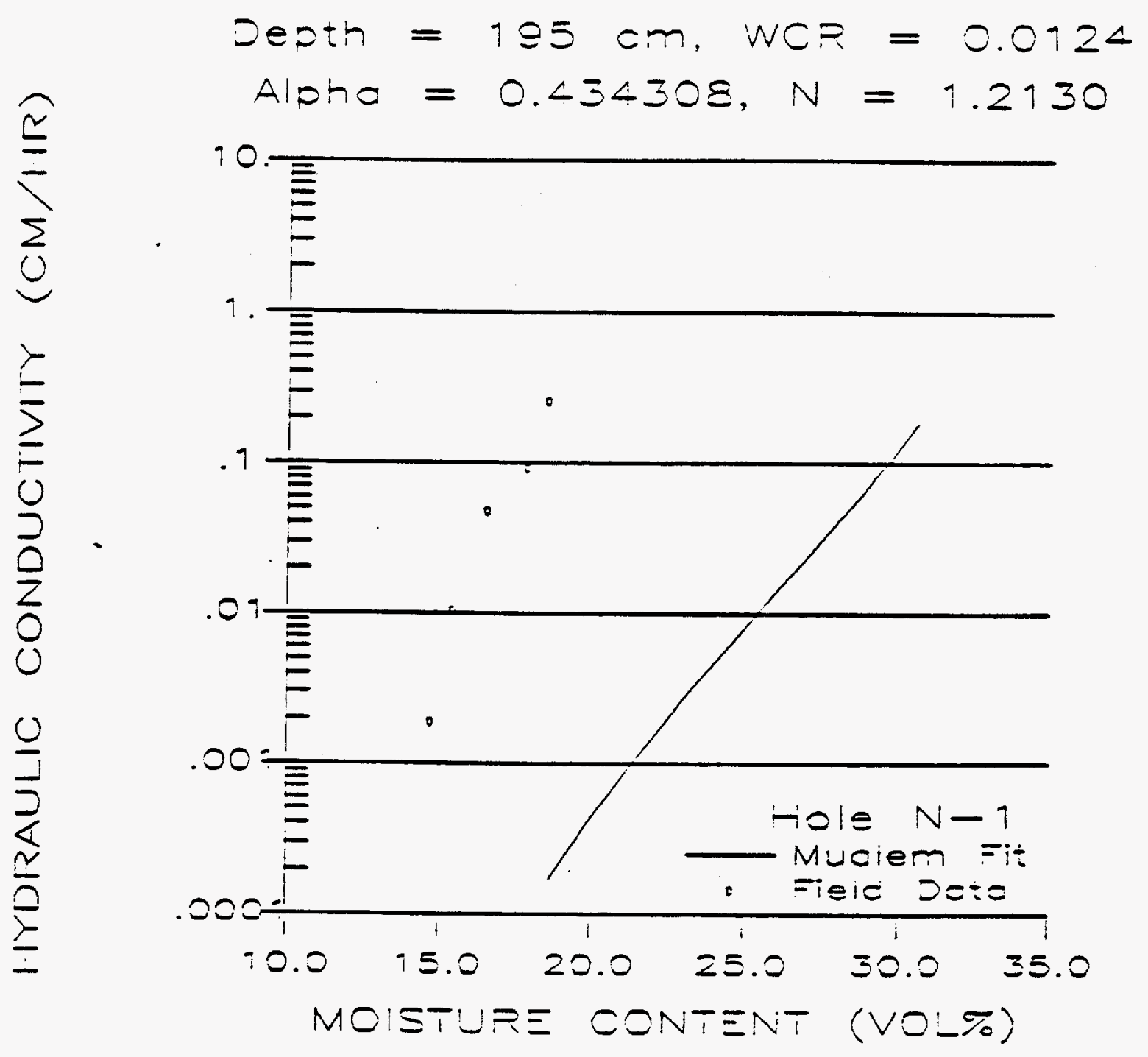




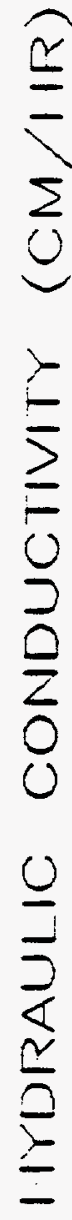

Zez:n $=$ i:5 cm. WCF = 0.0124 Alphe $=0.43 \angle 308, N=1.2130$ 10
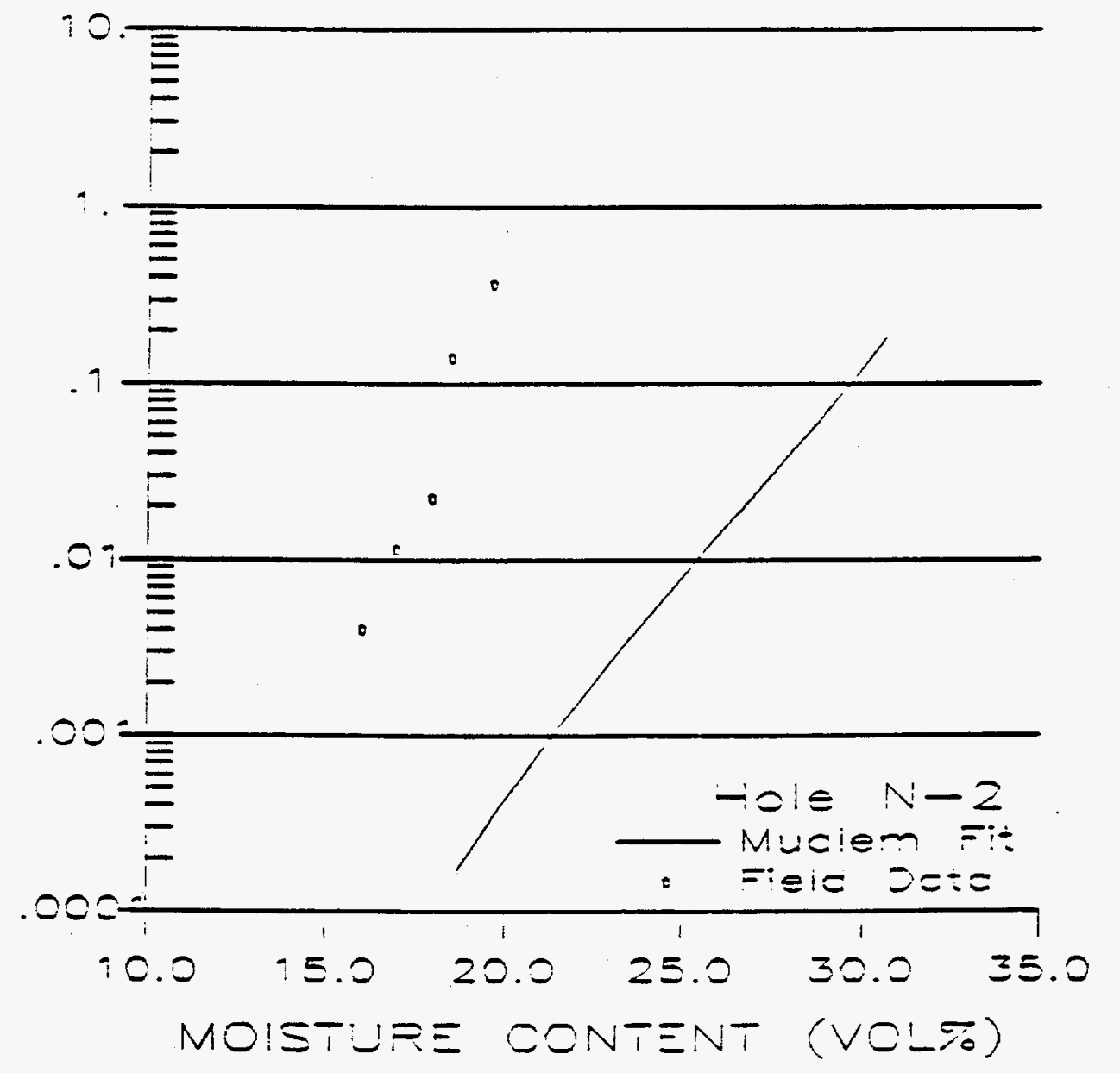
Appendix H

Plots of hydraulic conductivity vs degree of saturation field measured 


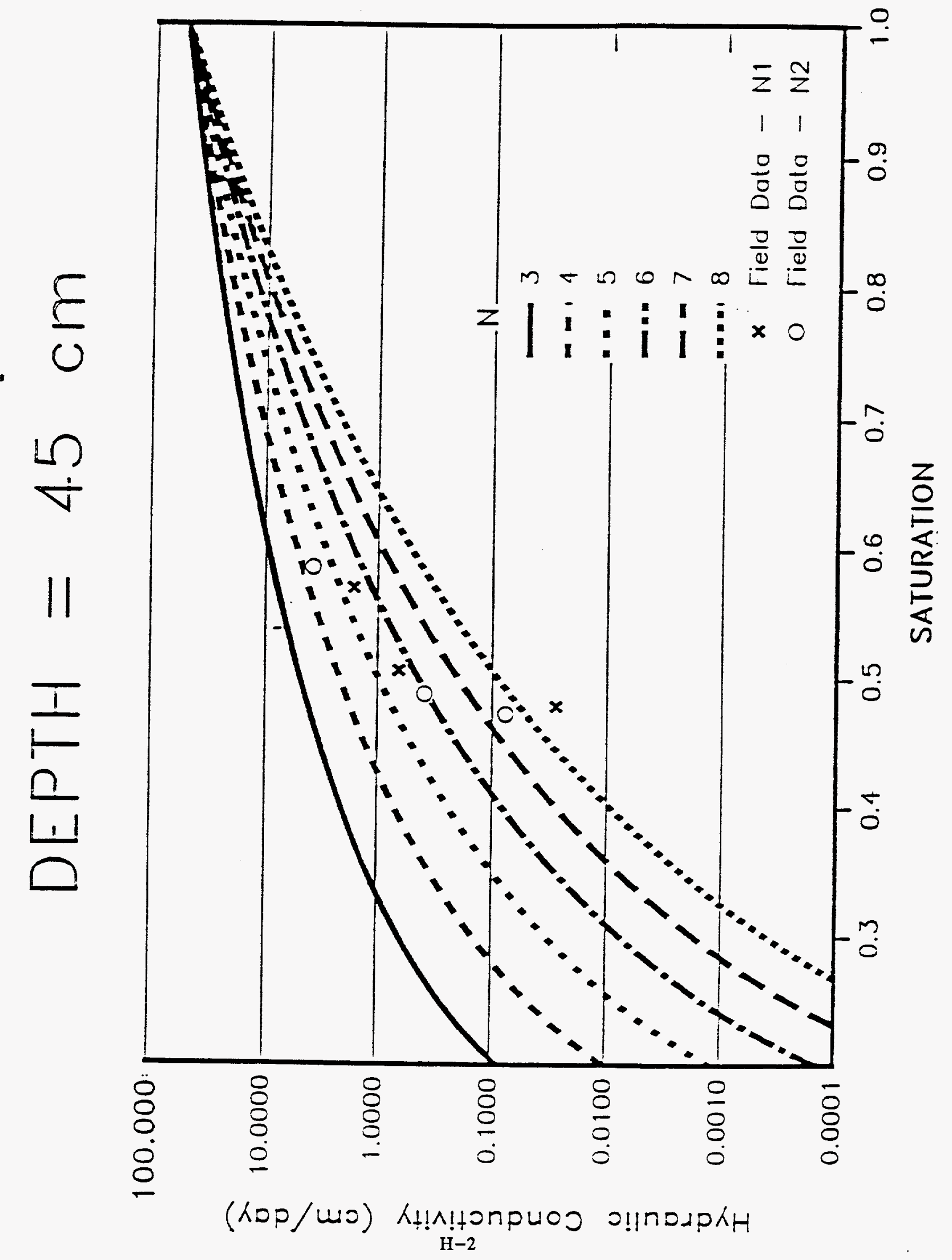




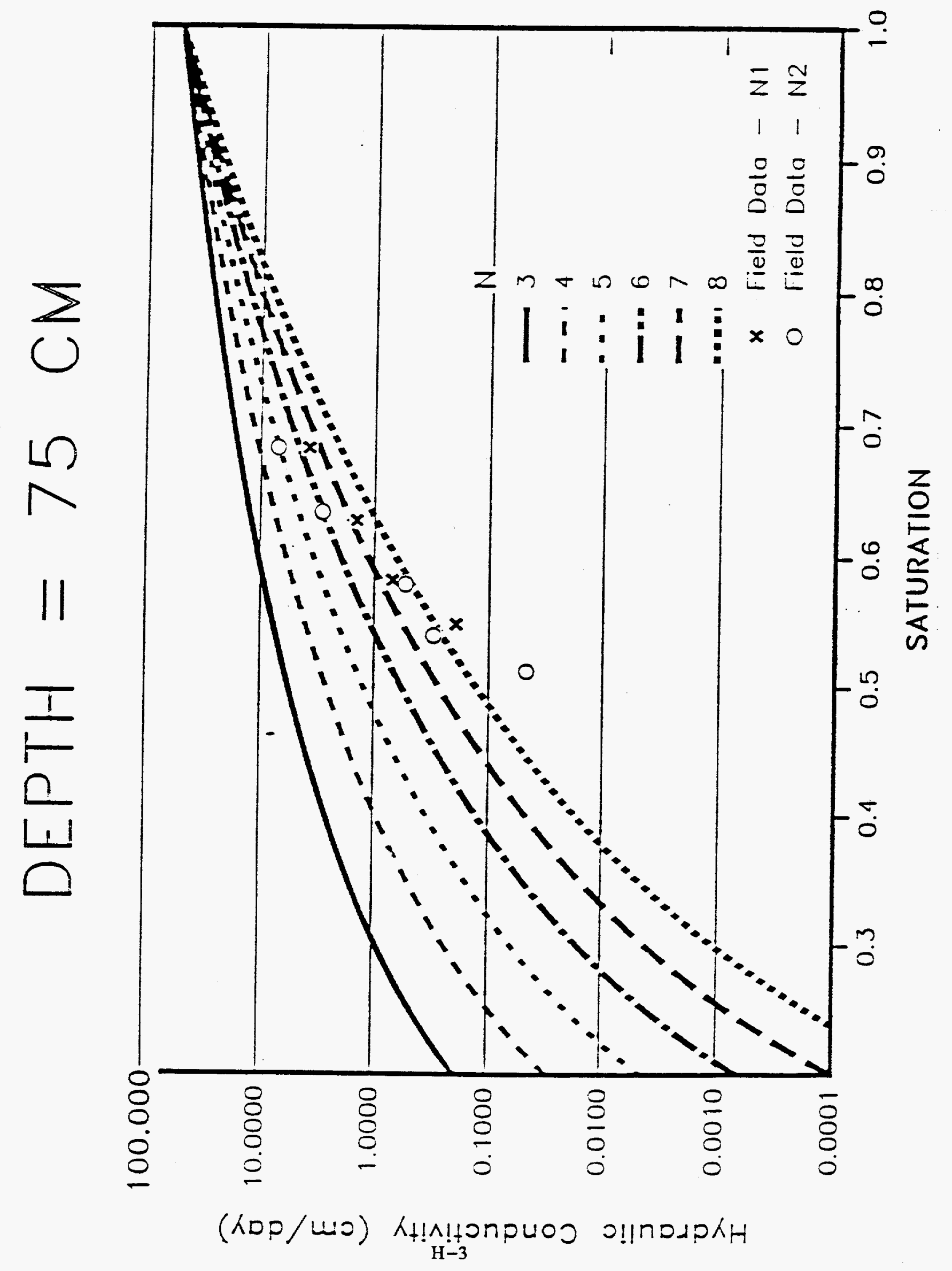




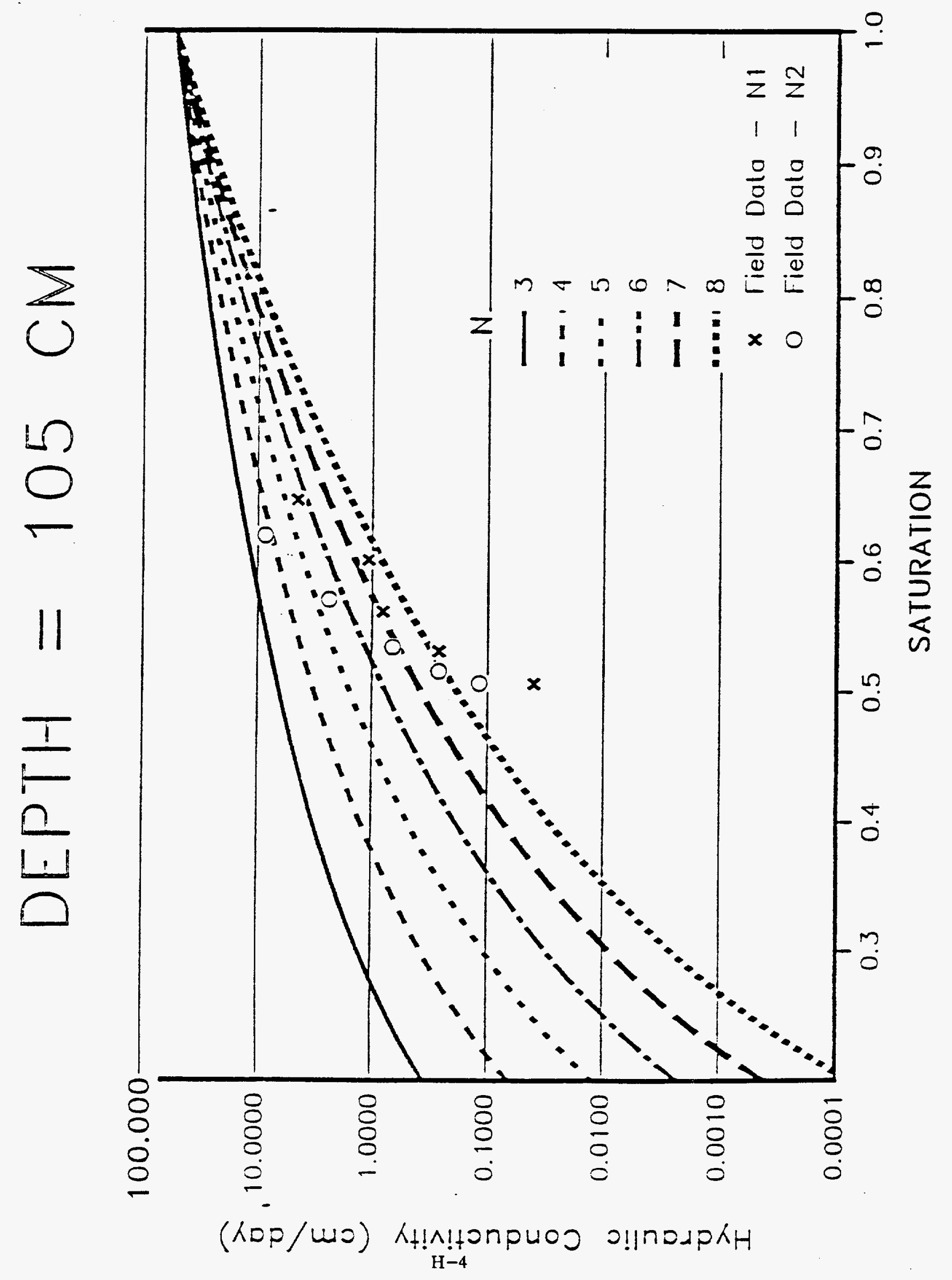




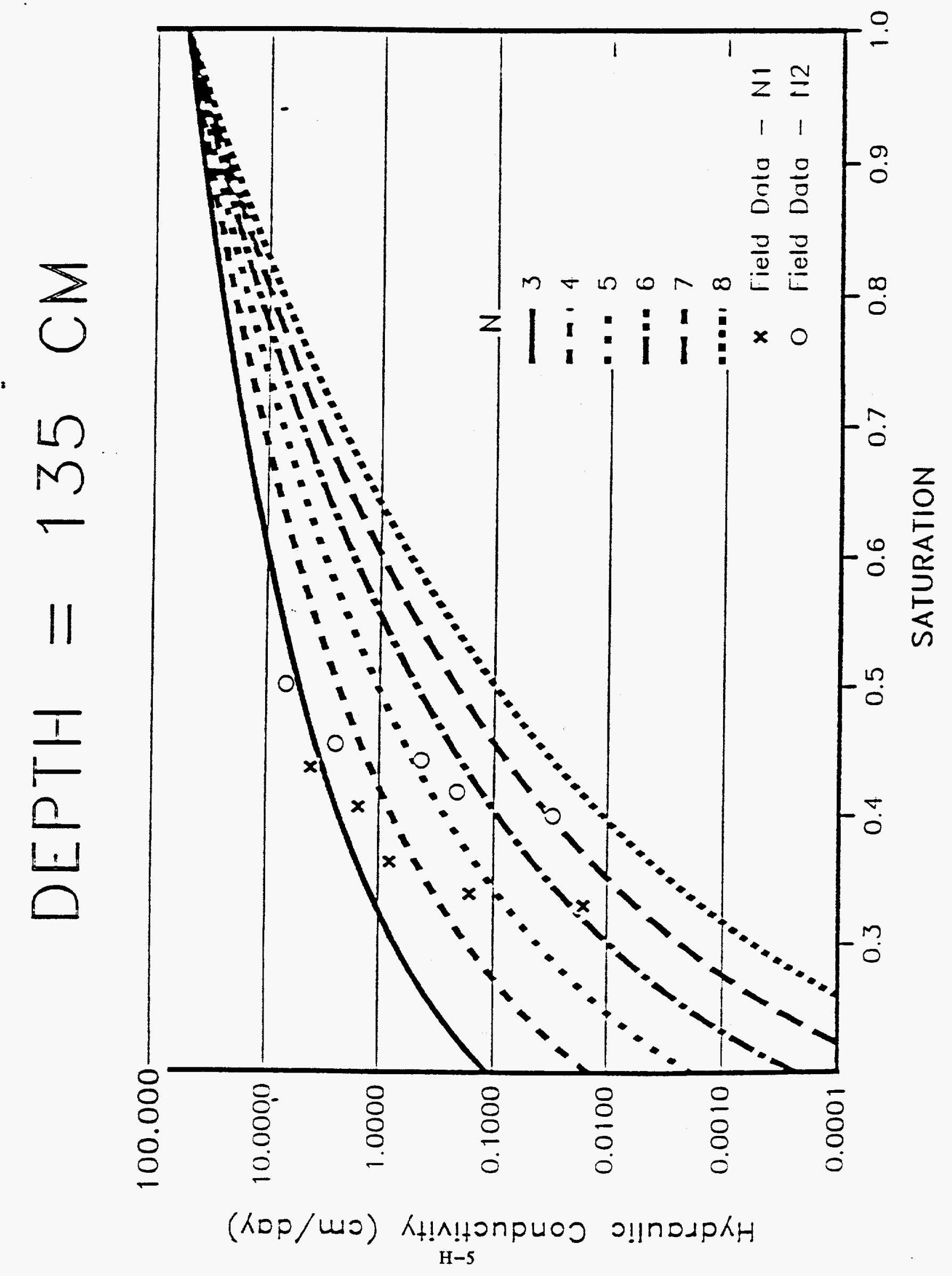




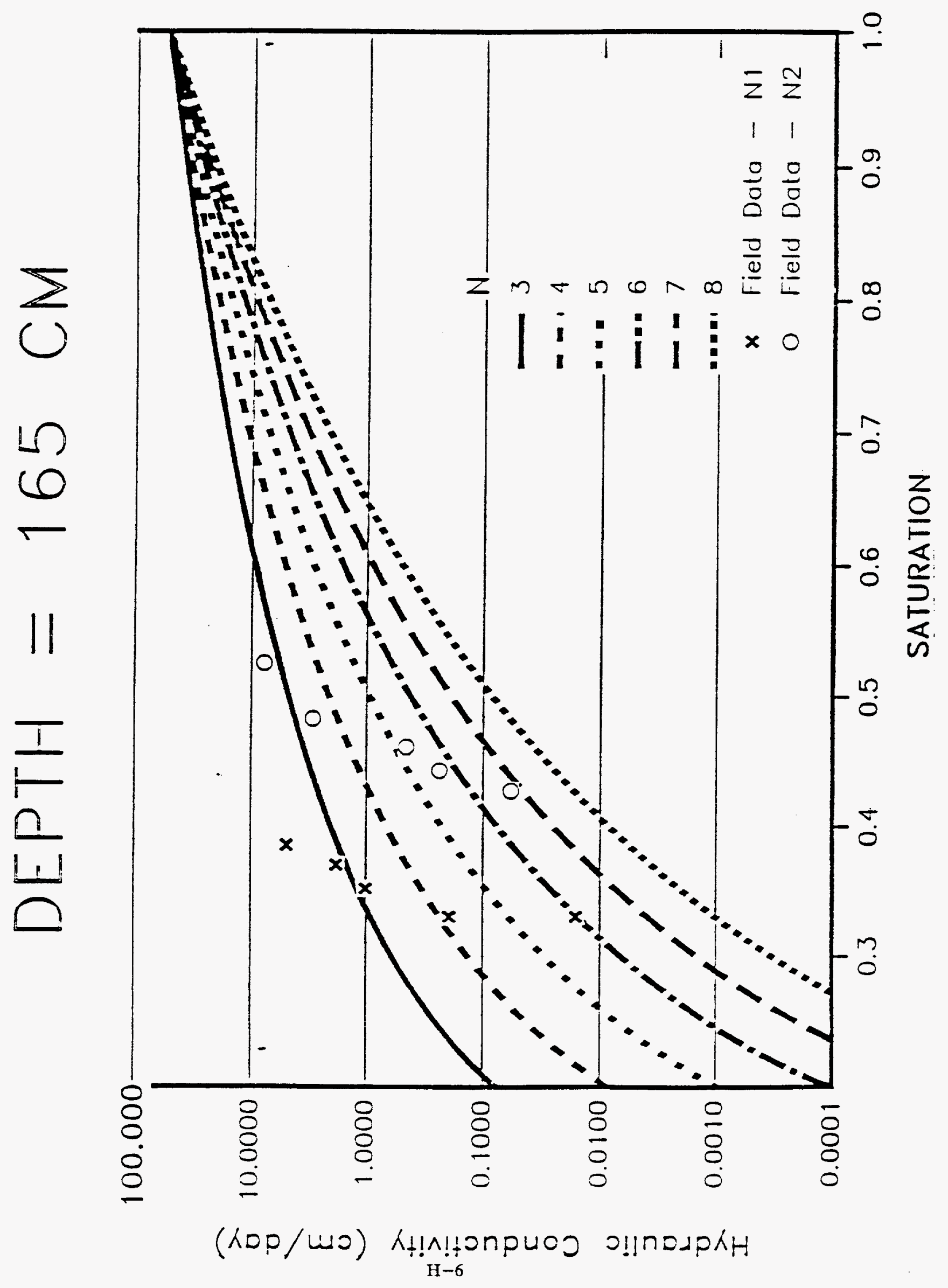




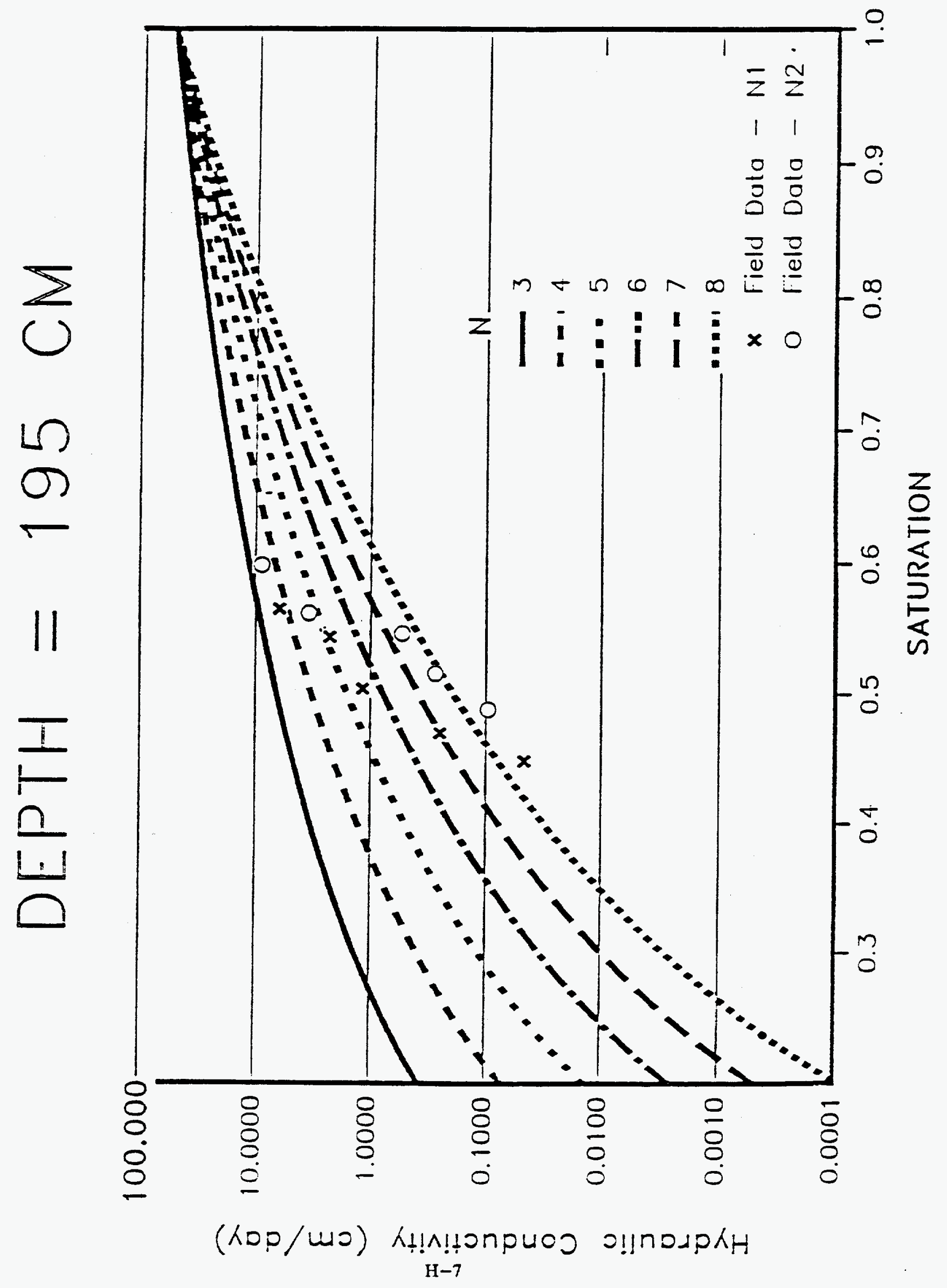




\section{Appendix I}

Simulated moisture distribution 
Ang 512,1619116 lloute Pagy I

ra

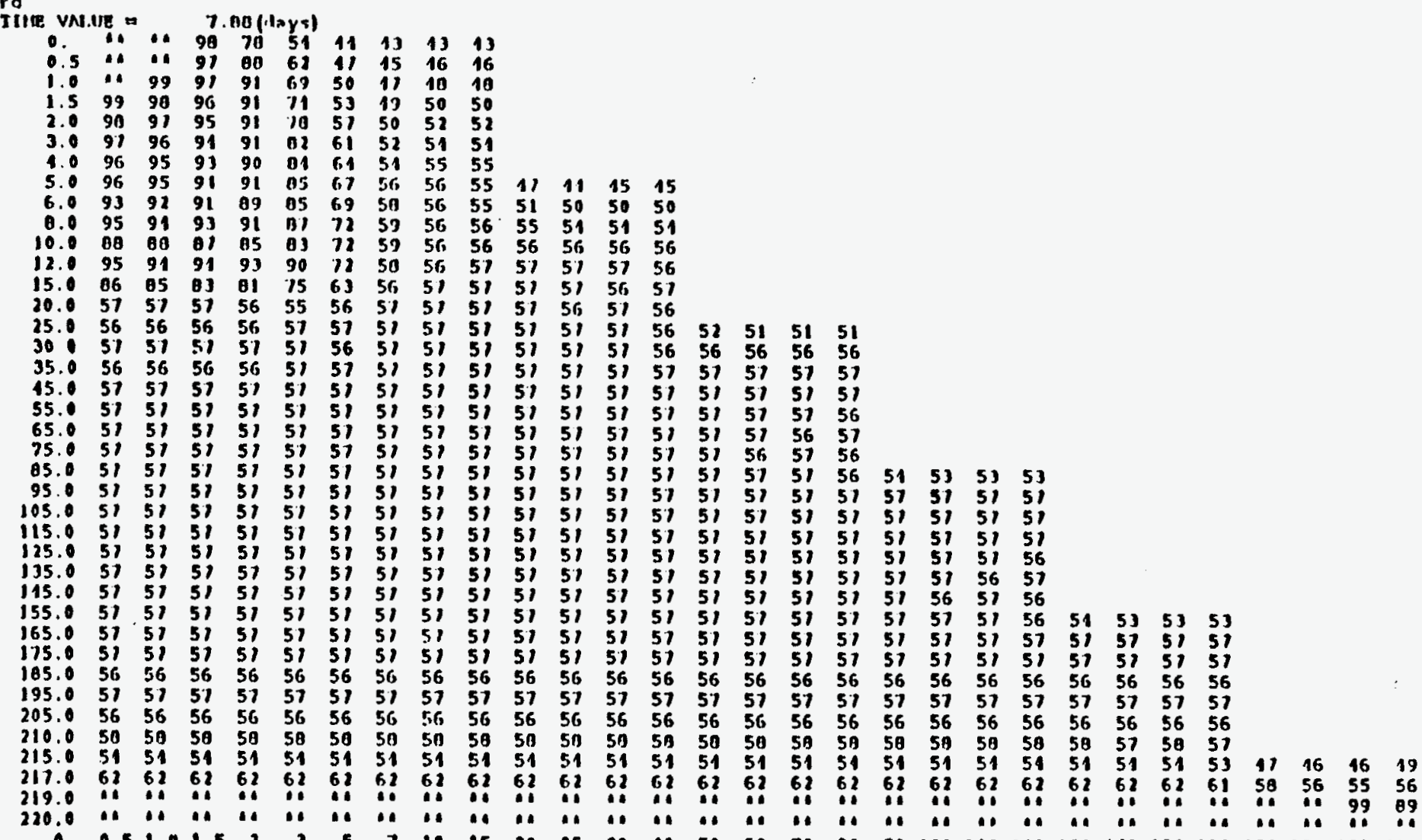

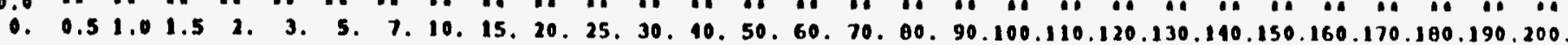




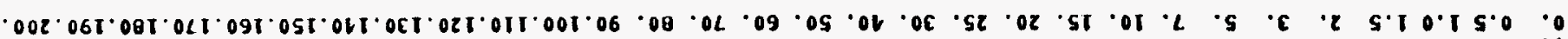

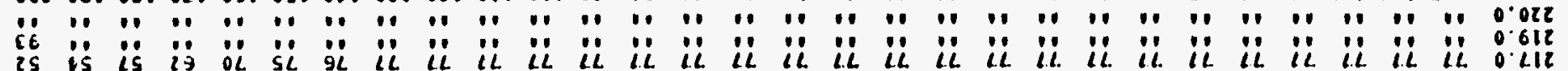

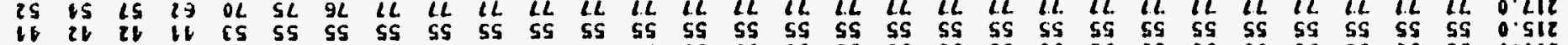

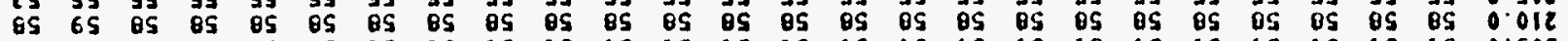
$5 S$ is is 15 is is is is is is is is is IS is is is is is is is is is is is 0.502

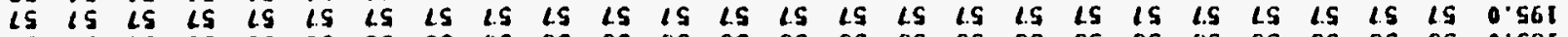

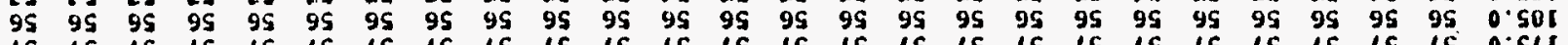

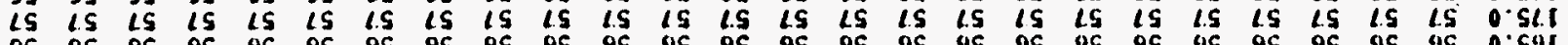

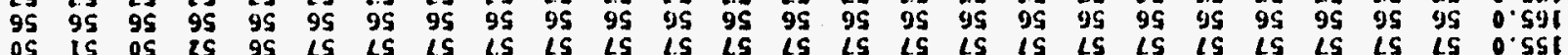

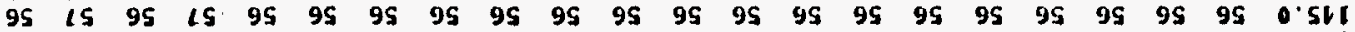

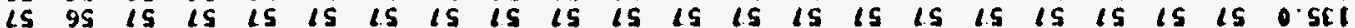

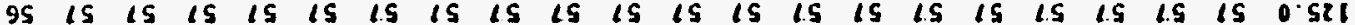

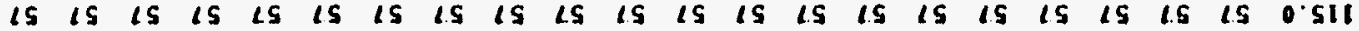

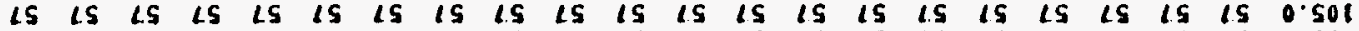

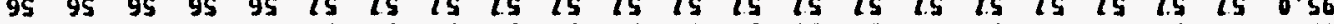

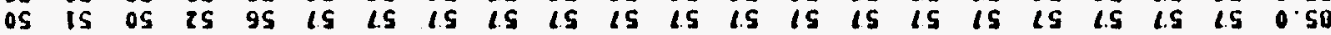

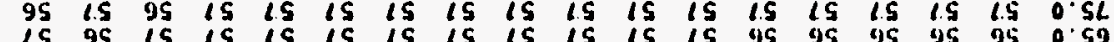

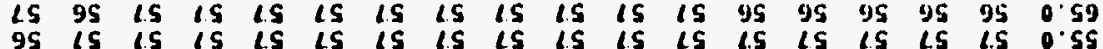

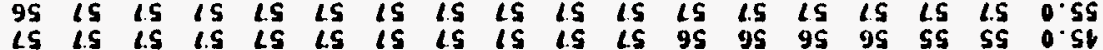

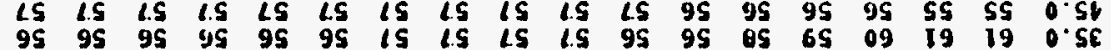

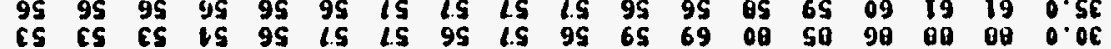

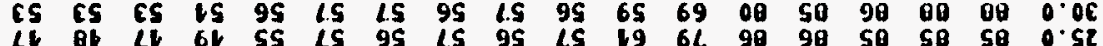

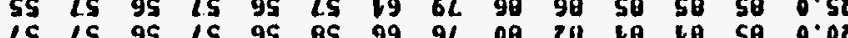

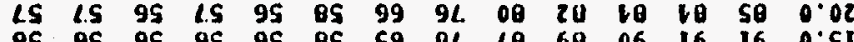

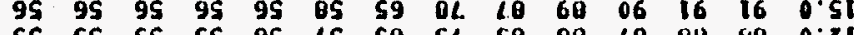
SS SS SS SS 95 Q IS $0 S$ IS 9b 94 gb 15 (5 96 97 gr ob OS is OS I9 10 I6 56 SG 960.

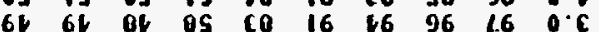

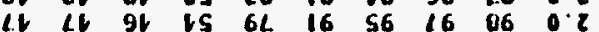
$9 v$ of st os bl $16 \quad 96 \quad 06 \quad 66 \quad \mathrm{~s}$. it 16 ch $16 \quad 69$ it $16 \quad 66 \quad 110$.

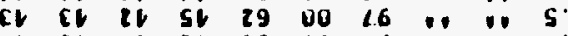

or it of $2 v$ is 
Ang 7 09:291906, thoutce Pngn 1

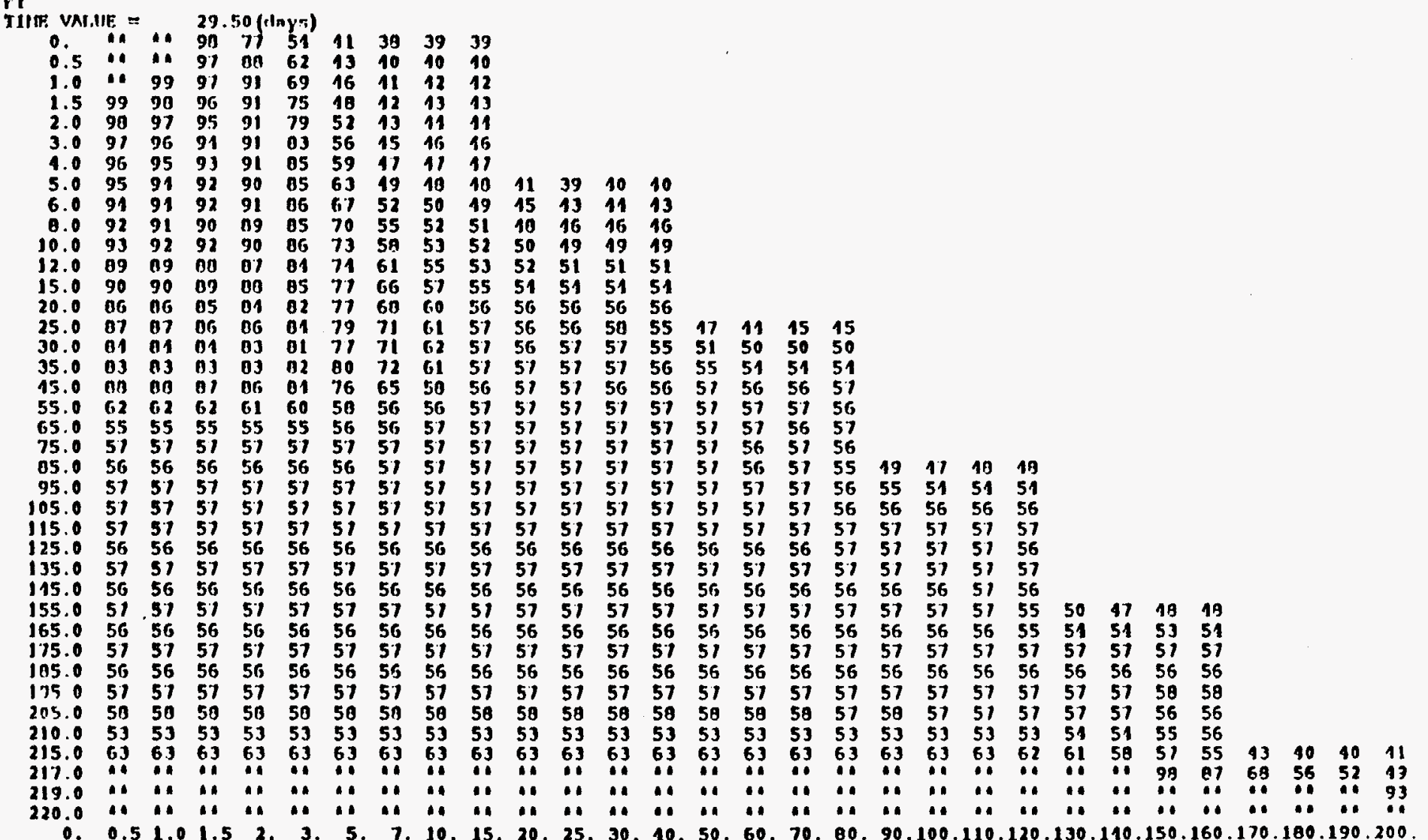


Ang 12 18:18 1986 thistle Pago 1

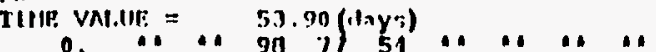

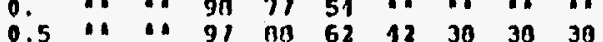

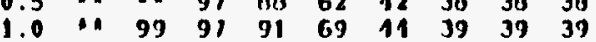

$\begin{array}{lllllllllll}1.5 & 99 & 9 n & 96 & 91 & 75 & 11 & 10 & 10 & 10\end{array}$

$2.0 \quad 93 \quad 97 \quad 95$ 9i 00 50 11 11 11

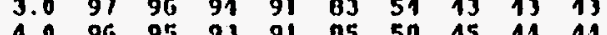

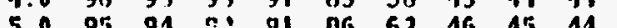

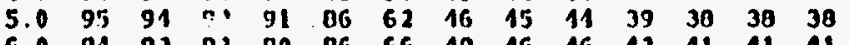

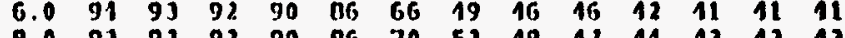

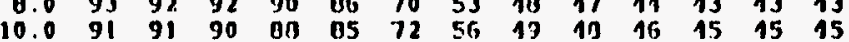

$\begin{array}{llllllllllllll}12.0 & 91 & 91 & 90 & 89 & 85 & 75 & 60 & 51 & 19 & 18 & 11 & 11 & 11\end{array}$

i

$\begin{array}{llllllllllllll}15.0 & 09 & 00 & 01 & 06 & 01 & 76 & 63 & 51 & 51 & 50 & 50 & 50 & 50 \\ 20.0 & 01 & \theta^{\prime} & 01 & 06 & B 1 & 70 & 61 & 51 & 53 & 52 & 52 & 52 & 52\end{array}$

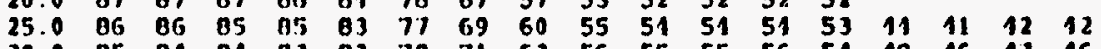

$\begin{array}{llllllllllllllllll}30.0 & 05 & 81 & B 1 & 03 & 82 & 70 & 71 & 62 & 56 & 55 & 55 & 56 & 51 & 13 & 16 & 11 & 16\end{array}$

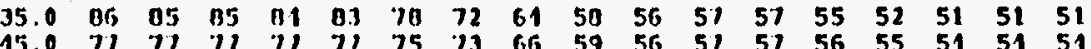

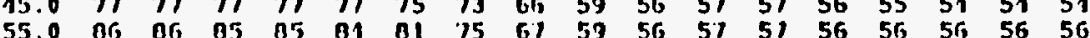

$\begin{array}{lllllllllllllllllll}55.0 & 11 & 11 & 11 & 11 & 76 & 71 & 72 & 65 & 51 & 56 & 51 & 51 & 51 & 51 & 51 & 51 & 51\end{array}$

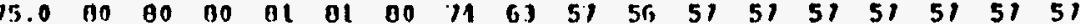

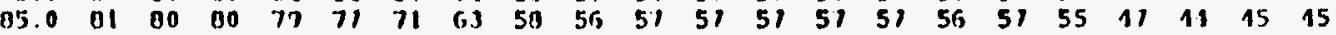

$\begin{array}{llllllllllllllllllllll}95.0 & 51 & 50 & 57 & 51 & 57 & 56 & 56 & 56 & 51 & 51 & 51 & 51 & 51 & 51 & 57 & 51 & 55 & 52 & 50 & 50 & 50\end{array}$

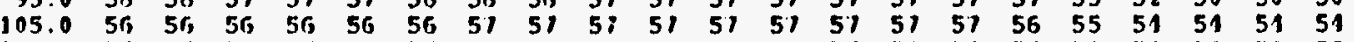

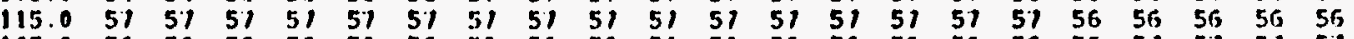

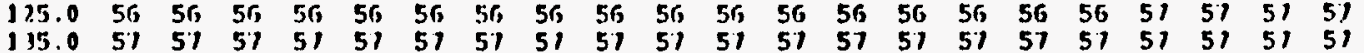

$\begin{array}{llllllllllllllllllllll}135.0 & 51 & 57 & 57 & 51 & 51 & 57 & 57 & 51 & 57 & 57 & 57 & 51 & 57 & 51 & 57 & 57 & 57 & 57 & 57 & 51 & 51 \\ 115.0 & 51 & 57 & 57 & 57 & 51 & 51 & 57 & 51 & 51 & 57 & 51 & 57 & 51 & 51 & 51 & 57 & 57 & 57 & 56 & 51 & 51\end{array}$

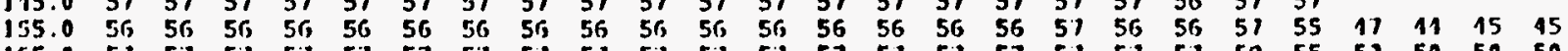

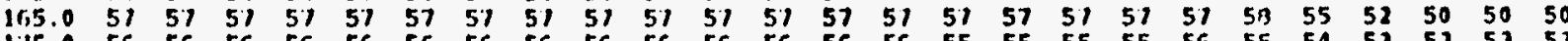

$\begin{array}{llllllllllllllllllllllllll}115.0 & 56 & 56 & 56 & 56 & 56 & 56 & 56 & 56 & 56 & 56 & 56 & 56 & 56 & 56 & 55 & 55 & 55 & 55 & 56 & 55 & 51 & 53 & 53 & 53 & 53 \\ 105.0 & 50 & 50 & 50 & 50 & 58 & 50 & 58 & 50 & 58 & 50 & 50 & 58 & 58 & 58 & 58 & 58 & 58 & 58 & 58 & 58 & 58 & 58 & 59 & 58 & 58\end{array}$

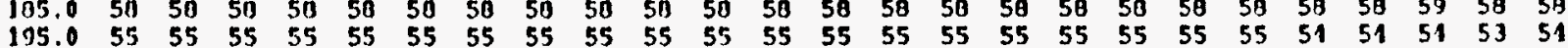

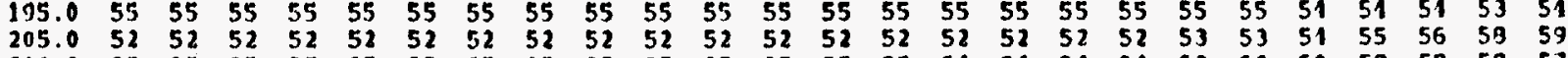

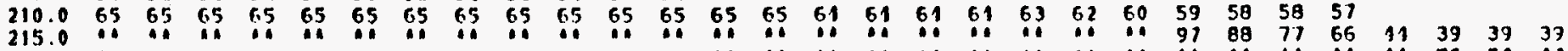

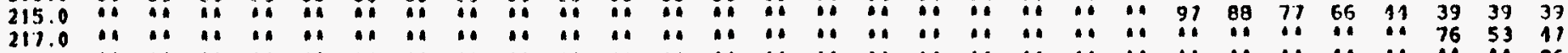

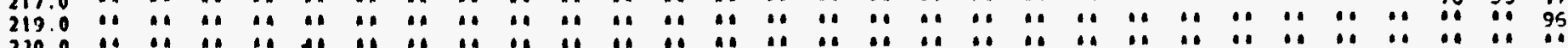

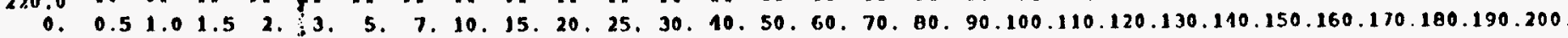


Ang 11 10:01 1906 thout rnge 1

IIM! VAL.UE $=82.01$ (inys)

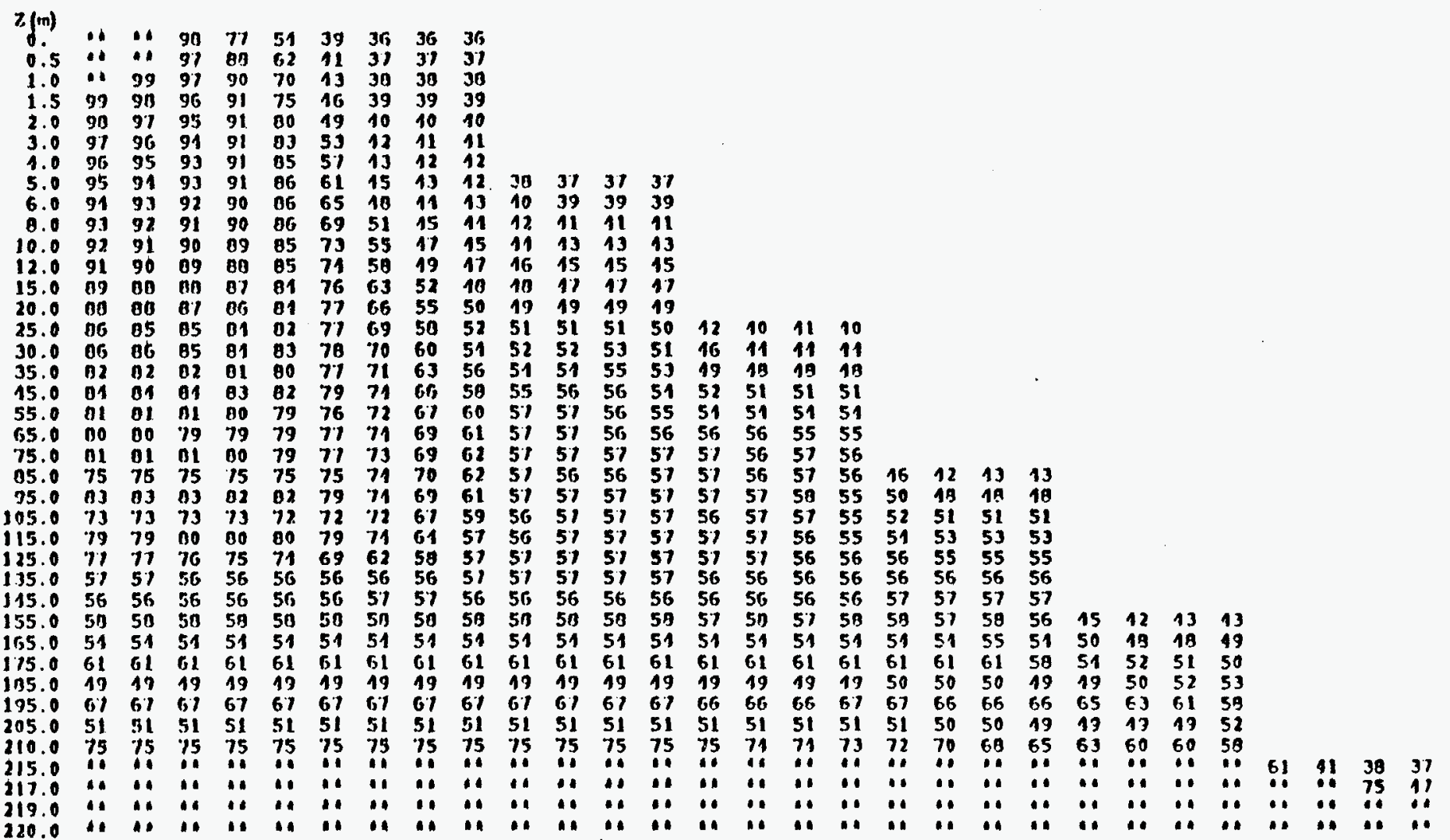

$x(m) 0,0.51 .01 .52,3,5.7,10,15,20,25,30,10,50.60,70,80,90.100 .110 .120 .130 .140 .150 .160 .170 .130 .190 .200$ 


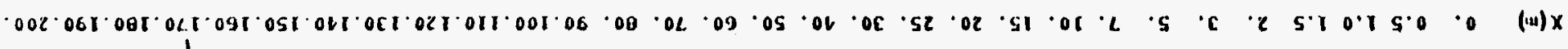

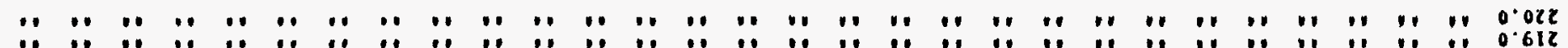
ss

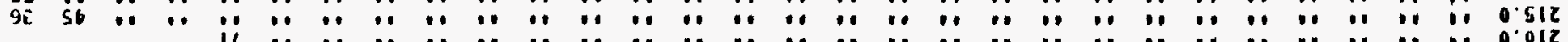

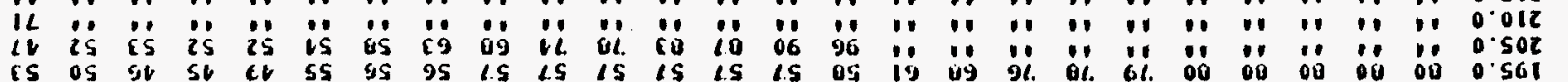

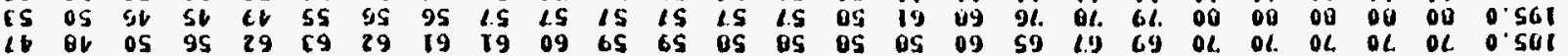

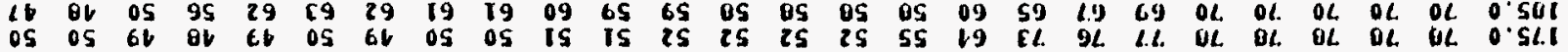

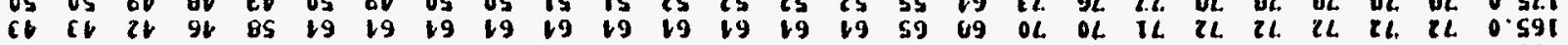

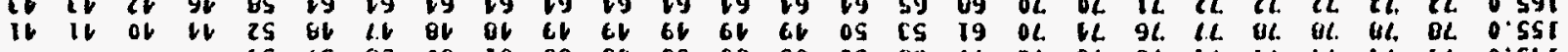

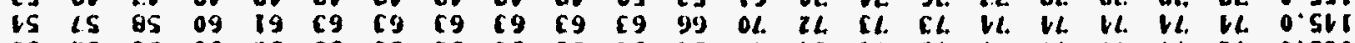

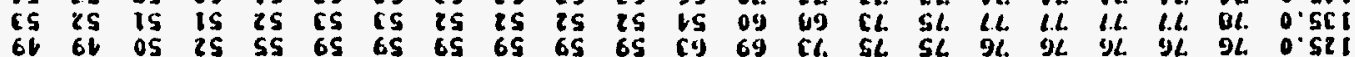

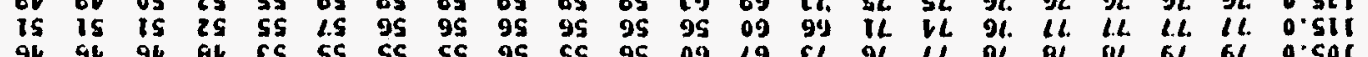

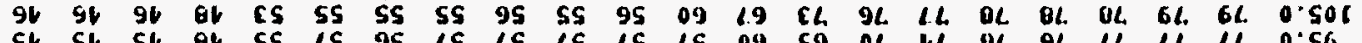

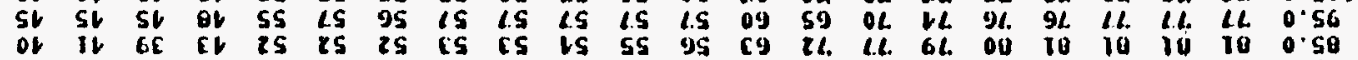

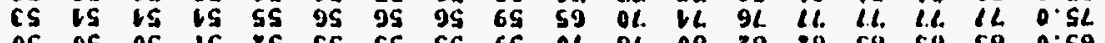

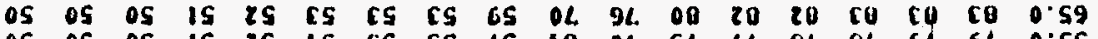

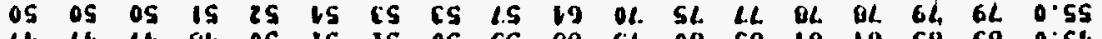

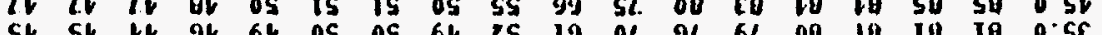
S. SV

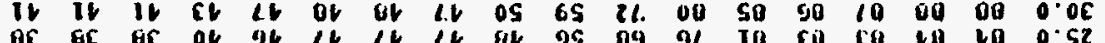

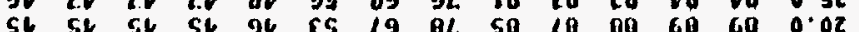

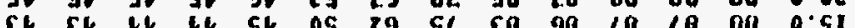

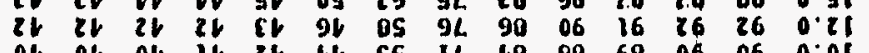

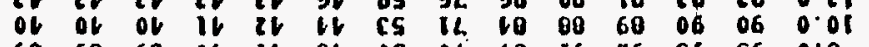

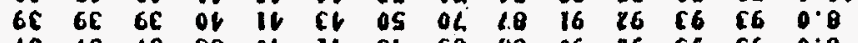

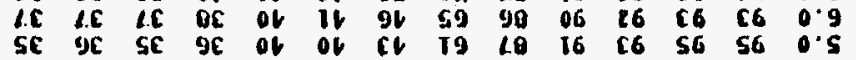
oc $6 \mathrm{C} \quad 24$ 9S $58 \quad 16$ f6 $56 \quad 96 \quad 0 . \mathrm{V}$

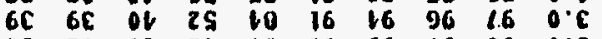
of of of ol 08 16 $56 \quad 16 \quad 86 \quad 0.2$

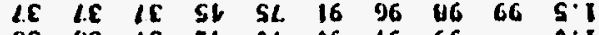

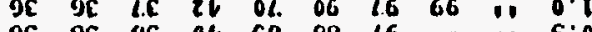

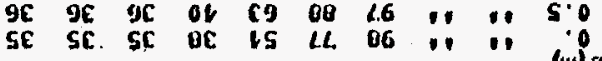

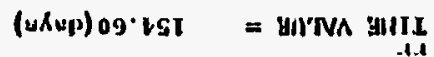

c boud nowing 9067 ec:or of buv 
IIIII: VALUE: $=259.00$ (1nya)

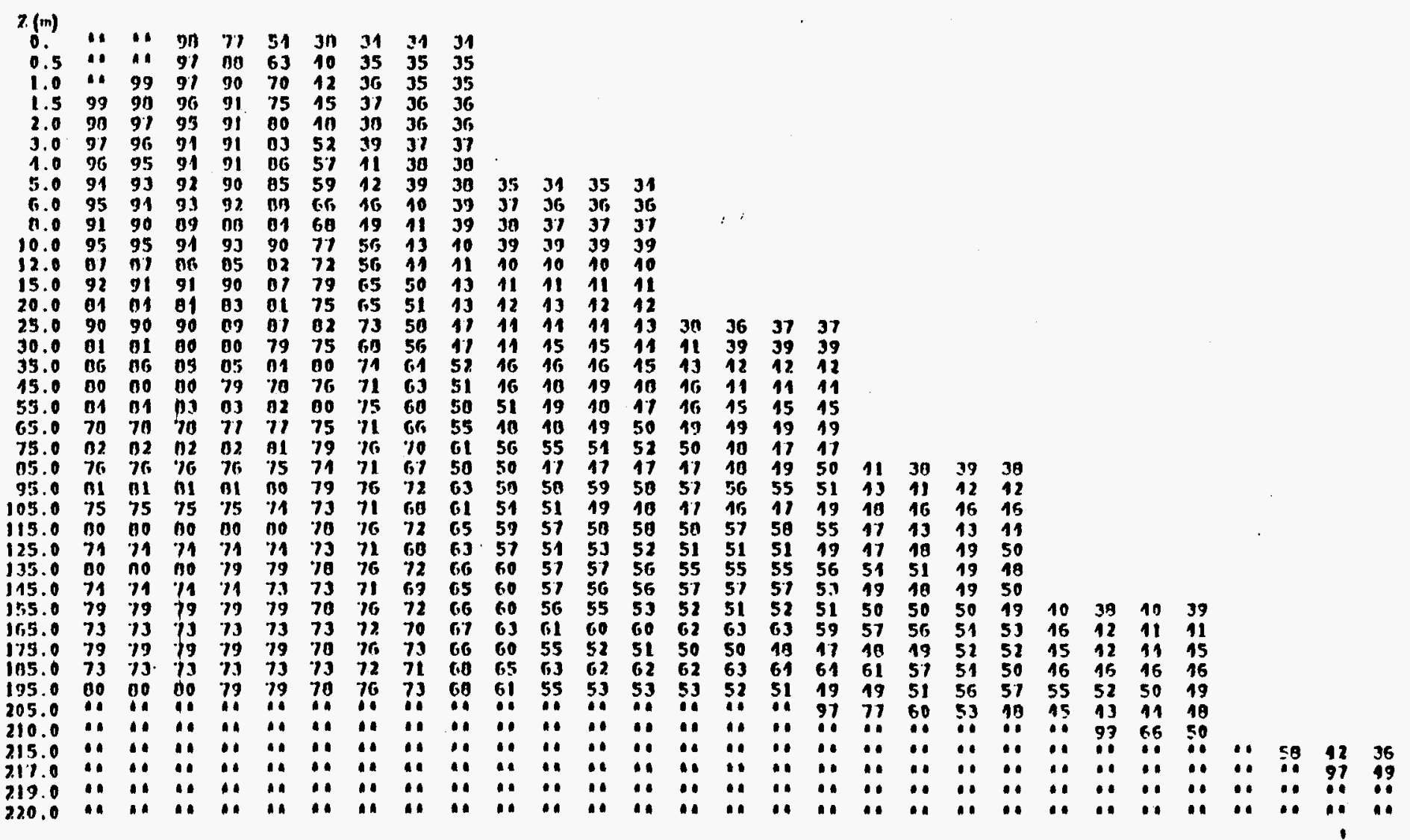

$x(m)$ 0. 0.51 .01 .5 2. 3. 5. 7. 10. 15. 20. 25. 30. 10. 50. 60. 70. 90. 90.100 .110 .120 .130 .110 .150 .160 .170 .180 .190 .200 


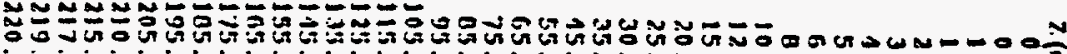

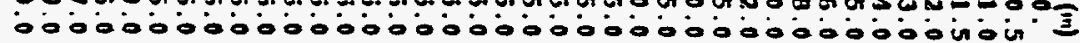

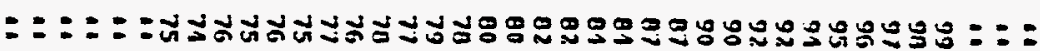

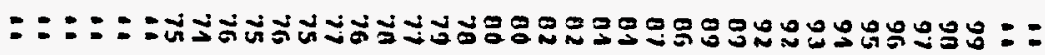

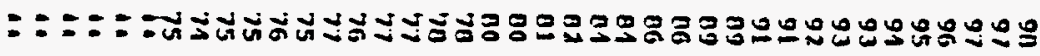
: : : ニ

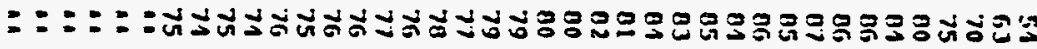

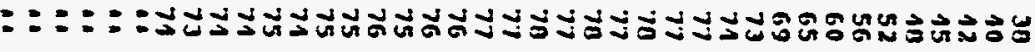
: : : : : : : : : :

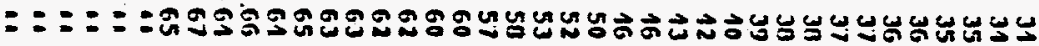

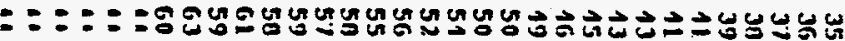

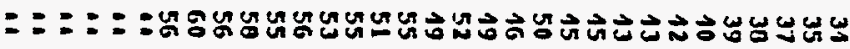

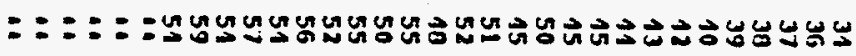

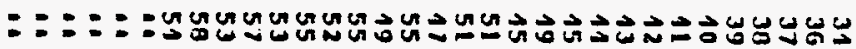

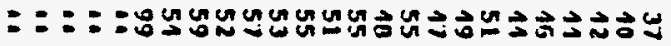

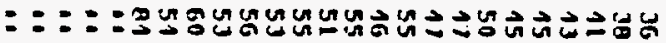

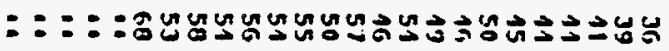

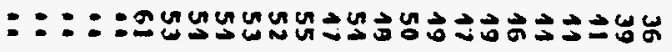

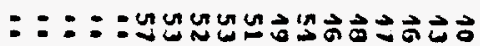

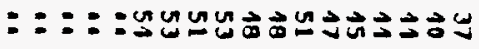

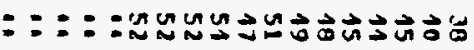

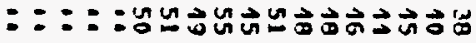

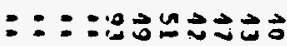
$:::: ロ コ ル ロ さ む ル さ$

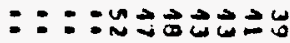

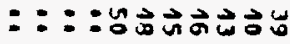

$::: \geq$

$::: 2$

$:=9$

: :さムั 


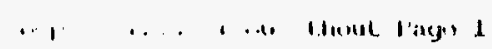

Tilis: vNI.U1: $=$

$101.60($ diny:s)

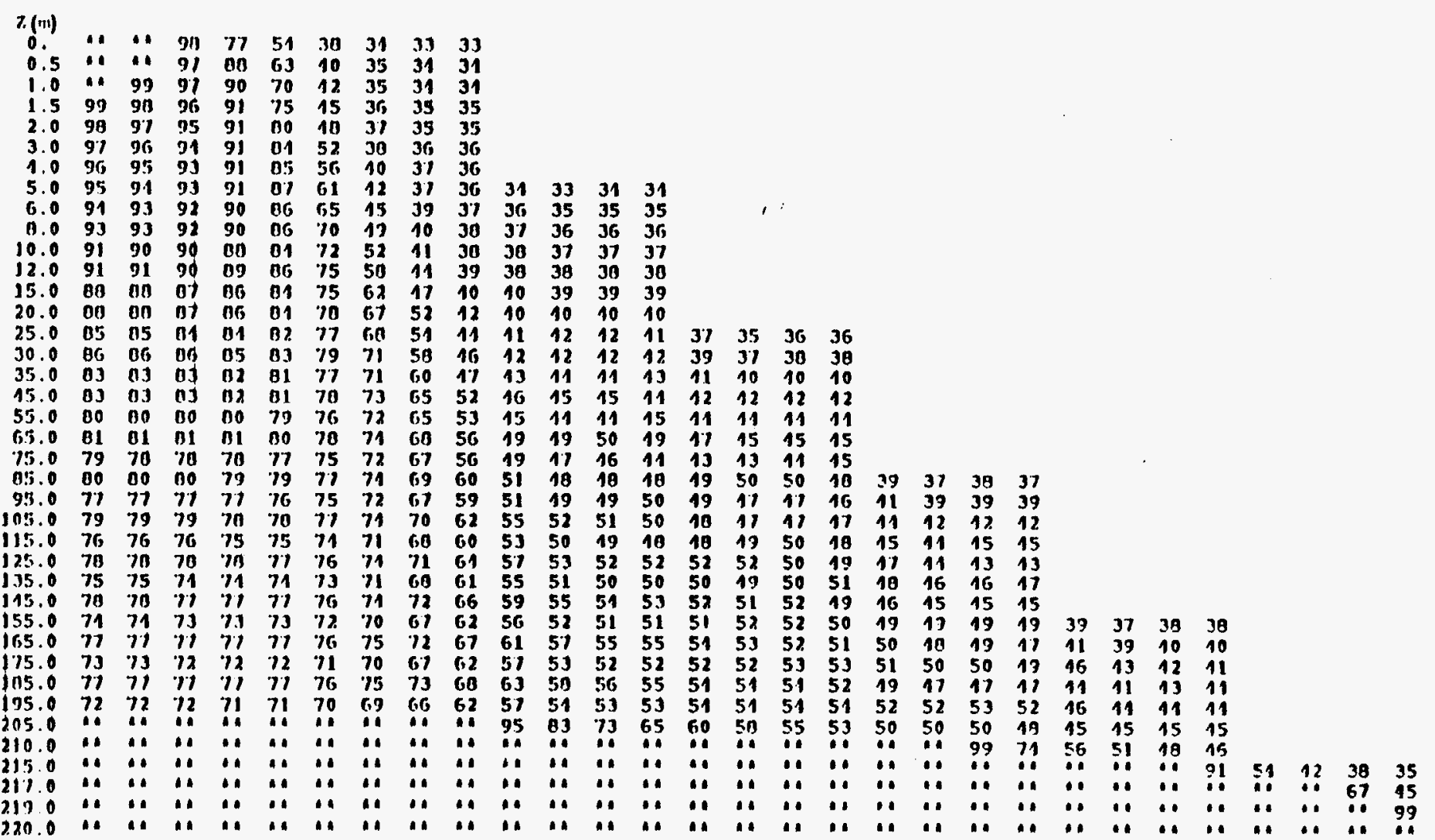

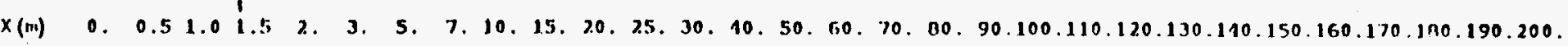


rinte vatue $=515.00$ (dnys)

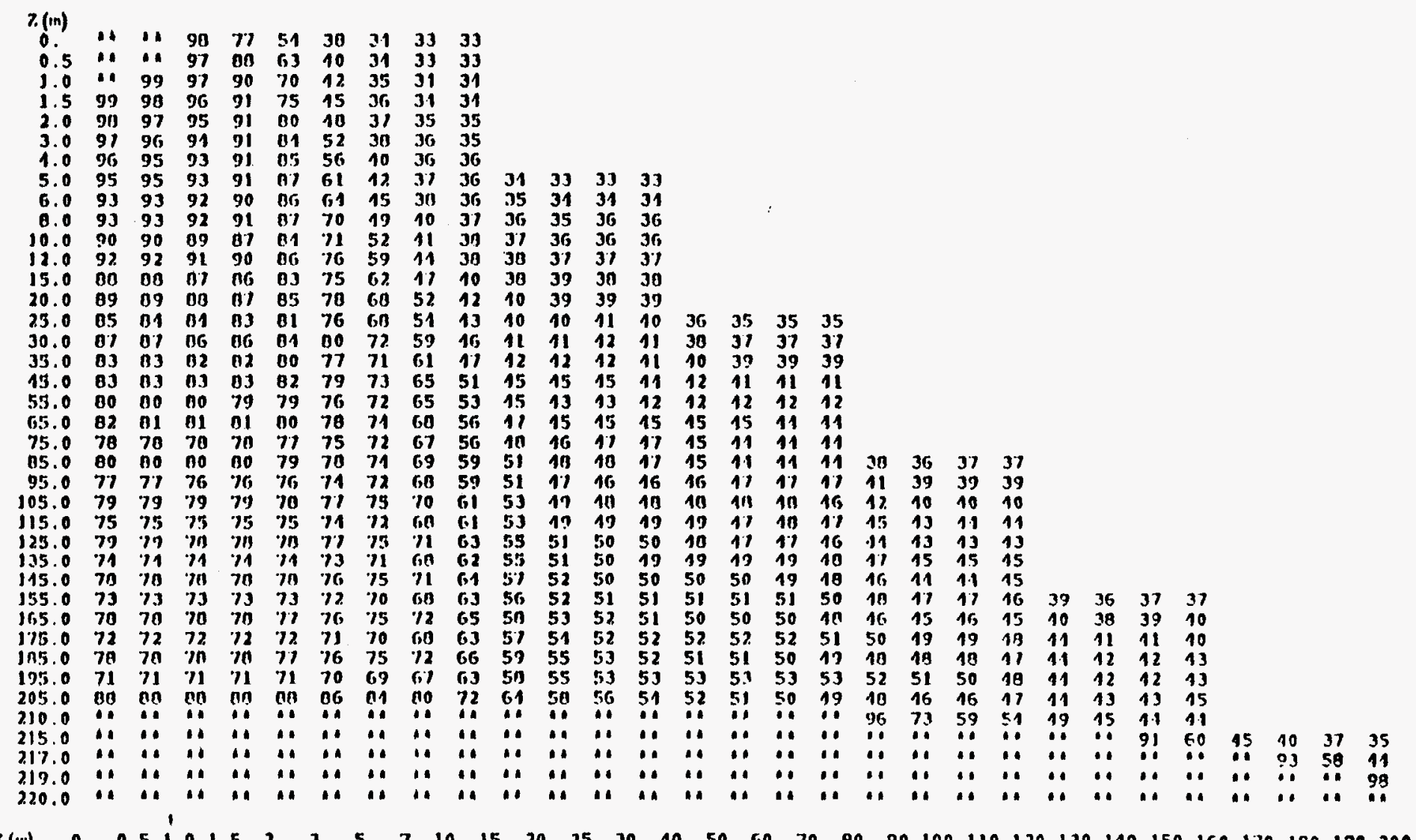

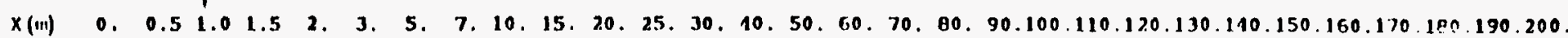




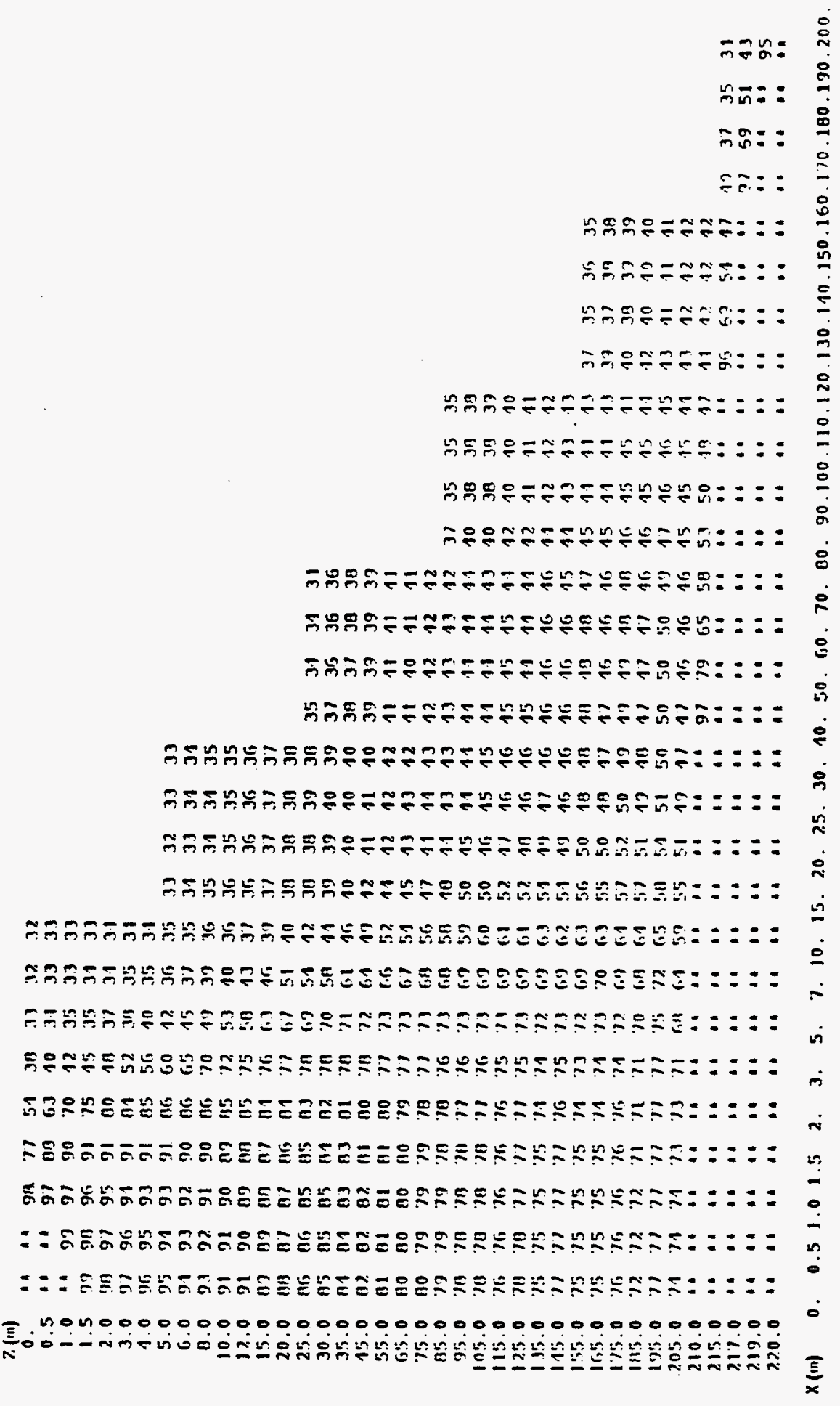




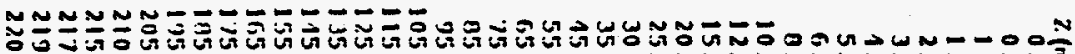

-

in

:

is

?

:

n

$\div$

5

$\overline{5}$

ก

ที

ธ

o

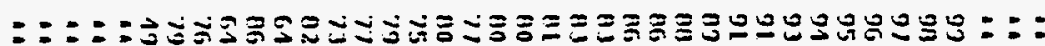
○: : :

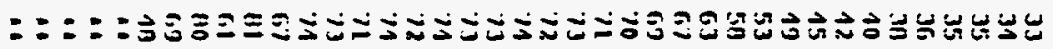
: : : : :

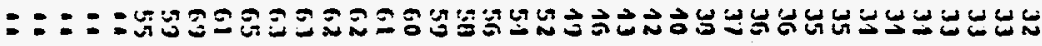

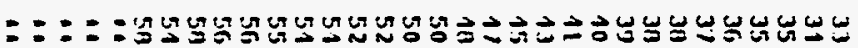
: : : : :

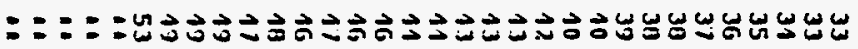

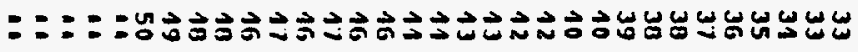

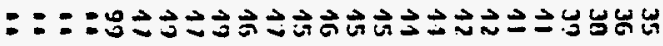

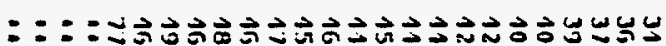

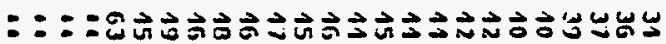

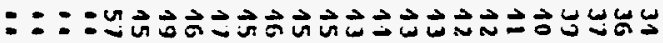

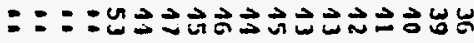

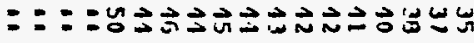

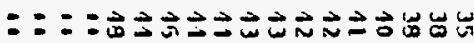

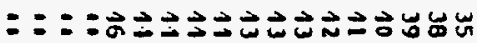

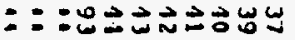

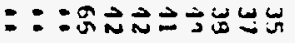

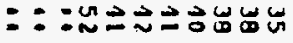

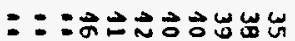

: :영

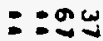

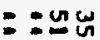

:ピロ゙ 


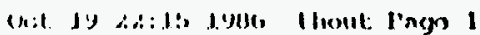

rvi.

TIIIII VAIUI: $=1010.00(1 \mathrm{ln} y \mathrm{~m})$

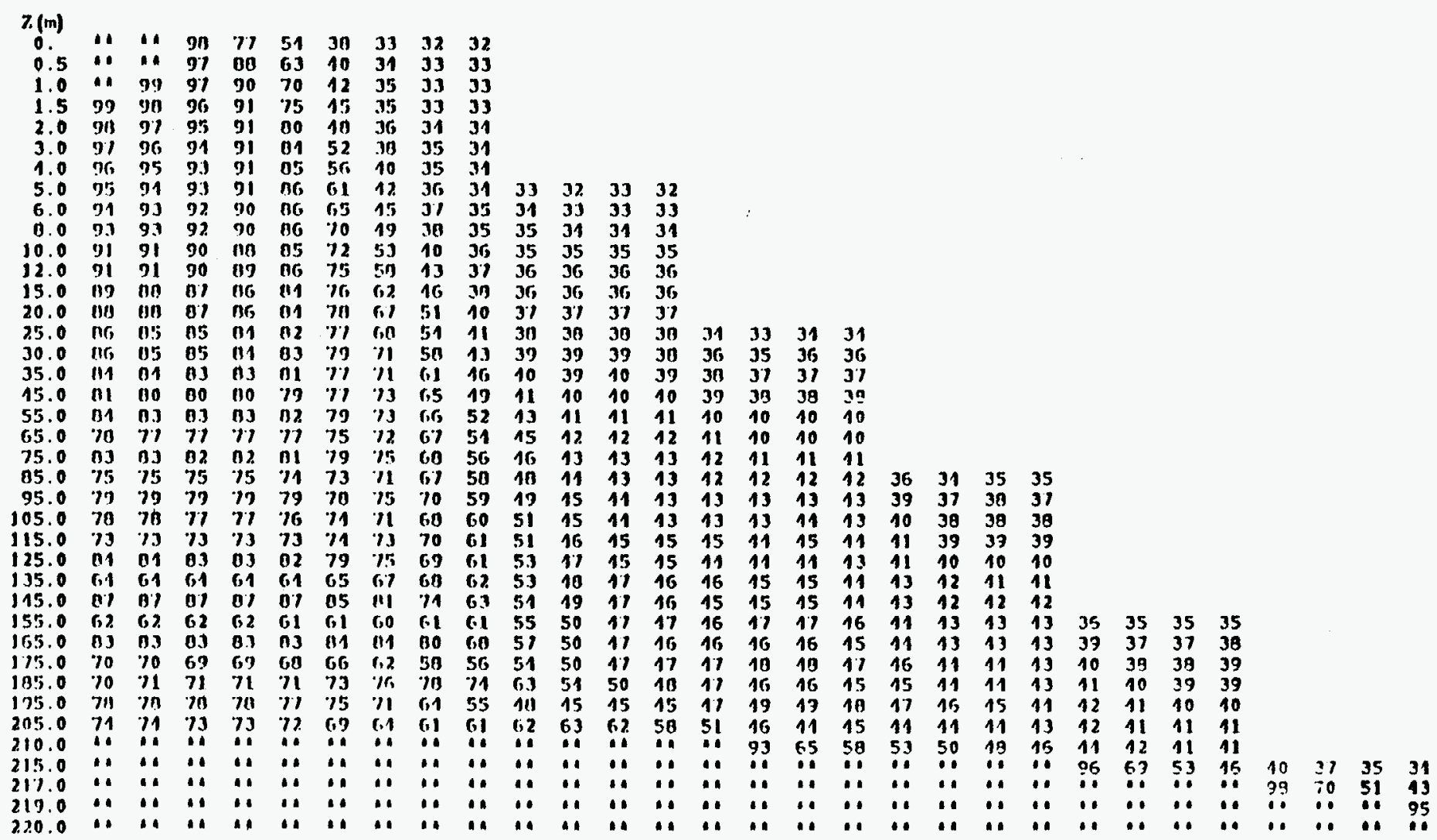

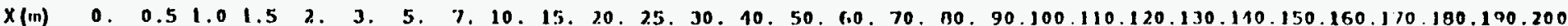




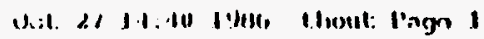

r!i

TINE VAIUR $=1101.00$ (1Ayn)

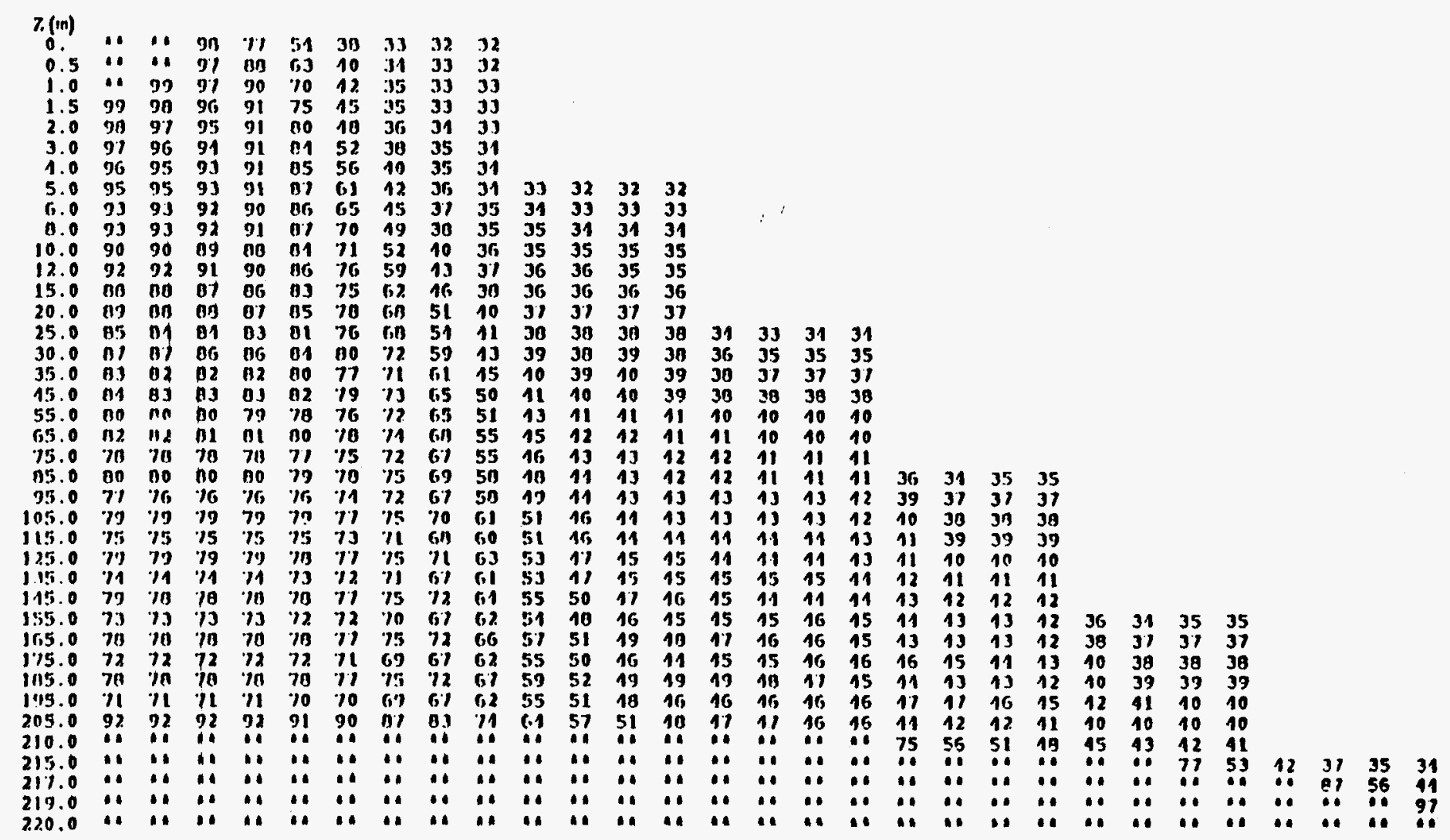

$X(11) \quad 0.0 .51 .01 .5$ 2. 3. 5. T. 10. 15. 20.25. 30. 10. 50.60.70. 00.90 .100 .110 .120 .130 .110 .150 .160 .170 .180 .190 .200 
Appendix J

Simulated velocity field

$\mathrm{J}-1$ 


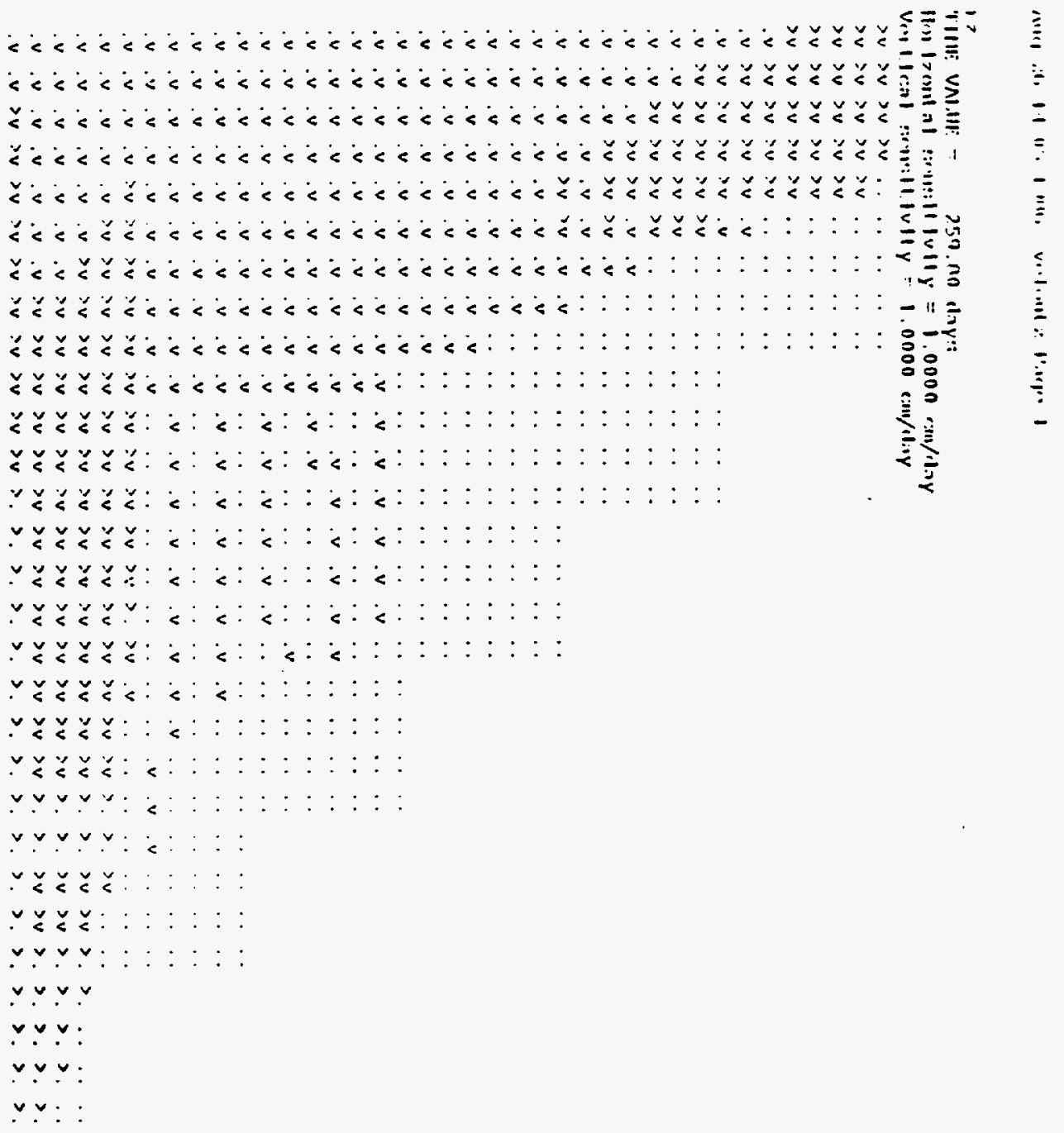




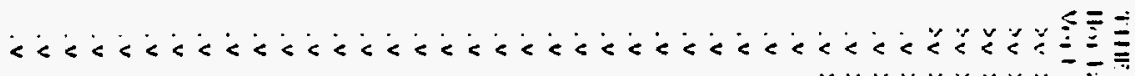

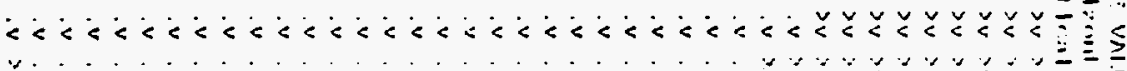

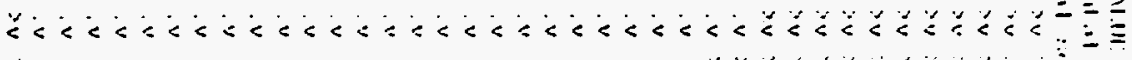

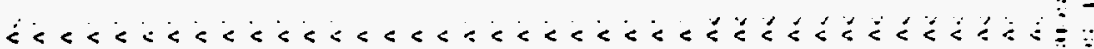

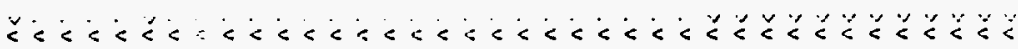

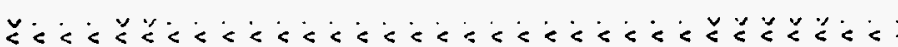

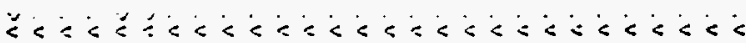

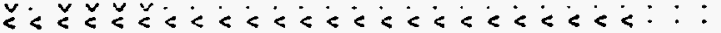

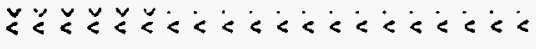

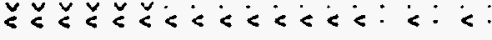

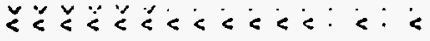

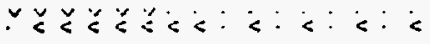

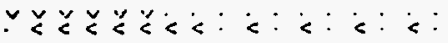

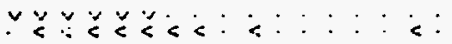

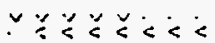

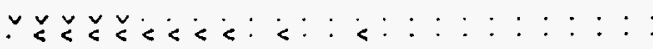

マ

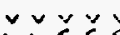

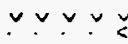

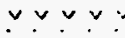

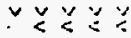

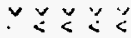

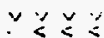

$\vee \vee \vee v$

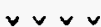

จนขอ

$\because \because 2$ :

$\because \sim 2$ :

$\because \because:$ 


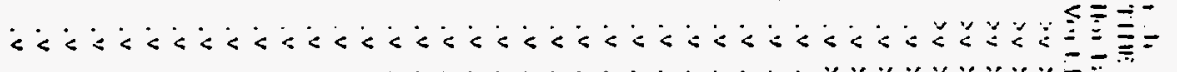

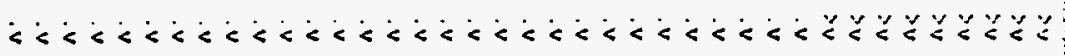

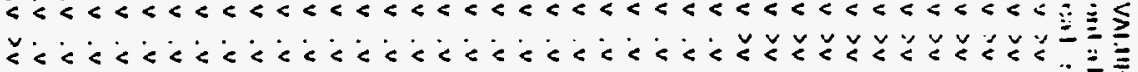

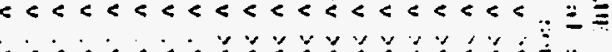

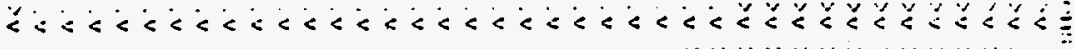

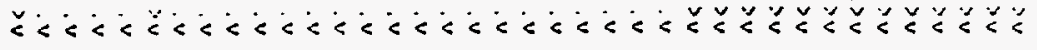

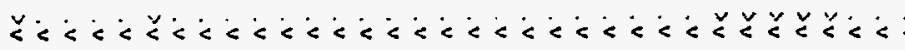

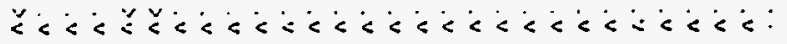

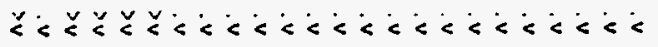

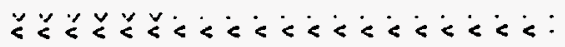

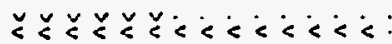

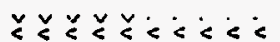

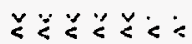

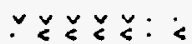

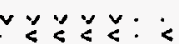

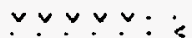

$\checkmark \vee \vee \vee \vee:$

$\because \simeq \vee \div ะ$ :

$\because \div \div \div \div::::::::::::$ : :

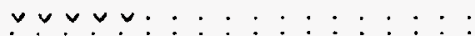

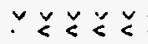

$\because \longleftarrow \check{x}$

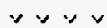

$\vee \vee \vee v$

$\vee \vee \vee \vee$

หทะ

$\because \vee \square$ :

$\checkmark v \vee$.

$\checkmark v$ :

$\because \vee$ 


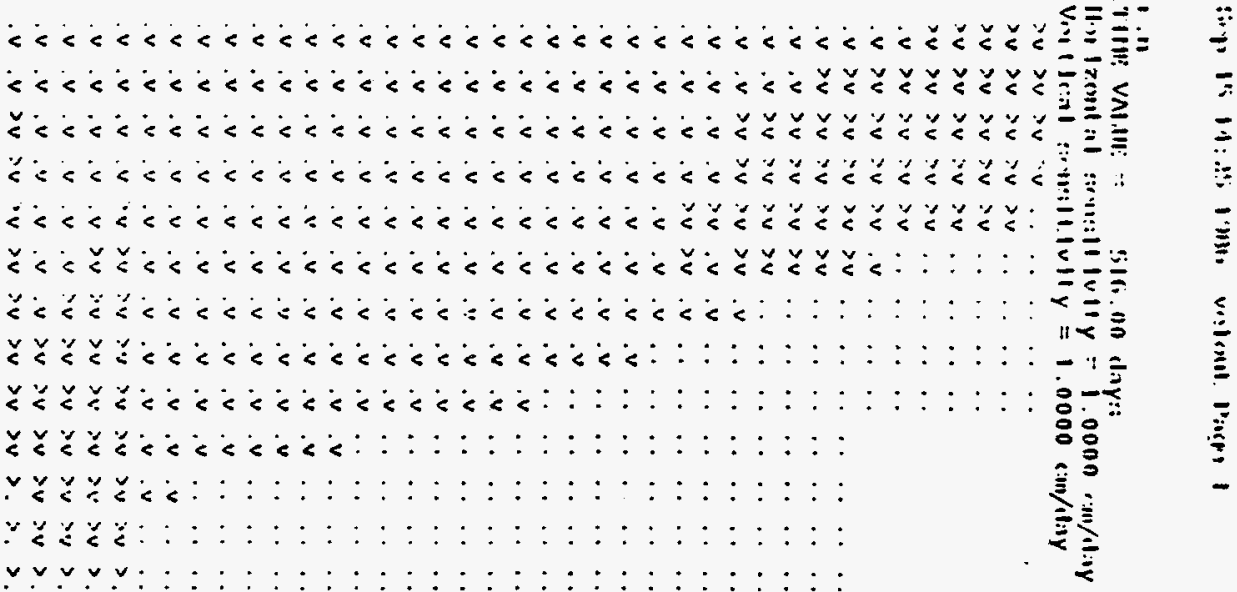

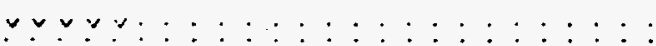

ฯ $\vee \checkmark$

$\because \vee \vee \vee v$

$\because \because \because \because$

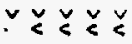

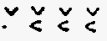

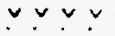

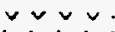

$\because \times \vee$

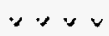

$\checkmark \times \vee v$

$\checkmark \vee v$.

$\because \check{v}$

$\because ะ \because$ :

$\checkmark \vee:$ :

$\because \vee$ 


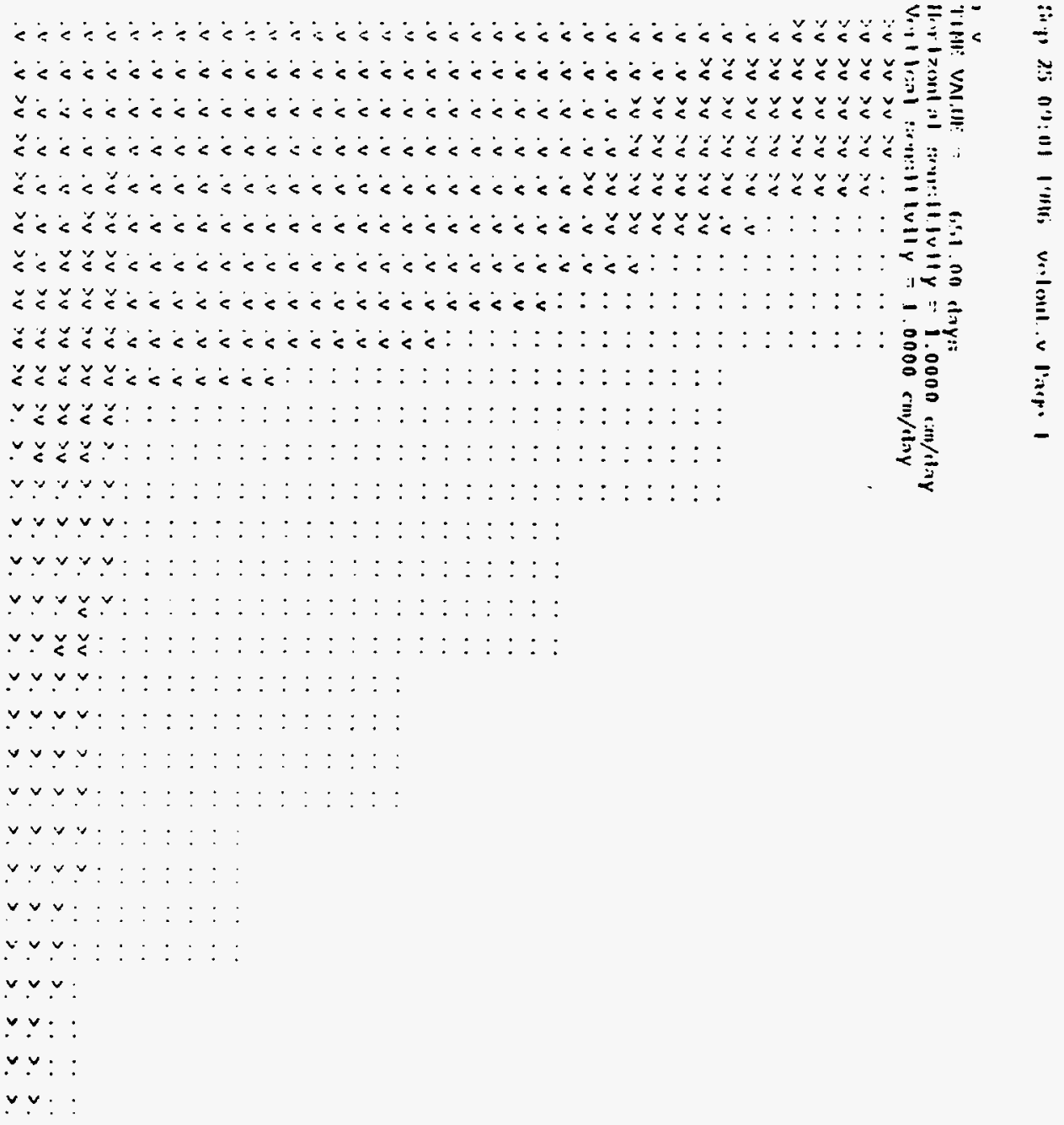




\section{$L-1$}

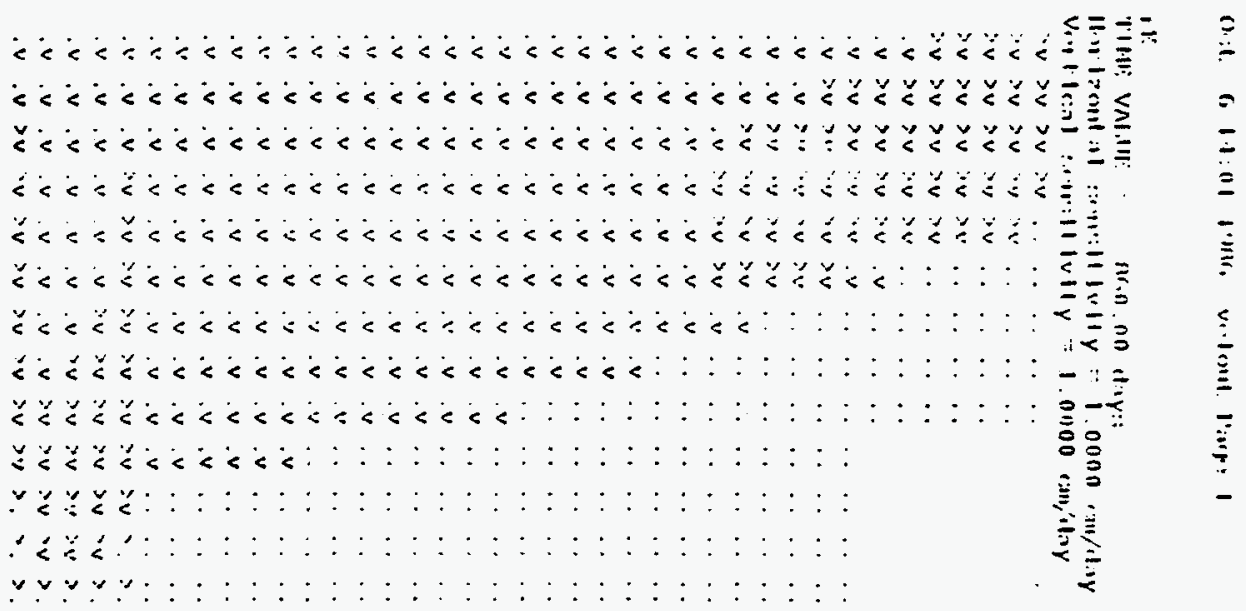

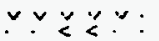

$\because \because:$ : :

$\because \because$

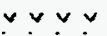

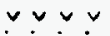

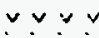

$\because v 2 v$

$\checkmark v \cdots$

…

$\because \because$ :

$\because \because$

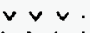

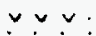

$\because \because:$

$\because 2:$

$\because$ 


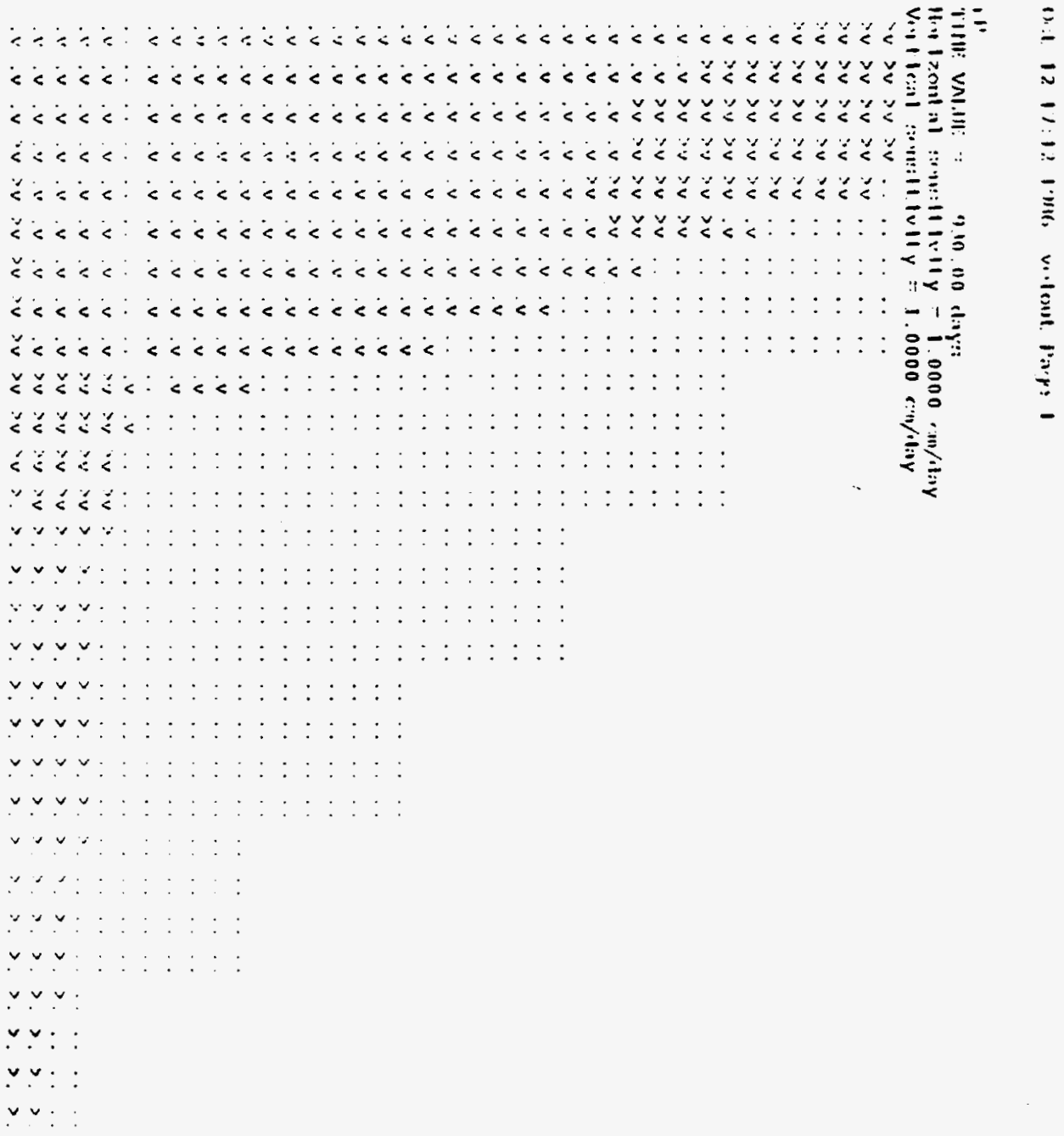




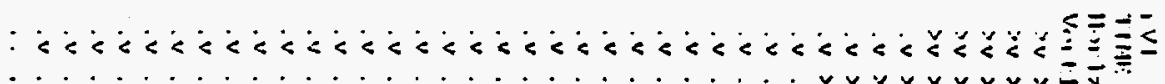

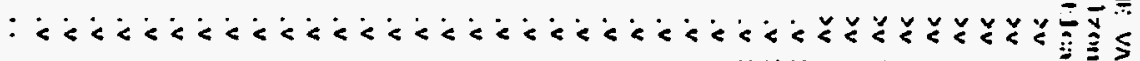

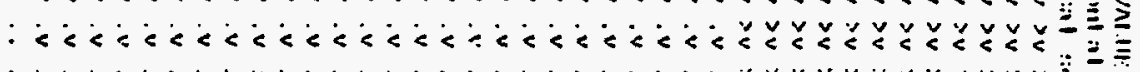

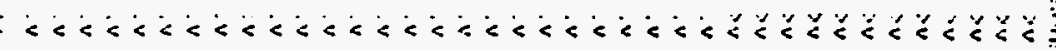

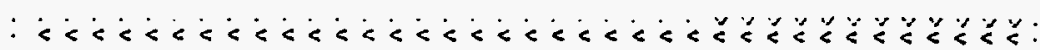

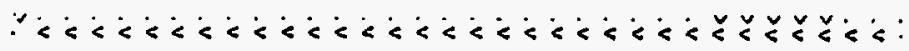

$\because<<<<<<=<<<<<<<<<<<<<<<<<<<<<<<$

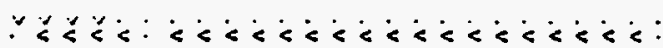

$\because \because \because<:<<<<<<<<<<<<<<$ :

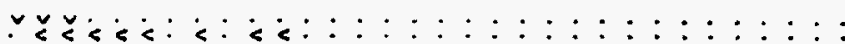

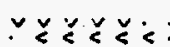

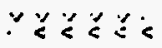

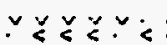

$\because \because \because ะ:$

$\because \square \vee$,

$\because \because 2$

$\because \because \geq 8$ :

$\because \because \frac{}{2}$

$\because ะ \vee \div$ :

$\because \because \div$

$\because \simeq \div$ :

$\because \vee v \%$

$\because \square$

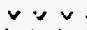

จะ

$\because \because$

$\because \because:$

$\because \because:$ :

$\because \because:$ 


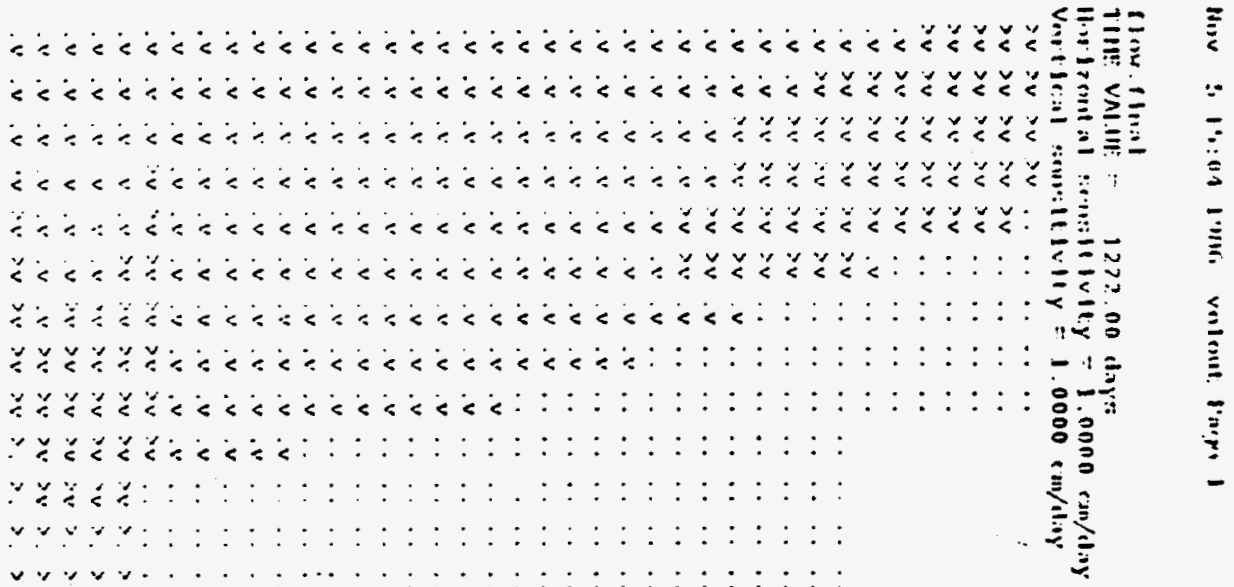

(

$\because \because \because$

$\because \because \because$

$\because \because \because$

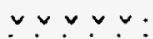

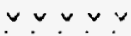

$\checkmark \vee \div$

$\because \because \because$

$\because \because \because$

$\because \because$

$\because \because$

$\because \because$

$\checkmark v v$

$\checkmark \vee:$ :

$\because$ 
Appendix K

Sensitivity of solution to changes in dispersivity

$\mathbf{K}-1$ 
Dac $013: 541986$ cossunt Pago 1

I.onglludinal DIspolstully (m) $=1.0$

Trasisverse Dlsparcivity (bi) $=0.1$

Tlaxs Sinco Pumping kexgan = 965. days

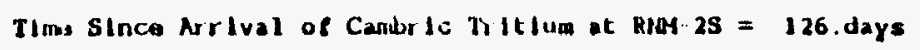

PlCu/ml 10.0

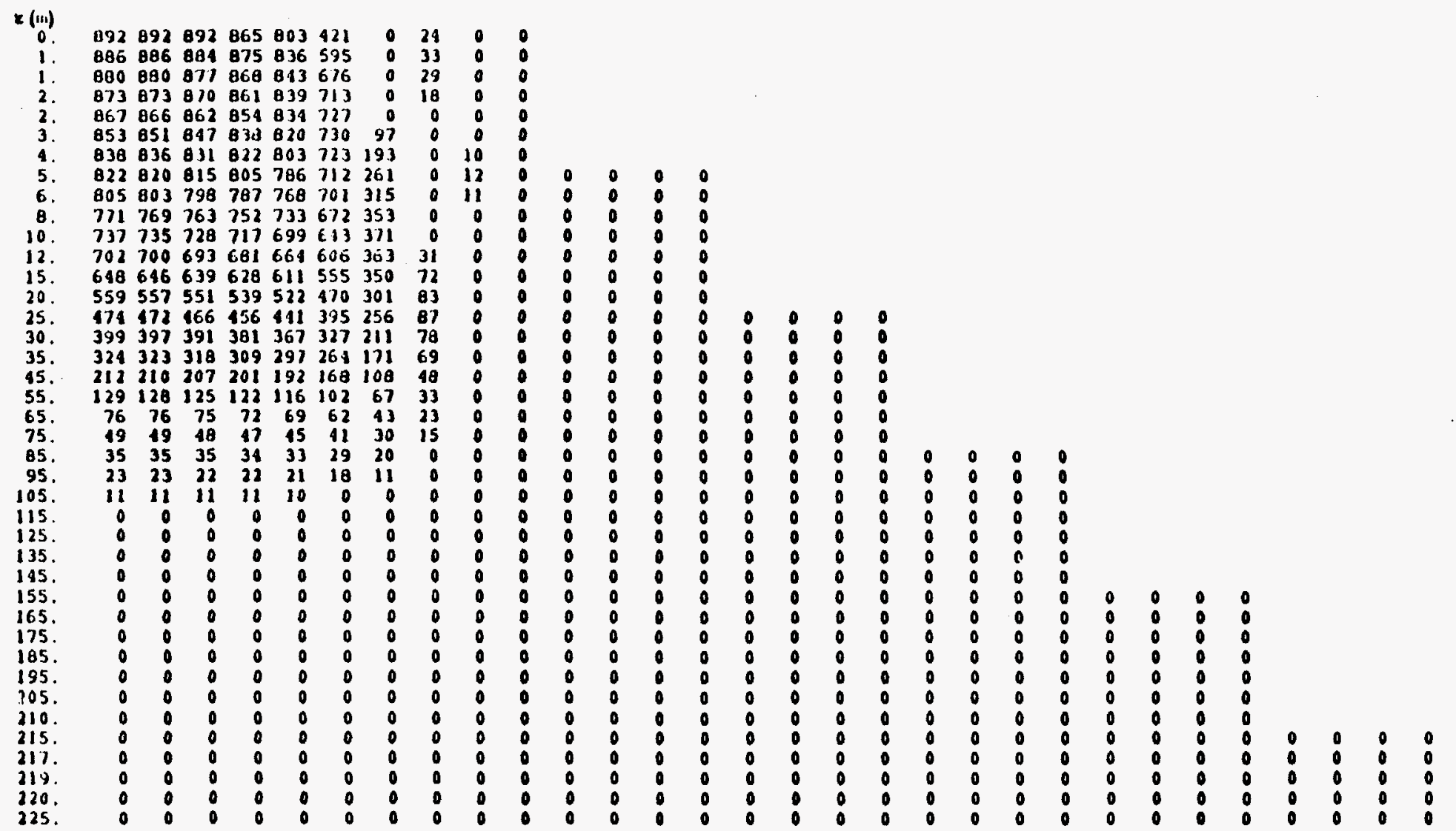

$\times$ (iii) $\quad 0.0 .51 .01 .5 \quad 2 \quad 3 \quad 5 \quad 7 \quad 10 \quad 15 \quad 20 \quad 25 \quad 30 \quad 40 \quad 50 \quad 60 \quad 70 \quad 80 \quad 90100110120130140150160170180190200$ 
Duc $613: 591906$ conout Pays 1

Longltidinal Dlspersivity (ii) $=1.0$

Tralsserse Dlsporalvity (in) $=0.1$

Ilius SInce Purpling Bugan $=1090$. days

Tines since Arrivel of Candirle Tritlum at Rapt-2s = 251.days

plcin/mi 1.0

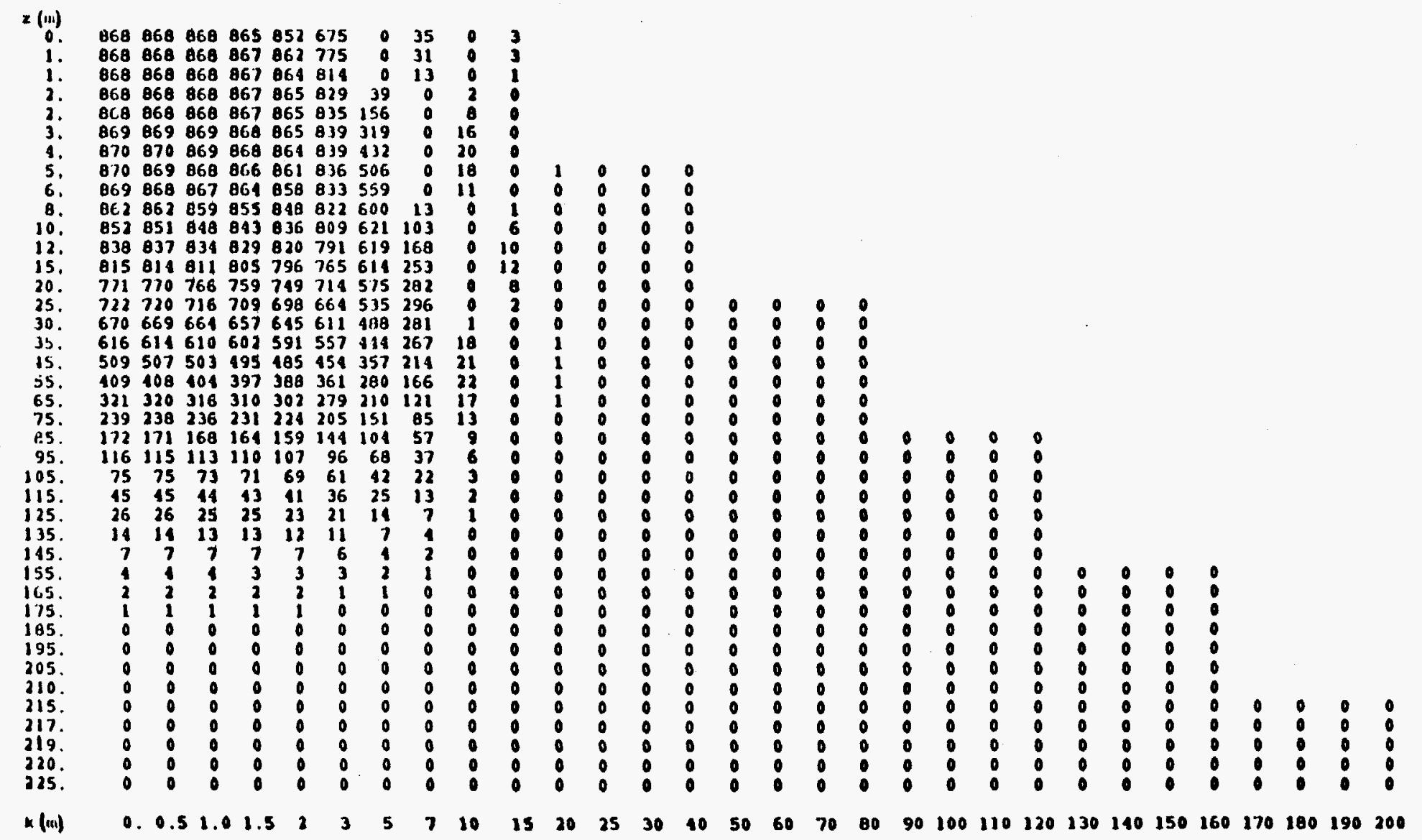




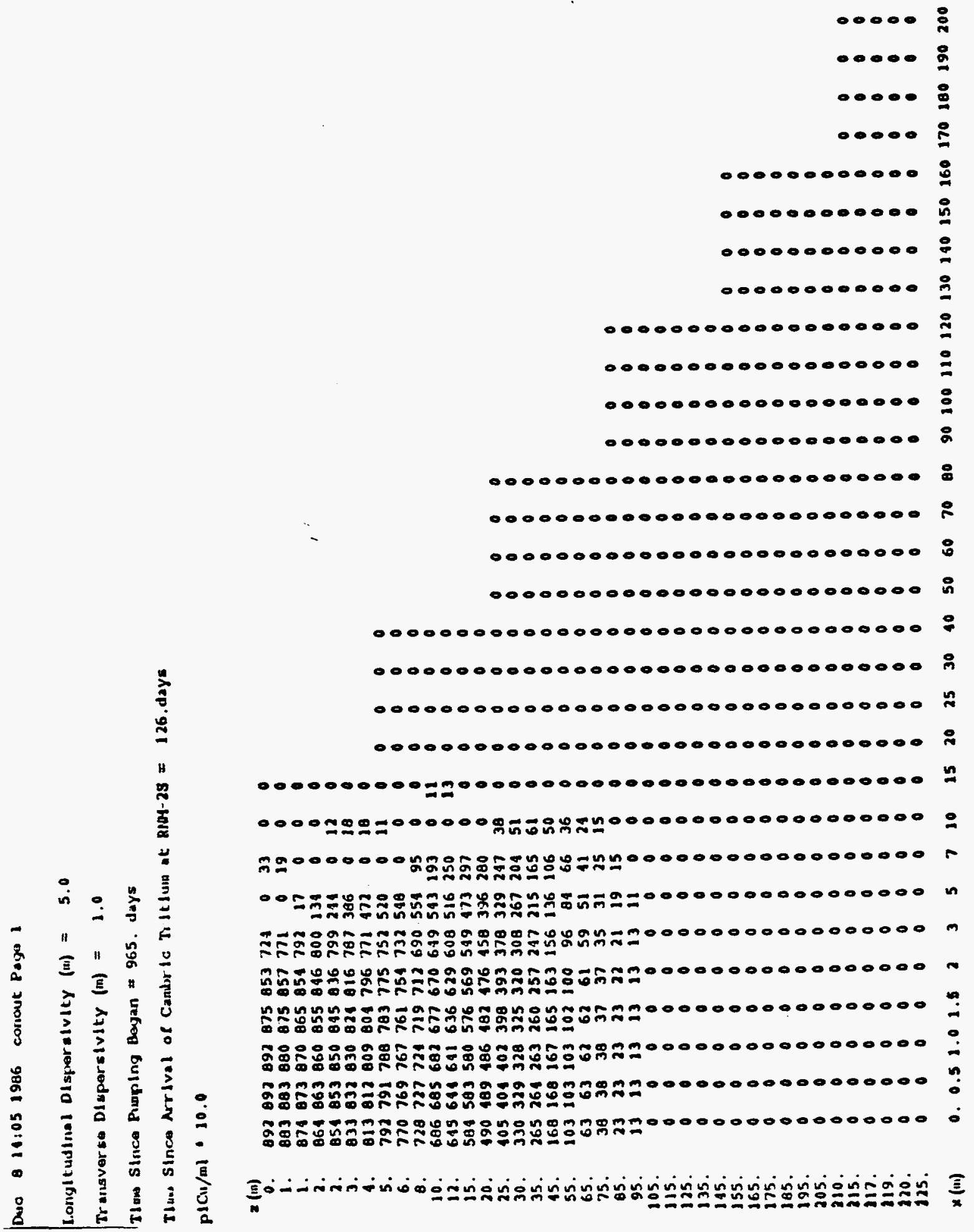




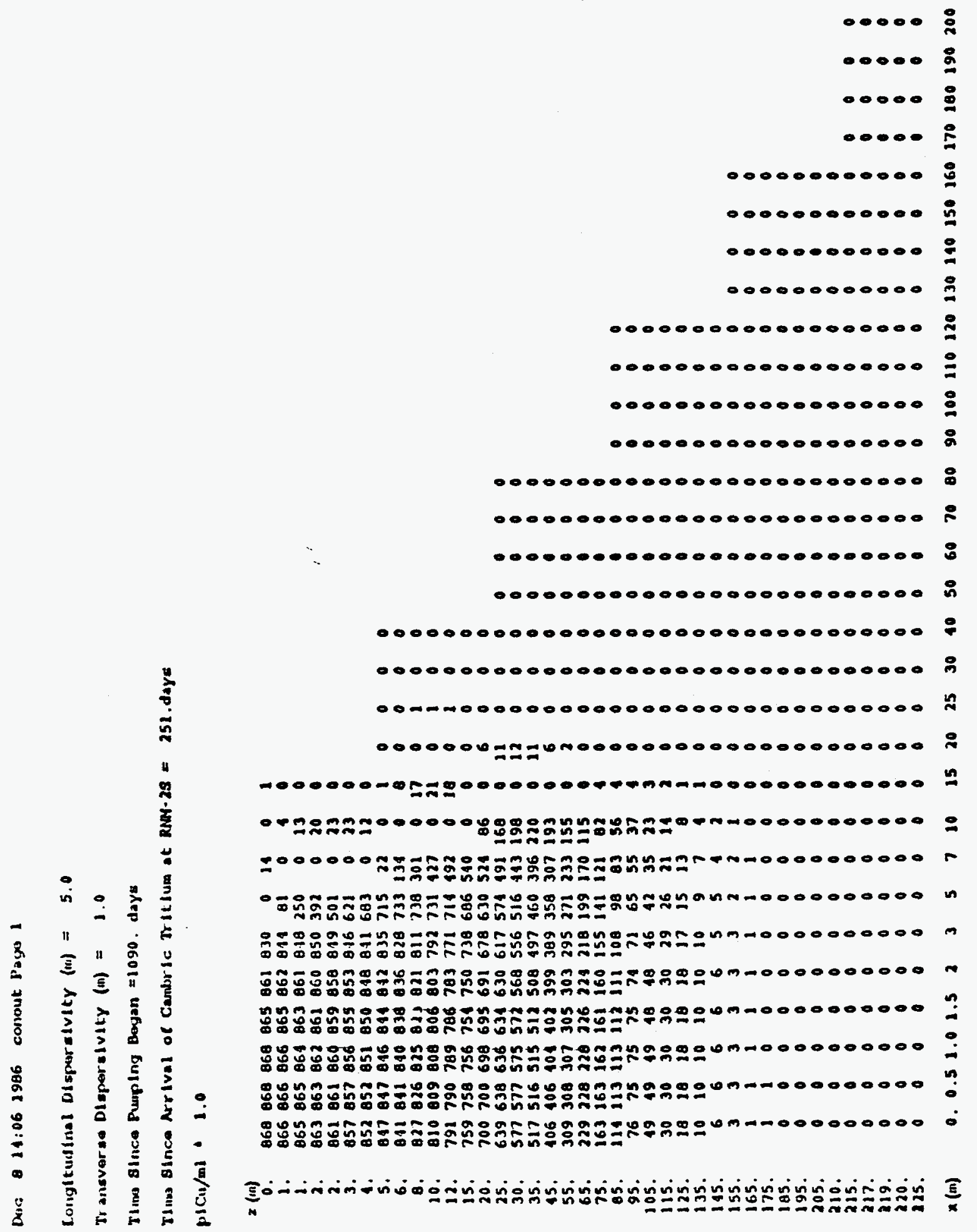




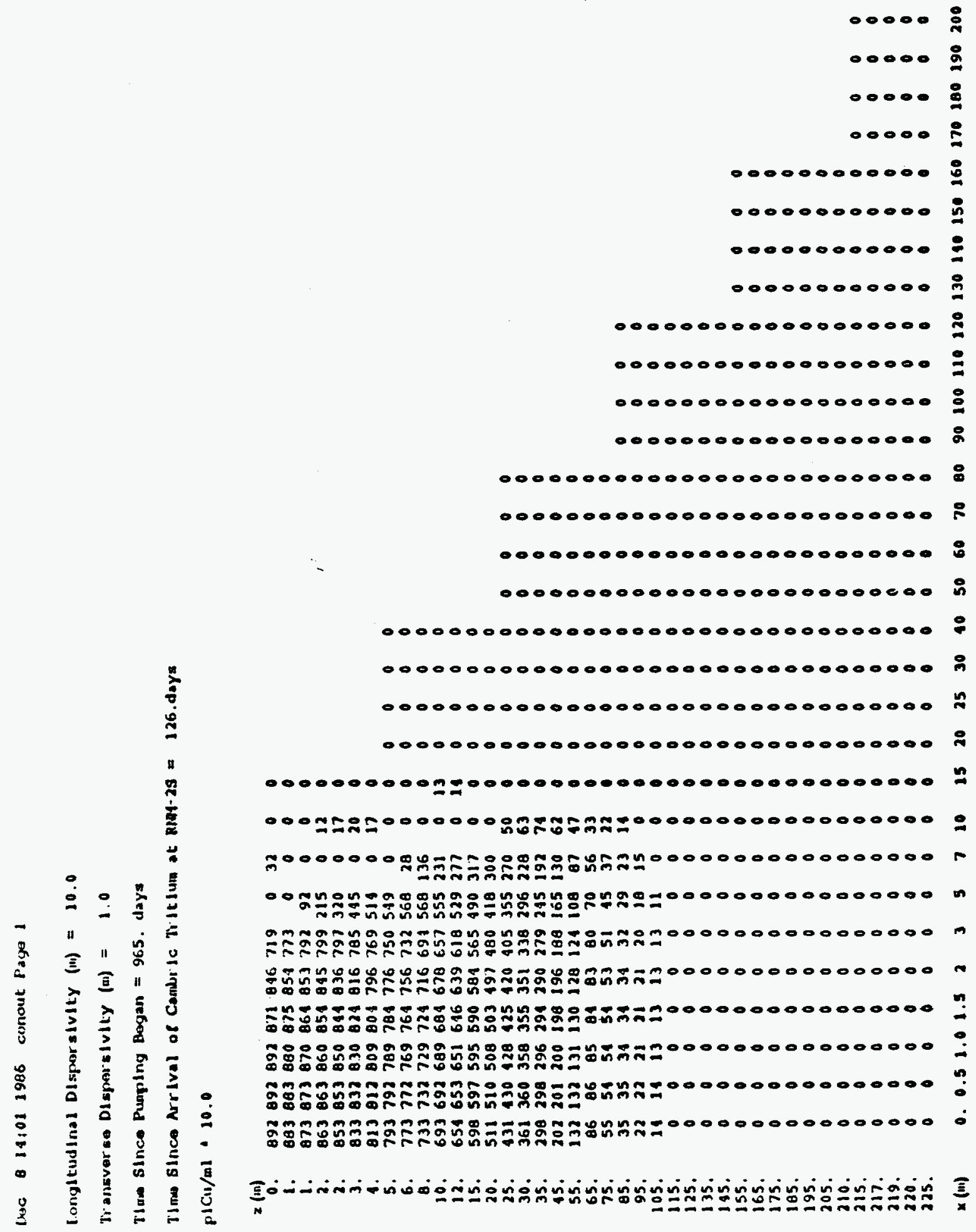




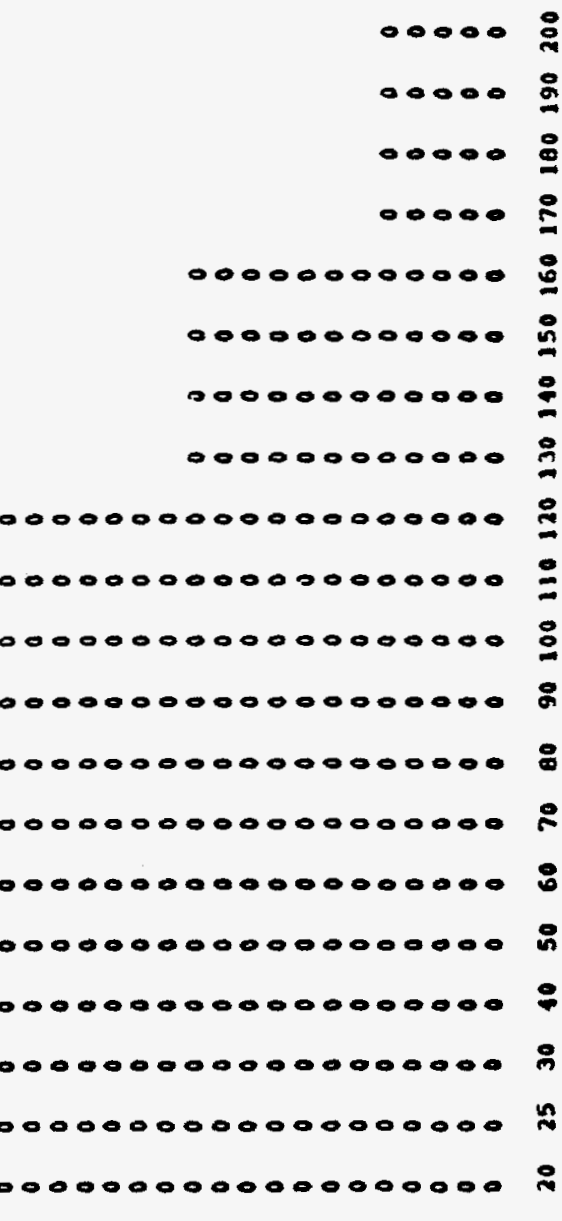

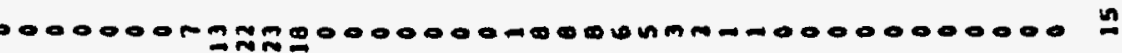

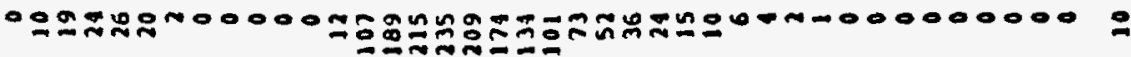

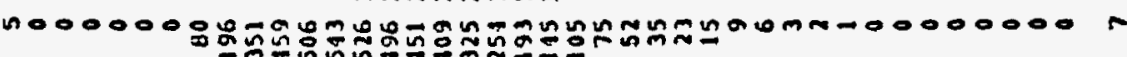

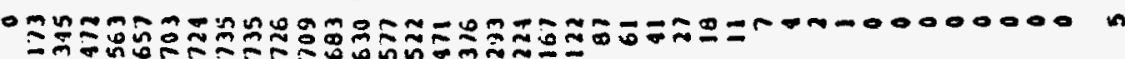
㝵ニニニニニ 由 由

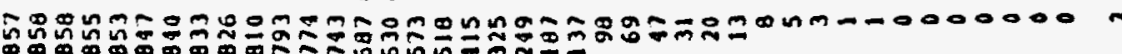

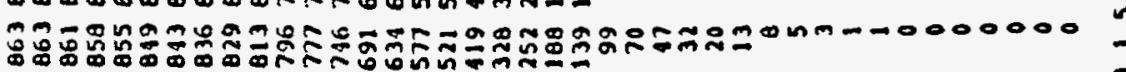

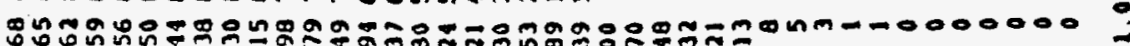

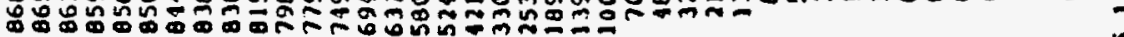

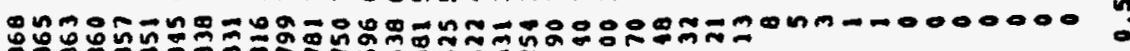

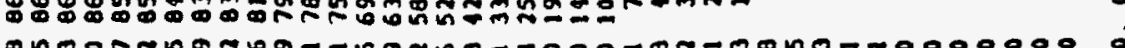

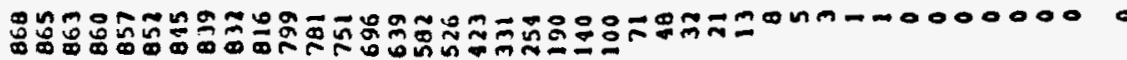

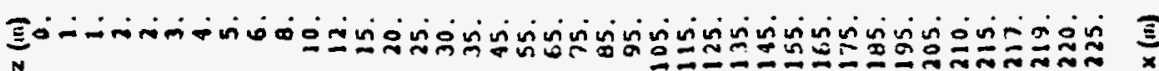




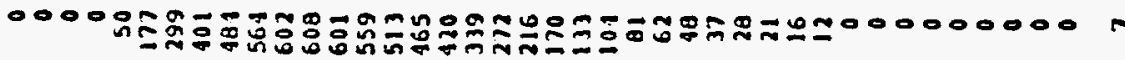

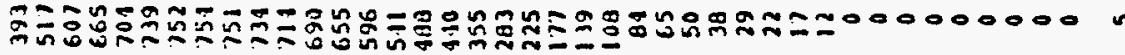

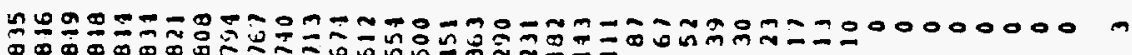

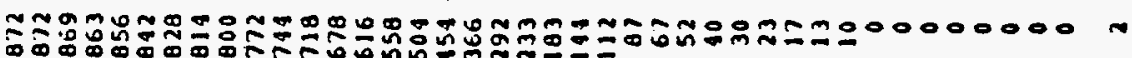

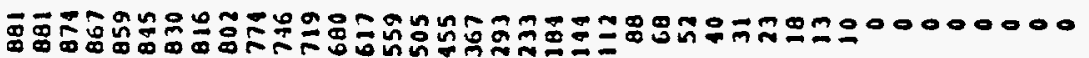

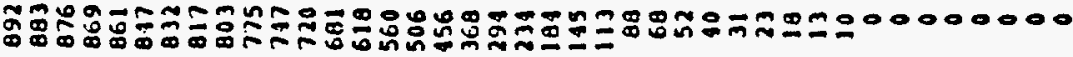

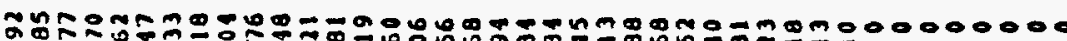

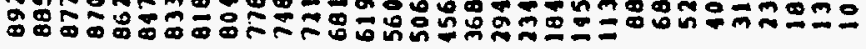

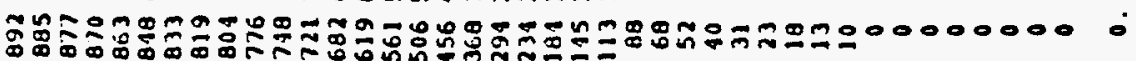
三о- - 
Whe 14:0s 19u6 conout Pachs I

longltudinal plsporstivity (m) $=100.0$

Transverse Disproralvity (ai) $=10.0$

Thua Since Purpling Bogan $=1090$. disys

Tilie Sluce Arrival of Canbric Tiftlum at RIM-2S = 251.day

plcu/al - 1.0

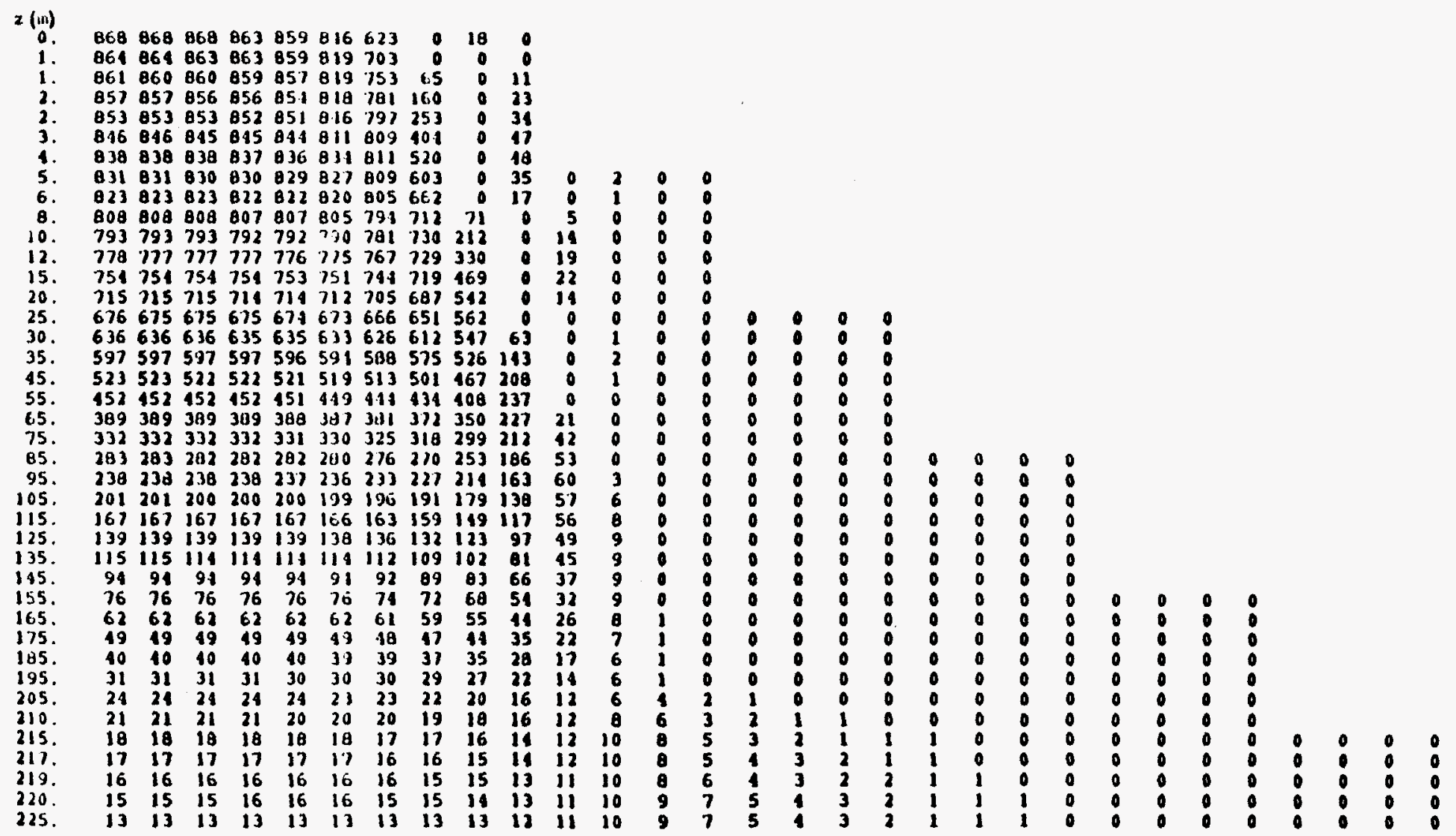

$x($ (ii) 


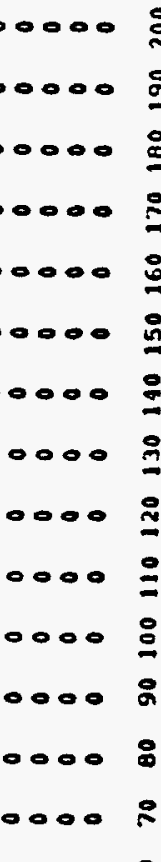

$00000000000000000000000000 \%$

00000000000000000000000000 i

000000000000000000000000000000000 ?

000000000000000000000000000000000 ค

000000000000000000000000000000000 N

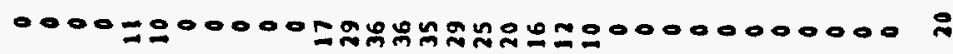

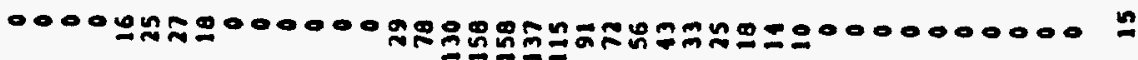

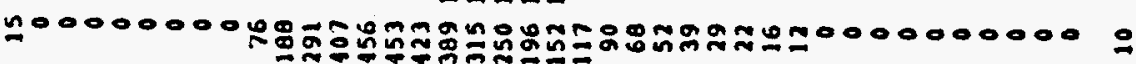

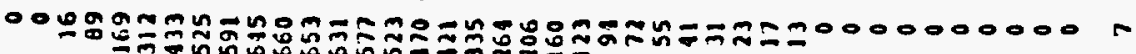

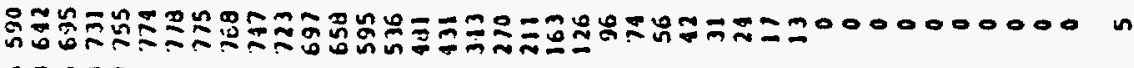

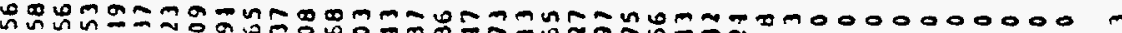
の

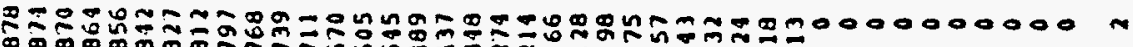

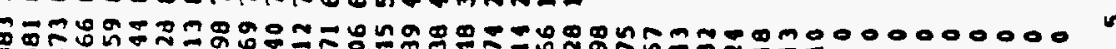

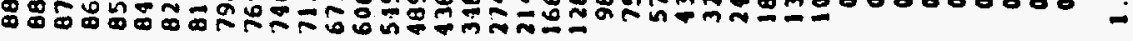

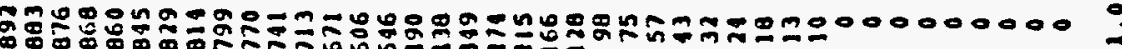

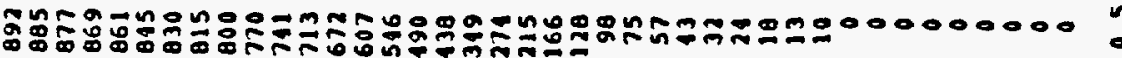

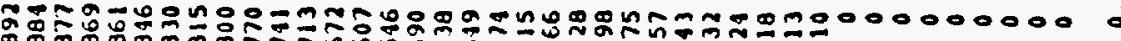

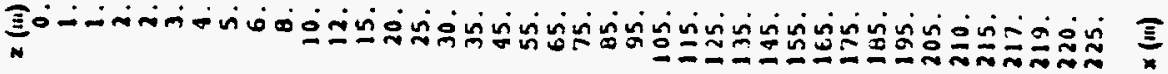


Dise 8 14:04 1986 conout Bup 1

Iongltusimal Dispersivity (Ii) $=100.0$

Ti ansuarse Disporsivity $(\omega)=30.0$

Tino Since Purying Bugan $=1090$. days

Tines Since Arrival of Canbi fo Ti lthlum at RRM- $25=251$.days

picu/wl 1.0

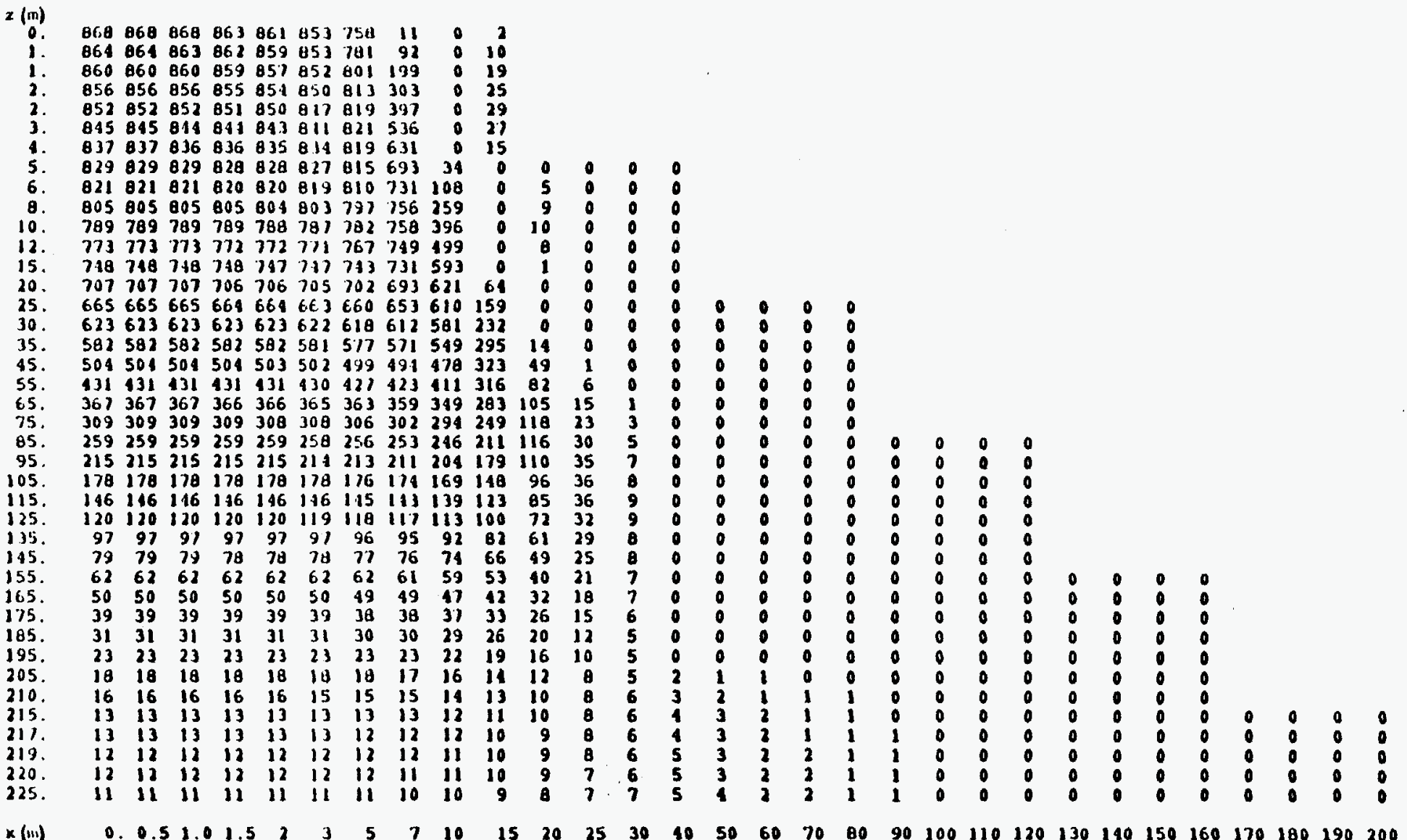


Appendix L

Sensitivity of solution to changes in molecular diffusion coefficient 


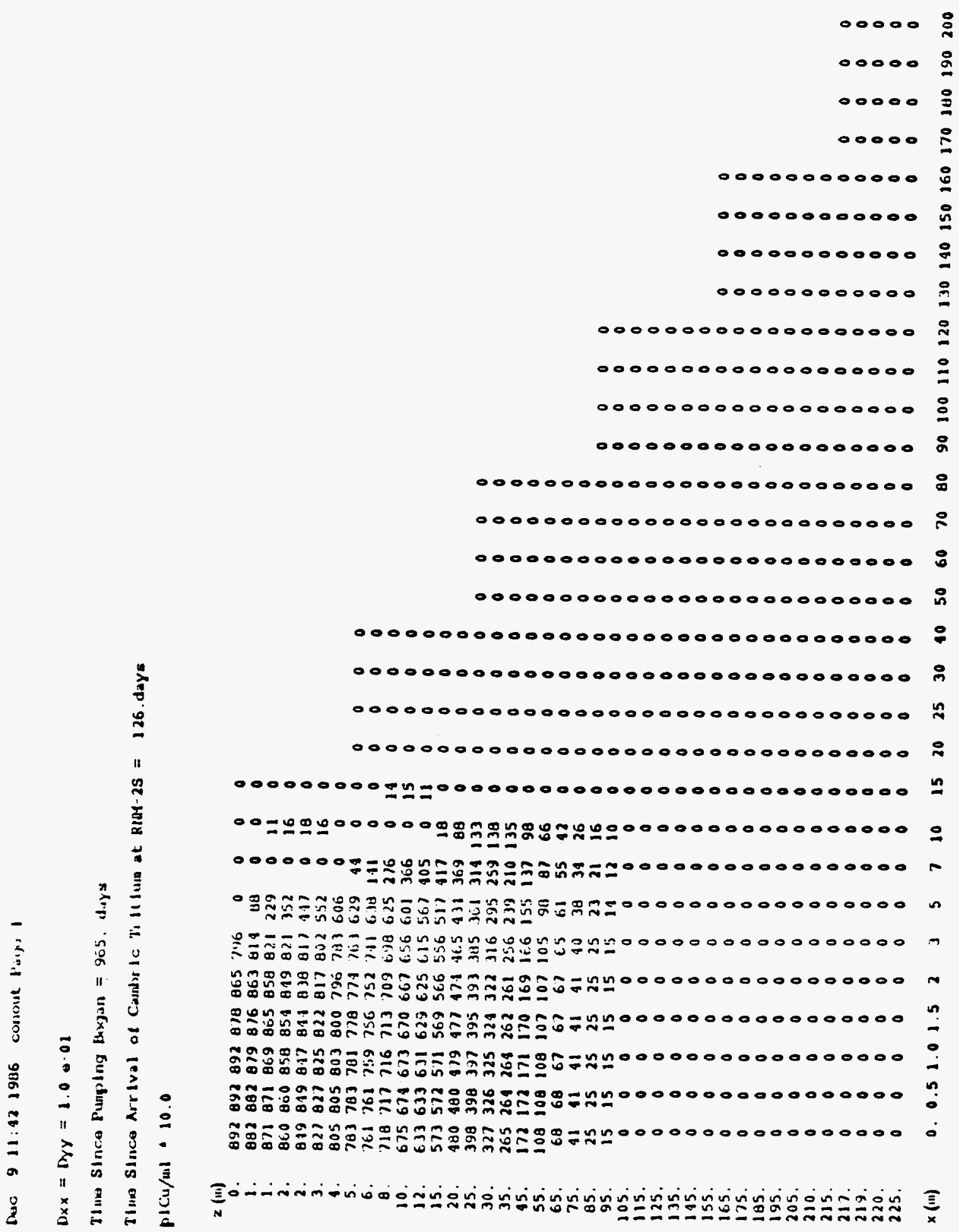




\section{Huc. $911: 131406$ consult tains 1}

$D_{x x}=0 y y=1.0-01$

Tius Since Punpling Bugan $=10 y 0$. dixy

Tlwes Since Arrival of Cambr lc Trltlum at enes-2S = 251. days

plcu/ml 1.0

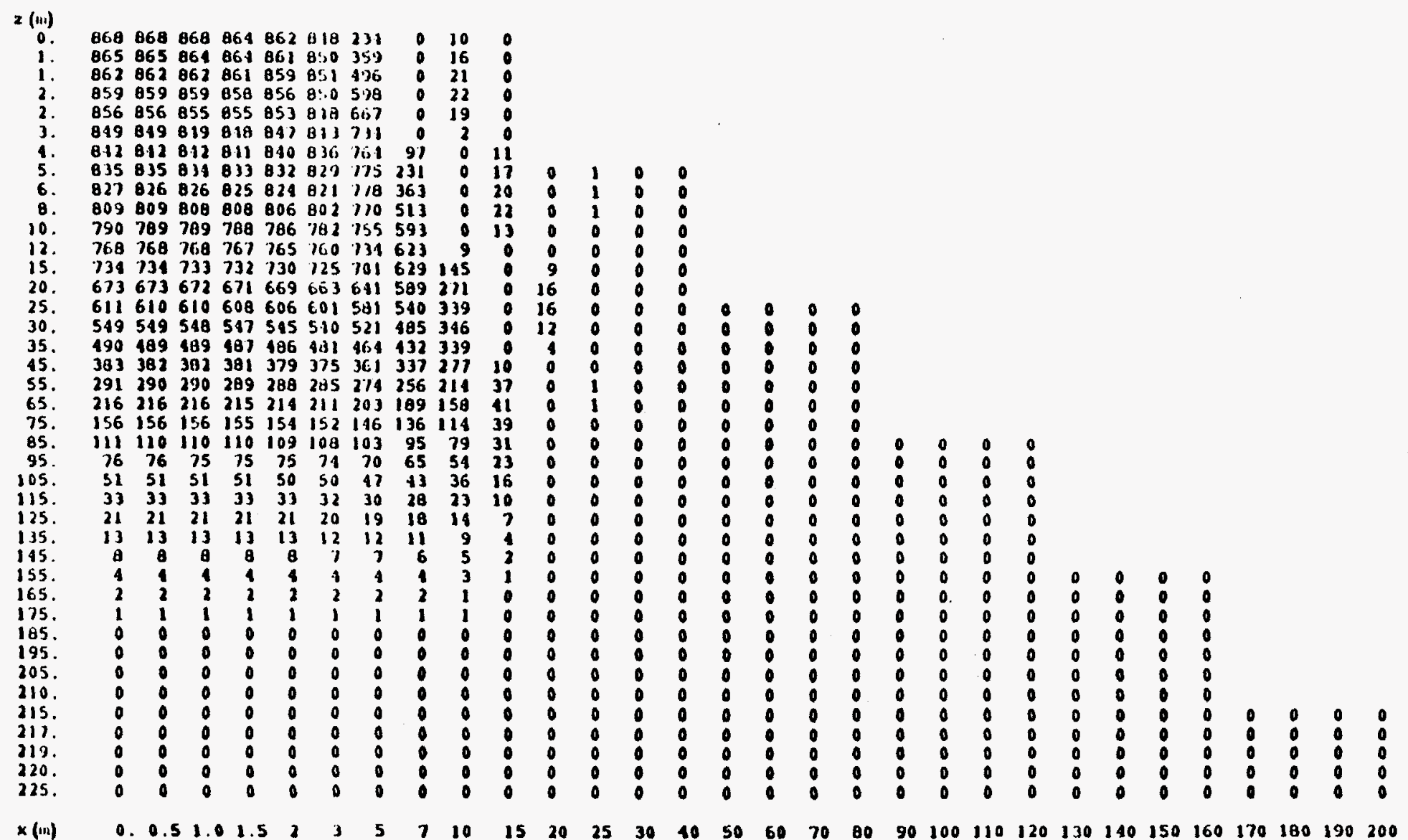




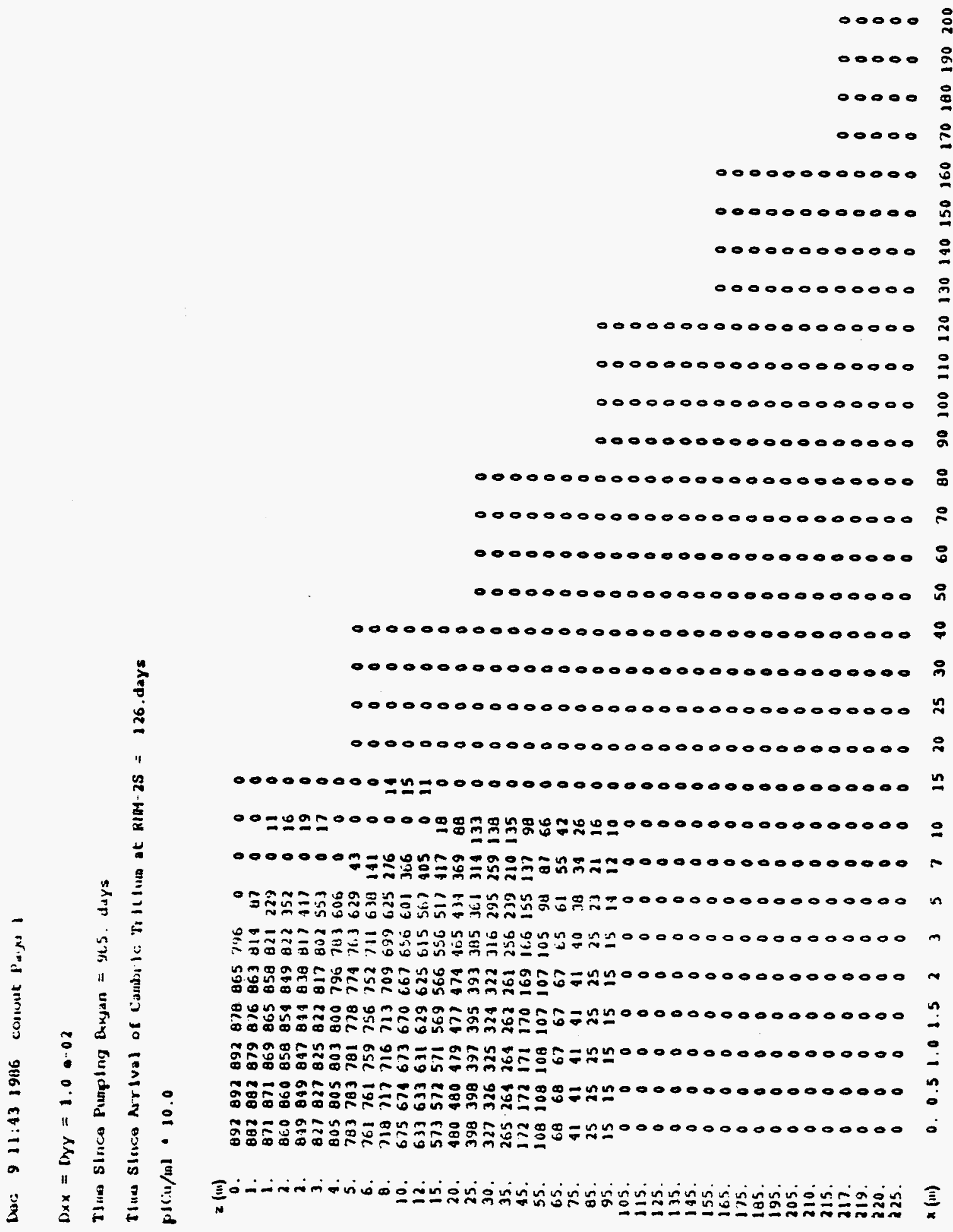


Inac 911:451986 conout b'as: 1

$$
D_{x x}=D_{Y Y}=1.00 .02
$$

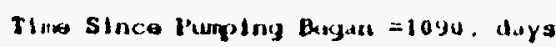

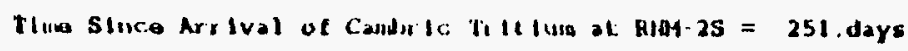

plcu/al 1.0

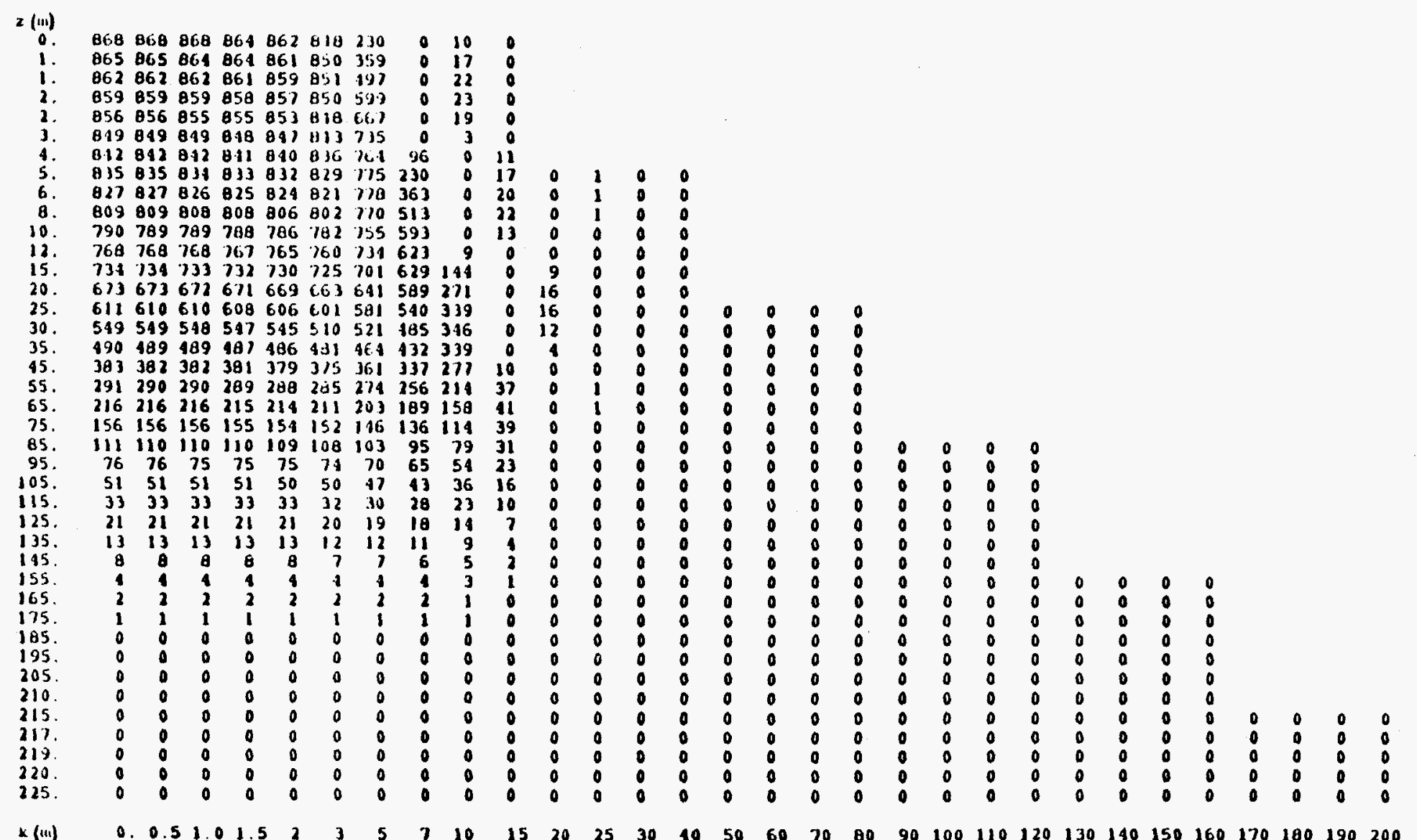




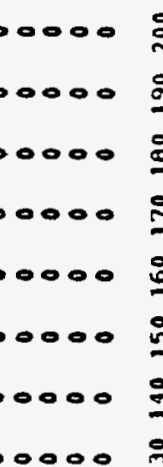

0000000000000000000

$0000000000000000000 ?$

0000000000000000000 :

0000000000000000000 g

000000000000000000000000008

00000000000000000000000000 ?

00000000000000000000000000 9

00000000000000000000000000 i

$000000000000000000000000000000000 \%$

$\sum_{\substack{0 \\ 0}}^{0}$

$000000000000000000000000000000000 \mathrm{~m}$

000000000000000000000000000000000 n

$000000000000000000000000000000000 \%$

000000000 ñ0000000000000000000000000000

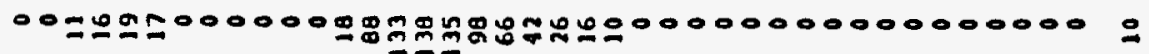

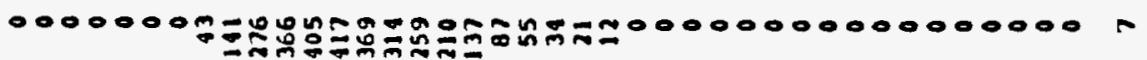

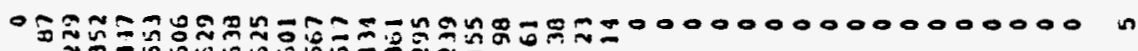

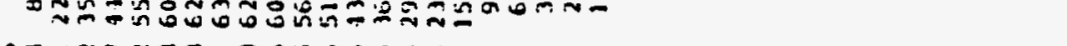

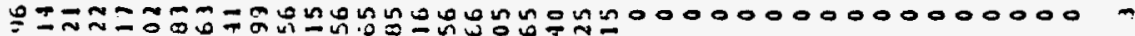

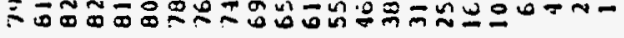

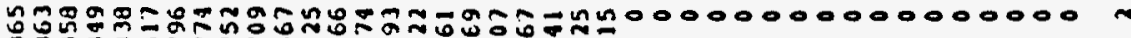


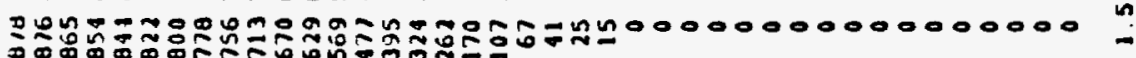

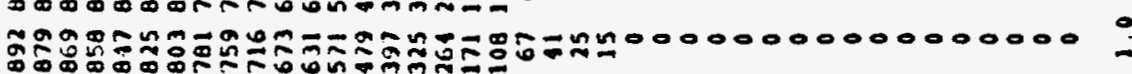

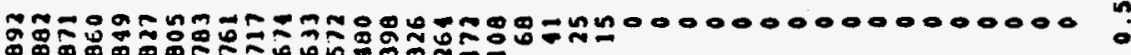

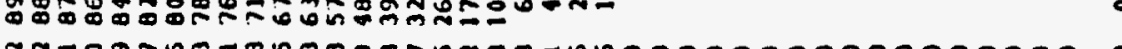

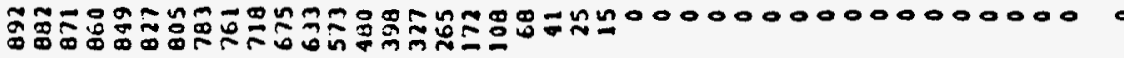

झ-수 


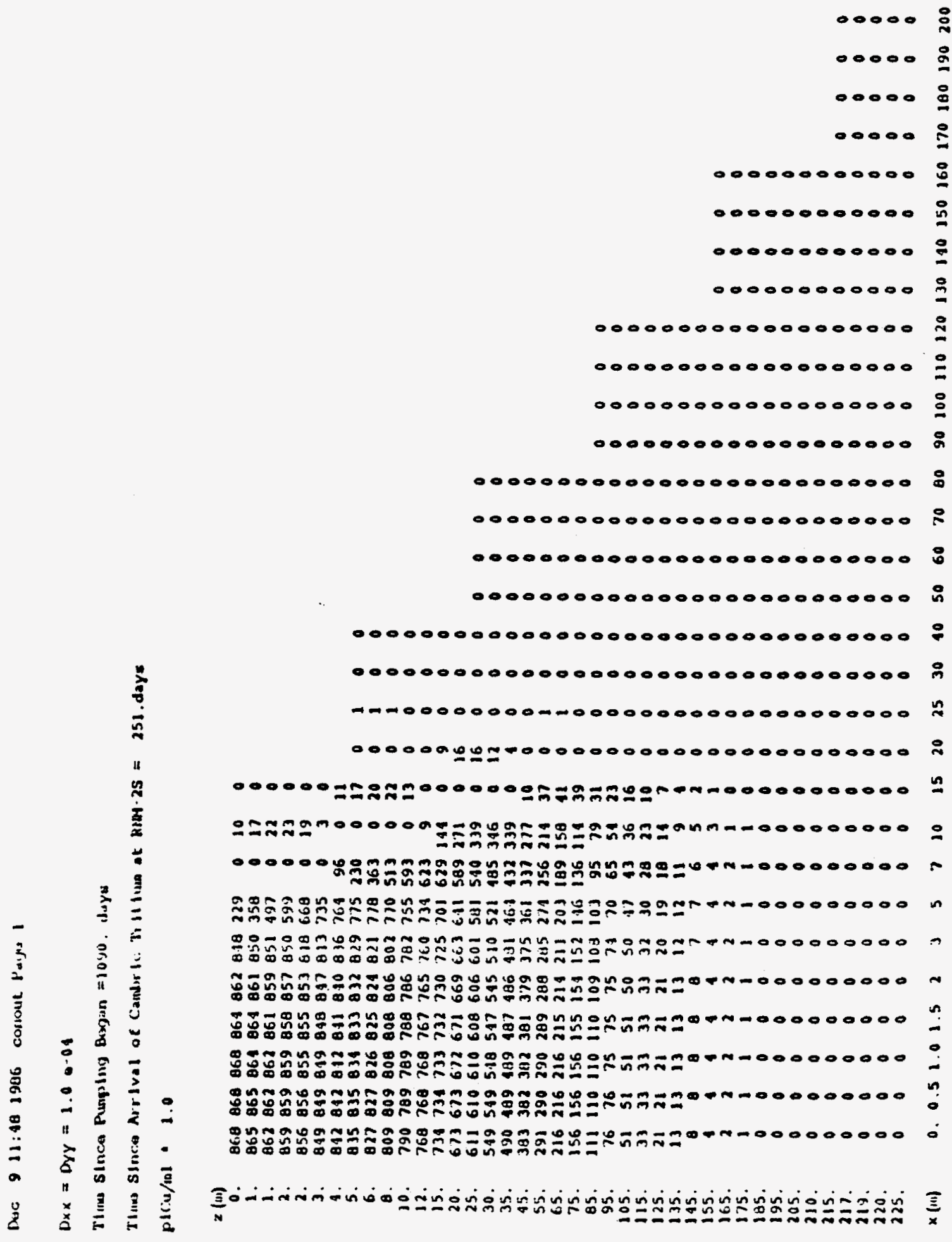




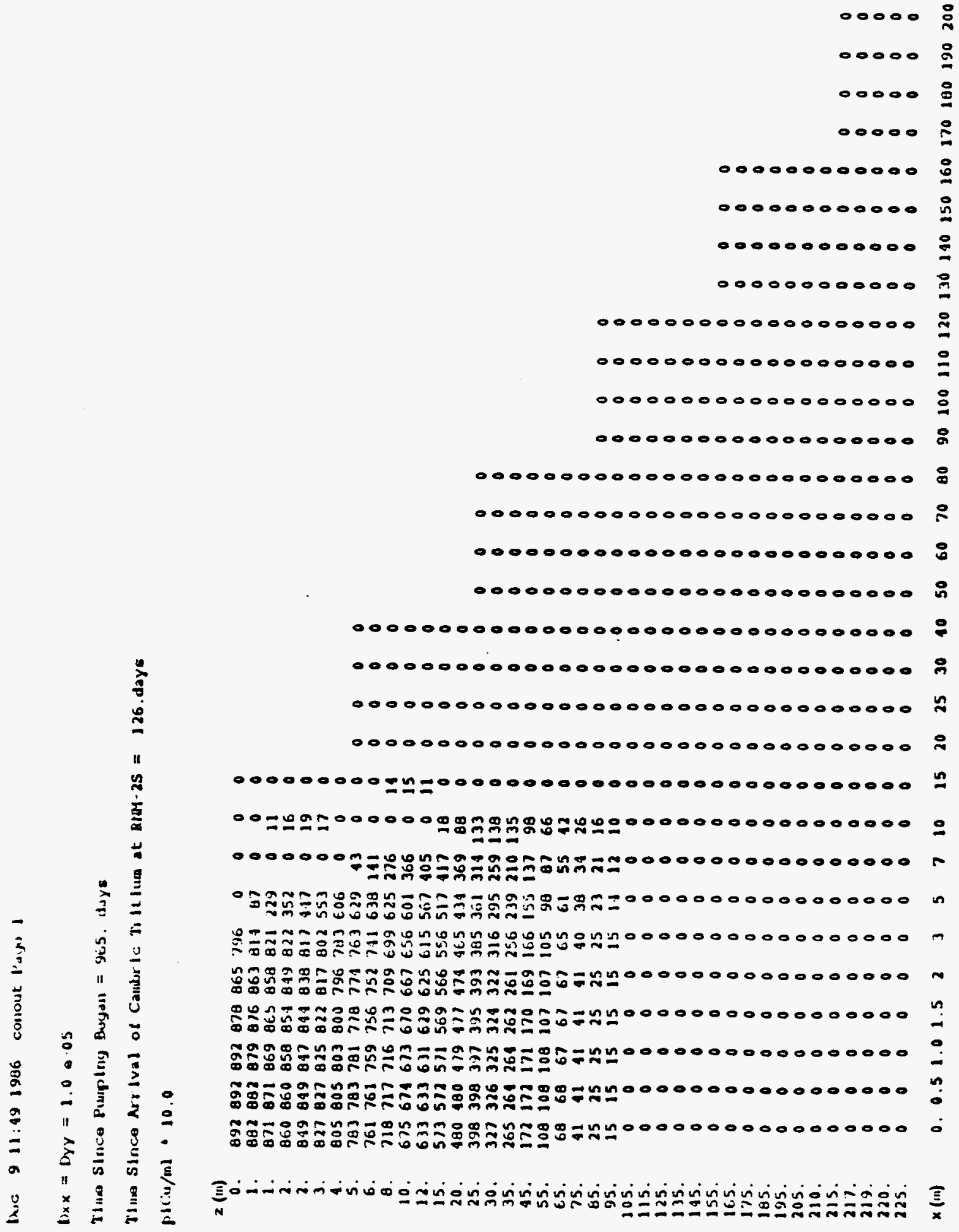




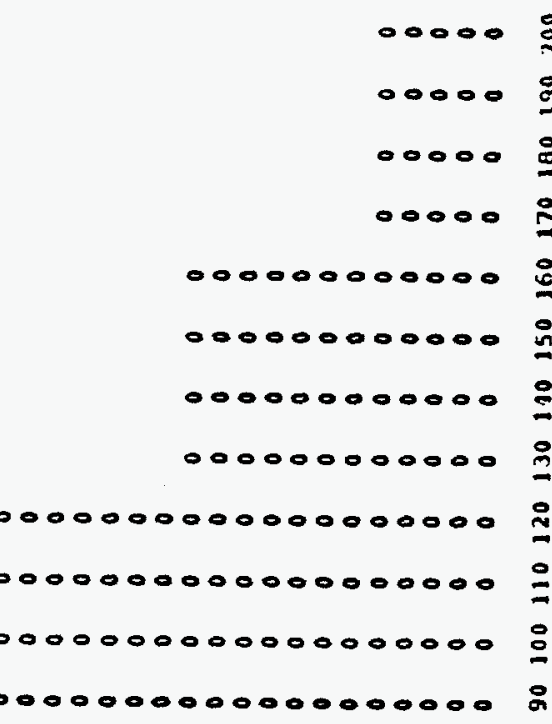

000000000000000000000000008

$00000000000000000000000000 \%$

00000000000000000000000000 :

00000000000000000000000000 in

$000000000000000000000000000000000 \%$

000000000000000000000000000000000 .

$-0-00000000-100000000000000000000 \stackrel{n}{n}$

000000.02000000000000000000000000 9

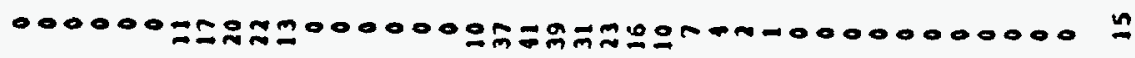

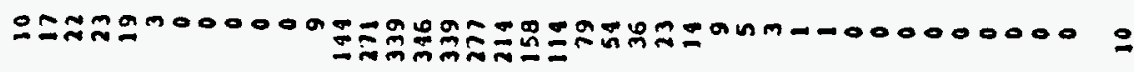

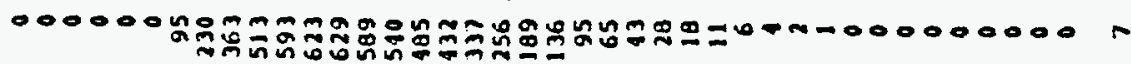

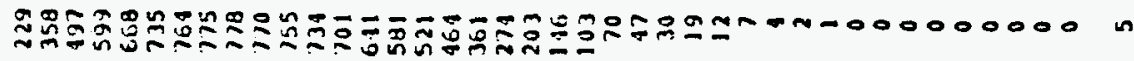

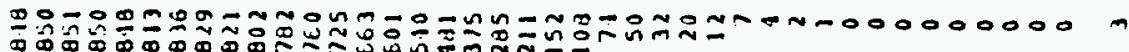

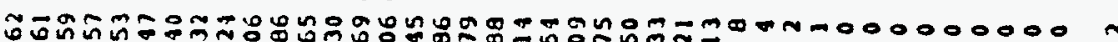

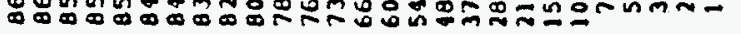

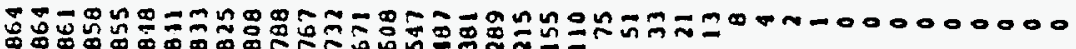

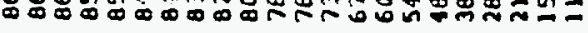

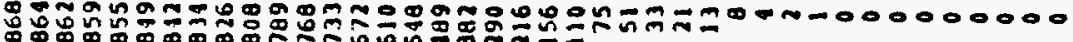

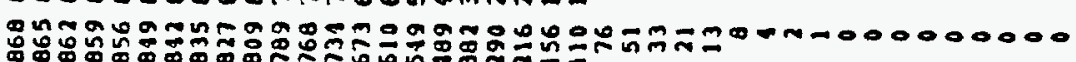

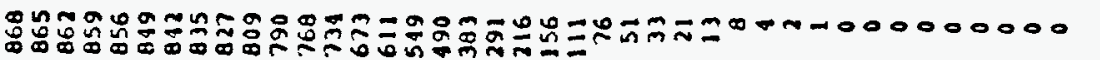
$\stackrel{8}{9}$ 용 $\stackrel{8}{2}$

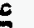

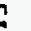

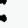

\section{ก} $?$ n

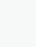

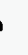
(n) n 
Appendix M

Simulated distribution of tritium

M-1 


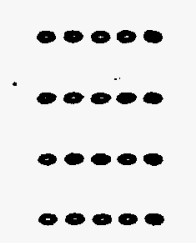

0000000000009

00000000000

000000000000?

000000000000 잉

$0000000000000000000 \%$

000000000000000000099

00000000000000000009

00000000000000000008

00000000000000000000000000 8

$00000000000000000000000000 \AA$

000000000000000000000000008

$00000000000000000000000000 \mathrm{~h}$

000000000000000000000000000000000 ?

000000000000000000000000000000000 月

000000000000000000000000000000000 h

000000000000000000000000000000000 (

0000000000000000000000000000000000000000 h

0000000000000000000000000000000000000000.9 0000000000 m9020000000000000000000000000 N

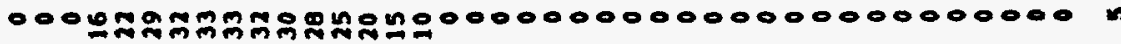

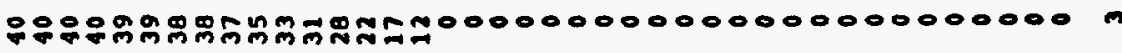

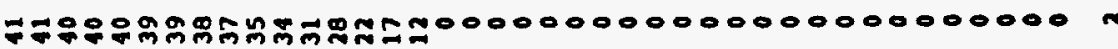

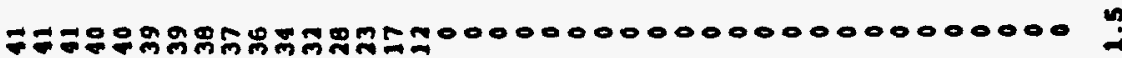

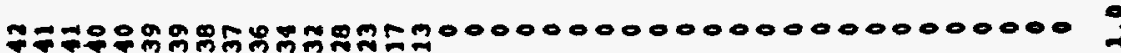

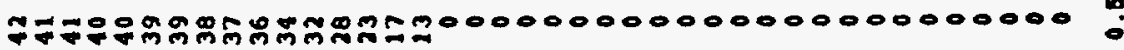

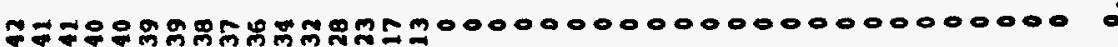

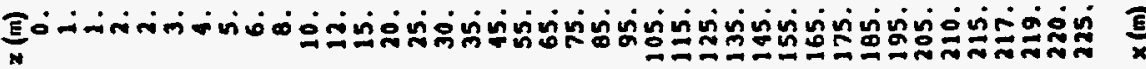


Nov $1316: 241986$ conout Pago 1

Run $=$ tpl

Time SInce Pumping began $=890$. daye

Time Since Arrival of Cambrle Tritlum at RNM2-5 51.deya

$\mathrm{plCu} / \mathrm{ml} \cdot 10.0$

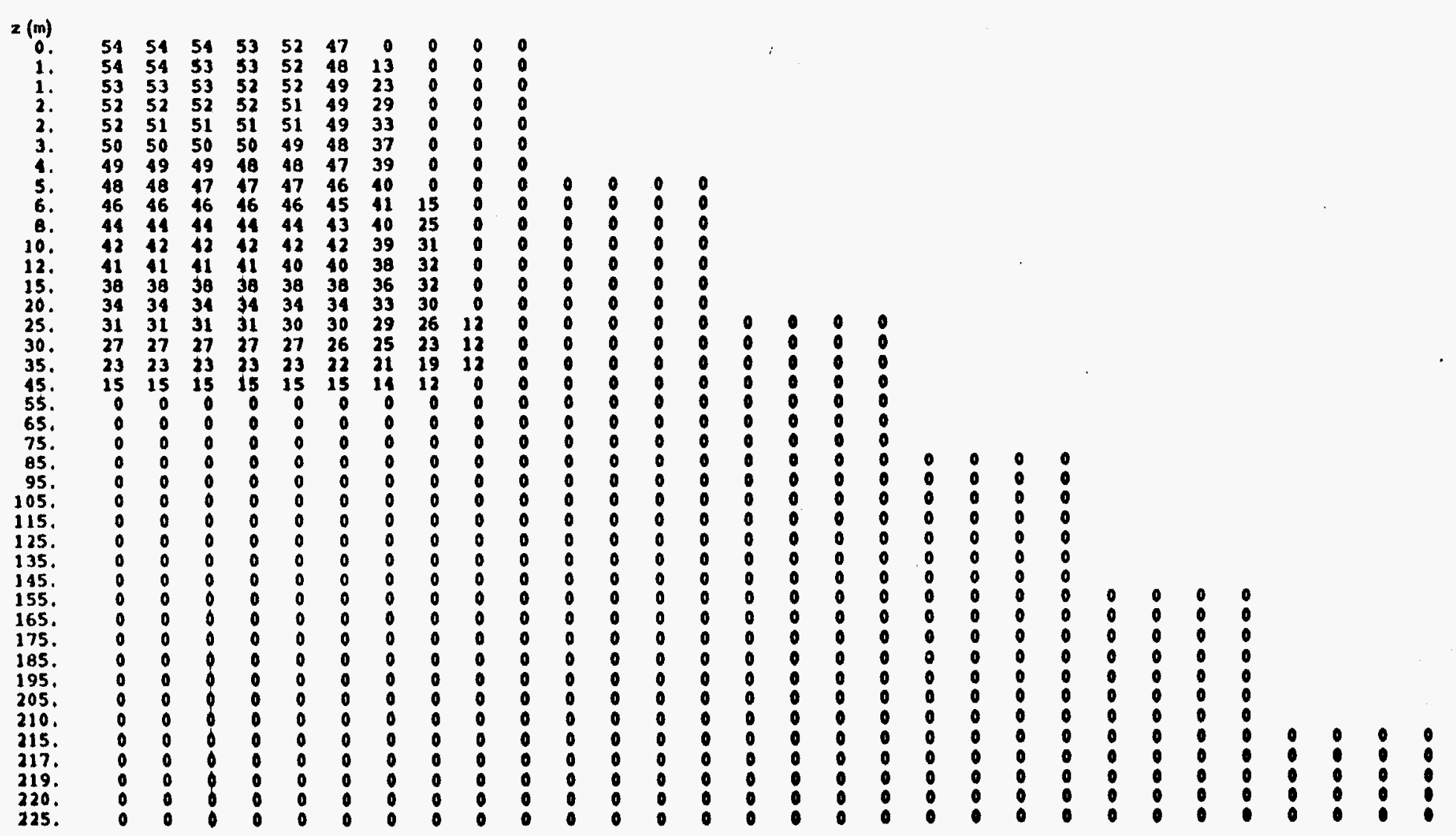

$x(m)$

$0.0 .51 .01 .5235 \% 10$

$15 \quad 20 \quad 25 \quad 30$

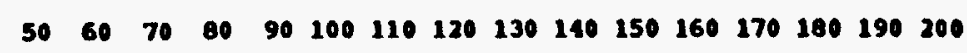


Nov 13 16:25 1986 conout Page 1

Run $=\operatorname{tp} 1$

Time Slnce Pumpling Began $=915$. daye

Time SInce Arrival of Cambric Tritlun at RNaz-8 76.dare

$\mathrm{plCu} / \mathrm{ml} \cdot 10.0$

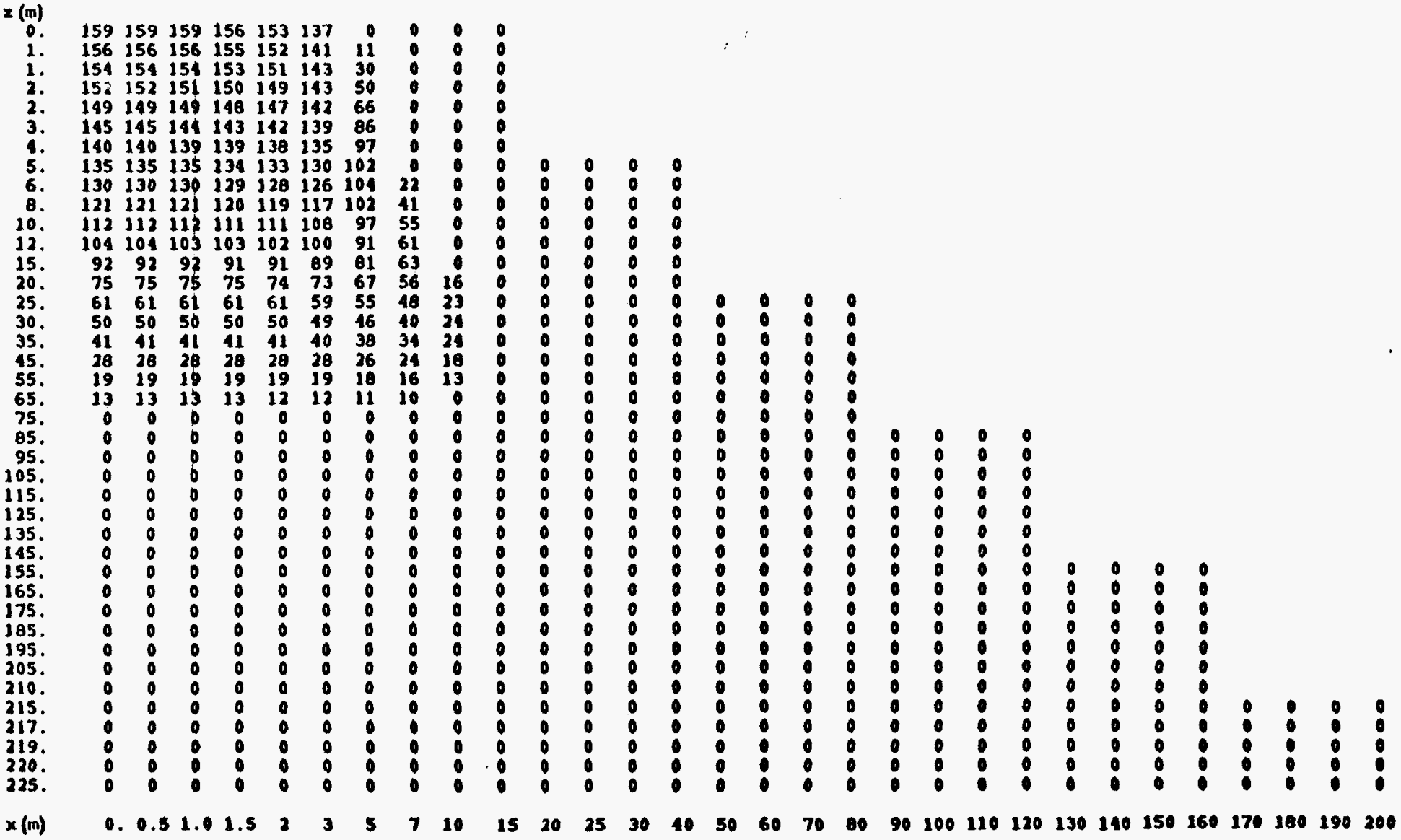



0000000000000000000000000000000009 000000000000000000000000000000000 i 000000000000000000000000000000000 in $000000000000000000000000000000000 \%$ 0000000000000000000000000000000000000000 "

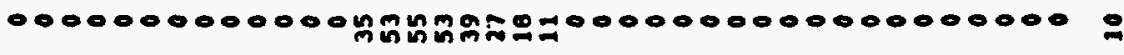

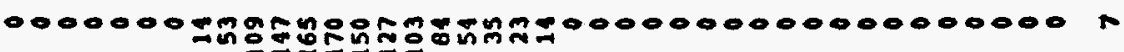

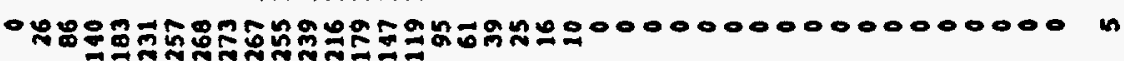
영유

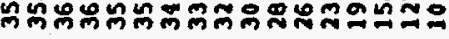

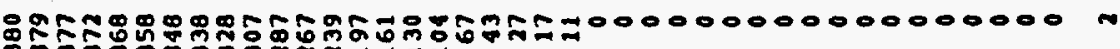

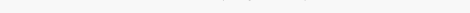

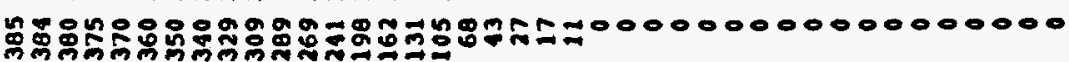

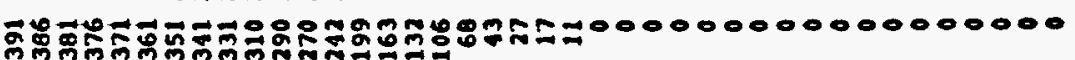

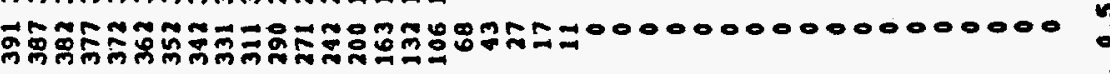

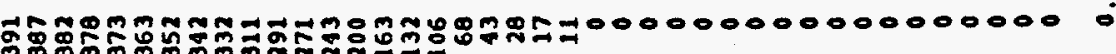

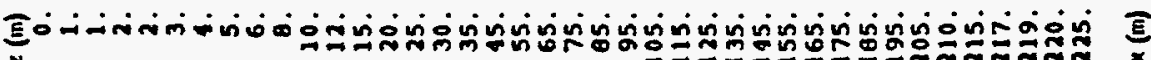




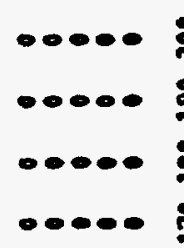

$-00000000008$

000000000000

000000000000 ?

-0000000000-8

$0000000000000000000 \%$

0000000000000000000

0000000000000000000

00000000000000000008

000000000000000000000000008

00000000000000000000000000 R

-000000000000000000000000?

00000000000000000000000000

000000000000000000000000000000000 ?

000000000000000000000000000000000 in

000000000000000000000000000000000 i

000000000000000000000000000000000 i

000000000 Inj-10000000000000000000000000000 h

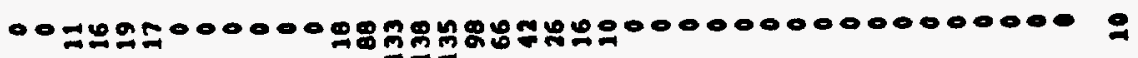

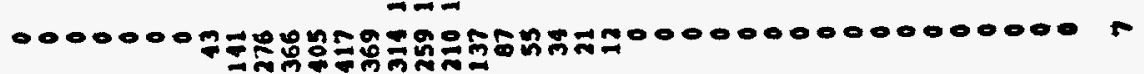

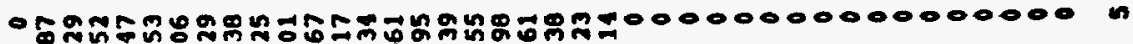

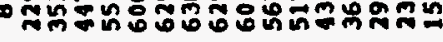

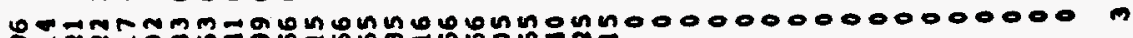

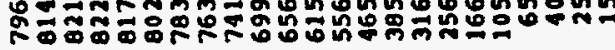

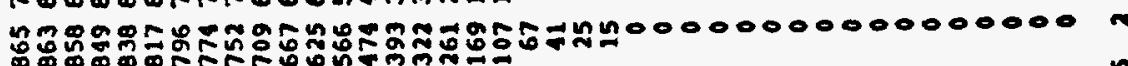

w

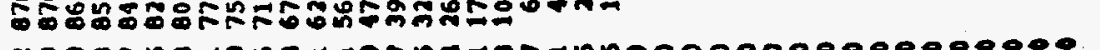

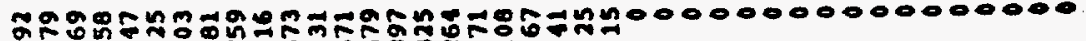

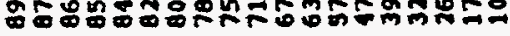

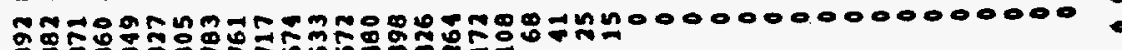

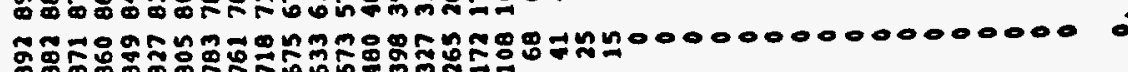

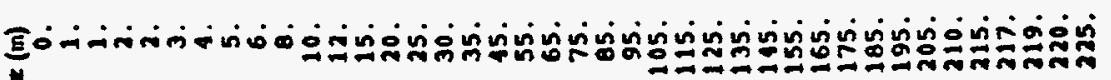




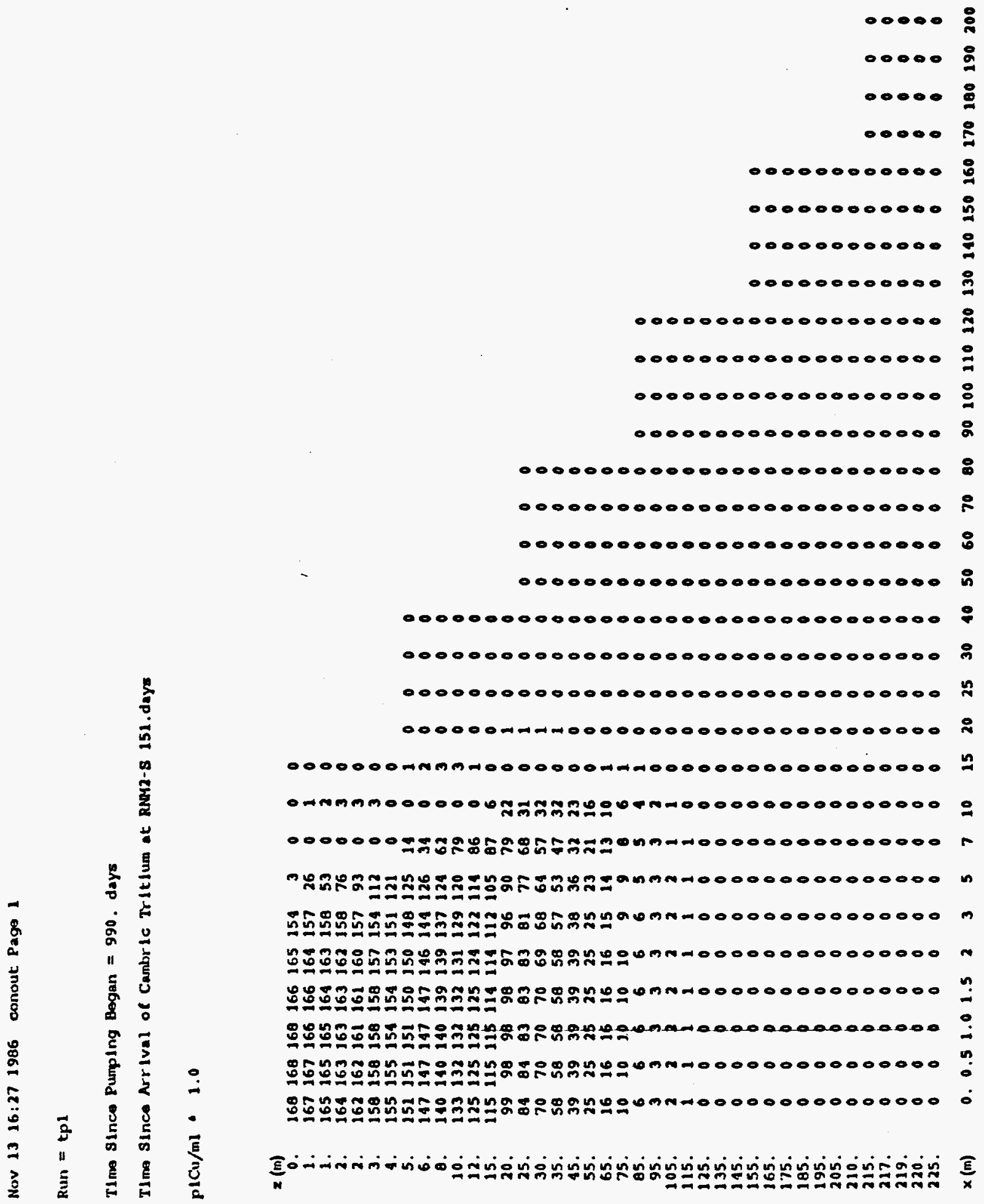


Nov 13 16:281986 conout Page 1

Run $=$ tp 1

TIne SInce Pumpling Began $=1015$. days

TIme SInce Arrival of Cambrle Ir It lum at RNa12-S 176.daye

pjCu/m1 1.0

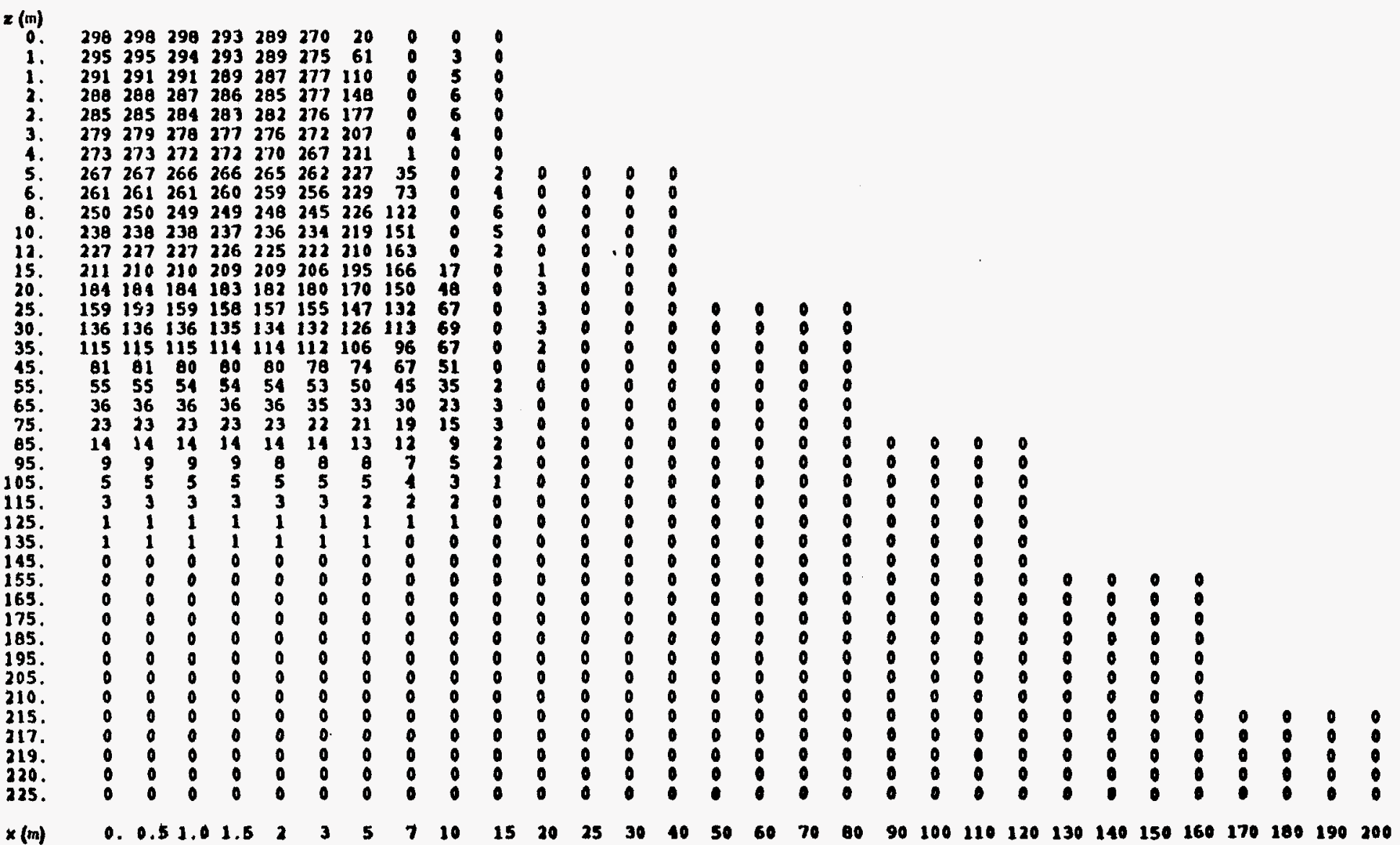




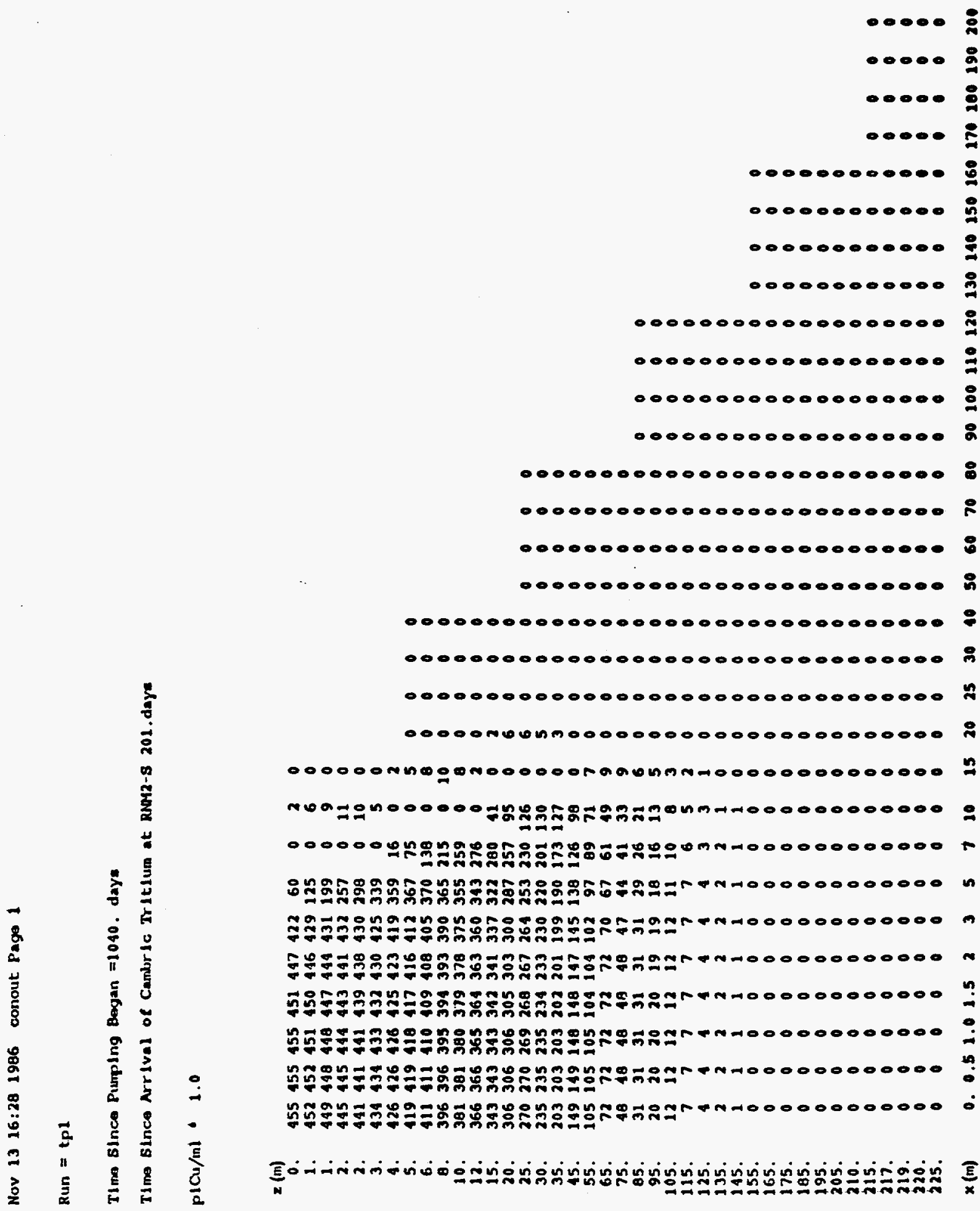




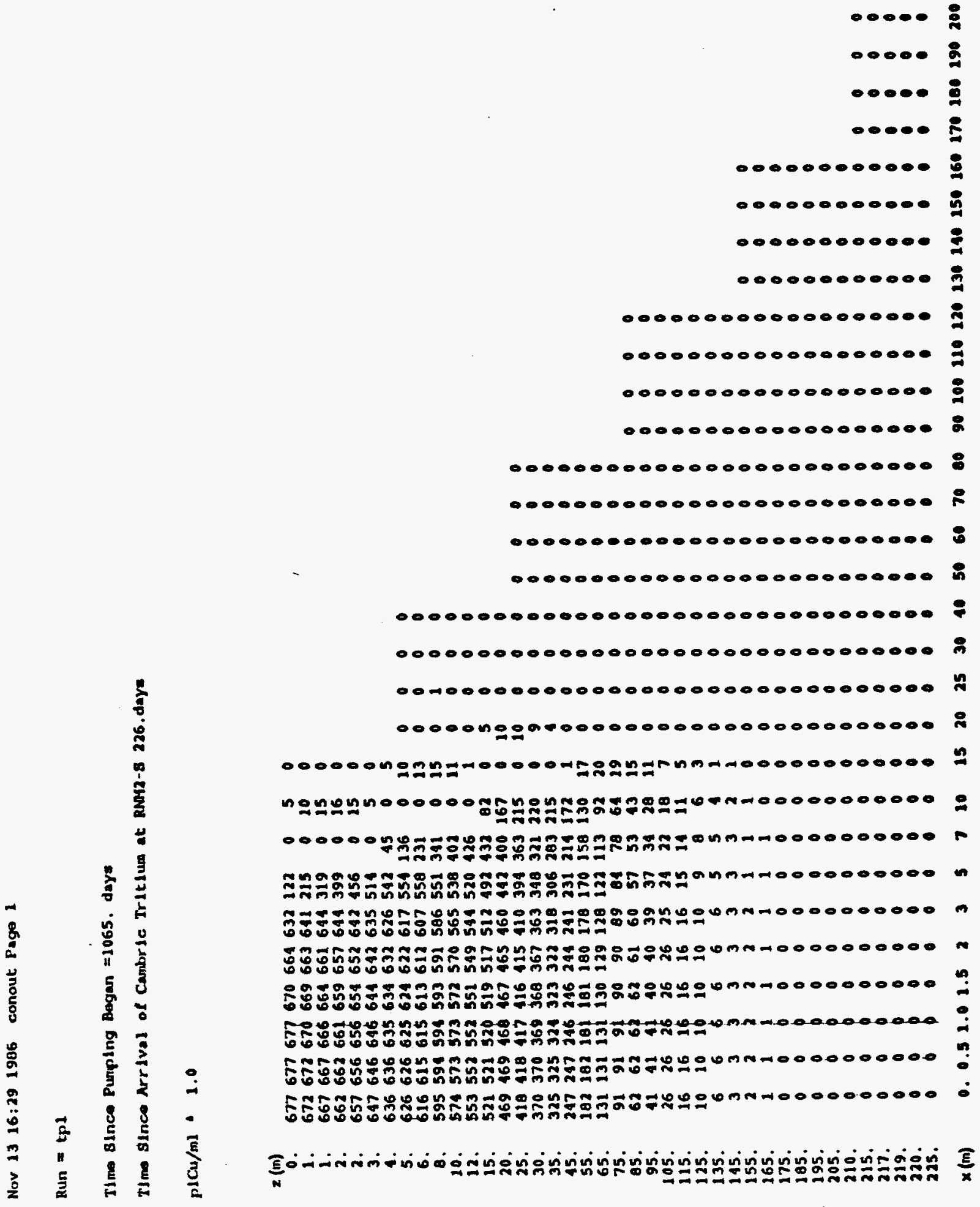

M-10 
oI $L s \quad r \quad s .10 .15 .0 .0$ 
Nov 13 17:04 1986 conout Page 1

Run $=t_{p}$

Time SInce Pumpling Degan =1115. days

Tium Since Arrival of Cambric Tittlum at RRH-2S 276.days

plcu/ml + 0.1

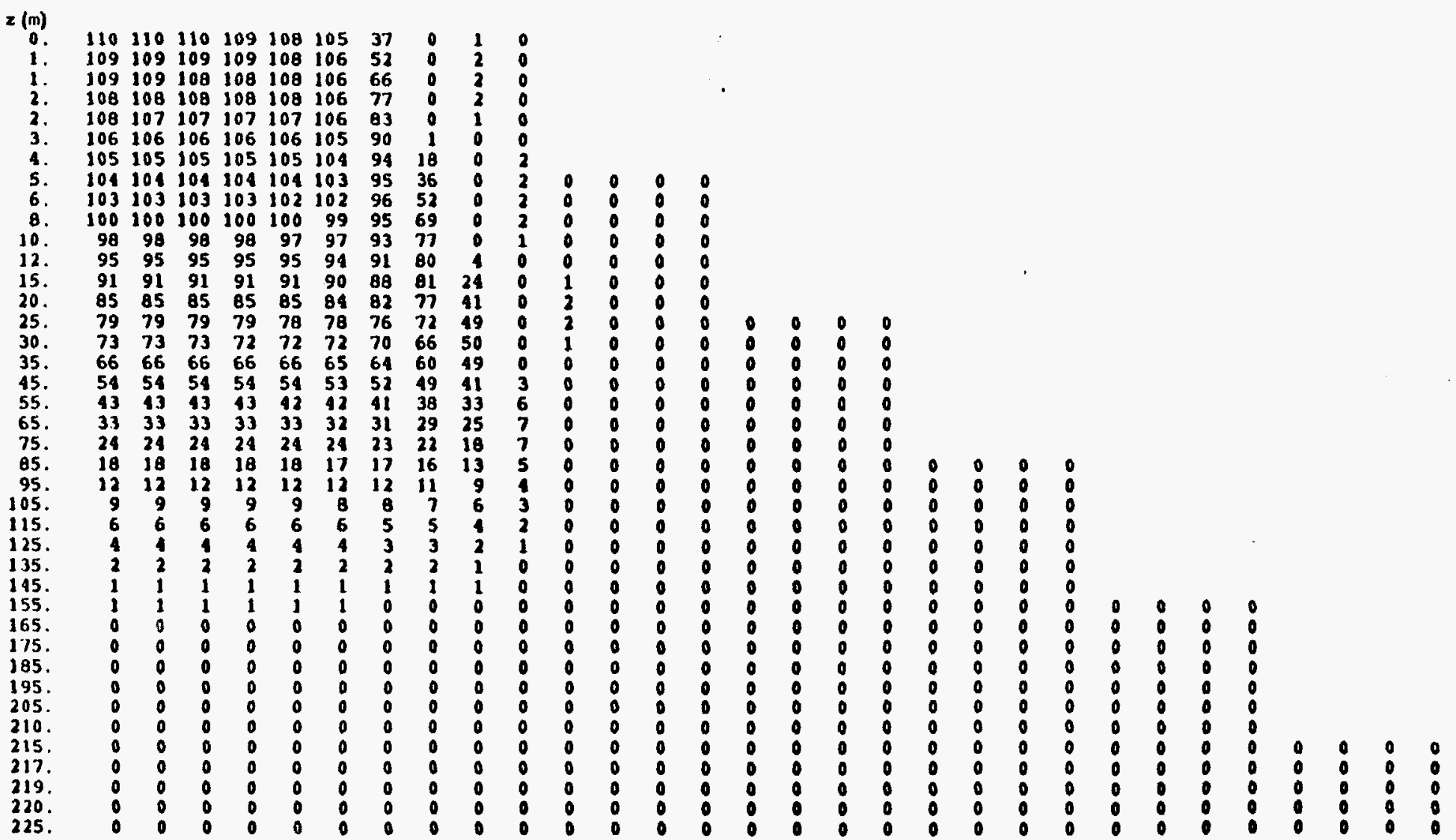

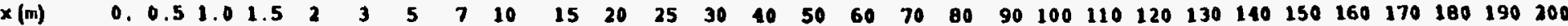


Nov 13 17:15 1986 conout Pago 1

Run $=1 . p 2$

Time Since Pumpling Bagan =1140, days

Time Since Arrival of Cambric Tilt lum at: RNM-2S 301.days

plcu/mi $\cdot 0.1$

2 (m)

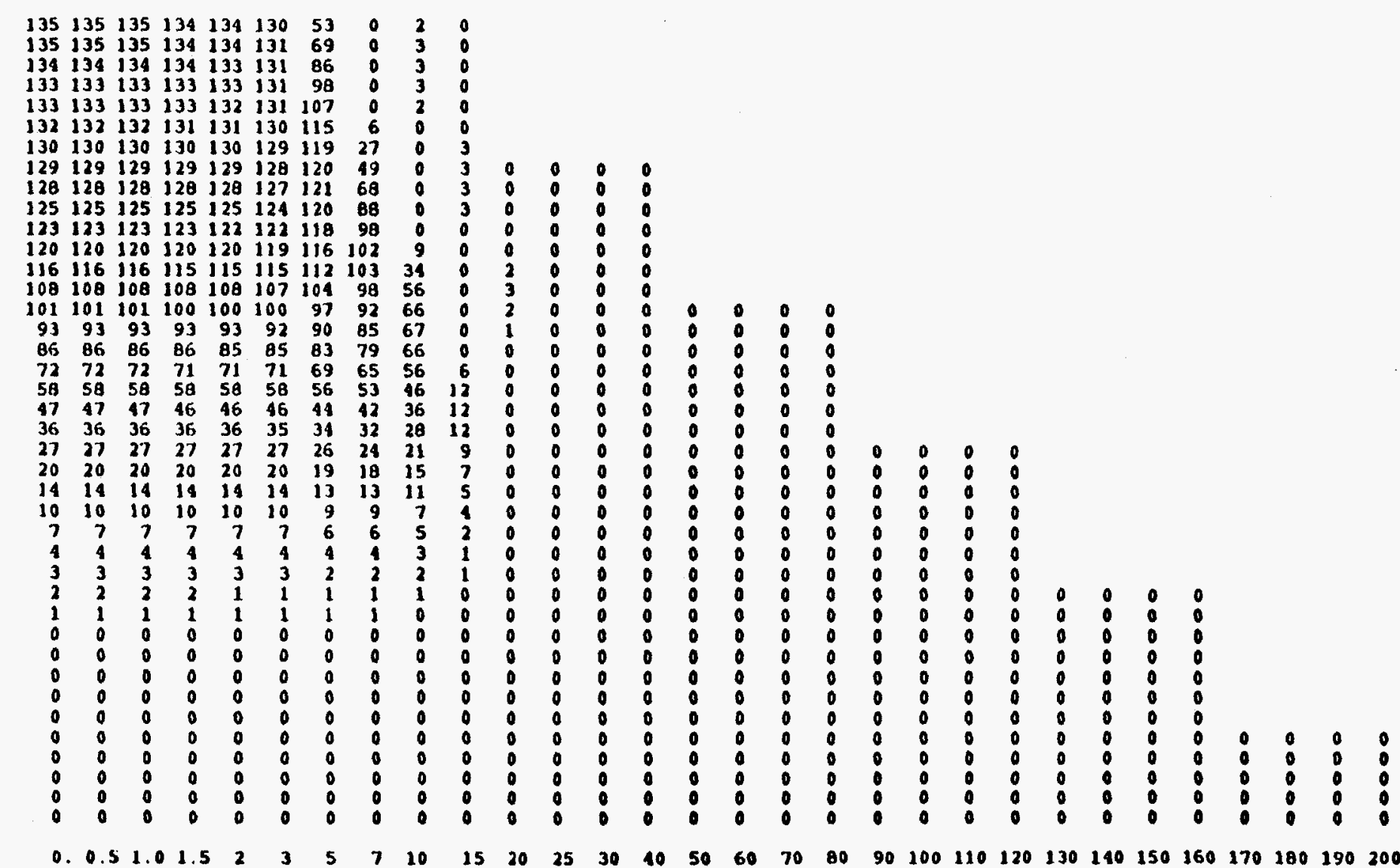


Nov 13 17:58 1986 conout Page 1

Run $=$ tp2 2

Tline SInce Fumpling Began =1165. days

TIme SInce Arrival of Cambric Tritlum at RNat 2S 326.days

plas/ml $\cdot 0.1$

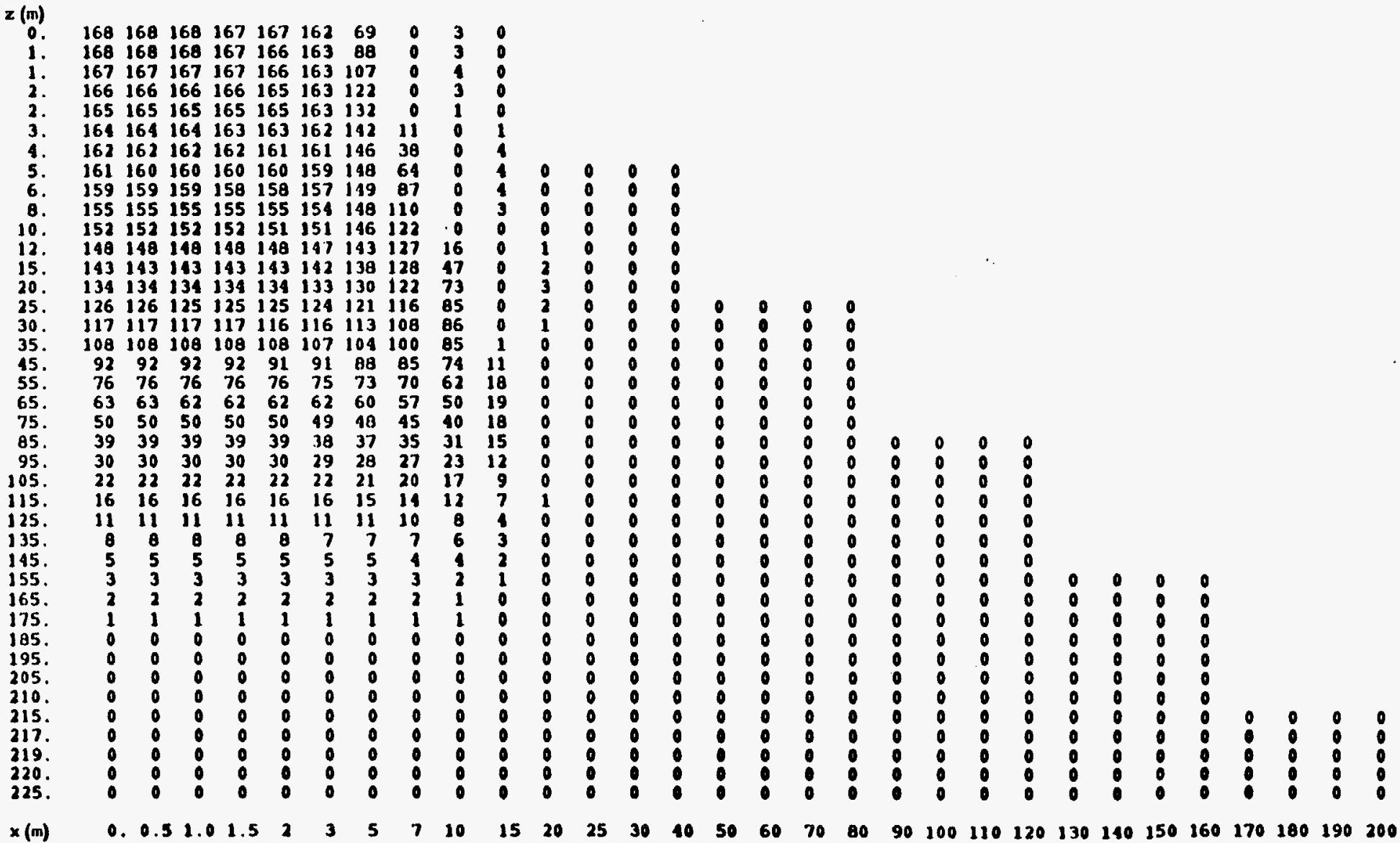


Nov 13 18:00 1986 conout Page 1

$\operatorname{Run}=\mathbf{t p}^{2}$

Tims Since Pumpling Began =1215. days

TIme SInce Arrival of Canbric Tritlum at RNoy-2S 376.days

plCu/ml 0.1

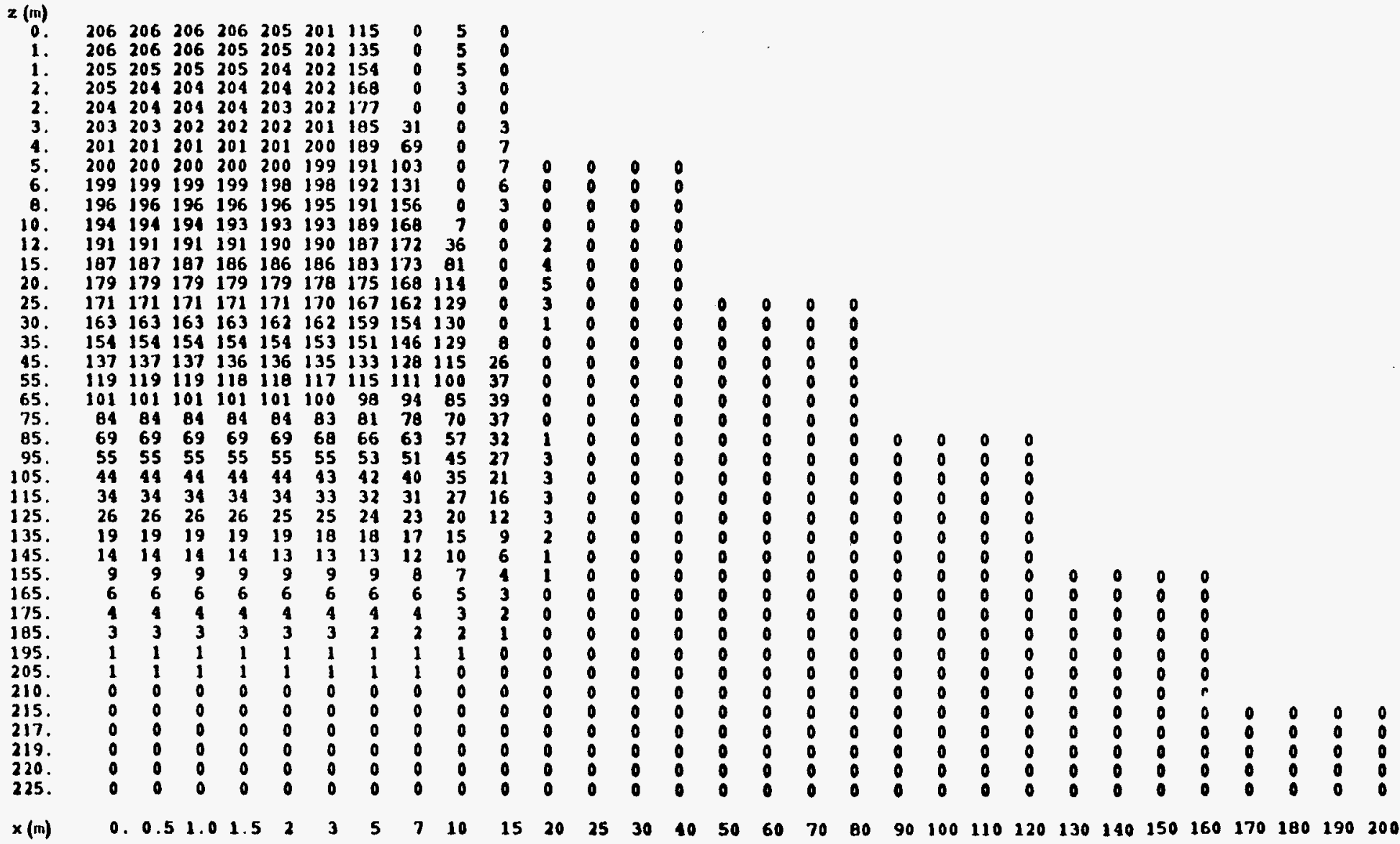


Nov 13 18:01 1986 conout Page 1

Run $=\operatorname{tp} 2$

Tima Since Purying Began $=1210$. days

Time Since Arrival of Cambric Tritium at RMM-2S 401.days

$p\{C u / m \mid \cdot 0.1$

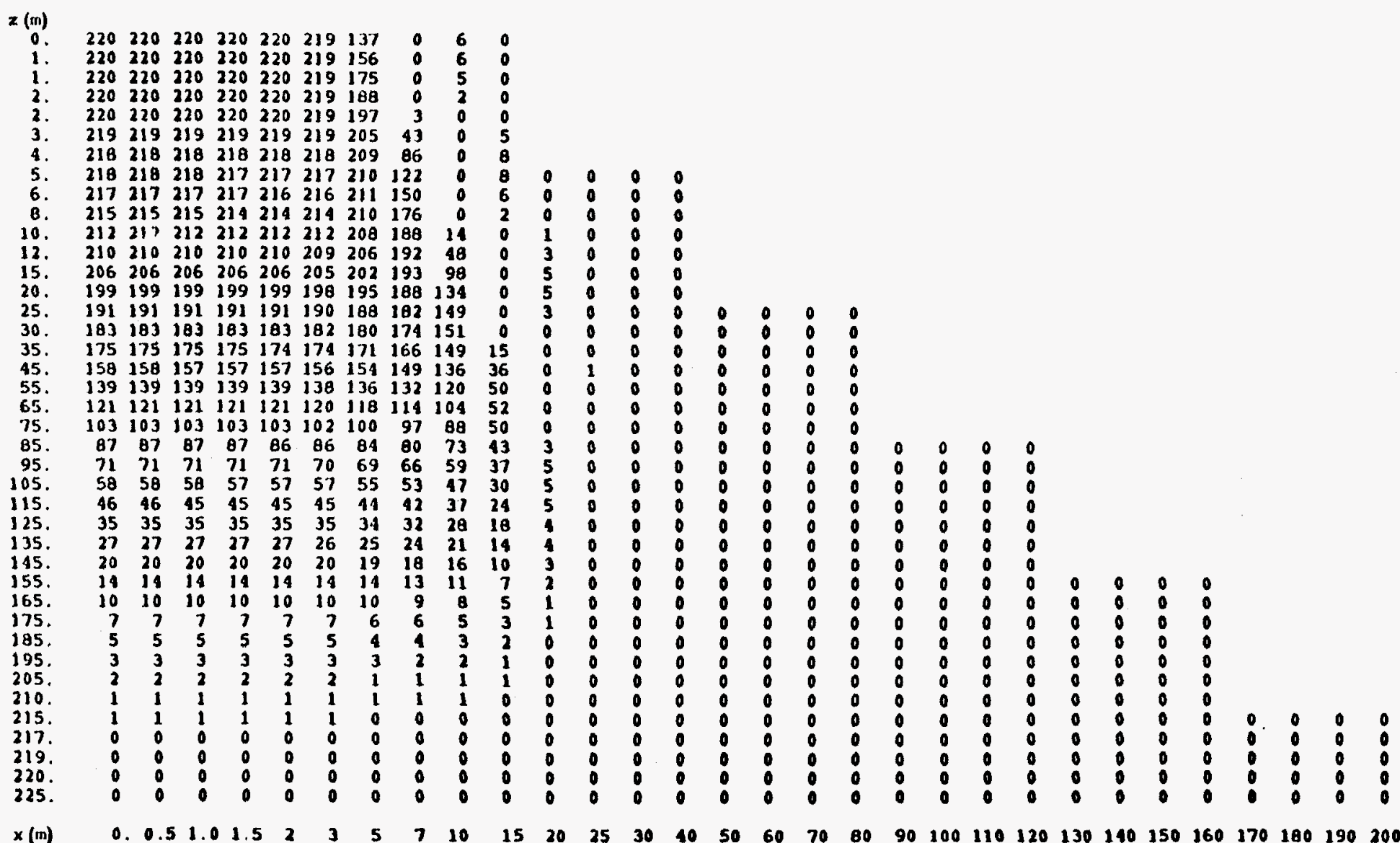


0000

0000000000000000000

00000000000000000000000000

000000000000000000000000000000000 ?

$000000000000000000000000000000000 \mathrm{~m}$

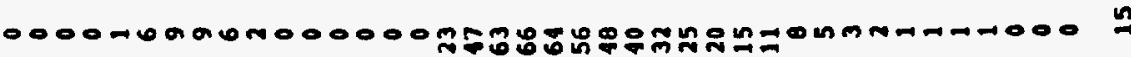

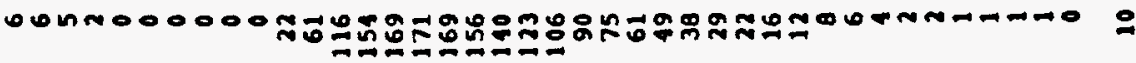

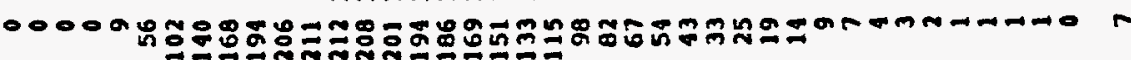

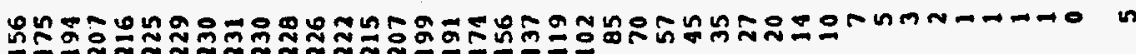

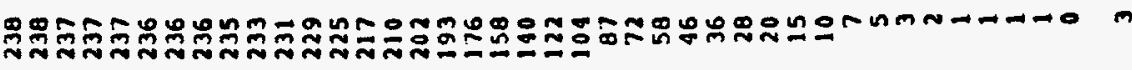

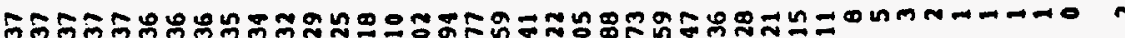

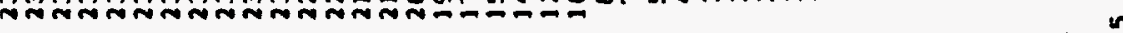

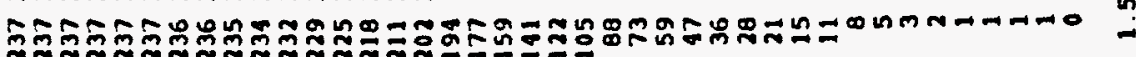

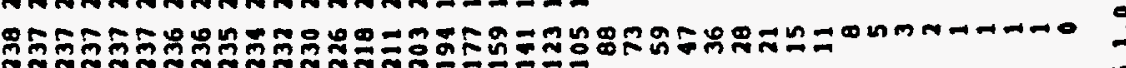

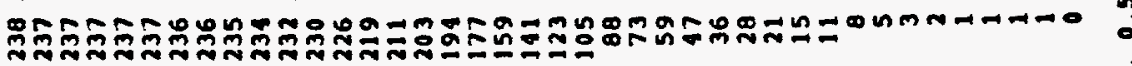

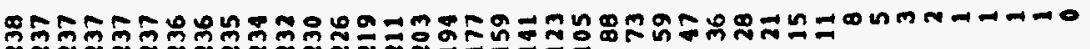


Nov 13 18:04 1986 conout Page

Run $=t_{p} 2$

Tlime Since Pumpling Bugan =1290. days

TIma Since Arrival of Cainloric Thit.lum at RRoy-2S 451.daya

plCu/ml 0.1

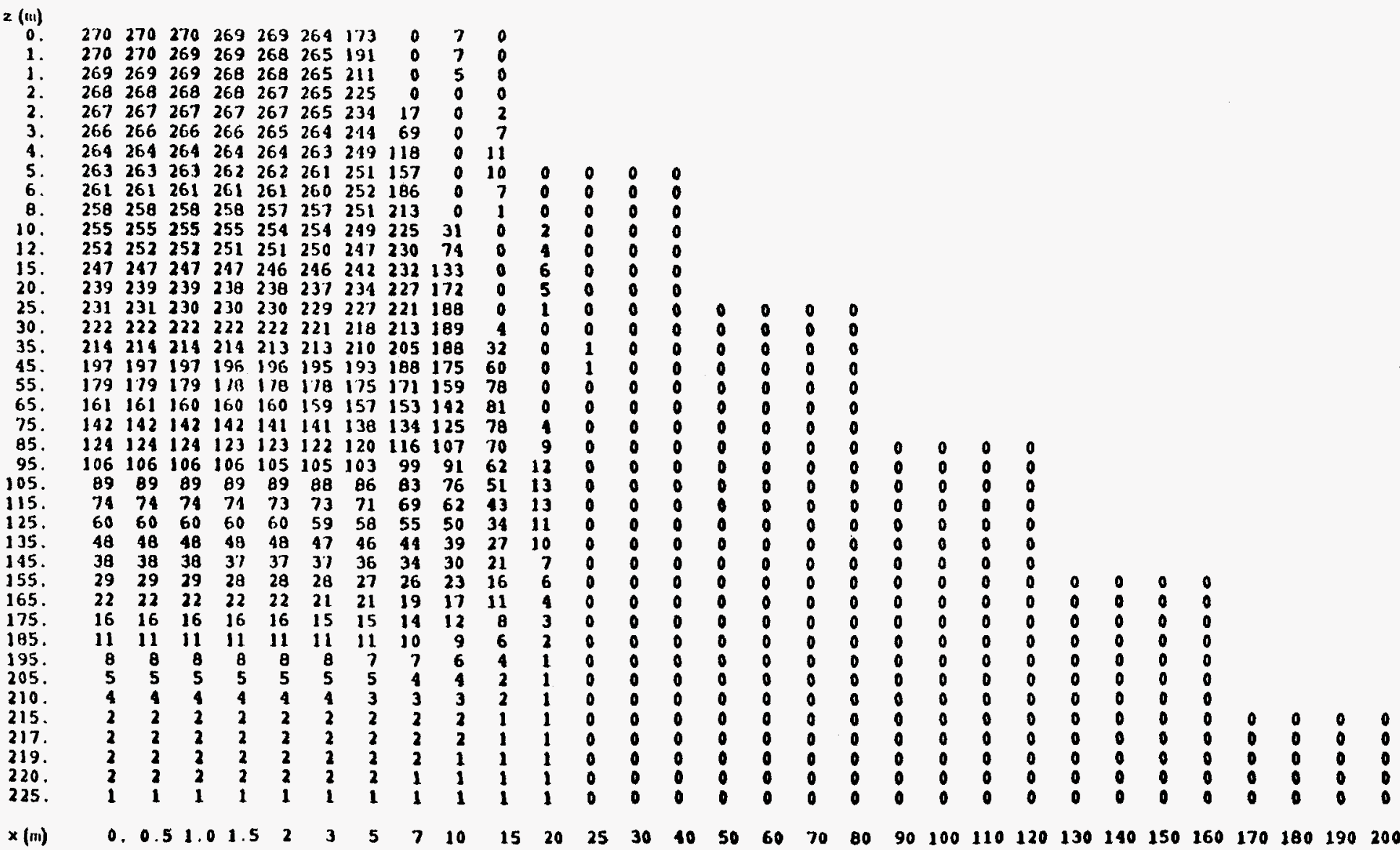




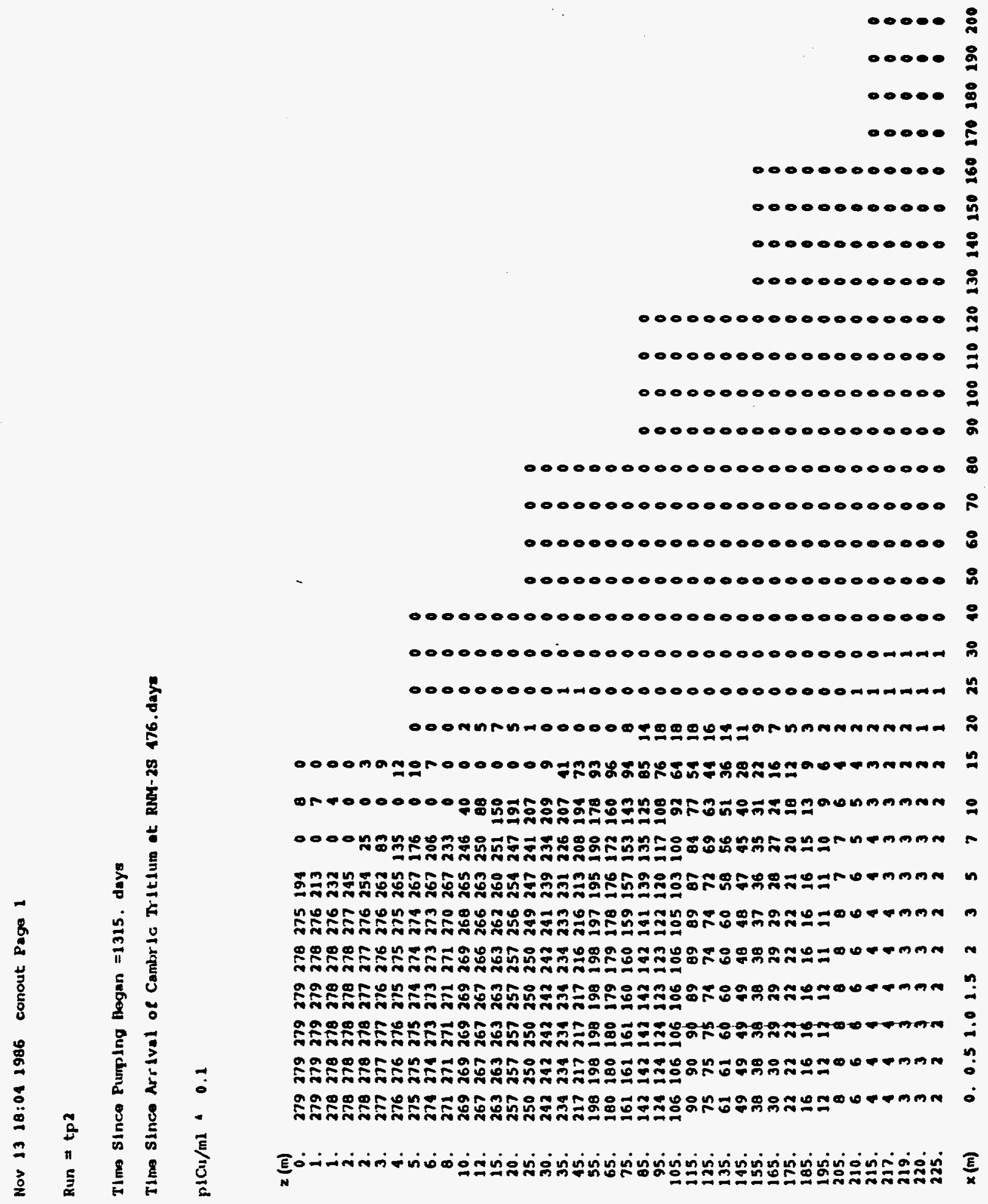




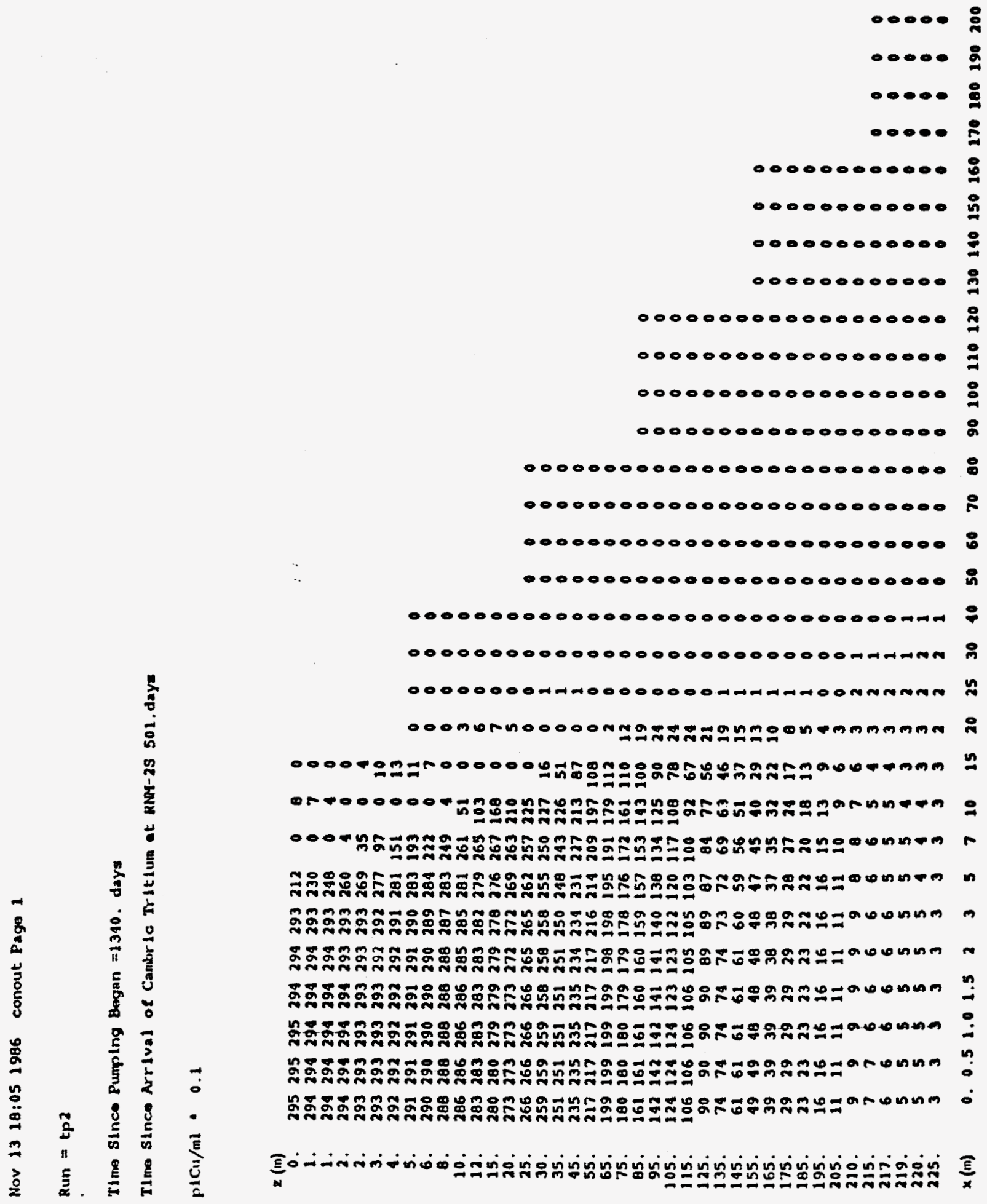


Nov 14 10:14 1986 conout Page 1

Run $=t_{p} 3$

Titwe Since Pumpling Began $=1365$. days

Time since Arrival of Cambric Tritlum at RNA-2S 526.daye

plcu/mi - 0.1

$\begin{array}{cccccccccccc}2(m) & & & & & & & & & & & \\ 0 . & 329 & 329 & 329 & 327 & 326 & 318 & 227 & 0 & 9 & 0 \\ 1 . & 328 & 328 & 327 & 327 & 326 & 320 & 245 & 0 & 7 & 0\end{array}$

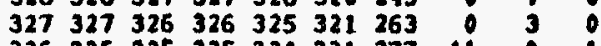

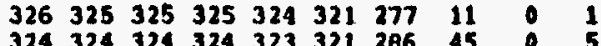

$\begin{array}{llllllllll}314 & 324 & 324 & 324 & 323 & 321 & 286 & 45 & 0 & 1 \\ 322 & 322 & 322 & 322 & 321 & 320 & 296 & 110 & 0 & 11\end{array}$

$320320320320319318301 \quad 167$

(316 316316 317 316304206

316316316316315314305239

8. $\quad 312312312312311310: 304266$

12. $\quad 305305305308308307302 \quad 279 \quad 62$

15. 305305305305304303300284117

15. $\quad 300300300300300299295286184$

25. $285285285285284284281 \quad 276 \quad 242$

35. 267277277277277276273260244

45. $\quad 253253$ 25 25025225126626124362

55. 235235235235235234231237215 in

65. 217217217217216216213209197128

75. $198198190198198197194 \quad 190180126 \quad 17$

85. $179179179179 \quad 179 \quad 178 \quad 175 \quad 171 \quad 161 \quad 116 \quad 25$

95. $\quad 160160160159159159156 \quad 152 \quad 143 \quad 106 \quad 31$

115. $\quad 123123123 \quad 122 \quad 122122 \quad 119 \quad 116 \begin{array}{llllllll}108 & 81 & 31\end{array}$

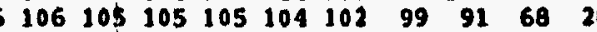

$\begin{array}{llllllllllll}135 . & 89 & 89 & 89 & 09 & 88 & 88 & 66 & 83 & 77 & 57 & 25 \\ 145 & 74 & 74 & 74 & 7 & 74 & 73 & 72 & 69 & 63 & 17 & 21\end{array}$

$\begin{array}{llllllllllll}145 . & 74 & 74 & 74 & 74 & 74 & 73 & 72 & 69 & 63 & 17 & 71 \\ 155 . & 60 & 60 & 60 & 60 & 60 & 60 & 58 & 56 & 51 & 30 & 18\end{array}$

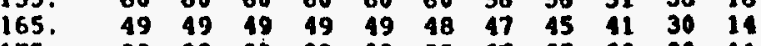

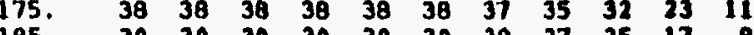

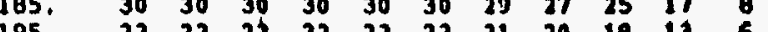

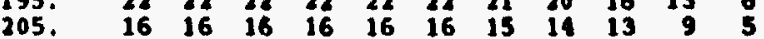

$\begin{array}{llllllllllll}210 . & 13 & 13 & 13 & 13 & 13 & 13 & 12 & 12 & 11 & 9 & 5\end{array}$

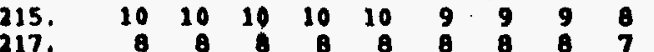

217.

220 .

225.

$\begin{array}{ll}7 & 7 \\ 5 & ?\end{array}$

8

7

$x(m)$

$1520 \quad 25$

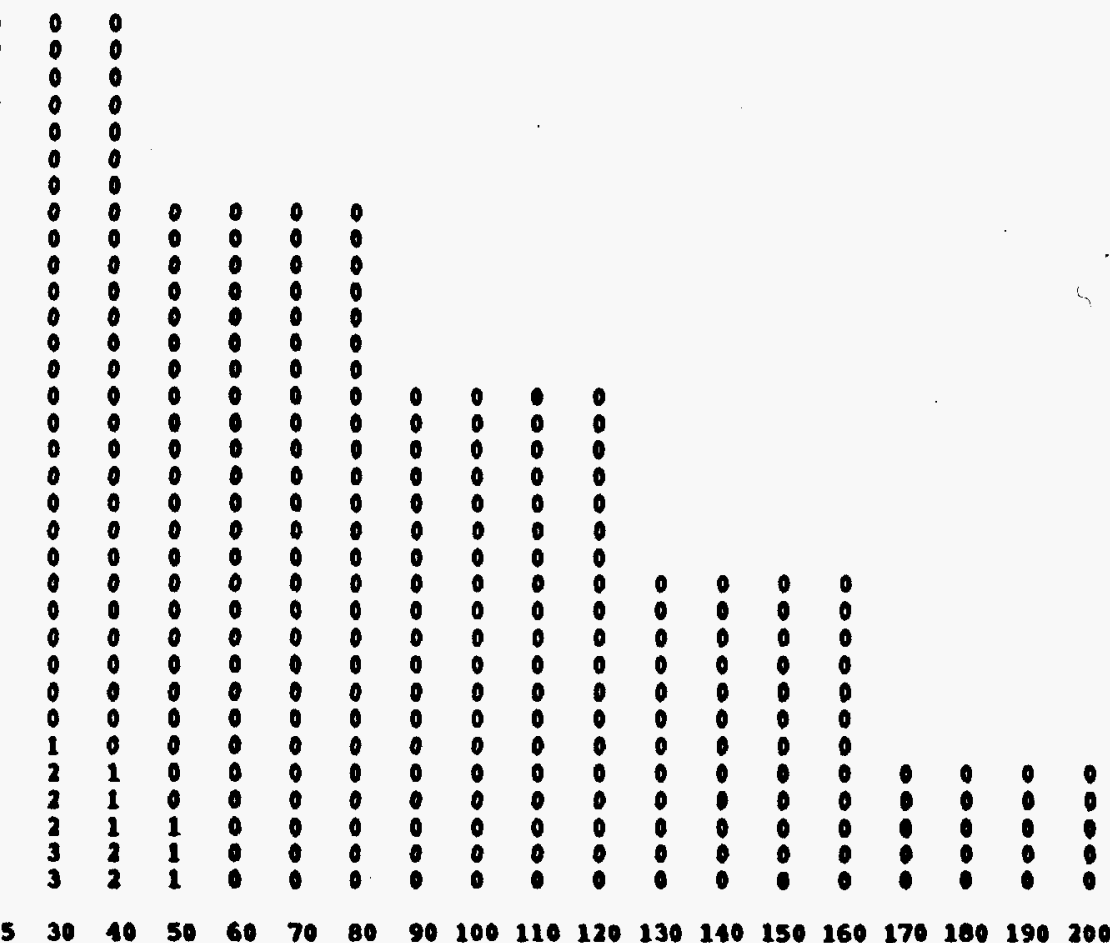




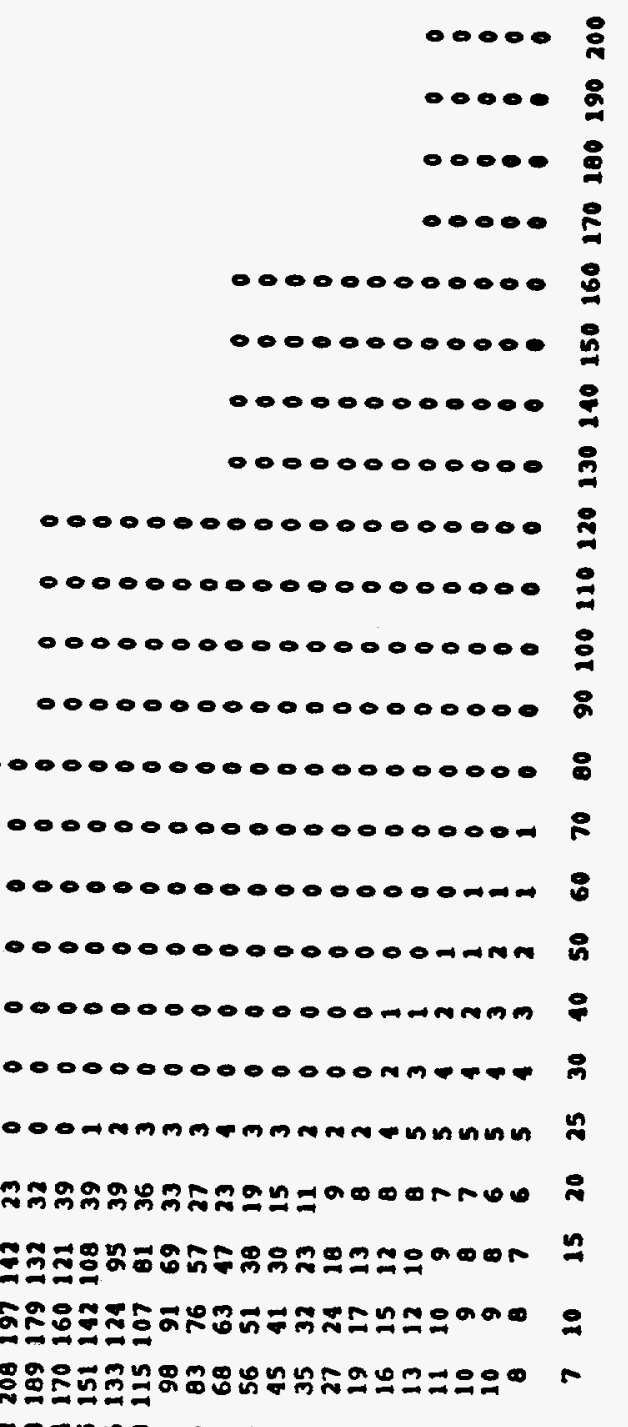

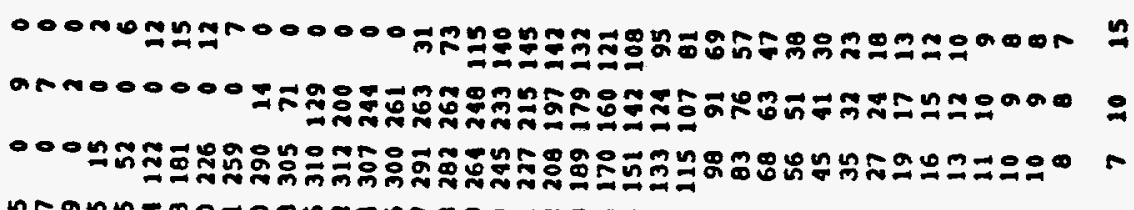

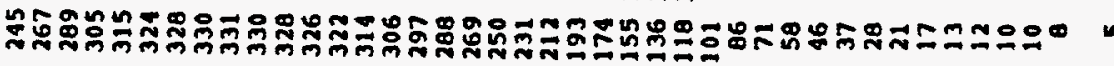

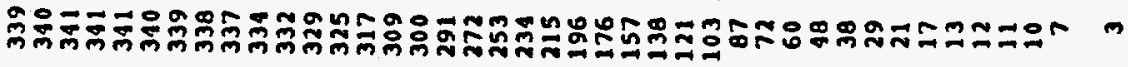

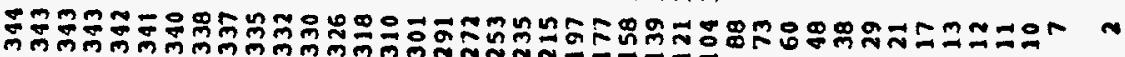

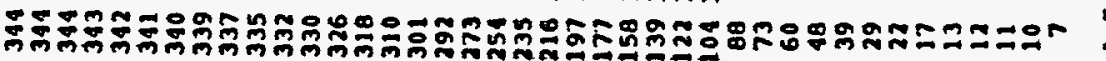

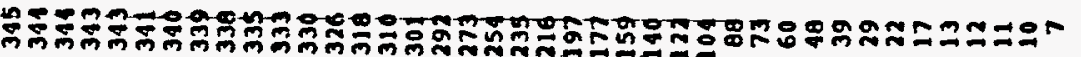

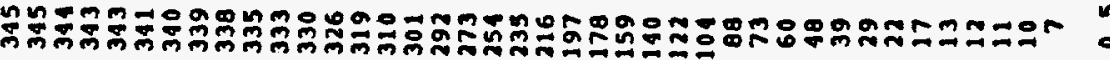

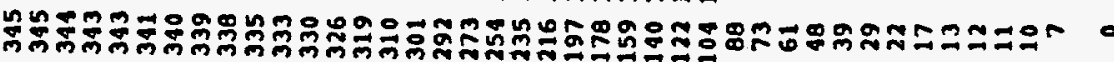

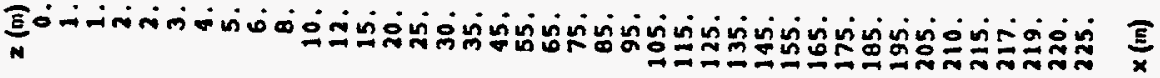


Nov 14 10:48 1986 conout Pago 1

Run $=\operatorname{tp} 3$

Tima Since Pumping Brgan =1415. days

TIme SInce Arrival of Cambrle Tritiun at RMH-2S 576.daye

plCu/ml 0.1

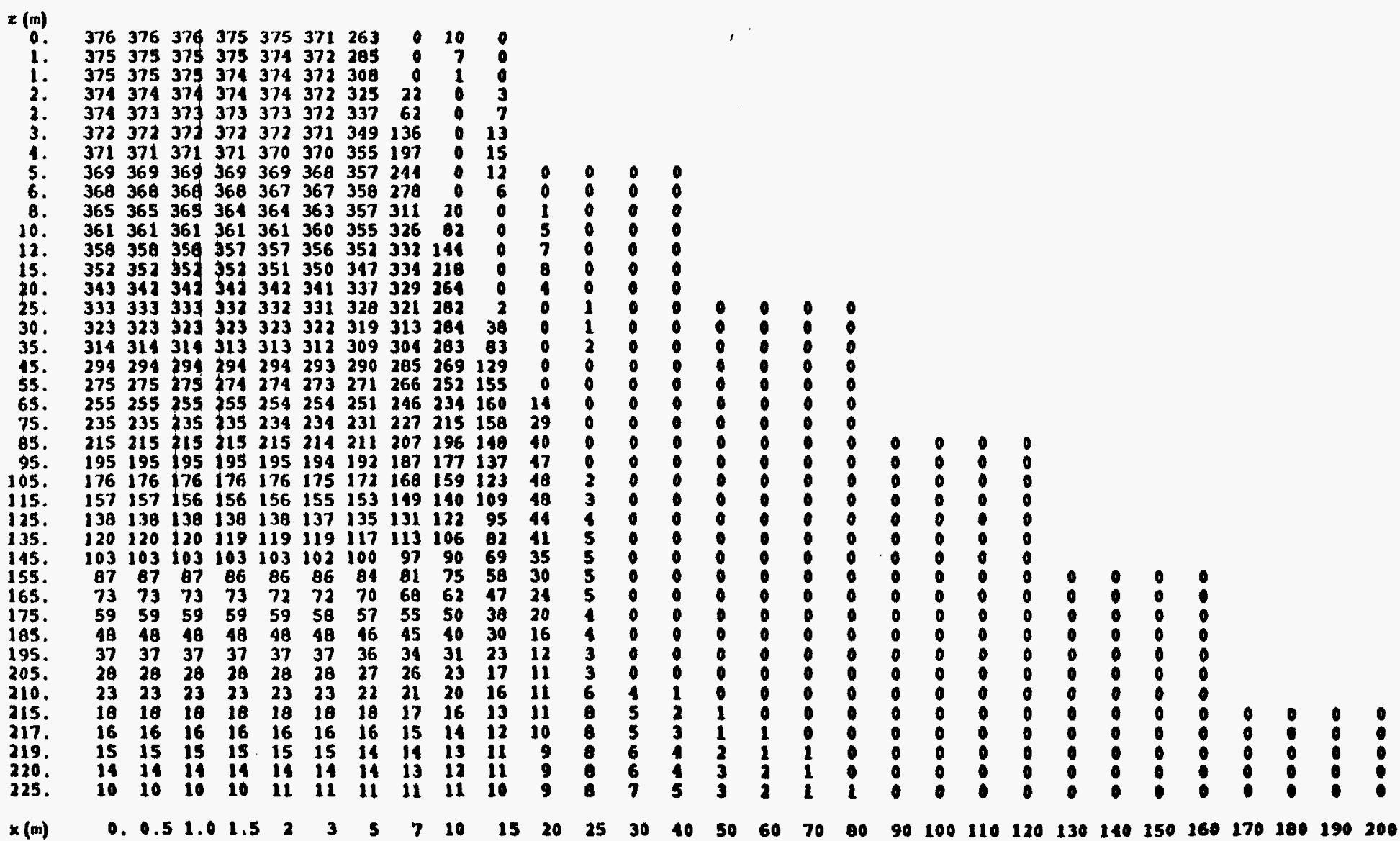


Nov 14 10:49 1986 conout Page 1

Run $=\operatorname{tp} 3$

Tlme Since Pumping Began =1440, days

Tlma since Arrival of Cambrle Tritlum at RaM-2S 601.daye

$p|C n / m| \cdot 0.1$

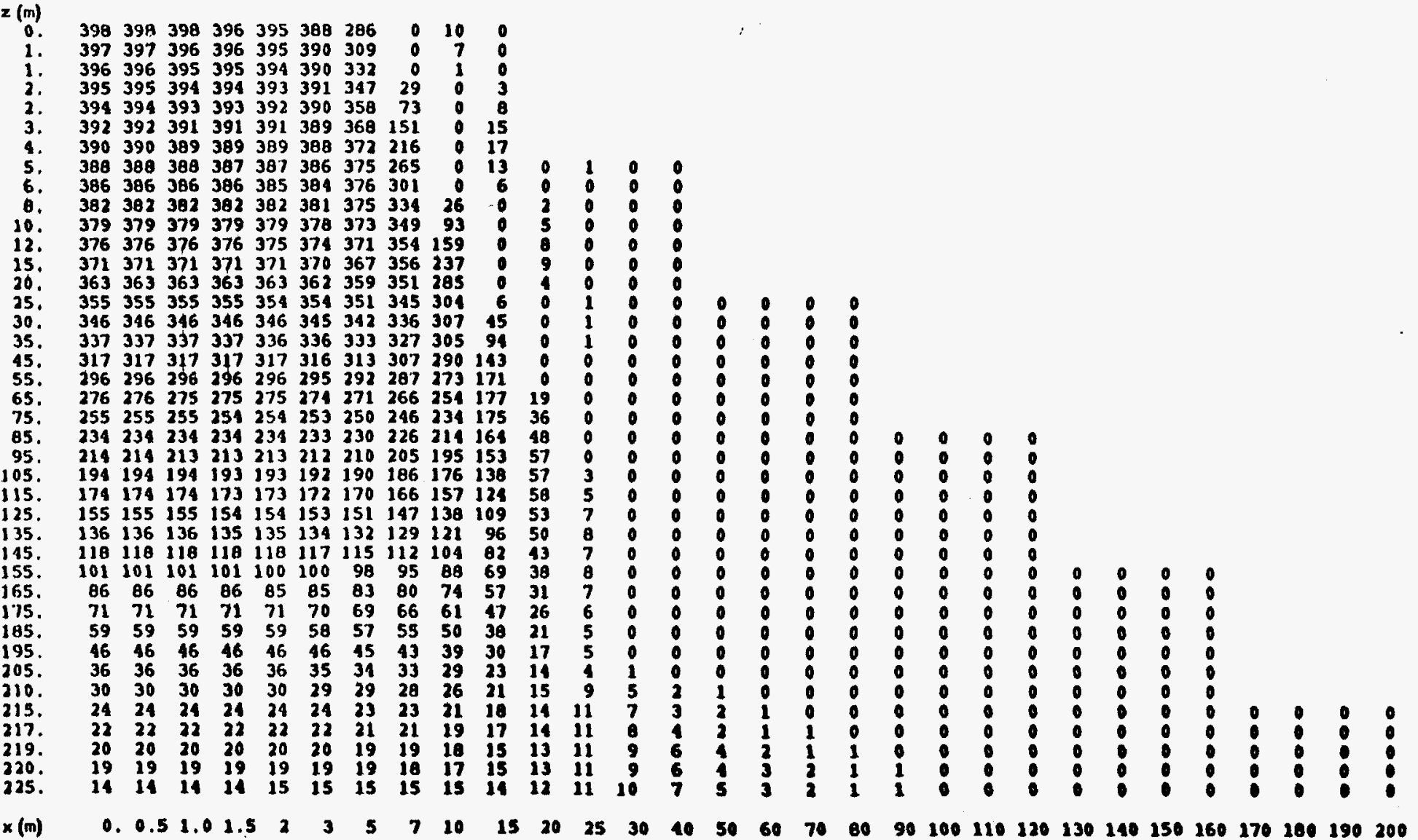




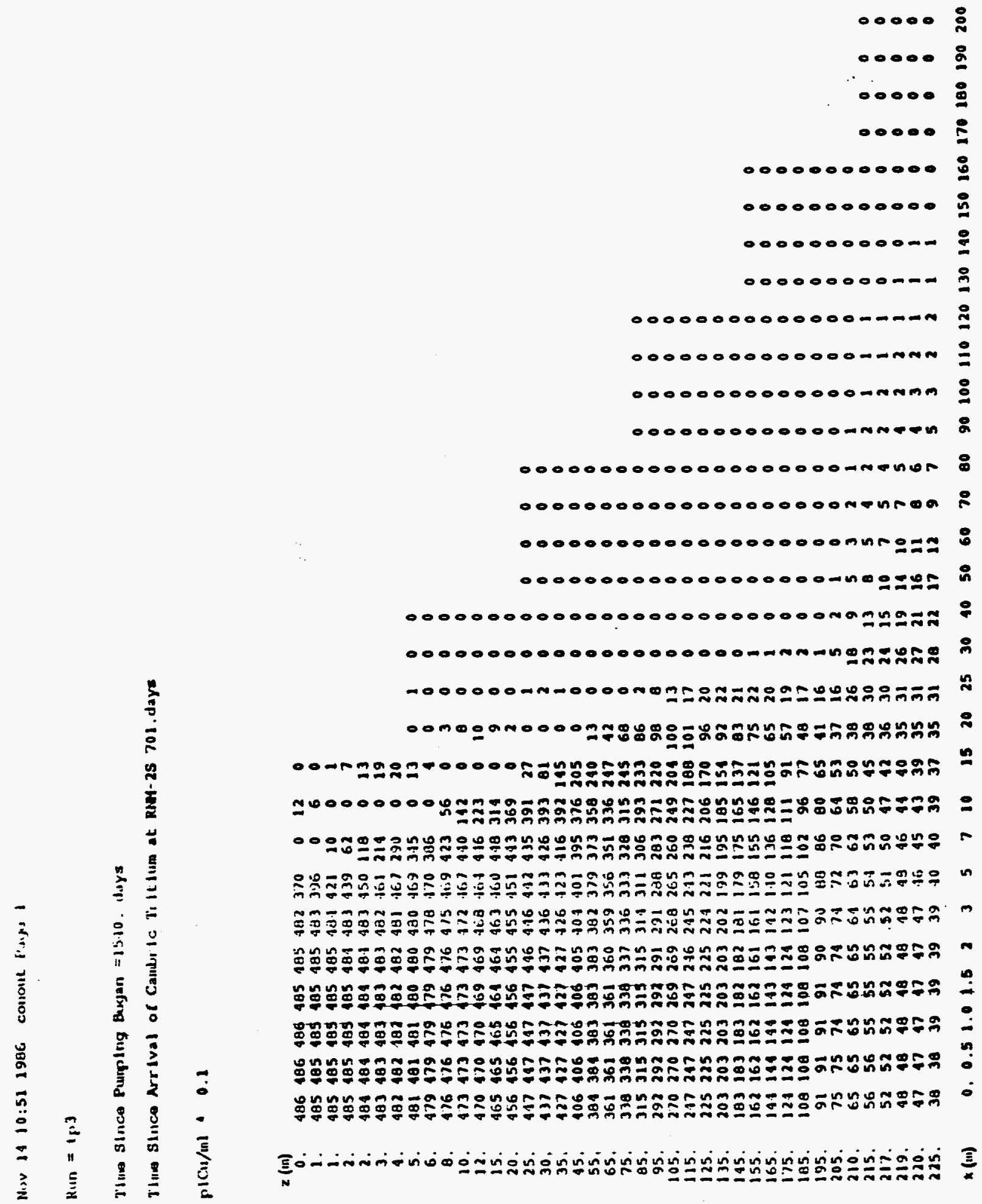


Nov $1519: 411946$ conout Propus I

Run $=\operatorname{tp4.5}$

TIno Sirice Pumpling Bugan =1615. duys

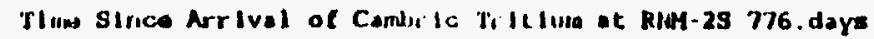

$1,1 \mathrm{Cu} / \mathrm{m} \cdot 0.1$

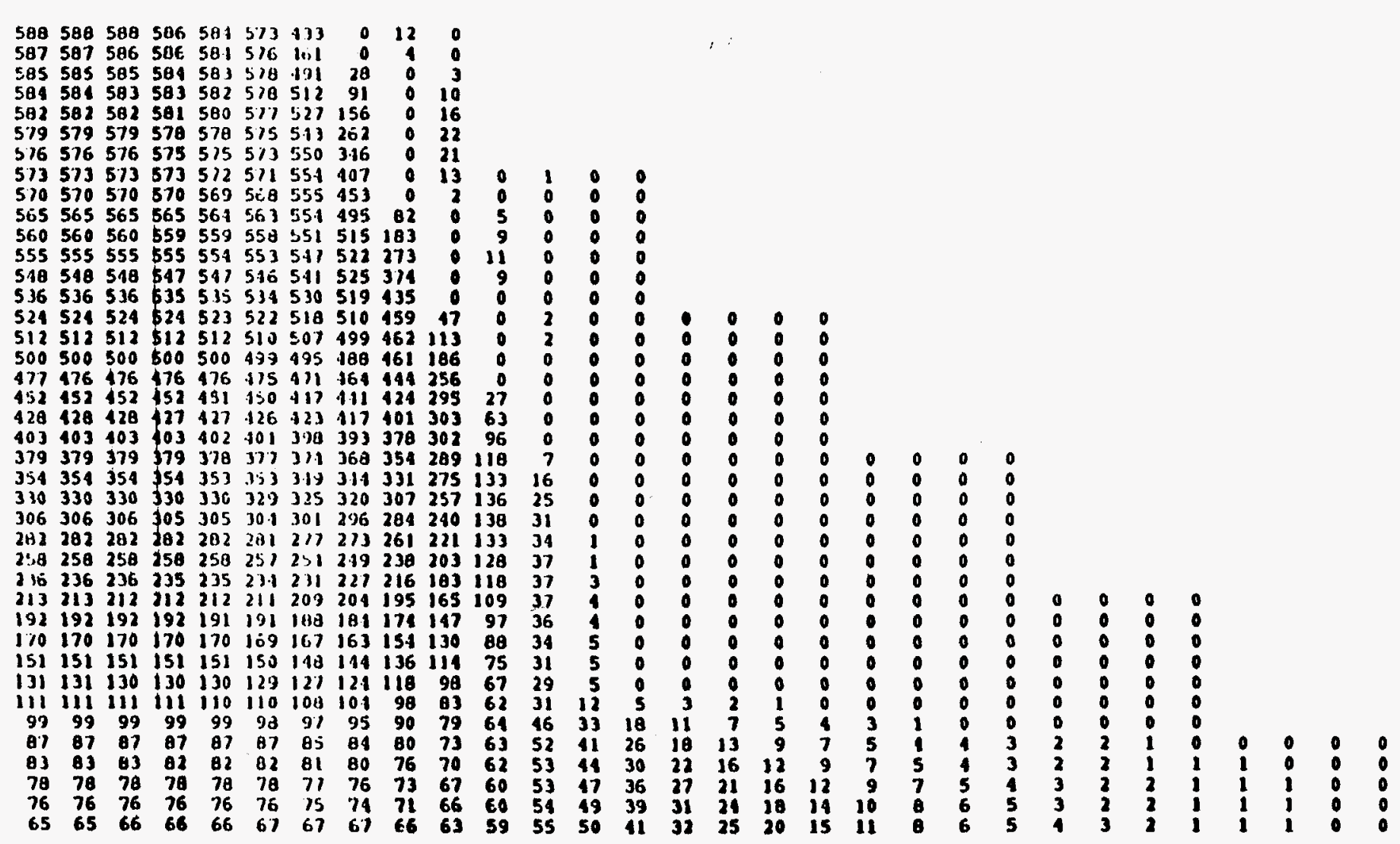

$x(n)$

$0.0 .51 .01 .5235710 \quad 15$

$52025 \quad 30$

$40 \quad 50$

$20 \quad 60$

90100110120130140150160170180190200 
Nuv 15 19:42 1906 conout P.s.e. 1

Ruri $=4.1 .5$

Tline Slincu Purying Bugan = 1 cro. dirys

Tine since Arrival of Canda ic Tilt lum at RNOH-28 801.days

$p \mid C u / m l \cdot 0.1$

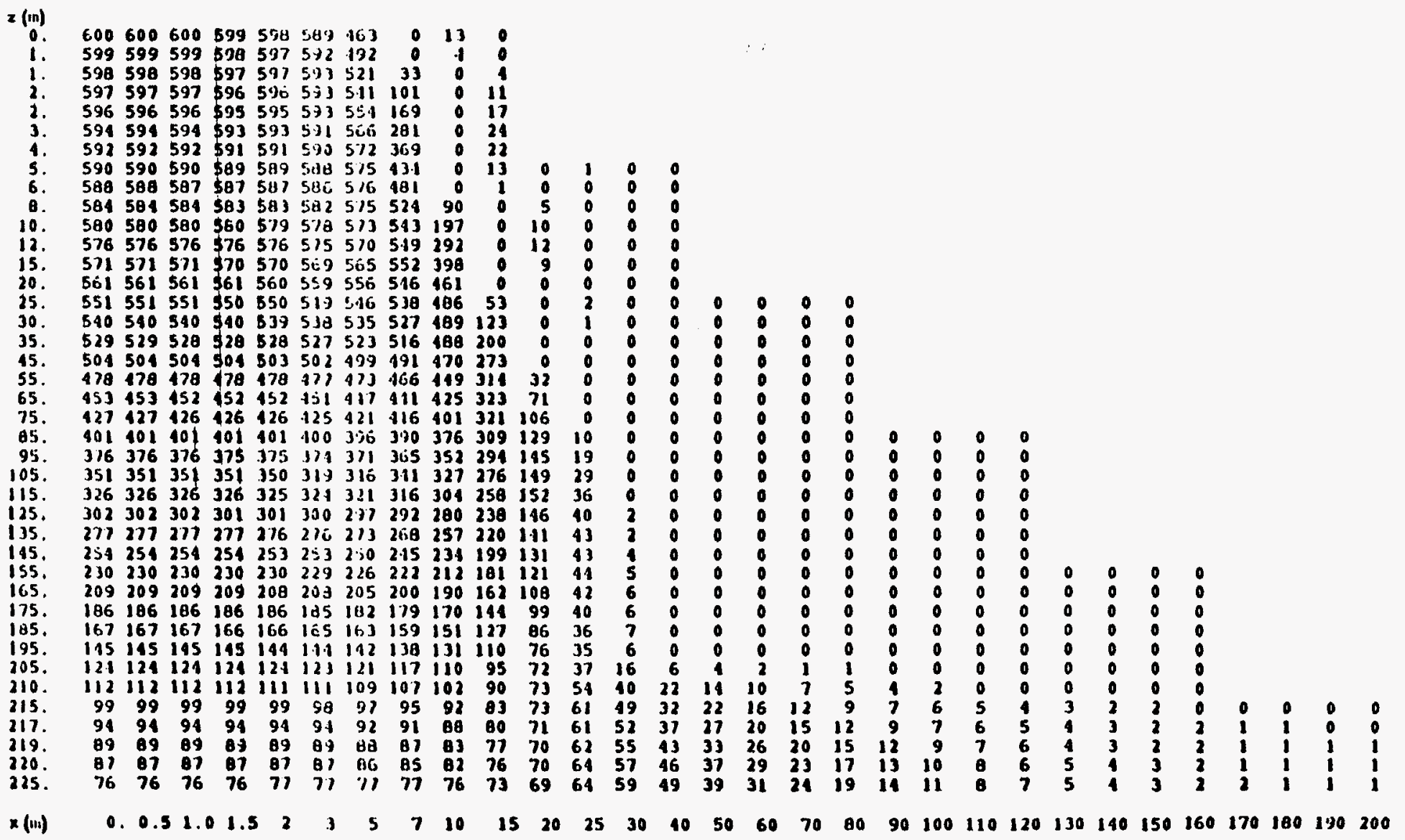




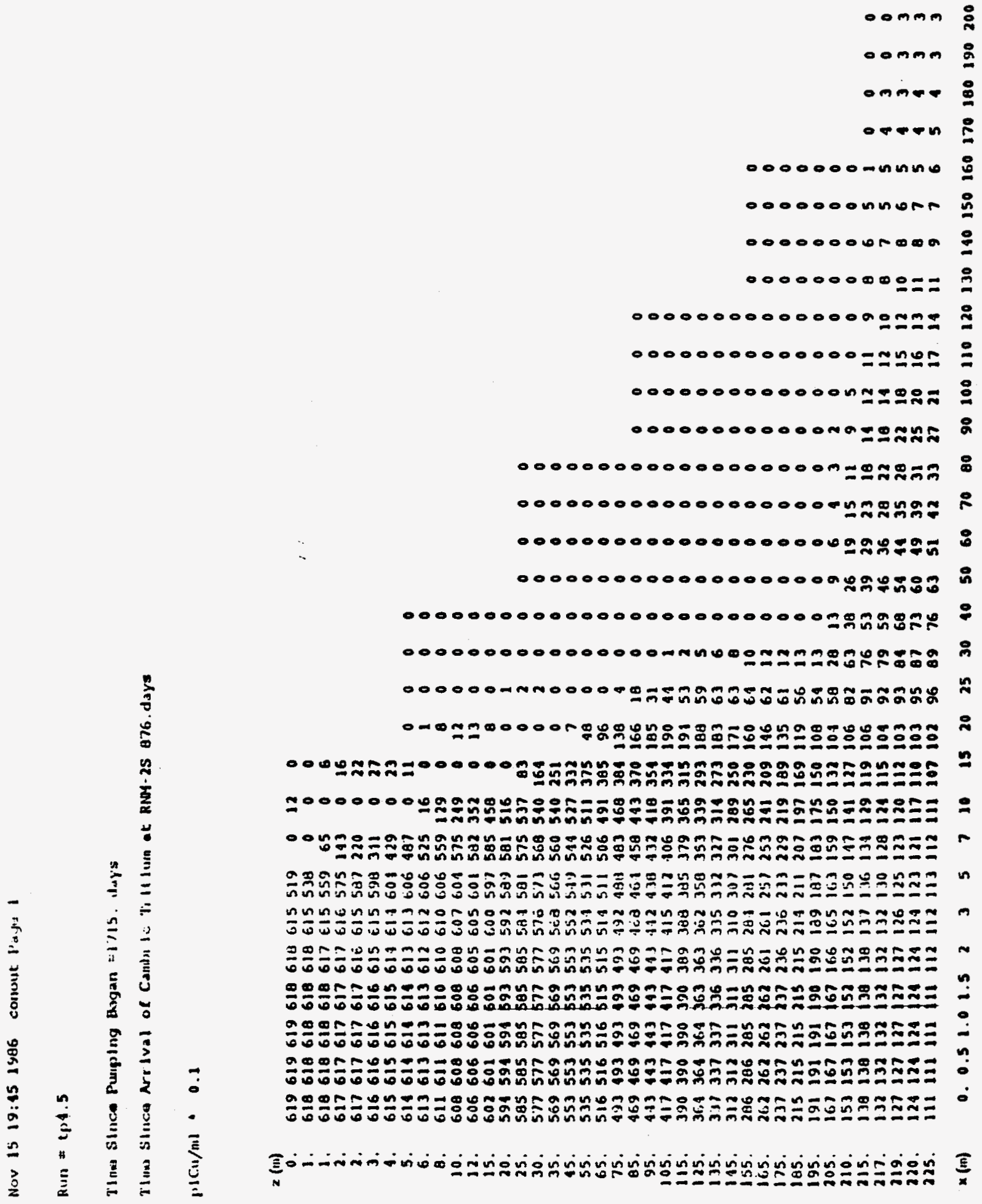

M-29 


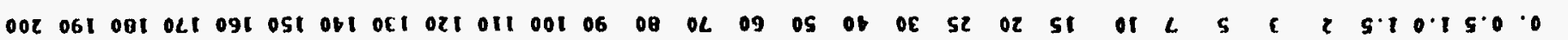

(ui) $x$

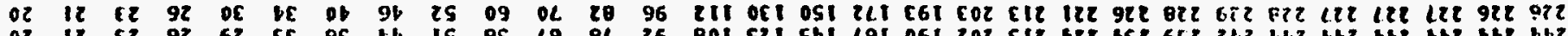

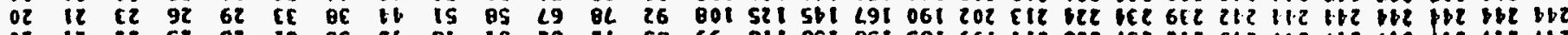

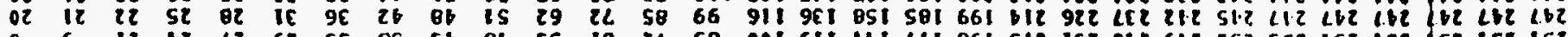

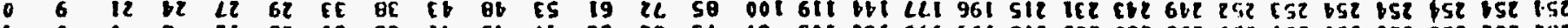

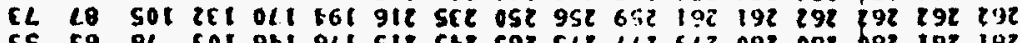

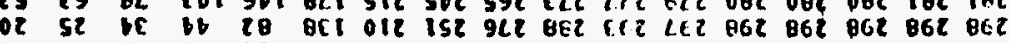

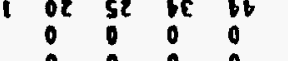

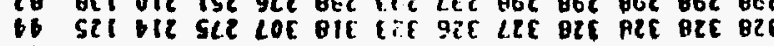

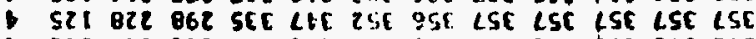

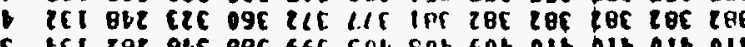

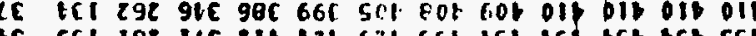

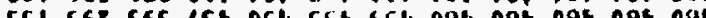

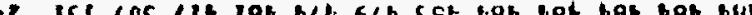
or 521 zIE CC seb obv las

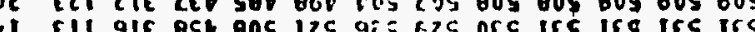

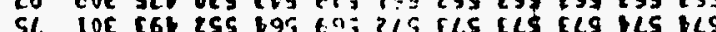

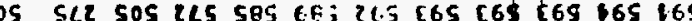
l.

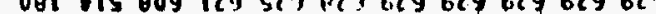
Lso 159 L59 259 896 519 (99 (3) 5?) 599593999999997 692 569

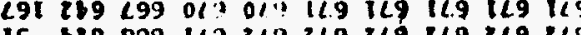
15

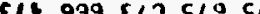

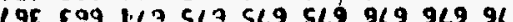
Let 59 1.3 $010 \quad 3<9$ 9L9 $9<9$ 9L9

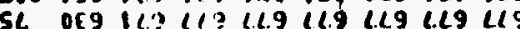

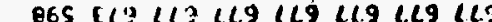

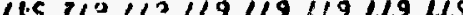

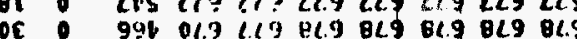
If - ILC SO? $8138<.9$ BL9 8L9 8L9 8L9

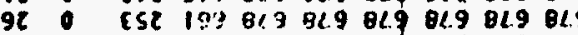

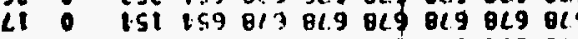
90

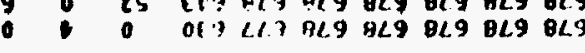




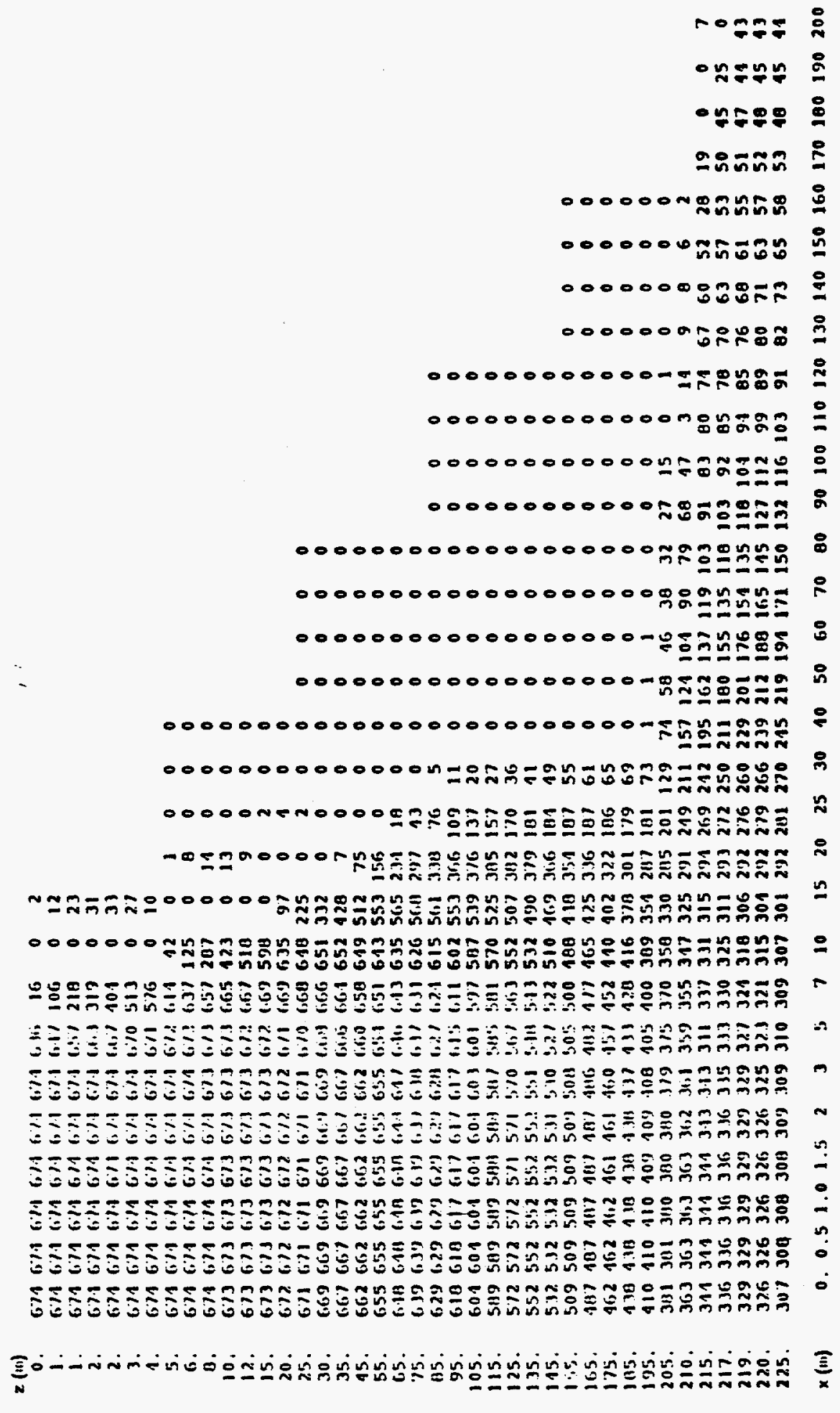




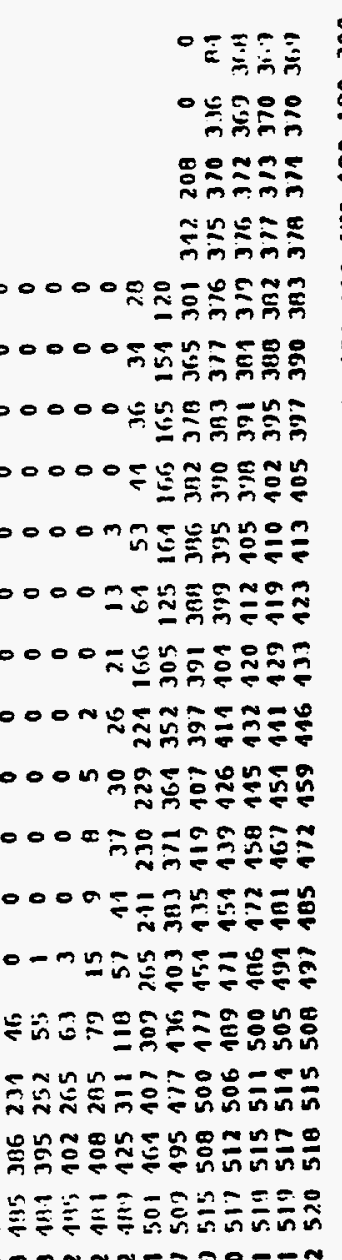

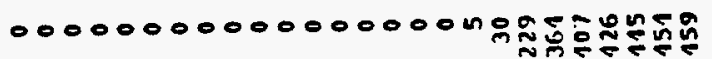

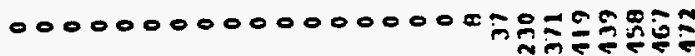

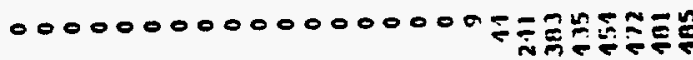

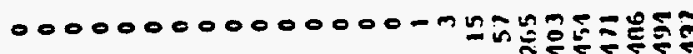

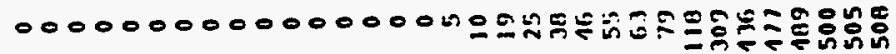

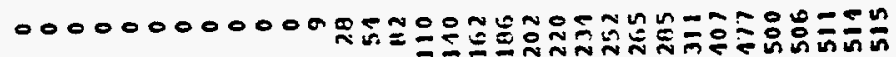

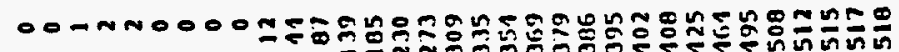

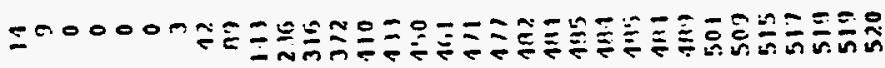

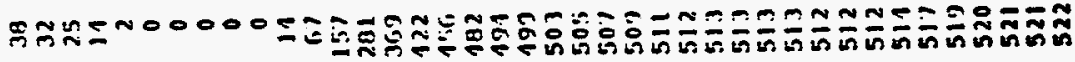

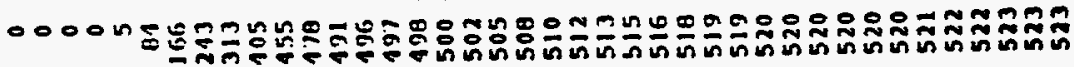

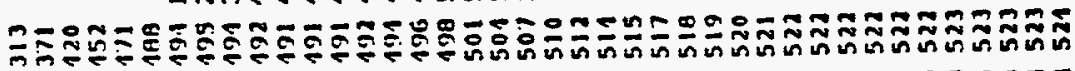

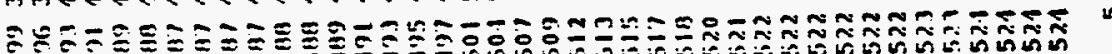

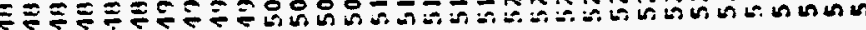

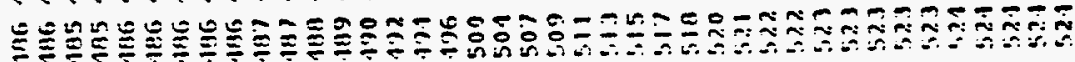

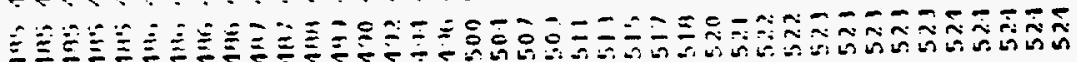

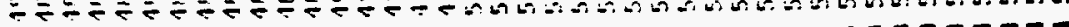

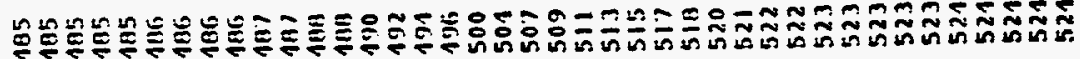

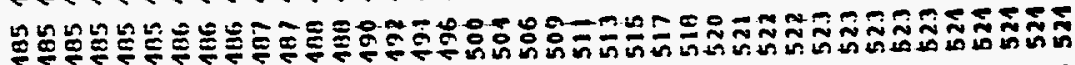
P

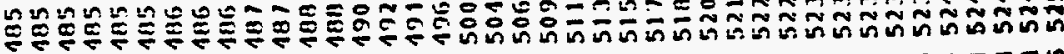

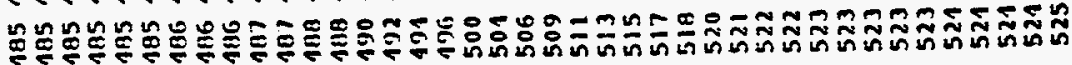


ku11 a 1,11

Tlums SInces P'unpliny Began =3!215. day:

Tlune SInce Arrival of Canbrte Trjtilun at RNM-2S26\% days

plcin/ml 0.1

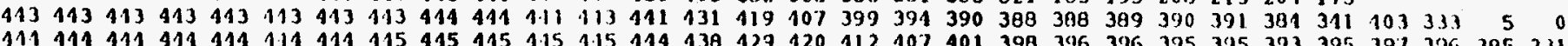

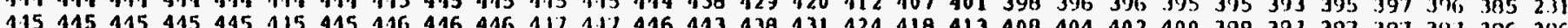

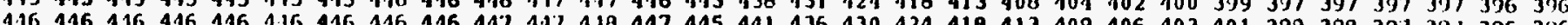

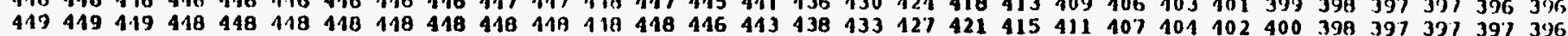

$x(\mathrm{~m})$ 
Appendix $\mathbf{N}$

Contour plots of simulated tritium concentration

$\mathrm{N}-1$ 


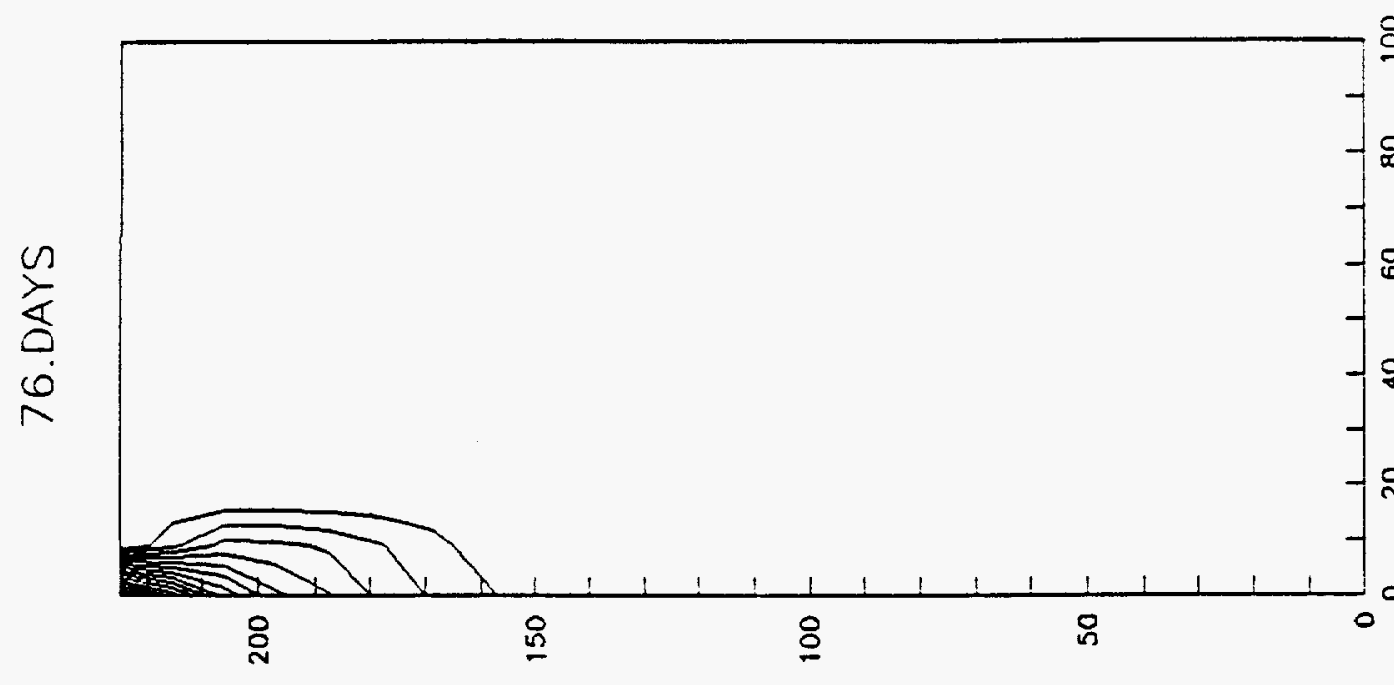

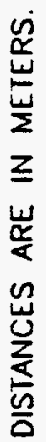
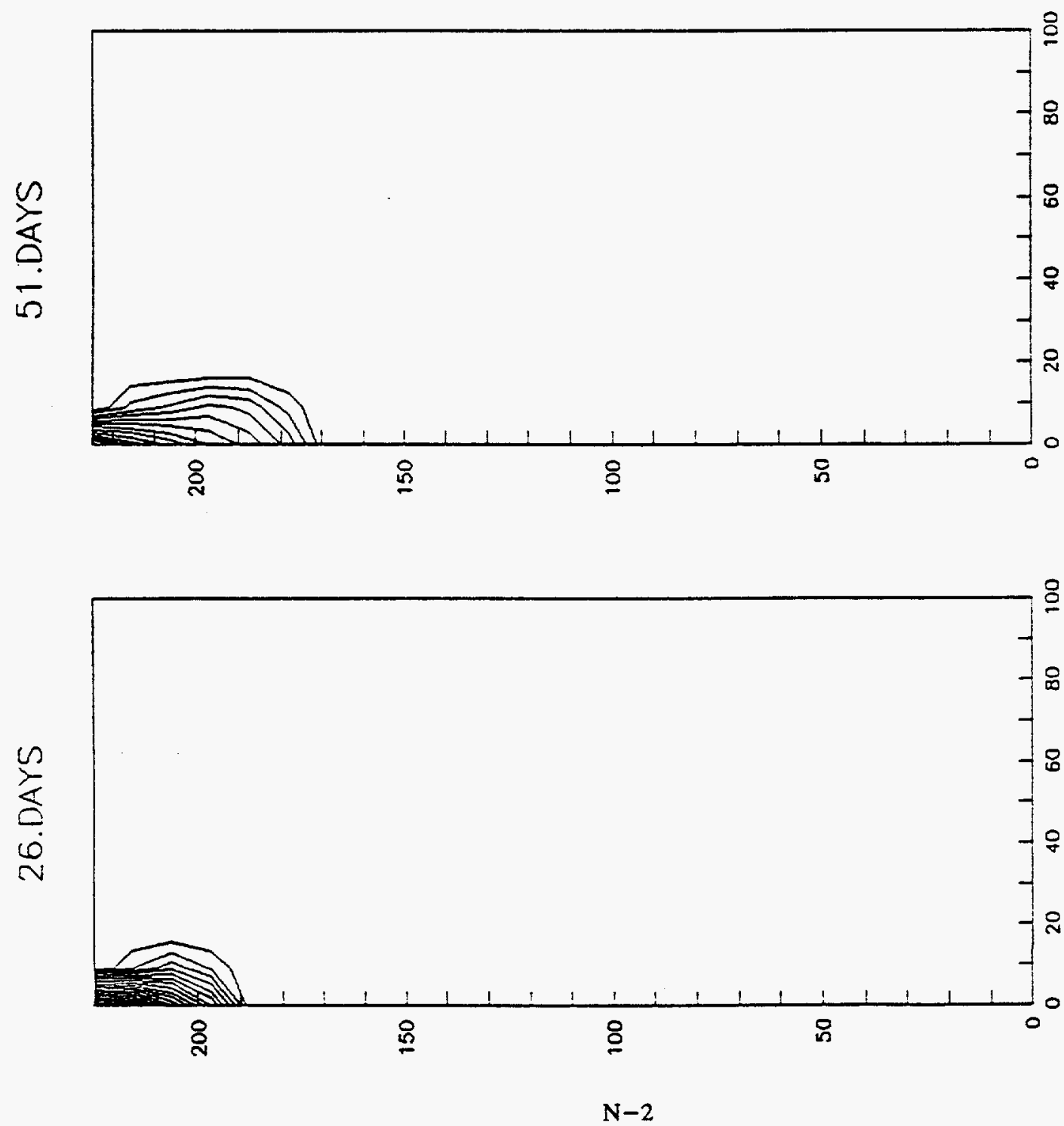

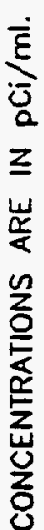

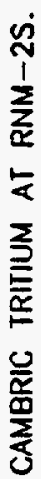

능

흠

峛

宸

㟔

$$
\mathrm{N}-2
$$




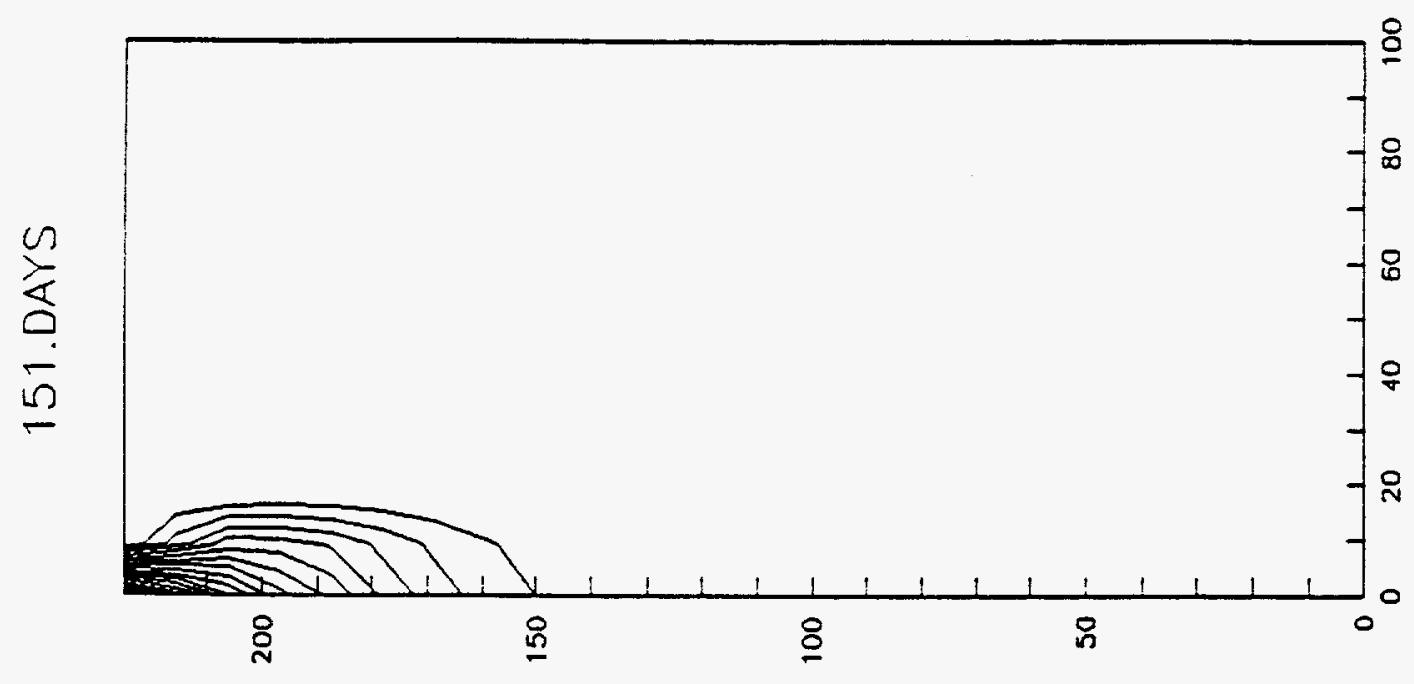

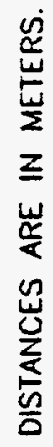
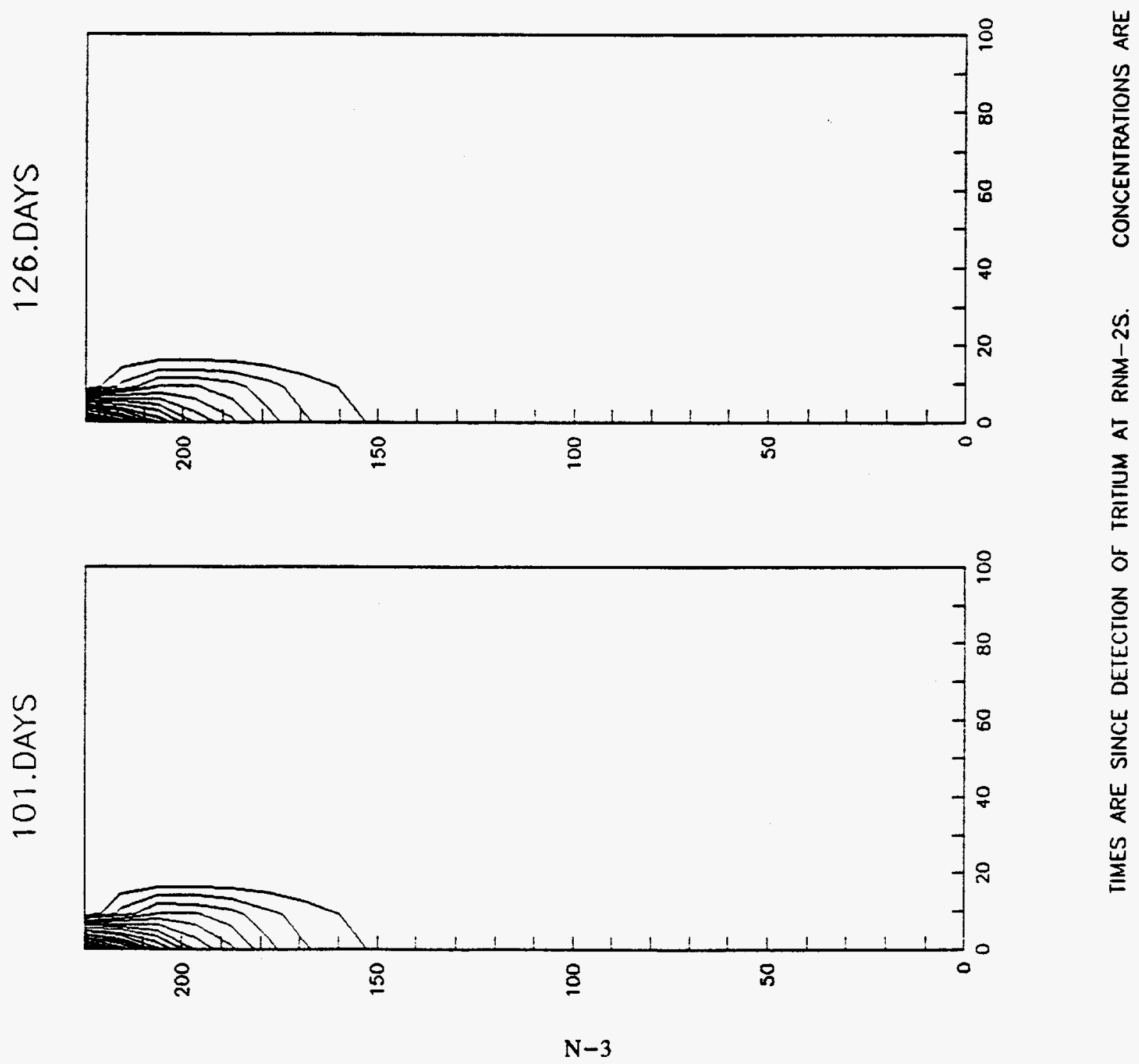

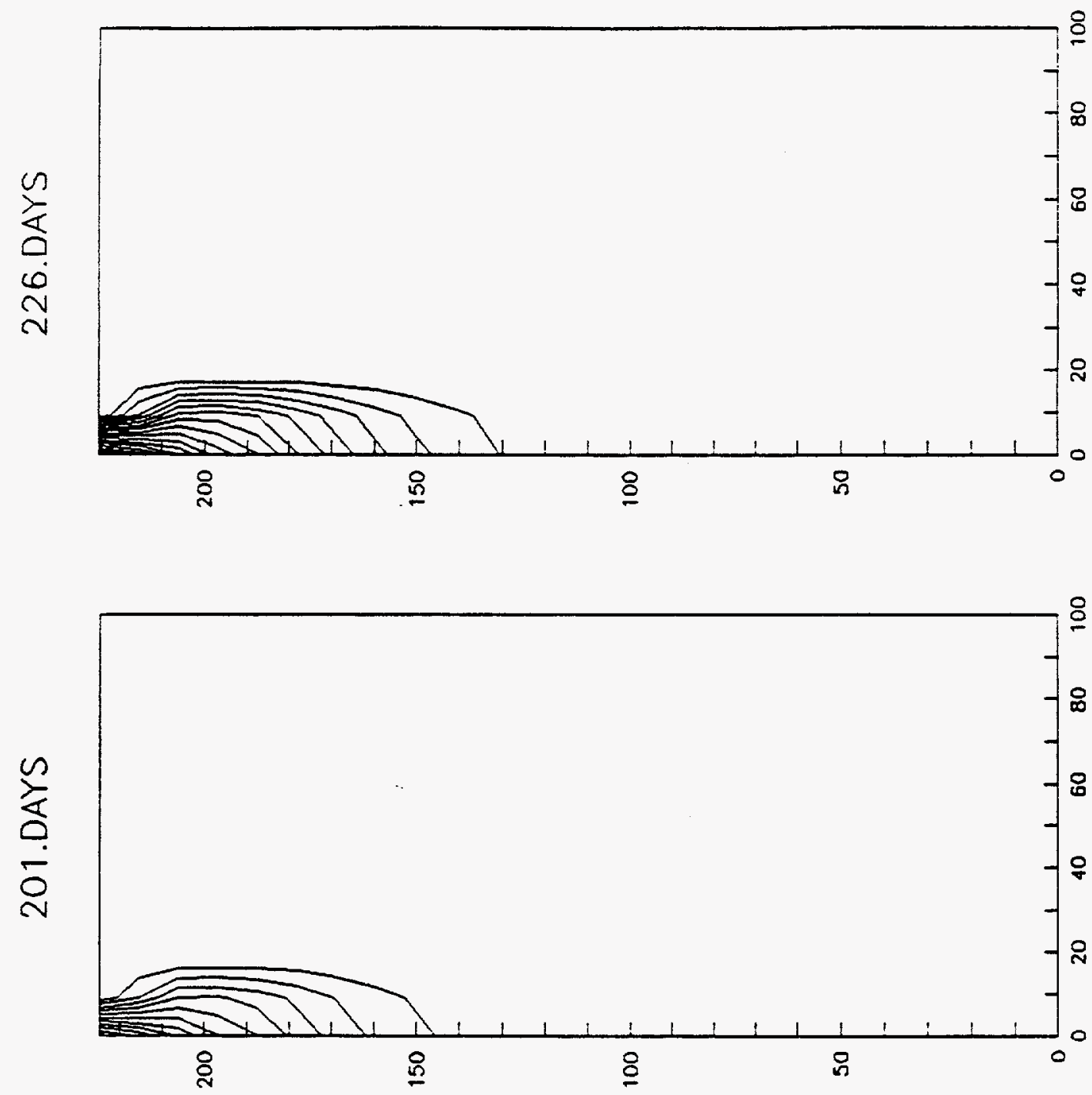

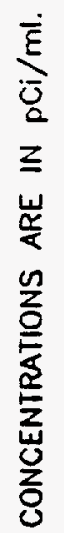

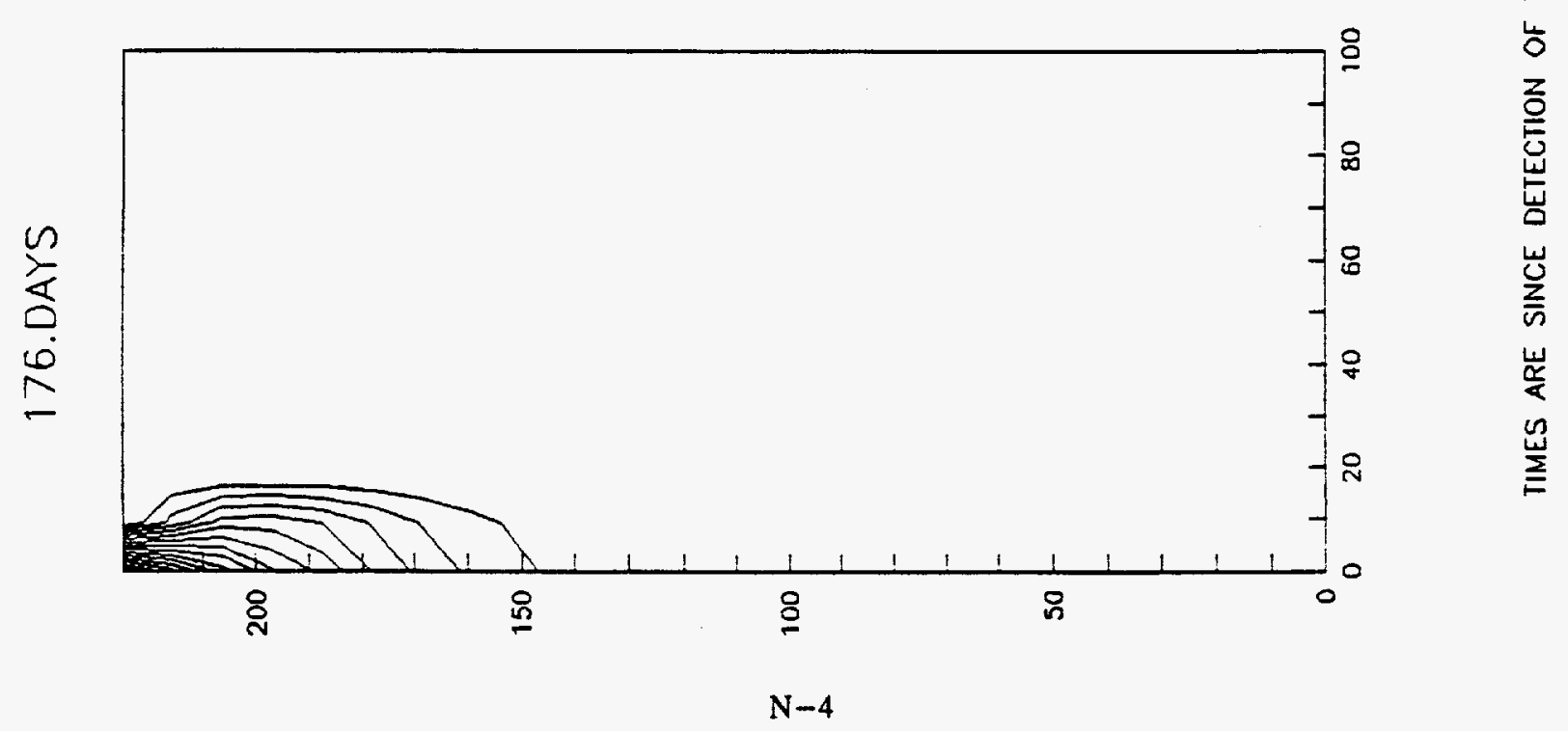




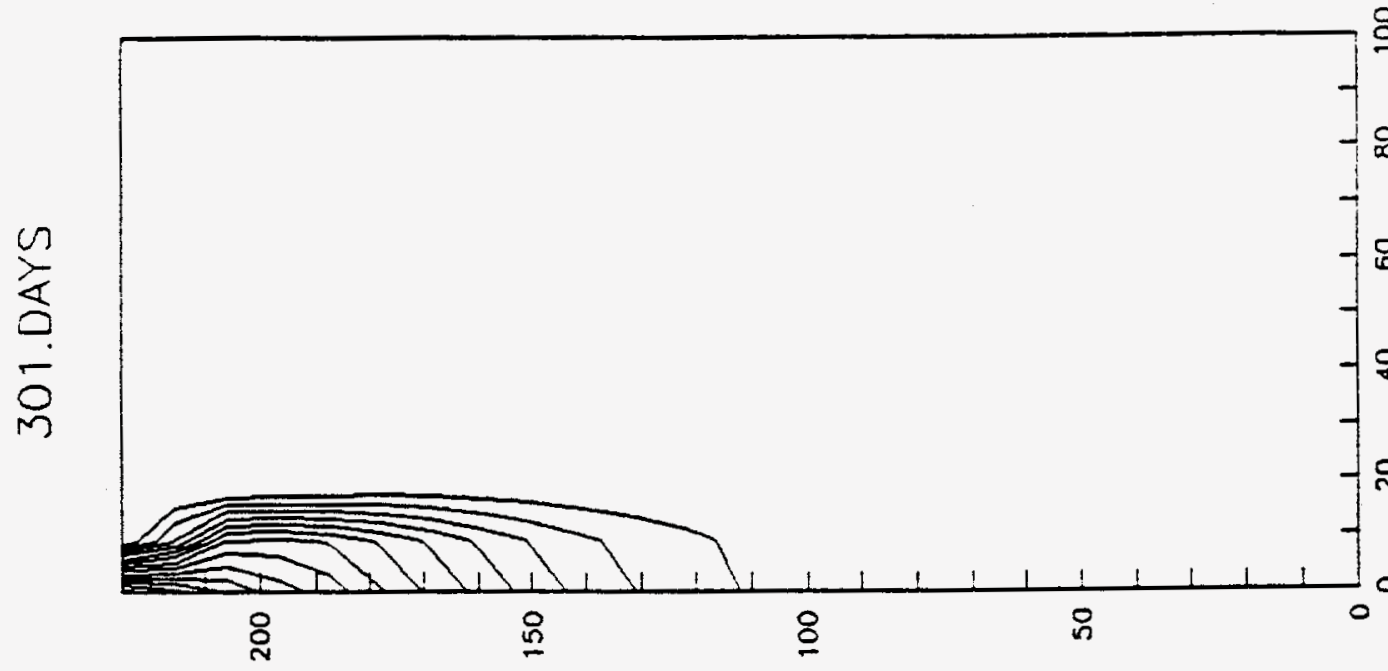

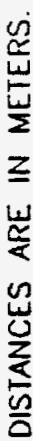
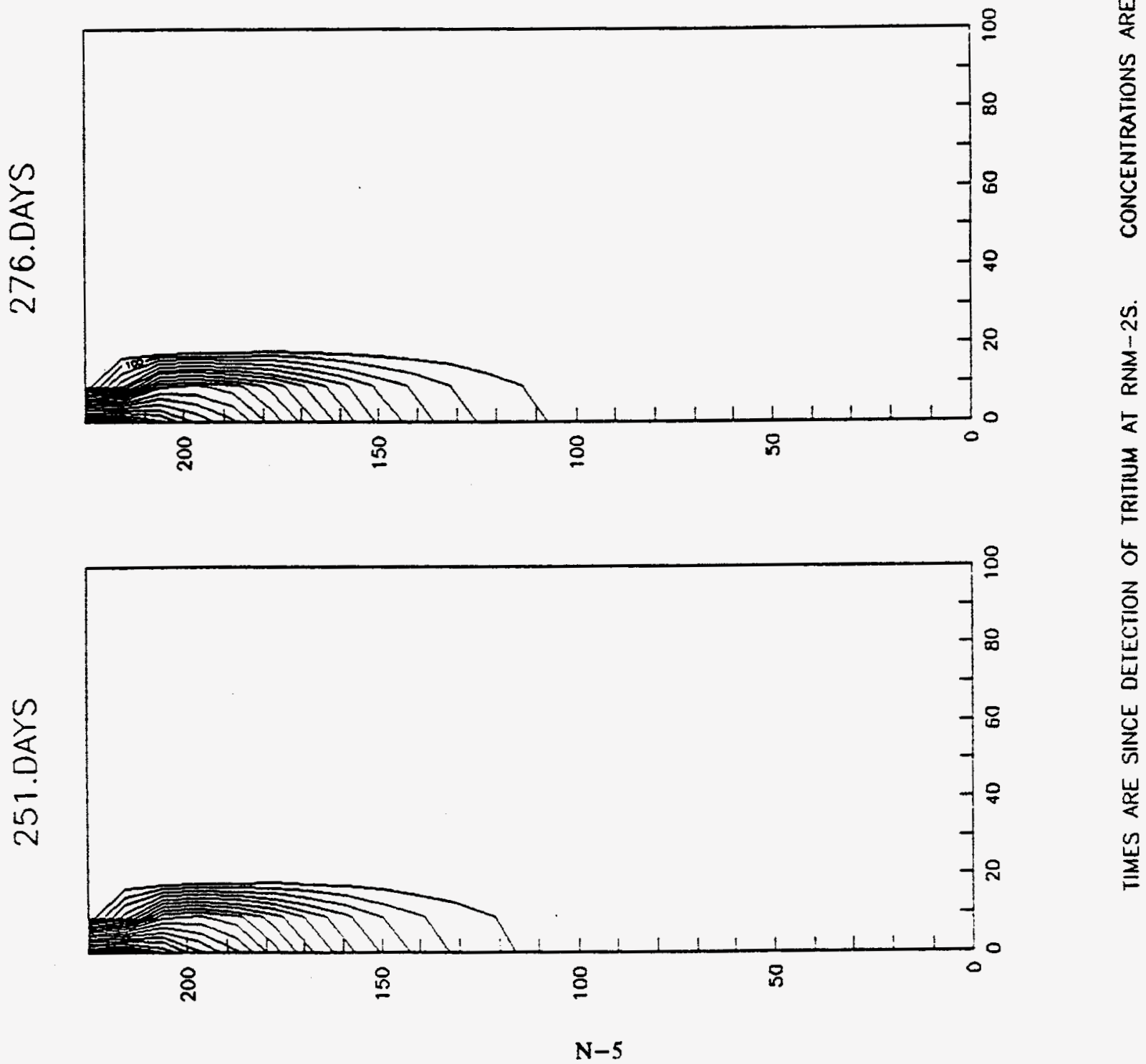

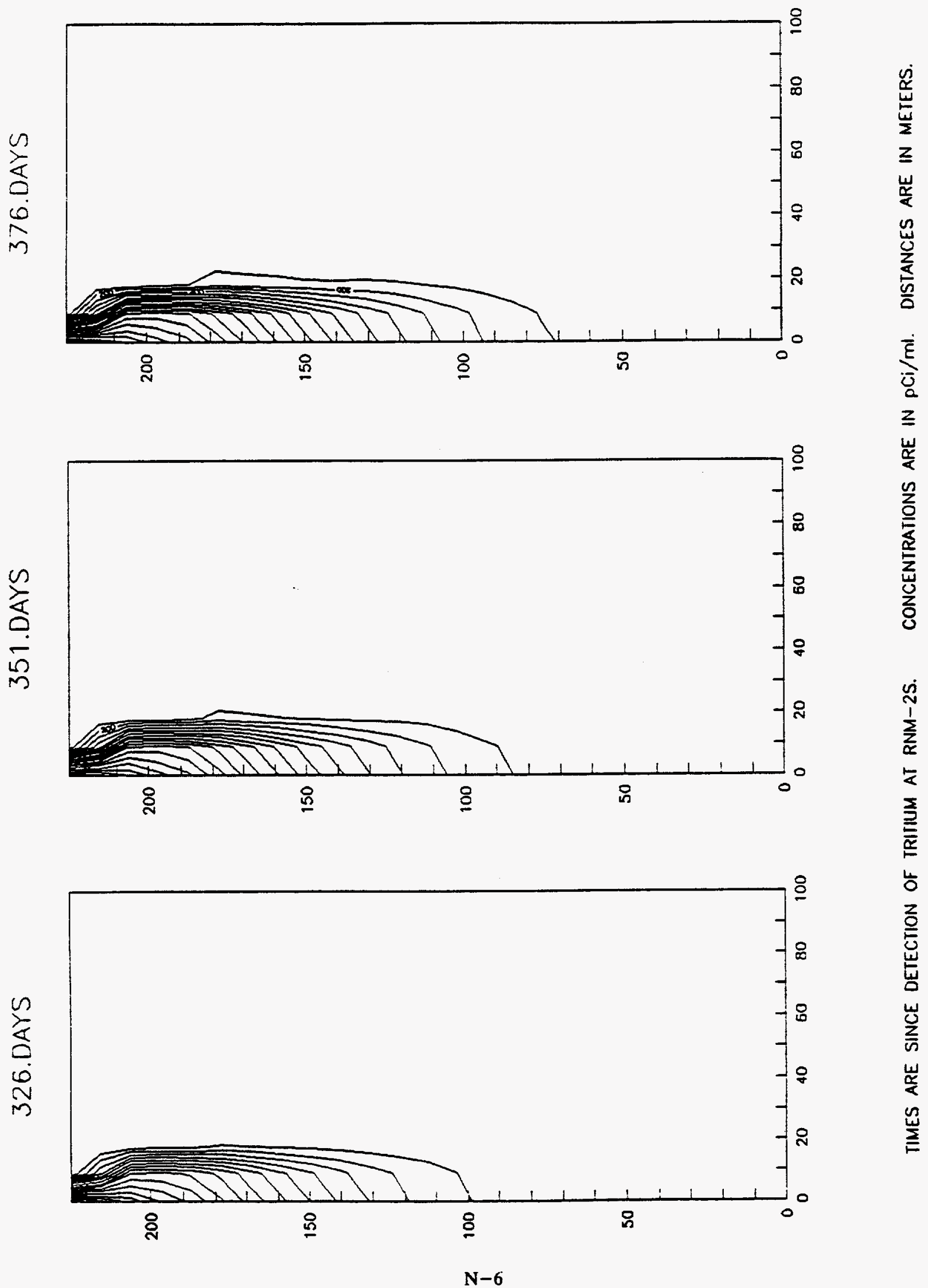


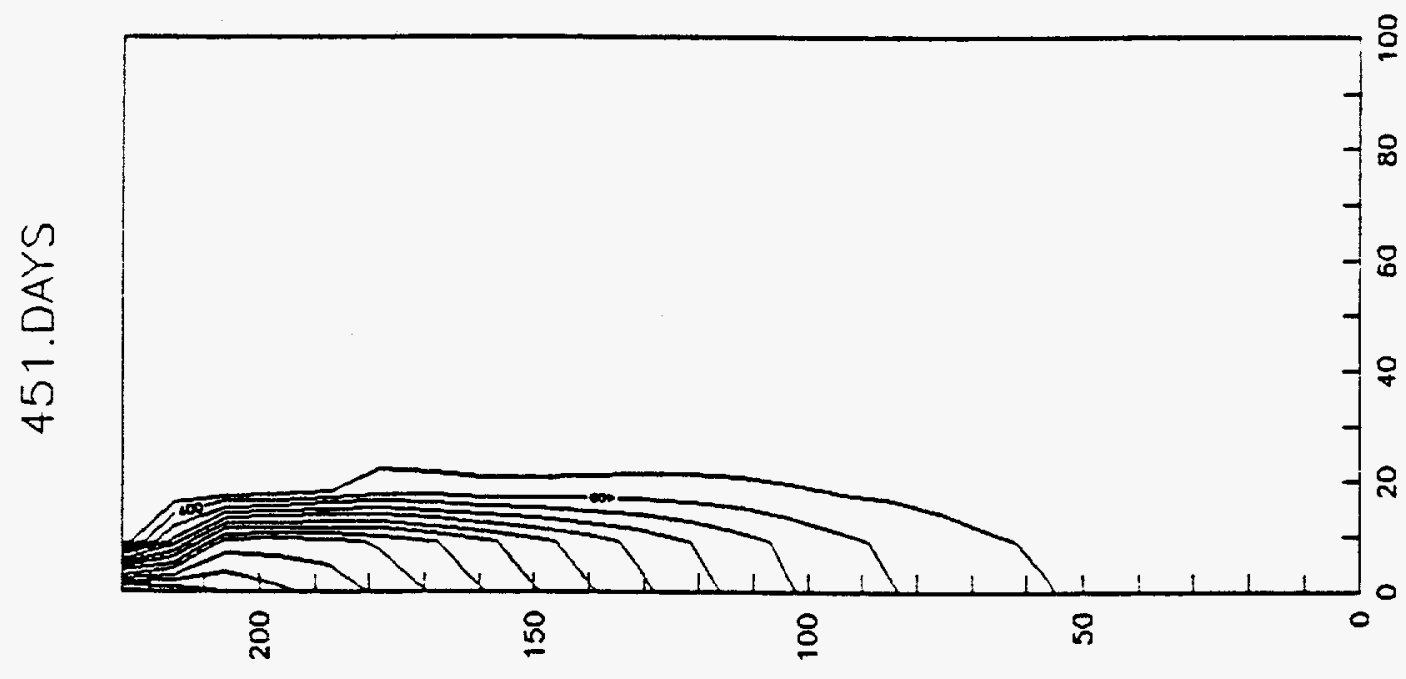

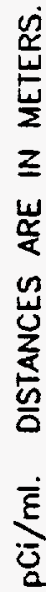

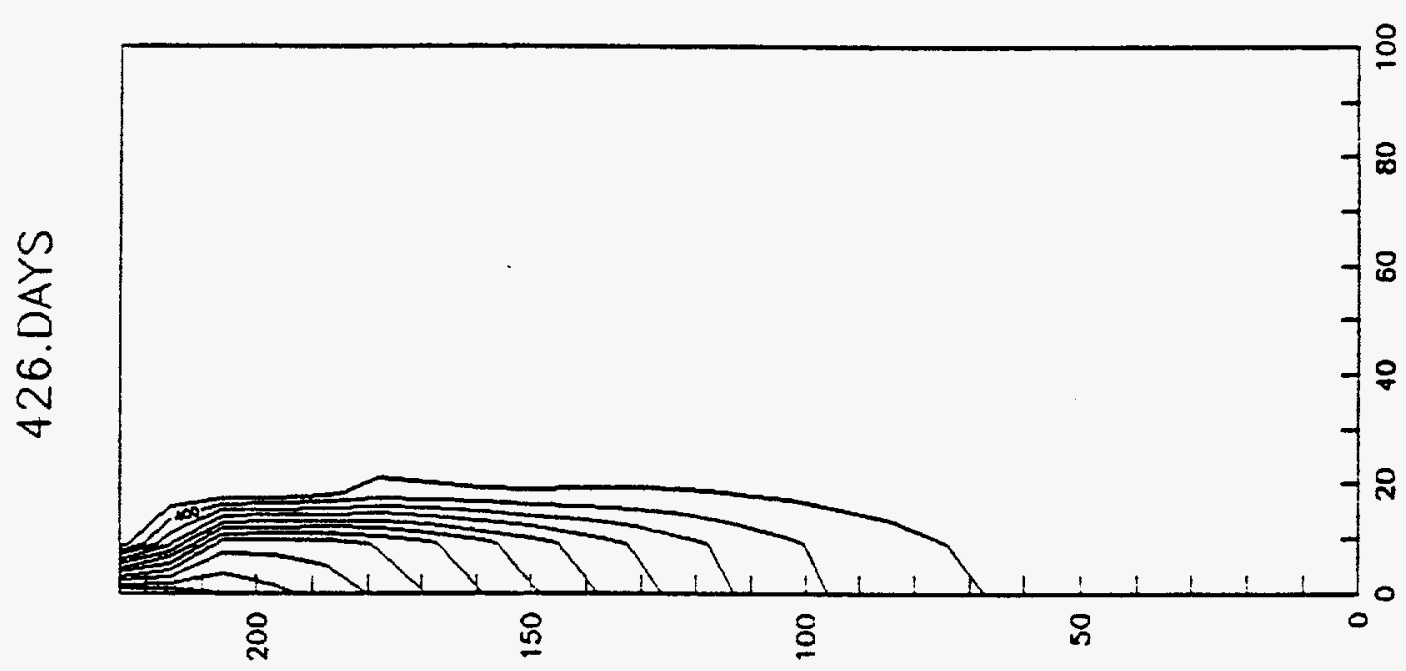

$\underline{z}$

宸

畩

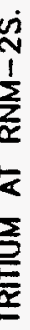

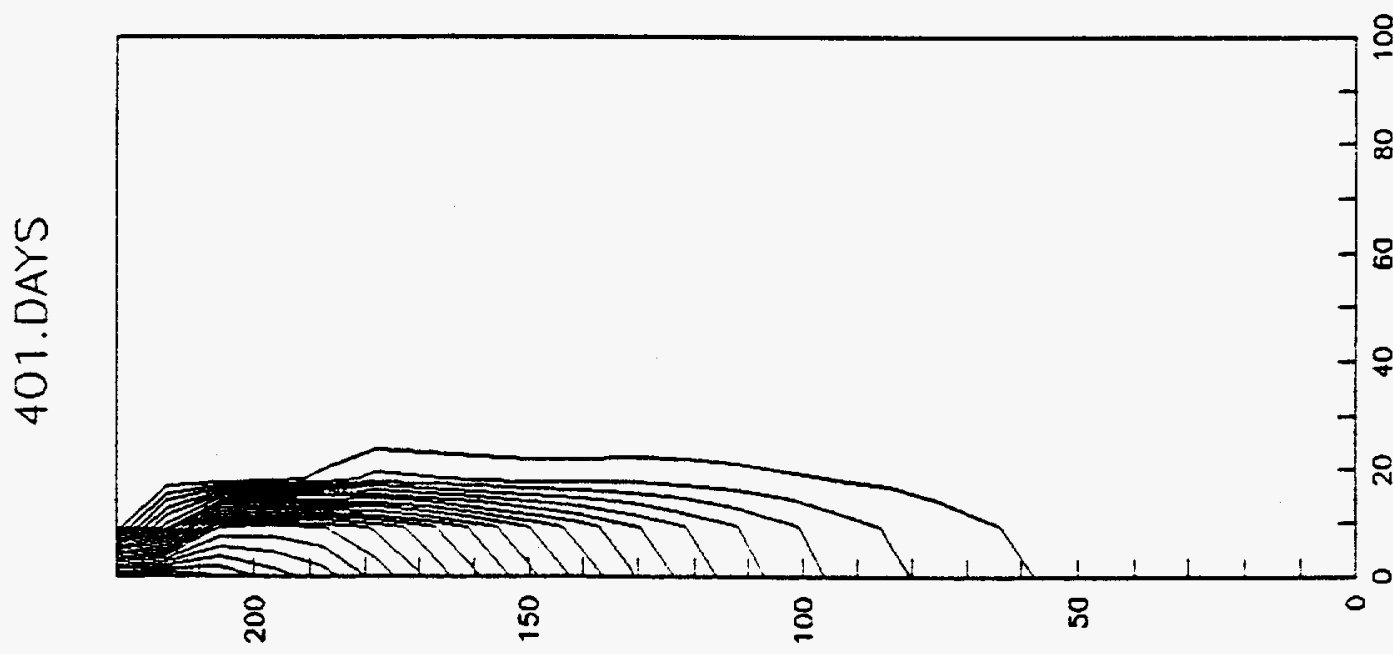

흥

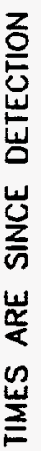

$\mathrm{N}-7$ 


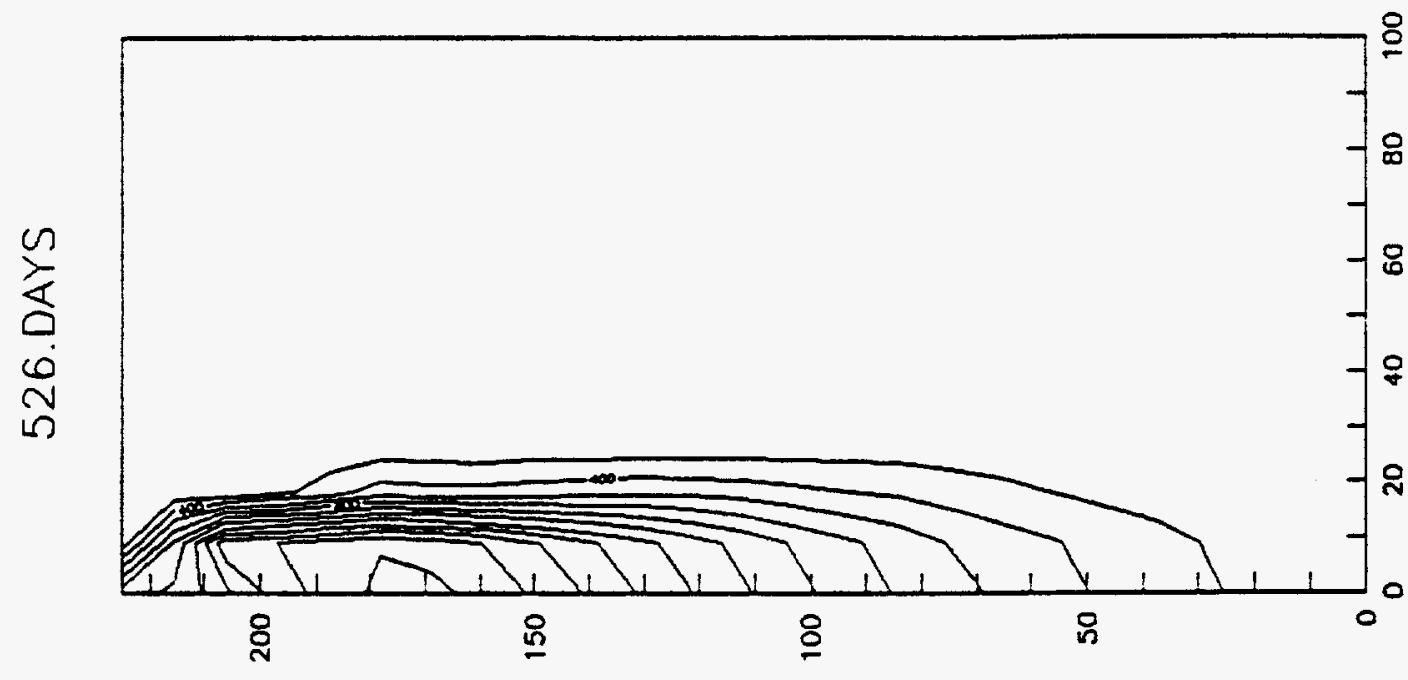

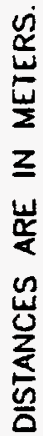
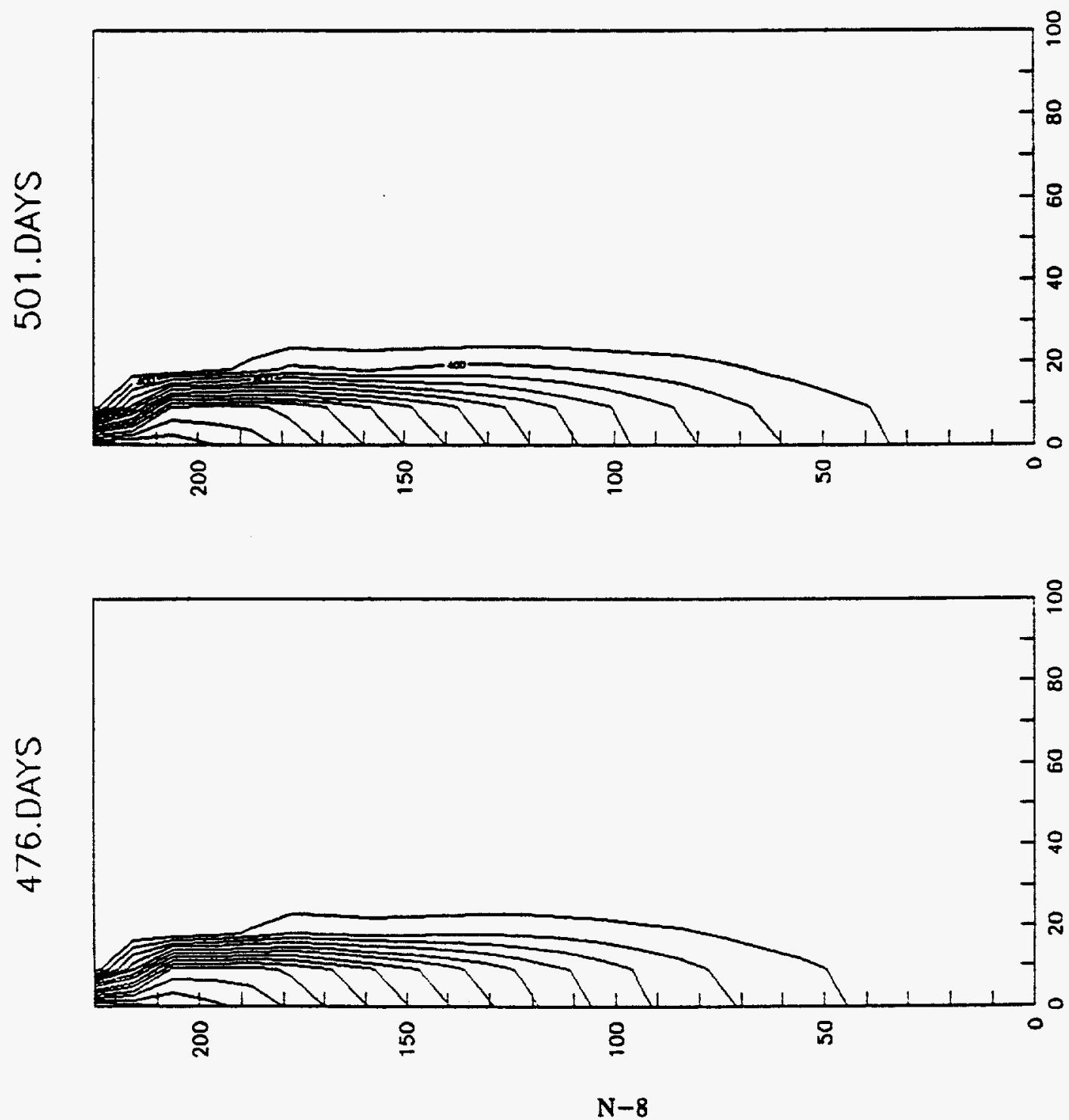


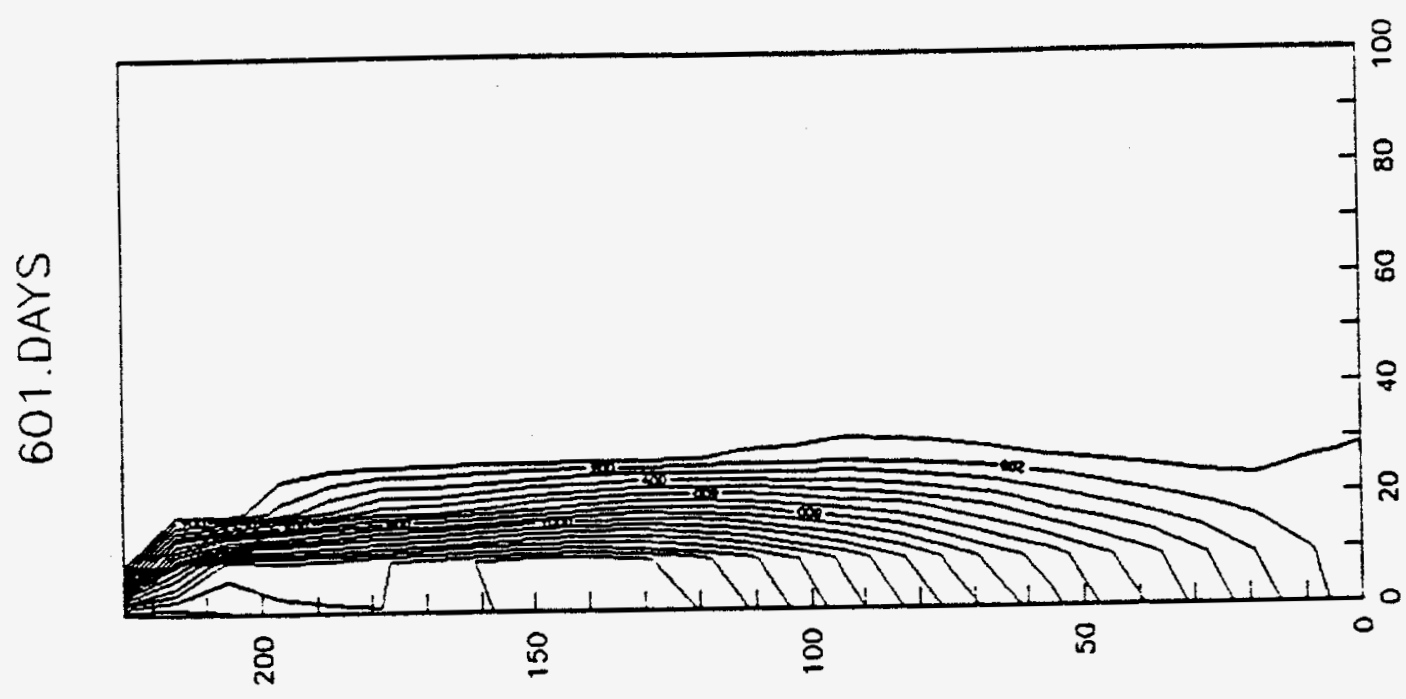

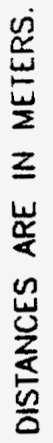

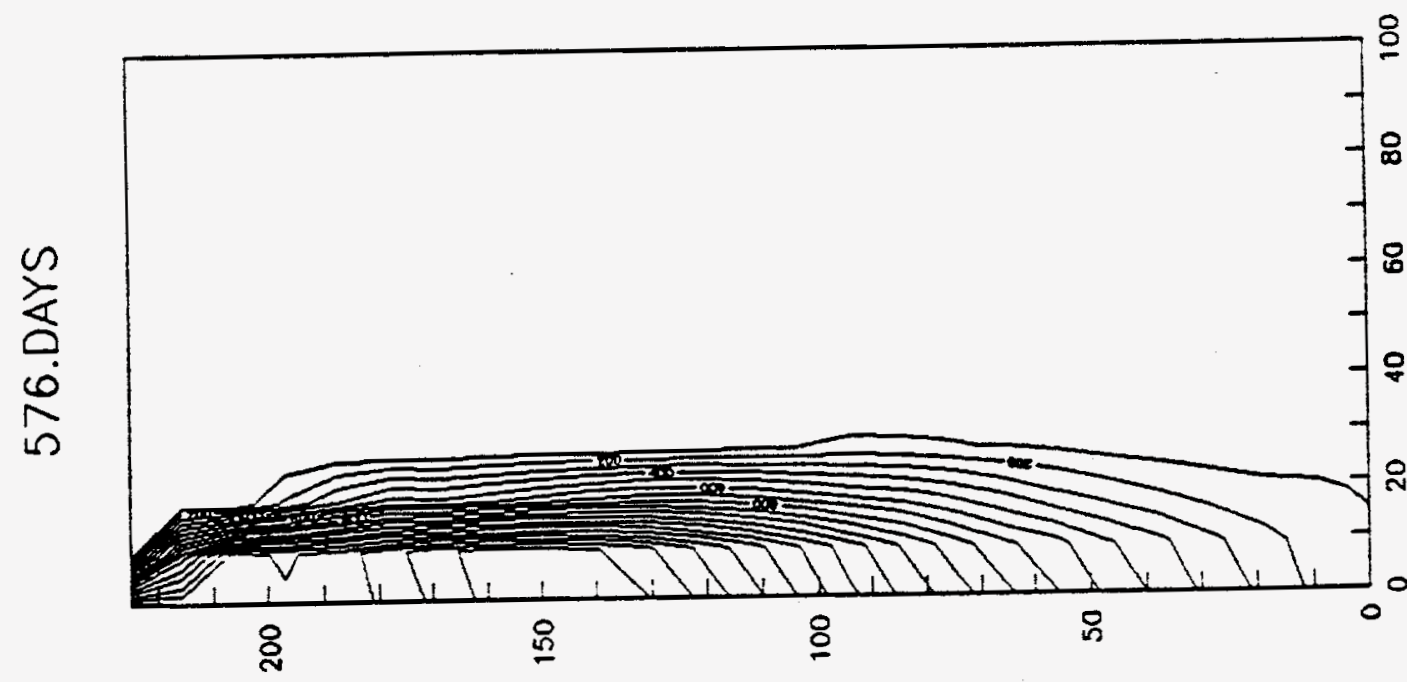

$\frac{\dot{\varepsilon}}{\dot{\sigma}}$

$\geqq$

岁

总

$\stackrel{d}{N}$
$\sum_{\alpha}^{1}$
$\frac{1}{\alpha}$
$\frac{2}{\bar{\alpha}}$

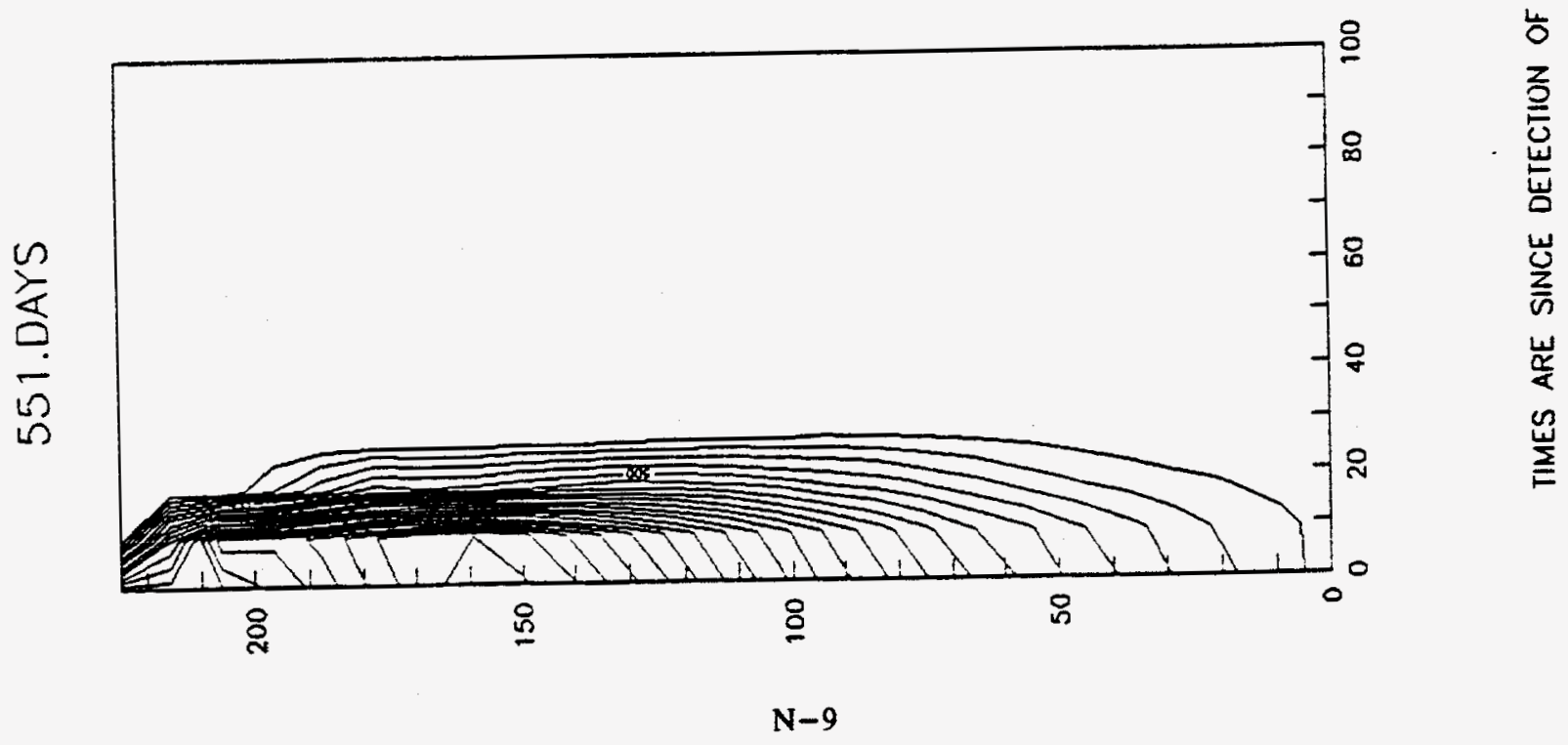



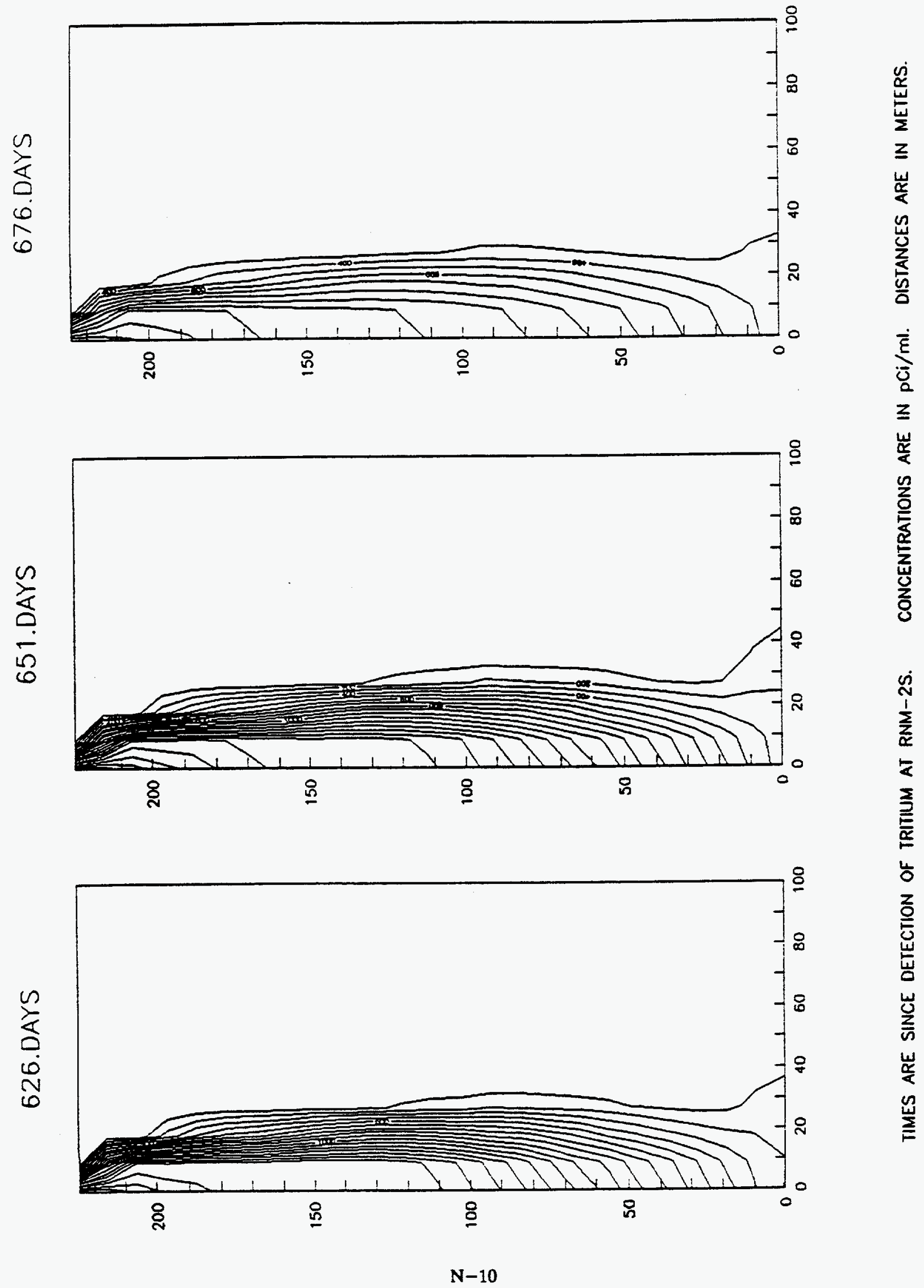


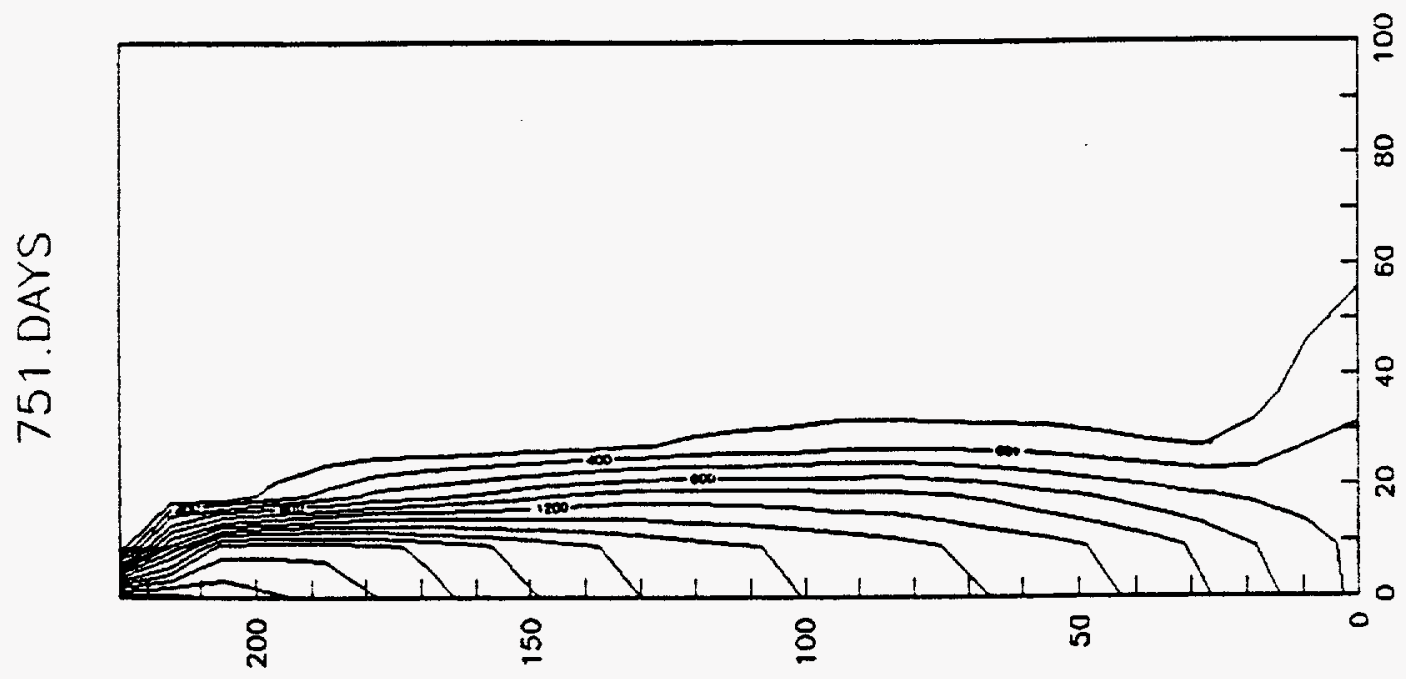

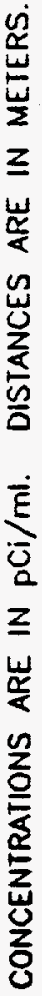

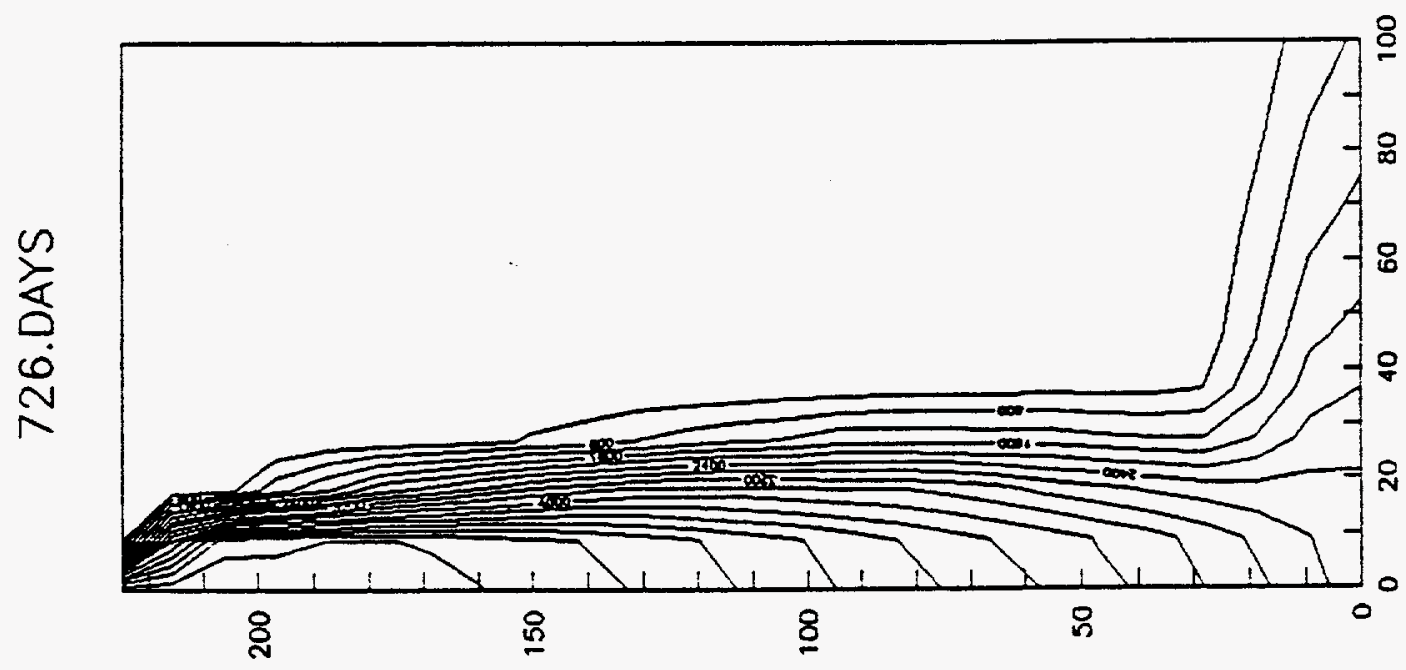

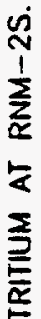

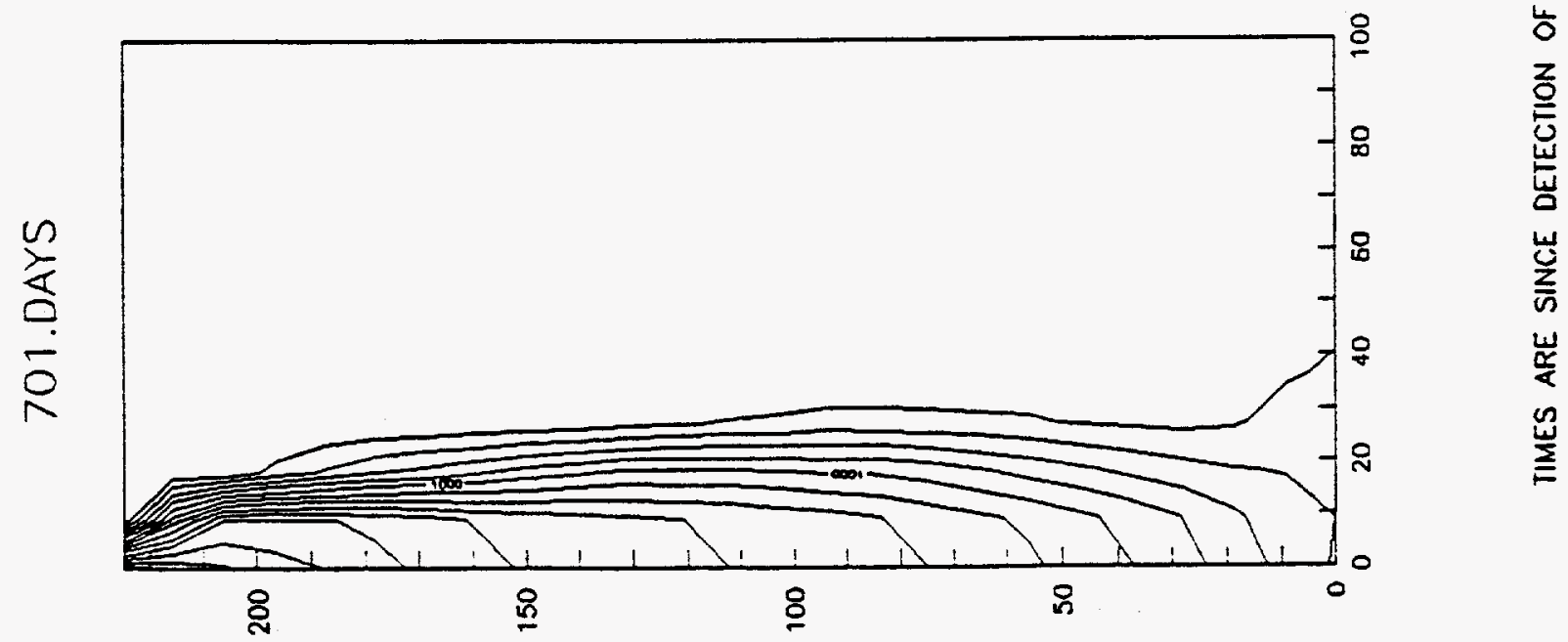

$\mathrm{N}-11$ 

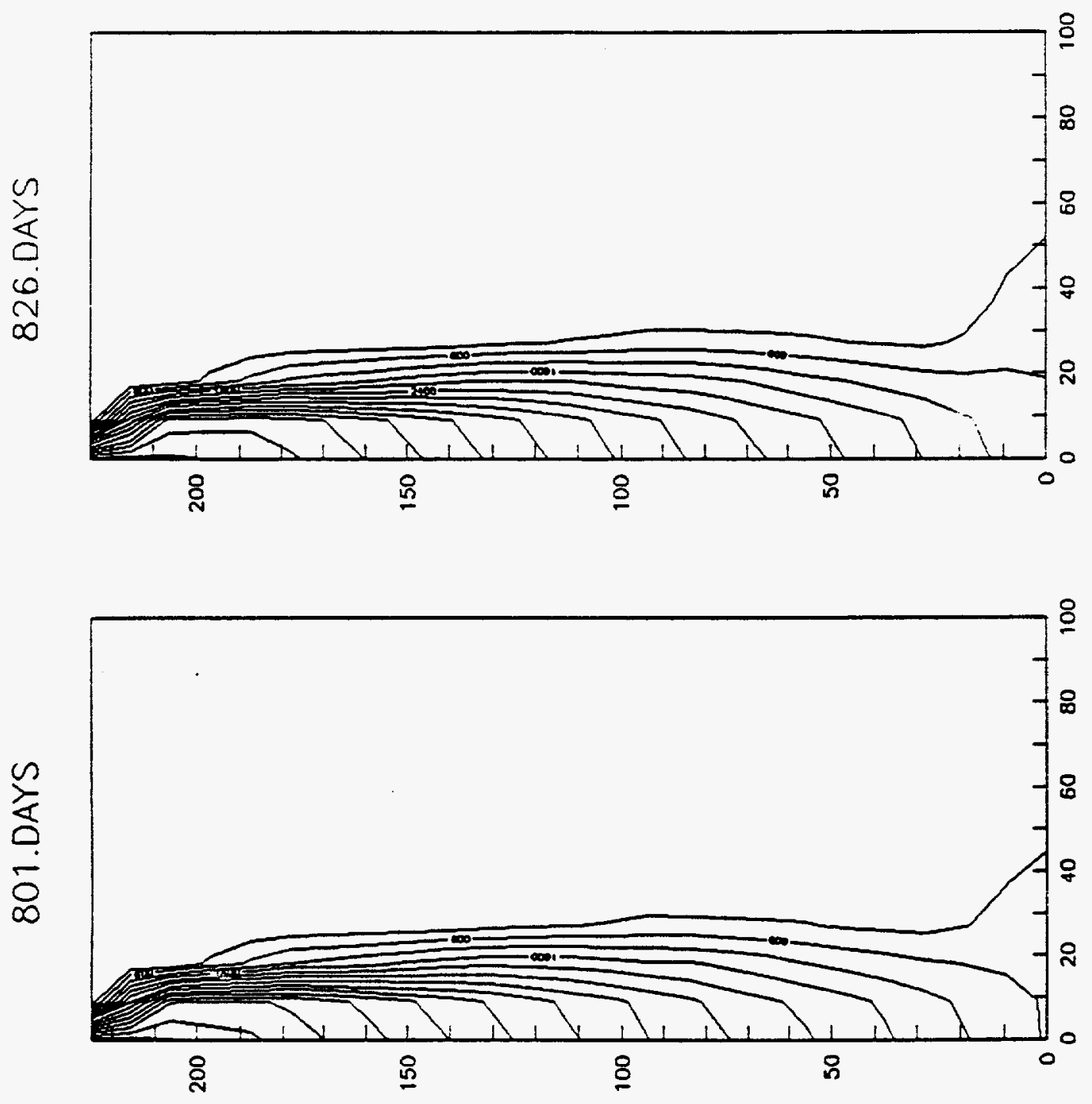

छั

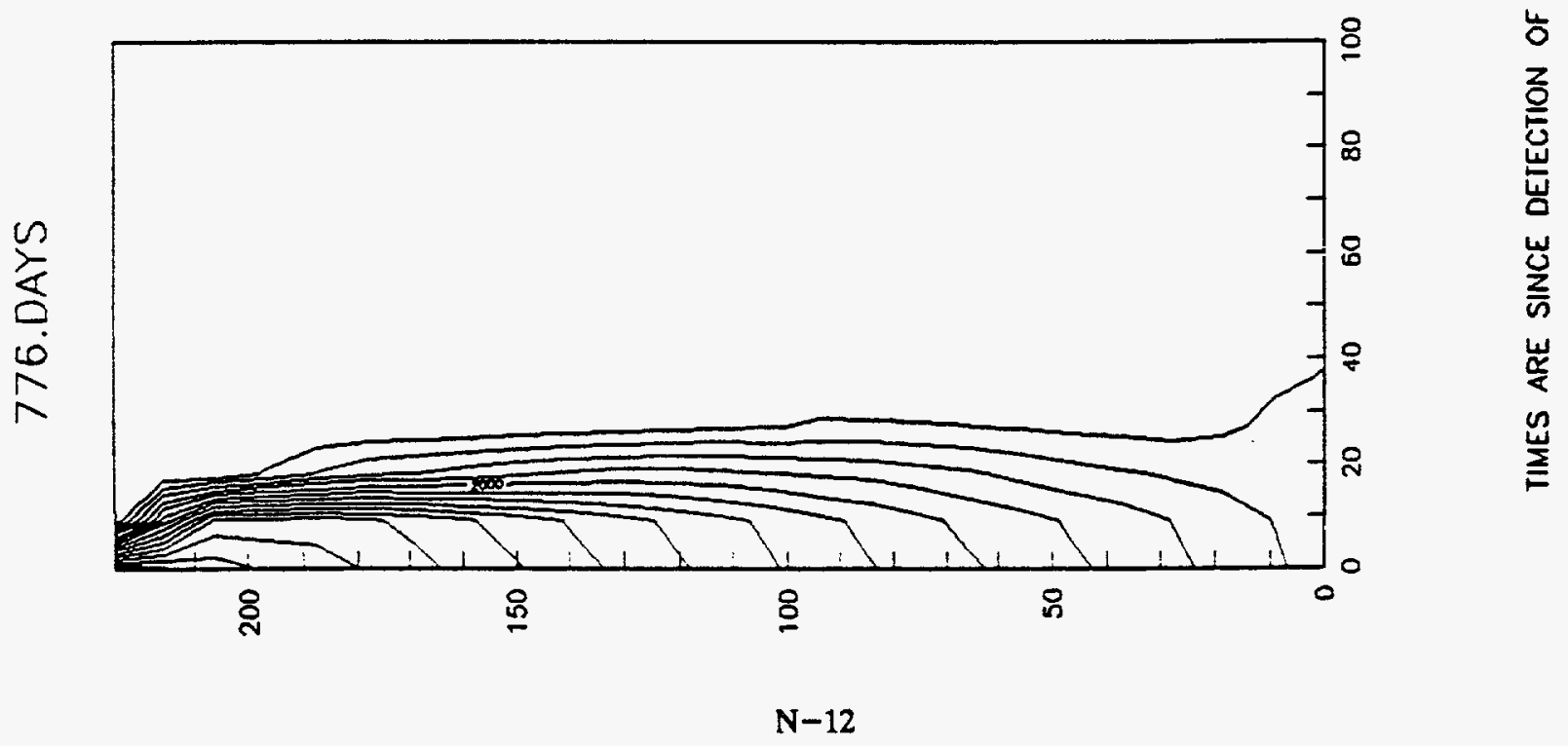



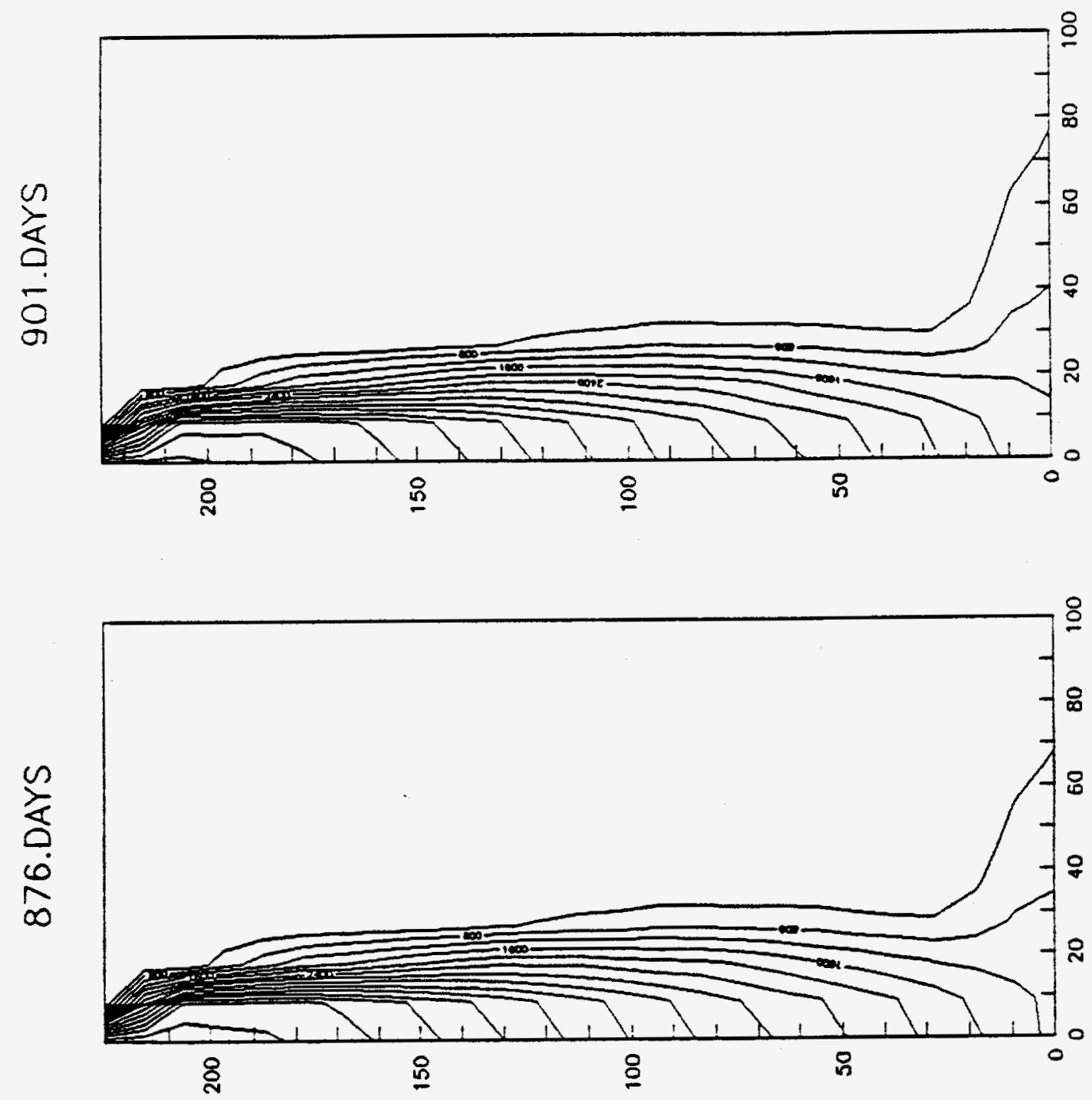

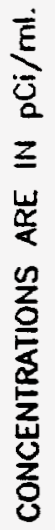

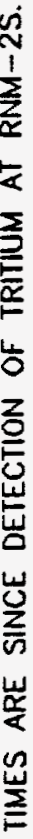

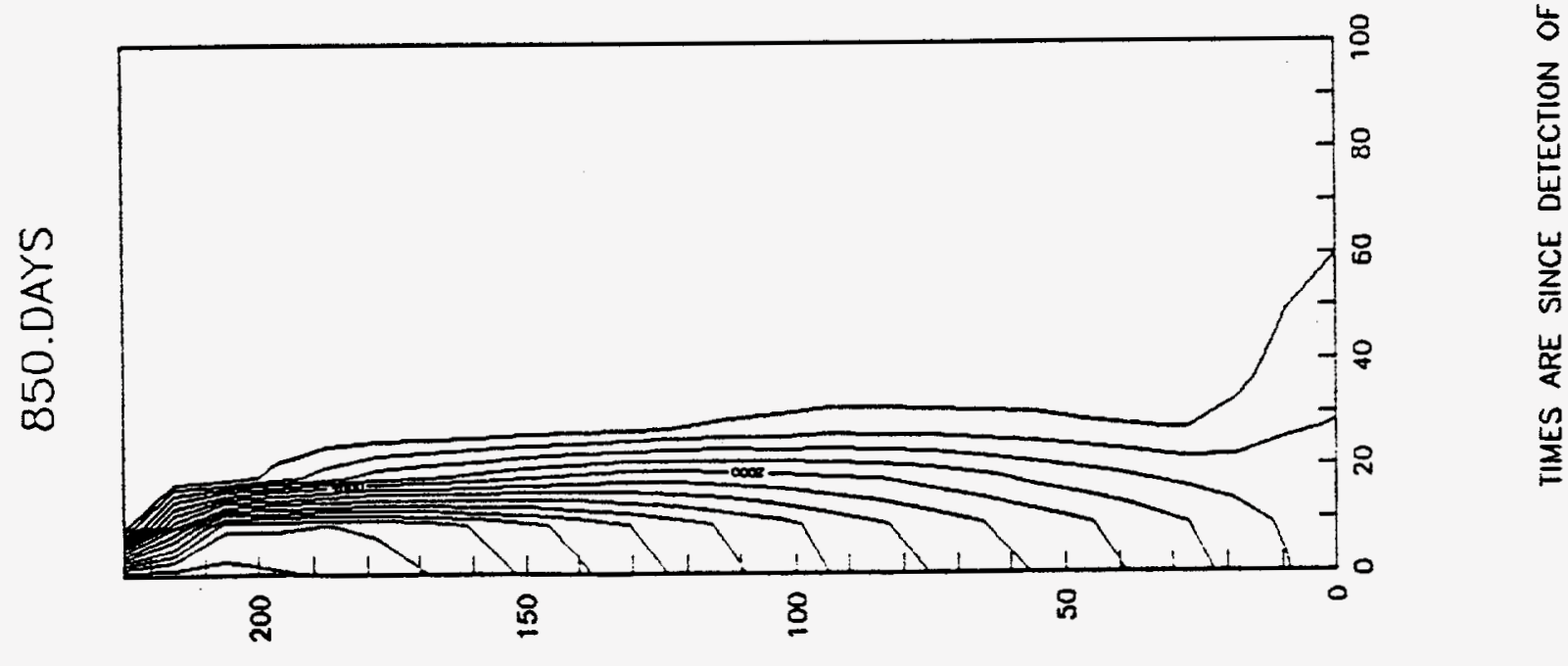




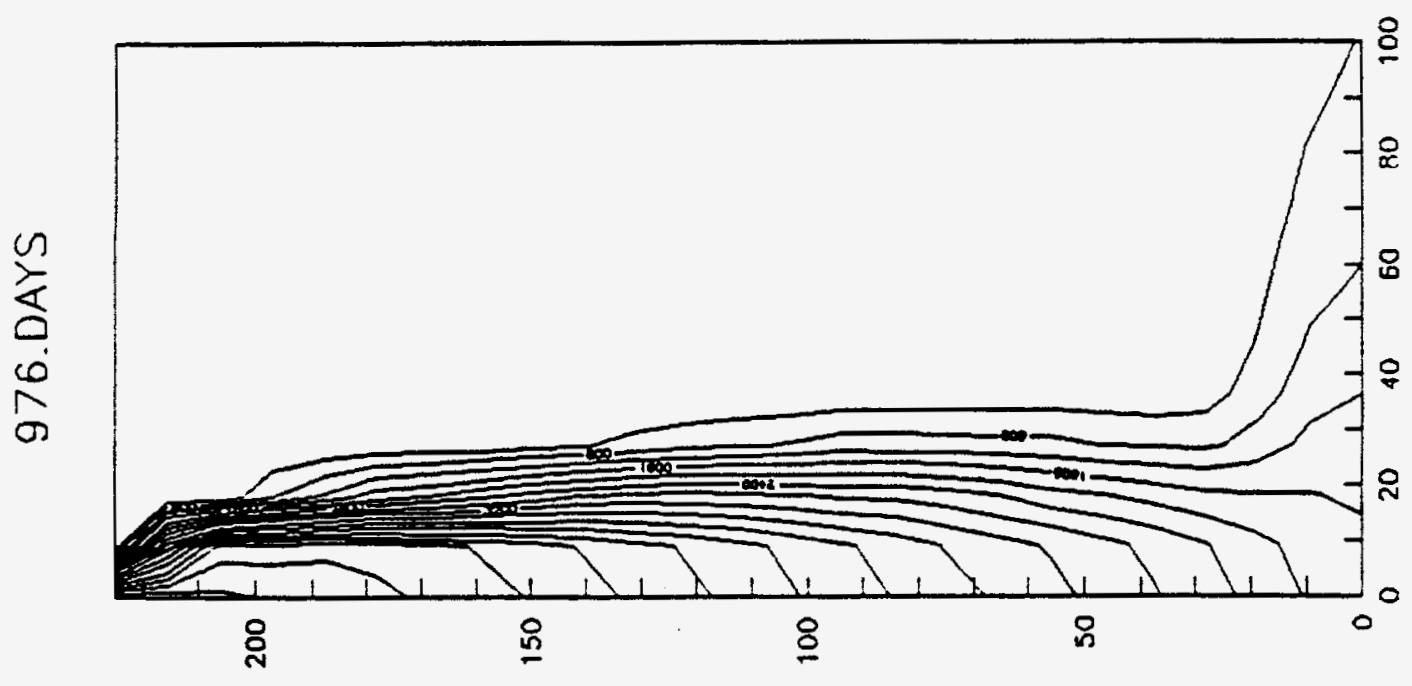

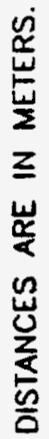

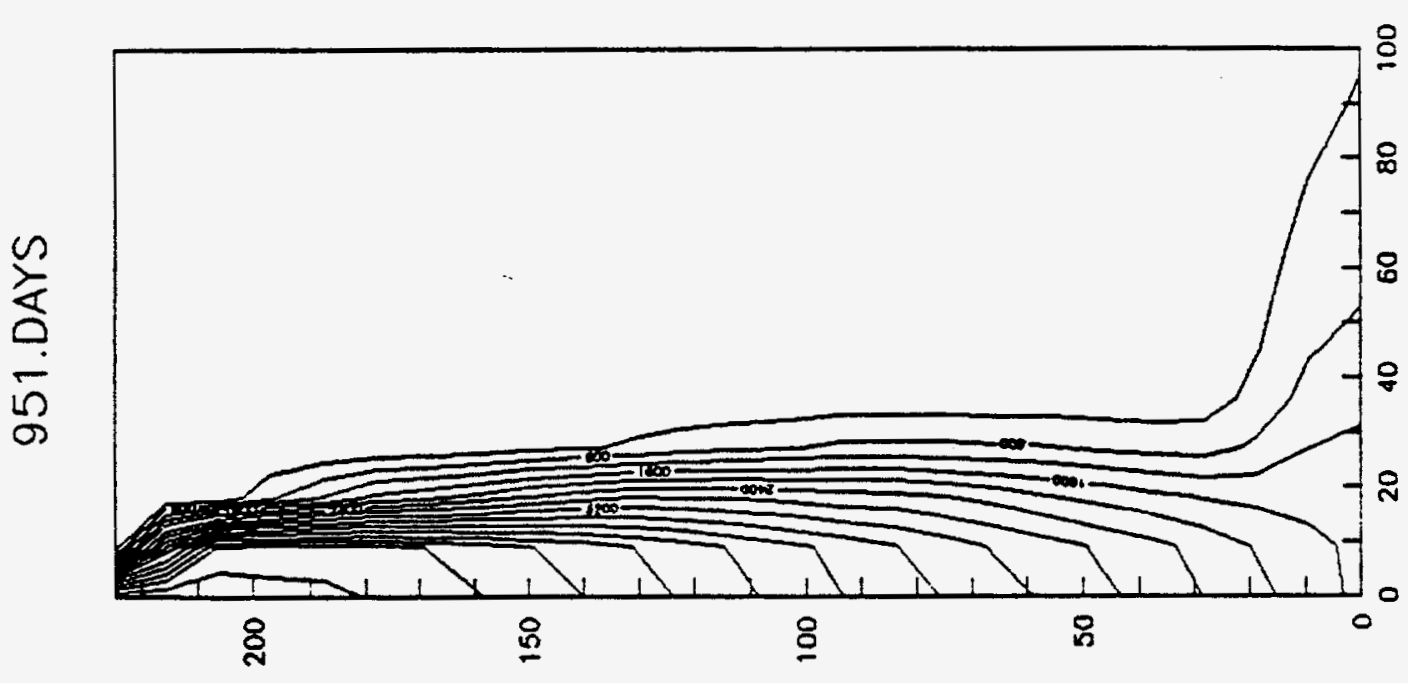

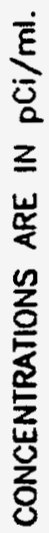

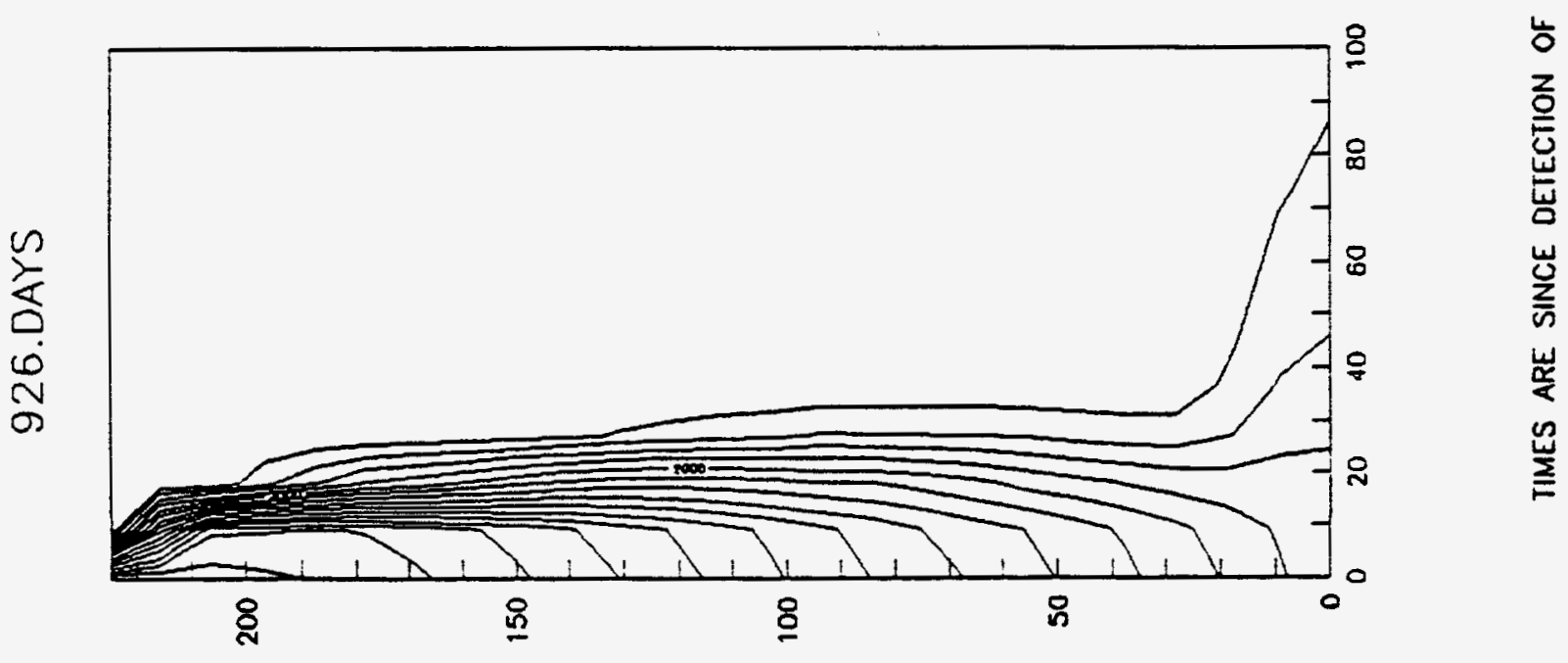




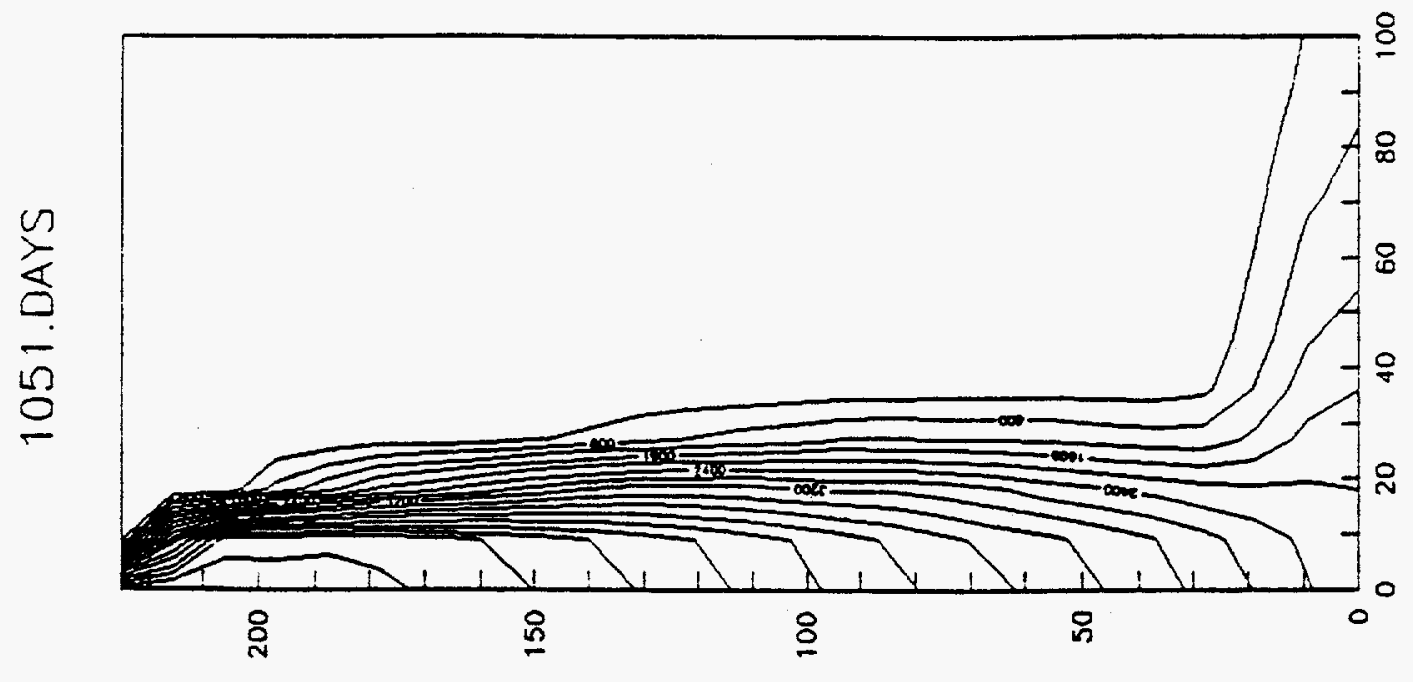

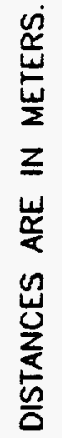
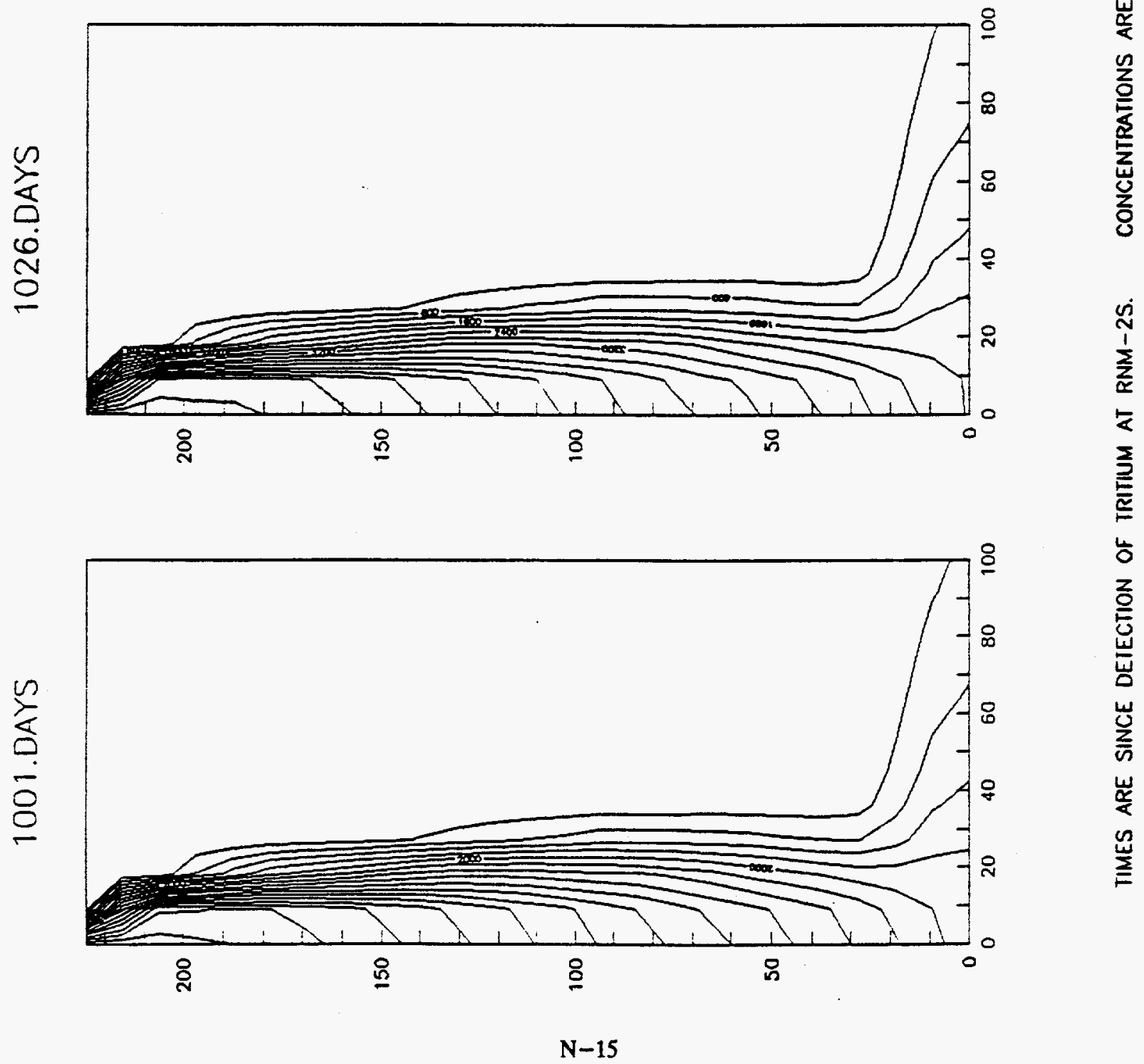


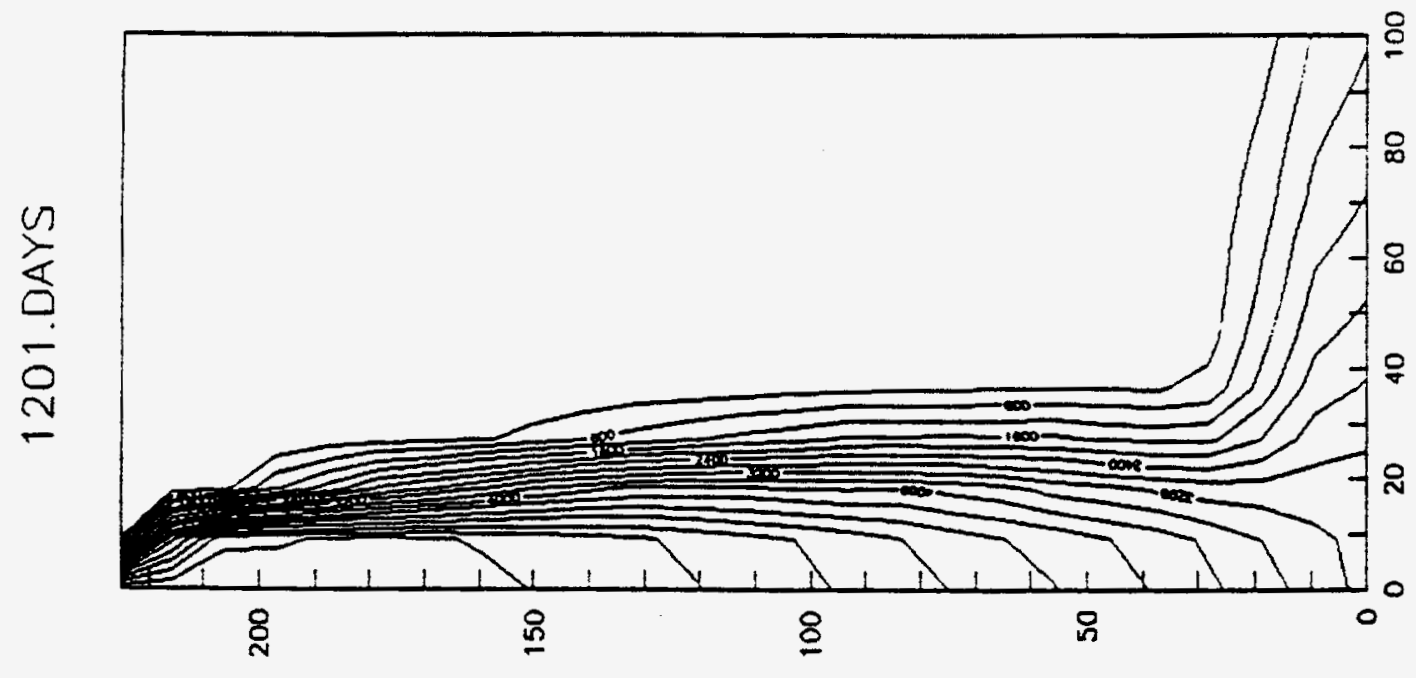

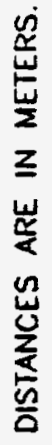
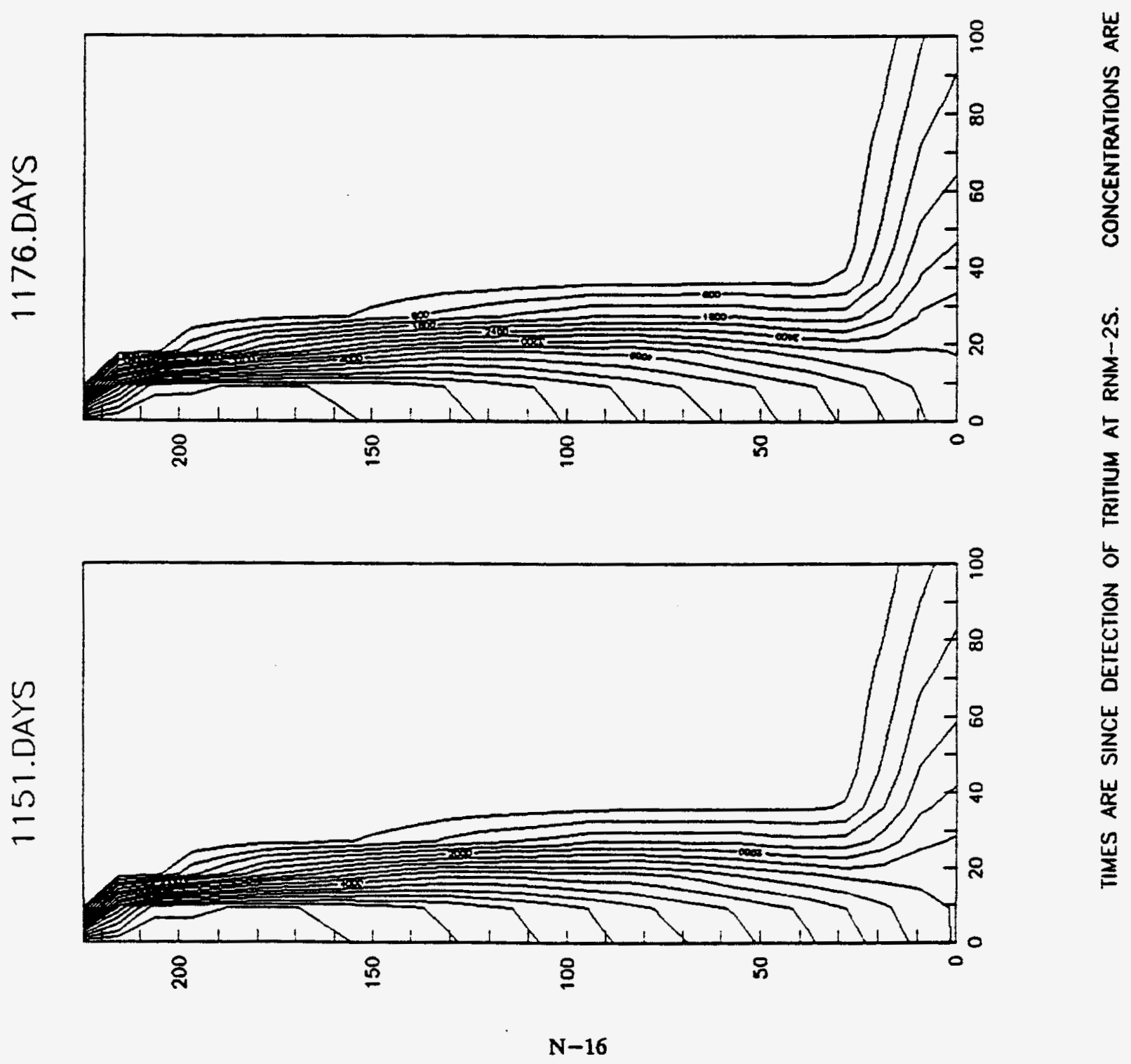


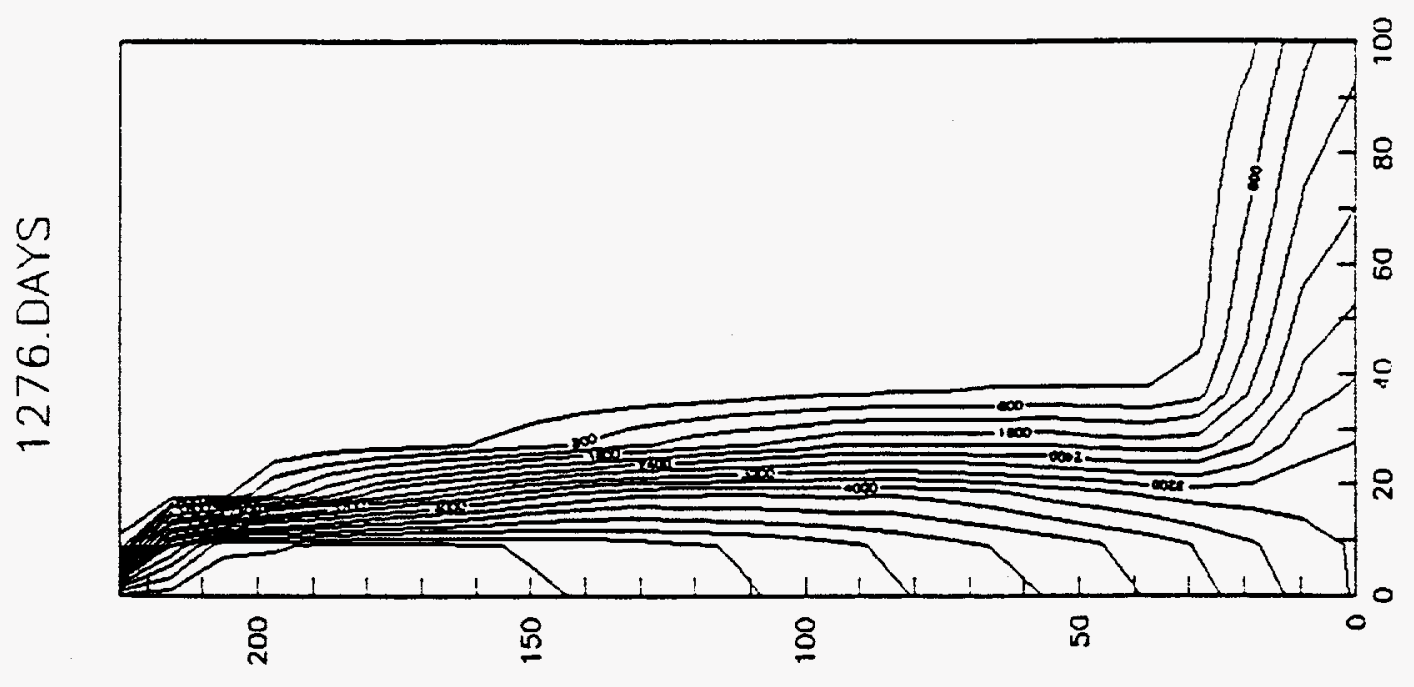

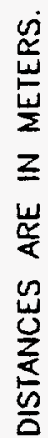
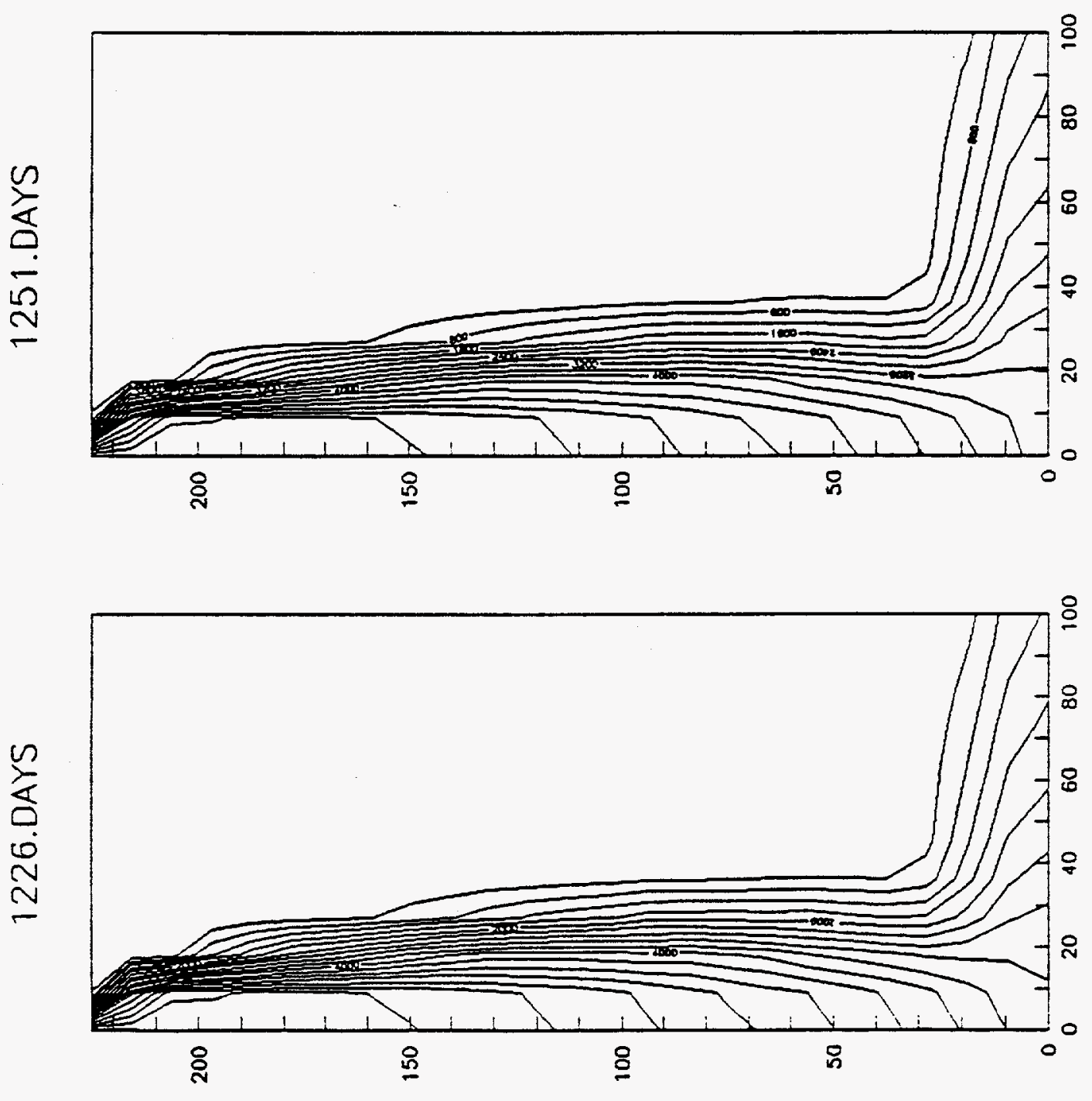

$\mathrm{N}-17$ 


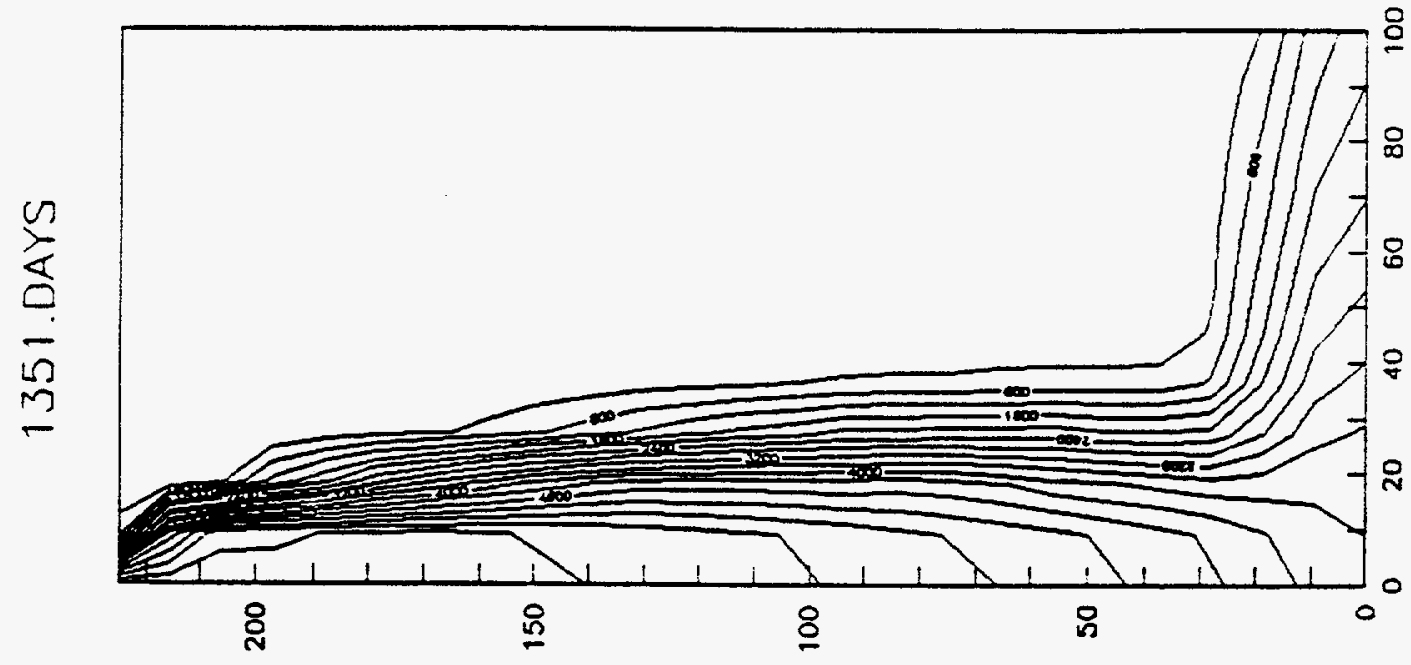

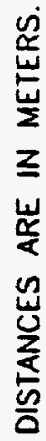

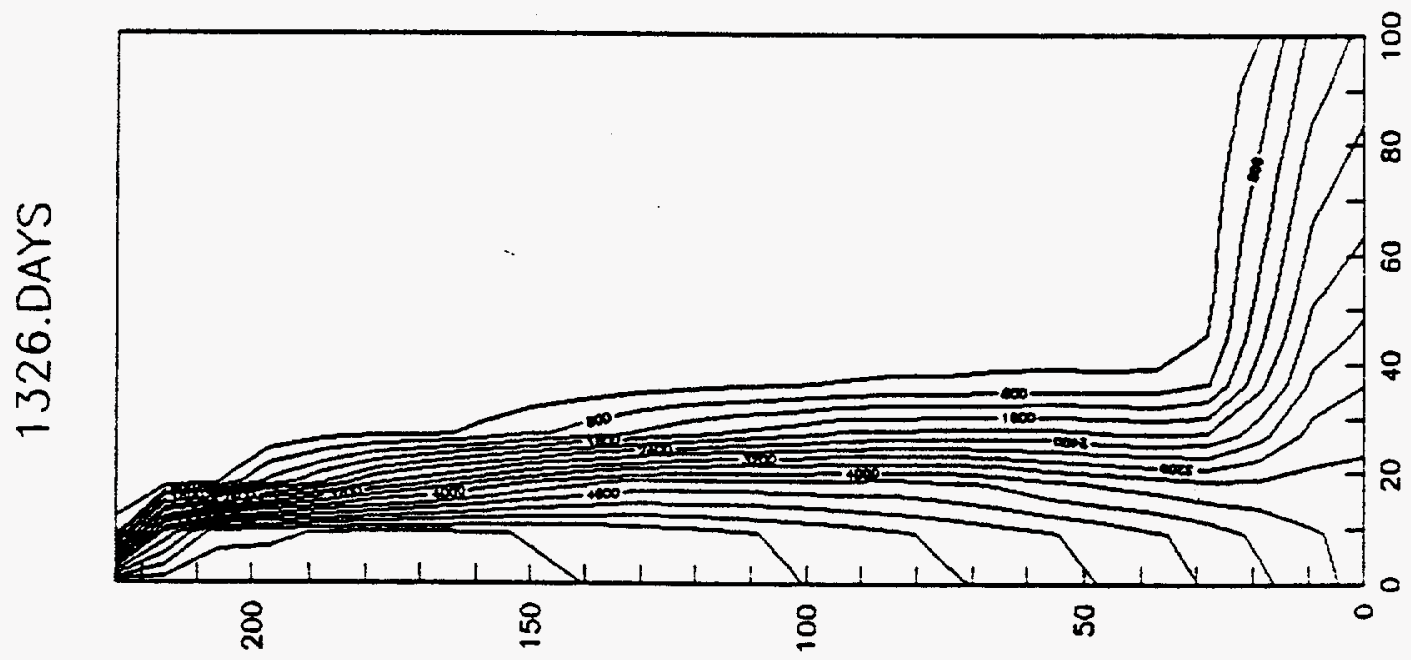

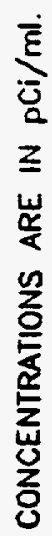

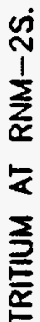

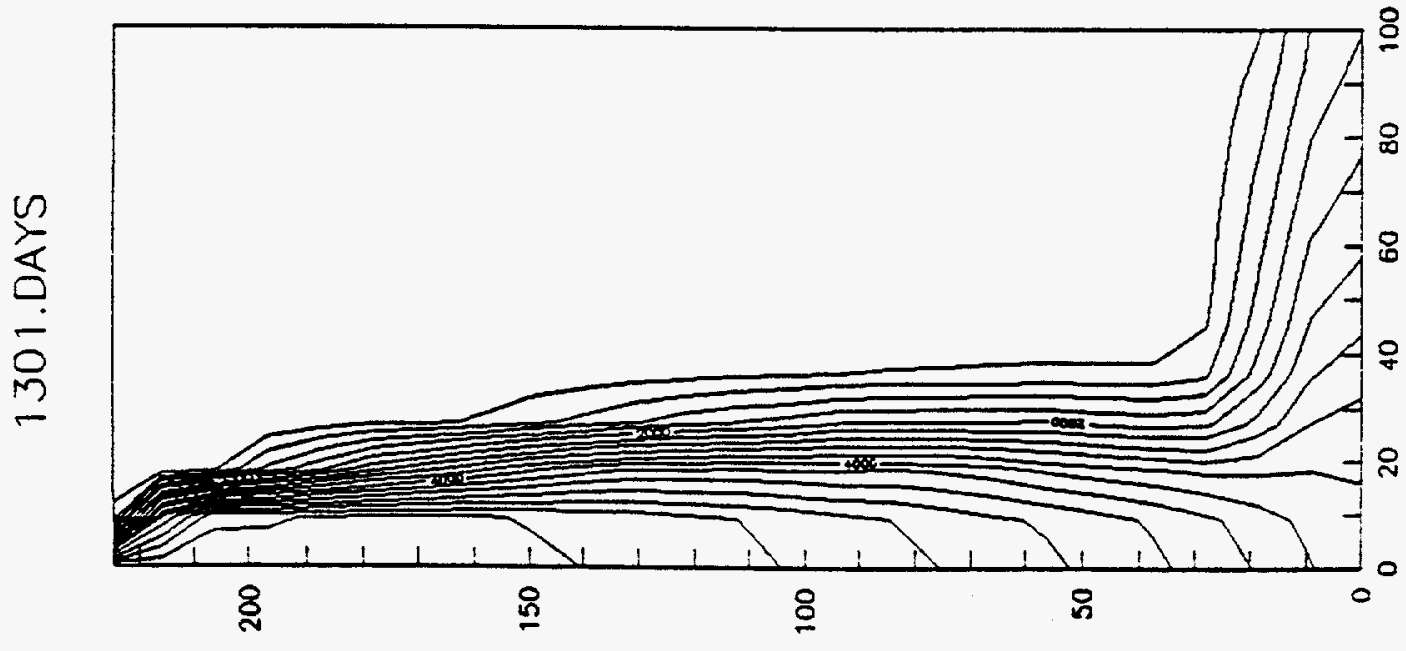

岁

$$
N-18
$$




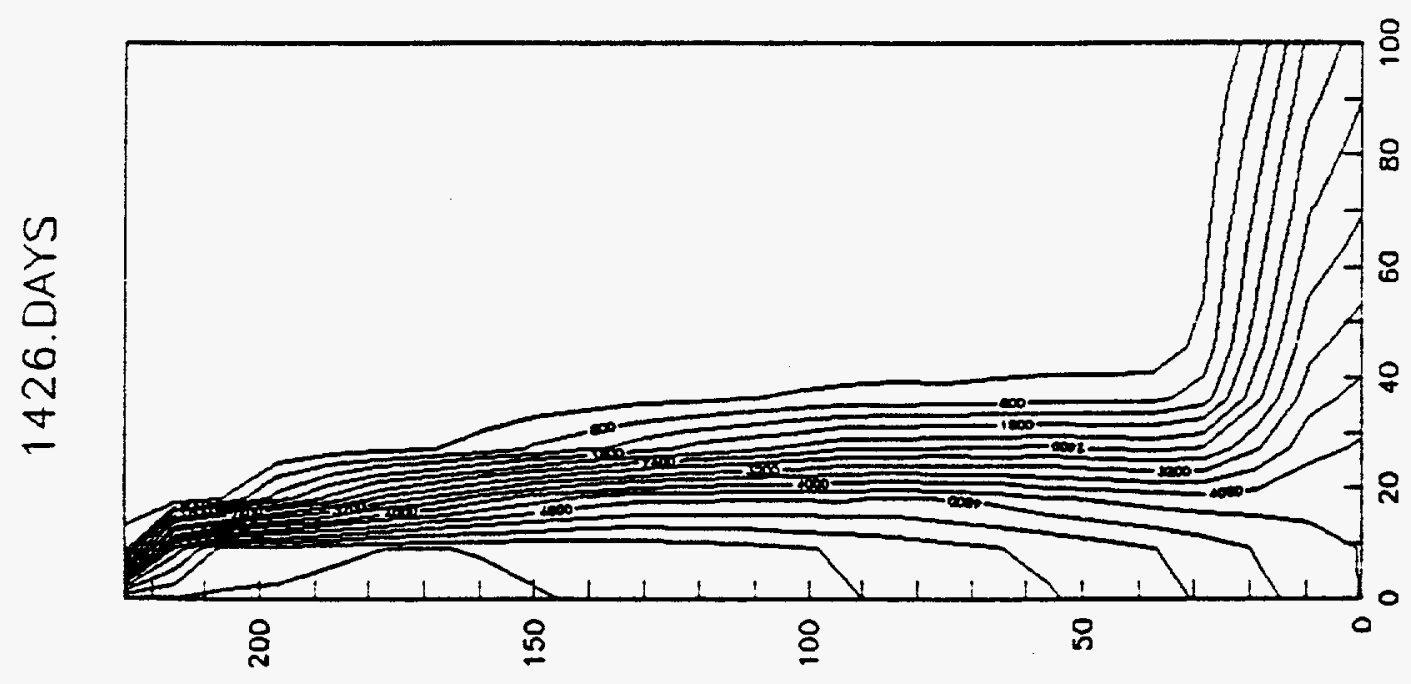

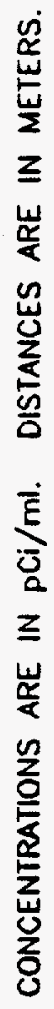
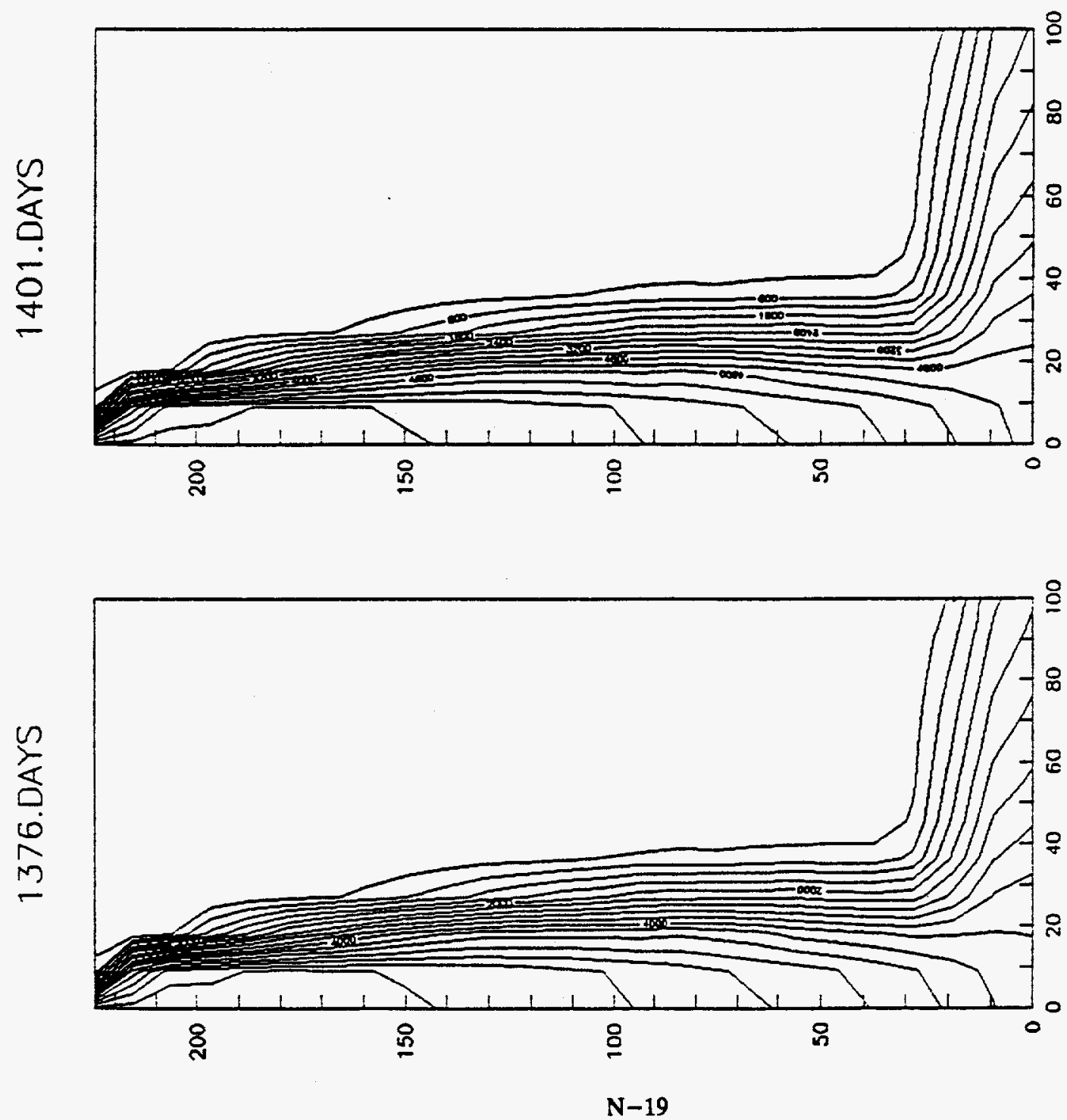

岱 


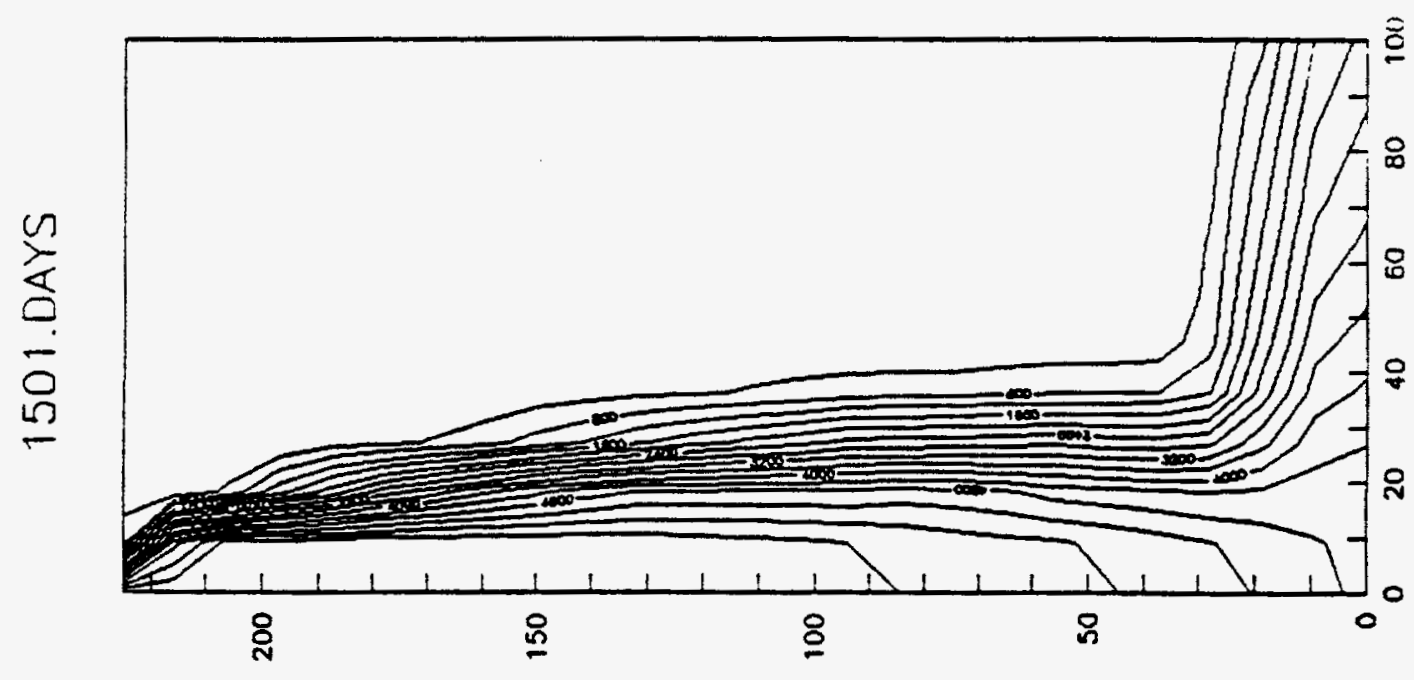

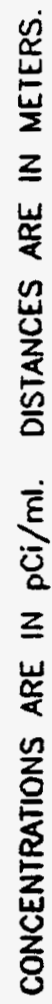
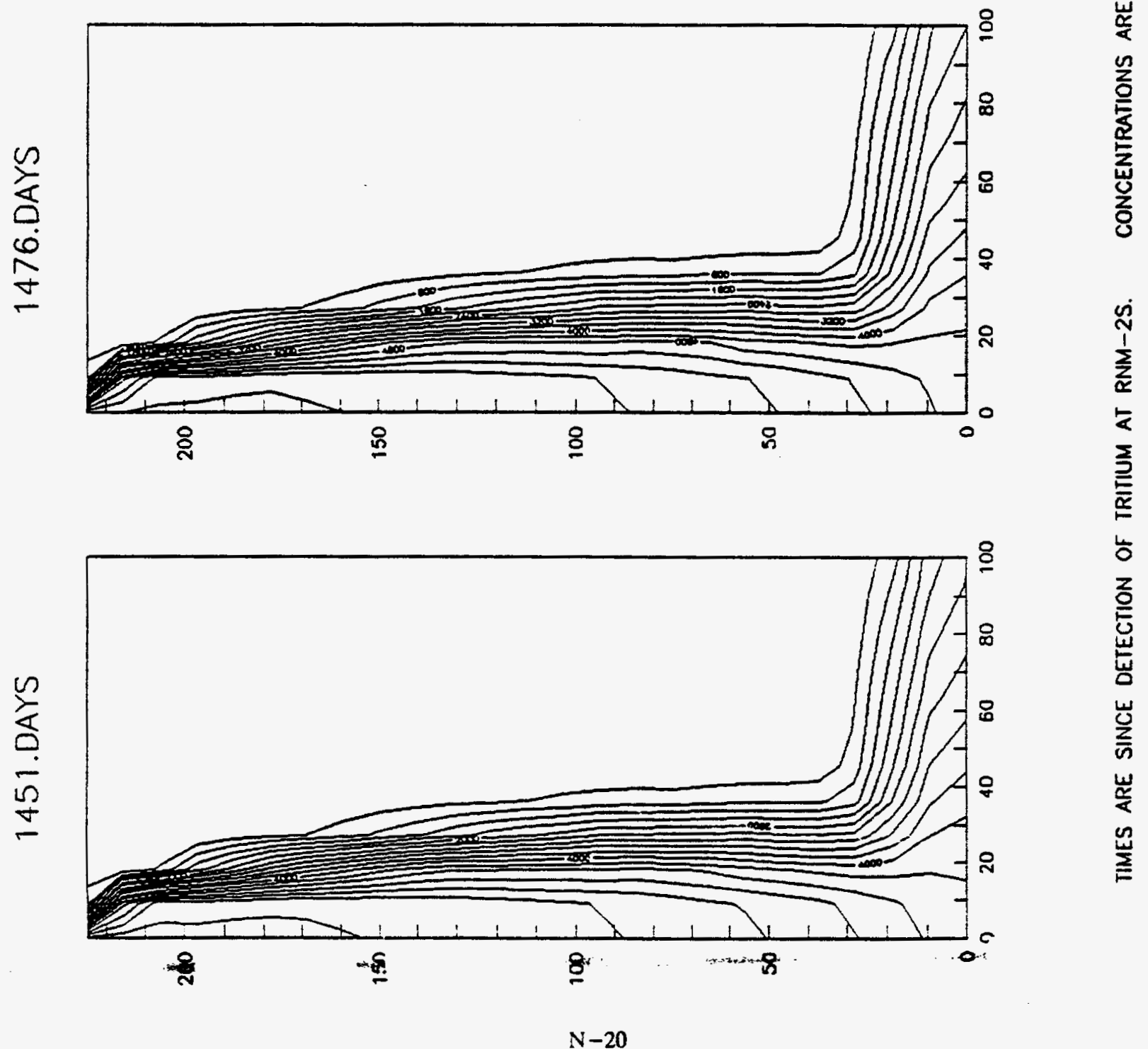


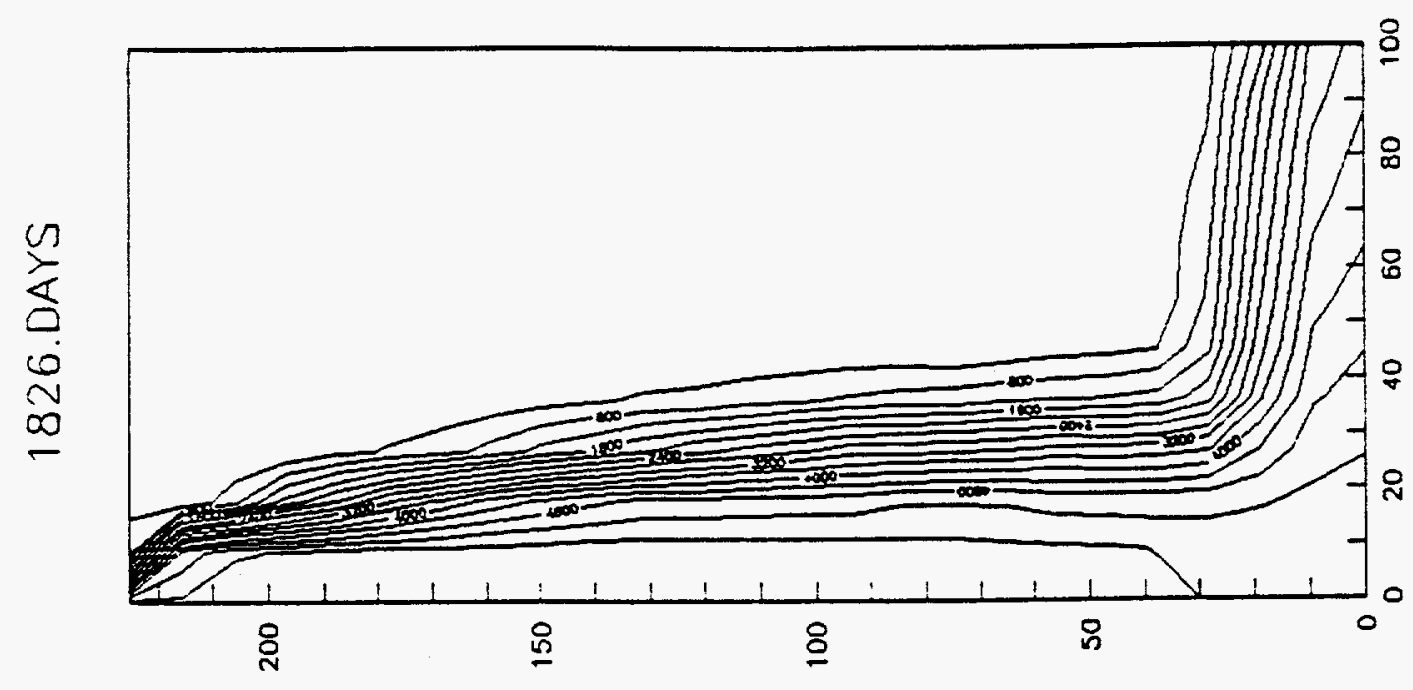

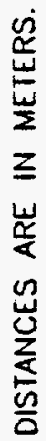
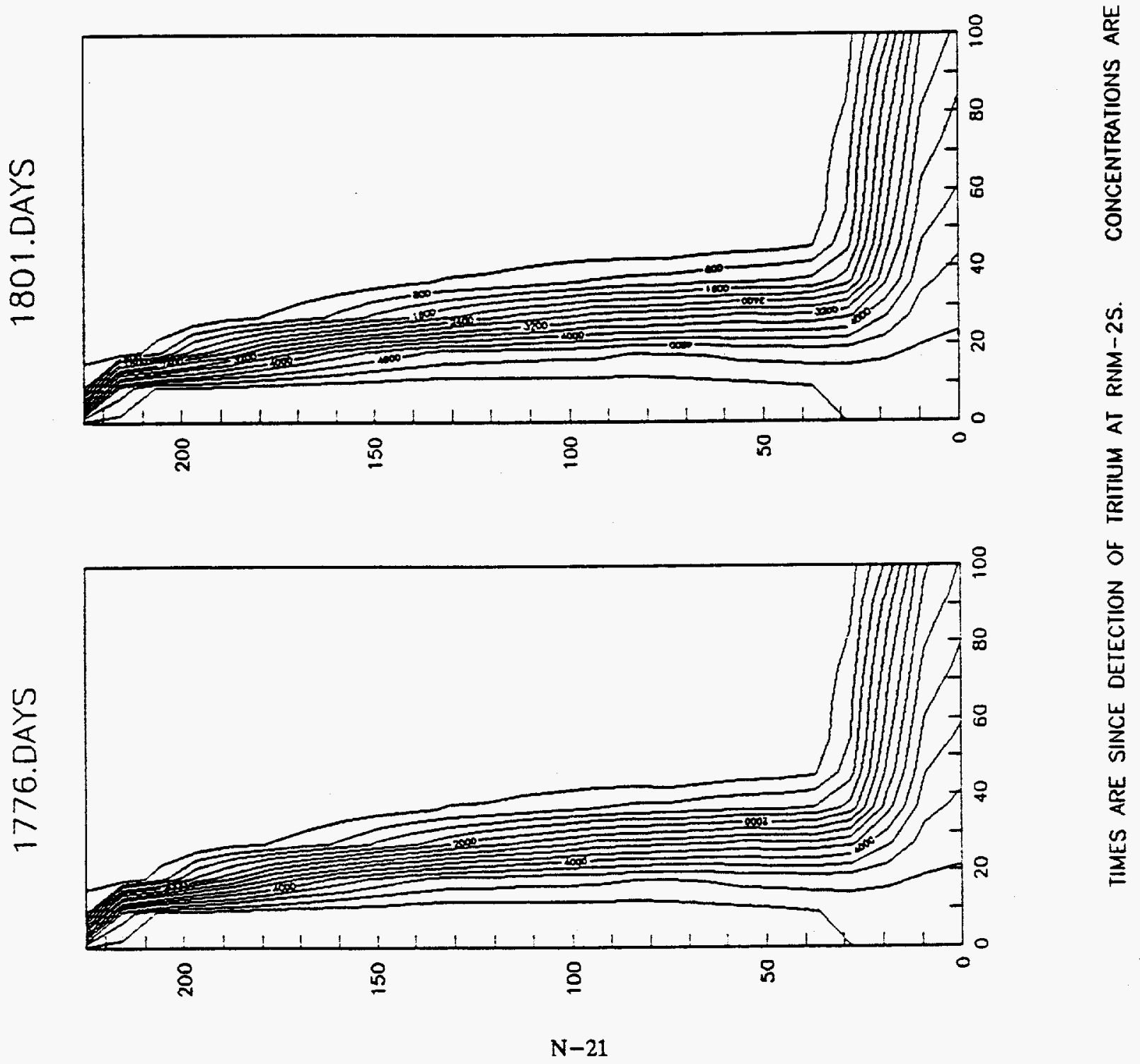


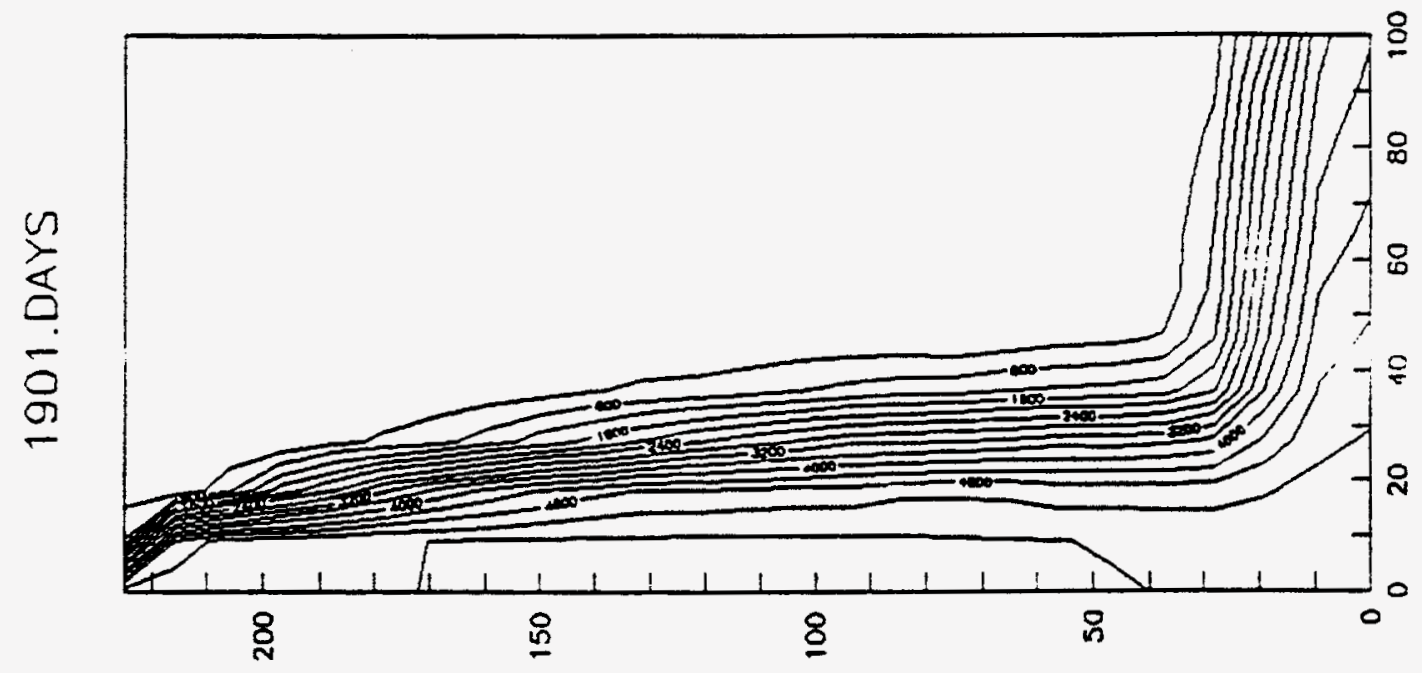

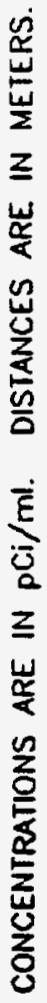

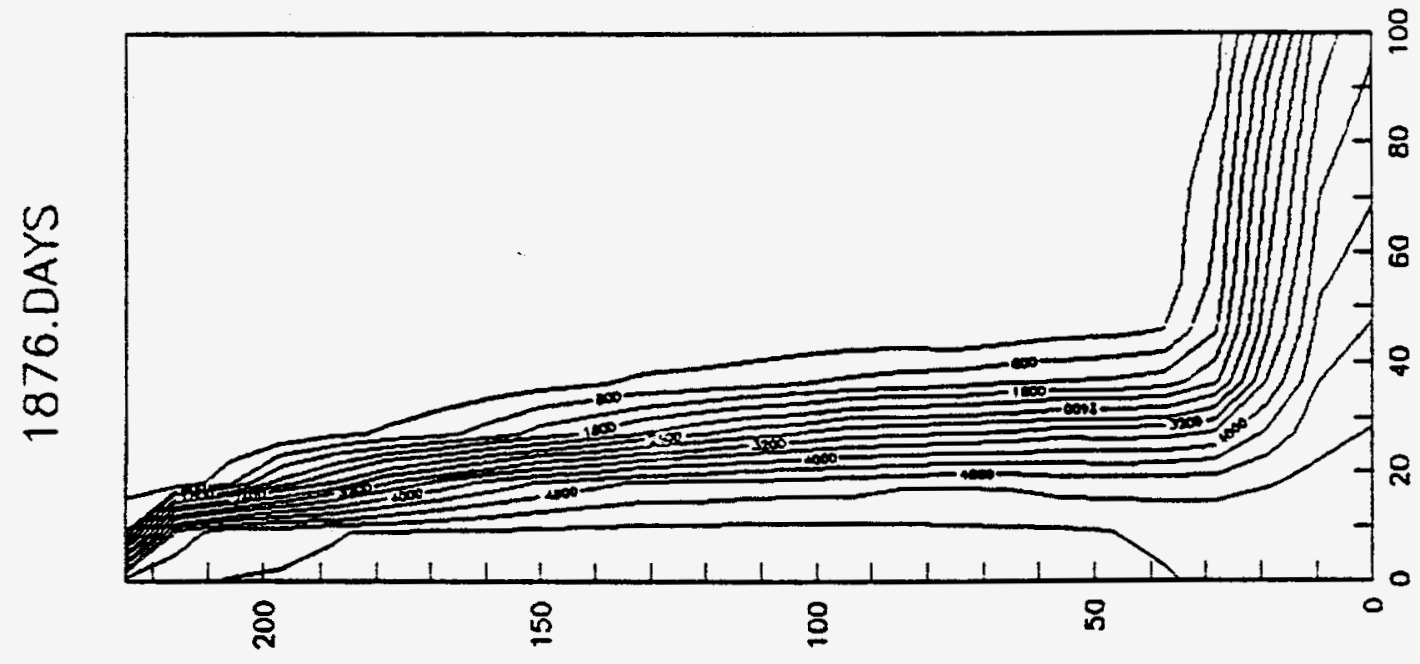

察

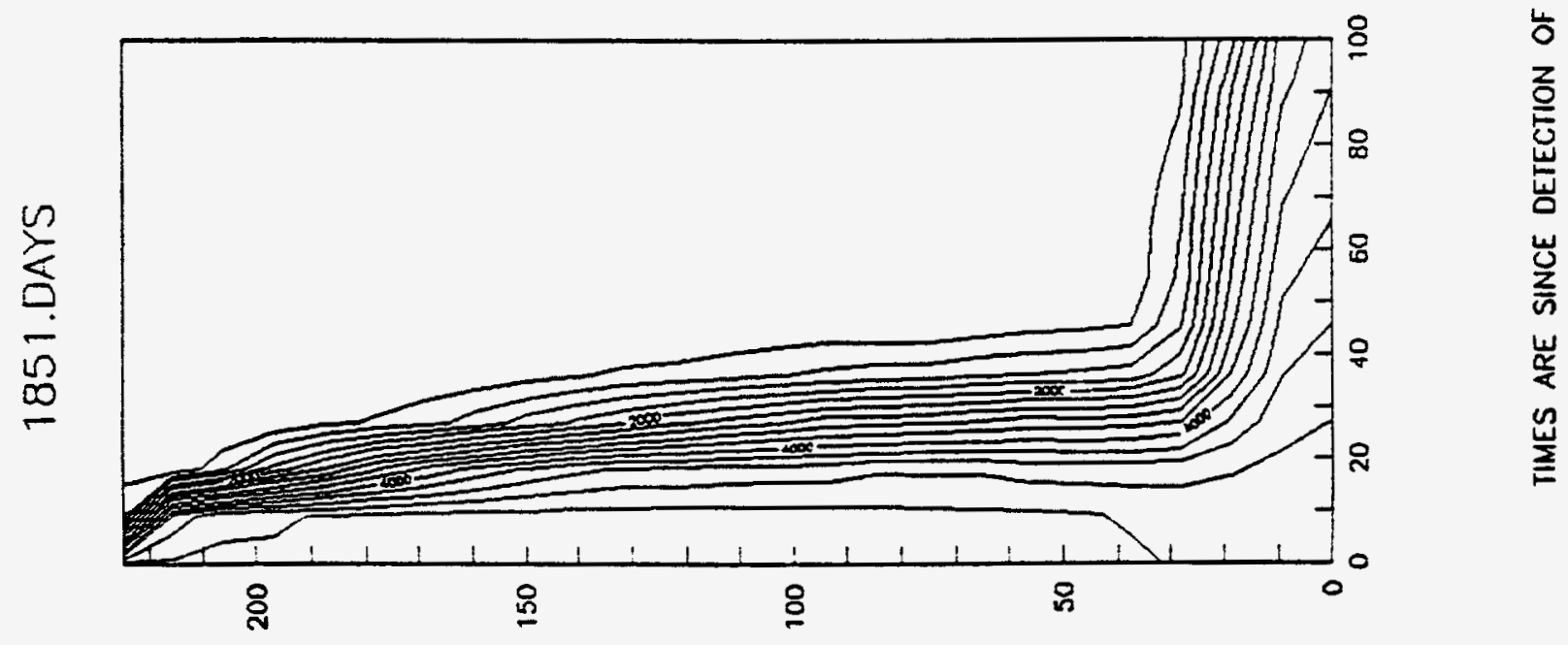

$\mathrm{N}-22$ 


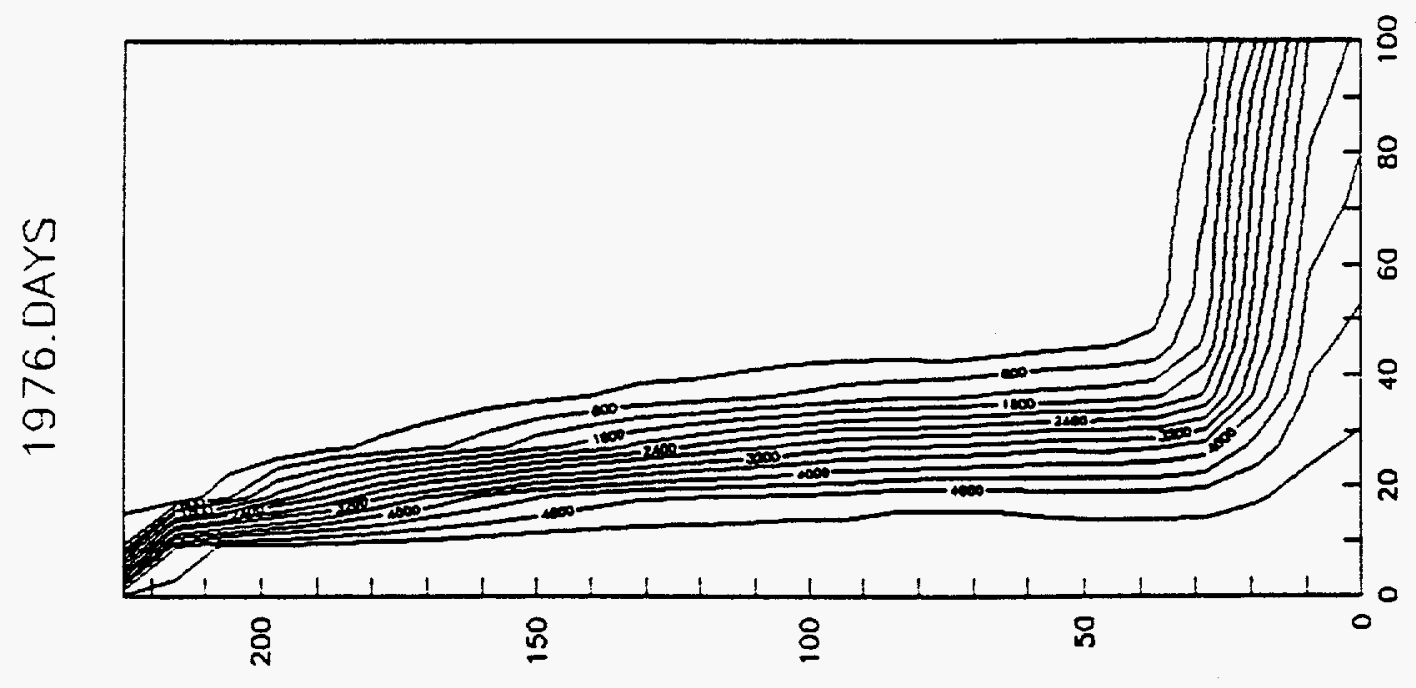

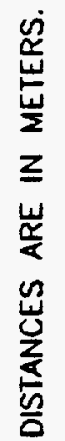
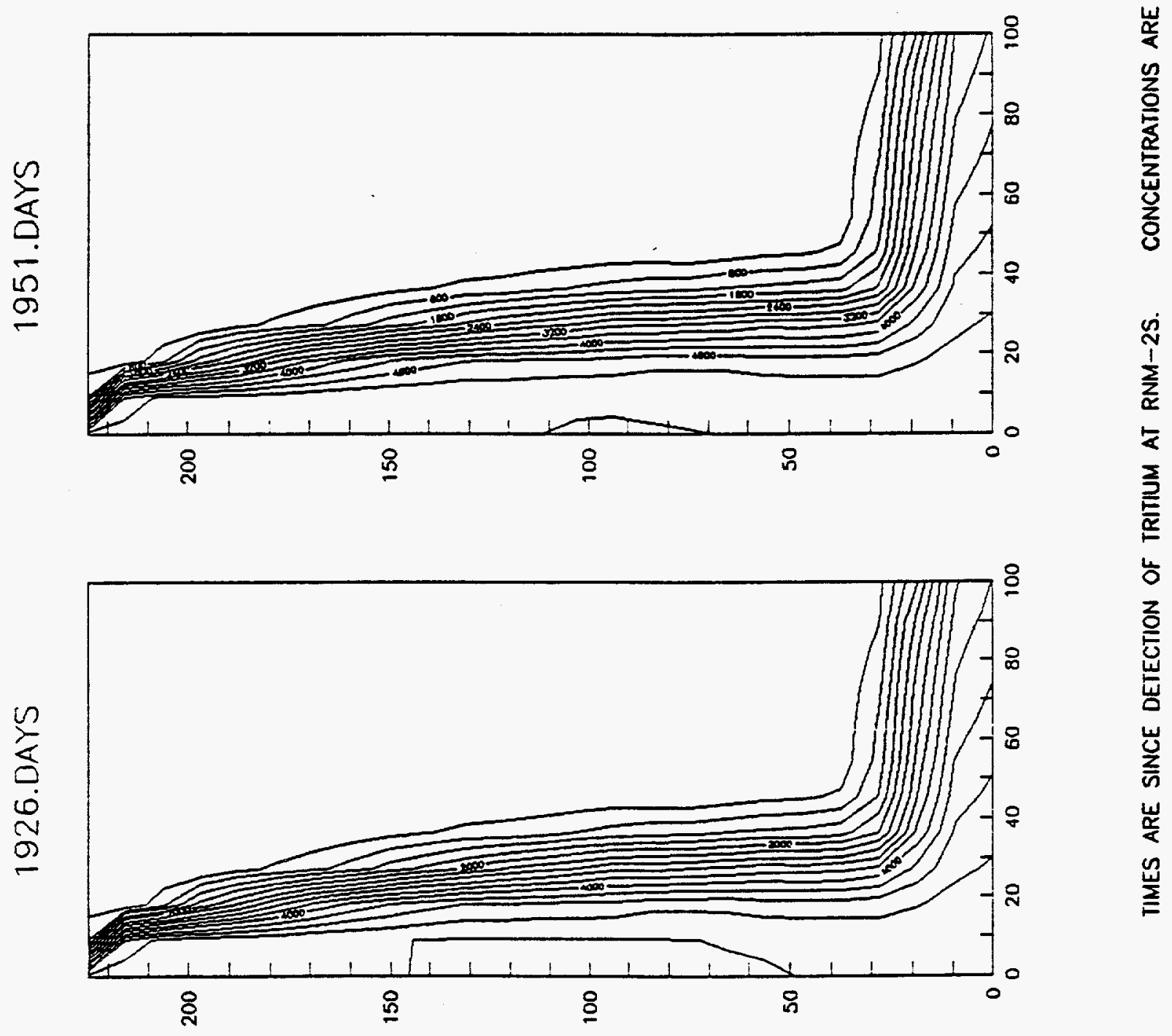

$\mathrm{N}-23$ 


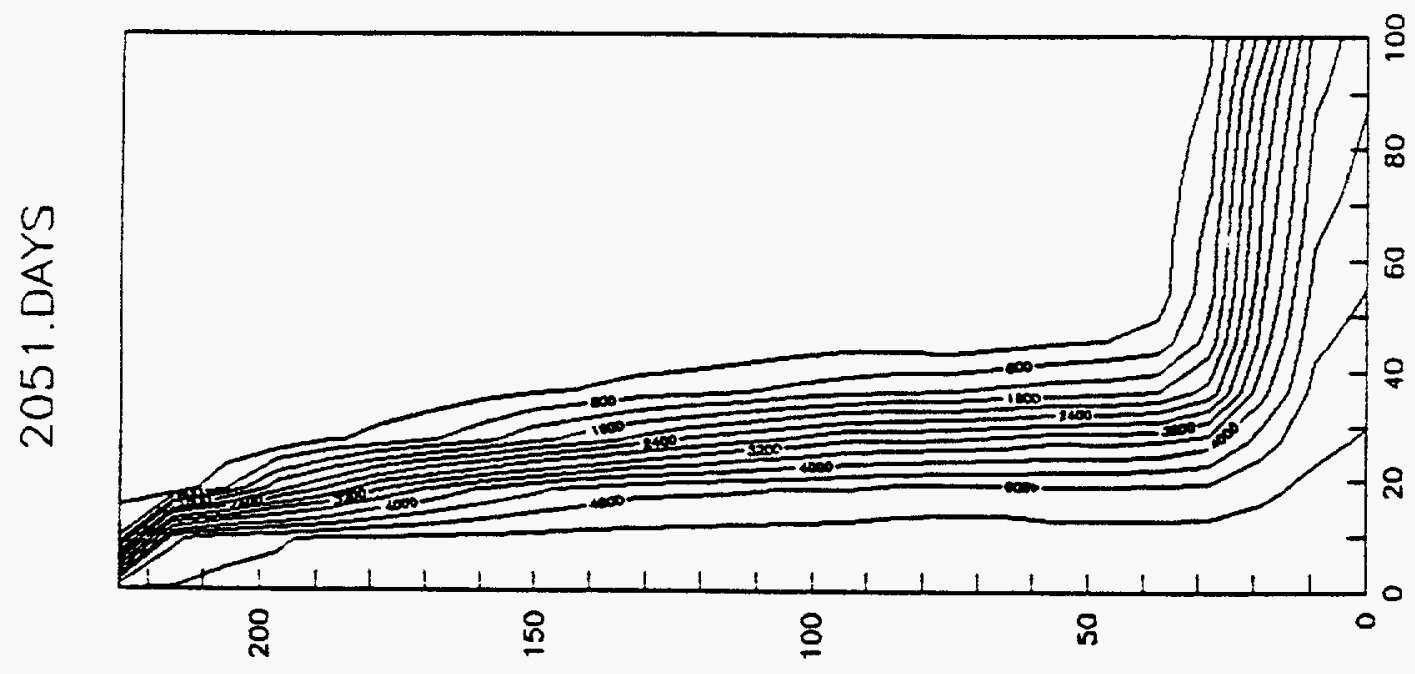

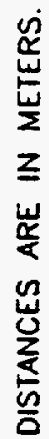

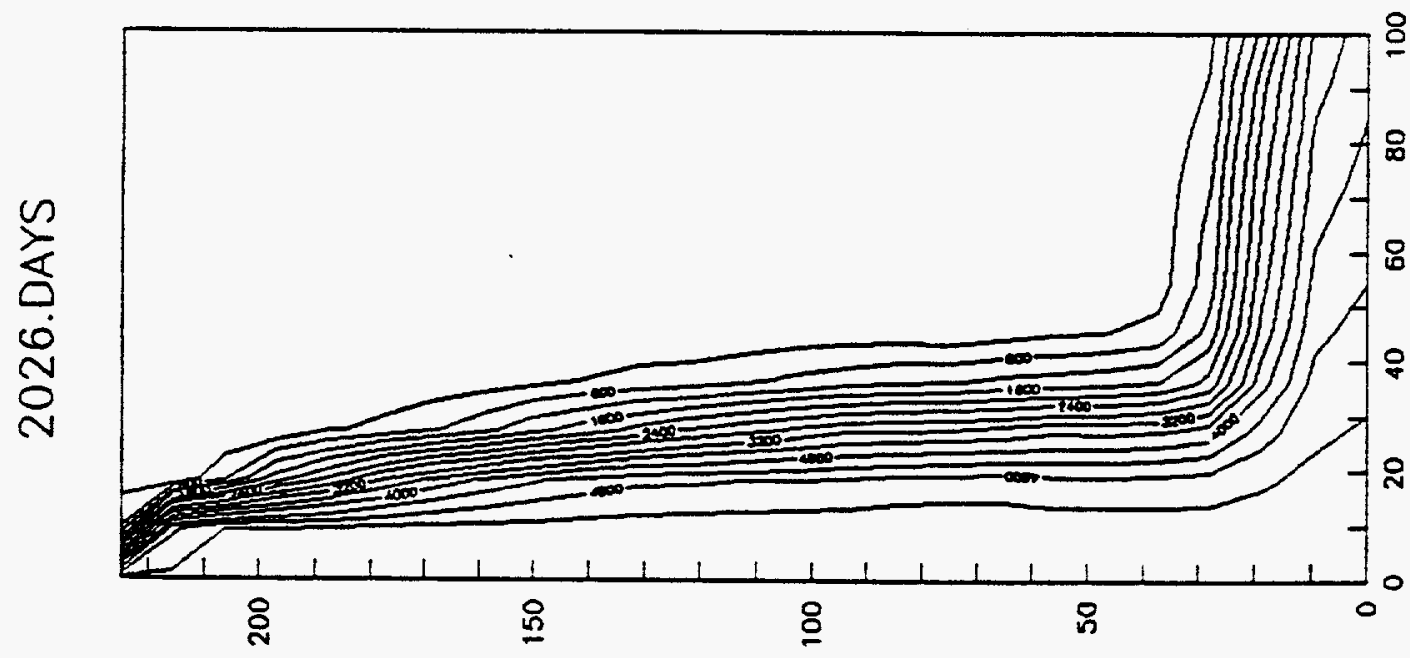

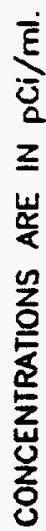

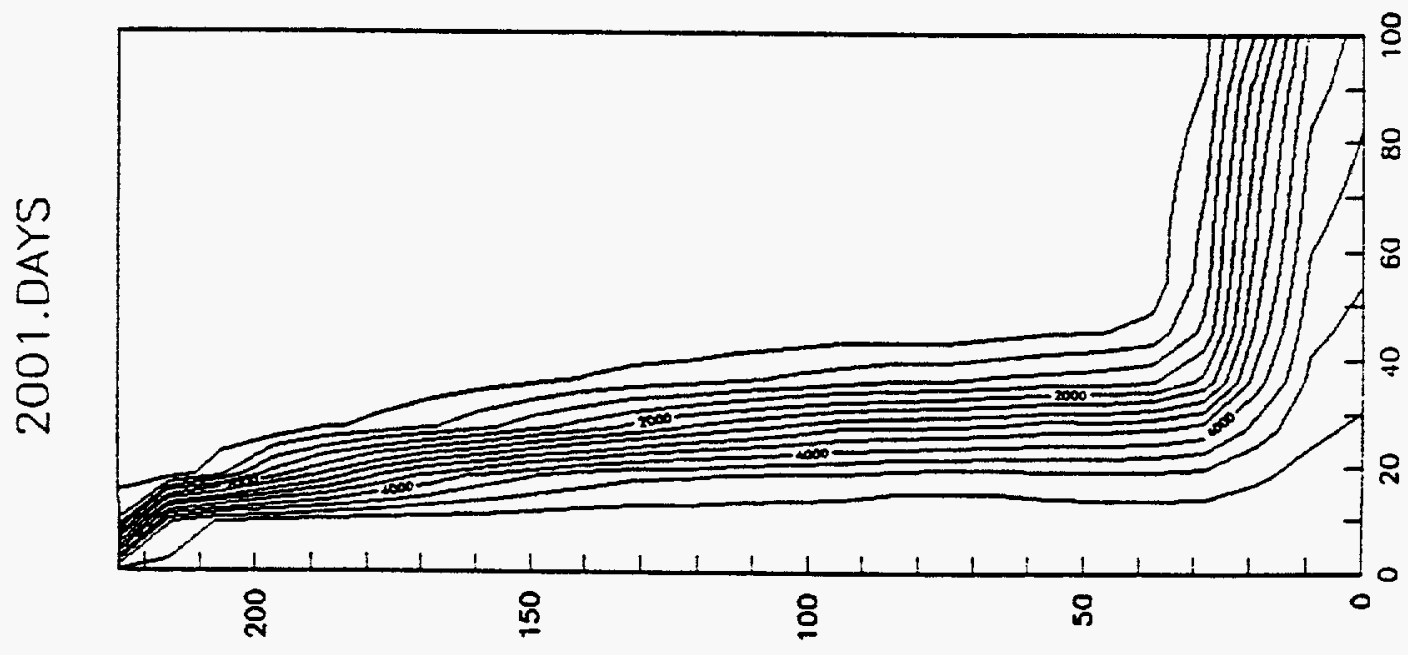

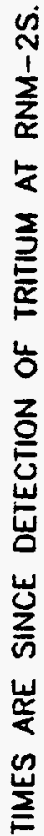




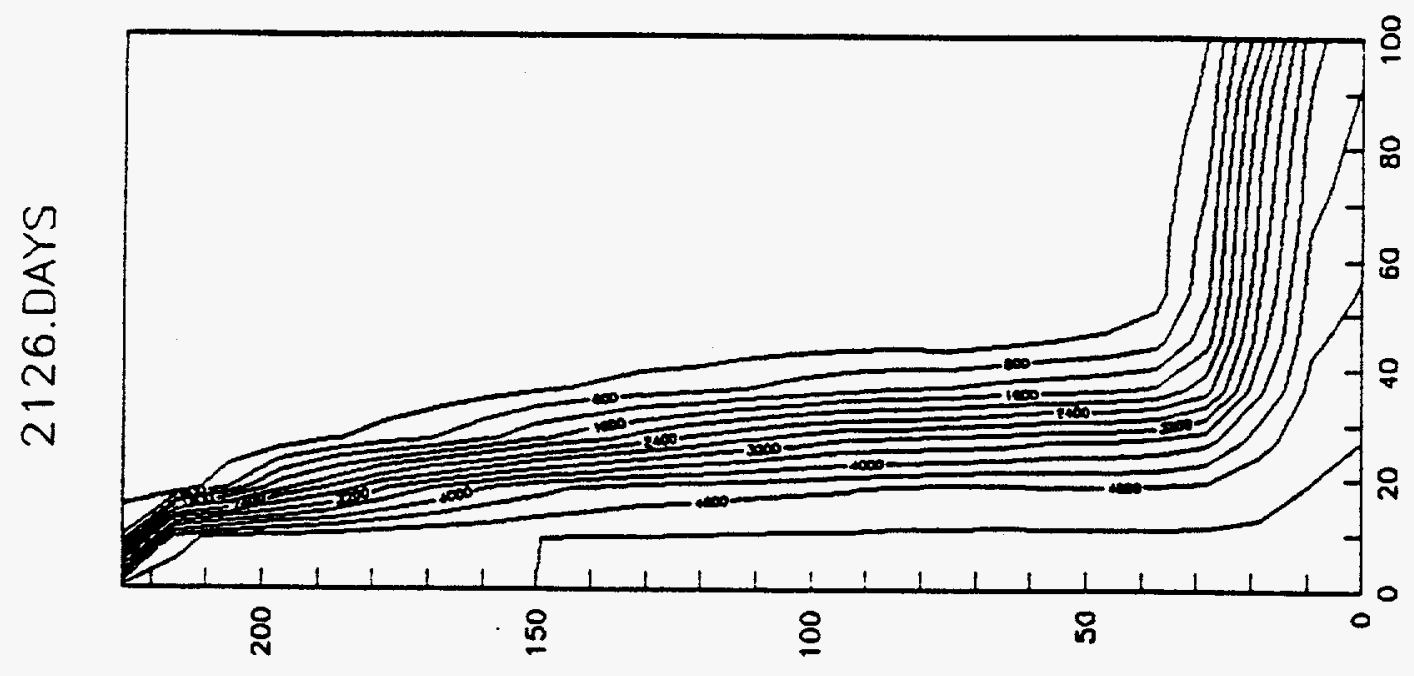

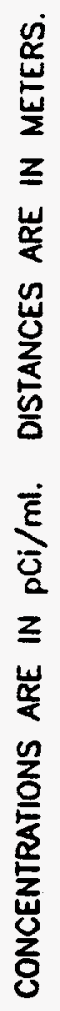
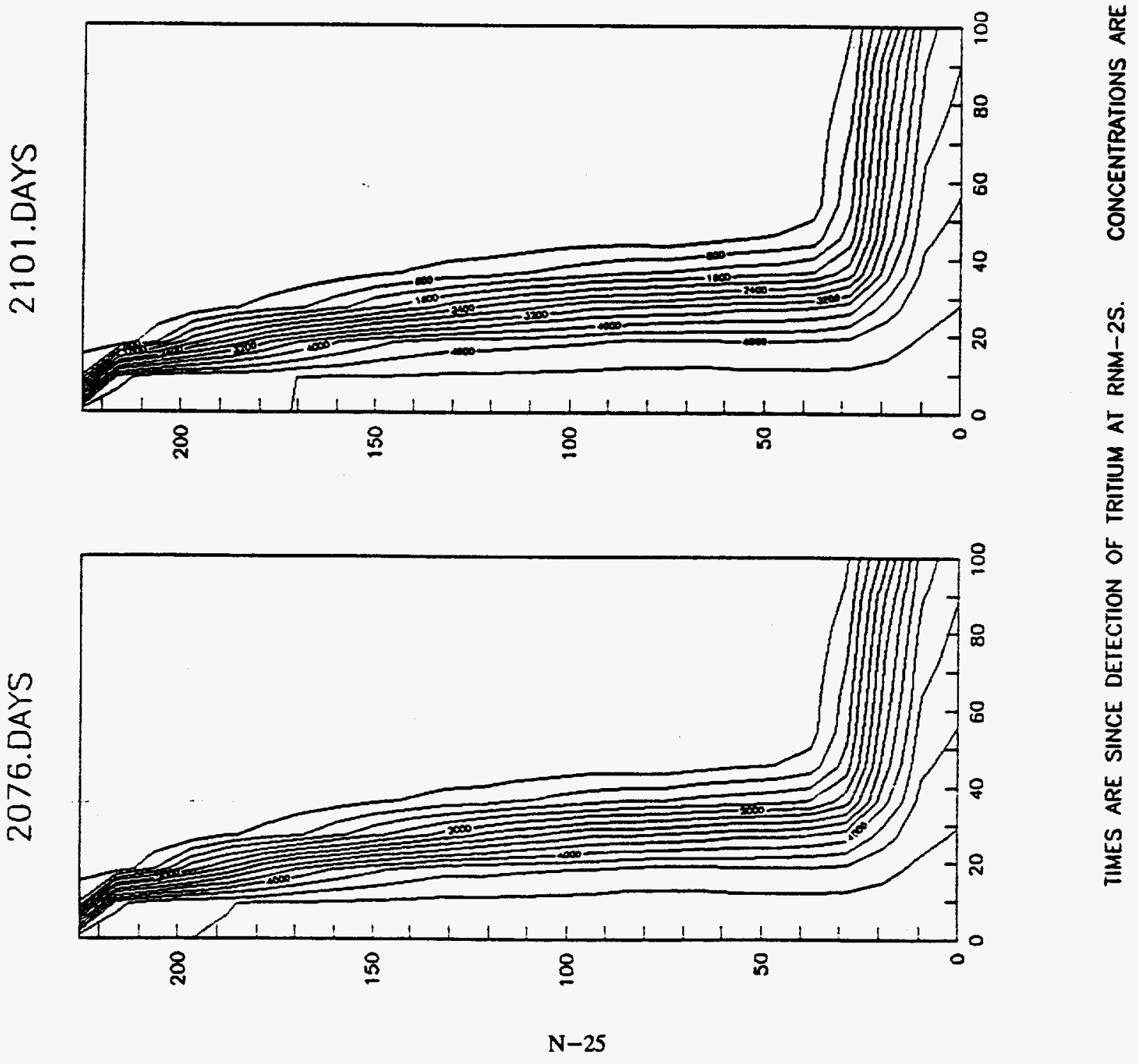


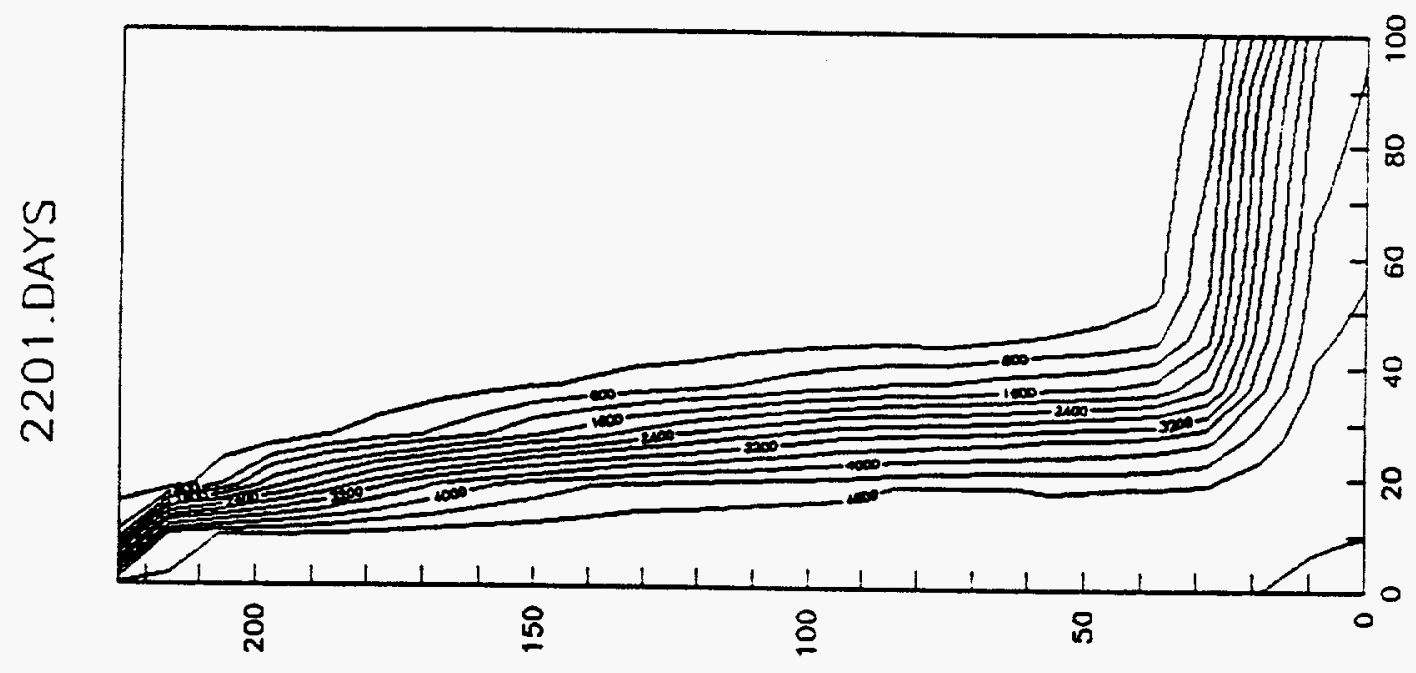

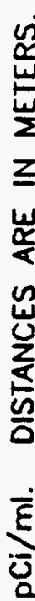

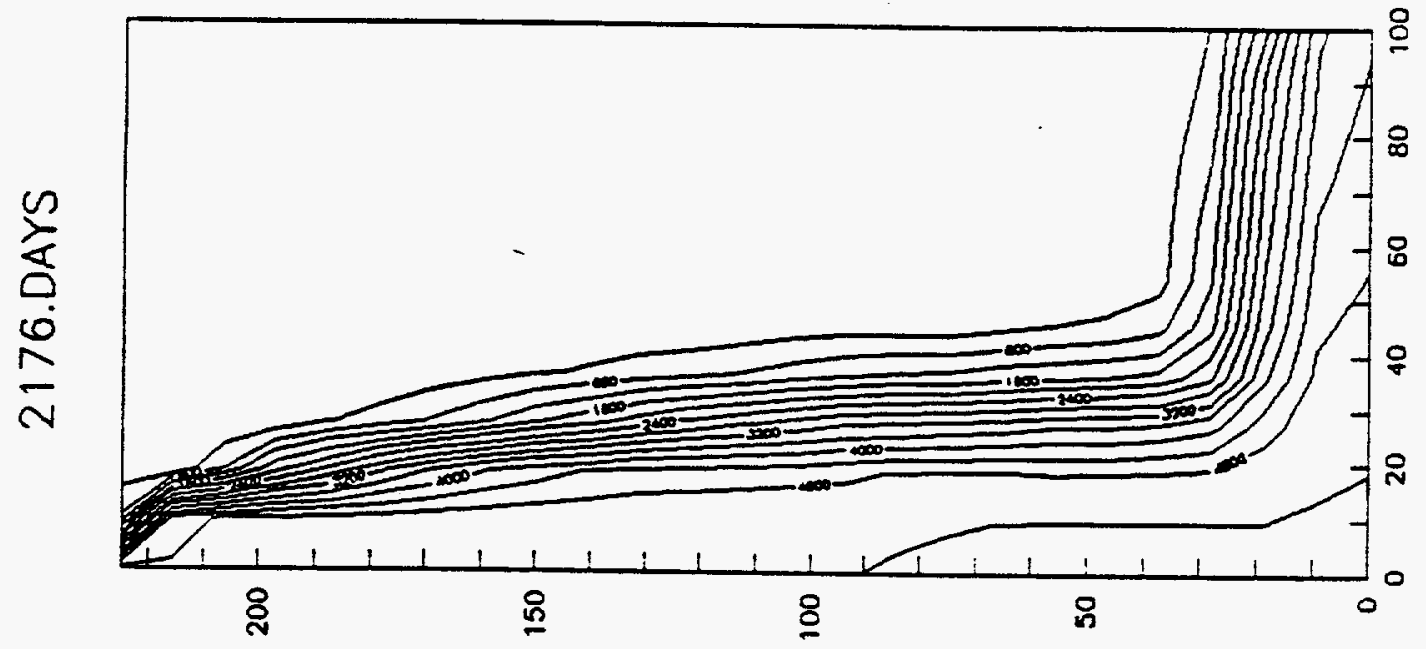

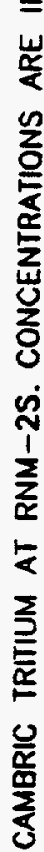

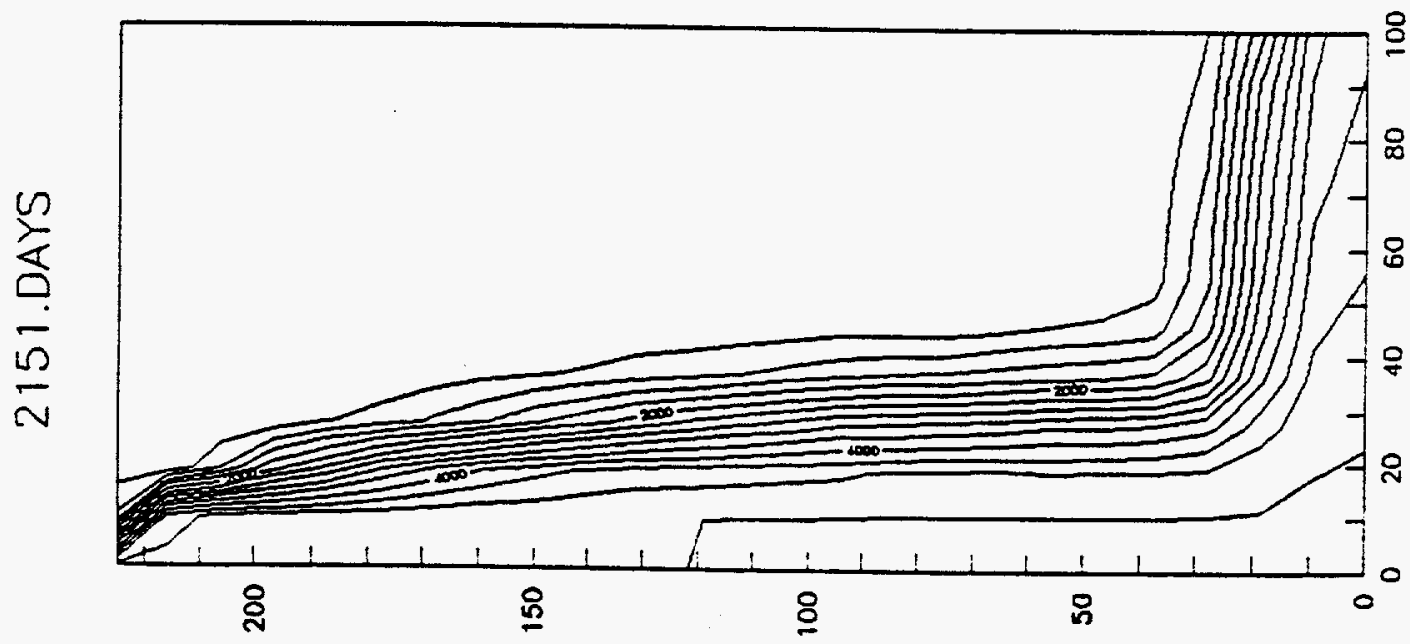

岁 


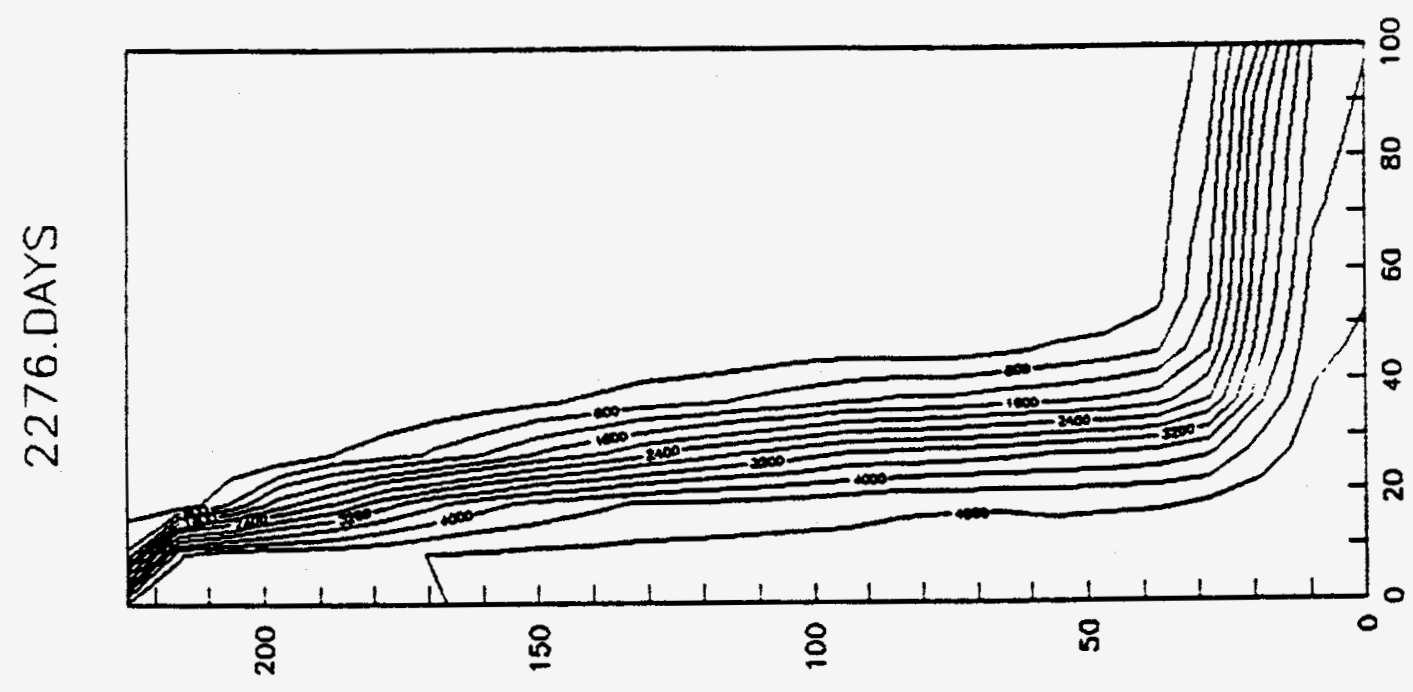

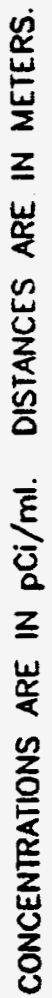
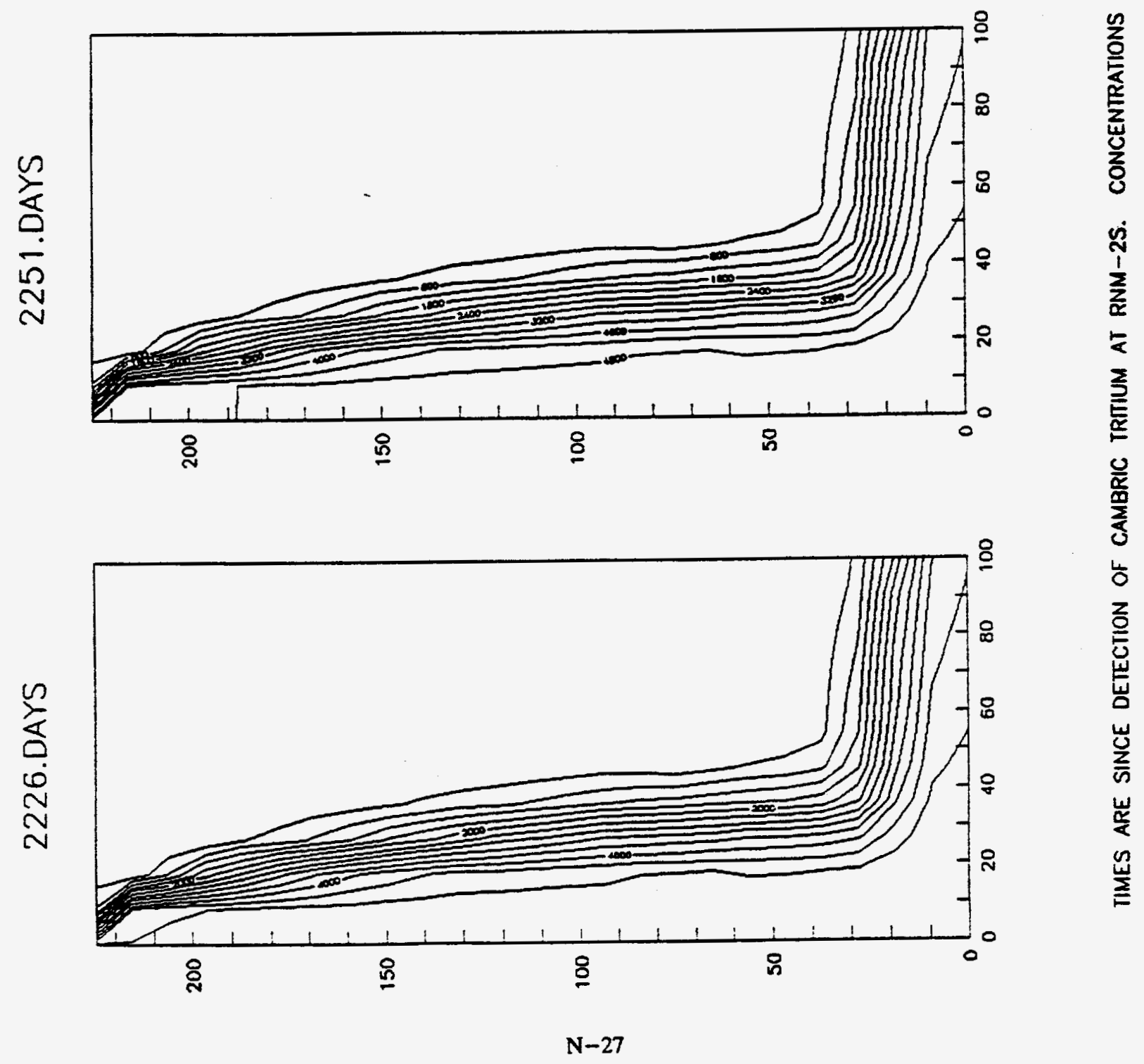


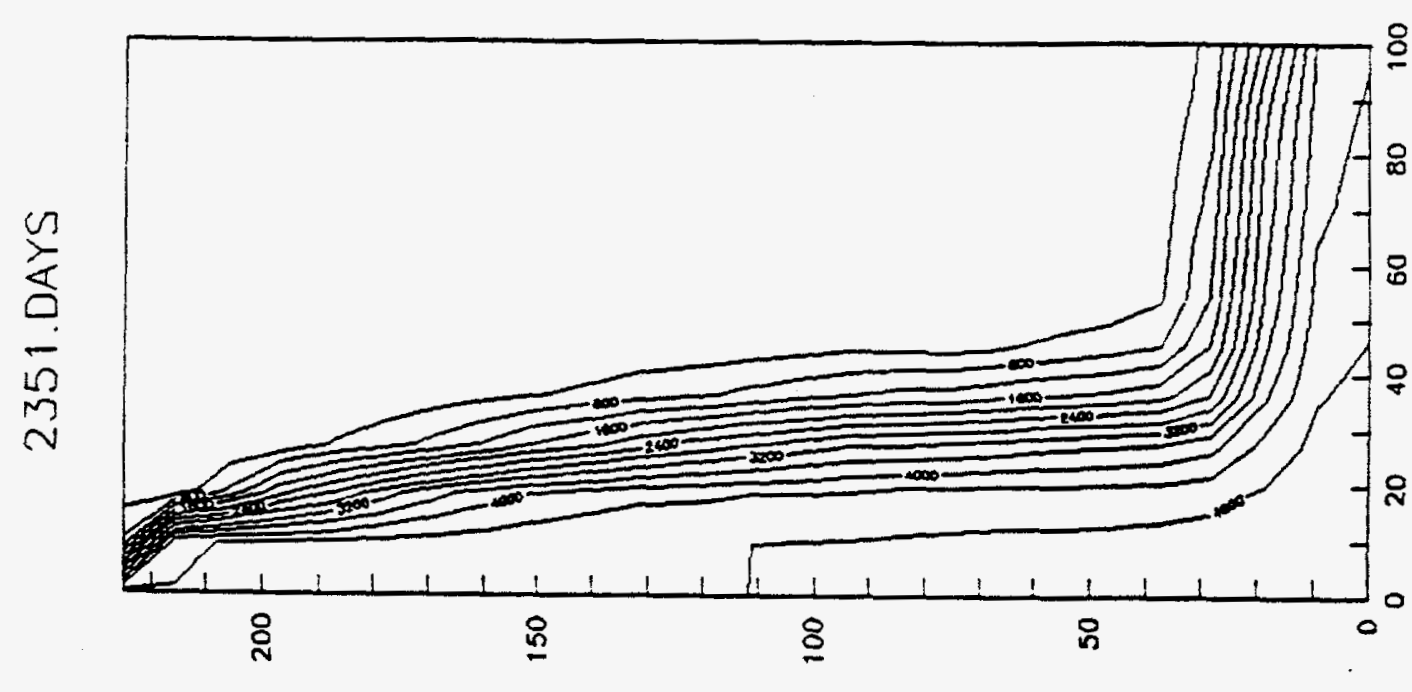

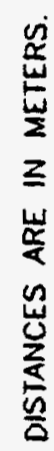

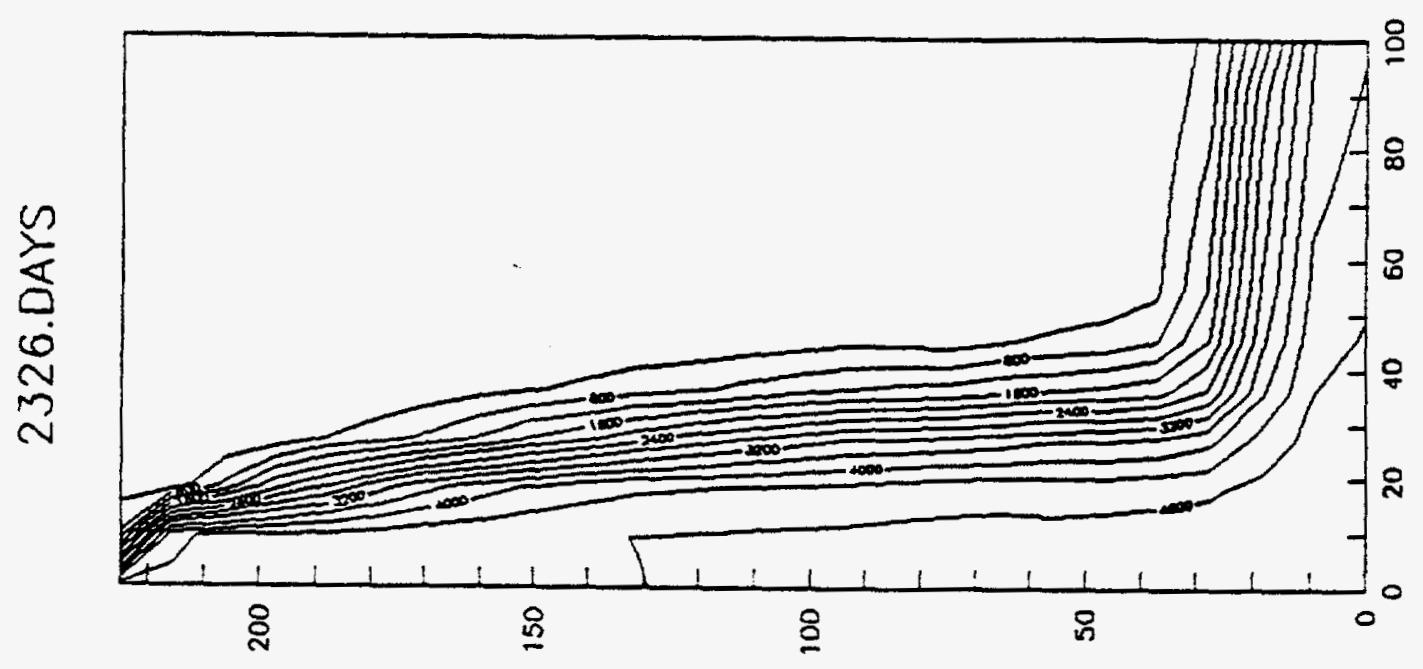

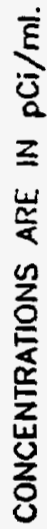

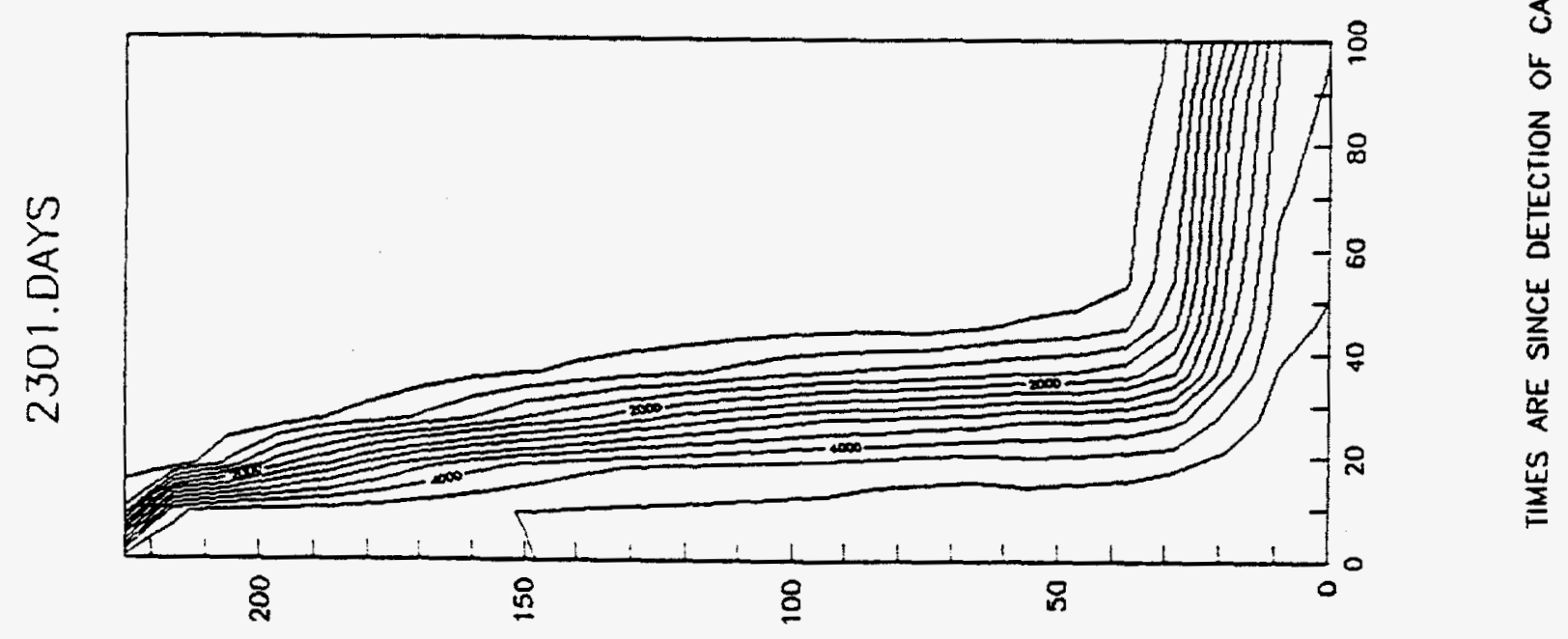




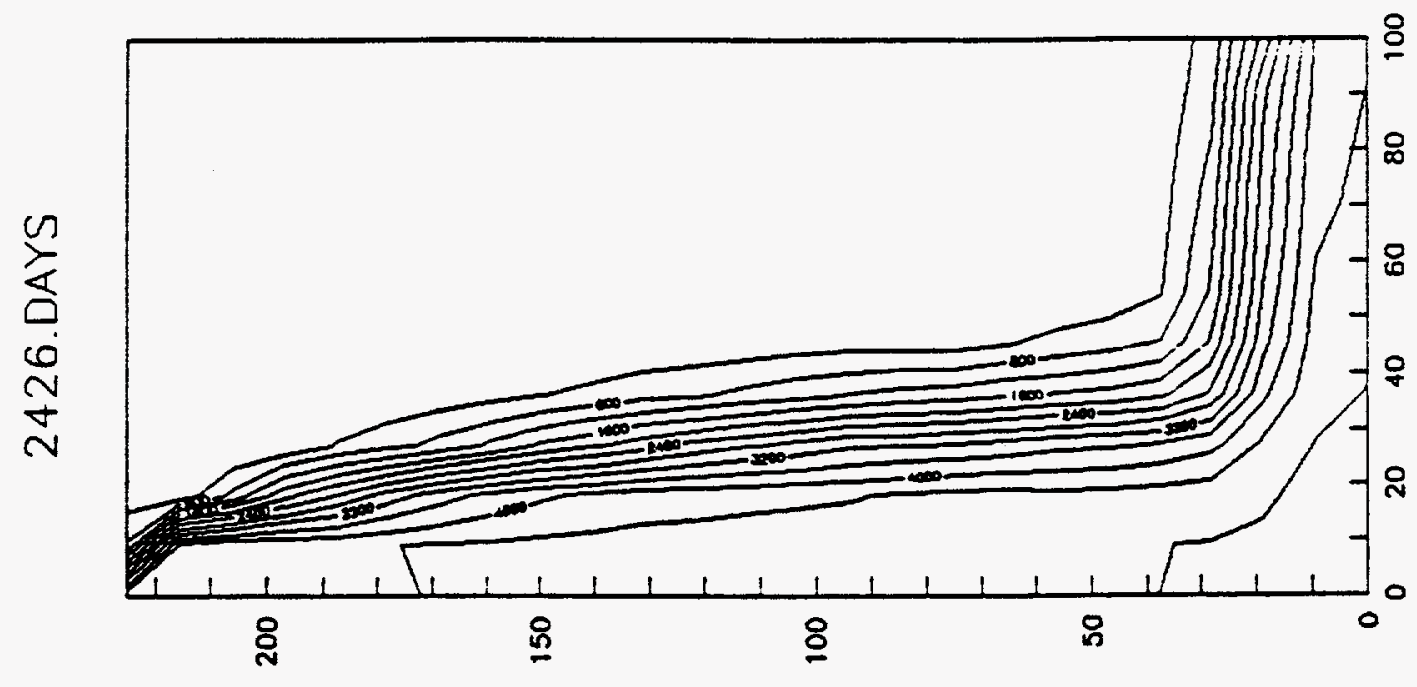

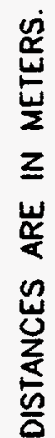
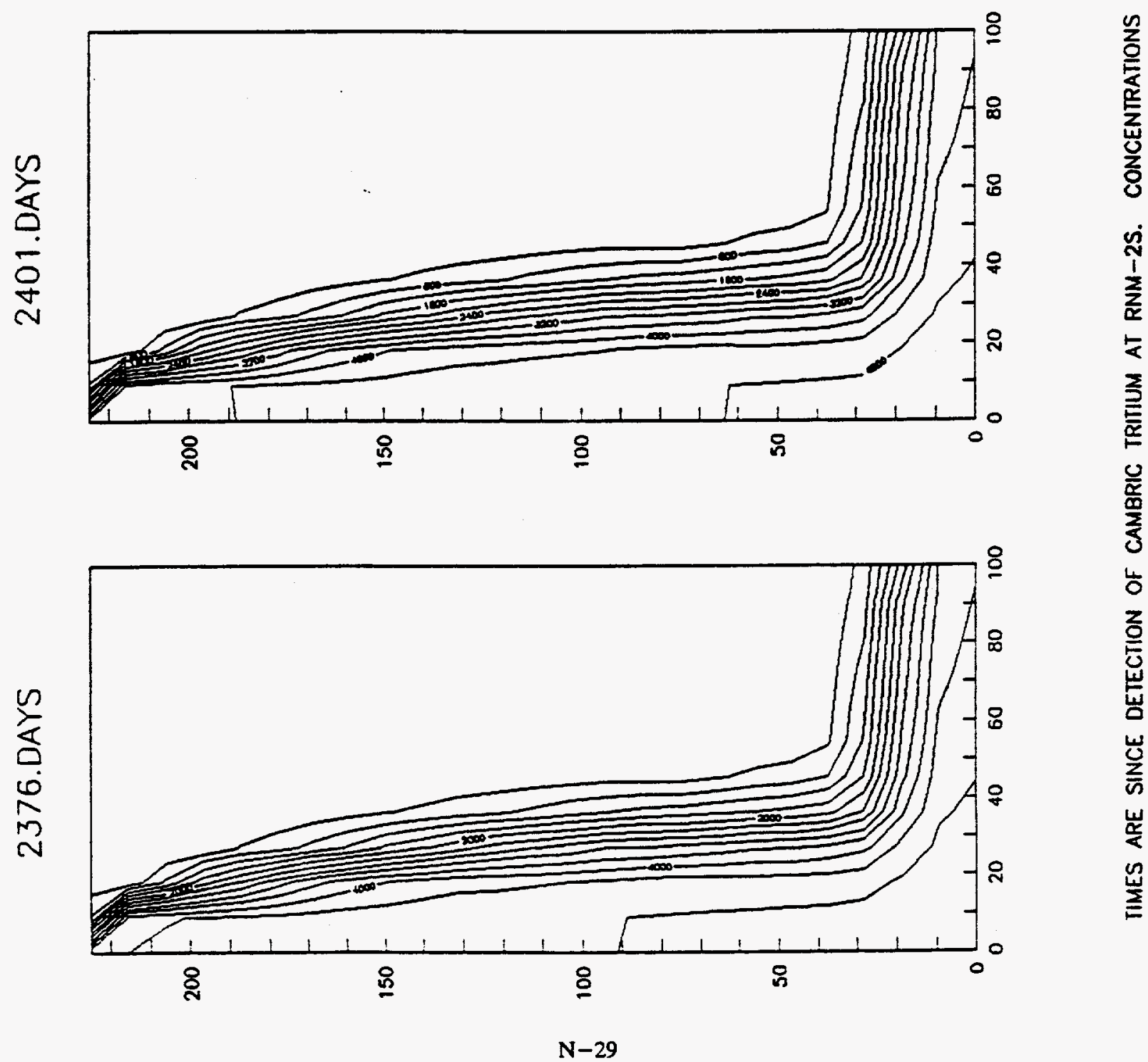


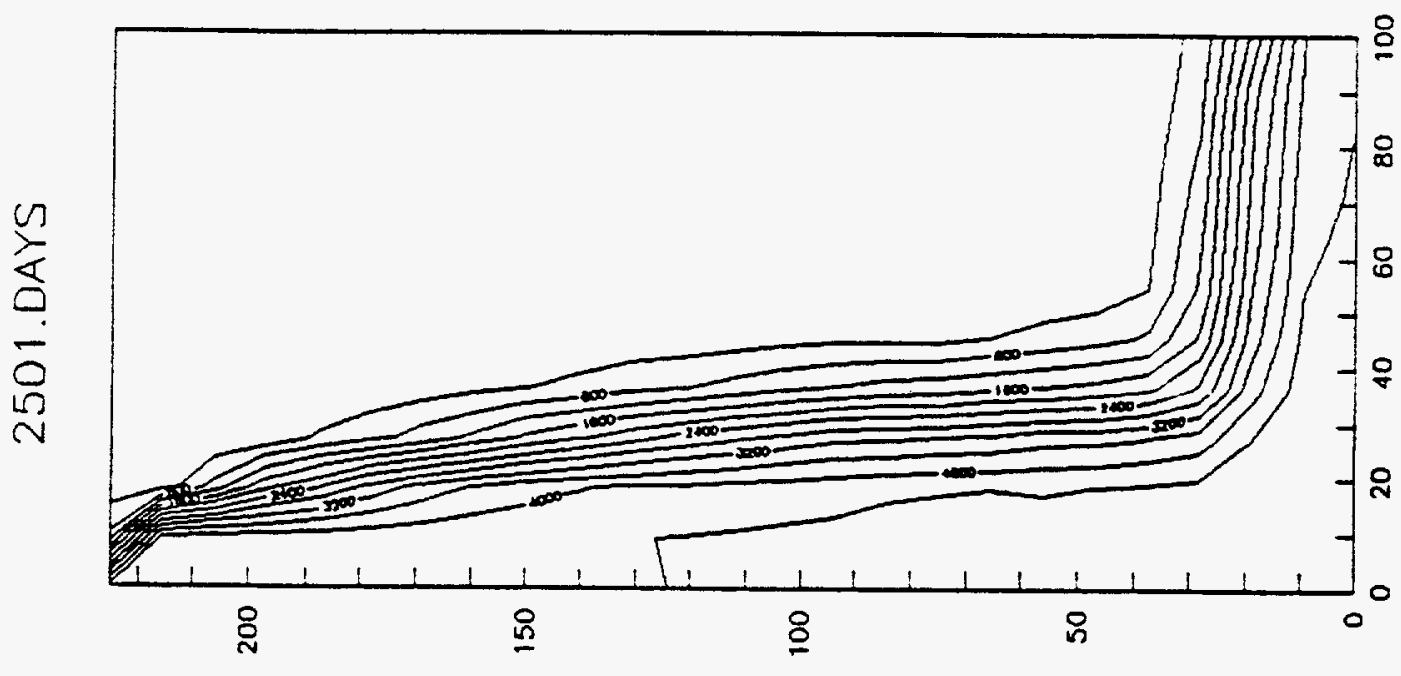

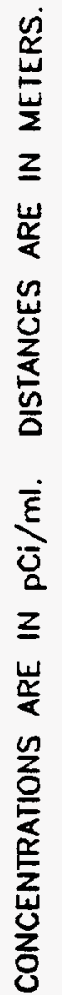
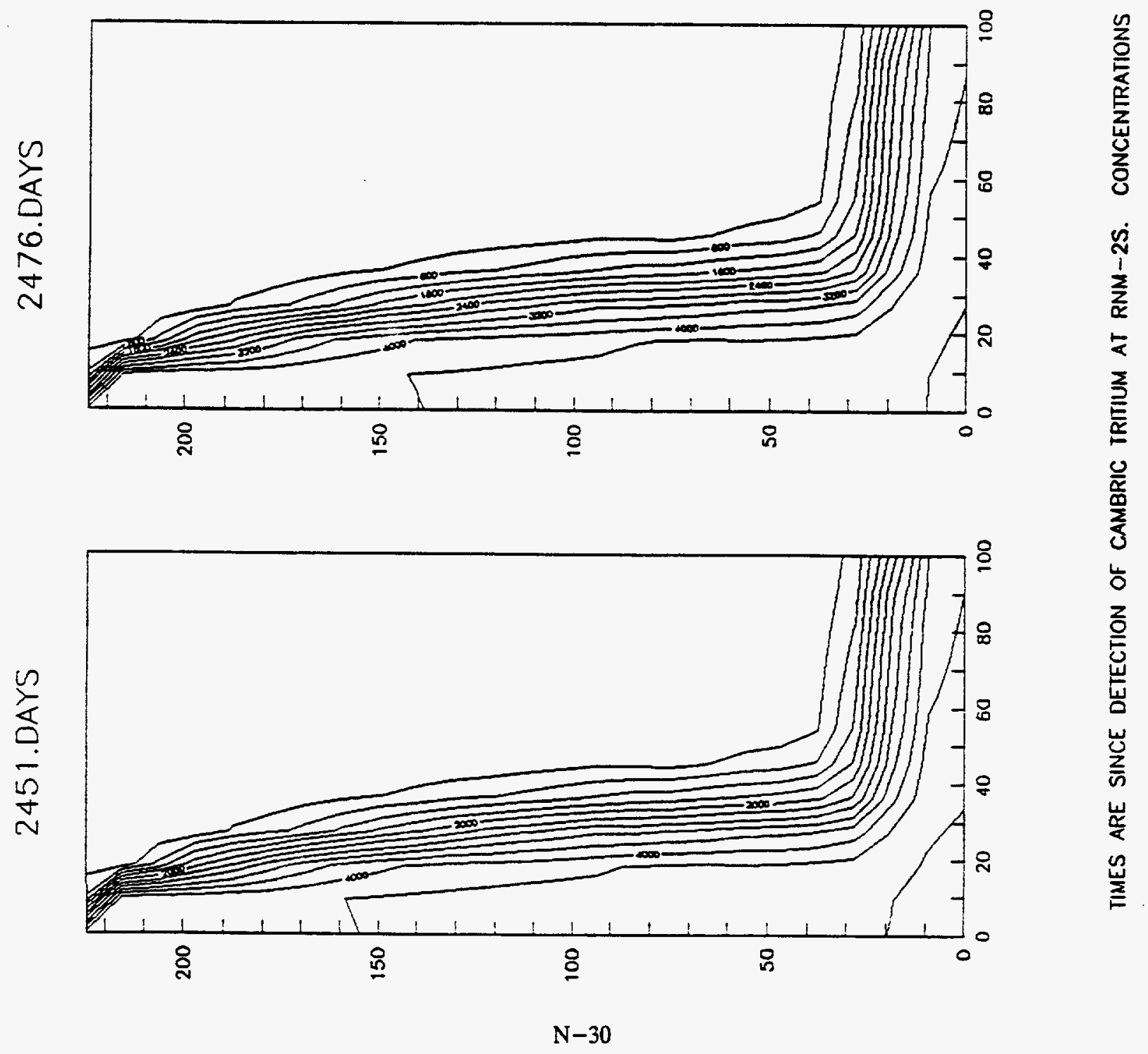


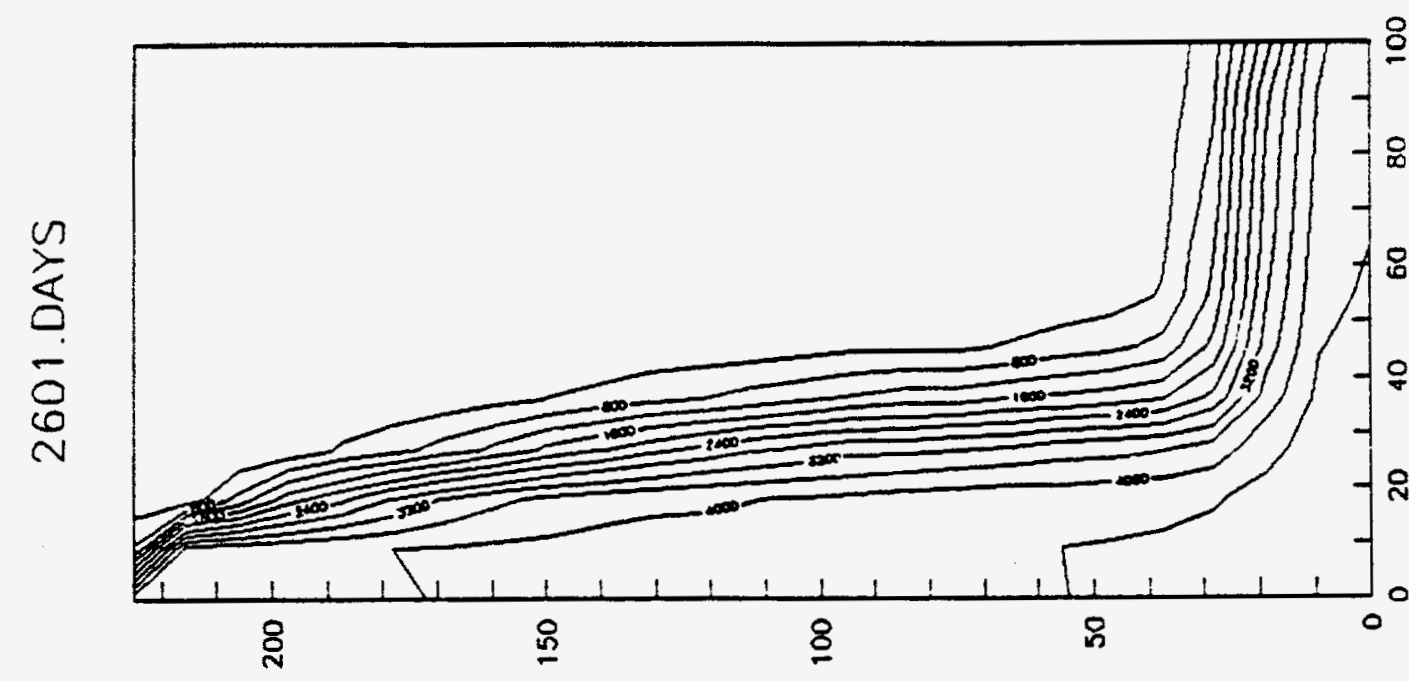

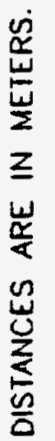
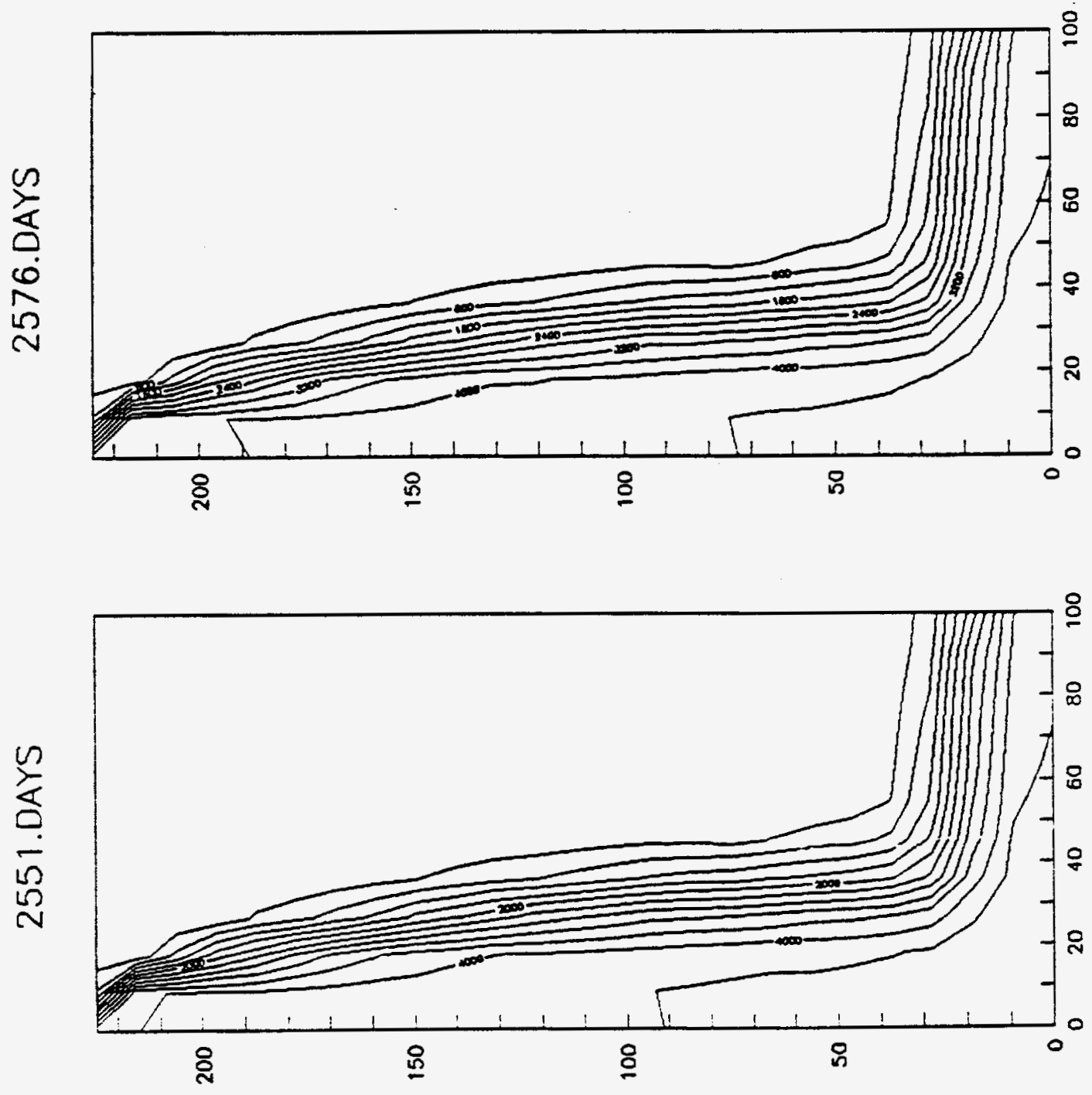

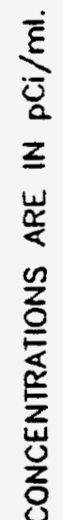

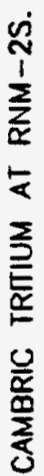

낭

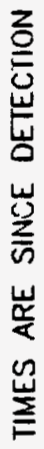




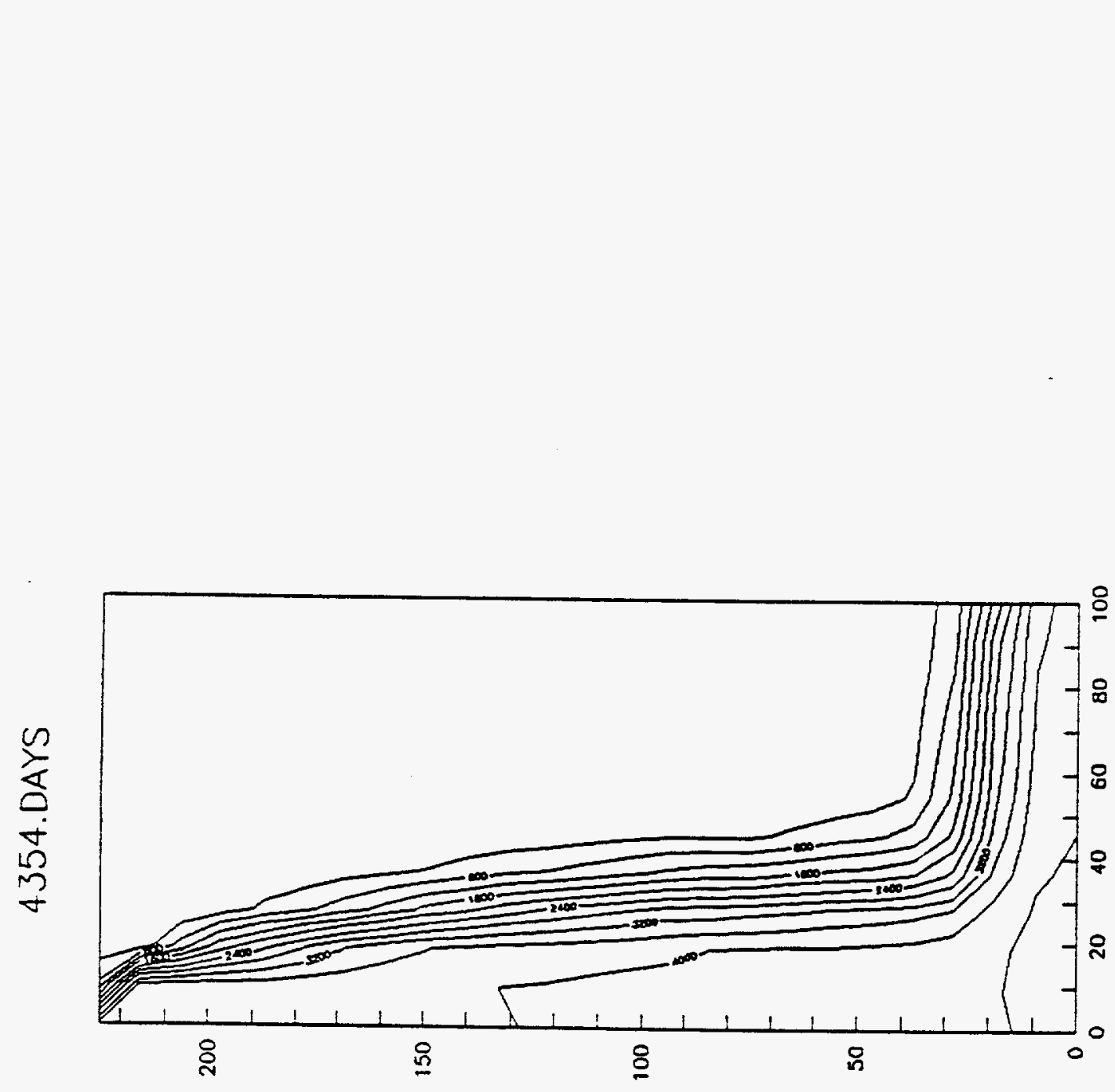

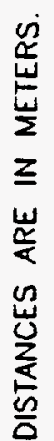

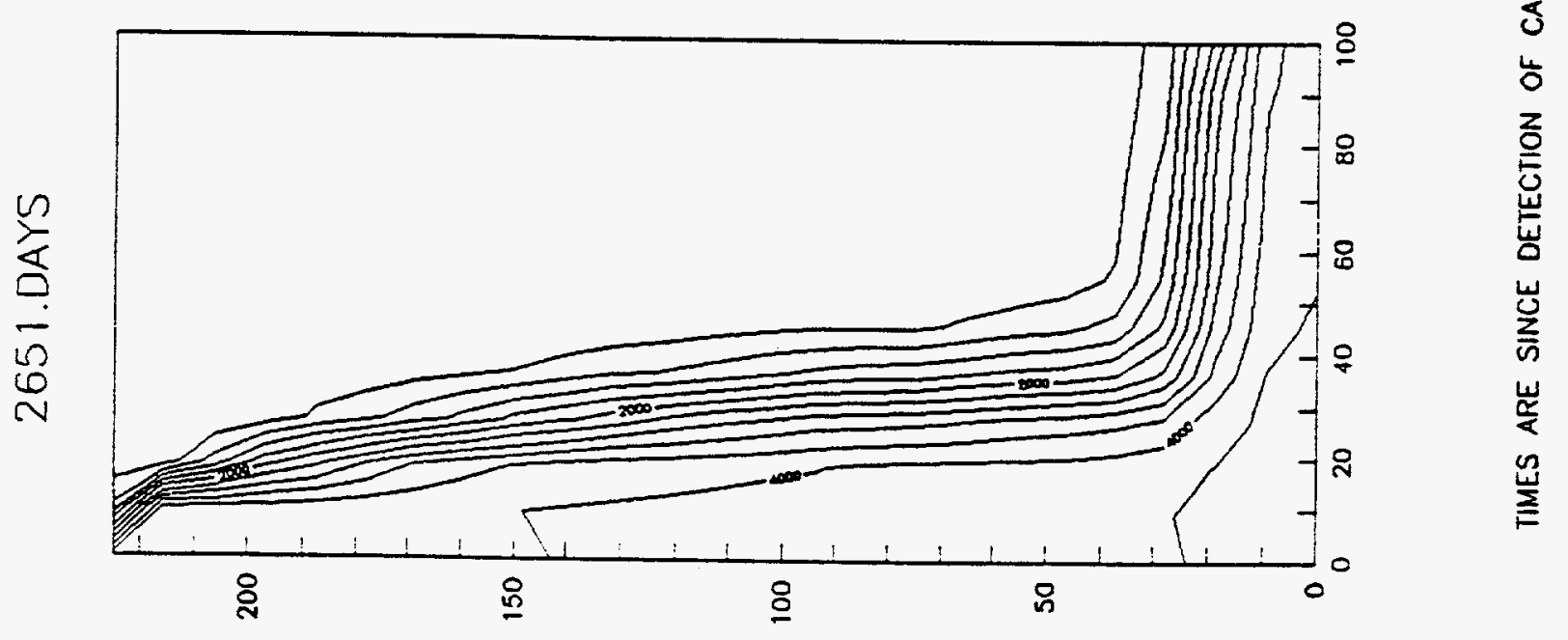




\section{DISTRIBUTION}

\author{
U.S. Department of Energy \\ Gylan Allen \\ Test Operations Division \\ Nevada Operations Office \\ U.S. Dept. of Energy \\ P.O. Box 98518 \\ Las Vegas, NV 89193-8518
}

Doug Duncan

Hydrology Program Manager

Office of Environmental Restoration \& Waste

Management

Nevada Operations Office

U.S. Dept. of Energy

P.O. Box 98518

Las Vegas, NV 89193-8518

Don Elle, Director

Environmental Protection Division

Nevada Operations Office

U.S. Dept. of Energy

P.O. Box 98518

Las Vegas, NV 89193-8518

Joseph N. Fiore, Acting Asst. Mgr.

Office of Environmental Restoration \& Waste

Management

Nevada Operations Office

U.S. Dept. of Energy

P.O. Box 98518

Las Vegas, NV 89193-8518

Joseph H. Kitchen

Technology and Program Management Division

Nevada Operations Office

U.S. Dept. of Energy

P.O. Box 98518

Las Vegas, NV 89193-8518

\section{Steve Lawrence}

Environmental Restoration Division

Nevada Operations Office

U.S. Dept. of Energy

P.O. Box 98518

Las Vegas, NV 89193-8518
John S. Ledbetter

Contracts Division

Nevada Operations Office

U.S. Dept. of Energy

P.O. Box 98518, MS 505

Las Vegas, NV 89193-8518

Steve Leedom

Test Operations Division

Nevada Operations Office

U.S. Dept. of Energy

P.O. Box 98518

Las Vegas, NV 89193-8518

Steve Mellington, Director

Environmental Restoration Division

Nevada Operations Office

U.S. Dept. of Energy

P.O. Box 98518

Las Vegas, NV 89193-8518

Technical Information Resource Center

Nevada Operations Office

U.S. Dept. of Energy

P.O. Box 98518

Las Vegas, NV 89193-8518

Richard Pearl

Environmental Protection Division

Nevada Operations Office

U.S. Dept. of Energy

P.O. Box 98518

Las Vegas, NV 89193-8518

\section{U.S. Department of Defense}

David Bedsun

Defense Nuclear Agency

U.S. Department of Defense

P.O. Box 98539

Las Vegas, NV 89193-8539

\section{Lawrence Livermore National Laboratory}

Lee Davisson

Nuclear Chemistry Division

Lawrence Livermore National Laboratory

P.O. Box 808, MS L237

Livermore, CA 94550 
Greg Nimz

Lawrence Livermore National Laboratory

P.O. Box 808, MS L233

Livermore, CA 94550

Los Alamos National Laboratory

Joe Thompson

Los Alamos National Laboratory

INC-11, MS J514

P.O. Box 1663

Los Alamos, NM 87545

\section{U.S. Geological Survey}

Virginia Glanzman

U.S. Geological Survey

Box 2506, MS 913

Denver Federal Center

Denver, CO 80225

Randy Laczniak

U.S. Geological Survey

Water Resources Division

6770 S. Paradise Rd.

Las Vegas, NV 89119

Paul Orkild

U.S. Geological Survey

Box 2506, MS 913

Denver Federal Center

Denver, CO 80225

Doug Trudeau

U.S. Geological Survey

Water Resources Division

6770 S. Paradise Rd.

Las Vegas, NV 89119

\section{Desert Research Institute}

Roger Jacobson

Desert Research Institute

Water Resources Center

P.O. Box 19040

Las Vegas, NV 89132-0040
Marjory Jones

Desert Research Institute

Water Resources Center

P.O. Box 60220

Reno, NV 89506-0220

Paul Seaber

Desert Research Institute

Water Resources Center

P.O. Box 19040

Las Vegas, NV 89132-0040

Reynolds Electrical \& Engineering Co.

Martha DeMarre

Chief, Document Research Section

Health Protection Dept.

Reynolds Electrical \& Engineering Co.

P.O. Box 98521

Las Vegas, NV 89193-8521

Brian Dozier

Reynolds Electrical \& Engineering Co.

2501 Wyandotte

Mercury, NV 89102

State of Nevada

Larry Franks

Nevada State Health Department

Radiological Health Section

620 Belrose Avenue

Las Vegas, NV 89158

\section{LIBRARIES}

Archives

Getchell Library

University of Nevada, Reno

Beverly Carter

MacKay School of Mines Library

University of Nevada, Reno

Stead Library

Desert Research Institute

Reno, Nevada

Southern Nevada Science Center

Water Resources Center, Library

P.O. Box 19040

Las Vegas, NV 89132-0040 
Document Section, Library

University of Nevada, Las Vegas

4505 Maryland Parkway

Las Vegas, NV 89154

Annie Kelley

State Documents Department

Nevada State Library

Capitol Complex

Carson City, NV 89710

Water Resources Research Archives

University of California

Room 40, North Gate Hall

Berkeley, CA 94720
International Technology Corp.

Rick Waddell

Geotrans

c/o IT

4330 Valley View

Suite 112

MS-439

Las Vegas, NV 89103

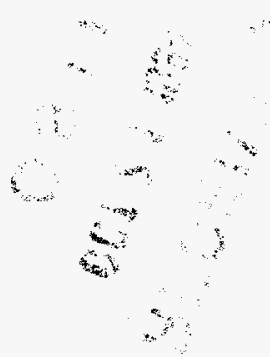

Joe Yeasted

International Technology Corp.

4330 S. Valley View, Ste. 114

Las Vegas, NV 89103 